Arne Hogrefe

Umstrittene Vergangenheit

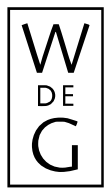




\section{Millennium-Studien}

zu Kultur und Geschichte des ersten Jahrtausends n. Chr.

\section{Millennium Studies}

in the culture and history of the first millennium C.E.

Herausgegeben von / Edited by

Wolfram Brandes, Alexander Demandt, Helmut Krasser,

Hartmut Leppin, Peter von Möllendorff

Band 24

Walter de Gruyter · Berlin · New York 


\title{
Umstrittene Vergangenheit
}

\author{
Historische Argumente \\ in der Auseinandersetzung \\ Augustins mit den Donatisten
}

von

Arne Hogrefe

Walter de Gruyter · Berlin · New York 
Diese Publikation wurde im Rahmen des Fördervorhabens 16TOA021 - Reihentransformation für die Altertumswissenschaften („Millennium-Studien“) mit Mitteln des Bundesministeriums für Bildung und Forschung im Open Access bereitgestellt. Das Fördervorhaben wird in Kooperation mit dem DFG-geförderten Fachinformationsdienst Altertumswissenschaften - Propylaeum an der Bayerischen Staatsbibliothek durchgeführt.

\section{(cc) BY-NC-ND}

Dieses Werk ist lizenziert unter der Creative Commons Attribution-NonCommercial-NoDerivatives 4.0 International Lizenz. Weitere Informationen finden Sie unter http://creativecommons.org/licenses/by-nc-nd/4.0/.

Die Bedingungen der Creative-Commons-Lizenz gelten nur für Originalmaterial. Die Wiederverwenung von Material aus anderen Quellen (gekennzeichnet mit Quellenangabe) wie z.B. Schaubilder, Abbildungen, Fotos und Textauszüge erfordert ggf. weitere Nutzungsgenehmigungen durch den jeweiligen Rechteinhaber.

$@$ Gedruckt auf säurefreiem Papier, das die US-ANSI-Norm über Haltbarkeit erfüllt.

ISBN 978-3-11-020363-9

ISSN 1862-1139

Bibliografische Information der Deutschen Nationalbibliothek

Die Deutsche Nationalbibliothek verzeichnet diese Publikation in der Deutschen Nationalbibliografie; detaillierte bibliografische Daten sind im Internet über http://dnb.d-nb.de abrufbar.

(C) Copyright 2009 by Walter de Gruyter GmbH \& Co. KG, 10785 Berlin

Dieses Werk einschließlich aller seiner Teile ist urheberrechtlich geschützt. Jede Verwertung außerhalb der engen Grenzen des Urheberrechtsgesetzes ist ohne Zustimmung des Verlages unzulässig und strafbar. Das gilt insbesondere für Vervielfältigungen, Übersetzungen, Mikroverfilmungen und die Einspeicherung und Verarbeitung in elektronischen Systemen.

Printed in Germany

Umschlaggestaltung: Christopher Schneider, Laufen 


\section{Meinen Eltern}





\section{Vorwort}

Die vorliegende Studie ist die überarbeitete Fassung meiner Arbeit, die im Wintersemester 2005/6 am Fachbereich Geschichte und Kulturwissenschaften der Philipps-Universität Marburg als Dissertation angenommen wurde. Für die Überarbeitung habe ich Fachliteratur bis 2007 berücksichtigt, soweit sie mir zugänglich war.

Mein besonderer Dank gilt meinem Doktorvater, Herrn Prof. Dr. R. M. Errington, der mir die Epoche der Spätantike nahebrachte und mich ermunterte, die Geschichte des Donatismus als Themengrundlage zu wählen. Er hat die Arbeit mit seinem Rat kritisch und konstruktiv begleitet. Für zahlreiche Ratschläge, Korrekturen und viele ermutigende Worte danke ich Herrn Prof. Dr. Hans-Ulrich Wiemer, der zudem die Aufgabe des Zweitgutachters übernommen hat. Ebenfalls danke ich Herrn Prof. Dr. Hartmut Leppin, der sich Zeit genommen hat, das Manuskript kritisch zu lesen und mir hilfreiche Anregungen und Empfehlungen für die Überarbeitung gab. Ihm und den anderen Herausgebern danke ich für die Aufnahme meiner Dissertation in die Reihe der Millennium-Studien. Dr. Sabine Vogt, Katrin Hofmann, Sabina Dabrowski und Christina Brückner betreuten die Arbeit beim Walter de Gruyter-Verlag und standen mir mit Rat zur Seite.

Die Konrad-Adenauer-Stiftung ermöglichte drei Jahre Forschungsarbeit durch meine Aufnahme in die Graduiertenförderung, die mir den nötigen finanziellen Freiraum verschaffte.

Vielen Personen, die den Entstehungsprozess begleitet haben, bin ich ebenso zu Dank verpflichtet. Genannt seien hier die Mitglieder des Seminars für Alte Geschichte an der Universität Marburg, insbesondere Dr. Florian Krüpe, der die Mühe des Korrekturlesens auf sich nahm und mich bei der Herstellung des Manuskripts unterstützte.

Für die jahrelange Geduld und Begleitung bin ich meiner Frau Cornelia Hogrefe zutiefst dankbar. Von meiner Großmutter, Frau Ilse Zacharias, habe ich viel Zuspruch und Hilfe erfahren. Meinen Eltern, die mich stets unterstützt und ermutigt haben, möchte ich dieses Buch widmen. 



\section{Inhalt}

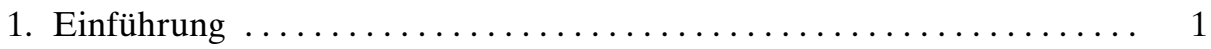

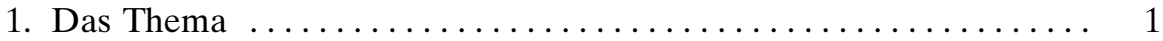

2. Zum Stand der Forschung $\ldots \ldots \ldots \ldots \ldots \ldots \ldots \ldots \ldots \ldots \ldots \ldots$

2. Der Donatismus zur Zeit Augustins $\ldots \ldots \ldots \ldots \ldots \ldots \ldots \ldots \ldots \ldots \ldots \ldots$

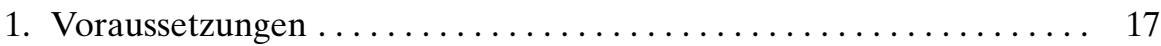

1.1 Die politische Situation in Nordafrika im 4. Jahrhundert n. Chr. 17

1.2 Die Situation der Donatisten in Afrika ............... 19

2. Die Entwicklung der Auseinandersetzung Augustins mit den

Donatisten ................................ 28

2.1 Der Beginn der Kontroverse (393-405) ............. 28

2.2 Das Unionsgesetz des Jahres 405 und die Folgen (405-411) . . 37

2.3 Die Konferenz von Karthago und die Folgen (411-430) ..... 54

3. Die Bücher gegen den Grammatiker Cresconius $\ldots \ldots \ldots \ldots \ldots \ldots, 61$

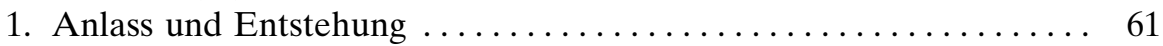

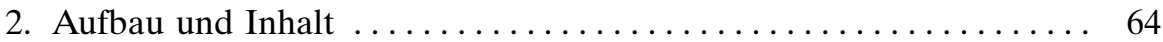

3. Themen der Auseinandersetzung $\ldots \ldots \ldots \ldots \ldots \ldots \ldots \ldots \ldots \ldots \ldots$

3.1 Die christliche Beredsamkeit .................... 66

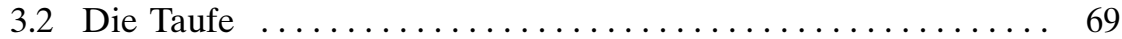

3.3 Die Einheit der Kirche ........................ 75

3.4 Die Verfolgung der Donatisten .................... 79

4. Die historische Argumentation $\ldots \ldots \ldots \ldots \ldots \ldots \ldots \ldots \ldots . \ldots . \ldots 4$

4.1 Die Darstellung der Entstehungsgeschichte durch Cresconius . 85

4.2 Die Argumentation Augustins .................... 92

4.2.1 Das Konzil von Cirta und die causa Silvani .......... 92

4.2.2 Die causa Caeciliani ......................... 97

4. Die antidonatistischen Briefe ........................... 107

1. Die Darstellung der donatistischen Kontroverse ............ 107

1.1 Im Gespräch mit Donatisten: Die Briefe 43 und $44 \ldots \ldots \ldots 109$

1.2 Auseinandersetzung mit donatistischen Bischöfen: Die Briefe 87

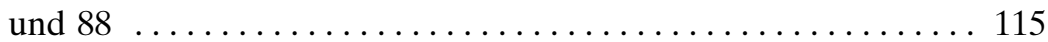

1.3 Aufruf zur Umkehr: Die Briefe 76 und 105 an die Donatisten . 119

1.4 Rechtfertigung des Zwangs: Der Brief 93 an den Rogatisten

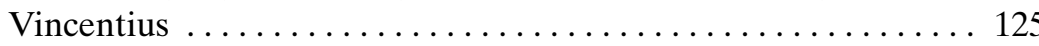


1.5 Widerstand gegen Donatisten: Die Briefe 53 und 89 an

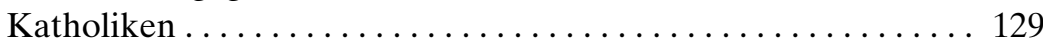

2. Die historische Argumentation $\ldots \ldots \ldots \ldots \ldots \ldots \ldots \ldots \ldots \ldots \ldots \ldots \ldots$

2.1 Die Briefe vor dem Unionsgesetz von 405 (epp. 43, 53, 76) .. 131

2.2 Kontinuität der Gesetzgebung: Die Briefe nach 405 (epp. 88, 89,

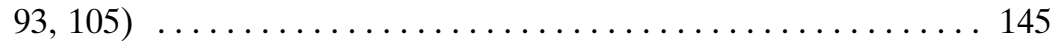

5. Augustinus und die Konferenz von Karthago im Jahr $411 \ldots \ldots \ldots \ldots 153$

1. Der Verlauf der Konferenz .......................... 154

1.1 Vorbereitungen und Ausgangspositionen .............. 154

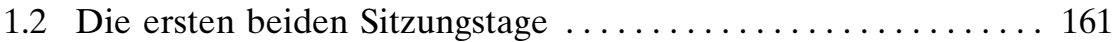

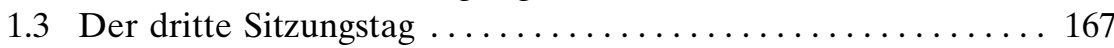

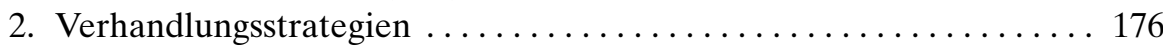

3. Die historische Argumentation ..................... 195

3.1 Das Konzil von Karthago gegen das Konzil von Cirta ....... 195

3.2 Der Streit um die Urteile von Miltiades und Konstantin ...... 200

3.3 Zusammenfassung: Argumentation und Beweisführung ...... 207

4. Die Schriften Augustins nach der Konferenz ............... 209

4.1 Der Kurzbericht über die Konferenz mit den Donatisten

(breuic.) ............................... 210

4.2 Der Traktat an die Donatisten nach der Konferenz (c. Don.) und

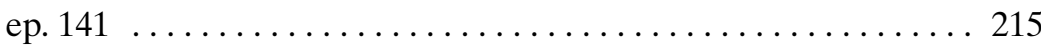

4.3 Augustins Beurteilung der Konferenz .............. 220

4.4 Ein Epilog: Die Zusammenkunft mit Emeritus in Caesarea ... 222

6. Donatistische Geschichtsbilder und Augustins Entgegnung ........ 228

1. Donatistische traditio-Anschuldigungen ................. 228

1.1 Mensurius von Karthago $\ldots \ldots \ldots \ldots \ldots \ldots \ldots \ldots \ldots \ldots \ldots$

1.2 Caecilianus von Karthago ........................ 234

1.3 Felix von Abthugni ........................... 236

1.4 Die römischen Bischöfe ....................... 240

2. Augustins Antwort: traditio-Anschuldigungen gegen donatistische

Bischöfe ................................... 245

2.1 Das Protokoll des Konzils von Cirta .................. 245

2.2 Die traditio-Anklage gegen Silvanus von Cirta .......... 252

3. Donatistische Traditionen über Verfolgung und Martyrium ....... 257

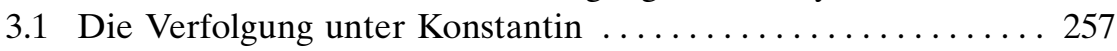

3.2 Die Verfolgung durch Macarius ................. 262

3.3 Zusammenfassung: Die donatistischen Traditionen über

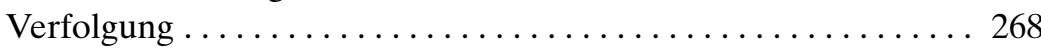


7. Die Entstehung des donatistischen Schismas: Historische Argumente zur causa Caeciliani .............................. 270

1. Das Konzil von Karthago und die Absetzung Caecilians ........ 270

1.1 Die Akten des Konzils von Karthago . ................. 270

1.2 Der interventor von Karthago .................... 276

2. Die Anklage der Donatisten gegen Caecilianus ............. 278

3. Die Konzile von Rom und Arles . . . . . . . . . . . . . . . . . . . . 290

4. Das Urteil Konstantins ............................ 303

4.1. Vom Konzil von Arles zum Urteil Konstantins in Mailand ... 304

4.2 Donatistische Traditionen und Deutungen .............. 311 4.2.1 Geschichtsdeutungen auf der Konferenz von Karthago . . 311 4.2.2 Geschichtsdeutungen bei Parmenianus ............ 322

4.3 Das Urteil Konstantins bei Augustinus .............. 328

8. Zusammenfassung und Schlussfolgerungen: Historische Argumente im donatistischen Streit ............................. 330

1. Der donatistische Streit zur Zeit Augustins ............... 331

2. Die Konferenz von Karthago ...................... 336

3. Das historische Selbstverständnis der Donatisten ............ 339

4. Augustins historische Quellen und ihre Interpretation ......... 343

5. Die Entstehungsgeschichte des donatistischen Schismas ......... 350

Exkurs: Zur Datierung des Konzils von Cirta ................ 355

Abkürzungen ........................................ 362

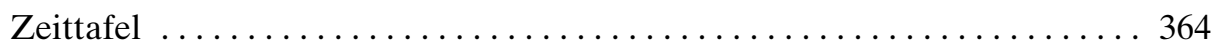

Quellen- und Literaturverzeichnis . ...................... 367

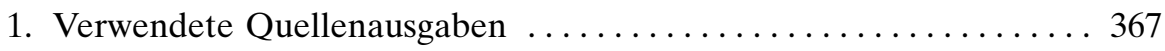

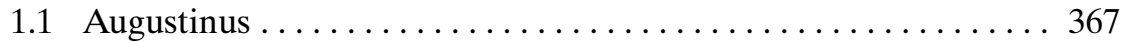

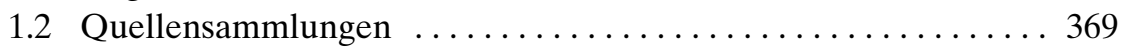

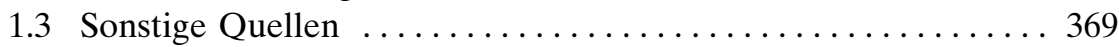

2. Verzeichnis der verwendeten Literatur $\ldots \ldots \ldots \ldots \ldots \ldots \ldots . \ldots 372$

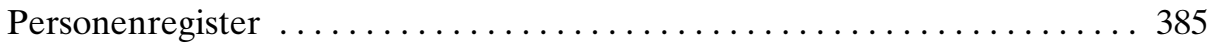

Sach- und Ortsregister .............................. 391 



\section{Einführung}

\section{Das Thema}

Nach dem Ende der Christenverfolgungen unter Diokletian und seinen Mitregenten in den Jahren 303-311 begann in den römischen Provinzen Nordafrikas innerhalb der Kirche eine Auseinandersetzung über die Frage, wie mit denjenigen Christen umzugehen sei, die sich der Staatsgewalt gebeugt und heilige Schriften und Kultgegenstände ausgeliefert hatten (sogenannte Traditoren). Der Streit spitzte sich zu, als in Karthago mit Caecilianus ein neuer Bischof ernannt wurde, der wegen seiner opportunistischen Haltung in der Verfolgungszeit von Teilen der Gemeinde abgelehnt wurde. Bald nach der Weihe Caecilians versammelten sich Bischöfe aus der Provinz Numidien unter der Leitung des Bischofs Secundus von Tigisi in Karthago. Diese setzten den neuen Bischof mit der Begründung ab, seine Weihe sei ungültig, da einer seiner Konsekratoren, Felix von Abthugni, ein Traditor sei, und wählten an Caecilians Stelle einen gewissen Maiorinus zum Bischof. Während letzterer sich der Unterstützung rigoristischer Gruppierungen sicher sein konnte, erhielten Caecilianus und seine Anhänger Beistand von zahlreichen Bischöfen und von Kirchenvertretern außerhalb Afrikas. Beide Parteien behaupteten nun, die legitime katholische Kirche in Afrika zu vertreten.

Nachfolger des bereits 313 verstorbenen Maiorinus wurde Donatus, der bis zu seinem Tod im Jahr 355 die entscheidende Persönlichkeit seiner kirchlichen Partei wurde, deren Mitglieder später nach ihm Donatisten genannt wurden. ${ }^{1}$ Entscheidend für den weiteren Verlauf dieses Schismas war das Eingreifen des Kaisers Konstantin (306-337), der sich nach der „Konstantinischen Wende“ als Förderer des Christentums verstand und die Kirche als Herrschaftsinstrument zu nutzen wusste. Die Donatisten wandten sich im Frühjahr 313 an den Kaiser, um von ihm die Anerkennung als die rechtmäßigen Vertreter der Kirche Afrikas zu erhalten. Die von Konstantin daraufhin einberufenen Synoden von Rom (Herbst 313) und Arles (Sommer 314) bestätigten jedoch, dass Caecilians Wahl und Weihe rechtmäßig verlaufen seien. Die Donatisten hingegen mussten

1 Um die beiden Gruppierungen des Schismas deutlich zu unterscheiden, wird in der vorliegenden Arbeit durchgängig die Bezeichnung „Donatisten“ für die Vertreter und Mitglieder der pars Donati verwendet. Damit schließe ich mich der üblichen Terminologie an. Gleichwohl ist zu berücksichtigen, dass diese Bezeichnung von ihren Gegnern abwertend verwendet wurde und die Donatisten sich selbst als Vertreter der (wahren) katholischen Kirche verstanden und daher als „katholisch“ bezeichneten. 
in der Folgezeit damit rechnen, auch durch die kaiserliche Gewalt bekämpft zu werden.

Als Augustinus im Jahre 391 in der Hafenstadt Hippo Regius zum Priester geweiht wurde, spaltete das donatistische Schisma bereits seit achtzig Jahren die Kirche in den afrikanischen Provinzen und war im Laufe der Zeit zu einem Teil des dortigen Alltagslebens geworden. Augustinus wollte diese Spaltung nicht akzeptieren; er sah sich als Christ und Diener Gottes verpflichtet, für die Einheit der Kirche einzutreten. Schon bald nach seinem Amtsantritt begann er, in der Frage des Schismas Stellung zu beziehen. Es sollte eine seiner Lebensaufgaben werden, gegen den Donatismus zu kämpfen.

Im Jahr 393 verfasste Augustinus für die Gläubigen seiner Gemeinde einen „Psalm gegen die Donatisten“. ${ }^{2}$ Dieser mit religiösem Eifer verfassten Streitschrift folgten in den nächsten dreißig Jahren zahlreiche Abhandlungen, Traktate, Briefe und Predigten Augustins. Auf ganz unterschiedliche Weise verfolgt er das Ziel, das Schisma in Afrika zu beenden: Er argumentiert und polemisiert gegen das Selbstverständnis und die Theologie der Donatisten, er versucht, Religionsgespräche durchzuführen, um mit Donatisten in einen Dialog zu treten, er predigt den Gläubigen, den „Irrtum“ der Donatisten zu erkennen, er ermutigt Bischöfe ebenso wie römische Beamte, im Kampf gegen die Donatisten unnachgiebig zu bleiben. Auf diese Weise entstand Augustins Werk antidonatistischer Schriften, von denen heute noch ein verhältnismäßig großer Teil erhalten ist. ${ }^{3}$

Ebenso variantenreich wie die Art und Weise der Auseinandersetzung mit den Donatisten gestaltete Augustinus seine Argumentationsmethoden: Er verwendete theologische und ekklesiologische, moralische, aber auch historische Argumente. Die letztgenannte Methode, die historische Argumentation Augustins, bildet die thematische Grundlage und den Untersuchungsgegenstand der vorliegenden Arbeit.

Drei Perspektiven werden in diesem Zusammenhang eingenommen: Es soll zum einen untersucht werden, wie zur Zeit Augustins die Entstehung und die Geschichte des donatistischen Schismas thematisiert und argumentativ verwendet wurde. Es ist zu fragen, in welchem Kontext, gegenüber welchen Menschen und mit welchen Zielen Augustinus und die Katholiken historische Überlieferungen heranzogen und für ihre Argumentation interpretierten.

2 Edition: R. Anastasi, Psalmus contra Partem Donati, Padova 1957. Zur Datierung vgl. Congar, BA 28, 139; Monceaux VII, 80 f., 275. - Im Folgenden werden sämtliche Schriften Augustins nach den Abkürzungen des AL zitiert, und zwar ohne Nennung des Autors. Bei längeren Textanalysen erfolgen die Stellennachweise im Fließtext.

3 Als „antidonatistisch“ werden im Folgenden nicht nur die Schriften bezeichnet, die Augustinus explizit gegen Donatisten richtete, sondern alle, in denen der Donatismus grundsätzlich thematisiert wird. - Zu den Editionen der antidonatistischen Schriften Augustins s. u. Anm. 25. 
Geschichtsbilder und Geschichtsdeutungen zeigen sich jedoch auf beiden Seiten. Daher ist zum anderen die donatistische Perspektive zu berücksichtigen. Augustins Schriften geben nicht nur Einblick in das Verständnis der Katholiken seiner Zeit, sondern auch in das der Donatisten. Indem Augustinus sich mit Argumenten der Gegner auseinandersetzt, werden auch deren historische Kenntnisse und Positionen deutlich. Folglich wird zu fragen sein, in welchem Rahmen die Donatisten historisch argumentierten und welche Ziele sie verfolgten, überdies, auf welche Quellen sie zurückgreifen konnten und wie diese interpretiert wurden. Die Gegenüberstellung der donatistischen und augustinischen Deutungen wirft Licht auf die Unterschiede der Überlieferung und die gegensätzliche Ausprägung von Geschichtstraditionen.

Zum Dritten dient die Analyse der historischen Argumente dazu, die Geschichte des donatistischen Schismas selbst zu erhellen und in einigen Details präziser darzustellen als bisher. Gerade wegen der vielfältigen historischen Bezüge sind Augustins Schriften heute eine der wichtigsten Quellen für die Geschichte des Donatismus. Durch die quellenkritische Auseinandersetzung mit diesen Texten soll offengelegt werden, welche Möglichkeiten Augustins Ausführungen bieten und welche Grenzen gesetzt sind, Antworten zur Entstehung und Verlauf des donatistischen Schismas zu geben.

Die historischen Argumente stehen bei Augustinus niemals allein, sondern sind stets verbunden mit den theologischen und kirchlichen Streitfragen sowie mit Ermunterungen und Appellen. In allen bekannten Schriften findet sich eine gleichbleibende Argumentationsmethodik, und es ist auffällig, dass dieses Grundschema bereits in der ersten antidonatistischen Schrift, dem Psalmus contra Partem Donati, deutlich ausgeprägt ist. Anhand dieses Beispiels soll das Argumentationsschema kurz vorgestellt werden:

Augustinus verwendet drei Argumentationsstränge, mit denen er die Schuld der Donatisten an der Spaltung der Kirche begründen möchte. Zum einen behandelt er die Themen „Taufe“ und „christliche Gemeinde“. Da die Donatisten den katholischen Priestern vorwarfen, Nachfolger der Traditoren zu sein, lehnten sie die Taufe der Katholiken als ungültig ab und wiederholten die Taufe, falls ein Katholik konvertierte. Aus katholischer Sicht war dies ein Sakrileg, aus donatistischer Sicht notwendig, um die Reinheit der Kirche zu bewahren. Augustinus verurteilt diese Praxis der ,Wiedertaufe“. Er verweist auf die Heilige Schrift und begründet mit ihr, warum aus seiner Sicht die Gültigkeit der Taufe unabhängig vom Taufspender sei und die Kirche bereit sein müsse, auch Sünder in ihren Reihen zu ertragen. Eine Kirche frei von Sündern, wie die Donatisten forderten, könne es nicht geben. ${ }^{4}$

4 Ps. c. Don. 216-228, 242-253. 
Zum Zweiten spricht Augustinus Gewaltanwendungen zwischen Donatisten und Katholiken an. Die Donatisten sahen sich selbst als verfolgte Kirche, als „Kirche der Märtyrer“, und betrachteten die Katholiken ebenso als Verfolger wie die staatlichen Gewalten, durch die sie bekämpft wurden. Augustinus stellt im Gegensatz dazu heraus, dass die Donatisten in vielfältiger Weise Gewalttaten begingen, indem sie Katholiken verfolgten und misshandelten; zudem hätten auch die Donatisten staatliche Gewalt in Anspruch genommen, um gegen Abspaltungen in den eigenen Reihen vorzugehen. Es sei notwendig, die Gewalt zu beenden und Frieden zu schaffen. ${ }^{5}$

Der dritte Aspekt der Argumentation ist schließlich die Entstehungsgeschichte des donatistischen Schismas. Augustinus erläutert, wie es zu der Spaltung in Karthago kommen konnte, wer „Schuld“ daran gehabt habe, dass die Kircheneinheit verloren ging. Er möchte beweisen, dass die Behauptung der Donatisten, Caecilianus sei von Traditoren zum Bischof geweiht worden, falsch sei. ${ }^{6}$ Auch in den Reihen der Donatisten habe es Traditoren gegeben, so Augustins These, der Grund für die Spaltung sei damit hinfällig. ${ }^{7}$

Ausgehend von der gleichbleibenden Thematik variierte Augustinus jedoch im Hinblick auf die Adressaten. Im Falle des Psalmus wollte er erreichen, dass „der Fall der Donatisten dem einfachen Volk, vor allem den Unwissenden und Ungelehrten bekannt werde“, wie er später formulierte. ${ }^{8}$ Als ehemaligen Rhetoriklehrer in den Metropolen des Römischen Reiches fiel es ihm nicht schwer, mit rhetorischem Geschick diese Aufgabe umzusetzen und die Gläubigen seiner Gemeinde zu erreichen: Er gestaltete den Psalmus als Abecedarium in zwanzig Strophen, eingebettet zwischen einem Prolog und einen Epilog, der in Form einer Prosopopöie der „Mutter Kirche“ an ihre Gläubigen verfasst ist. Zu Beginn und zwischen den Strophen setzte er jeweils einen Kehrvers (hypopsalma), der von der gesamten Gemeinde gesungen werden sollte. ${ }^{9}$ Offensichtlich wählte Augustinus diese Form, weil er darin eine geeignete Möglichkeit sah, seinem „ungelehrten“ Publikum die „Wahrheit“ über den Donatismus einprägsam zu vermitteln. Seine Gemeinde setzte er gleichsam als Richter in der causa schismatis ein, wenn er im Prolog die Streitfrage vorgibt, wer denn die Schuld daran trage, dass der „Friede Christi“ zerrissen worden sei, und wenn er mit dem Kehrvers an sie appelliert, gemeinsam über die „Wahrheit“ zu urteilen: Vos qui

5 Ps. c. Don. $160-167$.

6 Ps. c. Don. $62-65$.

7 Ps. c. Don. $40-44$.

8 Retr. I 20: Volens etiam causa Donatistarum ad ipsius humilliimi uulgi et omnino imperitorum atque idiotarum notitiam peruenire.

9 Zur Form des Psalmus, die in der antiken lateinischen Literatur sehr ungewöhnlich ist, vgl. Congar, BA 28, 140 f.; Bonner, Augustine, 254 f.; J.H. Baxter, On St. Augustine's Psalmus contra Partem Donati, Sacris Erudiri 4, 1952, 21-26. C. Springer, The Artistry of Augustine's Psalmus contra Partem Donati, AugStud 16, 1985, 65-75. 
gaudetis de pace, modo uerum iudicate. Augustinus selbst begibt sich in die Rolle des Verteidigers der katholischen Kircheneinheit und in die Rolle des Anklägers, der ein engagiertes Plädoyer gegen die Donatisten hält: Die Donatisten hätten die Einheit der Kirche zerrissen und „Altar gegen Altar“ gestellt, ${ }^{10}$ sie verbreiteten Lügen und könnten nichts von ihren Anschuldigungen beweisen. ${ }^{11}$

Das Beispiel des Psalmus contra Partem Donati verdeutlicht, dass eine Analyse der historischen Argumente nur im gesamten Kontext der jeweiligen antidonatistischen Schrift möglich ist. Darüber hinaus zeigt sich, wie die Frage nach der historischen Argumentation zu verstehen ist: Es geht nicht um eine Form der Geschichtsschreibung, sondern um eine Form der Beweisführung in einem Streitfall. Es geht nicht um eine zusammenhängende Darstellung geschichtlicher Ereignisse, sondern um Zuspitzung auf einzelne Zeugnisse und Beweismittel, die zu einer Entscheidung über Schuld und Unschuld führen sollen. Aufgabe und Ziel dieser Untersuchung ist es demzufolge, Augustins rhetorischen Aufbau $\mathrm{zu}$ analysieren, den Argumentationsrahmen zu erfassen und zu klären und so den Stellenwert, die Bedeutung und den Informationsgehalt der historischen Aussagen zu bestimmen.

Die Quellenbasis der Untersuchung legen jene antidonatistischen Schriften Augustins, in denen die Geschichte des Schismas thematisiert wird. Außer den noch heute erhaltenen großen Abhandlungen gegen die Donatisten ${ }^{12}$ fallen zahlreiche Briefe darunter ${ }^{13}$ sowie einige Predigten. ${ }^{14}$ Hinzu kommen weitere

10 Ps. c. Don. 30, 80, 116, 293.

11 Ps. c. Don. 39-45.

12 Unter dem Begriff „Schriften gegen die Donatisten“ werden heute die zwölf erhaltenen Abhandlungen Augustins zusammengefasst, die Michael Petschenig als Scripta contra Donatistas herausgegeben hat (CSEL 51-53).

13 Zur Briefsammlung Augustins und die den Donatismus betreffenden Briefe s. u. Kap. 4.

14 Für Augustins Predigten wird allgemein der Begriff sermones verwendet. Im Schriftenverzeichnis des Possidius ist dagegen von tractatus die Rede. Die unter der Bezeichnung enarrationes in Psalmos gesammelten Schriften sind formal ebenfalls Predigten. - Monceaux (VII 287-292) verzeichnet 42 sermones, in denen sich Augustinus in irgendeiner Weise auf den Donatismus bezieht, außerdem 26 Titel aus den enarrationes in Psalmos sowie 16 aus den Auslegungen des Johannesevangeliums (in Evangelium Iohannis tractatus). In den Predigtsammlungen, die erst nach Monceaux entdeckt und herausgegeben worden sind, finden sich weitere Texte mit Bezug zum Donatismus. Als wichtigste Predigten sind aus den von G. Morin zusammengestellten Sammlungen (Miscellanea Agostiniana Bd. 1) zu nennen: s. Denis 12, 19; s. Guelf. 28, 32; s. Frang. 1; s. Casin I 133. Von den Predigten, die F. Dolbeau zu Beginn der 90er Jahre entdeckt hat (vgl. Vingt-six sermons au peuple d'Afrique, Paris 1996), sind bezüglich des Donatismus die sermones Dolbeau 2; 24, 26, 27 von Interesse. - Einen Überblick über alle sermones unter Einbeziehung der neuesten Editionen: É. Rebillard, Augustine Through the Ages, $773-792$, s. v. sermones. - Eine vollständige Übersicht über die zu seiner Zeit bekannten antidonatistischen Abhandlungen, Briefe und Predigten bietet Monceaux VII, 275-292. 
Quellen, die aus der Zeit Augustins überliefert sind und in denen ebenfalls historische Positionen zum Donatismus zum Tragen kommen. Hierzu gehören die im Codex Theodosianus überlieferten Gesetze und die Akten afrikanischer Konzilien des 4. und 5. Jahrhunderts, ${ }^{15}$ vor allem aber die Protokolle und Dokumente der Konferenz von Karthago aus dem Jahr 411, bei der Katholiken und Donatisten über die Spaltung der Kirche diskutierten. ${ }^{16}$ Weiterhin ist das antidonatistische Werk des Bischofs Optatus von Mileve zu nennen, der eine Generation vor Augustinus wirkte und in seiner Argumentation für Augustinus ein Vorbild darstellte. Seine Darstellung ist eine wichtige Vergleichsquelle zu Augustinus. ${ }^{17}$

Die folgenden Kapitel der Arbeit lassen sich in drei Hauptteile gliedern: Der erste Teil (Kapitel 2) dient der der historischen Einführung. Die Situation der Kirche in Afrika zur Zeit Augustins und die Entwicklung des Donatismus im 4. Jahrhundert $\mathrm{n}$. Chr. werden hier in ihren Zusammenhängen dargestellt. Es soll gezeigt werden, unter welchen politischen und gesellschaftlichen Rahmenbedingungen die Auseinandersetzung Augustins mit dem Donatismus erfolgte. Das Kapitel enthält eine Überblicksdarstellung zum donatistischen Schisma zur Zeit Augustins (390-430 n. Chr.) und eine Übersicht über die wichtigsten antidonatistischen Schriften Augustins sowie ihre Einordnung in den historischen Kontext.

Der zweite Teil (Kapitel 3-5) beinhaltet die quellenkritischen Untersuchungen und Interpretationen ausgewählter Schriften Augustins sowie des Aktenmaterials der Konferenz von Karthago. Die ausführlichen Darstellungen von Textinhalten und Entstehungssituationen ist der bereits erwähnten Verknüpfung der verschiedenen Argumentationsbereiche geschuldet. Gleichwohl kann und soll eine Vertiefung der theologischen Streitpunkte des donatistischen Schismas nicht geleistet werden; der Fokus wird stets auf die historischen Argumente ausgerichtet sein.

Anhand der Analyse von Augustins Werk contra Cresconium (Kapitel 3) und zentralen antidonatistischen Briefen (Kapitel 4) sollen Augustins Auseinandersetzung mit dem Donatismus, seine Argumentationsmethoden, seine Rhetorik und Polemik exemplarisch betrachtet werden. Darüber hinaus richtet sich der Blick auf den Gebrauch historischer Argumente und auf den Kontext

Monceaux’ Auflistung ist zu ergänzen um die später entdeckten Briefe und Predigten. Eine gute Einführung in die antidonatistischen Schriften Augustins bietet W. Geerlings, Augustinus - Leben und Werk. Eine bibliographische Einführung, Paderborn u. a. 2002, $82-98$.

15 Edition: Concilia Africae, ed. Ch. Munier, Turnhout 1974 (CCL 149).

$16 \mathrm{Zu}$ den Akten der Konferenz vgl. u. Kap. 5 Anm. 2.

17 Edition: Optat de Milève, Traité contre les Donatistes, 2 Bde., ed. M. Labrousse, Paris 1995/1996 (SC 412/413). 
ihrer Verwendung. Die Schrift contra Cresconium bietet sich in diesem Zusammenhang an, da es einerseits ein zentrales Werk aus dem umfangreichen schriftlichen Disput mit dem donatistischen Bischof Petilianus von Cirta darstellt, ${ }^{18}$ andererseits Augustinus darin sowohl zu den theologischen als auch zu den historischen Fragen ausführlich Stellung bezieht. Die antidonatistischen Briefe ermöglichen darüber hinaus, Veränderungen in Augustins Argumentation im Laufe der Zeit und hinsichtlich unterschiedlicher Adressaten zu beobachten. Sowohl contra Cresconium als auch die antidonatistischen Briefe enthalten historische Erläuterungen und im Wortlaut zitierte Dokumente, die für die Entstehungsgeschichte des donatistischen Schismas von großer Bedeutung sind.

Die ausführliche Darstellung der Konferenz von Karthago im Jahr 411 (Kapitel 5) ist eine unumgängliche Ergänzung der vorausgehenden Textanalysen, da hier Donatisten und Katholiken gleichermaßen zentrale Fragen der Geschichte des Schismas erörterten. Doch nicht nur die erhaltenen Akten der Konferenz sind eine wertvolle Quellen für die historischen Positionen beider Seiten, sondern auch Augustins Schriften, die er infolge der Konferenz verfasste und entsprechend berücksichtigt werden (Kapitel 5.4).

Im dritten Teil der Arbeit (Kapitel 6-8) werden schließlich die geschichtlichen Bezüge, die sich in Augustins Schriften finden lassen, systematisch dargestellt und mithilfe weiterer zur Verfügung stehender Quellen überprüft und interpretiert. Im Kapitel 6 stehen zwei zentrale Begriff des donatistischen Streits im Mittelpunkt: traditio und persecutio. In diesen beiden Begriffen zeigen sich insbesondere zwei Facetten eines donatistischen Geschichtsbildes: Die wahre Kirche bildet einen Hort der Bekenner und eine Gemeinschaft der Verfolgten, sie ist die Kirche der Märtyrer im Kampf gegen Traditoren und Verfolger. Die geschichtlichen Überlieferungen dienen zur Verteidigung und Rechtfertigung dieses Selbstverständnisses, vor allem zur Pflege der Erinnerungskultur der Märtyrer.

Augustinus setzt an dieser Stelle an und nimmt die Streitfrage der traditio als einen Ausgangspunkt seiner historischen Beweisführung. Seine diesbezüglichen Entgegnungen werden in diesem Zusammenhang ebenfalls thematisiert (Kap. 6.2).

Das Kapitel 7 widmet sich der Entstehungsgeschichte des donatistischen Schismas, die sich aus dem Blickwinkel Augustins als Auseinandersetzung um den „Fall Caecilianus“, der causa Caeciliani, darstellt. Die unterschiedlichen Ansatzpunkte, geschichtlichen Rekonstruktionen und Deutungen sollen untersucht und hinsichtlich ihrer Überzeugungskraft für die Auseinandersetzung und ihrer historischen Glaubwürdigkeit interpretiert werden.

18 Zum Zusammenhang s. u. Kap. 3.1. 
Im Schlusskapitel werden zum einen die Ergebnisse der vorangehenden Kapitel zusammengefasst, zum anderen sollen die Grundlagen der historischen Argumentation und die historischen Deutungen, die zum Streit um die Vergangenheit zwischen Donatisten und Katholiken führten, abschließend beurteilt werden.

\section{Zum Stand der Forschung}

Die antidonatistischen Schriften Augustins haben einen erheblichen Anteil an der Herausbildung kirchlicher Lehren, so dass sie seit jeher im Interesse der Dogmen- und Theologiegeschichte standen. Die neuzeitliche historische Auseinandersetzung $^{19}$ mit Augustins Schriften als kirchengeschichtlicher Quelle begann im späten 16. Jahrhundert und fand ihren ersten Höhepunkt in dem Werk Lenain de Tillemonts, der eine Kirchengeschichte der ersten sechs Jahrhunderte verfasste. $^{20}$ Ein wesentlicher Schritt zur Aufarbeitung der Überlieferung bedeutete auch die erste vollständige Edition der Schriften Augustins durch die Mauriner, die im Jahre 1700 abgeschlossen wurde. ${ }^{21}$

Waren die frühen Darstellungen zum Donatismus katholisch-theologisch motiviert, erfolgten die ersten historisch-kritischen Interpretationen der Quellen Ende des 19. Jahrhunderts. Der Donatismus wurde nicht mehr einseitig kirchengeschichtlich als Teil der „Ketzergeschichte“ wahrgenommen und entsprechend verurteilt, sondern als durchaus auch politisch und gesellschaftlich interessantes historisches Phänomen der Spätantike. ${ }^{22}$ Im Mittelpunkt der Be-

19 Die nicht überschaubare Fülle an Literatur sowohl zu Augustins Werk und Wirken als auch zur Geschichte der Spätantike und der Zeit Konstantins zwingt zur Konzentration auf entscheidende Forschungsergebnisse und eine Auswahl an neueren Darstellungen. Im Folgenden verweise ich auf einige zentrale Arbeiten zum Donatismus, auf deren Ergebnissen diese Arbeit aufbaut. Eine ausführliche Darstellung der Forschungsgeschichte soll hier nicht erfolgen. Siehe dazu den sehr guten Forschungsbericht von den Anfängen bis in die 80er Jahre des 20. Jahrhunderts von B. Kriegbaum, Kirche der Traditoren oder Kirche der Märtyrer, Die Vorgeschichte des Donatimus, 16-43. - Zur Interpretation donatistischer Theologie vgl. A. Schindler, Die Theologie der Donatisten und Augustins Reaktion, in: Internationales Symposion über den Stand der AugustinusForschung 1987, hg.v. C. Mayer u. K.-H. Chelius, Würzburg 1989, 131-147, sowie J. Alexander, AL 2, 622-638, s. v. Donatistae. Vgl. auch I. Hakizimana, Recherches augustiniennes des dernières 35 années sur la controverse antidonatiste: synthèse critique, Teresianum 57, 2006, 335-389.

20 Lenain de Tillemont, Mémoires pour servir à l'histoire ecclésiastique des six premiers siècles, 16 Bde., Paris 1693-1712.

21 Die Edition der Mauriner aus den Jahren 1679-1700 ist abgedruckt bei Migne, PL, Bde. 32-47.

22 Erstmals W. Thümmel, zur Beurtheilung des Donatismus, Eine kirchengeschichtliche Untersuchung, Halle 1893. 
trachtung stand die Frage nach der Überlieferung und Authentizität der Quellen zur Entstehungsgeschichte des Donatismus, insbesondere der Darstellung des Optatus von Mileve und seines Urkundenanhangs. Gegen Otтo Seeck, der zahlreiche Dokumente als bewusste Fälschungen verwarf, ${ }^{23}$ wandte sich LUC Duchesne, der seinerseits ein „Dossier des Donatismus“ postulierte, das die Katholiken zur Zeit des Optatus zusammengestellt hätten und später auch von Augustinus verwendet worden sei. ${ }^{24}$ Während sich Duchesnes Ansicht eines fest umrissenen Dossiers nicht halten ließ, folgten die meisten Historiker der Annahme, dass die Mehrheit der überlieferten Quellen authentisch sei. Gleichwohl ist die Diskussion nicht abgeschlossen. Einzelne Texte werden immer wieder in ihrer Authentizität angezweifelt und verlangen daher stets erneut nach einer eingehenden Prüfung. Die Kommentare und Interpretationen SeEcks und Duchesnes stellen dafür nach wie vor die Diskussionsgrundlage und werden daher an den entsprechenden Stellen dieser Arbeit herangezogen.

$\mathrm{Zu}$ Beginn des 20. Jahrhunderts erschienen in der Reihe Corpus Scriptorum Ecclesiasticorum Latinorum erstmals kritische Editionen des augustinischen Werkes. M. Petschenig bearbeitete die antidonatistischen Schriften Augustins, A. Goldbacher gab die Briefe Augustins heraus. Beide Ausgaben stellen bis heute die maßgebliche Grundlage der wissenschaftlichen Arbeit. ${ }^{25}$

Eine erste umfassende und bis heute wichtige Darstellung zum Donatismus legte Paul Monceaux in den Bänden vier bis sieben seines Werkes Histoire littéraire de l'Afrique chrétienne vor, die in den Jahren 1912 bis 1923 erschienen. ${ }^{26}$ Monceauxs Verdienst liegt in der detaillierten Aufarbeitung aller zu seiner Zeit verfügbaren Quellen. In diesem Zusammenhang bearbeitete er nicht nur die antidonatistischen Schriften des Optatus von Mileve (Bd.6) und Au-

23 Otto Seeck, Quellen und Urkunden über die Anfänge des Donatismus, ZKG 10, 1889, 505-568. Einige Revisionen und Neuinterpretationen legte Seeck zwanzig Jahre später vor, vgl. Urkundenfälschungen des 4. Jahrhunderts, I. Das Urkundenbuch des Optatus, ZKG 30, 1909, 181-227. - Noch kritischer als Seeck gegenüber der Authentizität der urkundlichen Quellen D. Voelter, Der Ursprung des Donatismus nach den Quellen untersucht und dargestellt, Freiburg/Tübingen 1883.

24 L. Duchesne, Le Dossier du Donatisme, Mélanges d'archéologie et d'histoire 10, 1890, 589-650.

25 Sancti Aureli Augustini scripta contra donatistas, ed. M. Petschenig, 3 Bde., Wien/ Leipzig 1908-1910 (CSEL 51-53); S. Aureli Augustini Hipponiensis episcopi epistulae, ed. A. Goldbacher, 4 Bde. Wien 1895-1923 (CSEL 34, 44, 57, 58). Zu den Briefen vgl. auch u. Kap. 4.1. - Für die Predigten liegt bislang keine kritische Gesamtausgabe vor. Der Großteil der sog. sermones findet sich in PL 38-39 und PLS 2. Augustins Psalmenauslegungen (ennarrationes in Psalmos) sind kritisch ediert von E. Dekkers und J. Fraipont, Turnhout 1955/56 (CCL 38-40) sowie in einer noch nicht abgeschlossenen Neuausgabe von C. Weidmann (CSEL 93), H. Müller (CSEL 94) und F. Gori (CSEL 95), Wien $2003 \mathrm{ff}$.

26 P. Monceaux, Histoire littéraire de l'Afrique chrétienne, 7 Bde., Paris 1912-1923. 
gustins (Bd.7), einschließlich einer umfassenden Chronologie der Schriften, sondern versuchte auch, die literarische Tätigkeit der Donatisten in ihrem Kontext zu analysieren und zu würdigen (Bde. 5 und 6) sowie den Donatismus als Gesamtphänomen zu beurteilen (Bd. 4). Trotz dieses Verdienstes ist nicht zu übersehen, dass es Monceaux nicht gelungen ist, sich aus der katholischen Perspektive zu lösen und das theologische Selbstverständnis des Donatismus unvoreingenommen zu beurteilen. ${ }^{27}$ Er rechtfertigt die katholischen Positionen, und seine Darstellung donatistischer Hauptfiguren wie Parmenianus und Petilianus münden stets in polemischen Kommentaren, die eine vermeintliche Sturheit und Verblendung der Donatisten geißeln. Obwohl der Forschungsstand veraltet ist, bleibt Monceauxs Werk für die Beschäftigung mit Augustins historischer Argumentation und mit donatistischen Geschichtstraditionen aufgrund seines Informationsreichtums unentbehrlich. Gleichzeitig fordert es zur kritischen Auseinandersetzung mit der Quelleninterpretation auf.

Monceaux deutet den Donatismus als Folge menschlicher Verfehlungen, theologischer Differenzen und eines religiösen Fanatismus. Damit richtet er sich auch gegen jene Forschungstendenzen, die in der ersten Hälfte des 20. Jahrhunderts mehr an Einfluss gewannen und den Donatismus sozialgeschichtlich, vor allem als Ausdruck gesellschaftlicher und wirtschaftlicher Gegensätze in Nordafrika interpretierten. ${ }^{28}$ Die Beachtung gesellschaftlicher und politischer Phänomene bedeutete eine entscheidende Horizonterweiterung für das Verständnis des Donatismus. Andererseits zeigten weitere Studien, dass die religiösen Faktoren nicht einfach ausgeblendet werden können und dürfen. Für die Forschung war nunmehr zu klären, in welcher Weise religiöse und soziale Einflüsse für die Entstehung und Entwicklung des Donatismus ausschlaggebend waren.

Von nachhaltiger Bedeutung ist diesbezüglich die bis heute einzige Gesamtdarstellung zum Donatismus von W.H.C. Frend, die 1952 erschien. ${ }^{29}$ Frend stellt die sozialgeschichtlichen Zusammenhänge für seine Interpretation in den Vordergrund, indem er vor allem einen ethnischen Konflikt zwischen der berberisch sprechenden Landbevölkerung und den romanisierten Stadtbewohnern

27 A. Schindler, Theologie der Donatisten, 133: ,[E]s war Monceaux [...] nicht möglich, jene inneren Zusammenhänge des donatistischen Denkens angemessen zu würdigen, die der Logik Augustins zuwiderlaufen oder besser: auf einer von Augustinus nicht wahrgenommenen Ebene liegen."

28 Den sozialgeschichtlichen Hintergrund stellte erstmals W. Thümmel (Zur Beurtheilung des Donatismus, Halle 1893) heraus. Die These, dass der Donatismus eine sozialrevolutionäre Bewegung sei, vertrat am nachhaltigsten F. Martroye, Une tentative de révolution sociale en Afrique. Donatistes et Circoncellions, Revue des questions historiques 32, 1904, 353-416; 33, 1905, 5-53.

29 W.H.C. Frend, The Donatist Church: A Movement of Protest in Roman North Africa, Oxford 1952. 
Nordafrikas als Hintergrund des Donatismus postuliert. Ein weiterer Konflikt sei der wirtschaftliche Gegensatz der ausgebeuteten armen Landbevölkerung zu den reichen Gutsbesitzern bzw. den wohlhabenden Städten. Frends Darstellung ist zweifellos eine stringente Abhandlung und Beurteilung des Donatismus und nach wie vor als Standardwerk grundlegend. Allerdings lässt sich ein oftmals unkritischer Umgang mit den literarischen und archäologischen Zeugnissen feststellen, wodurch nicht selten Fehlinterpretationen zustande kommen. Aufgrund ihrer großen Breitenwirkung finden sich diese Interpretationen immer wieder auch in neuesten Darstellungen, obwohl sie in der Forschung als überholt angesehen werden. ${ }^{30}$

Neben Frend kann noch die Darstellung „Autonomisme et christianisme dans l'Afrique romaine“" von J.-P. Brisson, die in Paris 1959 erschien, als Versuch einer Gesamtdeutung des Donatismus gelten. BRISSON sieht ebenfalls die wirtschaftlichen und sozialen Unterschiede in Nordafrika als wesentlichen Faktor der Kirchenspaltung. Gegen FREND hebt er jedoch die theologischen Besonderheiten des afrikanischen Christentums hervor: Eine Ursache des Schismas liege darin, dass die Donatisten, die sich in der Tradition Cyprians wähnten, die kirchliche Autonomie Nordafrikas gegen die Vereinahmung durch den Kaiser verteidigen wollten.

In den letzten 60 Jahren sind zahlreiche Einzelstudien und Darstellungen zum Donatismus erschienen. Wohl auch aufgrund der Komplexität der Thematik sind weitere Versuche von Gesamtdarstellungen unterblieben. ${ }^{31}$ Für den Inhalt dieser Arbeit sind insbesondere drei Themenbereiche relevant, zu denen einige grundlegende Forschungsansätze kurz skizziert werden sollen: Zum Ersten die Schriften Augustins, sein Leben und seine Zeit, zum Zweiten die Entstehungsgeschichte des donatistischen Schismas und zum Dritten das historische Selbstverständnis der Donatisten.

Eine umfassende Analyse zum antidonatistischen Werk Augustins findet sich nach Monceaux in der Monographie von G. G. Willis „Saint Augustine and the Donatist Controversy“32. Willis bietet eine ausführliche Darstellung der Geschichte von Augustins Kampf gegen den Donatismus mit Schwerpunkten auf den ekklesiologischen und theologischen Fragestellungen sowie der Rechtfertigung von Zwangsgewalt. Als Kompendium für Augustins antidonatistische Schriften und ihren Hauptthemen ist Willis' Darstellung durchaus

30 Vgl. bereits die Kritik von A. H. M. Jones, Were Ancient Heresies National or Social Movements in disguise?, JThS 10, 1959, 280-298.

31 Vgl. aber die hervorragende Übersicht von A. Schindler, TRE 1, 1977, 650-700, s. v. Afrika I, sowie die Zusammenfassungen zum Donatismus im Augustinus Lexikon: S. Lancel, AL 1, 606-622, s. v. Donatistae (I. Partie historique); J. Alexander, AL 1, 622 638, s. v. Donatistae (II. Theological Part).

32 G. G. Willis, Saint Augustine and the Donatist Controversy, London 1950 [ND 2005]. 
geeignet, doch geht sie in den Einzelfragen zum Donatismus nicht über MoNCEAUX hinaus.

Wesentlich weiterführender ist die Einleitung Yves Congars zur Ausgabe der antidonatistischen Schriften Augustins in der Reihe der Bibliothèque Augustinienne. ${ }^{33}$ Congar gelingt es, den Diskussionsstand seiner Zeit zum Donatismus allgemein und zu Augustins Kampf gegen die Donatisten zusammenzufassen, offene Fragestellungen zu benennen und entscheidende Aspekte herauszustellen. Neben dieser Einleitung zum Gesamtwerk geben die historischen und theologischen Kommentare und die Interpretationen von Émilien LaMIrande, Albert C. De Veer und B. Quinot wichtige Hintergrundinformationen und Impulse zum Verständnis von Augustins Auseinandersetzung mit dem Donatismus. ${ }^{34}$

Der Donatismus ist überdies Bestandteil von Abhandlungen zu Augustins Leben und Werk. ${ }^{35}$ Aus der biografischen Literatur sind aufgrund ihrer Sachkenntnis und ihres Detailreichtums und einer besonderen Schwerpunktsetzung auf den Donatismus vor allem die Darstellungen von Peter Brown ${ }^{36}$ und GeRALD BONNER ${ }^{37}$ zu nennen. SERGE LANCEL hat die Ergebnisse seiner langjährigen Forschungen zu Augustinus ebenfalls in einer Biografie zusammengetragen. ${ }^{38}$ Hinsichtlich der Chronologie der Schriften und des Lebens Augustins ist die Darstellung von Othmar Perler/J.-L. Maier „Les voyages de saint Augustin“ nach wie vor ein Standardwerk, wenngleich einzelne Ergebnisse korrekturbedürftig geworden sind. ${ }^{39}$

Das Verhältnis Augustins zum nordafrikanischen Episkopat steht im Zentrum der Studie von Remí Crespin. ${ }^{40}$ Mithilfe seiner Interpretationen erschlieBen sich wichtige Zusammenhänge für den Entstehungshintergrund, den his-

33 Euvres de Saint Augustin, Traités anti-donatistes, Paris 1963-1968, BA 28-32. Congars Einleitung in BA 28, 9-124.

34 Von Lamirande siehe auch: Aux origines du dialogue interconfessionnel: Saint Augustin et les donatistes: vingt ans de tentatives infructueuses (393-411), Studia canonica 32, 1998, 203-228; ders., La Conférence de Carthage (411) et les réactions de saint Augustin: un procès singulier, fatal aux donatistes, Studia canonica 32, 1998, 415-440.

$35 \mathrm{Zu}$ den unterschiedlichen Annäherungen und Schwerpunkten, insbesondere zur neuesten Augustinusbiografie von J. O'Donnell (Augustine: An New Biography, New York 2005) vgl. N. Baker-Brian, Modern Augustinian Biographies: Revisions and CounterMemories, ZAC 11, 2007, 151-167.

36 P. Brown, Augustine of Hippo, London 1967 [2. Aufl. 2000]. In der Neuauflage unterzieht Brown seine Darstellungen einer kritischen Revision auf Grundlage der neueren Forschungsergebnisse. Vgl. auch den Sammelband: P. Brown, Religion and Society in the Age of St. Augustine, London 1972.

37 Augustine of Hippo: Life and Controversies, Norwich ${ }^{2} 1986$.

38 S. Lancel, Saint Augustin, Paris 1999.

39 Othmar Perler/J.-L. Maier, Les voyages de saint Augustin, Paris 1969.

40 R. Crespin, Ministère et sainteté, Pastorale du Clergé et solution de la crise donatiste dans la vie et la doctrine de St. Augustine, Paris 1965 [= Diss. Lyon 1961]. 
torischen Kontext und der Theologie der antidonatistischen Schriften Augustins und den Donatismus in dieser Zeit.

$\mathrm{Zu}$ den umstrittenen inhaltlichen, quellenkritischen und chronologischen Fragen bezüglich der Entstehungsgeschichte des Donatismus sind ebenfalls weiterführende Einzelstudien erschienen: Einen Entwurf über den Ursprung und Verlauf der Verfolgung der Donatisten bis zur Zeit Augustins bietet die Studie von ERnST Ludwig GrasmücK. ${ }^{41}$ Der Schwerpunkt dieser Arbeit liegt auf der Herausbildung der kaiserlichen Zwangsgewalt (coercitio) gegen die Donatisten.

Zur Auswertung der Schriften Augustins als Quelle für die Entstehung des donatistischen Schismas sind Beiträge von Timothy D. Barnes, ${ }^{42}$ Serge LAN$\mathrm{CEL}^{43}$ und insbesondere von KLAUS MARTIN GIRARDET ${ }^{44}$ weiterführend. Die umfangreichste Studie der letzten Jahre zu dieser Thematik hat BERNHARD KRIEGBAUM vorgelegt. ${ }^{45}$ Er untersucht ausführlich die Hintergründe, die zur Abwahl Caecilians als Bischof Karthagos führten. Trotz problematischer Interpretationen im Detail kann Kriegbaum überzeugend darlegen, dass es vor allem theologische und persönliche Streitigkeiten waren, die die Spaltung auslösten. Die Frage, warum sich das Schisma verfestigen und der Donatismus so lange in Afrika halten konnte, wird jedoch nicht beantwortet.

Mit dieser Frage beschäftigen sich dagegen andere Forschungsarbeiten, in denen versucht wird, dem Selbstverständnis der Donatisten näher zu kommen. Dabei wurde deutlich, dass der Donatismus keinesfalls pauschal als eine einheitliche Bewegung oder Ideologie angesehen werden darf, sondern dass es zu unterschiedlichen Zeiten verschiedene Strömungen und Ausrichtungen gab, die

41 E.L. Grasmück, Coercitio, Staat und Kirche im Donatistenstreit, Bonn 1964 [= Diss. Bonn 1959].

42 T.D. Barnes, The Beginnings of Donatism, JThS 26, 1975, 13-22. Grundlegend für die Chronologie auch Barnes, The New Empire of Diocletian and Constantine, Cambridge/ London 1982.

43 S. Lancel, Les débutes du Donatisme, la date du Protocole de Cirta et l'élection épiscopale de Silvanus, RÉAug 25, 1979, 217-229.

44 K.M. Girardet, Kaisergericht und Bischofsgericht. Studien zu den Anfängen des Donatistenstreits (313-315) und zum Prozeß des Athanasius von Alexandrien (328-346), Bonn 1975; ders., Konstantin d. Gr. und das Reichsgericht von Arles, in: Oecumenica et Patristica, Stuttgart/Berlin/Köln 1989, S. 151-174; ders., Die Petition der Donatisten an Kaiser Konstantin (Frühjahr 313). Historische Voraussetzungen und Folgen, Chiron 19, 1989, 185-206; ders., Das Reichskozil von Rom (313) - Urteil, Einspruch, Folgen, Historia 41, 1992, 104-116.

45 B. Kriegbaum, Kirche der Traditoren oder Kirche der Märtyrer?, Die Vorgeschichte des Donatismus, Innsbruck 1986. Zu weiteren Einzelfragen s. a. ders., Ein neuer Lösungsvorschlag für ein altes Problem: die sogenannten preces der Donatisten (Optatus I. 22), Studia Patristica 22, 1989, 277-282; ders., Zwischen den Synoden von Rom und Arles. Die donatistische Supplik bei Optatus, AHP 28, 1990, 23-61; ders., Die Religionspolitik des Kaisers Maxentius, AHP 30, 1992, 7-54. 
den Donatismus prägten. Darüber hinaus lässt sich feststellen, dass zwischen den Katholiken und Donatisten in Nordafrika sehr große Übereinstimmungen herrschten, wenn man die religiöse Praxis betrachtet. So ist die starke Märtyrerverehrung ein Phänomen der afrikanischen Kirche, die nicht nur den Donatisten eigen war. ${ }^{46}$

In seiner Darstellung „Donatisten und Katholiken“ analysiert EmIN TengSтRöм die möglichen Zusammenhänge der sozialen, politischen und wirtschaftlichen Aspekte im Donatismus. ${ }^{47}$ Insbesondere gegen die Thesen Frends stellt Tengström heraus, dass die in den literarischen Quellen überlieferten einzelnen Ereignisse und Handlungen nicht verallgemeinert werden dürfen, sondern in ihrem individuellen Kontext verstanden und interpretiert werden müssen. Die Arbeit Tengströms besticht durch ihre gründliche Quellenkritik und bietet daher nach wie vor wichtige Anregungen für die Interpretation einzelner Phänomene des Donatismus.

In zahlreichen Beiträgen hat James Alexander unterschiedliche Aspekte des Donatismus beleuchtet. Vor allem ausgehend von den Überlieferungen zur Konferenz von 411 gelingt es ihm, einzelne Seiten des Donatismus zu erhellen. ${ }^{48}$ In den letzten Jahren hat die Frage nach dem Selbstverständnis der Donatisten vor allem durch die Forschungsergebnisse Maureen Tilleys neue Impulse erhalten. ${ }^{49}$ Auf Grundlage der literarischen Quellen, insbesondere der überlieferten donatistischen Märtyrerberichte, untersucht TiLLEY das donatistische Bibelverständnis und theologische Positionen. Als wichtigstes Ergebnis formuliert sie die These, dass die Donatisten in den Zeiten, in denen sie nicht verfolgt wurden, ihre Identität nicht mehr in einer „Kirche der Märtyrer" sahen, sondern

46 Vgl. Schindler, Theologie der Donatisten, 136-141 - Zur Auswertung der archäologischen Quellen: Y. Duval, Loca sanctorum Africae, Le culte des martyrs en Afrique du IVe au VIIe siècle, 2 Bde., Rom 1982.

47 E. Tengström Donatisten und Katholiken: soziale, wirtschaftliche und politische Aspekte einer nordafrikanischen Kirchenspaltung, Göteborg 1964.

48 Vgl. u. a. J. S. Alexander, A Note on the Interpretation of the Parable of the Treshing Floor at the Conference of Carthage of A.D. 411, JThS 24, 1973, 512-519; Aspects of Donatist Scriptural Interpretation at the Conference of Carthage, Studia Patristica 15, 1984 (TU 128), 125-130; ders., Count Taurinus and the Persecutors of Donatism, ZAC 2, 1998, 247-267; ders., St Augustine and his Opponents - Criteria for Discerning Donatist Sermons, in: Studia patristica 38, 2001, 3-7. S. auch die Übersicht über die donatistische Theologie in: AL 1, 622-638, s. v. Donatistae (II).

49 Vgl. M. A. Tilley, The Bible in Christian North Africa: the Donatist World, Minneapolis 1997; dies., From Seperatist Sect to Majority Church: the Ecclesiologies of Parmenian and Tyconius, in: Studia Patristica 33, Leuven 1997, 260-265; vgl. ferner: Donatist Martyr Stories, hg.v. M. A. Tilley, Liverpool 1996. 
vielmehr nach alttestamentlichem Vorbild in der Vorstellung einer heiligen Versammlung (collecta) inmitten unreiner Feinde. ${ }^{50}$

Tilley richtet $\mathrm{zu}$ Recht ihr Augenmerk auf bisher weniger verwendete Quellen, um dem Selbstverständnis der Donatisten näher zu kommen. Allerdings stellen gerade die überlieferten Märtyrerakten erhebliche Anforderungen an die Quellenkritik und bergen die Gefahr voreiliger oder unkritischer Schlussfolgerungen. Oftmals lassen sich die Urheberschaft und Überlieferungen der Texte nur schwer und kaum eindeutig als „donatistisch“ erschließen. Alan DEARn hat am Beispiel der sog. „Akten der Abitinischen Märtyrer“ gezeigt, wie einer historischen und theologischen Interpretation schnell die Grundlage entzogen werden kann, wenn die Authentizität eines Textes mit guten Gründen in Zweifel gezogen wird. ${ }^{51}$

Ausgangspunkt der historischen Arbeit sind die Quellen. Zahlreiche Quellen zur Geschichte des Donatismus sind in den letzten Jahren neu herausgegeben und kommentiert worden und schaffen somit eine günstige Basis für Vergleichsstudien zwischen Augustinus und der übrigen Überlieferung. Hierzu gehören zum einen die ausführlich eingeleitete und kommentierte Ausgabe der antidonatistischen Schrift des Optatus von Mileve von M. Labrousse $^{52}$ und zum anderen die Arbeiten Serge Lancels zu den Akten der Konferenz von Karthago im Jahre 411, die maßgebliche Fortschritte für die historische Deutung erbracht haben, vor allem für das Verständnis von Organisation und Verlauf der Konferenz. ${ }^{53}$ Eine kaum zu entbehrende Grundlage für eine Studie zum Donatismus sind die prosopografischen Arbeiten von André Mandouze, die eine Fülle an Informationen und Anregungen bereithalten. ${ }^{54}$ Eine hilfreiche Kompilation der wichtigsten Quellen zur Geschichte des Donatismus hat überdies JEAN-LouIs MAIER vorgelegt. ${ }^{55}$ Weit verstreute Texte aus der Geschichtsschreibung, Aktensammlungen und Rechtskodizes sind hier - mit einer französischen Übersetzung und Anmerkungen versehen - leicht zugänglich zusammengestellt worden.

50 Neben der zitierten Literatur vgl. hierzu besonders M. A. Tilley, Sustaining Donatist Self Identity from the Church of the Martyrs to the collecta of the Desert, JECS 5, 1997, $21-35$.

51 A. Dearn, The Abitinian Martyrs and the Outbreak of the Donatist Schism, JEH 55, 2004, 1-18.

52 Optat de Milève, Traité contre les Donatistes, 2 Bde., Paris 1995/96, SC 412/13.

53 Actes de la conférence de Carthage en 411, ed. S. Lancel, 4 Bde., Paris 1972-1991 (SC 194/95/224/373); Gesta conlationis Carthaginiensis anno 411, ed. S. Lancel, Turnhout 1974 (CCL 149 A). Vgl. u. Kap. 5.

54 Prosopographie de l'Afrique chrétienne 303-533, Paris 1982. Zur Problematik der prosopografischen Arbeit in Zusammenhang mit den Schriften Augustins vgl. André Mandouze, Augustin et Donat, in: Augustinus Afer, Fribourg 2003, 125-130.

55 Le Dossier du Donatisme, 2 Bde., Berlin 1987/89 (TU 134/135). 
In der vorliegenden Untersuchung werden die Forschungsansätze zur Geschichte des Donatismus einerseits und zur Interpretation der antidonatistischen Schriften Augustins andererseits berücksichtigt und überprüft. Die Ausrichtung auf die historische Argumentation setzt zweifellos Grenzen: Lediglich ein Ausschnitt der komplexen Gesamtthematik kann beachtet werden und nicht alle Details lassen sich mit gleicher Gründlichkeit einbeziehen. Aber diese Fokussierung auf einen Aspekt des donatistischen Streits eröffnet auch Möglichkeiten; sie schärft den Blick auf einige, manchmal bedeutende Einzelheiten: Hintergründe und Methoden der Auseinandersetzung zur Zeit Augustins, die Herausbildung und Verwendung von geschichtlichen Überlieferungen und die Wechselwirkung von Geschichtsdarstellungen und Rechtfertigung eigener Überzeugungen werden in dieser Arbeit in der Darstellung akzentuiert und in der Deutung weiterentwickelt. 


\section{Der Donatismus zur Zeit Augustins}

\section{Voraussetzungen}

1.1 Die politische Situation in Nordafrika im 4. Jahrhundert n. Chr.

Im ausgehenden vierten Jahrhundert herrschten im Westen des Römischen Reiches keine stabilen politischen Verhältnisse. ${ }^{1}$ Nach dem Tod seines Bruders Gratian im Jahre 383 war der zunächst noch minderjährige Valentinian II. zum alleinigen Augustus im Westen aufgestiegen. Doch blieb der junge Kaiser in einer schwachen Position. Gegen den Usurpator Magnus Maximus konnte er sich nicht mit eigener Kraft durchsetzen, sondern war auf die Hilfe seines Mitkaisers Theodosius angewiesen, der Maximus zunächst eine offizielle Anerkennung gewährte, später jedoch in einem Feldzug besiegte und hinrichten ließ (August 388). Durch das Eingreifen des Theodosius blieb Valentinian zwar Kaiser, jedoch war er abhängig in seinem Handeln und in seiner Herrschaft auf die Präfektur Gallien beschränkt. Nachdem der mächtige fränkische magister militum Arbogast dem Kaiser in aller Öffentlichkeit den Gehorsam verweigert hatte, kam Valentinian II. im Mai 392 unter nicht geklärten Umständen ums Leben. $^{2}$ Mit Hilfe Arbogasts wurde Flavius Eugenius zum Augustus ernannt, ${ }^{3}$ ein Schritt, den Theodosius nicht akzeptierte. Stattdessen ließ er seinen Sohn Honorius im Januar 393 in Konstantinopel zum Augustus ausrufen und besiegte im September des folgenden Jahres Eugenius und Arbogast am Fluss Frigidus in der Nähe von Aquileia. Am 17. Januar 395 starb Theodosius in Mailand, und die Herrschaft ging an seine Söhne Arcadius und Honorius über. Zuvor hatte er die Sorge für seine Söhne und das Reich in die Hände des Heermeisters Stilicho gelegt. Diese Entscheidung bedeutete die entscheidende Weichenstellung für die Politik der nächsten Jahre: Stilicho spielte bis zu seinem Sturz im August 408 die dominierende Rolle im westlichen Teil des Römischen Reiches. Honorius war Kaiser bis zu seinem Tod im August 423.

Die römische Diözese Africa, die seit Diokletian sechs Provinzen umfasste, ${ }^{4}$ galt auch noch gegen Ende des 4. Jahrhunderts als wohlhabender und prospe-

1 Eine Übersicht der Ereignisse bei J. Curran, CAH XIII, 78-110; R. C. Blockley, CAH XIII, 111-137; A. Demandt, Die Spätantike, 124-157.

2 Zos. IV 53-54.

3 Zur Person PLRE I, 293, s. v. Flavius Eugenius 6.

4 Zur Diözese Africa gehörte Mauretania Sitifensis, Mauretania Caesariensis, Numidia (Hauptstadt Cirta/Constantina), Africa Proconsularis (Karthago), Byzacena (Ha- 
rierender Teil des Reiches. Im Gegensatz zu den Nordprovinzen herrschte weitgehende Sicherheit vor äußeren Feinden und das wirtschaftliche und gesellschaftliche Leben in den zahlreichen Städten und auf den großen Landgütern florierte. ${ }^{5}$ Allerdings wurde die politische Ordnung durch Gewalt und Aufstände erschüttert, die vor allem mit den Namen der Brüder Firmus und Gildo verbunden sind. Wohl im Jahr 372 eroberte Firmus, ${ }^{6}$ der Sohn des mauretanischen Berberfürsten Nubel, möglicherweise durch die eigenmächtige Herrschaft des comes Africae Romanus herausgefordert, ${ }^{7}$ mit Hilfe von Berberstämmen und desertierten römischen Soldaten einige Gebiete und Städte in Mauretanien und Numidien und unterwarf sie seiner Gewalt. Nach langem Widerstand unterlag Firmus schließlich im Jahre 375 den römischen Truppen unter der Führung des magister equitum Flavius Theodosius. ${ }^{8}$

Gildo, Bruder des Firmus, ${ }^{9}$ durchlief eine Laufbahn in der römischen Armee und wurde wohl im Jahr 385 comes Africae. ${ }^{10}$ In dieser Stellung beutete er Land und Menschen aus und bereicherte sich selbst in erheblicher Weise. In den Quellen wird Gildo als habgieriger und korrupter Despot dargestellt, der Afrika

drumetum) und Tripolitana (Leptis Magna). Die Diözese unterstand der Verwaltung des Prätorianerpräfekten für Illyricum, Italien und Afrika, der durch den in Karthago residierenden vicarius Africae vertreten wurde. Dem Vikar unterstanden die einzelnen Provinzstatthalter mit Ausnahme des Prokonsuls für Africa Proconsularis, der direkt dem Kaiser verpflichtet war. Neben der Zivilverwaltung besaß der comes Africae als militärischer Oberbefehlshaber weitgehende Befugnisse. Zur römischen Provinz Afrika, ihrer Verwaltung und den geographischen und wirtschaftlichen Bedingungen vgl. C. Lepelley, Cités I, passim; ders. AL 1, 180-205, s. v. Africa; B.H. Warmington, The North African Provinces from Diocletian to the Vandal Conquest. - $\mathrm{Zu}$ den bekannten Amtsträgern der Provinz s. A. C. Pallu de Lessert II, passim; Maier II, 17-21.

5 Africa Proconsularis, Numidia und Byzacena waren wesentlich dichter besiedelt als die übrigen Provinzen.

6 Die wichtigsten Quellen sind Ammianus Marcellinus (XXIX-XXX), Orosius (VII 33), Zosimus (IV 16), Symmachus (or. 6.4) und Aurelius Victor (Epit. 45.7). Zu Firmus: PLRE I, 340, s. v. Firmus 3; Mandouze, PAC, 457, s. v. Firmus 1; Seeck, RE VI 2, 238 f., s. v. Firmus; Grasmück, 148-150; Congar, BA 28, 729 f.

7 Vgl. Amm. XXIX 5.2-3; Zos. IV 16.3. Zu Romanus: Mandouze, PAC, 997 f., s. v. Romanus 1; PLRE I, 768, s. v. Romanus 3; J. Alexander, Count Taurinus and the Persecutors of Donatism, ZAC 2, 1998, 247-267, hier: $254 \mathrm{f}$.

8 Zur Person: PLRE I, 902-904, s. v. Flavius Theodosius. Er war der Vater des späteren Kaisers Theodosius. Seit 369 magister equitum im Westen, wurde er kurz nach seinem Sieg über Firmus 375 oder 376 in Karthago hingerichtet.

9 Quellen zur Herrschaft Gildos: Claudian, de bello Gildonico, ders., de consulatu Stilichonis; Zosimus (V 11) und Orosius (VII 36) Vgl. zum Folgenden Seeck, RE VII 1, 1360-1363, s. v. Gildo; PLRE I, 395 f., s. v. Gildo; Mandouze, PAC, 539, s. v. Gildo 1; H.J. Diesner, Gildos Herrschaft und die Niederlage bei Theveste, Klio 40, 1962, 178-186; C. Gebbia, Ancora sulle 'rivolte' di Firmo e Gildone, in: L'Africa romana, Sassari 1988, $117-129$.

10 In CTh IX 7.9 (vom 30.12.393) wird Gildo als comes et magister utriusque militiae per Africam bezeichnet. 
mit seinem Terror knechtete. ${ }^{11}$ Da Gildo die Getreidelieferungen an Rom gedrosselt hatte, nur halbherzig Loyalität gegenüber Honorius zeigte sowie beständig Klagen über seine Terrorherrschaft laut wurden, drohte ihm um das Jahr 397 ein Einschreiten Stilichos. Daraufhin versagte Gildo Honorius die Gefolgschaft und unterstellte sich demonstrativ dem Ostkaiser Arcadius. Er unterbrach die Getreidelieferung nach Rom vollständig, woraufhin er vom Senat zum Staatsfeind erklärt wurde. Ein Heer unter Führung seines Bruders Mazciel, der vor Gildo nach Italien geflohen war, setzte nach Afrika über und besiegte Gildo im Frühjahr 398. Nach über einem Jahrzehnt der Herrschaft wurde Gildo abgesetzt und hingerichtet, sein großes Vermögen konfisziert. ${ }^{12}$

In den folgenden Jahren stabilisierte sich die Lage in Afrika, bis es unter der Führung des comes Africae Heraclianus erneut zu einem Aufstand kam. Heraclianus, der während der Kämpfe gegen die Goten in Italien noch auf Seiten des Kaisers gestanden hatte, revoltierte gegen Honorius im Jahre 413. Sein Heer unterlag jedoch bei Rom und Heraclianus wurde hingerichtet. ${ }^{13}$ Eine einflussreiche Stellung besaß seit 423 der comes Africae Bonifatius, ${ }^{14}$ der sich trotz zahlreicher Machtkämpfe nach dem Tod des Honorius behaupten konnte und die Provinz gegen die Vandalen zu verteidigen suchte. Das vorläufige Ende der römischen Herrschaft in Afrika erfolgte mit der Eroberung der Provinzen durch die Vandalen unter Geiserich.

\subsection{Die Situation der Donatisten in Afrika}

Die Kirche der Donatisten hatte sich im Laufe des 4. Jahrhunderts in den afrikanischen Provinzen etabliert. ${ }^{15}$ Unter Kaiser Constans war es im Jahre 347 nochmals zu einer Verfolgung von Donatisten gekommen, bei der Bischöfe ins Exil verbannt, Kirchen konfisziert und offener Widerstand bestraft wurde. Diese Erfahrungen der Unterdrückung, ausgehend von dem kaiserlichen Be-

11 Die Darstellung der Verbrechen Gildos ist allerdings - vor allem bei Claudian - polemisch zugespitzt, um Gildo als Staatsfeind herabzusetzen. Die immense Selbstbereicherung Gildos, u. a. durch privaten Verkauf des für Rom bestimmten Getreides und ungerechtfertigte Konfiszierungen, finden jedoch durch Gesetzesfragmente Bestätigung (CTh VII 8.7, 9; IX 42.16, 19; Not. Dig. Occ. XII 5).

12 CTh VII 8.7; IX 42.19

13 Zur Person: PLRE II, 539 f., s. v. Heraclianus 3; Mandouze, PAC, 552 f., s. v. Heraclianus.

14 Zur Person: R. A. Markus, AL 1, 653-655, s. v. Bonifatius comes Africae; PLRE II, 237-240, s. v. Bonifatius 3; Mandouze, PAC, 152-155, s. v. Bonifatius 13; vgl. H.-J. Diesner, Die Laufbahn des comes Africae Bonifatius und seine Beziehungen zu Augustin, in: Kirche und Staat im spätrömischen Reich, Berlin ${ }^{2} 1964,100-126$.

15 Für die Zeit zwischen 321 und 347 existieren nur wenige Quellen zum Donatismus. Vgl. auch zum Folgenden die Übersichtsdarstellung bei Schindler, TRE 1, 1997, 657-662. 
auftragten Macarius, schlugen sich in Märtyrerberichten nieder. Die Erinnerung an die „macarianische Verfolgung“ sollte bis in die Zeit Augustins nachwirken. ${ }^{16}$ Im Gegensatz dazu stand die Regierungszeit Julians (361-363): Alle Religionsgemeinschaften wurden toleriert, und die Donatisten erhielten die Gelegenheit, ihre Kirche zu reorganisieren. Verbannte Bischöfe durften zurückkehren und ehemals konfiszierte Basiliken und Güter wurden zurückgegeben. ${ }^{17}$

Unter Julians Nachfolgern im Westen des Römischen Reiches scheint der erreichte status quo im Großen und Ganzen erhalten geblieben zu sein. Der donatistische Bischof Karthagos Parmenianus entfaltete in einer mehr als dreißig Jahre währenden Amtszeit bis zu seinem Tod im Jahr 392 sein Wirken in zahlreichen theologischen Schriften und antikatholischer Propaganda. ${ }^{18}$ Gleichzeitig erarbeitete der Donatist Tyconius seine exegetischen und theologischen Schriften. ${ }^{19}$ Auf der Gegenseite erschien 366/7 in einer ersten Auflage das antidonatistische Werk des Optatus von Mileve, der sich gegen die polemischen Schriften Parmenians zur Wehr setzte. ${ }^{20}$ Possidius, Bischof von Calama und Biograf Augustins, behauptet, dass vor Beginn des antidonatistischen Kampfes durch Augustinus eine donatistische Mehrheit in Afrika geherrscht habe. $^{21}$ Nach Schätzungen lässt sich von etwa 300 donatistischen Bischöfen ausgehen, mit Schwerpunkten in Numidien und Mauretanien. ${ }^{22}$ In vielen Städ-

$16 \mathrm{Zu}$ den Ereignissen der Verfolgung unter Macarius und ihrem Nachwirken im donatistischen Verständnis vgl. u. Kap. 6.3.2.

17 Amm. XXII 5.3-4; Opt. II 16-17, 23-26; III 10-11; VI 1-8 (mit Berichten über schändliche Verbrechen der Donatisten nach ihrer Begünstigung); Aug. c. litt. Pet. II 184. Vgl. M. Di Maio, The Emperor Julian's Edicts of Religious Toleration, The Ancient World 20, 1989, 25-54; Frend, Donatist Church, 187-192; Grasmück, Coercitio, 132 139.

18 Zu Leben und Werk: Monceaux V, 221-240; Mandouze, PAC, 816-821, s. v. Parmenianus; Tilley, Bible, 96-112.

19 Erhalten ist der Liber Regularum, eine Schrift zur Bibelhermeneutik. Zu Tyconius: Monceaux V, 165-219; Mandouze, PAC, 1122-1127, s. v. Tyconius; Congar, BA 28, 718-720; P. Bright, A Conflict of Christian Hermeneutics in Roman Africa, Berkeley 1989; Tilley, Bible, 112-128.

20 Vgl. Labrousse, SC 412, 9-56; Monceaux V, 241-306; Mandouze, PAC, 795-797, s. v. Optatus 1.

21 Poss. vita 7.2. - Es ist indessen anzunehmen, dass Possidius die Stärke der Gegner bewusst übersteigert, damit Augustins „Erfolg“ umso größer wirken kann.

22 Im numidischen Bagaï versammelten sich im Jahr 394 Augustinus zufolge 310 donatistische Bischöfe, Anhänger Primians (vgl. die Zusammenstellung bei Maier II, Nr. 56, 84-91). Die genannte Anzahl erscheint durchaus glaubhaft (vgl. Kriegbaum, ZKTh 124, 2002, 271, gegen Congar, BA 28, 743). Der überlieferte Synodalbrief des bereits zuvor abgehaltenen Gegenkonzils der Anhänger Maximians in Cabarsussa (24. Juni 393) nennt 53 Unterzeichner (Aug. en. Ps. 36. 2.18-23; vgl. Maier II, Nr. 54, 73-82). Doch diese Liste ist unvollständig. Augustinus selbst gibt die Zahl der Teilnehmer mit 100 an, was jedoch rhetorisch bedingt ist. Positiv zur Zahl 100 allerdings C. Weidmann, Augustinus und das Maximianistenkonzil von Cabarsussi, Wien 1998, 40-42. Bei der 
ten existierten katholische und donatistische Gemeinden nebeneinander. Wenig deutet darauf hin, dass die Donatisten in dieser Zeit in ihrer Religionsausübung behindert und gar verfolgt worden wären. Im Gegenteil: Weder staatliche Autoritäten noch die katholische Kirche scheinen ein größeres Interesse an der Bekämpfung des Donatismus gezeigt zu haben. Der vicarius Africae des Jahres 377 und spätere Prätorianerpräfekt Flavianus soll laut Augustinus den Donatisten zugetan gewesen sein, ${ }^{23}$ und der katholische Bischof Genethlius von Karthago, Vorgänger des Aurelius, wurde später von Donatisten für sein Eintreten zu Gunsten ihrer Partei gelobt. ${ }^{24}$

Von den Machthabern Firmus und Gildo erhielten die Donatisten Hilfe gegen Abspaltungen aus ihren eigenen Reihen. Aus den wenigen konkreten Berichten, die ausschließlich bei Augustinus überliefert sind, lässt sich allerdings keine generelle Unterstützung der Revolten der beiden Brüder durch die Donatisten ableiten, wie in Teilen der Forschung geschehen. ${ }^{25}$ Augustinus selbst verallgemeinert nicht, sondern stellt lediglich Beispiele vor, um zu zeigen, dass die Donatisten militärische Gewalt in Anspruch genommen haben. Während er das Beispiel Firmus nur an wenigen Stellen nennt, ${ }^{26}$ insistiert er in seiner Propaganda sehr häufig auf der Beziehung des donatistischen Bischofs Optatus von Thamugadi zu Gildo. Er stellt diesen Bischof als Schandfleck der Donatisten

Konferenz von Karthago im Jahre 411 wurden schließlich 285 donatistische Bischöfe gezählt (zur Problematik vgl. u. Kap. 5.1.2). Vgl. die Schätzungen von Lancel, SC 194, $181 \mathrm{f}$.

23 Ep. 87.8. - Zur Person: PLRE I, 347 f., s. v. Virius Nicomachus Flavianus 15; R. M. Errington, The Pretorian Prefectures of Virius Nicomachus Flavianus, Historia 41, 1992, 458 f.; T. Honoré, Virius Nicomachus Flavianus, Konstanz 1989, 9-17.

24 Ep. 44.12.

25 Ich schließe mich hier den Ausführungen von Tengström (Donatisten, 79-90) an und seiner berechtigten Kritik u. a. an Frend, Donatist Church, 73, 197-199.

26 Lediglich durch zwei Beispiele bei Augustinus wissen wir etwas über Beziehungen zwischen Firmus und den Donatisten: So erhielten die Donatisten von Firmus Unterstützung gegen die Abspaltung der Rogatisten in Mauretania Caesariensis (ep. 87.10; c. ep. Parm. I 16; c. litt. Pet. II 184. Vgl. unten Kap. 4.1.4). Zudem ließ angeblich der donatistische Bischof des numidischen Rusicade für Firmus die Tore der Stadt öffnen und gab sie mit ihren katholischen Bewohnern der Plünderung preis (ep. 87.10). Tengström hat zu Recht betont, dass hier von Einzelfällen die Rede ist. Im Falle der Rogatisten nahmen die Donatisten Firmus' Hilfe in Anspruch, so wie sie unter anderen Umständen auf die römische Obrigkeit zurückgriffen. „Die Donatisten haben also die faktischen politischen Machthaber - sowohl Firmus wie die gewöhnliche Administration - im Interesse der eigenen Kirche zu benutzen gewusst." So Tengström (Donatisten, 81) gegen Frend (Donatist Church, 198 f.): ,The Donatists lent their support to the rebel [sc. Firmus], as legitimate Emperor, and in return for the help which he had received Firmus repressed the Rogatists around Cartenna." Den Bericht über die Eroberung von Rusicade kannte bereits Augustinus nur vom Hörensagen und benutzte ihn für seine Polemik gegen den donatistischen Bischof Emeritus, den Adressaten der ep. 87 (vgl. u. Kap. 4.1.2). 
heraus und bezeichnet ihn durchgängig als fanatischen Anhänger Gildos. ${ }^{27} \mathrm{Bi}$ schöfe der donatistischen Abspaltung der Maximianisten, ${ }^{28}$ so Augustinus, seien mit Hilfe des Optatus und Truppen des Gildo zur Umkehr gezwungen worden, ${ }^{29}$ und auch die katholische Kirche habe unter bewaffneten Banden des Optatus leiden müssen. ${ }^{30}$ Dass Optatus unter den donatistischen Bischöfen nicht die Regel, sondern eine extremistische Ausnahme darstellte, betont Augustinus jedoch selbst. Die Donatisten waren also alles andere als fanatische Anhänger des Optatus und damit auch nicht in toto Anhänger Gildos. ${ }^{31}$ Nur einzelne donatistische Bischöfe sind durch Firmus oder durch Gildo protegiert worden oder bedienten sich umgekehrt der Unterstützung der jeweiligen Machthaber, um gegen die aus ihrer Sicht illegitimen Häresien vorzugehen.

Bemerkenswert bleibt indessen, dass der Name Gildo in der Bevölkerung derart negativ belegt war, dass Augustinus die Donatisten durch die Verbindung mit dem Namen Gildo zu diskreditieren beabsichtigte. In Anbetracht der Intention Augustins, gerade auch donatistische Leser von der Schuld des Optatus

27 Augustinus bezeichnet Optatus als Gildonianus (c. ep. Parm. II 4, 42; III 4; bapt. II 16; c. litt. Pet. I 11, 14, 26; Cresc. III 66; IV 31; Emer. 9; ep. 53.6), satelles Gildonis (c. ep. Parm. II 8, 34; c. litt. Pet. II 209, 232; Cresc. III 16) und als amicus Gildonis (c. litt. Pet. II 184). Er behauptet, Optatus sei nach der Niederlage Gildos im Gefängnis gestorben, da er als satelles Gildonis angeklagt war (c. litt. Pet. II 209). - Vgl. die Zusammenstellung und Auswertung der Quellen bei Mandouze, PAC, 797-801, s. v. Optatus 2. Optatus ist nur durch Augustinus bekannt. Die Vielzahl der Erwähnungen steht im Gegensatz zu den tatsächlichen Kenntnissen über Optatus, der als exemple par excellence für donatistische Gewalt steht.

28 Vgl. u. S. $24 \mathrm{f}$.

29 C. litt. Pet. I 11; Cresc. III 66; IV 32.

30 C. litt. Pet. II 184. Die Verbindung der bewaffneten Anhänger des Optatus zu Gildo wird zwar nicht direkt hergestellt, doch ist sie aufgrund der Kontakte von Optatus selbst $\mathrm{zu}$ Gildo wahrscheinlich. Infolge der Gewalttaten sei Opatus vom vicarius Seranius zu einer Geldstrafe von 10 Pfund Gold verurteilt worden.

31 Mit Tengström (Donatisten, 85-90), der zu Recht den Argumentationszusammenhang bei Augustinus herausstellt: Es ging Augustinus nicht um eine Anklage der Donatisten als Anhänger Gildos, sondern um die Frage, warum in der Kirche der Reinen ein Verbrecher wie Optatus, der Anhänger Gildos, geduldet werde. Auch wenn laut ep. 76.3 die Donatisten Optatus später einen Märtyrer nannten, spricht dies nicht zwangsläufig für eine breite Unterstützung seiner Person. Augustinus verallgemeinert an dieser Stelle in seiner Polemik. Andernorts wird deutlich, wie groß die Kritik der Donatisten an Optatus war (vgl. Cresc. III 16, 49, 66; IV 31 f.). Entsprechend kritisch sind die Interpretationen der Augustinusstellen zu Optatus bei einigen Forschern zu betrachten. Etwa bei Monceaux IV, 64 f.; Frend, Donatist Church, 225 f.; Seeck, Geschichte III, 354-356, oder Stein, Geschichte, 315 (,...wußte sich Gildo, auf die Sekte [der Donatisten] gestützt, bald eine große persönliche Machtfülle zu erwerben, ...“). Differenzierter urteilt Grasmück (Coercitio, 163), der vermutet, die übrigen donatistischen Bischöfe hätten sich aus Furcht der Allianz Gildo - Optatus untergeordnet. S. auch Lepelley, Cités II, 471-473; Brown, Religion and Society, 318, 321. 
von Thamugadi zu überzeugen, kann der Negativklang Gildos keinesfalls durch eine Assoziation seiner Person mit dem Donatismus zustande gekommen sein. Vielmehr ruft er allgemein Gildos Regiment ins Gedächtnis, unter dem ganz Afrika zu leiden hatte, und weckt damit bei Katholiken und Donatisten gleichermaßen böse Erinnerungen. ${ }^{32}$

Eine wichtige Rolle in der Auseinandersetzung zwischen Donatisten und Katholiken spielten die sogenannten Circumcellionen. ${ }^{33}$ Die Circumcellionen lassen sich als eine Gruppierung rigoristischer und gewaltbereiter Donatisten beschreiben, die sich aus Männern und Frauen der ländlichen Bevölkerung vor allem in Numidien zusammensetzte (agrestes, plebs rusticana). Sie hielten sich auf den großen Landgütern auf und verdienten dort vermutlich ihren Lebensunterhalt als freie Arbeiter. ${ }^{34}$ Die Circumcellionen zogen, mit Schlagstöcken bewaffnet, in Gruppen umher und tyrannisierten katholische Kleriker, Landbesitzer und donatistische Konvertiten. Sie bezeichneten sich selbst als agonistici und verwendeten den Schlachtruf deo laudes. Dies lässt auf die religiöse Motivation der Gruppierung schließen. Die Circumcellionen waren extreme Anhänger der in Afrika stark verbreiteten Märtyrerkulte und zeigten offenbar

32 Vgl. c. ep. Parm. II 4.

33 Das Phänomen der Circumcellionen ist in den Quellen nur schwer fassbar und seine Deutung in der Forschung sehr umstritten. Ihrer häufigen Erwähnung in den Quellen steht ein Mangel an konkreten Informationen über ihre Herkunft, ihre Zielsetzung und ihr Selbstverständnis gegenüber. Diese Diskrepanz erklärt sich durch die zahlreichen, aber stets gleich lautenden Aussagen Augustins über Gewalttaten von Circumcellionen an Katholiken, die nichts über den Hintergrund dieser Gruppierung verraten. Durch Optatus von Mileve sind die Circumcellionen erstmals für die Zeit der Verfolgung unter Macarius belegt (III 4), später (außer bei Augustinus) unter anderem bei Possidius von Calama (vita 10,12), in den Konzilsakten der afrikanischen Kirche und bei einigen späteren katholischen Theologen erwähnt sowie in dem Unionsgesetz vom 30. Januar 412, das infolge der Konferenz von 411 erlassen wurde. Die Circumcellionen stellen ein eigenes Forschungsgebiet dar, das hier keinesfalls in seiner Breite dargestellt werden kann. Gute Übersichten bei C. Lepelley, AL 1, 930-936, s. v. Circumcelliones; A. Schindler, TRE 1, 662-665. Vgl. ferner Tengström, Donatisten, 24-78 (eine ausführliche Auseinandersetzung mit den Quellen, aber nicht immer zutreffende Ergebnisse); Diesner, Kirche und Staat, 78-90; G. Gottlieb, Die Circumcellionen, Bemerkungen zum donatistischen Streit, AHC 10, 1978, 1-15 (mit einer guten Übersicht der Forschungstendenzen); R. Lorenz, Circumcelliones - cotopitae - cutzupitani, ZKG 82, 1971, 54 59; M. Overbeck, Augustin und die Circumcellionen seiner Zeit, Chiron 3, 1973, $457-$ 463.

34 Augustinus gibt in c. Gaud. I 32 einen Hinweis auf die Herkunft des Wortes, die eine plausible Erklärung für die Entstehung der Fremdbezeichnung Circumcellionen darstellt. Man bezeichnete die agonistici im Volksmund als jene, die um die cellae ziehen oder lagern. Diese cellae waren entweder Lagerhäuser oder auch Märtyrerkapellen. Frend hat auf archäologische Funde hingewiesen, die auf eine Verbindung von Märtyrerplätzen mit Lagerhäusern deuten. Vgl. Frend, Donatist Church, 173 f.; ders., The Cellae of the African Circumcellions, JThS 3, 1952, 87-89. 
in der Verteidigung ihrer Kirche selbst eine große Martyriumsbereitschaft. ${ }^{35}$ Durch Optatus von Thamugadi ließen sich die Circumcellionen instrumentalisieren, eine Verbindung, auf die Augustinus immer wieder aufmerksam macht. Jedoch gab es auch Donatisten, die auf Distanz zu den Circumcellionen und Gewaltanwendungen gingen. ${ }^{36}$

Es ist zu beachten, dass Augustinus den Begriff Circumcellionen undifferenziert verwendet für bewaffnete Scharen von Donatisten, die grausamen Terror und Gewalt an Katholiken üben. An vielen Stellen spricht er allgemein von der Gewalt der Circumcellionen, er nennt aber auch einige Einzelbeispiele, mit denen er die Untaten der Circumcellionen vor Augen führt, stets in der Absicht, die Gewalt und Grausamkeit herauszustellen und dies den Donatisten generell anzulasten ${ }^{37}$ Augustinus nutzt also bekannte Vorkommnisse für seine antidonatistische Argumentation und Polemik, sei es als Allgemeinplatz, sei es anhand von Einzelfällen. Das heißt, nicht jede von Augustinus geschilderte Gewalttat muss zwangsläufig von Circumcellionen begangen worden sein, und nicht jeder Anhänger der Circumcellionen muss ein Gewalttäter gewesen sein.

Im Jahre 392 starb Parmenianus, der einflussreiche donatistische Bischof Karthagos. Sein Nachfolger wurde Primianus, dessen Wahl jedoch zu einer Spaltung innerhalb der Donatisten führte, das sogenannte Maximianistische Schisma, das in der Argumentation Augustins gegen die Donatisten eine sehr wichtige Rolle spielen sollte. ${ }^{38}$

35 Gegen die Interpretation aus CTh XVI 5.52, dass es sich bei den Circumcellionen um einen ordo freier Landarbeiter gehandelt habe (erstmals bei Ch. Saumagne, Ouvriers agricoles ou rôdeurs de celliers? Les circoncellions d'Afrique, Annales d'histoire économique et sociale 6 (28), 1934, 351-364, später u. a. bei Brisson, Autonomisme, $334-$ 341, Diesner, Kirche und Staat, 54-57 und Tengström, Donatismus, 44-52) vgl. die Argumente bei Gottlieb, AHC 10, 1978, $8 \mathrm{f}$. und J.E. Atkinson, Out of Order: the Circumcellions and Codex Theodosianus 16,5,52, Historia 41, 1992, 488-499. - In der Forschung wurden die Circumcellionen als sozialrevolutionäre Bewegung gegen die römische Herrschaft bzw. der punisch sprechenden Landbevölkerung gegen die romanisierte Oberschicht gedeutet (F. Martroye, Revue des questions historiques 32, 1904, 353-416; 33, 1905, 5-53; später weiter entwickelt v.a. von Diesner, Kirche und Staat, 17-21, 53-90 und Frend, Donatist Church). Kritik an dieser Interpretation u.a. von A.H.M. Jones (Were Ancient Heresies National or Social Movements in Disguise, JThS, 10, 1959, 280-298) und P. Brown (Religion and Society, 237-259). Wenngleich sich Momente sozialen Protestes nicht leugnen lassen, so dürften die Circumcellionen in erster Linie aus religiöser Motivation gehandelt haben, die auch ihr Selbstverständnis bestimmte; vgl. Tengström, Donatisten, 66-74; Schindler, TRE 1, 665.

36 Cresc. IV 31-34, 77; s. u. Kap. 3.3.4.

37 Vgl. die Auflistung bei Gottlieb, AHC 10, 1978, 4-6.

38 Einzige Quelle zum Maximianistischen Schisma sind die zahlreichen Anspielungen bei Augustinus. Vgl. auch zum Folgenden: B. Kriegbaum, Die donatistischen Konzilien von Cebarsussa (393) und Bagai (394), ZKTh 124, 2002, 267-277; A. de Veer, L'exploitation 
Innerhalb der donatistischen Gemeinde Karthagos war die Wahl Primians zum neuen Bischof im Jahre 392 umstritten. Primianus ging jedoch streng gegen seine Kritiker vor und exkommunizierte vier Diakone, darunter einen gewissen Maximianus. Dieser aber ließ die Sache nicht auf sich beruhen, sondern versammelte Ende 392 /Anfang 393 zur Untersuchung des Falles 43 Bischöfe in Karthago. Primianus lehnte es ab, sich vor diesem Gremium zu verantworten, woraufhin die Bischöfe Primianus verurteilten. Am 24. Juni 393 kamen mehr als einhundert Bischöfe in der byzacenischen Stadt Cabarsussa zusammen, die Primianus endgültig verurteilten und seines Amtes enthoben und Maximianus zum Bischof Karthagos ernannten. ${ }^{39}$ Während sich Maximianus vor allem auf die Bischöfe der Proconsularis und Byzacena stützen konnte, blieb das numidische Episkopat mehrheitlich auf der Seite Primians. Doch erst Monate später, am 24. April 394, konnte er in der Stadt Bagaï 310 Bischöfe zu einem Konzil versammeln, die Maximianus als Schismatiker verdammten, ebenso seine zwölf Konsekratoren. ${ }^{40}$ Allen Anhängern Maximians wurde eine Frist eingeräumt, in der sie ohne Buße zu den Donatisten zurückkehren durften. In den folgenden Jahren gingen die „Primianisten“ gegen die Maximianisten vor, wobei sie sich auch staatlicher Hilfe bedienten. ${ }^{41}$

Im Codex Theodosianus sind einige Gesetze überliefert, die Aufschluss über die rechtliche Situation der Donatisten in Afrika geben können. Zwar wird der Begriff „Donatisten“ in einem Gesetz erstmals im sogenannten Unionsedikt vom Februar des Jahres 405 verwendet, für die Zeit zuvor existieren jedoch Gesetze gegen Häretiker und gegen die Wiedertaufe, die zum Teil auf die Donatisten bezogen werden können. ${ }^{42}$ Nach der Herrschaft Julians erließ Valentinian I. im Jahr 373 ein Verbot der Wiedertaufe, ein Gesetz, das sein Nachfolger Gratian ausdrücklich bestätigte. ${ }^{43}$ Weitere Verbote der Wiedertaufe

du schisme maximianiste par S. Augustine dans sa lutte contre le Donatisme, RechAug 13, 1965, 219-237; C. Weidmann, Augustinus und das Maximianistenkonzil von Cabarsussi, Wien 1998; Frend, Donatist Church, 213-224. Zu Primianus: Monceaux VI, 111-143; Mandouze, PAC, 905-913, s. v. Primianus 1; Lancel, SC 194, $201 \mathrm{f}$.

39 En. Ps. 36. 2. 18-23.

40 Cresc. III 22, 59; IV 5.

41 Trotz Verfolgung gab es im Jahr 411 nachweislich noch Maximianisten. Zur Konferenz wurden sie jedoch nicht zugelassen (Gesta conl. Carth. I 10; vgl. Lancel, SC 194, 35 f.).

42 Zum Folgenden: Monceaux IV, 254-258; Congar, BA 28, 732 f.; Quinot, BA 30, 792 f.; Grasmück, Coercitio, 139 ff.; Tengström, Donatisten, 95-104; F. Morgenstern, Die Kaisergesetze gegen die Donatisten in Nordafrika (Mitte 4. Jh. bis 429), ZRG RA 110, 1993, 103-123; K. L. Noethlichs, Die gesetzgeberischen Maßnahmen der christlichen Kaiser des vierten Jahrhunderts gegen Häretiker, Heiden, Juden, Köln 1971, passim.

43 CTh XVI 6.1 (vom 20. Februar 373 an den Prokonsul Iulianus): „Wir betrachten denjenigen Bischof seines Priesteramtes unwürdig, der in unerlaubter Anmaßung die heilige Taufe zweifach ausführt und gegen die Grundsätze aller durch Wiederholung diesen Gnadenerweis verschmutzt.“ (Antistitem, qui sanctitatem baptismi illicita usurpatione geminauerit et contra instituta omnium eam gratiam iterando contaminauerit, sacerdotio 
sind bis zum Jahr 405 nicht überliefert. ${ }^{44}$ Gegen Häresien in Afrika richten sich indessen zwei weitere Gesetze: Gratian erließ im April 376 ein generelles Verbot von häretischen Versammlungen unter Androhung der Konfiskation der Versammlungsstätten ${ }^{45}$ und Honorius verfügte die Bestrafung von Manichäern und ihren Beschützern im Mai 399. ${ }^{46}$

Was sagen diese Gesetze über die Situation der Donatisten aus? Zweifellos praktizierten die Donatisten aus katholischer Sicht eine Wiedertaufe. Allerdings stellte diese keinesfalls den Regelfall dar. Der donatistischen Doktrin zufolge wurden Wiedertaufen nur dann durchgeführt, wenn ein Katholik zu den Donatisten konvertierte. Solche Übertritte fanden zwar statt, jedoch wird die große Mehrheit der Christen - ähnlich den Konfessionen heute - entweder der einen oder der anderen Kirche angehört haben, ohne jemals über einen Wechsel aus der angestammten Zugehörigkeit nachgedacht zu haben. ${ }^{47}$ Es ist daher anzunehmen, dass viele donatistische Priester oder Bischöfe in ihrer Amtszeit niemals Wiedertaufen durchführten und insofern gegen kein Gesetz zur Wiedertaufe verstießen. Aufgrund der Existenz der Gesetze gegen die Wiedertaufe kann daher nicht auf eine weitgehende Verfolgung donatistischer Priester oder gar der gesamten Kirche geschlossen werden. Andere Quellen belegen vielmehr das Gegenteil: Die Taufe eines zuvor katholischen Diakons durch den donatistischen Bischof Maximinus von Hippo um das Jahr 393 scheint kein Anlass

indignum esse censemus.) Vgl. Maier II, Nr. 40, 44-46; CTh XVI 6.2 vom 17. Oktober 377 an Flavianus, Prokonsul Afrikas; CTh XVI 5.5 vom 20. August 379 an den PPO Italiens und Afrikas Hesperius. - Eine oftmals postulierte Verbindung von CTh XVI 5.5 zu einem angeblichen „Toleranzedikt“ Gratians im Jahre 378 (vgl. etwa Grasmück, Coercitio, 152; Tengström, Donatisten, 98) ist nahezu auszuschließen, vgl. R. M. Errington, Church and State in the First Years of Theodosius I, Chiron 27, 1997, 21-72, hier: $29-33$.

44 Im Codex Theodosianus finden sich dagegen aus dieser Zeit zahlreiche Gesetze gegen Arianer und arianische Abspaltungen, die besonders durch Theodosius und den einflussreichen PPO Orientis Rufinus (vgl. PLRE I, 778-781, s. v. Fl. Rufinus 18) forciert worden waren, während Valentinian II. zunächst indifferent blieb. Für die Zeit nach seiner Bekehrung zur Orthodoxie durch Ambrosius (387) fehlen für Valentinian II. die Quellen. Für Afrika verhinderte sicher auch der Einfluss Gildos jedwede Art der Religionspolitik durch den Kaiser. Vgl. Noethlichs, Maßnahmen, 121-125.

45 CTh XVI 5.4 (Gratian am 22. April 376 an den Prokonsul(?) Hesperius). - Tengström (Donatisten, 96 f. Anm. 5) sieht in diesem Schreiben zu Recht kein antidonatistisches Gesetz. Hier ist allgemein von Häretikern die Rede, zu denen die Donatisten noch nicht gezählt wurden. Gegen Grasmück (Coercitio, 151), der einen eindeutigen Zusammenhang mit den Donatisten infolge der Firmusrevolte sieht. Diese Verbindung ist umso unverständlicher, da sich Grasmück der Korrektur von PPO in Procos. Hesperius anschließt (vgl. Seeck, Regesten, 116 u. 246). Gerade in Africa Proconsularis spielte Firmus keine Rolle.

46 CTh XVI 5.35 vom 17. Mai 399 an den vicarius Africae Dominator.

47 Augustinus erwähnt in ep. 93.17, wie viele Menschen aus Tradition oder Trägheit an ihren Glauben festhielten; vgl. auch u. Kap. 2.2.2. 
einer staatlichen Verfolgung gewesen zu sein. Augustins Beschwerde über diesen Vorgang lässt auf einen außergewöhnlichen Zwischenfall schließen, der durch Gespräche geregelt werden sollte (ep. 23). In die gleiche Richtung deutet der Fall des donatistischen Bischofs Crispinus von Calama: Die von ihm erzwungene Taufe mehrerer Katholiken brachte die katholische Kirche gegen ihn auf. Der angestrengte Prozess vor dem Prokonsul führte zwar zu einer Verurteilung, aber Crispinus legte Berufung ein und scheint letztlich nicht belangt worden zu sein. ${ }^{48}$ Dieses Beispiel zeigt, dass es sich um einen Ausnahmefall handelte und dass selbst solch einer kaum auf Grundlage von Gesetzen geahndet wurde. $^{49}$

Entsprechend ist die Anwendung antihäretischer Gesetze zu sehen. Sicherlich konnten Donatisten der Häresie angeklagt werden, doch musste ihnen diese erst nachgewiesen werden. Die donatistische Kirche war jedoch in den Augen vieler Menschen nichts anderes als die katholische Kirche. Die Donatisten hatten nachweislich Erfolg mit regulären Anklagen gegen die Maximianisten. Dies zeigt eindeutig, dass zum einen zwar antihäretische Gesetze zur Anwendung kommen konnten, wenn eine Anklage vorlag und Verstöße gegen Gesetze nachgewiesen werden konnten. Zum anderen galt die donatistische Kirche jedoch nicht per se als häretisch, und sie war selbst in der Lage, Abweichler in den eigenen Reihen mit juristischer Hilfe zu bekämpfen. Bis zum Unionsgesetz des Jahres 405 war die donatistische Kirche keine Häresie, die als solche der Verfolgung durch Gesetze unterlag. Allerdings bestand für donatistische Priester die Gefahr, aufgrund von Wiedertaufen angeklagt und verurteilt zu werden. Für katholische wie donatistische Kleriker bestand gleichermaßen die Möglichkeit einer Anklage wegen Aufruhr und Gewalt sowie häretischer Umtriebe. Entscheidend war aber das Verhalten des Einzelnen. Augustins Beispiel Optatus von Thamugadi lässt erkennen, dass dieser nicht als Donatist, sondern als Anhänger des verfemten Gildo eingekerkert wurde.

Das Interesse der kaiserlichen Politik war in diesen Jahren nicht primär auf die religiösen Probleme in der afrikanischen Provinz ausgerichtet. Solange in Afrika Ruhe herrschte und die Getreidelieferungen regelmäßig kamen, wurden die Provinzen ihrer eigenständigen Verwaltung überlassen. Diese Politik begünstigte beispielsweise den Aufstieg Gildos. Erst als dieser seine Machtbefugnisse deutlich überschritt, griff der Kaiser wieder ein. Der Hof war an einer Beruhigung der Lage interessiert und ging entsprechend gegen jede Art öffentlicher Provokation vor. Ob diese religiös motiviert waren oder nicht, spielte

48 Ep. 66; s. Denis 19.8; vgl. Grasmück, Coercitio, 197 f.

49 Vgl. die Argumente von A. Schindler, Die Unterscheidung von Schisma und Häresie in der Gesetzgebung und Polemik gegen den Donatismus (mit einer Bemerkung zur Datierung von Augustins Schrift: contra epistulam Parmeniani), in: Pietas, FS Kötting, Münster 1980, $230 \mathrm{f}$. 
nur eine untergeordnete Rolle. Insofern dienten auch die Gesetze gegen Wiedertaufe und Häresie primär dazu, Unruhen zu verhindern, die durch religiöse Auseinandersetzungen ausgelöst wurden.

Man wird folglich davon ausgehen dürfen, dass die donatistische Kirche auch nach Kaiser Julian bis zum Unionsgesetz des Jahres 405 eine weitestgehende Freiheit besaß, ihre Religion zu praktizieren. Die von Valentinian und Gratian erlassenen Gesetze galten der Erhaltung der öffentlichen Ruhe. Donatisten waren dann der juristischen Verfolgung ausgesetzt, wenn sie als Gefahr angesehen wurden. Dies galt unter anderem für die Anhänger Firmus' und Gildos unter den Donatisten, ebenso für gewaltbereite Donatisten, die Circumcellionen, oder auch Bischöfe, die sich provozierend verhielten. DonatistSein galt indessen gemeinhin nicht als Häresie. Gerade diese Situation eines „konfessionellen“ Nebeneinanders jedoch nahm Augustinus zum Anlass, seinen Kampf gegen den Donatismus aufzunehmen.

\section{Die Entwicklung der Auseinandersetzung Augustins mit den Donatisten}

\subsection{Der Beginn der Kontroverse (393-405)}

Die katholische Kirche Afrikas erscheint in Bezug auf das donatistische Schisma bis in das letzte Jahrzehnt des 4. Jahrhunderts hinein sehr passiv. Im Jahr 348, nach der Bekämpfung des Donatismus durch Macarius, fand unter Bischof Gratus ein Konzil in Karthago statt, in dessen Akten der Dank der Bischöfe an den kaiserlichen Beauftragten kundgetan wird. Das nächste afrikanische Konzil, das in den Quellen erwähnt wird, fand erst 390 in Karthago statt, der Donatismus wurde jedoch nicht thematisiert. ${ }^{50} \mathrm{Zu}$ Recht wird daher der Aufbruch zu einem erneuerten Kampf gegen den Donatismus durch die katholische Kirche mit den Bischöfen Aurelius von Karthago und Augustinus von Hippo verbunden. Über die Person des Aurelius ist verhältnismäßig wenig bekannt, ${ }^{51}$ doch ist es für sein Engagement bezeichnend, dass bereits kurz nach seinem Amtsantritt (392/3) ein afrikanisches Konzil in Hippo Regius unter seinem Vorsitz einberufen wurde, ab 401 folgten zahlreiche weitere Konzile, manchmal sogar zwei in einem Jahr.

Jenes Konzil von Hippo fand am 8. Oktober 393 statt. Die versammelten Bischöfe thematisierten unter anderem das donatistische Schisma und diskutierten über das Verhältnis der beiden Kirchen zueinander. Sie kamen zu der für

50 Crespin, Ministère, 32 f., 35, 45-47; Grasmück, Coercitio, 159 f.

51 Mandouze, PAC, 105-127, s. v. Aurelius 1; A. La Bonnardière, AL 1, 1986/94, 550-566, s. v. Aurelius episcopus. 
sie ernüchternden Bestandsaufnahme, dass es in vielen ländlichen Gebieten Nordafrikas keine ordinierten katholischen Priester gebe und die geistliche Betreuung der Gläubigen gefährdet sei. ${ }^{52}$ Um diesem Mangel abzuhelfen, beschloss die Synode, donatistischen Bischöfen unter bestimmten Bedingungen die Möglichkeit zur Rückkehr in die katholische Kirche nicht nur als Laien, sondern als Kleriker offenzuhalten. Grundsätzlich wurde die Wiederherstellung von Frieden und Einheit als ein vordringliches Ziel formuliert. ${ }^{53}$ Möglicherweise sah sich Augustinus durch diese Synode veranlasst, sich intensiver mit dem Donatismus auseinanderzusetzen. Sicher ist jedenfalls, dass er in der Folgezeit seine ersten antidonatistischen Schriften verfasste, darunter den Psalmus contra Partem Donati, jenes beachtenswerte Lehrstück für seine Gemeinde in Hippo, das über die Geschichte und Lehre der Donatisten aufklären sollte. ${ }^{54}$

Als Entgegnung auf einen Brief des Donatus von Karthago, ${ }^{55}$ der offenbar in den donatistischen Gemeinden verbreitet war, schrieb Augustinus seine erste antidonatistische Abhandlung, das heute verlorene Buch contra epistulam Donati (c. ep. Don.), in dem er in ähnlicher Argumentationsweise wie im Psalmus das donatistische Taufverständnis zu widerlegen suchte. ${ }^{56}$ In seinen ersten Jahren als Bischof suchte Augustinus den Dialog mit den Donatisten, darunter mit seinem „Gegenbischof“ in Hippo, Proculeianus. ${ }^{57}$ Gut dokumentiert sind seine Gespräche mit dem donatistischen Bischof Fortunius von Thubursicum und den donatistischen Laien aus dessen Diözese. ${ }^{58}$ Über Augustins Argumentationsweise in dieser Zeit wären wir heute noch besser informiert, wenn seine zwei Bücher contra Partem Donati erhalten wären. Deutlich wird indessen, dass er damals jegliche Zwangsgewalt gegen die Donatisten ablehnte. ${ }^{59}$

52 Conc. Hipp. Can. 37 (ed. Munier, CCL 149, 43 f.):[...] tantum autem inopia clericorum ordinandorum in Africa patiuntur ecclesiae ut quaedam loca omnino deserta sint [...]. Zum Konzil: Maier II, Nr. 55, 82-84; Crespin, Ministère, 53.

53 Conc. Hipp. Can. 37. - Die Bedingungen für eine Rückkehr donatistischer Laien war auf einem Konzil von Rom am 6. Januar 386 festgelegt worden. Vgl. den Brief des Papstes Siricius an die afrikanischen Bischöfe (Siricius ep. 5), ed. Munier, CCL 149, 5464; Maier II, Nr. 48, 60-62, dazu Crespin, Ministère, 48-60; de Veer, BA 31, 766-771. Auf zwei weiteren Konzilien in Karthago, im August 397 und im Juni 401, finden sich ebenfalls Aussagen, die die Offenheit der katholischen Kirche für übertrittswillige Donatisten bestätigen. Vgl. Munier, CCL 149, 186, 194-198; Maier II, Nr. 62, 101 f.; Nr. 65, 106-110.

54 S. o. Kap. 1.1.

55 Donatus, Namensgeber der Donatisten und Nachfolger des Maiorinus als (donatistischer) Bischof in Karthago von 313-347; s. Mandouze, PAC, 292-303, s. v. Donatus 5; Alexander, AL 2, 644-646, s. v. Donatus.

56 Retr. I 21; vgl. Monceaux VII, 85 f.; Schindler, AL 2, 1063 f., s. v. Epistulam Donati heretici (Contra-).

57 Ep. 33; vgl. Poss. indic. VI 25.

58 Epp. 43/44; s. u. Kap. 4.1.1.

59 Retr. II 5; Poss. indic. VI 2; geschrieben um das Jahr 397. 
Zum Vordenker und Wortführer der Donatisten zur Zeit Augustins avancierte der Bischof von Cirta, Petilianus. ${ }^{60}$ In Entgegnung auf einen offensichtlich weit verbreiteten Brief Petilians schrieb Augustinus in den Jahren 400/401 die ersten beiden Bücher gegen Petilianus (contra litteras Petiliani), in denen er die Argumente seines donatistischen Kollegen zum Taufsakrament, zur Kirche und zur Verfolgung Schritt für Schritt analysiert und zu widerlegen sucht. ${ }^{61}$ Als weitere Replik auf Petilianus entstand das Buch ad catholicos fratres (cath. fr.), mit dem er seinen katholischen Kollegen Argumente gegen die Donatisten in die Hand geben wollte. ${ }^{62}$

Acht Jahre nach dem Konzil von Hippo und nur mäßigen Erfolgen ihrer Kampagne gegen die Donatisten entschieden sich die afrikanischen Bischöfe auf einem Konzil in Karthago im September 401, nicht länger den gegebenen Zustand zu akzeptieren. Sie beschlossen, in Zukunft zu versuchen, donatistische Kleriker und Laien auf dem Überzeugungsweg für die katholische Kirche zurückzugewinnen, indem Legaten zu donatistischen Gemeinden entsandt werden sollten. Zudem bestätigte man die Entscheidung des Konzils von Hippo, donatistischen Klerikern den Übertritt zu erleichtern, indem ihnen eingeräumt wurde, dass sie in ihrem geistlichen Stand verbleiben könnten, wenn der katholische Bischof der Diözese dies akzeptierte. Diese Regelungen tragen zweifellos die Handschrift Augustins, der zu diesem Zeitpunkt noch ein fast unerschütterliches Vertrauen in den Erfolg von Religionsgesprächen und die Überzeugungsarbeit setzte.

Zwei Jahre später, auf einem Konzil am 25. August 403 in Karthago, entwickelten die afrikanischen Bischöfe nochmals einen Versuch, Religionsgespräche mit den Donatisten durchzuführen. ${ }^{63}$ Diese Gespräche sollten nunmehr in jeder Stadt unter der Leitung der städtischen Magistrate abgehalten werden. Bischof Aurelius von Karthago wandte sich mit einer entsprechenden Bitte an den Prokonsul Septiminus und an den vicarius Africae, die die Beamten anweisen sollten, Gespräche vor Ort zu organisieren. Septiminus stimmte dem

60 Zur Person: Mandouze, PAC, 855-868, s. v. Petilianus; Quinot, BA 30, 11-16; Monceaux VI, 3-17; zu seiner Rolle im Jahr 411: Lancel, SC 194, 221-238.

61 Edition: Petschenig, CSEL 52, 3-227. Vgl. retr. II 25; Poss. indic. VI 6-7. Durch die Arbeitsweise Augustins ist Petilians epistula ad presbyteros et diaconos vollständig erhalten und bietet somit einen hervorragenden Einblick in die Theologie des Donatisten. Petilianus wollte mit seinem Schreiben allen donatistischen Klerikern eine Hilfestellung für die Auseinandersetzung mit den Katholiken geben. Vgl. dazu Quinot, BA 30, 41-70; eine ausführliche Erörterung, allerdings mit starker katholischer Polemik bei Monceaux (V, 311-328: rekonstruierter Text; VI, 17-35).

62 Edition: Petschenig, CSEL 52, 231-322; vgl. Poss. indic. VI 20; Quinot, BA 30, $485-$ 497.

63 Vgl. Maier II, Nr. 68-69, 118-123; Lancel, SC 194, 14-18; Grasmück, Coercitio, 195197; Crespin, Ministère, 64. 
Unternehmen zu, die Reaktion des Vikars ist nicht erhalten. ${ }^{64}$ Diese Entscheidung der katholischen Bischöfe zu einem weiteren Schritt war keinesfalls durch den Erfolg bisheriger Gespräche begründet, sondern angesichts zunehmender Schärfe der Auseinandersetzung ein letzter Versuch, überhaupt mit den Donatisten zu einem konstruktiven Dialog zu kommen. Es ist nicht bekannt, ob es in einzelnen Städten zur Durchführung der Gespräche kam, aber die Haltung der donatistischen Wortführer geht aus der Reaktion des karthagischen Bischofs Primianus auf das Gesprächsangebot seines katholischen Kollegen Aurelius hervor: Es sei unwürdig, ließ jener verlauten, dass die Söhne der Märtyrer und die Nachkommen der Traditoren an einem Ort zusammenkämen. ${ }^{65}$ Diese ablehnende Haltung wurde durch ein donatistisches Konzil in Karthago zur Richtlinie für alle Bischöfe. ${ }^{66}$ Gespräche mit der anderen Partei, mit oder ohne Vermittlung durch städtische Beamte, mussten zurückgewiesen werden.

Parallel zu den vergeblichen Gesprächsversuchen verfasste Augustinus in den Jahren bis 405 neben etlichen Briefen, in denen er seine Position zum Donatismus darlegt ${ }^{67}$ seine theologisch bedeutsamsten antidonatistischen Werke. In Entgegnung auf eine epistula ad Tyconium des Bischofs Parmenianus, des wohl einflussreichsten Theologen der Donatisten, schrieb Augustinus die drei Bücher contra epistulam Parmeniani. Parmenianus hatte sein Verständnis einer „reinen“ Kirche gegen die Auffassung des Tyconius dargelegt. Augustinus greift die Fragen der Ekklesiologie und der Tauflehre auf und versucht, die Widersprüche der donatistischen Position offenzulegen. ${ }^{68}$ Bald darauf formulierte Augustinus sein Taufverständnis in Abgrenzung zu den Donatisten und auf Grundlage des afrikanischen Kirchenvaters Cyprian in den „sieben Büchern über die Taufe" (de baptismo libri septem).${ }^{69}$ Er verurteilt darin die donatistische

64 Gesta conl. Carth. III 174; vgl. Maier II, Nr. 70, 123 f. - Auf der Konferenz von 411 wurden sowohl Akten aus dem Archiv des Prokonsuls als auch aus dem des Vikars vorgelegt (breuic. III 5).

65 Primians Äußerungen sind fragmentarisch erhalten. Gesta conl. Carth. III 116: Indignum est ut in unum conueniant filii martyrum et progenies traditorum; vgl. breuic. III 4, 11; c. Don. 1, 20, 39, 53; Cresc. IV 57. Vgl. Maier II, Nr. 71, 124-126. - In Calama verweigerte Crispinus seinem katholischen Kollegen Possidius das Gespräch; Cresc. III 50; Maier II, Nr. 72, $126 \mathrm{f}$.

66 Augustinus erwähnt mehrmals dieses Konzil: Cresc. III 49-50; ep. 76.4; Augustins Gegenbischof Proculeianus lehnte mit Berufung auf den Konzilsentscheid ein Zusammentreffen ab; ep. 88.7.

67 S. u. Kap. 4.

68 Zu c. ep. Parm: retr. II 17; Poss. indic. VI 4; Edition: Petschenig, CSEL 51, 19-141. Zu Parmenians epistula und Augustins Abhandlungen: Congar, BA 28, 197-207; Monceaux V, 231-237; VII 88-92.

69 Edition: Petschenig, CSEL 51, 145-375; vgl. retr. II 18; Poss. indic. VI 5; Bavaud, BA 29, passim; Monceaux VII, 92-98; Schindler, AL 1, 574-582, s. v. Baptismo (De-). - Die Datierung von c. ep. Parm. und bapt. ist umstritten. Ein Teil der Forschung nimmt eine Datierung um 400 an (u. a. Monceaux VII, 92, 275, G. Madec, Introduction aux Revi- 
Praxis der Wiedertaufe und erläutert, dass die Gültigkeit der Taufe nicht vom Taufspender abhänge. In dieser Phase schrieb Augustinus eine weitere Schrift, den heute verlorenen Traktat contra quod attulit Centurius a Donatistis (c. Cent.), in dem er die Argumente des donatistischen Laien Centurius widerlegt. ${ }^{70}$ Schließlich verfasste Augustinus um das Jahr 403 sein drittes Buch gegen Petilianus (c. litt. Pet. III), mit dem er eine polemische Entgegnung Petilians auf sein erstes Buch beantwortete. Im Ton schärfer als zuvor beharren beide Kontrahenten auf ihrem Verständnis von Kirche und Taufsakrament. ${ }^{71}$

Am 16. Juni des Jahres 404 versammelten sich in Karthago die katholischen Bischöfe erneut zu einem Konzil. Aus den überlieferten Exzerpten der Konzilsakten $^{72}$ lässt sich erschließen, dass die Auseinandersetzung zwischen Donatisten und Katholiken inzwischen schärfer geworden war: Es wird von einer Gesandtschaft der Bischöfe Theasius und Evodius ${ }^{73}$ zum Kaiser berichtet, der sich gerade in Rom aufhielt. Die Instruktionen für die Boten enthalten die Klagen, dass die Donatisten ablehnend auf das ein Jahr zuvor unterbreitete Gesprächsangebot der Katholiken reagiert hätten und dass vor allem der Terror der Circumcellionen solche Gespräche torpediert hätte. Daher forderten die Bischöfe, dass den katholischen Kirchen unverzüglich durch die Gesetzgeber der einzelnen Städte und Ländereien Schutz gewährt werde. An den Kaiser richteten sie die Bitte, er möge dort, wo von den Donatisten Gewalt ausgeübt werde, zwei bereits bestehende Häretikergesetze des Theodosius auf die Donatisten anwenden. Zum einen ein Gesetz, das am 4. Mai 389 gegen die arianische Abspaltung der sog. Eunomianer erlassen worden war und die Ausstellung von Testamenten untersagte sowie den Verlust zahlreicher Privilegien

sions et à la lecture de saint Augustin, Paris 1996, 90 f., 164), ein anderer Teil eine spätere Datierung (frühestens 404) aufgrund der Anordnung dieser Schriften in den Retraktationen nach contra Felicem (sicher datiert auf Dezember 404), vgl. insbesondere Schindler, Unterscheidung, 228-236. Da die Reihenfolge der Retraktationen nicht konsequent chronologisch ist, mangelt es an eindeutigen Indizien, und eine sichere Datierung ist nicht möglich. Vgl. zur Diskussion Perler/Maier, 249-255, besonders 255 Anm. 2 und 3; Madec, aaO, 152-154.

70 Retr. II 19; Poss. indic. VI 12.

71 In Petilians Schrift stand wiederum die Frage nach der Gültigkeit des Taufsakraments außerhalb der donatistischen Kirche im Mittelpunkt. Offensichtlich enthielt sie aber auch zahlreiche persönliche Angriffe auf Augustinus, der die Wortwahl Petilians als „gewalttätig“ und „emotional“ charakterisiert. Vgl. Monceaux VI, 35-51; Quinot, BA 30, 565-580; Frend, Donatist Church, 255 f. - Zu c. litt. Pet. III vgl. Quinot, BA 30, 99113.

72 Reg. Conc. Carth. 93 (Munier, CCL 149, 211-214), vgl. Maier II, Nr. 74, 129-134.

$73 \mathrm{Zu}$ Theasius, Bischof von Memblone: Mandouze, PAC, 1105 f., s. v. Theasius. - Evodius, Bischof von Uzalis, war ehemaliger kaiserlicher agens in rebus (conf. IX 17) und ein enger Vertrauter Augustins. Dies dürfte entscheidend gewesen sein, ihn nach Ravenna zu senden. Mandouze, PAC, 366-373, s. v. Evodius 1. 
verkündete. ${ }^{74}$ Jedoch solle dies Gesetz nicht bei jenen Donatisten Anwendung finden, die nur aufgrund der finanziellen Einbußen, nicht aber aus Überzeugung zu den Katholiken überträten. Zum anderen ein Gesetz vom 15. Juni 392, in dem das Verbot der Ordination von Klerikern außerhalb der katholischen Kirche unter Androhung einer Geldstrafe von 10 Pfund Gold festgelegt worden war. $^{75}$

Außer diesen mündlichen Anweisungen gab die Synode den beiden Gesandten auch Briefe an den Kaiser und an die wichtigsten Hofbeamten und Militärs (eminentissimas potestates) mit, die die gestellten Forderungen nochmals bekräftigen sollten. Überdies wurde festgelegt, weitere Briefe an die afrikanischen Richter zu versenden, damit diese den Schutz der katholischen Kirche durch die Stadt- und Gutsverwaltungen gewährleisten, bis die Gesandten zurückgekehrt seien. Schließlich erhielten die beiden Boten noch Empfehlungsschreiben für den Bischof von Rom sowie für andere katholische Bischöfe, die sie antreffen werden.

Über das Zustandekommen dieser Konzilsentscheidung berichtet Augustinus einige Jahre später dem comes Bonifatius: Die Forderungen, die dem Kaiser von den Legaten schließlich überbracht werden sollten, waren demnach ein Kompromiss zwischen einem Teil des Episkopats, der ein Ende der „donatisti-

74 CTh XVI 5.17 (gerichtet an den PPO Orientis Tatianus): Eunomiani spadones nec faciendi nec adipiscendi habeant licentiam testamenti. [...] post hanc nostri oraculi sanctionem non habeant possidendi licentiam, non petendi, non etiam relinquendi heredem nomine principali, non fideicommissario, non legatorio, non tacito fideicommisso uel quamcumque in huiuscemodi negotiis nuncupationem iuris ordo constituit [...]. Nihil ad summum habeant commune cum reliquis. Vgl. Maier II, Nr. 49, 62-65.

75 CTh XVI 5.21 (gerichtet an den PPO Orientis Tatianus): „Bezüglich der häretischen Irrtümer verfügen wir, dass diejenigen, die nachweislich Kleriker ordiniert oder ein Amt als Kleriker angenommen haben, eine Strafe von zehn Pfund Gold zu leisten haben.“ (In haereticis erroribus quoscumque constiterit uel ordinasse clericos uel suscepisse officium clericorum denis libris auri uiritim multandos esse censemus, [...]). Vgl. Maier II, Nr. 52, 69-71. - Beide von den Bischöfen geforderten Gesetze finden sich im CTh lediglich in Ausführungen, die als Adressaten Tatianus ausweisen und damit für den östlichen Reichsteil bestimmt waren. Offensichtlich waren diese Gesetze aber im Jahre 404 in Afrika bekannt. In diesem Zusammenhang ist auffällig, dass Optatus von Thamugadi bereits im Jahre 398 zu 10 Pfund Gold Strafe verurteilt worden war (c. litt. Pet. II 184), ebenso Crispinus von Calama (ep. 66.2; Poss. vita 12) im Jahre 403/04 (vgl. dazu auch Schindler, Unterscheidung, $230 \mathrm{f}$.). Aufgrund dieser Verurteilungen ist es wahrscheinlich, dass auch für den westlichen Reichsteil bereits Häretikergesetze galten, die denen von CTh XVI 5.17 und 5.21 entsprachen, später aber nicht für den CTh berücksichtigt wurden. Die Forderung von 404 bedeutet folglich, dass die afrikanischen Bischöfe in den ihnen bekannten Gesetzen eine geeignete Grundlage für eine Gesetzgebung gegen die Donatisten sahen und eine gezielte Anwendung gegen die Donatisten erreichen wollten. Sollten sich aber die katholischen Bischöfe tatsächlich direkt auf CTh XVI 5.17 berufen haben, könnten sie auch durch die kaiserlichen Archive darauf gestoßen sein, denn das Gesetz wurde in Mailand erlassen (Seeck, Regesten, 275). 
schen Häresie" durch strenge Strafmaßnahmen wünschte, und einem anderen Teil, darunter Augustinus selbst, der sich zunächst gegen einen Bekehrungszwang aussprach. Der Entschluss, an die weltliche Gewalt zu appellieren, fiel, nachdem die Befürworter von Strafmaßnahmen Beispiele aus der Geschichte aufgezählt hatten, in denen berichtet wurde, wie viele Donatisten sich durch Zwang dem rechten Glauben wieder zugewandt hätten. ${ }^{76}$ Als Zugeständnis an Augustinus und die „gemäßigten“ Bischöfe kann der Wunsch gelten, die angedrohten Strafen nur bei hartnäckigem Widerstand anzuwenden. Ein Bekehrungszwang mit der Folge, viele Schein-Katholiken zu erhalten, sollte unbedingt vermieden werden.

Ebenfalls bei Augustinus finden sich Berichte, die über die Ergebnisse der Gesandtschaft der katholischen Bischöfe in Rom Auskunft geben. ${ }^{77}$ Allerdings erscheint dabei der Ablauf der Ereignisse undurchsichtig. Nach Augustins Aussagen waren es nämlich nicht die offiziellen Gesandten, die den Kaiser dazu brachten, ein schärferes Gesetz gegen die Donatisten zu verkünden, sondern zuvorderst andere afrikanische Bischöfe, die donatistische Gewalttaten hätten erdulden müssen und am Hof als Bittsteller gegen die Donatisten aufgetreten seien. Augustinus stellt vor allem die Geschichte des Bischofs Maximianus von Bagaï heraus, der nur durch Gottes Eingreifen den Terror der Donatisten überlebt habe. Zusammen mit weiteren Bischöfen, die in Afrika von Circumcellionen aus ihren Gebieten vertrieben worden waren, sei Maximianus am Hof in Ravenna erschienen und habe dort seine Wunden vorgeführt. ${ }^{78}$ Daraufhin

76 Correct. 25; vgl. ep. 88.7 und ep. 93.16 f., wo Augustinus ebenfalls seinen Entscheidungsprozess beschreibt. - Zum Konzil und den Entscheidungen vgl. Monceaux IV, 376-378; van der Meer, Augustinus, 119 f.; Lamirande, Studia canonica 32, 1998, 224 226.

77 Ep. 88.7; correct. 26; vgl. auch Cresc. III 47. Zusammenfassend de Veer, BA 31, 812 f.

78 Augustinus erzählt in correct. 27 f., Cresc. III 47 und ep. 88.7 die Geschichte des Maximianus, die in vielen Teilen stilisiert und dramatisiert ist (vgl. u. Anm. 84). In Cresc. steht die ausführlichste Fassung, in den anderen beiden Texten gibt es einige Kürzungen und Veränderungen im Detail. Folgendes schreibt Augustinus: Maximianus hatte einen Prozess gegen Donatisten angestrengt, um wieder in den rechtmäßigen Besitz seiner Basilika auf dem fundus Calvia zu kommen. Nachdem er diesen Prozess gewonnen hatte, wurde Maximianus eines Tages von einem aufgebrachten Mob überfallen. Er floh unter den Altar seiner Kirche. Die Gewalttäter jedoch zerstörten den Altar, schlugen Maximianus mit Knüppeln und Steinen und verletzten ihn schwer mit einem Dolch. Er wäre verblutet, wenn nicht der Staub, durch den er gezogen wurde, die Adern verstopft hätte. Als dann Katholiken ihm helfen wollten, entriss die Bande ihn, malträtierte ihn noch heftiger und warf ihn, als sie dachten, er sei tot, von einem Turm. Er fiel aber weich in einen Misthaufen. In der Nacht kam ein Bettler zufällig zu der entlegenen Stelle, weil er dort seine Notdurft verrichten wollte, und fand Maximianus. Er holte seine Frau und eine Lampe und erkannte den Bischof. Sie brachten ihn nach Hause und informierten einige katholische Gemeindemitglieder. Maximianus wurde auf wundersame Weise wieder gesund und mit seinen Wunden, die zahlreicher als seine Körperteile waren, 
habe der Kaiser bereits die bekannten Gesetze gegen die Donatisten verkündet. Die Delegation des Konzils von Karthago sei erst später gekommen, so dass deren Anträge nicht mehr relevant gewesen seien. ${ }^{79}$

Bei Betrachtung der Zusammenhänge, in denen Augustinus diese Vorkommnisse berichtet, scheinen indessen Zweifel an der Darstellung angebracht zu sein. ${ }^{80}$ In den beiden Briefen, die als Quelle zur Verfügung stehen, möchte Augustinus im Rückblick die Entscheidung zur Applikation der Häretikergesetze auf die Donatisten rechtfertigen. Einmal gegenüber einem der wichtigsten donatistischen Bischöfe, ${ }^{81}$ ein weiteres Mal gegenüber dem katholischen comes Bonifatius, der sich bei Augustinus über den Grund der Zwangsmaßnahmen gegen die Donatisten informieren wollte. ${ }^{82}$ Eine ähnlich formulierte Rechtfertigung findet sich auch in der Schrift gegen Cresconius. Dort wird jedoch nur ein indirekter Zusammenhang zwischen den Gewalttaten an Maximianus und der Verkündung der Häretikergesetze hergestellt. Augustinus berichtet zunächst detailliert über die Gewalt an Maximianus und in einem weiteren Fall, ${ }^{83}$ äußert

konnte er allen Leuten die Gewalt der Donatisten vor Augen führen. Am Ende erbat Maximianus, so Augustinus, die Unterstützung des Kaisers, nicht zur eigenen Rache, sondern zur Verteidigung der Kirche. - Zur Person und den Ereignissen vgl. de Veer, BA 31, 815-817; Mandouze, PAC, 723-725, s. v. Maximianus 6. Mandouze identifiziert diesen Maximianus wohl zu Recht mit dem gleichnamigen Bischof, den Augustinus in ep. 69 erwähnt (zur Diskussion dieser Frage vgl. die Literatur bei de Veer, aaO).

79 Ep. 88.7: „Von unserem Konzil schickten unsere Bischöfe Gesandte an den Hof. Sie sollten darum bitten, dass nicht alle Bischöfe und Kleriker eurer Partei zu jener Geldstrafe von zehn Pfund Gold verurteilt werden sollen, die gegen alle Häretiker verfügt worden ist, sondern allein diese, an deren Orten die katholische Kirche Gewalttaten eurer Anhänger erdulden muss. Als aber die Legaten nach Rom kamen, hatten bereits die schrecklichen und noch frischen Wunden des katholischen Bischofs von Bagaï den Kaiser gerührt, solche Gesetze zu erlassen, die dann tatsächlich gesandt worden sind." (ex consilio autem nostri episcopi legatos ad comitatum miserunt, qui impetrarent, ut non omnes episcopi et clerici partis uestrae ad eandem condemnationem $X$ librarum auri, quae in omnes haereticos constituta est, tenerentur sed hi soli, in quorum locis aliquas a uestris uiolentias ecclesia catholica pateretur. sed sic cum legati Romam uenerunt, iam cicatrices episcopi catholici Bagaitani horrendae ac recentissimae imperatorem commouerant, ut leges tales mitterentur, quales et missae sunt).

80 Correct. 26.

81 Ianuarianus war Bischof in Casae Nigrae und donatistischer Primas von Numidien. Obwohl der Adressat von ep. 88 nicht eindeutig zu identifizieren ist, so scheint dies nach Poss. indic. VI 21 doch sehr wahrscheinlich. Den Brief kann man auf etwa 406-411 datieren. Vgl. Mandouze, PAC, 579, s. v. Ianuarianus; Monceaux VII, 282.

82 Vgl. o. Kap. 2 Anm. 14 - Zum Anlass von correct. s. u. Kap. 2.2.3.

83 Cresc. III 47. Augustinus erzählt hier das Beispiel des katholischen Bischofs Servus von Thubursicum-Bure: Dieser hatte vor dem Prokonsul auf die Rückgabe eines Grundstücks geklagt, das die Donatisten angeblich gewaltsam an sich gerissen hatten. Während beide Parteien noch auf ein Urteil warteten, kam es zu einem bewaffneten Überfall, bei dem Servus' Vater, ein alter Priester, so schwer verletzt wurde, dass er 
sich dann aber sehr allgemein, dass solche Untaten dazu beigetragen hätten, die alten Gesetze anzuwenden und neue gegen die Donatisten zu beschließen (inde factum est, ut et praeteritae omnes contra uos leges excitarentur et istae conderentur nouae, Cresc. III 47). Allen Texten gemeinsam sind die hervorgehobene Präsentation des Maximianus, die ausführlichen Schilderungen seiner Leiden und die wundergleiche Genesung, die große Ähnlichkeiten mit Märtyrerberichten aufweisen. ${ }^{84}$ Augustinus malt seinen Lesern, gleich ob Katholiken oder Donatisten, drastische Bilder der Gewalt vor Augen, um deutlich zu zeigen, dass in einer solchen Situation kein anderer Ausweg mehr da war, als mit Gewaltanwendung und Strafen zu drohen. So wie den Kaiser die frisch vernarbten Wunden des Maximianus zum Handeln veranlasst haben, so sollen die Leser die Entscheidung des Kaisers nachvollziehen. In der Formulierung gegenüber Ianuarianus stellt Augustinus überdies nicht den Wunsch des Konzils von 404 nach Anwendung der Häretikergesetze heraus, sondern betont im Übermaß die milde Forderung der Bischöfe, nur dort zu strafen, wo Gewalt begangen wurde. Augustinus versucht also in seinen Darstellungen, die Rolle der katholischen Bischöfe herunterzuspielen und die Verantwortung für die Zwangsmaßnahmen auf den christlichen Kaiser abzuschieben: Honorius allein habe eine Antwort auf die Gewalt gegeben, die ihm durch die anwesenden Opfer deutlich vor Augen geführt worden sei.

Was folgt daraus für die Darstellung der genannten Vorgänge? Angesichts des guten Informationsaustausches zwischen den Bischöfen und den guten Kontakten Augustins gibt es keinen Grund, an der Anwesenheit von Maximianus und anderen Bischöfen am Kaiserhof und ihrer Absicht, dem Kaiser persönliche Klagen vorzubringen, zu zweifeln. Dass jedoch der Entscheidungsprozess in Rom so verlaufen ist, wie ihn Augustinus darstellt, ist unwahrscheinlich. Es ist vielmehr anzunehmen, dass die Ereignisse weit weniger dramatisch und mehr von politischen Erwägungen bestimmt waren. Wahrscheinlich haben Honorius oder der zuständige Hofbeamte die Klagen und Anträge sowohl von Theasius und Evodius als auch von Servus, Maximianus und anderen entgegengenommen und anschließend nach Beratungen über die Situation die Entscheidungen getroffen. Die Vorschläge des Konzils in Karthago werden ebenso berücksichtigt worden sein wie die Berichte über Gewalttaten. Die ex-

wenige Tage später starb. Vgl. de Veer, BA 31, 809 f., 814 f.; Mandouze, PAC, 1066 f., s. v. Servus (dei) 1.

84 Augustins Bericht über Maximianus ist alles andere als eine nüchterne Darstellung der Fakten. Vielmehr erzählt er die Geschichte dramatisierend und schmückt sie mit Märtyrersymbolik aus (die Blutsymbolik, das Entheiligen des sakralen Raumes durch die Feinde, das wundersame Überleben der schrecklichsten Torturen). Wahrscheinlich kannte Augustinus die Geschichte ohnehin nur in dieser Form als mündliche Erzählung. Zur späteren Verehrung des Maximianus als Opfer donatistischer Verfolgung und Heiligen vgl. Mombritius, Sanctuarium, 160-163. 
plizite Erwähnung der von den katholischen Bischöfen zur Applikation vorgeschlagenen Gesetze dürfte auf die Eingabe der karthagischen Gesandten zurückgehen. ${ }^{85}$

\subsection{Das Unionsgesetz des Jahres 405 und die Folgen (405-411)}

Als Ergebnis der Abwägungen am Hof verkündete Honorius am 12. Februar 405 das sogenannte Unionsedikt. Dieses Edikt ist nicht im vollständigen Wortlaut erhalten. Im Codex Theodosianus finden sich jedoch zwei kurze Fragmente sowie zwei ergänzende Schreiben an den Prätorianerpräfekten Hadrianus, in denen die Umsetzung des neuen Gesetzes gefordert wird. Im ersten Fragment wird die Einheit des katholischen Glaubens beschworen und die Verirrung von Donatisten und Manichäern verdammt. Versammlungen dieser Gruppen sollen ebenso nach den bestehenden Gesetzen bestraft werden wie die Ausübung der Kultpraktiken. ${ }^{86}$ Das zweite Fragment besteht lediglich aus einem kurzen Satz, der lautet: ,Wir dulden nicht die abweichenden Irrtümer der Wiedertäufer. “87

Die Aussagen dieser beiden Texte enthalten auf den ersten Blick keine grundlegend neuen Bestimmungen, wenn man auf die Maßnahmen blickt, die bereits unter den Kaisern Konstantin (im Jahre 316) und Constans (347) gegen die Donatisten ergriffen worden waren. Hier werden ebenfalls donatistische

85 Vgl. den Wortlaut in CTh XVI 6.4. - Es ist also unwahrscheinlich, dass der Kaiser bereits entschieden hatte, als die offizielle Gesandtschaft eintraf, wie gemeinhin in der Forschung von Augustinus übernommen wurde. Vgl. etwa Monceaux IV, 378 f.; de Veer, BA 31, 366 f., Anm.1; Grasmück, Coercitio, 203; Frend, Donatist Church, 262; Lamirande, Studia canonica 32, 1998, 224; Mandouze, PAC, 369; Lancel, Augustin, 408 f. Zudem spricht auch die Chronologie gegen eine solche Interpretation: Das Konzil in Karthago fand am 16. Juni statt. Die Gesandten werden bald darauf ihre Reise angetreten haben und wahrscheinlich Ende Juni oder im Juli am Hof in Rom eingetroffen sein. Die Gesetze wurden am 12. Februar des folgenden Jahres in Ravenna verkündet, also etwa ein halbes Jahr später in einer anderen Stadt. Eine spontane Entscheidung durch die Berichte des Maximianus und der vertriebenen Bischöfe, die sich ebenfalls im Sommer 404 am Hof aufgehalten haben, scheint mir im Hinblick auf diese Zeitspanne nicht gegeben.

86 CTh XVI 5.38: Nemo manichaeum, nemo donatistam, qui praecipue ut comperimus furere non desistunt, in memoriam reuocet. Vna sit catholica ueneratio, una salus sit, trinitatis par sibique congruens sanctitas expetatur. Quod si quis audeat interdictis sese illicitisque miscere, et praeteritorum innumerabilium constitutorum et legis nuper a mansuetudine nostra prolatae laqueos non euadat et, si turbae forte conuenerint seditionis, concitatos aculeos acrioris commotionis non dubitet exserendos. - Am 5. März erging die Anweisung an den Prokonsul von Afrika, Diotimus, das Gesetz in den Regionen seines Amtsgebietes zu veröffentlichen (CTh XVI 11.2); Mandouze, PAC, 280 f., s. v. Diotimus. 
Versammlungen verboten und Strafen gegen Wiedertaufe ausgesprochen. ${ }^{88}$ Obwohl sich die Forderung, bereits bestehende Gesetze gegen Häretiker in aller Schärfe anzuwenden, in zahlreichen kaiserlichen Anweisungen findet, ${ }^{89}$ zeigt die Nennung der Donatisten in einem Atemzug mit den „Erzhäretikern“ der Manichäer eine neue Qualität in der Beurteilung der afrikanischen Schismatiker. Dass in dem Edikt die Donatisten erstmals juristisch per definitionem als Häretiker gebrandmarkt werden, geht aus dem Begleitdekret an den Prätorianerpräfekten Hadrianus hervor. Dieses Schreiben wiederholt die Bestimmungen des Erlasses und liefert einleitend die Begründung für die Gleichstellung der Donatisten mit den Häretikern:

„Durch die Autorität dieses Dekretes haben wir Sorge getragen, dass die Gegner des katholischen Glaubens ausgerottet werden. Daher haben wir beschlossen, gerade diese Sekte durch eine neue Verordnung zu vernichten, die die Bezeichnung ,Schisma' bevorzugte, um nicht ,Häresie' genannt zu werden. Man sagt nämlich, dass die sogenannten Donatisten in ihren Verbrechen soweit gegangen seien, dass sie die allerheiligste Taufe in strafbarer Verwegenheit wiederholen und so die Mysterien immer wieder mit Füßen treten. Auf diese Weise infizieren sie die Menschen, die - gemäß der Überlieferung - einmal durch das Geschenk der Gottheit rein gewaschen worden sind, mit der Seuche einer gottlosen Wiederholung. So kam es, dass aus dem Schisma die Häresie entstand." ${ }^{\circ 0}$

Diese Aussagen widersprachen der weitverbreiteten Ansicht, dass die Donatisten trotz aller Differenzen den orthodoxen Bekenntnissen gemäß glaubten und lediglich Teile der Kirche nicht anerkannten. ${ }^{91}$ Mit der Entscheidung, die donatistische Wiedertaufe nicht nur als Verbrechen wider die allerheiligste

88 Vgl. o. Kap. 2.1.2. - Gegenüber den Donatisten ordnete Constans im Jahre 347 die Konfiskation der Kirchen an, verbot die Wiedertaufe und verbannte donatistische Bischöfe ins Exil, vgl. Opt. II 15; III 1-3; Passio Marculi; Passio Max. et Isaac (vgl. Maier I, Nr. 36 f., 256-291); Congar, BA 28, 731-733; Tengström, Donatisten, 93 f. Vgl. u. Kap. 6.3.2.

89 Vgl. u.a. CTh XVI 5.25 (13.3.395 an den PPO Orientis Rufinus), CTh XVI 5.35 (17.5.399 an den Vikar von Afrika bezüglich der Manichäer).

90 CTh XVI 6.4 (= Maier II, Nr. 76, 136-140): Aduersarios catholicae fidei exstirpare huius decreti auctoritate prospeximus. Ideoque intercidendam specialiter eam sectam noua constitutione censuimus, quae, ne haeresis uocaretur, appellationem schismatis praeferebat. In tantum enim sceleris progressi dicuntur hi quos donatistas uocant ut baptisma sacrosanctum, mysteriis recalcatis, temeritate noxia iterarint et homines semel, ut traditum est, munere diuinitatis ablutos contagione profanae repetitionis infecerint. Ita contigit ut haeresis ex schismate nasceretur.

91 Vgl. die Definition des donatistischen Grammatikers Cresconius, die Augustinus zitiert (Cresc. II 6): „Die Häresie ist eine Abspaltung aufgrund unterschiedlicher Lehren, das Schisma dagegen eine Trennung innerhalb der gleichen Lehre." (haeresis est diuersa sequentium secta, schisma eadem sequentium separatio). Augustinus begründet gerade mit diesem Zitat gegen Cresconius, warum Donatisten Häretiker seien: diese würden nämlich durch ihre Wiedertaufe demonstrieren, dass sie doch keine übereinstimmende Lehre mit der katholischen Kirche hätten. 
Taufe zu verdammen, sondern gleichzeitig als Kriterium für die Einordnung unter die Häresien zu verkünden, war es nun möglich, Donatisten so zu behandeln, wie es aus der Sicht des Kaisers Häretikern gebührte. Dies war eine deutliche Neueinschätzung der Lage in Afrika. ${ }^{92}$

In dem Schreiben an Hadrianus werden nach dem zitierten Einleitungsteil eine Reihe von Strafandrohungen bekannt gegeben, die ein Bild von dem geplanten verschärften Vorgehen gegenüber den Donatisten vermitteln: Wer eine Wiedertaufe ausführt, wird vor das Gericht des zuständigen Provinzgouverneurs (praeses) gestellt und mit Vermögensverlust bestraft werden. Ein Land- oder Hausbesitzer, der wissentlich häretische Versammlungen auf seinem Besitz duldet, soll ebenfalls sein Eigentum verlieren; falls er aber nichts von den Umtrieben weiß, sollen die verantwortlichen Prokuratoren oder Hausverwalter gegeißelt und lebenslang ins Exil vertrieben werden. Sklaven, die zur Wiedertaufe gezwungen werden, dürfen in der katholischen Kirche Zuflucht suchen, wo ihnen Schutz und die Freiheit von ihren ungläubigen Herren gewährt werden soll. ${ }^{93}$ Alle Personen, die wiedergetauft oder eine solche Tat nicht verurteilt haben, sollen ihr Recht verlieren, Testamente auszustellen, Geschenke zu empfangen oder irgendwelche Verträge abzuschließen; die gleiche Strafe soll diejenigen treffen, die Wiedertaufen dulden. Insbesondere die Provinzstatthalter (moderatores), die führenden Dekurionen (principales) und die defensores civitatum, die offensichtlich in die Umsetzung der antidonatistischen Gesetzgebung eingebunden worden waren, sollen im Falle einer Missachtung der Anordnungen oder bei Gewaltausübungen gegen die katholische Kirche eine Geldstrafe von 20 Pfund Gold bezahlen. ${ }^{94}$ Diese Ausführungen zeigen, dass vor allem die donatistischen Kleriker und die führenden Laien, nicht aber die einfachen Gläubigen von Strafandrohungen betroffen waren. Nicht die Zugehörigkeit zur donatistischen Partei wird bestraft, sondern die Durchführung von Wiedertaufen und die Organisation von donatistischen Zusammenkünften bzw. die Duldung derartiger Veranstaltungen. ${ }^{95}$ Auffälligerweise ist nicht explizit von

92 Zur Beurteilung dieses juristischen Wendepunktes Quinot, BA 30, 789-791; de Veer, BA 31, 759-764; Lamirande, BA 32, 706-709; Schindler, Unterscheidung, 228-236; Monceaux IV, 73, 259 f.; Brown, Religion and Society, 305 f.; Lancel, Augustin, 409.

93 Zum Umgang der Kirche mit Sklaven allgemein Gaudemet, L'Église, 565-567. Vgl. auch F. Decret, Augustin et l'esclavage, Dialogues d'histoire ancienne 11, 1985, 675685.

94 CTh XVI 6.4. - Zu den veränderten Aufgabenbereichen der defensores ciuitatum zu Beginn des 5. Jahrhunderts vgl. R. M. Frakes, Contra Potentium Iniurias, The Defensor Civitatis and Late Roman Justice, München 2001, 165-193, zum genannten Gesetz S. $168 \mathrm{f}$.

95 CTh XVI 6.4.3: Sciant ii uero, qui ex supradictis sectis iterare baptisma non timuerunt aut qui consentiendo hoc facinus propria huius societatis permixtione damnauerint, [...] bezieht sich lediglich auf die Ausführenden der Taufe und diejenigen, die die Mög- 
der Exilstrafe für Kleriker die Rede. Jedoch ließ sich diese ebenfalls heranziehen, indem man auf bestehende Häretikergesetze zurückgriff. Augustinus selbst bezeugt später, dass entsprechende Gesetze auf die Donatisten angewandt worden seien. ${ }^{96}$

Das Unionsgesetz von 405 bedeutete folglich ein Verbot jeglicher Durchführung religiöser Kulthandlungen durch die Donatisten. Die genannten Strafandrohungen gehen über diejenigen hinaus, die 404 vom karthagischen Konzil gefordert worden waren (Konfiskation, Geldstrafen und der Verlust bürgerlicher Privilegien), denn sie ordnen auch Geißelung und Verbannung an, Strafen, die bereits gegen Manichäer, Arianer und andere als Häretiker geltende Gruppen im 4. Jahrhundert zum Tragen gekommen waren. ${ }^{97}$

Die Aussagen, die die Bestrafung von Nachlässigkeit bzw. Nachsichtigkeit in der Durchführung der Bestimmungen betreffen, lassen sich ebenfalls in anderen Gesetzestexten dieser Zeit finden. Sie zeugen nicht gerade von großer Zuverlässigkeit der Beamten, vielmehr eröffnen sie einen Einblick in die Probleme des spätantiken Staates, in dem aufgrund von Korruption und Vetternwirtschaft die Umsetzung von Gesetzen und Verordnungen oftmals auf der Strecke blieben. ${ }^{98}$ Gleichwohl wird durch die nachdrückliche Formulierung im Brief an Hadrianus deutlich, dass Kaiser Honorius den Donatisten in Afrika ernsthaft Einhalt gebieten wollte. Diese neue Haltung des Kaisers wird auch durch eine zusätzliche Maßnahme unterstrichen: Hadrianus erhielt eine weitere Anweisung, die beinhaltete, dass überall dort, wo in Afrika das kaiserliche Edikt aufgestellt werde, der Text des Reskriptes von Kaiser Julian an die Donatisten vorangestellt werden solle, damit die Beständigkeit des katholischen Glaubens und die Hoffnungslosigkeit des donatistischen Irrglaubens allen bekannt gemacht werde. ${ }^{99}$

lichkeit hätten, eine solche Handlung zu unterbinden. Vgl. correct. 25-26; ep. 93.10, 19, wo Augustinus nur Strafen gegen Kleriker aufzählt.

96 Ep. 89.2; ep. 93.10, 19; correct. 26. - Eine kurz vor der Promulgation des Unionsgesetzes erschienene Verfügung an den PPO Hadrianus (Const. Sirm. 2 vom 4. Februar 405; vgl. CTh XVI 2.35) regelte den Umgang mit abgesetzten Bischöfen: Der Verbannte müsse sich lebenslang mindestens hundert Meilen von seinem ehemaligen Bischofssitz entfernt aufhalten. Ferner sei ihm untersagt, in seiner Angelegenheit an den Kaiser zu appellieren.

97 Zusammenfassend Noethlichs, Maßnahmen, $111 \mathrm{f}$, , 161-165.

98 Dazu allgemein R. MacMullen, Corruption and the Decline of Rome, New Haven u.a. 1988; K. L. Noethlichs, Beamtentum und Dienstvergehen. Zur Staatsverwaltung in der Spätantike, Wiebaden 1981, 159-181.

99 CTh XVI 5.37. - Ein Teil des Wortlauts vom Reskript Julians, das den Donatisten die freie Religionsausübung und die Rückkehr in ihre Basiliken ermöglichte, ist durch Augustinus (c. litt. Pet. II 224) überliefert. Vgl. Maier II, Nr. 39, 42 f.; Grasmück, Coercitio, $132-139$. 
Inwieweit das Unionsgesetz vom Februar 405 in Afrika zur Durchführung kam und welche Konsequenzen sich für den Donatismus ergaben, darüber geben einige Gesetzestexte und Exzerpte aus den Konzilsprotokollen der afrikanischen Kirche Auskunft. Hauptquelle ist jedoch auch hier Augustinus, der in seinen Schriften aus diesem Zeitraum oder im Rückblick die Ergebnisse der kaiserlichen Kirchenpolitik beschreibt:

Die donatistische Fassung des Liber Genealogus datiert den Beginn einer neuen Verfolgung der Christen durch das Unionsedikt auf den 26. Juni 405. ${ }^{100}$ Folglich ist zu diesem Zeitpunkt dieses Gesetz in Karthago veröffentlicht worden, und die Behörden haben erste Maßnahmen gegen die Donatisten ergriffen. Am 8. Dezember 405 erhielt der Prokonsul Diotimus einen Brief vom Kaiser, in dem er zur strengen Durchführung der Gesetze gegen widerspenstige Donatisten angehalten wurde. ${ }^{101}$ Zwei Jahre später erließ Honorius ein Gesetz, in dem er nochmals die strenge Ausführung der bestehenden Gesetze verfügte. Obwohl die bisherigen Maßnahmen durchaus Erfolg gezeigt hätten, bestehe nach wie vor ein großes Potential an Irrlehren und Widerstand gegen die Gesetze, woran auch die Trägheit der Richter und die Nachsichtigkeit der Beamten Schuld tragen. Alle bestehenden Anordnungen seien daher mit größter Anstrengung durchzuführen; die entsprechenden Sanktionen müssten zur Geltung kommen. $^{102}$

Offensichtlich brachten diese Bestimmungen jedoch nicht die gewünschten Ergebnisse. Im Gegenteil: ein weiteres Gesetz vom 15. Januar 409 lässt auf eine weitgehende Unwirksamkeit der bisherigen Anordnungen schließen. ${ }^{103} \mathrm{Im}$

100 Lib. Gen. 627 (ed. Th. Mommsen, MGH, Chronica minora 1, S. 196): „Unter demselben Konsulat [2. Konsulat Stilichos], an den 6. Kalenden des Juli begann die Verfolgung der Christen, die am Tag vor den Kalenden des Februar in Ravenna beschlossen worden ist.“ - Das letztgenannte Datum (31.1. 405) scheint ein Fehler des Chronisten zu sein. Vgl. Maier II, Nr. 82, 147-149.

101 CTh XVI 5.39: „Wir verfügen, dass die Häretiker des donatistischen Irrglaubens, falls sie geständig sind oder unter Einhaltung der gesetzlichen Bestimmungen überführt worden sind, an welchen Ort auch immer der geschuldeten Strafe ohne Aufschub zugeführt werden." (Donatistae superstitionis haereticos quocumque loci uel fauentes uel conuictos legis tenore seruato poenam debitam absque dilatione persoluere decernimus).

102 Const. Sirm. 12 an den PPO Curtius am 15.11.407, aufgestellt in Karthago am 5. Juni 408 (ein Ausschnitt des Gesetzes in CTh XVI 5.43). Gleichzeitig erhielt der amtierende Prokonsul Porphyrius die Anweisung, die Durchführung der Gesetze zielstrebig zu verfolgen. Jene Häretiker aber, die ein Bekenntnis zur katholischen Kirche ablegten, sollten nicht weiter strafrechtlich verfolgt werden (CTh XVI 5.41 vom 15.11.407).

103 Const. Sirm 14 (15.1.409 an den PPO Italiae et Africae Theodorus; vgl. CTh XVI 2.31 und 5.46). Die Datierung ist nicht ganz sicher. Const. Sirm. gibt das VIIII. Konsulat des Honorius und das V. des Theodosius an, also das Jahr 412. CTh XVI 5.46 datiert auf das VIII. Konsulat des Honorius und das III. des Theodosius, also 409, während CTh XVI 2.31 auf die VII. Kalenden des IV. Konsulats des Honorius und des Konsulats des Eutychianus datiert, d.h. den 25. April 398. Theodorus wird überall als Empfänger 
Gesetzestext werden vor allem die Behörden und Richter für die Mängel verantwortlich gemacht. Mit scharfen Worten wird ihre Toleranz und Konnivenz gegenüber den Verbrechen an der katholischen Kirche angegriffen: Bischöfe seien aus ihren Kirchen getrieben und misshandelt worden, doch die zuständigen Richter hätten diese Vorkommnisse weder entsprechend geahndet noch seien sie ihrer Verpflichtung nachgekommen, dem Kaiser Bericht zu erstatten, obwohl die Taten öffentlich begangen und sogar gemeldet worden seien. ${ }^{104} \mathrm{Um}$ diesen Zuständen Einhalt zu gebieten, werden bei Gewalt gegen Kleriker und Entweihung von Kultorten schwerste Strafen bis zur Todesstrafe angedroht, ebenso sollen nachsichtige Richter und untätige Beamte mit hohen Strafen belegt werden.

Die Ausführungen vermitteln einen Einblick in die aktuelle Situation in den afrikanischen Provinzen. Ein Großteil der Beamten und Richter zeigte Desinteresse an der Umsetzung der kaiserlichen Religionspolitik. Donatisten, aber auch andere religiöse Minderheiten konnten ihren Kulten ungestört nachgehen oder sich Anzeigen und Angriffen erfolgreich widersetzen. Gewalttätige Übergriffe einzelner Gruppen wurden nicht geahndet, sei es aufgrund der unwilligen Beamten, sei es wegen der mangelnden Möglichkeiten der militärischen Gewalt. Am Hofe wollte man die eklatanten Defizite unter Kontrolle bekommen und griff $\mathrm{zu}$ noch härteren Strafandrohungen. Die Kapitalstrafe gegen gewalttätige Häretiker, die in diesem Gesetz zur Norm wird, findet sich erstmals in einem Brief des Kaisers an den Prokonsul Donatus vom November 408. ${ }^{105}$

genannt. Den Quellen zufolge hatte Theodorus wahrscheinlich nur 408/9 das Amt des PPO für Italien und Africa inne (vgl. PLRE II, 1086 f., s. v. Theodorus 9). Insofern ist die Konjektur für Const. Sirm. 14 gerechtfertigt, vgl. Seeck, Regesten, 316.

104 Const. Sirm 14: Per prouinciam Africam tantum quorundam temeritati licuisse conperimus, ut Christianae legis antistites de propriis domibus raptos uel, quod est atrocius, de ecclesiae catholicae penetralibus protractos cruciatibus diuersis afficerent, [...]. Tanti sceleris nefas et immane flagitium numquam ante conpertum Africanorum iudiciorum auctoritas nec creditae sibi potestatis iure persequitur nec debita cura referendi in nostram fecit notitiam peruenire. - Der Wortlaut des Gesetzes zeigt deutlich, dass die katholischen Bischöfe in Afrika erhebliche Beschwerden beim Kaiser vorgebracht haben müssen. Bekannt ist eine Gesandtschaft des afrikanischen Konzils vom Oktober 408 (s. u. Anm. 109) sowie ein Brief Augustins an den MO Olympius (ep. 97, vgl. u. Anm. 125). Dieses Gesetz ist ebenso wie CTh XVI 5.44 (s. Anm. 105) als Reaktion auf diese Beschwerden zu verstehen, die sich nicht allein auf die Donatisten, sondern auch auf Auseinandersetzungen mit zwischen Heiden und Katholiken bezogen (vgl. ep. 104.5). Zum historischen Hintergrund der Gesetze vgl. E. T. Hermanowicz, Catholic Bishops and Appeals to the Imperial Court, A Legal Study of the Calama Riots in 408, JECS 12, 2004, 481-521, hier insbesondere 503-509.

105 CTh XVI 5.44 (vom 24.11.408). - Die Forderung der Todesstrafe zeigt sich in der Formulierung supplicium iustae animaduersionis expromi praecipimus: „Wir verfügen, dass die (Todes-)strafe als gerechte Strafaktion angewendet wird." Augustins ep. 100 an diesen Donatus stützt dieses Verständnis, da der Bischof von Hippo den Prokonsul vom Einsatz der Todesstrafe abhalten möchte (s. u. S. 48 f.). - Vgl. dazu Maier II, 160 Anm. 7; 
Die wachsende Ungeduld und der Wunsch nach schärferen Maßnahmen wird bereits hier sehr deutlich. Die Todesstrafe als äußerstes Mittel bestärkt den Eindruck, dass die vorhergehenden Bestimmungen wenig bewirkt hatten und Honorius die Umsetzung des Unionsgesetzes bzw. die Gesetze gegen alle nichtkatholischen Gruppen forcierte. Ein Erlass aus dem Juni 409 unterstreicht nochmals diese Haltung: Wenn jemand gegen die bisherigen Gesetze Einspruch erhebt, sollen dessen Eingaben unbeachtet bleiben. ${ }^{106}$

Die Informationen, die den afrikanischen Konzilsakten dieser Jahre entnommen werden können, weisen hinsichtlich der Situation in Afrika in die gleiche Richtung wie die Gesetzestexte. Am 23. August 405 fand das erste Konzil der katholischen Bischöfe nach dem Einheitsgesetz statt. Nur ein kurzes Exzerpt ist überliefert; wir erfahren aber, dass es bisher nur in Karthago selbst zu Maßnahmen gegen die Donatisten gekommen sei. Daher verfassten die Bischöfe Briefe an die zuständigen Richter, um sie aufzufordern, ihren Aufgaben nachzukommen. Auch dem Kaiser sollte gleichzeitig mit einem Dankesschreiben der karthagischen Gemeinde, in der offensichtlich die Kircheneinheit hergestellt worden war, ein Brief zukommen, der nochmals die Bekämpfung des Donatismus im gesamten Afrika erbat. ${ }^{107}$

Zwei Jahre später, auf dem Konzil vom 13. Juni 407 befassten sich die Bischöfe mit dem Problem, wie mit konvertierten donatistischen Klerikern umzugehen sei. Grundsätzlich wurde festgelegt, dass donatistische Gemeinden zusammen mit ihrem Bischof zur katholischen Kirche zurückkehren könnten. ${ }^{108}$ So wird zwar deutlich, dass es Übertritte in größerer Zahl gegeben hat, jedoch werden weder genauere Umstände noch die tatsächliche Anzahl genannt. Es bleibt überdies offen, inwiefern sich eine gesamte, mit ihrem Bischof zum Katholizismus konvertierte Gemeinde in ihrer Kultpraxis von ihren bisherigen Formen unterschied. Ganz offensichtlich blieb trotz „Kircheneinheit“ in vielen Orten eine Parallelstruktur von zwei Kirchen erhalten.

Aufgrund vermehrter gewalttätiger Übergriffe durch „Heiden und Häretiker" wurde von dem Konzil, das am 13. Oktober 408 abgehalten wurde, erneut

Pietri, Geschichte des Christentums, 516. - Ein weiteres Gesetz (CTh IX 40.19, 11.11.408 an den Prokonsul Donatus) verfügte die Verhaftung und Proskription der Anhänger Gildos. - Seeck (Geschichte III, 362 f.) hält den MO Olympius für den maßgeblichen Initiator der strengen Gesetze. Dies mag durchaus der Fall gewesen sein, jedoch setzt sich diese Politik nicht so stark von der unter Stilicho vor August 408 bzw. nach der Absetzung des Olympius im Laufe des Jahres 409 ab.

106 CTh XVI 5.47 (26.6.409 an den PPO Italiae et Africae Iovius).

107 Reg. Conc. Carth. 94 (Munier, CCL 149, 214); Maier II, Nr. 80, 144-146. - Für die bereits konvertierten Häretiker wurde der Modus festgelegt, dass der zuständige katholische Bischof jeden Einzelfall prüfen und dann Bußzeit und Rückkehr in die Gemeinschaft festsetzen sollte, vgl. Coll. Hisp. c. 23 (Munier, CCL 149, 368).

108 Reg. Conc. Carth. 99 (Munier, CCL 149, 216); vgl. Maier II, Nr. 83, 149-151; vgl. Monceaux IV, $380 \mathrm{f}$. 
eine Gesandtschaft nach Ravenna geschickt. ${ }^{109}$ Die Gesetze vom November 408 und Januar 409, die von einer noua adque inusitata audacia der Donatisten und anderen Häretikern sprechen und ein schärferes Vorgehen gegen sie fordern, ${ }^{110}$ sind mit Sicherheit eine Reaktion des Kaisers auf die Berichte des afrikanischen Konzils.

Das umfangreiche Aktenmaterial der Conlatio Carthaginiensis des Jahres $411^{111}$ enthält ebenfalls Hinweise über die Situation in Afrika nach 405. Die Anzahl der 411 in Karthago anwesenden Bischöfe ist mit offiziell 285 auf donatistischer und 286 auf katholischer Seite angegeben und somit ausgewogen. ${ }^{112}$ Zwar ist damit wenig über die tatsächliche Verbreitung und den Einfluss der jeweiligen Parteien ausgesagt, man kann aber zumindest eine große Überlegenheit einer der beiden Kirchen ausschließen. Während der Verhandlungen konstatierte der donatistische Bischof Petilianus ebenfalls eine Ausgewogenheit der beiden Parteien in Afrika, wobei er bemerkte, dass an vielen Orten die Katholiken lediglich mithilfe von Gewaltmaßnahmen während der Abwesenheit der donatistischen Gemeindeleiter im Exil Scheinbischöfe (imagines) eingesetzt hätten. ${ }^{113}$ An anderer Stelle wies er darauf hin, dass die Katholiken auf dem Land über keine Gemeinden verfügten, während umgekehrt Alypius, katholischer Bischof von Thagaste, den Mangel von donatistischen Bischöfen in den Städten anmerkte. ${ }^{114}$ Im Verfahren zur Feststellung der anwesenden Bischöfe wurden auch einige Fälle von Konversionen donatistischer Bischöfe oder ihrer

109 Reg. Conc. Carth. 106 (Munier, CCL 149, 219): „Auf diesem Konzil [13.10.408] übernahmen die Bischöfe Restitutus und Florentius die Gesandtschaft gegen die Heiden und Häretiker, in der Zeit als Severus und Macarius ermordet und wegen ihrer Aufgabe auch die Bischöfe Evodius, Theasius und Victor verwundet worden sind." (In hoc concilio susceperunt legationem Restitutus et Florentius episcopi contra paganos et haereticos eo tempore Seuerus et Macarius occisi sunt et propter eorum causam Euodius, Theasius et Victor episcopi caesi sunt). Vgl. Maier II, Nr. 86 f., S. 157-159; Monceaux IV, $381 \mathrm{f}$; Hermanowicz, JECS 12, 2004, 500-504.

110 CTh XVI 5.44 (an den Prokonsul von Afrika Donatus am 24.11.408), vgl. o. Anm. 104 u. 105.

111 Zur Konferenz ausführlich u. Kap. 5.

112 Gesta conl. Carth. I 213-215, zu der problematischen Zählung der Bischöfe Lancel, SC 194, 110-118.

113 Gesta conl. Carth. I 165.

114 Gesta conl. Carth. I 181 f.; vgl. Lancel, SC 194, 134-143; Tengström, Donatisten, 126 f. Gegenüber Marcellinus, dem staatlichen Beauftragen für die Konferenz, äußern sich die katholischen Bischöfe während des Konzils folgendermaßen (ep. 129.6): „Die Zahl unserer Mitbischöfe, Kleriker und Laien ist seit langem größer und am größten in der Proconsularis. Mit Ausnahme von Numidien werden sie von uns auch in den anderen Provinzen Afrikas leicht überwunden." (nostrorum coepiscoporum et clericorum atque laicorum longe maior est numerus et maxime in proconsulari provincia, quamquam excepta Numidia consulari etiam in ceteris provinciis Africanis nostrorum numero facillime superentur). 
Gemeinden angesprochen, allerdings wurden auch umgekehrt Beispiele von Erfolgen der Donatisten genannt. ${ }^{115}$

Offensichtlich gab es bezüglich der beiden Kirchen einen Stadt-Land-Gegensatz. Während donatistische Kleriker in den Städten, durch die Gesetze gezwungen, ihre Kirchen verlassen mussten, blieb die Situation auf dem Land unentschieden. Vor allem im traditionell donatistisch dominierten Numidien war es bis 411 nicht gelungen, donatistische Gemeinden in größerem Umfang zur katholischen Kirche zurückzuführen.

Sowohl in den Akten der Konferenz von 411 als auch in einigen anderen Texten erfahren wir von einer Gruppe donatistischer Bischöfe, die sich am Kaiserhof in Ravenna eingefunden hatten und denen am 30. Januar des Jahres 406 eine Audienz beim zuständigen Prätorianerpräfekten ${ }^{116}$ gewährt wurde. Es ist nicht ersichtlich, ob die Bischöfe in Afrika von ihren Sitzen vertrieben worden waren oder ob es sich um eine offizielle Delegation handelte. In Ravenna jedenfalls, so berichtet Augustinus, wünschten sie ein Gespräch mit dem am Hof anwesenden katholischen Bischof Valentinus. ${ }^{117}$ Wahrscheinlich baten sie darüber hinaus um eine Rücknahme der Repressionen und eine friedliche Lösung des Konflikts. Der Prätorianerpräfekt wies ihre Gesuche mit Verweis

115 Einige Beispiele seien genannt: Offensichtlich ist die donatistische Gemeinde von Uzari ohne ihren Bischof Calipodius katholisch geworden (Gesta conl. Carth. I 129), in Karthago 411 vertritt Calipodius trotzdem seine Stadt (I 188). Der donatistische Bischof von Quiza in Mauretanien ist mit seinen Verwandten konvertiert (I 143), Primulus von Vaga mit seiner Gemeinde (I 176; vgl. auch I 138). Bischof Victor von Hippo Diarrhytus wurde verfolgt und ins Gefängnis geworfen (I 142 [zwischen 408 und 410 - dies ist das einzige genauere Datum für die Verfolgungen dieser Zeit, vgl. Lancel, SC 195, 791 Anm.1]). In der Stadt Thagaste gab es offenbar 411 noch nicht wieder eine donatistische Gemeinde (I 136). Auf der anderen Seite wird von einem katholischen Diakon berichtet, der sich wiedertaufen ließ (I 203), und in Liberalia hatten die Donatisten eine katholische Basilika übernommen (I 133; SC 195, S. 768). - Zu verallgemeinernd sind in diesem Zusammenhang die Interpretationen dieser Aktennotizen durch Frend, Donatist Church, 265-267. Es darf nicht übersehen werden, dass in Karthago 411 die große Mehrheit der Städte zumindest nominell wieder sowohl einen donatistischen als auch einen katholischen Bischof aufweisen konnte. An wie vielen Orten zwischenzeitlich die donatistischen Sitze vakant gewesen waren, lässt sich aus dieser Quelle nicht beurteilen. Ein Beispiel für die Schwierigkeit, an einem Ort das Vorhandensein der einen oder anderen Gruppe nachzuweisen oder zu negieren, ist der Disput zwischen dem katholischen Bischof Eunomius von Marazana, der angibt, es habe keine donatistische Gemeinde an seinem Ort gegeben, und seinem donatistischen Kollegen Habetdeum, der behauptet, es habe etwa 3000 Donatisten und einen Bischof gegeben, die jedoch verfolgt worden seien (I 133, SC 195, 758-760).

116 Wahrscheinlich Fl. Macrobius Longinianus, der zu diesem Zeitpunkt PPO Italiae et Africae war. Vgl. PLRE II, 686 f., s. v. Fl. Macrobius Longinianus.

117 Ep. 88.10. Nach der Formulierung Augustins war Valentinus offenbar ein afrikanischer Bischof, womöglich in der Ortschaft Vaianensis, und der spätere katholische Primas Numidiens; vgl. Mandouze, PAC, 1130-1132, s. v. Valentinus 2. 
auf die bestehenden Gesetze gegen die Donatisten zurück, und die Bischöfe mussten unverrichteter Dinge zurückkehren. ${ }^{118}$ Die Donatisten blieben jedoch in Ravenna frei und unbehelligt; ein weiteres Indiz dafür, dass zu diesem Zeitpunkt lediglich konkrete Gesetzesverstöße in Afrika geahndet wurden.

Augustinus setzte seine literarische Arbeit gegen Donatisten nach dem Unionsgesetz unvermindert fort. Gegen den Grammatiker Cresconius, der mit einer Schrift seinen Bischof Petilianus gegen Augustins Angriffe aus dem ersten Buch gegen Petilianus verteidigt hatte, schrieb Augustinus im Jahre 405/6 eine weitere große Abhandlung, die „vier Bücher gegen Cresconius“ (contra Cresconium grammaticum et donatistam libri quattuor), ${ }^{119}$ in denen er erstmals ausführlich mit historischen Argumenten und Verweisen auf das Maximianistische Schisma arbeitet.

Veranlasst durch diese Arbeit beabsichtigte Augustinus, den Donatisten die von ihm zitierten historischen Dokumente aus den Archiven zugänglich zu machen. Er tat dies in der Schrift contra Donatistam nescio quem (retr. II 28), in der er die wichtigsten Dokumente kurz erläuterte und die entsprechenden Zeugnisse als Anhang hinzufügte. Mit dem gleichen Material stellte er ein Dossier zusammen, dem er den Titel probationum et testimoniorum contra

118 Die Darstellung der Ereignisse in ep. 88.10. Die Ablehnung von Petitionen verurteilter Bischöfe ist in Const. Sirm. 2 (vom 4. 2. 405) verankert. - Ob die Donatisten in Ravenna einen Antrag auf eine allgemeine Konferenz (wie häufig vermutet wird), oder vielleicht weitergehende Forderungen stellten, geht aus den Quellen nicht klar hervor. In Karthago 411 wurden die gesta praefectoria verlesen, jedoch ist in den Gesta conl. Carth. lediglich die Präambel mit der Datierung notiert worden (III 141). Die Donatisten, vor allem Petilianus und Emeritus, verneinten ein offizielles Gesuch an den Kaiser, während die Katholiken dies in den Akten bestätigt fanden (vgl. Gesta conl. Carth. III 110, 124, 128-130; 140 f., 170, 173). Es ist aber sehr wahrscheinlich, dass die donatistischen Bischöfe eine Petition an den Kaiser richteten. Warum sollten sie sonst am Hof auftauchen? Der Tribun Marcellinus bestätigt dies (III 141: Iam nunc ex lectione gestorum qui petitor adsistat euidenter apertque monstrabitur), und die spätere donatistische Ablehnung ist leicht erklärbar aus ihrer eigenen Doktrin, die die Unterstützung durch die weltlichen Mächte ablehnt. Zusammenfassend Lancel, SC 194, 19-21; vgl. Monceaux IV, 79, 284 f. - Seeck, Regesten, 310 (übernommen von Grasmück, Coercitio, 205 Anm. 216) meint unter Berufung auf Gesta conl. Carth. III 141, 170, 173, Primianus habe sich vor dem Gericht des Prätorianerpräfekten verantworten müssen. Dies ist abwegig. Zum einen ist keiner der in Ravenna anwesenden donatistischen Bischöfe namentlich genannt, zum anderen ist nirgends die Rede von einer Gerichtsverhandlung. Unter anderem haben Monceaux (IV, $284 \mathrm{f}$.) und Frend (Donatist Church, 268) aus breuic. III 4 auf eine Teilnahme Primians in Ravenna geschlossen. An dieser Stelle ist jedoch lediglich allgemein von der Bereitschaft Primians zu einer Anhörung vor einem Präfekten die Rede. Monceaux (aaO) nennt zudem noch Maximinus von Siniti als Teilnehmer in Ravenna, Frend (aaO) neben Primianus noch Petilianus. Beide Angaben entbehren jeglicher Grundlage in den Quellen; dazu Lancel, SC 194, 20 Anm. 3.

119 Ausführlich zu diesem Werk s. u. Kap. 3. 
Donatistas liber unus gab (retr. II 27). ${ }^{120}$ Die Argumentation gegen die Donatisten unter Ausnützung des Maximianistischen Schismas ist das Thema der Schrift admonitio Donatistarum de Maximianistis liber unus. Diesen Traktat richtete Augustinus gezielt an weniger Gebildete und hoffte, aufgrund der Kürze der Schrift eine große Verbreitung zu erreichen (retr. II 29). In ausführlicherer Weise schrieb Augustinus zu dieser Thematik ein Buch de Maximianistis contra Donatistas, das ebenso wie die drei zuvor genannten Schriften nicht mehr erhalten ist. ${ }^{121}$ Die Konzentration der Argumentation auf die Parallelen zwischen donatistischen und Maximianistischen Schisma gerade für die theologischen Laien, die Augustinus in c. litt. Pet. I bereits herausstellte und in Cresc. IV detailliert ausführte, wird hier besonders deutlich.

Auch die Auseinandersetzung mit Petilianus fand eine Fortsetzung: Nachdem ihm ein Buch über die Taufe übermittelt worden war, dessen Autor der Bischof von Cirta sein sollte, schrieb Augustinus eine Widerlegung gleichen Titels (de unico baptismo), in dem er seine „katholische“ Position zur Taufe nochmals systematisch gegen den Exklusivismus der Donatisten darstellte. ${ }^{122}$

Einige Briefe Augustins aus der Zeit nach 405 geben Einblick in den Zustand der beiden Kirchen in Afrika nach dem Unionsedikt. So will Augustinus den rogatistischen Bischof Vincentius zur Rückkehr in die katholische Kirche ermuntern, indem er ihm vor Augen hält, wie viele Donatisten, ja ganze Städte sich schon der Einheit angeschlossen hätten. ${ }^{123}$ Auch wenn Augustinus in diesem Schreiben übertreiben mag, es zeichnet sich dennoch das Bild ab, das bereits anhand der Konzilsakten aus Afrika deutlich wurde: Zumindest formell traten nicht wenige Donatisten und ganze Gemeinden zum Katholizismus über. ${ }^{124}$

Aufschlussreich ist ein Brief Augustins an den magister officiorum Olympius aus dem Herbst des Jahres 408. ${ }^{125}$ Demnach habe es zwar zahlreiche Konver-

120 Augustinus beschreibt in retr. II 27 folgenden Ablauf: Zunächst ließ er Dokumente aus den verschiedenen Archiven zusammenstellen und versprach öffentlich, diese Zeugnisse zugänglich zu machen. Auf dieses Versprechen hin schrieb ein unbekannter Donatist einen Traktat gegen Augustinus, das dieser jedoch gleich widerlegte, nämlich mit c. n. Don. Dieser Schrift fügte er die genannten Dokumente hinzu. Aus beiden Texten entstand die Schrift prob. et test., deren Erscheinen er durch Anschlag an die Kirchenmauern öffentlich ankündigte.

121 Retr. II 35; vgl. Monceaux VII, $115 \mathrm{f}$.

122 Edition: Petschenig, CSEL 53, 3-34; vgl. retr. II 34; Poss. indic. VI 13; de Veer, BA 31, 647-737; Monceaux VII, $116 \mathrm{f}$. - Die genannten Themen verarbeitete Augustinus auch in zahlreichen Predigten; vgl. Willis, Augustin, 68-70; Monceaux VII, 161-165.

123 Vgl. ep. 93, 1-2. 17-20. Ausführlich zu diesem Brief u. Kap. 4.1.4.

124 Vgl. o. S. 43.

125 Ep. 97. Der Brief datiert nach dem Konzil von Karthago (14.10. 408), aber wohl vor der Verkündung der antihäretischen Gesetze vom November 408. Olympius wurde nach dem Sturz Stilichos zum MO ernannt. Laut Zosimus (V 46) avancierte er zum ein- 
sionen zur katholischen Kirche gegeben, aber das Gewaltpotential der Häretiker sei wieder größer geworden: Diese glaubten, dass nach dem Tode Stilichos die Gesetze gegen sie nicht mehr in Kraft seien und gingen daher umso heftiger gegen die Katholiken vor. Augustinus fordert daher auch im Namen aller seiner Mitbischöfe von Olympius ein scharfes Eingreifen gegen die neue Gewaltwelle. Es soll deutlich werden, dass die Gesetze des Honorius immer noch in Kraft seien. Der Brief ist in einem sehr dringlichen Tonfall verfasst; Augustinus fleht Olympius geradezu um Beistand und schnelles Handeln an. Die vermehrten Auseinandersetzungen, die in den Regesten des Konzils von 408 bereits anklangen, finden hier ihre Bestätigung. Einen Grund für die geänderte Situation nennt Augustinus selbst: Die Absetzung und Hinrichtung Stilichos, des bis dahin wichtigsten Mannes im Reich, nutzten die Donatisten, aber auch andere Gruppen, um lauthals zu verbreiten, dass die Gesetze, die unter Stilichos Herrschaft verkündet wurden, zurückgenommen worden seien. ${ }^{126}$ Augustinus wendet sich direkt an den neuen mächtigen Mann, um die fortgesetzte Umsetzung der antihäretischen Gesetze einzufordern. Offensichtlich mit Erfolg, denn die oben beschriebenen Gesetze von 408 und 409 waren auch eine Reaktion auf seinen Brief und die Berichte über vermehrte Unruhen in den afrikanischen Provinzen. ${ }^{127}$

Der amtierende Prokonsul von Afrika, Donatus, dem eines jener Gesetze zum harten Durchgreifen zugegangen war, ${ }^{128}$ erhielt im Jahre 409 von Augustinus einen Brief, in dem dieser ihn bittet, auf die Durchführung der Todesstrafe zu verzichten. Die christliche Milde solle stärker zum Tragen kommen und der Zwang zur Bekehrung zu einer aufrichtigen Einsicht bei den Donatisten füh-

flussreichsten Berater des Kaisers; vgl. zur Person: PLRE II, 801 f., s. v. Olympius 2; M. Clauss, magister officiorum, $174 \mathrm{f}$.

126 Nach dem Tod Stilichos wurden viele seiner Anhänger aus ihren Ämtern gejagt und verfolgt (Zos. V 46). Eine vorübergehende Lähmung des Staatsapparates auch in Afrika und eine dadurch wieder gewonnene Bewegungsfreiheit unter den Donatisten ist durchaus möglich.

$127 \mathrm{Zu}$ den Gesetzen vgl. o. S. 41-43. Vgl. Frend, Donatist Church, 270; Tengström, Donatisten, 108; Grasmück, Coercitio, 210. - In ep. 105.6 berichtet Augustinus von falsa indulgentia, die von Donatisten in Afrika verbreitet worden seien. Monceaux (IV, 260) verbindet diese Anspielung mit der Situation nach Stilichos Tod und glaubt, die Donatisten hätten ein gefälschtes, kaiserliches Toleranzedikt in Umlauf gebracht. Auf dieser Grundlage datiert Monceaux (VII, 283) ep. 105 auf Anfang 409. Diese Verbindung erscheint durchaus plausibel, sie bleibt allerdings unsicher. Denn für die Datierung von ep. 105 gibt es keine eindeutige Information; lediglich die Ausführungen deuten auf die Zeit zwischen 405 und 411. Möglich ist daher auch, dass Augustinus auf eine andere donatistische Agitation mit gefälschten Gnadenerlassen anspielt, die irgendwann nach 405 stattgefunden hat.

128 S. o. Anm. 105 - Zur Person: PLRE II, 375 f., s. v. Donatus 1. 
ren. ${ }^{129}$ Trotz dieser Bitten, die Augustins bleibende Ablehnung der Todesstrafe für Häretiker demonstriert, zeigt auch dieser Brief, wie jener an den magister officiorum, eine für Augustinus nach wie vor sehr unbefriedigende Situation, da die Donatisten offenbar glaubten, die bestehenden Gesetze nicht mehr beachten zu müssen. Augustinus bittet daher um eine Klarstellung der Situation. ${ }^{130}$ Die gegenüber Olympius beschriebene Lage hat sich in Augustins Umfeld offenbar noch nicht geändert. Vier Jahre waren seit dem Unionsgesetz vergangen, und es scheint, als hätten die Donatisten wieder an Stärke und Selbstbewusstsein hinzugewonnen, da es an der Durchsetzung der gesetzlichen Bestimmungen mangelte. Augustins Angaben sprechen somit für einen geringen Erfolg in der Durchsetzung der Kircheneinheit, trotz der scharfen Anweisungen aus Ravenna bis in das Jahr $409 .^{131}$

129 Ep. 100.1: „Von daher wünschen wir, dass sie auf den rechten Weg gebracht werden aus Furcht vor Richtern und Gesetzen, nicht aber, dass sie getötet werden, damit sie nicht den Strafen des ewigen Gerichts anheimfallen." (unde ex occasione terribilium iudicum et legum, ne in aeterni iudicii poenas incidant, corrigi eos cupimus, non nefari).

130 Ep. 100.2: „Die donatistischen Häretiker sollen schnell durch die Erlasse eurer Exzellenz erfahren, dass die Gesetze, die gegen ihre Irrlehre eingebracht wurden, nach wie vor Bestand haben. Schon jetzt glauben sie, diese Gesetze seien nichts wert, und prahlen damit, dass sie so auf uns keine Rücksicht nehmen bräuchten." (cito interim per edicta excellentiae tuae nouerint haeretici Donatistae manere leges contra errorem suum latas, quas iam nihil ualere arbitrantur et iactant, ne uel sic nobis parcere aliquatenus possint).

131 Die Beschreibungen donatistischer Gewalttaten in der Diözese von Hippo Regius in ep. 105.3-4 beziehen sich trotz der Bezeichnung als recentia facta mehrheitlich auf die Zeit vor 405 und geben somit kaum Auskunft über Auswirkungen des Unionsgesetzes. Augustinus zieht diese Beispiele heran, um die antidonatistischen Gesetze als Folge der Gewalttaten aufzuzeigen ([...] uobis [Donatistis] omnia ista ut iuberentur, coegistis). Unter den fünf namentlich genannten Opfern der Donatisten befindet sich auch Possidius von Calama. Der Überfall auf ihn ist aus anderen Quellen bekannt und fand wahrscheinlich kurz vor dem Unionsgesetz statt (Poss. vita 12). Auffällig ist, dass Augustinus gegenüber seinen donatistischen Adressaten in Hippo Regius viele Beispiele von Gewalt aufführt, die sie aus eigener Erfahrung kennen konnten, da sie in Ortschaften der Diözese Hippo geschahen: Marcianus von Urga, Marcus von Casphalia, Restitutus von Victoriana, Maximinus von Siniti. Letztgenannter ist der Empfänger von Augustins ep. 23 und donatistischer Konvertit, der nun als katholischer Priester tätig ist. Die in ep. 105.4 beschriebene Hetze gegen ihn könnte aus der Zeit nach 405 stammen; die chronologische Folge ist aber unsicher. Vgl. Mandouze, PAC, 693, 697, 972, der die meisten Berichte ebenfalls vor 405 datiert, mit Ausnahme von Maximinus (PAC, 728, s. v. Maximinus 2); vgl. auch Lancel, SC 194, 22 Anm. 1. - Ebenfalls nicht in den Zeitraum nach 405 gehört Augustins ep. 86 an Caecilianus. Zwar datiert u. a. Goldbacher diesen Brief vor 411, jedoch ist Monceaux، (IV, $265 \mathrm{f}$., VII, 285) Datierung auf 413 wahrscheinlicher. Der Vergleich zu ep. 151 an denselben Adressaten, die eindeutig nach dem Tod des comes Marcellinus geschrieben wurde (ep. 151.6), zeigt inhaltliche Parallelen, die auf eine ähnliche Abfassungszeit schließen lassen. Zur Diskussion vgl. Mandouze, PAC, 177-179, s. v. Caecilianus 6. 
Offensichtlich kam es jedoch im Laufe des Jahres $410 \mathrm{zu}$ einer zwischenzeitlichen Änderung der konsequenten Linie des Kaisers. Allgemein wird angenommen, dass es ein „Toleranzedikt“ gegeben habe, das den Donatisten die Möglichkeit gab, wieder in den Besitz ihrer Basiliken zu kommen und ihre Bischöfe aus dem Exil zurückkehren zu lassen. ${ }^{132}$ Ein solches Gesetz ist nicht überliefert, allerdings findet sich im Codex Theodosianus eine Bestimmung, in der die Aufhebung eines entsprechenden Erlasses verkündet wird. ${ }^{133}$ In den Regesten des afrikanischen Konzils vom 14. Juni 410 wird von einem Gesetz gesprochen, das die freie Wahl des Kultes innerhalb des christlichen Glaubens gestattete, ${ }^{134}$ und Augustinus verweist auf ein Gesetz, das den Donatisten die Religionsfreiheit wiedergegeben habe. ${ }^{135}$ Offensichtlich konnte in dieser Phase Macrobius als neuer donatistischer Bischof von Hippo Regius ohne Schwierigkeiten oder Widerstände unter dem Geleit von Circumcellionen eingesetzt werden. ${ }^{136}$

132 Dazu de Veer, Une mesure de tolérance de l'empereur Honorius, REByz 24, 1966, 189 195; Tengström, Donatisten, 109 f.; Frend, Donatist Church, 272-274; Lancel, SC 194, 22-24; Seeck, Geschichte III, $364 \mathrm{f}$.

133 CTh XVI 5.51 (vom 25.8.410 an den comes Africae Heraclianus): „Da der Erlass vollständig aufgehoben ist, aufgrund dessen sie sich zu ihren Riten eines häretischen Aberglaubens geschlichen hatten, sollen alle Feinde des heiligen Gesetzes wissen, dass sie mit Proskription und Tod zu bestrafen sind, wenn sie in ihrer zu verfluchenden Verwegenheit weiterhin versuchen, sich öffentlich zu versammeln.“ (Oraculo penitus remoto quo ad ritus suos haereticae superstitionis obrepserant, sciant omnes sanctae legis inimici plectendos se poena et proscribtionis et sanguinis, si ultra conuenire per publicam exsecranda sceleris sui temeritate temptauerint). - Eine Doublette dieses Gesetzes befindet sich in CTh XVI 5.56, vgl. Maier II, Nr. 93, 171-173. Zur Verwendung des Wortes oraculum im juristischen Sinne vgl. Lancel, SC 194, 22 Anm. 4.

134 Reg. Conc. Carth. 107 (Munier, CCL 149, 220): „Auf diesem Konzil unternahmen die Bischöfe Florentius, Possidius, Praesidius und Benenatus eine Gesandtschaft gegen die Donatisten, in der Zeit, als das Gesetz verkündet worden ist, dass jeder nach seinem freien Willen eine Kultform des christlichen Glaubens annehmen könne." (In hoc concilio legationem susceperunt contra donatistas Florentius, Possidius, Praesidius et Benenatus episcopi, eo tempore quo lex data est ut libera uoluntate quis cultum christianitatis exciperet).

135 Ep. 108.18: „Sie [die Circumcellionen] prahlen mit ihren früheren Verdiensten um euch [Donatisten], indem sie aufzählen, wie viele Ortschaften und Basiliken eure Priester durch sie bereits vor jenem Gesetz, durch das ihr euch eurer wiederhergestellten Freiheit erfreutet, in ihre Hände bekamen, weil sie, was uns gehörte, verwüstet und unsere Priester vertrieben hatten." (iactant enim praecedentia circa uos merita sua demonstrantes et enumerantes ante istam legem, qua gaudetis uobis redditam libertatem, quot loca et basilicas per eos presbyteri uestri uastatis nostris fugatisque tenuerunt, ...). Zur Datierung dieses Briefes auf das Jahr 410 vgl. Monceaux VII, 283.

136 Ep. 108.14. 
Die Existenz einer Verfügung, die den Donatisten eine freie Religionsausübung erlaubte, muss aufgrund dieser Zeugnisse als gesichert gelten. ${ }^{137}$ Weniger deutlich sind indessen die Hintergründe dieses Erlasses. Folgt man den Angaben aus dem Codex Theodosianus, scheint die Religionsfreiheit durch eine Petition irgendwelcher Personen an den Kaiser erwirkt worden zu sein. Es ist nicht auszuschließen, dass sich wie im Jahr 406 donatistische Bittsteller am Hof eingefunden hatten, um gegen ihre Verfolgung zu protestieren; nachweisen lässt sich dies jedoch nicht.

Wer auch immer versuchte, beim Kaiser Einfluss zu nehmen, zur Erklärung der geänderten Haltung am Kaiserhof ist ein Zusammenhang mit der politischen Situation des weströmischen Reiches in den Jahren 409/10 anzunehmen. Nach dem Sturz Stilichos versuchten unterschiedliche Gruppen am Kaiserhof Einfluss zu gewinnen. Kriege an den Grenzen und nicht zuletzt die Belagerung Roms durch Alarich brachten das Reich in eine sehr kritische Lage. Um Afrika musste Honorius bangen, als der von Alarich in Rom als Augustus eingesetzte Attalus versuchte, diese Provinz seiner Herrschaft unterzuordnen. ${ }^{138}$ Diese äuBeren Umstände dürften den Kaiser veranlasst haben, zur Bündelung seiner Kräfte religiöse Toleranz walten zu lassen, von der nicht nur die Donatisten, sondern auch Heiden und andere Gruppen profitierten. ${ }^{139}$ Die Kürze dieser

137 Außer den genannten Quellen lassen sich weitere Hinweise finden: In c. Gaud. I 27 spielt Augustinus wahrscheinlich auf das Jahr 410 an, wenn er von einer libertas perditionis für die Donatisten spricht. In der kaiserlichen Instruktion an Marcellinus zur Durchführung der Konferenz von 411 (Gesta conl. Carth. I 4, wiederholt in III 29; ein Auszug in CTh XVI 11.3) wird auf eine Rücknahme von Gesetzen gegen die Donatisten angespielt (vgl. Lancel, SC 194, 27).

138 Zos. VI 8-9, 11; vgl. CTh XI 28.6 (25.6.410 an den Prokonsul Afrikas Macrobius).

$139 \mathrm{Zu}$ der Genese und den Hintergründen des sog. Toleranzerlasses von 410 sind in der Forschung unterschiedliche Aspekte angesprochen worden. Bereits Seeck (Geschichte III, 362-365) machte ,heidnische Würdenträger“ für eine geänderte Politik des Honorius nach der Absetzung des MO Olympius verantwortlich. L. Leschi (Le dernier proconsul païen de la province d'Afrique (410 apr. J.-C.), in: II $^{\mathrm{e}}$ Congrès national des Sciences historiques, Algier 1930, 253-260) glaubt, der Heide Macrobius, Prokonsul von Afrika im Jahr 410, habe zusammen mit dem comes Africae Heraclianus und dem Prätorianerpräfekten Iovius die entscheidenden Weichen gestellt. Monceaux (IV, 81 f., $260 \mathrm{f}$.) vermutete, dass Honorius aus Furcht vor den Goten eine „Einheit der Bürger“ anstelle einer „Einheit der Kirche“ herstellen wollte. Dies ist sicherlich ein Teilaspekt, der jedoch nicht allein ausschlaggebend gewesen sein kann, da die Rücknahme des Toleranzgesetzes einen Tag nach der Plünderung Roms und damit gerade in einer sehr angespannten Phase verkündet wurde. De Veer (REByz 24, 1966, 189-195) lehnt Leschis These ab und erklärt unter Verweis auf Zosimus (V 46, s. u.), dass Kaiser Honorius durchaus selbst für die Toleranz verantwortlich gewesen sein könnte. Er stellt außerdem heraus, dass das entsprechende Gesetz nicht allein auf die Donatisten bezogen worden sei. Gegen die zu weit gehende Interpretation heidnischen Einflusses betont Brown (Religion and Society, 319) den entscheidenden Punkt: Honorius brauchte in der Krisenzeit den Rückhalt der afrikanischen Provinz. 
Toleranzphase zeigt allerdings deutlich, dass Honorius im Grundsatz nicht von seiner ursprünglichen Haltung abgerückt war. Doch werden die Ereignisse des Jahres 410 dazu beigetragen haben, den Wunsch nach einer endgültigen Lösung des Konflikts zu bestärken und die alte Idee eines allgemeinen „Religionsgesprächs" wieder aufleben zu lassen.

Der Blick über die Zeitspanne von 404 bis 411 zeigt deutlich, dass sich die Religionsstreitigkeiten in Nordafrika verschärften. Dies war offensichtlich auch eine Folge des durch die Gesetzgebung gewachsenen Drucks auf die Donatisten. Der Kaiser hatte versucht, zusammen mit der katholischen Kirche alle abweichenden Glaubenshaltungen per Gesetzgebung zu unterdrücken: Dort, wo Versammlungsverbote und die Konfiszierung von donatistischem Eigentum durchgesetzt werden konnten, kam es indessen zu Reaktionen, die sich entweder durch gewalttätige Unruhen oder aber durch resignierendes Konvertieren ausdrückte. An vielen Orten aber blieben die erlassenen antidonatistischen Gesetze unwirksam, da dem Einfluss der Reichsgewalt Grenzen gesetzt waren.

Die Ergebnisse des kaiserlichen Eingreifens waren somit ambivalent. In einigen Städten, darunter wohl Karthago, kam es zur Vereinigung der Kirchen und der Verbannung donatistischer Bischöfe. Über das Verfahren in den zahlreichen Kleinstädten und Landsitzen hingegen kann man nur Vermutungen anstellen. Aller Wahrscheinlichkeit nach verfehlte die Politik ihre Ziele in vielen

Tengström (Donatisten, 109 f. mit Anm. 5) stellt (wohl aufgrund der Darstellung bei Stein, Geschichte, 391, 401) eine direkte Verbindung von Zosimus V 46.2-5 zum Toleranzgesetz von 410 her. Zosimus berichtet hier von einem Gesetz, „das den Nichtchristen untersagte, den Gürtel am Kaiserhof zu tragen“ (d.h. keinen Militärdienst ausüben durften, vgl. F. Paschoud, Zosime, 304 f.; S. Rebenich, Zosimus, Neue Geschichte, Komm. z. St., 387 Anm. 111). Der Heerführer Generidus, ein Heide, (PLRE II, 500 f., s. v. Generidus) legte daraufhin sein Amt nieder. Da nun Honorius aber nicht auf die Dienste des Generidus verzichten wollte, hob er das entsprechende Gesetz wieder auf und gestand jedem das Recht $\mathrm{zu}$, „unter Beibehaltung der eigenen religiösen Überzeugung ein Amt zu verwalten und Kriegsdienste zu leisten“ (Zos. V 46.2-5). Die von Zosimus berichtete Episode fand offenbar nach der Absetzung des MO Olympius, vielleicht im Frühjahr 409 statt (Zos. V 46.1). Das erwähnte Gesetz ist mit großer Sicherheit jenes vom 14.11. 408, das an Olympius und den comes domesticorum Valens gerichtet war und den Ausschluss von „Feinden der katholischen Kirche“ vom Palastdienst forderte (CTh XVI 5.42, so auch Rebenich, aaO; M. Clauss, Magister Officiorum, 175). Eine Verbindung zu den Vorgängen 410, wie Tengström es sieht, ist indessen äußerst unwahrscheinlich, da Zosimus deutlich von einem Gesetz gegen die Hofbeamten spricht. Rebenich bezweifelt zudem die Richtigkeit von Zosimus' Darstellung: Generidus dürfte kaum eine Rücknahme des Gesetzes gelungen sein, vielmehr sei seine Sichtweise ein Teil der heidnischen Propaganda (Rebenich, aaO; Paschoud, Zosime, 305: „Le long développement consacré à Généridus est évidement un beau morceau d'apologie païenne“). Paschoud (Zosime, 302-304) zeigt außerdem die Widersprüche von Zosimus' Darstellung auf: So kann die Generidus-Episode nicht in Rom gespielt haben, da Honorius im entsprechenden Zeitraum in Ravenna residierte. Außerdem ist die militärische Stellung, die Generidus eingeräumt wird, sehr unklar. 
Gegenden, vor allem in Numidien. Generell kam es auf das Handeln, die Hartnäckigkeit bzw. die Konsequenz der katholischen Bischöfe und Beamten vor Ort an. ${ }^{140}$ Ein einflussreicher katholischer Bischof, der viel Unterstützung fand, konnte Donatisten leichter zur „Einheit“ zwingen lassen als einer, der diese Voraussetzungen nicht hatte. Entscheidend war, ob die maßgeblichen Persönlichkeiten einer Kommune die Gesetze unterstützten oder nicht. Jedwede Durchführung lag in den Händen lokaler Beamter und den zur Verfügung stehenden militärischen Einheiten. Ein Prozess konnte nur stattfinden, wenn ein Kläger vorhanden war. Es darf nicht verwundern, wenn in Gegenden, in denen Katholiken die Minderheit bildeten, wo Magistrate, Patrone, Richter oder Beamte zum Großteil selbst Donatisten waren, kein Interesse an einer Umsetzung der Gesetze gezeigt wurde. ${ }^{141}$

Die Präsenz militärischer Macht darf keinesfalls überschätzt werden. Die Truppenstärke war eher gering und kaum in der Lage, Forderungen nach einer Umsetzung der Gesetze tatsächlich nachzukommen. Die Formulierungen im Gesetz von 15. Januar 409 sprechen dieses Problem deutlich an: Falls nicht genügend Truppen zur Verfügung stehen, sollen diese beim comes Africae eingefordert werden. ${ }^{142}$

Augustins rege Aufklärungstätigkeit, darunter seine schriftliche Auseinandersetzung mit Donatisten, deuten insgesamt auf einen mäßigen Erfolg bei der Konversion von donatistischen Gläubigen hin. Gewalttaten, die er mit den Donatisten in Verbindung bringt, scheinen nicht abgenommen zu haben. Die Toleranzphase im Frühjahr 410 war kein plötzlicher Befreiungsschlag für die Donatisten, sondern eher eine zusätzliche Erleichterung. Offenbar konnten in dieser Zeit verbannte Bischöfe zurückkehren und ihre Kirchen weitgehend wieder in Besitz nehmen, andernorts konnten wieder öffentlich neue Bischöfe ordiniert werden. Die Situation, die sich somit für die Einberufung der Konferenz nach Karthago 411 ergab und die sich in den Bischofslisten und den Gegenüberstellungen katholischer und donatistischer Priester widerspiegelt, war für den Donatismus nicht ungünstig. Der in der Tradition verankerte Glaube der donatistischen Christen hatte mit dem Unionsgesetz von 405 keinesfalls ein Ende gefunden. Auch wenn es durch die Verfolgung zu einer Schwächung der donatistischen Kirche gekommen war, auch wenn sie in ihrer Zahl nicht mehr so stark waren wie zehn Jahre zuvor, die theologischen Anführer konnten durchaus mit einem Rückhalt in ihren Gemeinden, selbstbewusst und mit einem gewissen Optimismus im Jahre 411 in Karthago auftreten.

140 Brown, Religion and Society, $321 \mathrm{f}$., 326-329.

141 Brown, Religion and Society, 321: „In Africa, therefore, the problem of religious coercion was part of a general, crisis of authority' that was so marked a feature of the last century of Roman rule in that province." Vgl. auch Crespin, Ministère, 170-174.

142 Vgl. o. Const. Sirm. 14; s. auch Brown, Religion and Society, 307-309. 


\subsection{Die Konferenz von Karthago und die Folgen (411-430)}

Die Konferenz in Karthago ${ }^{143}$ zwischen Donatisten und Katholiken im Jahre 411 sollte das Schisma beenden. Kaiser Honorius entsprach mit dieser Konferenz formell dem Wunsch der afrikanischen Bischöfe nach einem allgemeinen, klärenden Religionsgespräch, im Grundsatz ging es jedoch um eine Bestätigung und öffentliche Bekräftigung der katholischen Einheit. Marcellinus, der kaiserliche Beauftragte für die Konferenz, urteilte nach drei Sitzungstagen am 8. Juni 411 im Sinne des römischen Kaisers und der katholischen Bischöfe, indem er pro catholicae unitate entschied. ${ }^{144}$ Der Urteilsspruch und die Akten der Konferenz wurden bereits am 26. Juni 411 veröffentlicht, ein deutliches Zeichen, dass die Veranstaltung vor allem dazu diente, der afrikanischen Bevölkerung zu demonstrieren, welcher Glaube der richtige sei. Marcellinus verdeutlicht in seinem Veröffentlichungsdekret, dass die Schuldfrage eindeutig geklärt worden sei und alle Anschuldigungen der Donatisten hätten widerlegt werden können. Davon ausgehend verkündete er die Konsequenzen: Die zuständigen Autoritäten in Städten und auf dem Land werden angewiesen, Versammlungen der Donatisten zu verbieten. Die Gemeinden sollen unverzüglich zur katholischen Kirche zurückkehren, ebenso Bischöfe, oder aber sie sollen der Bestrafung durch die Gesetze gegen Häretiker anheimfallen. ${ }^{145}$

Das Ergebnis der Konferenz findet seinen Niederschlag in einem erneuten Unionsgesetz vom 30. Januar 412: $:^{146}$ Wesentlich schärfer als im Jahre 405 werden darin Strafen festgelegt. Nicht nur den Priestern und Bischöfen, sondern auch allen Laien, die sich weigern, zur katholischen Kirche zu konvertieren, werden drastische Geldstrafen angedroht. ${ }^{147}$ Widerständige Kleriker der Donatisten sollen in unterschiedliche Länder ins Exil verbannt werden. ${ }^{148}$

Mit mehreren Schriften aus dieser Zeit wollte Augustinus erreichen, dass die Masse der Gläubigen Einblick in den Entscheidungsprozess der Konferenz erhielt. ${ }^{149} \mathrm{Zu}$ diesem Zweck schrieb er in rascher Folge das Breviarium der Konferenzakten (breuic.), einen Traktat an die Donatisten (c. Don.) sowie

$143 \mathrm{Zu}$ Verlauf und Entscheidungen der Konferenz unten Kap. 5. Im Folgenden soll lediglich die weitere Entwicklung des Donatismus skizziert werden.

144 Cap. Conl. Carth. III 585; breuic. III 43.

145 Vgl. das sog. edictum cognitoris vom 26.06.411 (SC 224, 972-979); Lancel, SC 194, 102 f.

146 CTh XVI 5, 52 (Honorius an den PPO für Italien und Afrika Seleucus); vgl. Maier II, Nr. 95, 175-179.

147 Die Höhe der Strafe wurde nach Rang festgelegt: So mussten viri illustres 50 Pfund Gold zahlen, einfache Leute (plebei) noch fünf Pfund (!) Gold.

148 Eine Erneuerung des Gesetzes mit modifizierten Geldstrafen erfolgte zwei Jahre später. CTh XVI 5.54 (Honorius an den Prokonsul von Afrika Iulianus am 17.06. 414); vgl. Maier II, Nr. 96, 179-183.

149 Zum Folgenden vgl. Crespin, Ministère, 94-99. 
ep. 141. In die Reihe dieser Schriften gehört außerdem ein heute verlorener Traktat, den Augustinus an die Adresse von Emeritus gerichtet hatte (ad Emeritum episcopum Donatistarum liber unus). Da ihm dieser Bischof als Hauptakteur der Donatisten auf der Konferenz erschienen war, bot es sich für Augustinus an, diese Schrift in Form eines offenen Briefes an Emeritus zu adressieren, um den Gläubigen alle entscheidenden Argumente gegen die Donatisten zusammengefasst vorzutragen. ${ }^{150}$

Augustinus und andere katholische Bischöfe präsentierten ihre Argumente auch an den Orten, an denen die Gläubigen am besten erreichbar waren: in den Kirchen. Jährlich zur Fastenzeit wurden in vielen Kirchen Auszüge aus den Konferenzakten im Gottesdienst vorgelesen. ${ }^{151}$ Aus einem Brief Augustins lässt sich entnehmen, dass ebenso aus einer seiner Schriften über die Konferenz gelesen wurde. Wahrscheinlich handelt es sich hierbei um eine der kürzeren Schriften und nicht um den Breviculus. ${ }^{152}$ Auch in seinen Predigten nutzte Augustinus stets die Gelegenheit, auf das Ergebnis der Konferenz hinzuweisen, seine Freude über Bekehrungen auszusprechen und die Einheit zu loben. ${ }^{153}$ Eine von Augustinus unabhängige Arbeit zur Verbreitung der Konferenzakten ist die bis heute erhaltene Aktenedition des Marcellus mit seiner Gliederung des Textes in Capitula, die wahrscheinlich noch im Jahre 411 erschienen ist. ${ }^{154}$

Über die konkreten Folgen der Entscheidung von 411 und der darauf folgenden Gesetzgebung sind aufgrund der schlechten Quellenlage nur wenige Aussagen möglich. Es ist wohl davon auszugehen, dass die in Karthago unterlegenen donatistischen Bischöfe keine einheitlichen Konsequenzen gezogen haben. Sie hatten die Wahl zwischen Annahme der aufgestellten Bedingungen zur Vereinigung der Kirchen und ihrer Ablehnung, mit der Gefahr sich den entsprechenden Bestrafungen auszusetzen. Sicherlich spielten individuelle persönliche Überzeugung, ihre regionale Herkunft und Situation vor Ort eine entscheidende Rolle für die Donatisten. Aus der Erfahrung der vorangegangenen Repressionen lässt sich schließen, dass es auf der einen Seite kompro-

150 Retr. II 46; Poss. indic. VI 18. Zu den Schriften Augustins nach der Konferenz Monceaux VII, 118-125.

151 Ep. 28*.2; Emer. 4. - Namentlich genannt werden u.a. die Städte Karthago, Hippo Regius, Thagaste und Cirta.

152 Vgl. die Formulierung in ep. 28*.2: Scripsimus etiam unum librum de ipsis gestis tractantes. Lamirande (Studia canonica 32, 1998, 434) vermutet wohl zu Recht c. Don. hinter dieser Andeutung. Anders Lancel (BA 46B, 407, 569) und Schindler (Augustinus-Briefe, 118), die von breuic. ausgehen.

153 Vgl. besonders s. 359 (gehalten bei der Einweihung der Basilika in Hippo Diarrhytus). Vgl. Monceaux VII, 169-173. - Weitere Predigten Augustins bald nach der Konferenz: s. Denis 20 (in Karthago am 18. Juni 411), s. 296 (ebenda am 29. Juni); vgl. ferner Io. eu. tr. 5. 11. 12.; s. Guelf. 25; s. 112.

154 Vgl. die Marcelli praefatio (SC 195, S. 416-419), dazu Lancel, SC 194, 357-363; Monceaux IV, 418-420. 
missbereite donatistische Gläubige und Bischöfe gab, die sich der „Einheit“ zumindest nominell anschlossen, auf der anderen Seite gab es Donatisten, die nicht bereit waren aufzugeben: Kurz nach der Konferenz wandten sich donatistische Bischöfe an den Kaiser, um gegen die Entscheidung zu protestieren, erwartungsgemäß blieben sie erfolglos. ${ }^{155}$ Viele werden die weitere Entwicklung abgewartet haben. Gerade in den stark donatistisch geprägten Gebieten mussten schließlich erst die entsprechenden Behörden tätig werden, was je nach lokalen Umständen lange dauern konnte. Als Beispiel sei das numidische Thamugadi genannt, eine der größten Städte der Provinz, in der offenbar erst im Jahr 420 ernsthaft der Versuch unternommen wurde, den donatistischen Bischof zur Einheit zu zwingen. ${ }^{156}$

Augustinus betont häufig den „Erfolg“ der Einheitsbemühungen. Von der Stadt Cirta, der donatistischen Hochburg in Numidien, berichtet er beispielsweise über eine Vielzahl von Übertritten in die katholische Kirche, weitere Anspielungen lassen sich in seinen Schriften aus dieser Zeit finden. ${ }^{157} \mathrm{Als} \mathrm{Au}-$ gustinus im September 418 das mauretanische Caesarea besuchte, existierte dort keine donatistische Gemeinde mehr. Emeritus, der donatistische Bischof und ehemalige Wortführer, lebte aber noch in der Stadt. Er willigte ein, sich mit Augustinus zu einem Gespräch zu treffen, verweigerte dann aber jegliche Antwort auf dessen Ausführungen - eine deutliche Demonstration, dass Emeritus seine persönliche Überzeugung nicht geändert hatte und nicht zu ändern bereit war. Augustinus veröffentliche dessen ungeachtet seine Darlegungen gegenüber Emeritus in dem gesta cum Emerito Donatistarum episcopo liber unus, einem weiteren Traktat, in dem er das Beispiel der Maximianisten als Argument gegen die Donatisten verwendet. ${ }^{158}$

Augustinus berichtet auch andernorts vom Widerstand der Donatisten: So erfährt man aus der Stadt Mutugenna, dass der donatistische Priester Donatus einen Suizidversuch unternahm, als er verhaftet werden sollte. ${ }^{159}$ Auch die Circumcellionen blieben weiterhin aktiv. In der Nähe von Hippo wurde ein katholischer Priester durch eine Gruppe von Circumcellionen misshandelt und ermordet. Gleichwohl konnten die Täter gestellt und verurteilt werden. ${ }^{160}$

155 Vgl. breuic. III 36; c. Don. 1; Poss. vita 13.

$156 \mathrm{Zu}$ diesem Fall s. u. S. $58 \mathrm{f}$.

157 Ep. 144.1-2; ep. 142; correct. 14, 30. In Briefen an den Tribun Marcellinus (epp. 133, 139) und an den Prokonsul Apringius (ep. 134) lobt Augustinus das staatliche Vorgehen gegen donatistische Gewalt, spricht sich jedoch vehement gegen die Verhängung der Todesstrafe aus, die offenbar angewendet wurde. Vgl. auch Tengström, Donatisten, 112116.

158 Vgl. retr. II 51. Zum Text und den Ereignissen ausführlich u. Kap. 5.4.4.

159 Ep. 173.

160 Vgl. Ep. 133 u. 134; vgl. Grasmück, Coercitio, 226-229. 
In diesem Zusammenhang darf die angespannte politische Lage im Römischen Reich nicht übersehen werden. Die Situation in der Provinz Afrika während der Gotenkriege wird besonders deutlich in der Revolte des comes Heraclianus im Jahr 413. Mithilfe von Truppen unter der Führung des comes Marinus wurde Heraclianus besiegt und im August 413 hingerichtet. ${ }^{161}$ Darauf folgte eine Verfolgung der unstreitigen und vermeintlichen Unterstützer des Usurpators, der auch Marcellinus zum Opfer fiel: Trotz Protesten und der Fürsprache des katholischen Episkopats einschließlich Augustins wurde der Vorsitzende der Konferenz von 411 zum Tode verurteilt. ${ }^{162}$ In Anbetracht dieser Umstände war zumindest zeitweise an eine systematische Umsetzung der Kircheneinheit nicht zu denken. Die Donatisten konnten vielmehr den politischen Spielraum des Bürgerkriegs zu ihren Gunsten nutzen. Vor allem die Entmachtung des Marcellinus sahen die Donatisten als Gelegenheit, die Gültigkeit der Entscheidungen von 411 in Frage zu stellen, ein Ansinnen, dem der Kaiser jedoch kein Gehör schenkte. ${ }^{163}$ Auch ein Edikt des Vikars Macedonius aus dem Jahr 414 sowie die durch Augustinus bekannten Einsätze der Militärtribune Bonifatius und Dulcitius ${ }^{164}$ bestätigen, dass die grundsätzliche Absicht, die Kircheneinheit in Afrika zu erreichen, kompromisslos beibehalten wurde. ${ }^{165}$

Bonifatius war im Jahre 417 qua Amt damit beauftragt, mit seinen Soldaten gegen Donatisten vorzugehen, wenn diese nicht von sich aus die Einheit mit der katholischen Kirche suchten. ${ }^{166}$ Da ihm die Bekämpfung der Donatisten - insbesondere im Vergleich zu den geduldeten Arianern - nicht einleuchtete, erkundigte er sich bei Augustinus über die Unterschiede zwischen Arianern und Donatisten und über die Rechtfertigung der Verfolgung der Donatisten. Als Antwort erhielt er einen ausführlichen Brief, die Schrift de correctione Donatistarum, in der Augustinus gegenüber Bonifatius erklärt, warum die Zwangsgewalt gegen die Donatisten rechtmäßig sei: Die Donatisten selbst hätten die Entscheidung des Kaisers gefordert, lehnten aber jetzt das Urteil und die Gesetze ab. Die coercitio sei notwendig, um die Gewalt der Donatisten zu be-

161 Heraclianus wird zum Staatsfeind erklärt (CTh IX 40.21) und alle seine Anordnungen annulliert (CTh XV 14.13); vgl. auch o. S. 19 mit Anm. 13. Zu Marinus: PLRE II, 724, s. v. Marinus 1; Mandouze, PAC, 704, s. v. Marinus 4.

162 Vgl. Augustins Brief an den PPO Caecilianus (ep. 151), in dem er das an Marcellinus begangene „Unrecht“ kritisiert. Vgl. Maier II, 183-186. PLRE II, 244-246, s. v. Caecilianus 1.

163 CTh XVI 5.55 (Honorius an den Prokonsul Iulianus von 30. August 414); vgl. Maier II, Nr. 97, $183 \mathrm{f}$.

164 Dulcitius war als Tribun und Notar Sonderbeauftragter zur Bekämpfung der Donatisten; vgl. unten zu Gaudentius. Zur Person: PLRE II, 381 f., s. v. Dulcitius 1; Mandouze, PAC, 330-333; s. v. Dulcitius 2.

165 Das Edikt erwähnt Augustinus in einen Brief an Macedonius (ep. 155.17); vgl. Maier II, Nr. 98, 185 f.).

166 Bonifatius war 417 tribunus militum, seit 423 comes Africae, vgl. o. Kap. 2 Anm. 14. 
kämpfen und ihnen die Augen für die Wahrheit zu öffnen. An den Katholiken Bonifatius appelliert er, seine Aufgabe als Dienst für die Kirche zu verstehen und ernst zu nehmen. ${ }^{167}$

Im donatistischen Selbstverständnis waren die Zwangsmaßnahmen gegen sie eine neue Verfolgung, der es zu widerstehen galt, um die wahre Kirche Christi zu erhalten. Dafür sollte man, wenn notwendig, bereit sein, als Märtyrer zu sterben, um keinen Verrat am Glauben zu begehen. Als ein Beispiel für dieses Verständnis gilt der Fall des donatistischen Bischofs Gaudentius von Thamugadi. ${ }^{168}$ Im Jahre 419 wandte sich der Militärtribun Dulcitius an Augustinus, um Rat zu erbitten, da sich Gaudentius beharrlich gegen eine Vereinigung der Kirchen wehrte. Als Dulcitius und seine Soldaten anrückten, zog sich Gaudentius mit seiner Gemeinde in die Basilika zurück und drohte, das Gebäude mit allen Menschen anzuzünden und so den Märtyrertod zu sterben, falls Gewalt angewandt werden sollte. Dulcitius schreckte vor einer Eskalation zurück und übersandte zwei Briefe, die Gaudentius an ihn geschrieben hatte, an Augustinus weiter. Dieser antwortete darauf mit seinem ersten Buch gegen Gaudentius und bald darauf - nach einer Replik des Gaudentius - mit einer weiteren Abhandlung. Diese beiden Bücher bilden die letzte antidonatistische Schrift Augustins, in der er nochmals seine Positionen zum Schisma darlegt und die Gesetze gegen die Donatisten mit ihrem Zwang zur Einheit rechtfertigt. ${ }^{169}$

Der Ausgang des Konflikts in Thamugadi ist nicht bekannt. Es ist möglich, dass Gaudentius seine Drohung verwirklichte, ebenso könnte es zu einem Kompromiss gekommen sein. Zwar dürfte dieser Fall in seiner Radikalität eine Ausnahme gewesen sein, im Grundsatz jedoch werden auch andere donatistische Bischöfe versucht haben, die Auflösung ihrer Kirche mit allen Mitteln zu verhindern. Er zeigt, dass einzelne Donatisten bereit waren, in dieser neuen „Zeit der Verfolgung“ ihrem Ideal der „Kirche der Märtyrer“ gerecht zu wer-

167 Der Brief an Bonifatius wird als ep. 185 der augustinischen Briefsammlung gezählt. Augustinus rechnet ihn aber in retr. II 48 als liber zu seinen Schriften, ebenso Possidius (indic. VI 17). Edition: Goldbacher, CSEL 57, 1-44. Vgl. J. Alexander, AL 2, 27-35, s. v. Correctione Donatistarum (De-); Monceaux VII, 122-125.

168 Gaudentius war vermutlich direkter Nachfolger des Optatus von Thamugadi. Die erneute Radikalität der Donatisten in dieser Stadt ist auffällig. Gaudentius gehörte auch zu den donatistischen Vertretern bei der Konferenz von 411. Zur Person: Mandouze, PAC, 522-525, s. v. Gaudentius 2; Lancel, SC 194, 199 f. Monceaux VI 198-202 - Zum Ablauf in Thamugadi vgl. auch retr. II 59; ep. 204 (an Dulcitius), dazu Maier II, Nr. 100, 191 f.; Lepelley, Cités II, 473 f.; van der Lof, Gaudentius de Thamugadi, Augustiniana 17, 1967, 5-13.

169 Edition der contra Gaudentium Donatistarum episcopum libri duo: Petschenig; CSEL 53, 199-278; vgl. retr. II 59; Poss. indic. VI 19, 37; vgl. Lamirande, BA 32, 491-505; Monceaux VI, 191-232. Eine Rekonstruktion der beiden Briefe des Gaudentius an Dulcitius auf Grundlage der Zitate Augustins bei Monceaux V, 329-334. 
den. ${ }^{170}$ Es wird aber auch deutlich, dass die Situation der Donatisten im Gegensatz zu den Jahren vor 411 deutlich schlechter geworden war: Die Organisation ihrer Kirche wurde zerstört und der Rückhalt von breiten Teilen der Bevölkerung brach weg; es blieben - soweit überhaupt eine Beurteilung möglich ist - donatistische Enklaven, einzelne Gemeinden, die sich gegenüber ihren Gegnern behaupten konnten. Nach wie vor gab es auch Donatisten, die ihre Überzeugung schriftlich verbreiteten. Man weiß von einem gewissen Fulgentius, der in den Jahren nach 411 eine Abhandlung schrieb, in der er die Tauflehre der Donatisten verteidigte. ${ }^{171}$

Die Quellenlage für die Zeit bis zur Eroberung der Provinz durch die Vandalen und darüber hinaus ist äußerst dürftig. Augustinus richtete in seinen letzten Lebensjahren seine Aufmerksamkeit auf die Lehre des Pelagius; er erwähnt lediglich in seinen Abhandlungen gegen Julian von Eclanum nochmals einige Argumente aus dem Donatistenstreit. ${ }^{172}$ Seine Erfahrungen aus der jahrelangen Auseinandersetzung mit den Donatisten verarbeitete er indessen in seiner berühmten Abhandlung über den Gottesstaat.

Der anhaltende Kampf gegen widerständige Donatisten zeigt sich in den Gesetzen, die unter dem neuen Kaiser Valentinian III. nach Afrika gesandt wurden: Am 4. August 425 erhielt der Prokonsul von Afrika, Georgius, die Anweisung, gegenüber allen häretischen Gruppen keine Schwäche zu zeigen. ${ }^{173}$ Es ist in Analogie zu der Umsetzung der antidonatistischen Gesetze nach 405 anzunehmen, dass in den größeren Provinzstädten die Kircheneinheit durchgesetzt wurde, während die Strukturen der Donatisten auf dem Lande erhalten blieben. Eine Einheit der Kirche in Afrika, die Augustinus und die römischen Kaiser erwünscht hatten und erkämpfen wollten, kam niemals zustande. Donatistische Gemeinden und Traditionen hatten über die Zeit der Vandalen-

170 Gaudentius berief sich auf die Tradition der Märtyrer und der verfolgten Kirche sowie die Autorität Cyprians; vgl. Gaud. I 26-32; II, 2-6.

171 Fulgentius und seine Schrift ist nur durch die Widerlegung bekannt, die wohl zwischen 432 und 450 ein namentlich nicht bekannter katholischer Autor schrieb: Libellus aduersus Fulgentium donatistam. Vgl. Maier II, Nr.111, 237-285 (Edition und Kommentar); Monceaux VI, 221-232; Mandouze, PAC, 506 f., s. v. Fulgentius.

172 C. Iul. I 7; c. Iul imp. I 10, 55, 75; vgl. retr. II 62, zu Julian: W. Geerlings, LACL, $360-$ 362, s. v. Julian von Eclanum; zur Kontroverse vgl. S. Lancel, Augustin, 577-612.

173 CTh. XVI 5. 63; Georgius ist nur durch dieses Gesetz bekannt; vgl. PLRE II, 503; s. v. Georgius; Mandouze, PAC, 535; s. v. Georgius. - Die Donatisten werden erstmals im Jahre 428 in einem Gesetz aus dem Ostteil des Reiches im Zusammenhang vieler anderer häretischen Gruppen genannt (CTh XVI 5.65; vgl. Maier II, Nr. 106, S. 210-216). Es ist unwahrscheinlich, dass diese Bestimmungen konkret in Afrika zur Anwendung kommen sollten, vielmehr ist davon auszugehen, dass die Donatisten inzwischen ihren Platz im Kanon aller Häretiker gefunden hatten und entsprechend mit aufgeführt werden. 
herrschaft hinaus Bestand. ${ }^{174}$ Durch einige Briefe Papst Gregors I. weiß man, dass noch Ende des 6. Jahrhundert Gemeinden und Bischöfe in Numidien existierten, die als „donatistisch“ gekennzeichnet werden und offenbar großen Einfluss in dieser Provinz besaßen. Erst mit der Invasion der Araber verliert sich die Spur des Donatismus. ${ }^{175}$

174 Seeck (Geschichte III, 377) vermutet, dass die Donatisten „bereitwillige Helfer“ der Vandalen gewesen seien. Dies entbehrt jedoch jeglicher Grundlage in den Quellen.

$175 \mathrm{Zu}$ den letzten Zeugnissen über den Donatismus siehe Maier II, 292-389. Zur ihrer Interpretation für die „letzte Phase“ des Donatismus vgl. Anette Hettinger, Katholiken und Donatisten. Die afrikanische Kirche im Spiegel der Briefe Gregors des Großen, AHC 24, 1992, 35-77; R. A. Markus, Donatism; The Last Phase, in: From Augustine to Gregory the Great, London 1983, Kap. VI [Wiederabdruck aus: Studies in Church History 1, Leiden 1964, 118-126]. 


\section{Die Bücher gegen den Grammatiker Cresconius}

\section{Anlass und Entstehung}

Neben den Schriften gegen Petilianus und Parmenianus bilden Augustins contra Cresconium grammaticum et donatistam libri quattuor das dritte große antidonatistische Werk seines Euvres. ${ }^{1}$ Die Abfassung dieser Schrift erfolgte in den Jahren 405/6, nachdem Augustinus den Brief eines donatistischen Laien namens Cresconius erhalten hatte, in dem dieser die Ausführungen aus seinem ersten Buch gegen Petilianus zu verteidigen suchte.

Cresconius $^{2}$ ist außer durch die nach ihm benannte Schrift nicht bekannt. Alle Informationen zu seiner Person gehen somit auf die Beurteilung Augustins zurück. Cresconius' Herkunftsort ist unbekannt, er scheint jedoch Afrikaner gewesen zu sein. ${ }^{3}$ Er war Grammatiker von Beruf, das heißt, er unterrichtete Sprachlehre und Literatur, und gehörte somit als studierter und belesener Mann der gebildeten Bevölkerungsschicht an. ${ }^{4}$ Augustinus bezeugt Cresconius ein gutes Verständnis für die Redekunst und Dialektik, an manchen Stellen aufgrund Cresconius' Kritik an diesen Lehren nicht ohne Ironie, aber grundsätzlich in aufrichtiger Anerkennung. ${ }^{5}$

Cresconius hatte den Brief des donatistischen Bischofs Petilianus „an die Diakone und Priester" gelesen und hielt die Argumente, die er dort zu Gunsten des Donatismus fand, für gut begründet und verteidigenswert. Er wollte nicht zulassen, dass Augustinus seinen Bischof durch falsche Anklagen bloßstellte. Er schrieb eine epistula, um jene Darstellungen zu widerlegen, die Augustinus mit seinem „ersten Buch gegen Petilianus“ (c. litt. Pet. I) gegen besagten Brief

1 Edition: Petschenig, CSEL 52, 325-582. Possidius (indic. VI 11) führt das Werk unter dem Titel contra epistulam Cresconi grammatici libri quattuor, während es in retr. II 26 unter ad Cresconium grammaticum partis Donati libri quattuor verzeichnet ist. Der oben genannte Titel ist in einigen Handschriften überliefert und für die einschlägigen Editionen gewählt worden. Zur Überlieferung des Textes, Petschenig, CSEL 52, XII-XV.

2 Zur Person: Mandouze, PAC, 230-238, s. v. Cresconius 4; PLRE II, 329, s. v. Cresconius 1; de Veer, BA 31, 11-17; Kaster, Guardians of Language, 263; Monceaux VI, 87-91 (mit z.T. sehr detaillierten Aussagen zu Leben und Charakter des Cresconius, die sich kaum an den Quellen nachprüfen lassen; vgl. die Kritik von de Veer, aaO., 12-14); M. Moreau, AL 2, 137-139, s. v. Cresconius grammaticus.

3 Cresc. III 29, IV 51, 83. Der Name Cresconius ist ebenfalls typisch afrikanisch.

4 Cresc. II 3, 10; zum Hintergrund vgl. Kaster, Guardians of Language, 11-230; Marrou, Augustin, 3-26; Vössing, Schule und Bildung, 367-376, $585 \mathrm{f}$. und passim.

5 Vgl. Cresc. I 16, 27, II 15, 23, IV 3, 38, 52, 54; Cresc. II 15: ,in der Wortkunst nicht nur mittelmäßig gelehrt..." (in arte uerborum non mediocriter doctus). 
Petilians vorgelegt hatte. ${ }^{6}$ Obwohl es sich formal um einen Brief mit Augustinus als Adressaten handelte, ${ }^{7}$ galt Cresconius' Brief in erster Linie den interessierten, vornehmlich donatistischen Gläubigen. In dieser Hinsicht entspricht dieser Brief den meisten Schriften der katholisch-donatistischen Kontroverse, die in der Regel Propagandamaterial für die Öffentlichkeit darstellten. Demzufolge ist es auch fraglich, ob Cresconius beabsichtigte, in eine direkte Diskussion mit Augustinus zu geraten. Sein Hauptanliegen war es, den Donatisten Augustins Fehler in der Argumentation und dessen Überheblichkeit vor Augen zu führen.

Einige Anspielungen im Text lassen vermuten, Cresconius habe nicht aus eigenem Antrieb, sondern im Auftrag donatistischer Bischöfe, vielleicht sogar auf Anraten Petilians, gegen Augustinus geschrieben. ${ }^{8}$ Eine solche Vermutung ist durchaus naheliegend, wenngleich wenig überzeugend: Augustinus wirft Cresconius vor, er schreibe doch nur, was er von anderen gehört habe (Cresc. II 21; III 20,58), andernorts wird deutlich, dass Cresconius Informationen über die Maximianisten-Thematik bei donatistischen Bischöfen einholte (III 17; IV 35, 41). Grundsätzlich gibt Cresconius die gängigen Argumente seiner Partei wieder und verlässt sich verständlicherweise gerade in schwierigen Fragen auf die Vorgaben der donatistischen Bischöfe. Cresconius berücksichtigte entsprechend Meinungen anderer Donatisten. Dennoch zeigt sich in Augustins Widerlegung, dass Cresconius durchaus eigenständig und aus eigener Motivation heraus schrieb. Folglich wird es sich kaum um eine „Auftragsarbeit“ gehandelt haben.

Nach Auskunft Augustins erreichte ihn Cresconius' Brief erst eine geraume Zeit (longe postea) nach seiner Abfassung; wahrscheinlich kam er lediglich durch Zufall in seinen Besitz (I 1). Eine genaue Datierung ist mit dieser vagen Angabe kaum möglich, jedoch können durchaus einige Jahre zwischen Cresconius' Brief und Augustins Antwort (405/6) gelegen haben. Da Cresconius nur

6 Augustinus bekam bei einem Aufenthalt in Cirta zunächst nur einen Teil von Petilians polemischem Brief gegen die Tauftheologie der Katholiken in die Hände (dieses Fragment endete an der Stelle, die Augustinus in c. litt. Pet. II 42 zitiert) und verfasste alsbald, im Jahr 400/401 die erste Widerlegung dieser Schrift (vgl. c. litt. Pet. I 1). Darin stehen zwei Themen im Mittelpunkt, die sich aus den Vorgaben Petilians ergaben: Augustinus nimmt ausführlich Stellung zu der Tauffrage (c. litt. Pet. I 2-18) und weist den Vorwurf zurück, alle Katholiken seien durch die traditio in Sünde verwickelt (I 1926). Nur wenige Zeit später erhielt Augustinus den vollständigen Brief Petilians, woraufhin er eine weitere Widerlegung schrieb (c. litt. Pet. II), in der er in Form eines Disputs Abschnitt für Abschnitt Petilians Brief zitiert und anschließend kommentiert. Vgl. auch o. Kap. 2.2.1.

7 Retr. II 26; Cresc. I 1, 16. Zum Inhalt und zur Beurteilung von Cresconius` Brief: Monceaux VI, 91-110; de Veer, BA 31, 20-27. Petschenig hebt in seiner Edition von Cresc. die direkten Zitate des Cresconius hervor, die Herausgeber der PL kennzeichnen auch die indirekten Zitate.

8 So de Veer (BA 31, 17) und ihm folgend Mandouze (PAC, 231) und Moreau (AL 2, 138). Anders sieht es Monceaux (VI, 91), der Cresconius eine eigene Motivation zubilligt. 
die erste Widerlegung Augustins kannte, ist ein früher Termin um das Jahr 401 wahrscheinlich. Späteste Datierung ist das Jahr 404, da Cresconius offensichtlich noch vor dem Unionsedikt von 405 schrieb. ${ }^{9}$

Augustinus verfasste seine vier Bücher formal als direkte Antwort auf Cresconius‘ Brief. Häufig zitiert er die Hauptaussagen seines Gegners wörtlich und wendet sich dann mit seinen Fragen, Gegenargumenten und Appellen an Cresconius persönlich. Auf diese Weise präsentiert Augustinus eine geschriebene Diskussion zu allen wichtigen Themen des Schismas, mit der er einen großen Leserkreis unter Donatisten und Katholiken zu erreichen hoffte. ${ }^{10}$ Die Ausführlichkeit und überaus detaillierte Widerlegung Augustins lässt darauf schließen, dass Cresconius' Brief eine weite Verbreitung gefunden hatte und einen ernstzunehmenden Einfluss besaß. In den Augen Augustins durfte er nicht unwidersprochen bleiben. ${ }^{11}$ In diesem Zusammenhang ist der Einschätzung von Albert de Veer zuzustimmen, der schreibt: „En principe, Augustin répondait à tout écrit donatiste qui lui tombait entre les mains sans en laisser rien passer, "12 jedoch setzte er mit contra Cresconium einen neuen Maßstab, da dieses Werk im Umfang und Inhalt weit über die zahlreichen anderen Schriften hinausgeht. Zwei Gründe sind dafür ausschlaggebend: zum einen Cresconius' Kritik an Augustins Argumentationsmethodik und seine abweichenden Überzeugungen zur Entstehungsgeschichte des Schismas und in der Maximianisten-Thematik, zum anderen die veränderte Situation für die Donatisten nach dem Unionsgesetz von 405. Beide Umstände veranlassten Augustinus, umfassender und gründlicher als zuvor zu allen Streitfragen Position zu beziehen.

Gerade nach den neuen Gesetzen gegen die Donatisten sah es Augustinus als dringende Notwendigkeit an, die Schritte einer erzwungenen Rückführung der Donatisten zur katholischen Kirche mithilfe einer gründlichen Aufklärungsarbeit in der gesamten Öffentlichkeit argumentativ zu stützen. Aus dieser Motivation heraus entstanden nicht nur die Bücher gegen Cresconius, sondern auch zahlreiche andere Abhandlungen und Traktate. ${ }^{13}$ Augustinus versuchte in den Jahren seit 405 sowohl die theologischen Grundlagen der Donatisten gründlich zu widerlegen als auch den beim donatistischen Klerus und Volk verankerten traditionellen Überzeugungen $\mathrm{zu}$ entgegnen, die bei Cresconius deutlich zu sehen sind. Die vier Bücher gegen Cresconius vereinen die Dis-

9 Zur Datierung von Cresconius' Brief vgl. Moreau, AL 2, 138; de Veer, BA 31, 18 f. (um 401); Monceaux IV, 498; VI, 91 (Ende 401); Mandouze, PAC, 231.

10 Zu Sprache und Stil Augustins de Veer, BA 31, 56-59. - A. Bruckmayr (Studie zu St. Augustins Traktat Contra Cresconium, 205) sieht in Cresc. die „Kultursprache“ der damaligen Zeit repräsentiert.

11 Vgl. Moreau, AL 2, 137.

12 De Veer, BA 31, 24 f.; vgl. auch Monceaux VII, 204.

13 Vgl. o. Kap. 2.2.2. 
kussion aller theologischen und historischen Streitpunkte in einer Ausführlichkeit, die sich in keiner anderen antidonatistischen Schrift findet.

\section{Aufbau und Inhalt}

Mit den vier Büchern gegen den Grammatiker und Donatisten Cresconius unternimmt Augustinus den Versuch, jene Aussagen ausführlich zu widerlegen, die Cresconius in seinem Brief an Augustinus zur Verteidigung Petilians vorgebracht hatte. ${ }^{14}$ Dabei werden alle zentralen Themen der donatistischen Kirchenspaltung angesprochen und diskutiert. Die Bücher I-III bilden eine erste Widerlegung Augustins, das Buch IV ist eine unabhängige zweite Widerlegung, wenn auch die gleichen Themen wieder aufgenommen werden. ${ }^{15}$

Nach einer allgemeinen Einleitung, in der er erläutert, welche Umstände zur Entstehung seiner Schrift beigetragen haben (Cresc. I 1), beginnt Augustinus im ersten Buch mit einer Darstellung der Grundlagen und der Motivation seines Kampfes gegen die Donatisten. Ausgehend von der Kritik des Cresconius an der Verwendung von Redekunst und Dialektik rechtfertigt Augustinus in propädeutischer Manier den Anspruch der Bischöfe, mit allen Mitteln die Wahrheit zu verteidigen. Dazu gehöre die Redekunst als Hilfsmittel der christlichen Verkündigung ebenso wie die dialektische Methode (Cresc. I 2-26). Außerdem behandelt Augustinus die unterschiedlichen Ansichten der beiden Parteien über Taufe und Wiedertaufe (I 26-39). Der letzte Abschnitt des ersten und die Einleitung des zweiten Buches beinhalten eine Zusammenfassung der bisherigen Darlegungen (I 40 - II 1).

In Buch II begründet Augustinus anhand der unterschiedlichen Auffassungen von Katholiken und Donatisten über die Taufe, warum die Donatisten zu Recht als Häretiker zu bezeichnen seien (II 4-20). Weitere Themen sind zum einen die Frage nach der Gültigkeit des Taufsakraments und ihrer Abhängigkeit von der conscientia des Priesters (II 21-38), zum anderen die Frage nach der Einheit der Kirche auf Grundlage der Schriften Cyprians (II 39-49).

Der Aufbau des dritten und längsten Buches orientiert sich an Cresconius. Augustinus geht dessen Brief noch einmal durch und widerlegt die Aussagen, die ihm noch nicht eingehend genug bearbeitet schienen. Entsprechend kommt es $\mathrm{zu}$ einigen Überschneidungen und Wiederholungen von Inhalten aus den ersten beiden Büchern, allerdings werden auch neue Themen angesprochen, darunter die historischen Bezüge zum Schisma. Eine Einteilung von Buch III fällt nicht leicht, da Augustinus oftmals ohne inhaltliche Verbindungen zu der

14 Vgl. o. Kap. 2.2.2.

15 Inhaltsübersichten zu Cresc.: de Veer, BA 31, 27-43; Monceaux VII, 109-114; Moreau, AL 2, Fasz. 1, 1996, 131-137, s. v. Cresconium grammaticum partis Donati (Ad-). 
nächsten Aussage des Cresconius übergeht und kommentiert, doch gibt folgende Gliederung die Grundlinien des Buches wieder:

Zunächst thematisiert Augustinus die ekklesiologischen Fragen der Kirchenspaltung unter Einschluss des Streites über die traditio (III 2-44), anschließend rechtfertigt er sich gegen den Vorwurf, die Katholiken seien die Verfolger der Donatisten, und verteidigt die Verfolgungen von Gewalttätern (III 45-67). Gegen die Zweifel des Cresconius an der Wahrheit der katholischen Geschichtsdarstellung erläutert Augustinus anhand von Aktenmaterial die Entstehung des Schismas (III 67-69, 78-84). Er betont die Verbindung der katholischen Kirche Afrikas zur weltweiten Kirchengemeinschaft und stellt die gottgewollte Einheit der Kirche heraus. Ferner wendet sich Augustinus gegen Cresconius' Behauptungen, dass stets die Minderheit die Wahrheit vertrete und auch die Donatisten weltweit ihre Anhänger hätten (III 70-77). ${ }^{16}$ Schließlich handelt Augustinus einzelne Kritikpunkte gegen sein Werk und seine Person ab (III 85-92). Offenbar will er seinen Lesern demonstrieren, wie unbegründet und künstlich die Kritik des Gegners im Verhältnis zu seinen eigenen Darlegungen sei. Zum Abschluss betont er nochmals den Widerspruch der Donatisten zu Cyprian und zur Heiligen Schrift (III 93).

Das vierte Buch ist eine zweite und eigenständige Widerlegung von Cresconius' Brief, da Augustinus alle Themen nochmals anspricht. Der Unterschied besteht nur in der Art der Auseinandersetzung: Allein das Schisma der Maximianisten bildet den zentralen Ansatz der Argumentation, denn Augustinus sieht darin die beste Möglichkeit, alle Anschuldigungen des Cresconius zu entkräften: in der Frage der Taufe, des Schismas und der Verfolgung. ${ }^{17}$ Dem entsprechend verfährt er im Buch IV fast durchgängig nach folgendem Argumentationsschema: Als erstes wird ein kurzer Satz zur Position seines Gegners oder seiner Gegner genannt, häufig als direktes Zitat des Cresconius, anschließend folgt eine Erläuterung seiner eigenen Position, die im Grunde den Ausführungen aus den ersten drei Büchern entspricht, und zuletzt die Vergleichsmomente mit den Maximianisten, um die Aussagen nochmals zu untermauern.

In der Gliederung von Buch IV spiegelt sich der Aufbau der ersten drei Bücher wider: Augustinus beginnt mit der Rechtfertigung seiner Verwendung von Redekunst und Dialektik zur Verteidigung der Wahrheit (IV 2-6). Die Streitfrage, ob das Wort Donatistae die korrekte Ableitung von ,Donatus' dar-

16 Vgl. die Gliederung von de Veer (BA 31, 37-42), die Moreau (AL 2, 133) übernommen hat. Die Kapitel III 67-83 allein „sur les origines du schisme“ zu bezeichnen ist bei aller notwendigen Verallgemeinerung doch irreführend. Explizit die Entstehungsgeschichte behandeln nur die Paragraphen III 67-69; 78-84. - Die thematischen Überschneidungen berücksichtigt dagegen Monceaux (VII, 111) in seinem Überblick.

17 Cresc. IV 1; vgl. Cresc. IV 50, 54, retr. II 26. 
stelle, führt Augustinus dann zu einer äußerst detaillierten Einleitung in die Geschichte des Maximianistischen Schismas und dessen Parallelen zum Donatismus (IV 7-11). Es folgen Ausführungen zur Taufe (IV 13-30) und über die Vermischung von guten und schlechten Christen innerhalb der Kirche (IV 3154), insbesondere am Beispiel des Optatus von Thamugadi (IV 31-34). Die anschließenden Erläuterungen zur Verfolgung (IV 55-62) wiederholen die langen Darlegungen aus Buch III lediglich in kürzerer Form. Sehr ausgiebig behandelt Augustinus wiederum den Gegensatz von Donatismus und weltweiter Kirche (IV 63-77). Schließlich geht Augustinus - wie bereits im dritten Buch auf einige übrig gebliebene Themen ein; so auf die gegenseitigen persönlichen Diskreditierungen (IV 78-79) oder die Verwendung von Metaphern (IV 81). Die Zusammenfassung der Ergebnisse führt zu einem letzten Aufruf Augustins an Cresconius und an alle Donatisten, sich der Schlagkraft der Argumente aus dem Maximianistischen Schisma zu beugen und zur katholischen Einheit zurückzukehren.

\section{Themen der Auseinandersetzung}

In den vier Büchern gegen Cresconius werden alle zentralen Themen der donatistischen Kirchenspaltung angesprochen und diskutiert. Im Folgenden sollen zunächst die wichtigsten Argumente von Cresconius und Augustinus zu den Themen Rhetorik und Dialektik, Taufe, Kirche sowie Verfolgung vorgestellt werden, um den argumentativen Zusammenhang zur historischen Argumentation herzustellen, die anschließend im Abschnitt 4. betrachtet wird.

\subsection{Die christliche Beredsamkeit}

Cresconius hatte in seinem Brief die Verwendung von Dialektik und Rhetorik in Augustins Argumentation angegriffen. Dies veranlasste Augustinus dazu, die Ziele und Methoden seiner Streitgespräche und -schriften gegen die Donatisten ausführlich zu begründen und dem Gegner seine Beurteilung von Rhetorik und Dialektik als Hilfsmittel der christlichen Verkündigung darzulegen. Cresconius' Einwand gegen die Redekunst richtet sich vor allem gegen die Funktion, einer falschen Aussage den Anschein der Richtigkeit zu geben (I 2). Dies zeigt sich, wenn er die Rhetorik als „Feind der Wahrheit“ und „Herrin des Irrtums“ brandmarkt (IV 2). In Cresconius' Augen ist Augustinus ein Vertreter der Lüge, dem letztlich keine noch so große Beredsamkeit helfe, aus der Lüge Wahrheit entstehen zu lassen.

Mit den gleichen Argumenten greift Cresconius Augustins Dialektik an. Auch die Dialektik diene der Verdrehung der Tatsachen; sie verkehre die 
Wahrheit in Lüge und die Lüge in Wahrheit und täusche so die unwissenden Menschen (I 16; II 23). Ausgehend von der Gefahr, die die Rhetorik und Dialektik in sich berge, hält es Cresconius für richtig, Gesprächen mit Augustinus aus dem Weg zu gehen. Die wahre Lehre solle nicht in einer Flut sophistischer Schwätzerei niedergeredet werden und die Menschen dürften nicht zur Unwahrheit überredet werden (I 3, 16). Er erteilt damit Augustins Bemühungen um Gespräche mit Donatisten eine deutliche Absage. Aus seiner Sicht können Gespräche zwischen Donatisten und Katholiken keinen Fortschritt bringen. Die Katholiken seien nicht bereit, sich der Wahrheit zu beugen und ihre Schuld anzuerkennen, stattdessen beharrten sie noch auf ihren falschen Überzeugungen und versuchten, ihre Lügen als Wahrheit zu verkaufen (I 11).

Cresconius vertrat wie viele andere (nicht nur donatistische) Christen die Ansicht, dass die klassische Rhetorik in ihrer aufgebauschten Künstlichkeit nicht für die christliche Verkündigung verwendet werden solle. Vermutlich hatte er unter anderem auch Cyprian im Sinn, der trotz klassischer Bildung als Bischof einen einfachen Stil zu schreiben pflegte. ${ }^{18}$ In dieses Verständnis passt auch Cresconius' Kritik an Augustins Gebrauch von Metaphern (III 89) und seine Klage über die lästerliche und grausame Sprache Augustins (III 90-91). In Augustins Reden, angefüllt mit rhetorischen Spielarten, konnte Cresconius nichts Christliches mehr erblicken. ${ }^{19}$ Trotz dieser Kritik und der Unterstellung, Augustinus verführe Menschen mit rhetorischer Raffinesse, ist nicht ersichtlich, dass Cresconius die Rhetorik pauschal verurteilte, sondern lediglich ihre Verwendung zu einer Verkehrung der Tatsachen angriff. Entsprechendes gilt für die Beurteilung von Cresconius' Verständnis der Dialektik. Cresconius griff die Methode an, mit der die Wahrheit verkehrt werde, und er unterstellte Augustinus, mit Hilfe der Dialektik die Menschen zu täuschen. Mit seinen Angriffen beabsichtigte Cresconius, Augustinus als einen Mann der vielen Worten, aber mit wenig Substanz darzustellen. Seine Leser sollten erkennen, dass Augustins gelehrtes Reden, seine gewundenen Phrasen und sein Bilderreichtum nicht der Wahrheit dienten, sondern lediglich die Unwahrheit verschleierten.

Gegen Cresconius' Auffassung stellt Augustinus die Berechtigung und die Notwendigkeit von Beredsamkeit und Dialektik dar. ${ }^{20}$ In beiden Fertigkeiten

18 Vgl. A. Dihle, Die griechische und lateinische Literatur der Kaiserzeit, München 1989, $393 \mathrm{f}$.

19 Auch Petilianus wirft Augustinus „sophistisches Geschwätz“ vor; vgl. c. litt. Pet. III 26.

$20 \mathrm{Zu}$ Augustins Definition von Eloquenz vgl. de Veer, BA 31, 742-744; F. Weissengruber, Augustins Wertung von Grammatik und Rhetorik im Traktat contra Cresconium, Hermes 105, 1977, 114-118; Marrou, Augustin, 510; W. Blümer, AL 2, 775-797, s. v. Eloquentia. Zu seinem Verständnis von Dialektik vgl. die Schriften de dialectica und de doctrina christiana (besonders Buch II). In dial. 1 definiert Augustinus die Dialektik als bene disputandi scientia. - Vgl. dazu de Veer, BA 31, 744-747; Weissengruber, Hermes 105, 1977, 115 f.; Marrou, Augustin, 240-248, 576-578; Bruckmayr, Studie, 208 f.; Hans 
sieht er eine wichtige Grundlage für die christliche Verkündigung. Die Dialektik helfe, das Wahre vom Falschen zu trennen, die Beredsamkeit diene dazu, die gewonnenen Erkenntnisse in angemessener Form auszudrücken; so ergänzten sie sich und bildeten eine Einheit (I 20). Eine Verfehlung des Nutzens sieht Augustinus lediglich, wenn diese Methoden nicht im Dienste der Wahrheit stehen. Die Vertreter der Wahrheit brauchten diese Qualifikationen jedoch nicht zu scheuen und zu fürchten, da sie zum guten Nutzen gereichen (I 40). Damit verteidigt Augustinus seine Methoden im Umgang mit den Donatisten und wehrt sich gegen die persönlichen Angriffe, er sei ein Wahrheitsverdreher, weil er dialektisch argumentiere und eloquent rede. Augustinus will den Vorbehalten und Ängsten entgegentreten, die Cresconius gegenüber Eloquenz und Dialektik geschürt hatte. Er will zeigen, dass es ihm nicht darum geht, andere Menschen zu überreden oder gar zu täuschen, sondern dass er konstruktive Gespräche zu den entscheidenden Fragen des Schismas für möglich hält, um die Einheit der Kirche wieder zu erlangen.

Gegen Cresconius führt Augustinus drei Vorwürfe an. Sein erster Vorwurf lautet, Cresconius ignoriere die Aussagen der Heiligen Schrift, das Verhalten Christi und der Apostel, wenn er Eloquenz und Dialektik anklage. Ein zweiter Vorwurf, er sei inkonsequent in seiner eigenen Lehre, wenn er die Methoden selbst anwende, die er verteufele. Der dritte Vorwurf lautet, es gebe keinen Grund für die Donatisten, Gespräche mit den Katholiken abzulehnen, da sich Cresconius' Vorbehalte gegen Beredsamkeit und Dialektik nicht aufrechterhalten ließen. Ohnehin handele Cresconius auch hier inkonsequent, da er mit seiner Antwort auf Augustins Brief bereits in einen Disput mit ihm trete (I 4, 16).

Im Vergleich der Ausführungen Augustins und der Aussagen Cresconius' lässt sich erkennen, dass Augustinus die Kritik seines Gegners nur zum Teil richtig versteht und zutreffend erwidert. Cresconius greift durchgängig Augustinus persönlich an; er warnt vor dessen rhetorischer und dialektischer Raffinesse und rät daher von Disputen mit ihm ab. Er kritisiert die Arroganz und Selbstgefälligkeit, mit der Augustinus eine Lösung für das Schisma finden will. Aber es geht Cresconius um die Verteidigung der Wahrheit. Auch er verurteilt Rhetorik und Dialektik lediglich dort, wo sie zur Verfälschung der Wahrheit missbraucht werden - und bei Augustinus beobachtet er einen solchen Missbrauch in schwerwiegender Weise. ${ }^{21}$ Das bedeutet, Augustinus trifft nur an den Stellen den Kern der donatistischen Anklagen, wo er sich selbst und seine Gesprächsbemühungen verteidigt, und erklärt, dass er selbst auf der Seite der Wahrheit stehe und in seinen Schriften die Wahrheit nicht verfälsche. Er ver-

Ruef, AL 2, 407-413, s. v. Dialectica, dialecticus; J. Pépin, Saint Augustin et la dialectique, Paris 1976, passim.

21 Vgl. de Veer, BA 31, 745. 
fehlt den Kern jedoch dort, wo er Cresconius mit allgemeinen Definitionen belehren will oder biblische Exempel heranzieht und ihm unterstellt, trotz dieser Zeugnisse Beredsamkeit und Dialektik zu verurteilen. Cresconius benötigte weder eine schulmäßige Belehrung noch sprach er den biblischen Persönlichkeiten die Beredsamkeit oder Dialektik ab.

Hinter Augustins Polemik gegen Cresconius lässt sich erkennen, dass beide im Grunde das gleiche Kriterium vertraten: Im Dienste der Wahrheit haben Rhetorik und Dialektik grundsätzlich ihre Berechtigung. Lediglich in der weitergehenden Beurteilung zeigen sich Differenzen. Augustinus betont die positiven Seiten, hebt den Erkenntniswert der Dialektik und den Nutzen eines guten Vortrags hervor. Cresconius dagegen bleibt distanziert zu diesen „Künsten“, stellt die Gefahren des Missbrauchs heraus und impliziert somit ein Bekenntnis zur christlichen Tugend der einfachen und direkten Rede. Letztlich ist jedoch die Diskussion um Rhetorik und Dialektik keine Frage von Zustimmung und Ablehnung, sondern eine Frage der richtigen Grundlage (des recte sentire), und dies sprechen sich beide Kontrahenten gegenseitig ab.

\subsection{Die Taufe}

Der Streit um die Taufe und die Frage nach der Würde des Taufspenders nimmt wie in der gesamten Kontroverse auch in den Büchern gegen Cresconius einen breiten Raum ein. Cresconius verteidigt Petilians Aussagen zur Taufe und begründet die donatistische Position: Außerhalb der wahren katholischen Kirche, d.h. der donatistischen Kirche, könne es keine rechtmäßige Taufe geben. Nur bei der Taufe innerhalb der Kirche wirke der Heilige Geist zur Vergebung der Sünden. ${ }^{22}$ Entsprechend müsse jede Taufe der anderen Partei abgelehnt werden, denn ihre Bischöfe stünden aufgrund der Erbsünde der traditio und persecutio außerhalb der Kirche. ${ }^{23}$ Cresconius äußert sein Unverständnis darüber, dass Augustinus auf der einen Seite die Donatisten als Häretiker verurteilt, auf der anderen Seite aber donatistische Bischöfe, Priester und Laien unter Wahrung ihres kirchlichen Standes ohne Buße wieder aufnimmt. ${ }^{24}$ Er kann sich in dieser Frage auf Cyprian berufen, der im Wesentlichen die Positionen der Donatisten stützt.

22 Cresc. I 33: unus deus, una fides, unum baptisma, una incorrupta et uera catholica ecclesia.

23 Cresc. I 26, 33; II 27,40; III 2, 38; IV 4, 20, 76. - Zur Tauflehre der Donatisten vgl. Congar, BA 28, 48-70.

24 Cresc. II 10-12. - Cresconius kennt Beispiele für solche Übertritte und nennt namentlich die numidischen Bischöfe Candidus von Villa Regia und Donatus von Macomades (II 12). Diese Bischöfe sind anderweitig nicht bekannt. Vgl. Mandouze, PAC, 185, s. v. Candidus 2; 309, s. v. Donatus 23. 
Augustinus stellt dieser exklusiven Haltung der Donatisten ein Taufverständnis entgegen, das die Anerkennung außerhalb der katholischen Kirche vollzogener Taufen einschließt. ${ }^{25}$ Wer im Namen Christi getauft wird, erhalte eine gültige Taufe, denn Christus selbst sei die Kirche (II 26). Diese Taufe Jesu Christi müsse daher auch unabhängig von der Zugehörigkeit der Kirche akzeptiert werden. Gleichwohl könne nur innerhalb der katholischen Kirche das Sakrament der Taufe zu einem guten Nutzen führen, während es außerhalb zum Schaden gereiche. ${ }^{26}$ Denn ausschließlich in der Kirche wirke der Heilige Geist, durch den allein die Sakramente für die Gläubigen heilbringend würden (II 1619, 34). Wenn nun die Katholiken die donatistische Taufe anerkennen, bedeute dies keinesfalls die Anerkennung der donatistischen Kirche (I 27, 32). Die Anerkennung donatistischer Sakramente bei gleichzeitiger Einordnung der Donatisten unter die Häretiker stellt für Augustinus keinen Widerspruch dar. Auch die Aufnahme von donatistischen Klerikern in die katholische Kirche verteidigt er gegen die Angriffe des Cresconius: Die Tradition und die Sakramente seien gemeinsam. Daher genüge die innere Umkehr, um sie als Kleriker in ihrem Amt anzuerkennen (II 12-14, 19).

In diesem Zusammenhang nimmt das das Thema der conscientia des Priesters eine zentrale Stellung ein. Dabei ging es um die Frage, ob eine Taufe ungültig sei, wenn der Priester sein Amt als Taufspender mit einer befleckten conscientia, einem unreinen Gewissen, ausübte. ${ }^{27}$ Die Donatisten gingen von einem conscientia-Begriff aus, bei dem die Zugehörigkeit des Priesters zur wahren Kirche als Maßstab für die Anerkennung seiner Dienste und Sakramente galt. In der donatistischen Kirche wurde die Taufe also nicht durch verborgene Sünden des Taufspenders ungültig, sondern die Kirche stellte die entscheidende Instanz zur Beurteilung der Priesterwürde dar. Solange ein Priester nicht von der Kirchengemeinschaft verdammt worden war, solange konnte er auch vollgültig die Sakramente verwalten. Auf dieser Grundlage erklärt Cresconius die Konsequenz für den einfachen Gläubigen: Das Gewissen der Priester könne nicht überprüft werden, aber jeder könne leicht in Erfahrung bringen, ob ein Priester aus der Kirche ausgeschlossen worden war oder nicht.

$25 \mathrm{Zu}$ Augustins Tauflehre in Bezug auf den Donatismus: C. García Mac Gaw, Le problème du baptême dans le schisme donatiste, Paris 2008; vgl. auch de Veer, BA 31, 764 766, 771-773; V. Grossi, AL 1, 583-591, s. v. Baptismus; C.P. Mayer, Taufe und Erwählung, 22-42; J. Ratzinger, Volk und Haus Gottes, 136-158; W. Simonis, Ecclesia visibilis et invisibilis, passim.

26 Cresc. I 27: nam re uera dicimus baptismum et illic esse, sed non dicimus et prodesse, immo uero dicimus et obesse. Vgl. I 34.

27 Zum conscientia-Verständnis bei den Donatisten und bei Augustinus vgl. Congar, BA 28, 55-60; C. Mayer, AL 1, 1218-1228, s. v. conscientia, besonders 1226 f.; de Veer, BA 31, 773-777; Stelzenberger, Conscientia bei Augustinus, passim; Vgl. de Veer, BA 31, 773-777. 
Das donatistische Verständnis von conscientia erklärt den Anlass des Schismas. Trotz ihrer Schuld seien Traditoren im Bischofsamt verblieben. Mit ihrer rechtmäßigen Verurteilung sei jedoch ihre belastete conscientia offenbar geworden und alle ihre Sakramente hätten die Gültigkeit verloren. Kein Getaufter dieser Bischöfe habe somit eine gültige Taufe erhalten und kein Nachfolger dieser Bischöfe eine gültige Weihe. Dadurch habe die katholische Kirche ihre Legitimität verwirkt. Die Verfolgung der wahren Christen durch die Katholiken verdeutliche zusätzlich, welche der Parteien die wahre Kirche darstelle. ${ }^{28}$ Davon ausgehend rechtfertigt Cresconius die Praxis der Taufe aller Katholiken: Die Donatisten tauften im Namen Christi, so wie auch die Apostel nach der Taufe des Johannes nochmals getauft hätten (III 10). ${ }^{29}$

Gegen die donatistische Auffassung deutet Augustinus den conscientia-Begriff im ethischen Sinne auf das Gewissen des Priesters bezogen. Auf dieser Basis unterstellt er den Donatisten, bei ihnen entscheide allein die persönliche Integrität des Taufspenders über die Anerkennung der Taufe. Er versucht seine Leser davon zu überzeugen, dass die Donatisten sich ganz auf das unsichere Urteil der Menschen verließen, wenn sie nur auf einen unbescholtenen Ruf des Taufspender in der Öffentlichkeit achteten, anstatt ihr Vertrauen auf den allwissenden Gott zu setzen (II 21-38). Hier greift Augustinus die Aussage des Cresconius über die publica fama des Taufspenders auf, die dieser sicherlich nur als eine zusätzliche Erläuterung angeführt hatte (II 21), und nutzt sie für eine scharfe Polemik gegen die Tauflehre der Donatisten (II 22-23, III 5): Nach der Lehre des Cresconius, so Augustinus, könne ein Priester trotz einer verunreinigten conscientia allein durch seinen untadeligen Ruf (fama bona) eine gültige Taufe vollziehen (II 22). Diese Vorstellung sei jedoch vollkommen verdreht und unsinnig, denn dem Betrug werde Tür und Tor geöffnet. Wenn die öffentliche Meinung über einen Priester entscheide, dann genüge es nämlich, einen guten Ruf vorzutäuschen, und dies bedeute, Gott verwende einen Lügner für sein Sakrament. ${ }^{30}$

Deutlich lässt sich hier sehen, wie Augustinus in seinen Argumenten die ekklesiologische Auffassung des conscientia-Begriff bei den Donatisten verkannte oder vielmehr unterschlug und dadurch erreichte, dass die donatistische Position in den Augen der Leser als abwegig erscheinen musste, gleichzeitig aber seine eigenen Ausführungen zur Tauf- und Kirchenlehre umso plausibler wirken konnten. Augustinus betont immer wieder die Unabhängigkeit der Taufe von der conscientia des Spenders: Urheber der Taufe sei allein Christus, der

28 Vgl. Cresc. II 40; III 2, 38; IV 20, 52.

29 Der Vergleich mit der Johannestaufe und der Häretikertaufe geht auf Cyprian zurück (Cypr. ep. 73.24). Vgl. die Argumentation bei Petilianus (c. litt. Pet. II 86), dazu Bavaud, BA 29, 616-618.

30 Cresc. II 25-27, 38; III 6-9, 13. 
heilig sei. Deshalb sei jede Taufe im Namen Christi gültig (III 6-13). Folglich hätten auch die traditio-Anklagen der Donatisten gegen katholische Bischöfe keinerlei Auswirkungen, ganz gleich ob sie bewiesen werden könnten oder nicht (II 26-27). Für die donatistische Wiedertaufe gebe es keinerlei Anlass.

Da Cresconius deutlich betont, dass auch bei den Donatisten selbstverständlich Christus den Ursprung der Taufe darstelle, versucht Augustinus, diese Aussage in einen Widerspruch zu Petilianus zu bringen (III 6-8, 12): Petilianus habe behauptet, der Taufspender sei Ursprung der Taufe ${ }^{31}$ Cresconius hingegen bestätige die katholische Ansicht; er solle also gegen seinen Bischof Petilianus anstatt gegen die Katholiken streiten. Doch auch hier verkennt Augustinus die Zusammenhänge der donatistischen Theologie. Petilians Aussage über die Notwendigkeit einer conscientia dantis pura stellt nach donatistischer Interpretation keinen Widerspruch zum Bekenntnis der Taufe Christi dar. Cresconius formuliert lediglich deutlicher, was auch Petilianus in seinem zweiten Brief schreibt: Christus sei Haupt und Ursprung der Taufe, aber Christus könne nur durch einen würdigen Priester handeln, und würdig sei, wer der donatistischen Kirche angehöre. ${ }^{32}$ Augustins polemisch zugespitzter Gegensatz zwischen einer ,Taufe durch Christus` bei den Katholiken und einer ,Taufe durch Menschen` bei den Donatisten offenbart sich somit als Konstrukt seiner Argumentation, vorgeführt, um für seine Leser Petilianus und Cresconius gegeneinander auszuspielen. ${ }^{33}$

Die unterschiedlichen Auffassungen von Augustinus und Cresconius über die conscientia spiegeln sich in den Diskussionen um den donatistischen Bischof Optatus von Thamugadi und über die Maximianisten wider. Augustinus verwandte diese Beispiele gerne, um zu demonstrieren, dass die Donatisten Gewalttäter bzw. verurteilte Sünder in ihren Reihen duldeten, sogar deren Taufen akzeptierten und daher keinen Grund hätten, die vermeintliche Verunreinigung der Katholiken durch schlechte Christen anzuprangern. In diesem Sinne hielt er auch Petilianus die Taten des Optatus und den donatistischen Umgang mit den Maximianisten vor. ${ }^{34}$ Petilianus lehnte es in seiner Replik ab, über Optatus zu urteilen und wich der Maximianisten-Thematik weitgehend aus (c. litt. Pet. III 46, 48). Cresconius gibt nun bezüglich des Optatus eine ähnliche Antwort: „Ich

31 Vgl. c. litt. Pet. II 8, 32.

32 Petilianus erklärt unmissverständlich, dass Augustinus den donatistischen Glauben falsch dargestellt habe. Christus sei natürlich Ursprung der Taufe, denn die Donatisten tauften im Namen der Dreieinigkeit. Gleichwohl müsse das sichtbare Sakrament vermittelt werden und dies könne nur von einem der Kirche angehörigen Taufspender vollzogen werden (c. litt. Pet. III 63-65, vgl. auch II 62). Vgl. Quinot, BA 30, 58-61.

33 Vgl. de Veer, BA 31, 777-779.

34 C. litt. Pet. I 10-13, 17-22, 26; II 13, 16, 35, 78, 94, 104, 120. 
jedenfalls spreche Optatus weder frei, noch verdamme ich ihn. “" ${ }^{35}$ Auch wenn Augustinus nicht verrät, ob Cresconius noch weitere Erläuterungen hinzufügt, wird deutlich, dass die Taten des Optatus den Donatisten zwar ein Dorn im Auge waren und sie ablehnten, ihn zu rechtfertigen, sie aber keinesfalls bereit waren, die conscientia des Optatus im Sinne Augustins zu verurteilen und die Gültigkeit seiner Taufen abzulehnen. Dies erklärt sich durch die oben erläuterte, den Donatisten eigene Bindung von Kirche und Sakrament. Optatus war niemals aus der Kirche ausgeschlossen worden, besaß also nach wie vor eine conscientia pura und sein Bischofsamt musste vollgültig akzeptiert werden. Selbst wenn ihn noch so viele Donatisten moralisch verurteilten, so blieb er doch unschuldig gemäß donatistischer Ekklesiologie. ${ }^{36}$

Anders sah die Situation beim Maximianistischen Schisma aus. ${ }^{37}$ Denn im Zuge der Wiedervereinigung von Maximianisten und Donatisten, so lautete Augustins Vorwurf, sei die Taufe von rechtmäßig verurteilten und exkommunizierten Bischöfen bei den Donatisten anerkannt worden. Wenn dieser Vorwurf der Wahrheit entsprach, bedeutete dies einen eklatanten Bruch donatistischer Doktrin, eine Tatsache, die Augustinus scharfsinnig bemerkt hatte und ausgiebig in seiner Polemik verarbeitete. Cresconius hatte die entsprechenden Anklagen Augustins gegen Petilianus ${ }^{38}$ offensichtlich sehr ernst genommen und sich eingehend bei donatistischen Bischöfen über die Verurteilung und Rekonziliation der Maximianisten Praetextatus und Felicianus erkundigt. Das Ergebnis seiner Forschung konnte ihn beruhigen: Nach Auskunft der Bischöfe seien zwar auf dem Konzil von Bagaï die Maximianisten schuldig gesprochen worden, jedoch habe man allen Abtrünnigen eine Frist zur Rückkehr eingeräumt. Erst nach deren Ablauf sei die endgültige Verurteilung erfolgt. Praetextatus und Felicianus aber seien neben einer Reihe anderer Bischöfe innerhalb dieser Frist wieder zu den Donatisten gekommen, so dass ihre Taufen anerkannt werden konnten. Folglich habe Augustinus über das Schisma der Maximianisten Unwahrheiten verbreitet, und seine Unterstellung einer inkonsequenten Lehre sei nicht haltbar. ${ }^{39}$ In Cresconius' Bemühen, Licht in die Geschichte des Maximianistischen Schismas zu bringen, zeigt sich wiederum sehr deutlich, dass die bleibende Bindung des Bischofs an die Kirche die wesentliche Grundlage für die Akzeptanz seiner Sakramente darstellte. Nach diesem Kriterium konnte Cresconius Augustinus mit gutem Gewissen widerlegen. Aus seiner Sicht hatte kein von der Kirche verdammter Bischof eine gültige Taufe vollzogen.

35 Cresc. III 16: ego quidem Optatum nec absoluo nec damno. Vgl. III 49, 66; IV $31 \mathrm{f}$.

36 So zu Recht de Veer, BA 31, 775; vgl. 781-783.

37 Zum historischen Zusammenhang s. o. Kap. 2.1.2.

38 C. litt. Pet. I 11-18.

39 Cresc. III 17-28; IV 33-55. 
Wie anders Augustinus Recht und Unrecht in der Kirche beurteilte, lässt sich in seiner Argumentation zu Optatus von Thamugadi sehen.$^{40}$ Wie im ersten Buch gegen Petilianus erwähnt er Optatus als Beispiel für die zuvor diskutierten Aussagen zur conscientia. Allerdings setzt er hier mit Rücksicht auf seine eigene Interpretation der fama bona-Aussage des Cresconius einen anderen Schwerpunkt. Augustinus verzichtet zunächst auf eine Wiederholung der Anschuldigungen und akzeptiert Cresconius' Haltung, da er eingestehen muss, keine schriftlichen Dokumente gegen Optatus vorlegen zu können (III 15-17). Dieses Eingeständnis ist bezogen auf den Eifer, mit dem Augustinus gewöhnlich seine Anklagen gegen Optatus vorbrachte, zunächst überraschend, jedoch bestätigt es den Eindruck, dass trotz der häufigen polemischen Verwendung dieser Persönlichkeit schon einige Jahre nach seinem Tod nur wenig Konkretes über Optatus und sein Wirken bekannt war. ${ }^{41}$ Da er gerade Cresconius' Vertrauen in die öffentliche Meinung kritisiert hatte, konnte Augustinus nun seinerseits nicht mehr seine Anklagen allein auf unbewiesenen Gerüchten aufbauen. Doch taktisch geschickt nützt er diese Beweisnot aus, um Cresconius' Position auf andere Weise zu erschüttern: Wenn nämlich wahr sei, was über Optatus berichtet werde, dann habe dieser weder eine reine conscientia nach der Lehre Petilians, noch eine fama bona gemäß der Lehre des Cresconius. Folglich sei die Taufe des Optatus nach keiner der beiden Vorstellungen gültig (III 15). Augustinus glaubte also, sowohl Petilianus als auch Cresconius durch das Beispiel Optatus mit ihren eigenen Worten widerlegen zu können. Doch mussten seine Leser zunächst Augustins Interpretation des conscientia-Begriffes teilen, um dieser Argumentation zu folgen.

Augustinus verwendet den Beweismangel im Fall Optatus noch für einen weiteren Vergleich: Da die Donatisten ihre Anschuldigungen gegen Caecilianus nie bewiesen hätten, so formuliert er, genüge es ja im Sinne von Cresconius, wenn die Katholiken über Caecilianus das gleiche sagten, wie die Donatisten über Optatus: Caecilianus sei weder zu verdammen noch freizusprechen (III 15 f.). Diese Parallelisierung der Beurteilung von Optatus und Caecilianus ist sicherlich das schlagkräftigere Argument. Denn wenn Augustinus der Nachweis gelingen sollte, dass Caecilianus nicht - wie die Donatisten glaubten - rechtmäßig verurteilt und aus der Kirche ausgeschlossen worden war, gab es zumindest ihrer Kirchenlehre gemäß keinen Grund mehr, ihn und seine Nachfolger zu verurteilen. Insofern verwundert die ausgedehnte historische Argu-

$40 \mathrm{Zu}$ Augustins Stellungnahme zur Maximianisten-Thematik s. u. Kap. 3.3.4 und 4.2.2.

41 Mandouze (PAC, 800) folgert aus der prosopographischen Zusammenstellung: „Transmise en défínitive par le seul Augustin, l'image posthume de O[ptatus] ainsi laissée à la postérité est donc moins celle d'un personnage historique que le révélateur d'une ambivalence proposant alternativement à la négociation entre deux Eglises rivales." 
mentation in den Büchern gegen Cresconius nicht, die diesen Nachweis zum Ziel hatte.

\subsection{Die Einheit der Kirche}

Die Verbundenheit der afrikanischen Katholiken mit der weltweiten Kirchengemeinschaft war für Augustinus das wichtigste Argument in der Frage, woran die wahre Kirche zu erkennen sei: Während die Donatisten ein Schisma begangen hätten und abgeschieden von der Christenheit in einer Provinz des Reiches ihr Dasein fristeten, stünden die afrikanischen Katholiken in Gemeinschaft mit der Kirche, auf der der Segen Gottes liege.

Cresconius versucht, den Anspruch der donatistischen Kirche zu verteidigen, indem er seine Sicht der Beziehungen zu den Kirchen in Übersee erläutert und die Entwicklung der Kirchenspaltung skizziert. Viele Bischöfe aus den östlichen Provinzen des Reiches, so führt er aus, hätten in der Vergangenheit mit der Tauflehre Cyprians übereingestimmt. Dies ließe sich anhand eines Konzils orientalischer Bischöfe und einiger Briefe dieser Bischöfe nachweisen. Das Einvernehmen mit Cyprian zeige, dass diese Bischöfe die donatistische Position in der Vergangenheit geteilt hätten. Später jedoch hätten die orientalischen Kirchen durch ihre Abkehr von Cyprian und ihre Anerkennung der Häretikertaufe den Bruch mit der wahren katholischen Kirche vollzogen. Da sie sich also vom wahren Glauben abgewandt hätten, sei die Trennung unvermeidlich gewesen und die Donatisten seien jetzt nicht mehr in Gemeinschaft mit den Orientalen (III 2-3).

Aufgrund der wenigen Anspielungen bei Augustinus ist nicht klar ersichtlich, auf welche Quellen sich Cresconius stützte. Mit großer Wahrscheinlichkeit kannte und verwendete er jedoch den Brief des Bischofs Firmilianus von Caesarea in Kappadokien an Cyprian, der in der cyprianischen Briefsammlung überliefert ist. ${ }^{42}$ Firmilianus stellt sich in diesem Brief im Streit um die Häretikertaufe hinter Cyprian und betont die Verbundenheit der Kirchen Asiens und Afrikas. Es findet sich dort auch der Hinweis auf ein Konzil in Iconium in Phrygien, bei dem sich die Bischöfe Kleinasiens gegen die Anerkennung der Häretikertaufe ausgesprochen hätten. ${ }^{43}$ Dieser Brief Firmilians belegt somit die theologische Übereinstimmung orientalischer Bischöfe mit ihren Kollegen in

42 Cypr. ep. 75.

43 Cypr. ep. 75.7, 19. - Das Konzil von Iconium ist explizit nur bei Firmilianus erwähnt; es fand wohl zwischen 230 und 235 statt. Jedoch spricht auch Dionysius von Alexandria (Eus. HE VII 5.5) von Bischofssynoden in Kleinasien, die Beschlüsse zur Tauffrage gefasst hätten. Wahrscheinlich bezieht er sich auch auf das Konzil von Iconium. 
Afrika zur Zeit Cyprians. ${ }^{44}$ Diese Übereinstimmung genügte Cresconius, da er die Kontinuität von Cyprian bis zu seiner Gegenwart selbstverständlich bei den Donatisten gewahrt sah. Aus diesem Verständnis heraus konnte er auch eingestehen, dass die Donatisten im Moment nicht mehr in Gemeinschaft mit den Kirchen im Osten seien. Denn die Verursacher dieses Bruchs seien ja nicht die afrikanischen Donatisten gewesen, sondern diejenigen Bischöfe der Kirche, die sich von der cyprianischen Tradition abgewandt und ihr vormaliges richtiges Urteil in ein falsches verkehrt hätten.

Um die Verbindungen der Donatisten zu anderen Kirchen in Übersee auch für seine Zeit zu belegen, verweist Cresconius auf die Anhänger der Donatisten in anderen Regionen (III 70). Außerdem zitiert er aus einem Synodalbrief des Konzils von Serdica. Da in der Adresse dieses Briefes der Name des Donatus als Bischof von Karthago auftaucht, sei bewiesen, so Cresconius, dass die in Serdica versammelten Bischöfe sehr wohl die Umstände der Kirchenspaltung in Afrika gekannt und sich eindeutig gegen die Traditoren und für die Gemeinschaft mit Donatus ausgesprochen hätten (III 38, IV 52).

Augustinus hatte diesen Brief bereits einige Jahre zuvor während eines Gesprächs mit dem donatistischen Bischof Fortunius zu lesen bekommen. Schon damals entgegnete er, dass das besagte Dokument zum einen ein Schreiben arianischer Bischöfe, zum anderen der Bezug zu Donatus von Karthago alles andere als eindeutig sei, da es sich schließlich auch um einen anderen Donatus handeln könnte. In dem von Fortunius vorgelegtem Text fehlte allerdings die Nennung der Bischofssitze. ${ }^{45}$ Verständlicherweise reagiert Augustinus sehr erstaunt, als er nun in Cresconius' Zitat den Namen Donatus und den Ortsnamen Karthago liest, und spekuliert über den Grund dieser Änderung: Eine derartige Zufügung von Herkunftsorten, stellt Augustinus heraus, sei unüblich in Briefen, die Bischöfe an ihre Kollegen richten. Von daher sei es für ihn gut denkbar, dass die Donatisten selbst später das Wort Carthaginis hinzugefügt hätten, um den genannten Donatus als den ihren zu reklamieren. Vielleicht hätten sich die östlichen Bischöfe aber auch nur im Namen des karthagischen Bischofs getäuscht. Doch selbst wenn der Brief tatsächlich an Donatus gerichtet worden sei, dann zeige dies nur eine Verbindung zu den Arianern, die Cresconius selbst als häretisch angesehen habe (vgl. II 4). Denn dieses Konzil von Serdica sei eine

44 Vgl. de Veer, BA 31, 779-781. De Veer vermutet, dass Cresconius sein Wissen aus einem Dossier zur Tauffrage geschöpft habe, in dem sich neben Cypr. ep. 75 auch Briefe des Dionysius von Alexandria befunden haben könnten. Dionysius nahm im Streit um Häretikertaufe eine vermittelnde Position ein. In den überlieferten Fragmenten seiner Briefe zeigt sich, dass er eine differenzierte Lösung anstrebte. Er befürwortete die Anerkennung der Taufe, aber nur wenn sie im Namen der Trinität durchgeführt worden sei. Sollte Cresconius tatsächlich Briefe des Dionysius eingesehen haben, fand er dort nur wenig Hilfe für seine Thesen.

Ep. 44.6; vgl. u. Kap. 4.1.1. 
Versammlung gegen den rechtgläubigen Athanasius gewesen; und überdies hätten rechtgläubige Bischöfe aus dem Osten niemals an den Bischof von Karthago geschrieben, ohne den Brief nicht auch an den Bischof von Rom zu richten, dessen Name im Briefkopf fehle (III 38, IV 52).

Das Konzil von Serdica, auf das Cresconius sich beruft, wurde im Herbst 343 (oder 342) durch Kaiser Constans mit dem Ziel einer Einigung im Arianischen Streit einberufen. Die mehrheitlich antinicaenisch eingestellten Ostbischöfe und die Westbischöfe, die das Nicaenum unterstützten, waren jedoch nicht gewillt aufeinander zuzugehen; beide Parteien tagten getrennt und exkommunizierten sich schließlich gegenseitig. ${ }^{46}$ Augustinus scheint zwar nicht umfassend über das Konzil informiert gewesen zu sein, doch wusste er offensichtlich über die Aufspaltung der Gruppen Bescheid und konnte so das ihm vorgelegte Dokument zu Recht jener Partei zuordnen, die er, ohne die theologischen Feinheiten zu beachten, als „arianisch“ bezeichnet. Die Donatisten nutzten diesen Konzilsbrief der ,,arianischen“ Partei ohne weitere Rücksicht auf den Inhalt, um eine Anerkennung ihrer Kirche durch andere Bischöfe auch nach der Kirchenspaltung in Afrika zu demonstrieren. ${ }^{47}$ Gegenüber Cresconius bekräftigt Augustinus die Nichtigkeit dieses Briefes als Beweis für diese donatistische Absicht: Sollte kein Brief von Serdica an Donatus verschickt worden sein, hätten die Donatisten keinen Beweis für ihre Verbundenheit mit anderen Bischöfen, wenn aber doch, dann offenbarten sie nichts anderes als ihr Einvernehmen mit Häretikern. In beiden Fällen stünden die Donatisten als Verlierer der Diskussion dar. ${ }^{48}$

46 Auf weitere Einzelheiten des Konzils soll hier nicht näher eingegangen werden. Vgl. H. Hess, The Early Development of Canon Law and the Council of Serdica, Oxford 2002, 95-113; L. W. Barnard, The Council of Serdica 343 A.D., Sofia 1983, 71-96; T. D. Barnes, Athanasius and Constantius, 71-81; Girardet, Kaisergericht, 106-162. - Die Anwesenheit des katholischen Bischofs Gratus von Karthago bei der Westpartei ist belegt durch Athanasius, Apol. c. Arianos 50. Frend (Donatist Church, 121 und 170 mit Anm. 2) geht davon aus, dass donatistische Bischöfe in Serdica anwesend waren. Dies lässt sich jedoch nicht aus der Textgrundlage von ep. 44.6 und Cresc. III 38 schließen.

47 Die gleiche Absicht verfolgte Fortunius gegenüber Augustinus in Thubursicum; vgl. ep. 44.6.

48 Bei Hilarius von Poitiers ist ein Synodalbrief der antinicaenischen Bischöfe aus Serdica überliefert, der mit dem von den Donatisten zitierten zu identifizieren ist (Hilarius, App. IV 1-18, ed. Feder, CSEL 65, 48-67; vgl. dazu Feder, Studien zu Hilarius von Poitiers; de Veer, BA 31, 805-809; Brisson, Autonomisme, 214-218). Dort wird im Incipit bezeugt, dass der Brief nach Afrika geschickt wurde: Incipit decretum synodi orientalium apud Serdicam episcoporum a parte arianorum quod miserunt ad Africam. In einer Unterzeichnerliste erscheinen getrennt aufgelistet die Bischofssitze und die Namen der Adressaten, darunter an dritter Stelle Donatus als Bischof von Karthago: Gregorio Alexandriae episcopo, Nicomediae episcopo, Carthaginis episcopo, [...], Amfioni, Donato, [...]. Offensichtlich gibt diese Abschrift jenen Text wieder, den auch Cresconius zitiert. Allerdings stellt sich nach wie vor die Frage, ob dieser Briefkopf dem Original entspricht oder ob es spätere, vielleicht donatistische Überarbeitungen gab. In 
Augustinus versuchte, Cresconius' Argumente zur weltweiten Verbundenheit der Donatisten als lächerlich darzustellen. Was konnte der Donatist präsentieren? Einen einsamen ,arianischen“ Konzilsbrief, versprengte donatistische Missionsbischöfe mit einer kläglichen Zahl Anhänger (III 71) und schließlich ein Beharren auf gemeinsamen Positionen mit östlichen Bischöfen in der Tauffrage, die längst von der Catholica widerlegt worden waren. Zweifellos waren die Argumente des Donatisten schwach im Hinblick auf einen Nachweis von verbündeten Kirchen in Übersee. Was jedoch Augustinus ausgiebig als Schwäche präsentiert, galt im grundsätzlichen Verständnis der Donatisten gerade als Stärke. Es ging Cresconius und anderen Donatisten gar nicht in erster Linie darum, eine weltweite Verbundenheit ihrer Kirche herauszustellen. Die zu diesem Zweck herangezogenen Beweise dienten lediglich zur Richtigstellung einer überzogenen und falschen Darstellung ihrer Gegner. Die Donatisten zeigten vor allem ihren Stolz, gegen die irrende Mehrheit als Minderheit die Wahrheit zu vertreten. So formuliert Cresconius: „Die Wahrheit liegt oft bei wenigen, der Irrtum bei vielen. “49 Die Wahrheit manifestierte sich für die Donatisten in der Tradition der afrikanischen Kirche, durch Tertullian, Cyprian und deren rechtgläubige Nachfolger in der Kirche der Donatisten. Augustinus dagegen vertrat sein Verständnis von Kirche, in der gute und schlechte Christen einen Platz hätten bis zu dem Tag, an dem Gott die endgültige Entscheidung treffen werde. Mit ihrem Schisma hätten die Donatisten die Einheit zerrissen und sich damit nicht nur klar gegen Cyprian, sondern vor allem gegen die zahlreichen Prophezeiungen der Heiligen Schrift gestellt, in denen das Wirken Gottes in allen Nationen verheißen wurde. ${ }^{50}$

In den Ausführungen zur weltweiten Einheit der Kirche stützt sich Augustinus insbesondere auf Aussagen Cyprians. Auf diese Weise versucht er, die Donatisten an einem empfindlichen Punkt zu treffen, da sie selbst Cyprian als die überragende Autorität der afrikanischen Kirche in vielen Streitfragen auf ihrer Seite glaubten. Auch Cresconius hatte sich verständlicherweise im Zusammenhang mit der Taufdiskussion auf Cyprian berufen, da dieser in der Frage

Anbetracht der Situation des Konzils von Serdica lässt sich davon ausgehen, dass die antinicaenische Partei tatsächlich auch in Donatus von Karthago, als Führer einer großen, gegen den römischen Bischof eingestellten Partei im Westen, einen Verbündeten suchte. Die spätere Existenz des Briefes bei den Donatisten und seine sorgfältige Verwahrung als Beweisstück dieser Verbindung bestätigt die Vermutung, dass Donatus tatsächlich ein Adressat dieses Briefes war. Auch Augustins Zweifel an der Authentizität des Briefes dürfte eher ein geschickter Zug in seiner Polemik gewesen sein, um die Gegner zusätzlich zu verunsichern. Allerdings äußerte sich Augustinus mit Recht sehr kritisch zu der Aufzählung der Ortsnamen. Gerade das Zeugnis aus ep. 45.6 spricht gegen die Abschriften des Briefes, die offenbar auch Cresconius besaß, und in denen wahrscheinlich der Präzisierung halber die Bischofssitze hinzugefügt worden waren.

49 Cresc. III 75: in paucis frequenter est ueritas, errare multorum est.

50 Cresc. III 39, 70-76, 93; IV 62, 64, 74. 
der Häretikertaufe die donatistische Position teilte. ${ }^{51}$ Augustinus lässt sich jedoch nicht ausführlicher auf Cyprians Aussagen zur Taufe ein, sondern verlagert die Diskussion auf einen anderen Aspekt, um offensiv gegen die Donatisten argumentieren zu können. Er stellt Cyprians Bekenntnis zur Einheit der weltweiten Kirche heraus und dessen deutliche Verurteilung jener, die sich aus Hochmut und Anmaßung von der Kirche abspalteten. Auch bei Cyprian sei ganz klar, dass die guten Christen die schlechten solange in ihren Reihen zu erdulden hätten, bis Gott am Ende der Zeit die Trennung vornehme. ${ }^{52}$ Aus diesem Grund sei es auch nicht notwendig, die von den Donatisten angeklagten Traditoren, Caecilianus und seine Anhänger, zu verteidigen. Selbst wenn ihre Schuld bewiesen werden sollte, könnten sie nicht aus der Kirche gestoßen werden. So kann Augustinus gegenüber Cresconius formulieren:

„Klage an soviel du kannst. Ich siege wenn du keine Beweise vorbringst, ich siege, wenn du Beweise vorbringst. Ich siege, sage ich, wenn du keine Beweise hast, weil du dein eigener Richter bist, ich siege, wenn du Beweise hast durch das Zeugnis Cyprians!“53

Die Abtrennung von der Kirche, das Verbrechen der Spaltung, mit dem die Donatisten die weltweite Christenheit anklagten, zeige letztlich ihre Missachtung Cyprians, der sich stets für die Kircheneinheit eingesetzt habe. ${ }^{54}$ Durch diese Verlagerung der Thematik gelingt es Augustinus, Cyprian nicht den Donatisten als Lehrmeister zu überlassen, sondern ihn als defensor catholicae unitatis et pacis (II 39) darzustellen, der das Handeln der Donatisten verurteile. In den Argumentationen zu den Themen Schisma und Verfolgung konnte er auf Cyprian als Autorität verweisen.

\subsection{Die Verfolgung der Donatisten}

Das Thema der persecutio erhielt in den Büchern gegen Cresconius besondere Aktualität, da die bislang schärfsten Gesetze gegen die Donatisten gerade erst erlassen worden waren. Da Cresconius seinen Brief vor diesen Gesetzen geschrieben hatte, fand bei ihm diese neue Phase der Auseinandersetzung noch keine Berücksichtigung. Bei Augustinus indessen, der auch in früheren Texten

51 Die Theologie Cyprians und ihre Verwendung bei den Donatisten kann hier nicht behandelt werden. Vgl. Bavaud, BA 29, 23-30; 597 f.; AL 1, s. v. Cyprian; Eine gute Zusammenfassung bei Kriegbaum, Kirche der Traditoren, 44-58.

52 Cresc. II 43, 45, 48; III 35, 73; IV 6.

53 Cresc. III 45: accusa quantum potes. uinco si non probas. uinco si probas. uinco, inquam, si non probas iudice te ipso, uinco si probas teste Cypriano.

54 Cresc. II 39-49; III 1-3. - Augustinus beruft sich neben Cypr. ep. 54.3 insbesondere auf die sog. sententia episcoporum des Konzils von 256 (I 38, II 39, III 2) und Cypr. de un. eccl. 5 . 
die Zwangsgewalt gegen Donatisten verteidigt hatte ${ }^{55}$ lässt sich ein intensives Bemühen um eine Rechtfertigung der neuen Gesetze erkennen.

Cresconius lehnt in seinem Brief sowohl Augustins Apologie der vergangenen katholischen Verfolgung von Donatisten ab als auch die Unterstellung, die Donatisten selbst begingen Gewalttaten und verfolgten die Maximianisten. ${ }^{56}$ Dabei argumentiert er auf Grundlage der donatistischen Gegenüberstellung der wahren, verfolgten Kirche und der Kirche der Traditoren und Persecutoren. Er sieht bei Augustinus das Eingeständnis, dass es tatsächlich zu einer Verfolgung gekommen sei, und urteilt entsprechend deutlich: Wer einen Christen verfolgt, ist ein Feind Christi. ${ }^{57}$ Die katholische Kirche akzeptiere nicht das freie Bekenntnis der Donatisten zur ihrer Kirche, sondern verfolge sie. ${ }^{58}$ Damit stelle sie sich in eine Reihe mit den Verfolgern der Christenheit (III 57).

Augustinus hatte gegen Petilianus ausgeführt, dass der donatistische Märtyrer Marculus und andere Donatisten nicht exekutiert worden seien, sondern Selbstmorde begangen hätten. ${ }^{59}$ Dies weist Cresconius zurück: Ein Konzil habe den Selbstmord ausdrücklich verboten und verurteilt. Marculus und andere Donatisten seien Opfer einer blutigen Verfolgung geworden und damit als Märtyrer zu betrachten (III 54).

So wie er der katholischen Seite die Gewaltanwendung zuweist, so lehnt Cresconius entschieden jegliche Verantwortung für jene Gewalttaten ab, die Augustinus den Donatisten vorgeworfen hatte. Die Anschuldigung, dass die Donatisten Verfolger der Maximianisten seien, ließe sich nicht aufrechterhalten. Die Plünderung der Basilika des Maximianus gehe nicht, wie von Augustinus behauptet, auf Optatus von Thamugadi zurück, sondern auf eine gewalttätige Volksgruppe, die nicht im Auftrag der Donatisten gehandelt habe (III 65, IV 55). Für andere Übergriffe oder die Gewalt der Circumcellionen könnten die Donatisten ebenso wenig verantwortlich gemacht werden (IV 77).

Augustinus bleibt trotz dieser Einwände seines Gegners bei der bereits gegen Petilianus angewandten Methode, Beispiele donatistischer Gewalt aufzuzählen, um deren Schuld zu erweisen. Ausführlich und mit Hinweis auf schriftliche Beweise beschreibt er jene donatistischen Gewalttaten, die sich im Vorfeld des Unionsgesetzes von 405 zugetragen hatten (III 46-53). Ein Trumpf war für Augustinus wiederum das Handeln der Donatisten gegen die Maximianisten. Deren Verfolgung hätten die Donatisten hartnäckig und mithilfe der

55 Vgl. c. litt. Pet. I 20; II $196 \mathrm{ff}$.

56 Cresc. III 65; IV 55, 77; vgl. c. litt. Pet. I 20, 26.

57 Cresc. III 57; IV 60; vgl. Petilians Ablehnung der Verfolgung: c. litt. Pet. II 173, 175, 177.

58 Diese Berufung der Christen auf die freie Wahl der Religion gegen ihre Verfolgung steht in der Tradition der Kirche, die den Verfolgern vorwarf, das Christsein an sich zu bestrafen, ohne dass die Christen dem Staat geschadet hätten (vgl. etwa Tert. Apol. 40; Orig. c. Cel. VIII 73-75.

59 C. litt. Pet. I 26. - Zur Märtyrergeschichte des Marculus s. u. Kap. 6.3.2. 
weltlichen Mächte betrieben. Damit lieferten sie selbst den Beweis für ihre Diskrepanz von Theorie und Praxis (III 58-65; IV 55-62).

Mit dieser Präsentation donatistischer Gewalttaten verfolgte Augustinus im Wesentlichen zwei Ziele: Zum einen sollte das Selbstverständnis der Donatisten als „Kirche der Verfolgten“ erschüttert werden, zum anderen sollte das Vorgehen gegen die Donatisten als ein Einschreiten gegen donatistisch motivierte Gewalt dargestellt werden. Dieser Zielsetzung blieb Augustinus treu. Die Auswahl seiner detailliert erzählten Beispiele zeigt jedoch deutlich, dass er vor allem die Notwendigkeit der neuen Gesetzgebung erklären wollte. Es war ihm nicht daran gelegen, ein differenziertes Bild des Donatismus oder gar der gegenwärtigen Lage in Afrika zu zeichnen, sondern eine möglichst eindrucksvolle Summe donatistischer Gewalt und eine bedrohliche Stimmung vorzuführen, die keinen anderen Ausweg zuließ, als die Hilfe des Kaisers zu erbitten.

Alle, die Circumcellionen, Optatus von Thamugadi und die anderen Exempel präsentieren für ihn „den Donatismus“, und angesichts der zahllosen Gewalttaten dieser Menschen wird aus seiner Perspektive das staatliche Vorgehen gerechtfertigt. Augustinus wollte die in seinen Augen richtige Relation von Gewalt gewahrt wissen: Im Vergleich zu den Verfolgungen, die den Katholiken durch die Donatisten zugefügt worden seien, trügen die Donatisten weitaus geringere Lasten, denn die antihäretischen Gesetze zeigten im Hinblick auf diese Gewalt die große Milde der Katholiken (III 47, 54).

Augustinus entgegnet auch auf Grundlage seines Kirchenverständnisses auf die persecutio-Vorwürfe der Donatisten, indem er zwischen einer gerechten und einer ungerechten Verfolgung differenziert. Auf der einen Seite gebe es eine gerechtfertigte Verfolgung, nämlich das Vorgehen gegen Gewalt und Terror zur Besserung der Menschen. Bei dieser Aufgabe spiele auch der christliche Herrscher eine Rolle, denn er habe das Recht, gegen Feinde der Gesellschaft und der Religion vorzugehen (III 45). Damit betont Augustinus, dass es unter einem wahren christlichen Kaiser im Grunde keine Christenverfolgung geben könne, denn dieser vertrete die Wahrheit gegen den Irrtum.

Auf der anderen Seite gebe es die ungerechte Verfolgung. Handlungen, die aus persönlicher Rache und aus den falschen Motiven heraus geschehen, könnten nicht gebilligt werden. Wo es möglich sei, würden solche Taten von den Katholiken untersagt (III 56). Trotzdem komme es, so Augustinus, sowohl bei den Donatisten als auch bei den Katholiken zu solchen ungerechten Verfolgungen, denn es gebe auf beiden Seiten Übeltäter, die in falscher Weise handelten.

Auch wenn er keinen direkten Bezug herstellt, so wird doch deutlich, dass Augustinus die Verfolgung der Donatisten unter Macarius, zumindest einzelne Handlungen, in die Kategorie der ,ungerechten Verfolgungen“ einordnet. ${ }^{60}$

60 Vgl. o. Kap. 2.1.2 und u. Kap. 6.3.2. 
Gegenüber der Darstellung des Cresconius über den donatistischen Märtyer Marculus reagiert Augustinus deshalb vorsichtiger als noch gegen Petilianus: Er habe sich nicht genau erkundigt, aber er habe gehört, dass Marculus Selbstmord begangen hätte; und dies halte er für glaubhafter als die donatistische Version einer von der römischen Staatsmacht verhängten Todesstrafe. ${ }^{61}$ Nach seinem Eingeständnis, über Optatus von Thamugadi nur wenige Informationen zu besitzen, weicht Augustinus hier ein weiteres Mal in seinen Anschuldigungen zurück. Er möchte die Taten des Macarius nicht offensiv verteidigen und verzichtet auf eine ausführliche Untersuchung. Es solle als Erklärung genügen, dass Gott allein die Wahrheit kenne und die Schuld der ungerechten Verfolgung des Macarius nicht pauschal auf die Katholiken übertragen werden sollte.

Der Argumentationsaufbau zeigt, dass sich die Auseinandersetzung mit den donatistischen persecutio-Vorwürfen für Augustinus nicht leicht gestaltete. Die Donatisten verfügten über einen einfachen und für viele einleuchtenden Grundsatz: Ein wahrer Christ verfolgt nicht, sondern erleidet demütig die Verfolgung. Um diesen Grundsatz zu widerlegen, griff Augustinus ebenfalls zu leicht verständlichen populistischen Argumenten. Die zahlreichen Beispiele der Gewalt sollten die Leser und Hörer davon überzeugen, dass die Donatisten entgegen ihren eigenen Aussagen selbst verfolgten, teilweise sogar mit staatlicher Hilfe. Darüber hinaus wollte er demonstrieren, dass die gesetzlichen Maßnahmen der christlichen Kaiser keine Verfolgung, sondern ein notwendiges Mittel zur Bekämpfung terroristischer Umtriebe waren. Diejenigen, die unter solcher Gewalt zu leiden hatten, folgten dieser Argumentation sicher gerne.

Doch gerade für Cresconius stellte sich die Situation völlig anders dar. Er leugnete nicht, dass es zu Gewalt gegen die Maximianisten oder anderen gekommen sei, aber er leugnete die Verantwortung der Donatisten für derartige Vorfälle. Hier zeichnen sich recht deutlich die unterschiedlichen Strömungen innerhalb des Donatismus ab, deren Eigenheiten in der Darstellung Augustins häufig verwischt werden. Es gab einzelne radikale Gruppierungen unter donatistischen Laien und Klerikern, die einen Selbstmord zum Martyrium erhoben und in gewaltsamen Übergriffen auf Katholiken Gottes Wille sahen. Es gab aber auch Donatisten, und vielleicht war dies die Mehrheit, die ihrer Religion in ihrer Kirche ohne Unterdrückung nachgehen wollten, und sich von plumper Gewalt und Fanatismus distanzierten. Zu diesen Donatisten gehörte auch Cresconius. Zwischen ihm, einem gebildeten Grammatiklehrer, und einem religiösen Eiferer konnten Welten liegen. Wenn also Cresconius seinem Gegner vorhält, Marculus könne kein Selbstmörder sein, da ein Konzilsbeschluss Selbstopferungen verboten habe, dann entsprach dies seiner vollen Überzeugung. Wahrscheinlich existierte auch ein derartiger Beschluss, aber trotzdem,

61 Cresc. III 54; vgl. Grasmück, Coercitio, 124, Anm. 641. 
daran lässt die Überlieferung keinen Zweifel, gab es Selbstmörder, die allerdings aus anderen donatistischen Kreisen entstammten als Cresconius. ${ }^{62}$

Es ist daher sehr fraglich, ob Augustins Beispiele für Gewalt unter den Donatisten Wirkung erzielen konnten. Aus der Sicht derer, die er mit seinen Schriften erreichen wollte, wartete Augustinus mit Taten auf, mit denen sie nichts zu tun hatten und für die sie jegliche Verantwortung abstritten. Insofern verteidigten sie sich mit einer Methode, die Augustinus selbst in seiner Argumentation häufig anwandte; denn auch er leugnete eine persönliche Verantwortung für die Vorwürfe der traditio oder persecutio und wehrte sich stets gegen die kollektive Verurteilung der katholischen Kirche durch die Donatisten. Dieses gegenseitige Unverständnis für die jeweilige Vielschichtigkeit in beiden Parteien gehörte zu den entscheidenden Gründen dafür, dass eine Annäherung der Gegner scheiterte.

Zweifellos ging Augustinus geschickt vor, wenn er in der Frage der Verfolgung das Selbstverständnis der Donatisten angriff. Die einleuchtende Sentenz lautete: „Es ist nicht notwendigerweise jener gerecht, der [Verfolgung] erleidet, noch ist jener notwendigerweise ungerecht, der sie ausübt. "63 Vor allem der durch Dokumente belegte Nachweis, dass die Maximianisten durch die Donatisten verfolgt worden seien, entkräftete die einseitigen Anklagen der Donatisten und stellte beide Parteien auf eine Stufe. Die schwierigere Aufgabe für Augustinus lag deshalb darin, eine moralische Überlegenheit der katholischen Gewaltanwendung gegenüber der donatistischen überzeugend darzustellen. Ob dies durch die Differenzierung von gerechter und ungerechter Verfolgung gelungen ist, steht zu bezweifeln. Augustins Grundlage einer gerechten Verfolgung durch einen christlichen Herrscher zur Bekämpfung der Heiden, Besserung der Sünder und Erhaltung der Einheit konnte von keinem Donatisten, der anstelle des christlichen Kaisers einen Verfolger sah, nachvollzogen werden - dies zeigen Cresconius' Aussagen in vielerlei Weise. Für die katholische Rechtfertigung waren Augustins Ausführungen hingegen grundlegend und für die Zukunft richtungweisend: Der Erhaltung von Frieden und Einheit für die Kirche und das Reich sollte Vorrang eingeräumt werden, wenn nötig auch mit dem Einsatz von Gewalt.

62 Vgl. Frend, Donatist Church, $176 \mathrm{f}$.

63 Cresc. III 65: non ergo qui eam [persecutionem] patitur consequenter iustus nec qui facit consequenter iniustus est. 


\section{Die historische Argumentation}

In der Auseinandersetzung mit den Themen Taufe, Kirche und Verfolgung sind von Cresconius und Augustinus Bezüge zur Geschichte des Schismas hergestellt worden. Einen Schwerpunkt der Diskussion nimmt indessen die Entstehungsgeschichte des Donatismus ein, die im Folgenden betrachtet werden soll. Das dritte und vierte Buch gegen Cresconius enthalten dazu - abgesehen von einigen Briefen - die ausführlichsten Darstellungen in den Schriften Augustins vor 411. Erstmals zitiert Augustinus längere Abschnitte aus kirchlichen und staatlichen Dokumenten, auf deren Existenz er zuvor nur hingewiesen hatte. Cresconius selbst hatte Augustinus in den historischen Fragen herausgefordert, indem er die Glaubwürdigkeit der katholischen Beweise in Frage stellte und dagegen die Wahrheit der donatistischen Überlieferungen postulierte. Augustinus reagierte auf diese Herausforderung, nahm die von Cresconius angesprochenen Themen auf und referierte zu diesen jeweils historische Einzelheiten, mit denen die Zweifel des Donatisten ausgeräumt werden sollten. Ein weiterer Grund für die umfassende historische Argumentation liegt in der Entscheidung Augustins, das Maximianistische Schisma für seine Rechtfertigung in den Vordergrund zu rücken. Die Parallelen zwischen der Entstehung des Maximianistischen Schismas und den Anfängen des Donatismus bedingen einige historische Aussagen.

Augustinus verfolgt hinsichtlich der Entstehungsgeschichte des Schismas zwei sich ergänzende Ziele: Auf der einen Seite wollte er die Unschuld des karthagischen Bischofs Caecilianus und seines Ordinators Felix von Abthugni beweisen, die von den Donatisten als Traditoren verurteilt und als Urheber des Schismas betrachtet wurden. Auf der anderen Seite wollte Augustinus zeigen, dass sich unter den Konsekratoren des donatistischen Gegenbischofs Maiorinus Traditoren im donatistischen Sinne befunden hätten, so dass die Donatisten gar keinen Grund hätten, an der Spaltung festzuhalten. ${ }^{64}$ Augustinus kommt wie bereits in den Schriften gegen Petilianus auch gegen Cresconius konkret auf zwei donatistische Bischöfe zu sprechen, denen er die traditio nachweisen möchte: Secundus von Tigisi und Silvanus von Cirta. Auffällig ist, dass Augustinus die Frage nach der traditio bei allen vier Personen als gerichtliche Streitfälle (causae) erörtert. Er selbst tritt als Ankläger gegen Secundus (causa Secundi) und Silvanus (causa Silvani) auf, umgekehrt wirkt er als Verteidiger Caecilians (causa Caeciliani) und des Felix von Abthugni (causa Felicis). Bevor diese Argumentationsweise näher dargestellt wird, sollen zunächst die Ansichten des Cresconius erschlossen werden, wie sie sich aus den Andeutungen und Zitaten Augustins ergeben.

64 Vgl. zu diesem Argumentationsschema den Psalmus contra Partem Donati (o. Kap. 1.1). 
4.1 Die Darstellung der Entstehungsgeschichte durch Cresconius

Augustinus hatte im ersten Buch gegen Petilianus die donatistischen traditioBeschuldigungen gegen Caecilianus und andere Bischöfe abgewiesen und Beweise gefordert. Seinerseits hatte er den Bischof Silvanus von Cirta der traditio beschuldigt, um die Verstrickung der ersten Donatisten in die traditio zu demonstrieren (c. litt. Pet. I 23). Auf dieser Grundlage bewegen sich Cresconius' Entgegnungen in der Streitfrage über die Urheber des Schismas. Dank der im Gegensatz zu Petilianus recht unbefangenen Weise des Cresconius, auf $\mathrm{Au}-$ gustins Argumente einzugehen, erhalten wir Einblick in das donatistische Geschichtsverständnis und einige Informationen, die über die üblichen Stereotypen hinausgehen. Cresconius' Positionen ergänzen in mancherlei Hinsicht das Bild der donatistischen Selbstdarstellung, das sich während der Konferenz des Jahres 411 zeigte. $^{65}$ Leider verzichtet Augustinus gerade bei den historischen Themen auf längere Zitate seines Gegners, so dass Cresconius' Ansichten nur aus den Kurzzitaten und den Widerlegungen Augustins zu erschließen sind. Cresconius ging indessen auf alle von Augustinus angesprochenen Themen ein. Er versuchte, sowohl Silvanus von Cirta zu entlasten als auch den Beweisforderungen nachzukommen und die Anschuldigungen gegen Caecilianus und dessen Anhänger zu bekräftigen.

Soweit ersichtlich präsentierte Cresconius bezüglich der causa Silvani drei Argumente, die den Bischof von Cirta von der traditio-Anklage entlasten sollten. Er stützte sich zum einen auf eine donatistische Überlieferung, in der Silvanus als Opfer einer Verfolgung dargestellt wird. Diese Tatsache ergibt sich lediglich aus einer Andeutung Augustins; sie beleuchtet aber einen wichtigen Aspekt der donatistischen Auffassung über Silvanus:

„Aber später, sagst du [Cresconius], wurde [Silvanus] ins Exil geschickt, da er während der Verfolgung von Ursacius und Zenophilus nicht [mit ihnen] in Gemeinschaft treten wollte.“66

Cresconius stellte einen Zusammenhang zwischen dem bei den Donatisten als Verfolger geltenden Militär Ursacius, dem Konsular Zenophilus und Silvanus her. Da Silvanus sich seinen Verfolgern nicht unterworfen habe, das heißt, bei den Donatisten geblieben sei, sei er ins Exil verbannt worden. Offenbar kannte Cresconius den Prozess und die Verurteilung des Silvanus durch Zenophilus, vielleicht sogar Teile der Akten und der darin enthaltenen Anklagen und Aussagen. Er betrachtete dieses Urteil jedoch nicht als Schuldbeweis gegen Silvanus, sondern als Beweis der politischen Verfolgung. Silvanus sei - so scheint

65 Vgl. u. Kap. 5.3.

66 Cresc. III 34: sed postea, inquis, Vrsatio et Zenophilo persequentibus cum communicare noluisset, actus est in exilium. 
die donatistische Version gelautet zu haben - aufgrund seiner Standhaftigkeit, nicht mit den Traditoren in Gemeinschaft zu treten, verurteilt und mit der Exilstrafe belegt worden. Die Rolle, die Ursacius dabei gespielt haben soll, ist nicht zu klären. Zwar kann man davon ausgehen, dass Ursacius auch in der Zeit der Verhandlungen vor Zenophilus in Afrika aktiv war, jedoch mangelt es an Quellen, um weitere Einzelheiten festzustellen. Offenbar gingen aber die Donatisten von einer Beteiligung des Ursacius in der causa Silvani aus. ${ }^{67}$ Vor dem Hintergrund dieser donatistischen Überlieferung und Deutung wird Cresconius' Überzeugung von der Unschuld des Silvanus verständlich: Silvanus hatte sich auch in der Verfolgung als standhaft erzeigt und war für seine Überzeugung ins Exil gegangen. Ein solcher Mann des Glaubens, bei manch einem gar ein Märtyrer, konnte in Cresconius' Augen kein Traditor sein.

In seinem zweiten Argument berief sich Cresconius auf die Beteiligung des Silvanus an der Verurteilung Caecilians in Karthago. ${ }^{68}$ Einer, der zusammen mit anderen Bischöfen einen Traditor verdammt, so das Argument, könne selbst kein Traditor sein. ${ }^{69}$ Aus der Sicht Augustins entbehrte diese Aussage jegliche Argumentationskraft, aus donatistischer Perspektive bestand durchaus ein logischer Zusammenhang, der auch für Cresconius ausschlaggebend gewesen sein dürfte: Ausgehend von der donatistischen Ekklesiologie sprach die Zugehörigkeit des Silvanus zu dem Kreis der siebzig in Karthago anwesenden Bischöfe eine deutliche Sprache. Als anerkanntes Mitglied der Heiligen Kirche stand Silvanus qua Amt auf der Seite der Wahrheit. Schuldig gesprochen im Namen Gottes und aus diesem Kreise ausgeschlossen wurde Caecilianus. ${ }^{70}$ Auf diese Weise kann Cresconius seinen donatistischen Lesern die Positionen verdeutlichen: Auf der einen Seite der offiziell als Traditor exkommunizierte Caecilianus, auf der anderen Seite der Bischof Silvanus, der Kämpfer gegen die traditio.

Das dritte Argument ergänzt die beiden vorgehenden und setzt gewissermaßen die Unschuld des Silvanus bereits voraus. Cresconius unterstellte Augustinus, dass die traditio-Anklage gegen Silvanus lediglich ein rhetorischer

67 Vgl. Mandouze, PAC, 1235, s. v. Vrsacius; PLRE I, 984, s. v. Vrsacius 1. Die Beteiligung von Ursacius an Repressionen gegen Donatisten im Jahre 317 wird durch eine donatistische Quelle bezeugt (s. pass. Don. 2). Vgl. ausführlich u. Kap. 6.3.1. - Der Prozess gegen Silvanus fand im Dezember 320 statt. Eine gemeinsame Verfolgung von Zenophilus und Ursacius, die Cresconius hier impliziert, ist wenig wahrscheinlich. Bei Petilianus (c. litt. Pet. II 202) wird keine Verbindung hergestellt. Es ist zwar nicht auszuschließen, dass Zenophilus und Ursacius gemeinsam gegen Donatisten vorgingen, da nachweislich erst 321 die Verfolgung der Donatisten ausgesetzt wurde, doch Cresconius übernahm wohl eine donatistische Tradition, die wie auch in anderen Fällen das crimen persecutionis (z.T. summarisch) an bestimmten Personen festmachte, ohne den historischen Kontext zu wahren.

68 Zum Konzil von Karthago s. u. Kap. 7.1.1.

69 Cresc. III 31, 34; IV 66.

70 Dieses Kirchenverständnis zeigt sich vor allem in der Tauffrage; vgl. o. Kap. 3.3.2. 
Schachzug sei, eine ausgeklügelt vorgetragene Gegenklage (anticategoria), mit der er die gerechtfertigten donatistischen traditio-Anklagen auf die Väter der Donatisten zurücklenken wolle. ${ }^{71}$ Da Cresconius davon ausging, dass die belastenden Akten des Konsulars Zenophilus, jene acta municipalia, auf die Augustinus sich auch gegenüber Petilianus beruft (c. litt. Pet. I 23), falsche Anklagen gegen Silvanus beinhalteten, während die Akten des Konzils von Karthago eindeutig die Schuld Caecilians beschrieben, konnte er seinen Lesern erklären, warum Augustinus aus seiner Sicht auf Grundlage falscher Tatsachen argumentiert und mit Hilfe eines rhetorischen Täuschungsmanövers die Unwahrheit $\mathrm{zu}$ verbreiten suchte. ${ }^{72}$ Der anticategoria-Vorwurf war somit kein Unschuldsnachweis, sondern der Versuch des Donatisten, Augustins Motivation offenzulegen. Seine Leser sollten sehen, dass Augustinus zu diesem Mittel habe greifen müssen, um überhaupt einen Ausweg aus den eigenen Verstrickungen in die traditio finden zu können.

Im Gegensatz zu Petilianus ging Cresconius nicht nur allgemein auf traditioVorwürfe ein, sondern bezog sich konkret auf die Anklage gegen Caecilianus. Er hatte offensichtlich erkannt, dass sich die Auseinandersetzung über die Anfänge des Schismas letztlich in der Person Caecilians zuspitzte. Von daher bemühte er sich, Caecilians Absetzung überzeugend als rechtmäßig darzustellen. Die eindeutig wichtigste Quelle für Cresconius waren die Akten des Konzils von Karthago. Die Donatisten zur Zeit Augustins besaßen nachweislich Abschriften dieser Akten des Konzils von Karthago. ${ }^{73}$ Da Cresconius den Urteilsspruch des Silvanus für seine Argumentation zitieren konnte, wird auch er Zugriff auf diese Dokumente gehabt haben.

Cresconius entnahm diesen Akten, dass die 70 teilnehmenden Bischöfe des Konzils in Karthago Caecilianus offiziell abgesetzt hatten (III 31, 34; IV 9). Er zitierte wörtlich die Sentenz des Silvanus von Cirta, um dessen Rolle als Feind der traditio besonders herauszustellen. ${ }^{74}$ Für Cresconius und die Donatisten genügte dieses eine Urteil, um sich der Schuld Caecilians gewiss zu sein. In ihrem Verständnis hatte ein einmal gesprochenes Urteil als unumstößlich zu gelten. Mit dieser Ansicht standen sie durchaus im Einklang mit dem älteren afrikanischen Kirchenrecht, das auch bei Tertullian und Cyprian überliefert ist, nach der Synodalurteile nicht angefochten werden konnten. ${ }^{75}$

71 Cresc. III 29 - Zu dieser rhetorischen Figur: Quint. III 10, 4.

72 Der Vorwurf der anticategoria steht im Zusammenhang mit Cresconius' Kritik an Augustins Rhetorik und Dialektik. Vgl. Weissengruber, Hermes 105, $120 \mathrm{f}$. und oben Kap. 3.3.1. - Zur Interpretation der Akten des Konsulars Zenophilus und des Verfahrens gegen Silvanus s. u. Kap. 6.2.2.

73 Cap. conl. Carth. III 346; breuic. III 26. Der Wortlaut ist nicht überliefert. S. u. Kap. 7.1.1.

74 Cresc. III 31: [...] interposuisti sententiam eius [Silvani]; vgl. III 34.

75 Geändert wurde diese Praxis erst im Laufe des 4. Jahrhunderts. Dazu unten S. 105. 
Außer diesem Urteil der Bischöfe postulierte Cresconius auch eine kaiserliche Verurteilung Caecilians und bekräftigte die traditio-Schuld des Felix von Abthugni, Caecilians Konsekrator:
„Du [Cresconius] sagst in den ersten Teilen deines Briefes, dass Kaiser Konstantin, als ihm das Verbrechen Caecilians deutlich wurde, er selbst diesen durch sein Urteil verdammte, in Brescia im Exil zu leben. Wer soll zweifeln, dass du darin entweder getäuscht wurdest oder selbst täuschst, wenn du auch Felix von Abthugni erwähntest, der vor einem Gericht des Prokonsuls von Ingentius durch irgendetwas der traditio überführt worden sein soll.“76

Cresconius erwähnte folglich von den weiteren Prozessen, die im Fall Caecilianus stattfanden, zwar die kaiserliche Entscheidung und die Verhandlungen über Felix, von den Urteilen der Bischofsgerichte in Rom und Arles erfahren wir dagegen nichts. ${ }^{77}$

In Bezug auf das Urteil Konstantins griff Cresconius auf donatistische Überlieferungen zurück, die durch andere Quellen bekannt sind: Die Behauptung, Caecilianus sei durch ein Urteil des Kaisers nach Brescia ins Exil verbannt worden, vertraten auch die donatistischen Bischöfe auf der Konferenz von 411 mit Hinweis auf Optatus von Mileve. ${ }^{78}$ Cresconius scheint seine Darstellung nicht mit Zitaten oder Quellenangaben belegt zu haben (III 83). Wie andere Donatisten leitete er aus den spärlichen und ungenauen Nachrichten über einen Aufenthalt Caecilians in Brescia dessen Verurteilung zu einer Exilstrafe ab. Nach Angabe Augustins behaupteten die Donatisten zudem, Caecilianus habe die bischöflichen Richter in Übersee bestochen und sich sogar bei der Entscheidung des Kaisers Vorteile verschafft. ${ }^{79} \mathrm{Ob}$ auch Cresconius diesen Standpunkt anführte, ist anhand des Textes nicht eindeutig (dicitis etiam trans-

76 Cresc. III 80: et dicis in primis partibus epistulae tuae, quod imperatori Constantino Caeciliani crimen cum fieret manifestum, ipse quoque eum ut Brixiae in exilio degeret sua sententia condemnauit. in quo te quis dubitet uel falli uel fallere, quando et Felicem Aptugnensem commemorasti in iudicio proconsulis ab Ingentio nescio quo traditione conuictum? - Die Handschriften führen übereinstimmend die Lesart „Vincentio“ an. Die sachlich richtige Konjektur in „Ingentio“ bei Petschenig (z. St.). Es bleibt zu fragen, ob der falsche Name eventuell auf eine mangelnde Information sowohl bei Augustinus als auch bei Cresconius zurückgeht.

77 Im Zusammenhang mit der Ablehnung von Gesprächen zwischen Donatisten und Augustinus deutet Cresconius an, dass die Gerichte der Bischöfe und die Verhandlungen vor dem Kaiser keine Lösung des Streits gebracht haben (Cresc. I 5). Anders als Augustinus hält Cresconius den gegenwärtigen Konflikt zwischen Donatisten und Katholiken für unlösbar. Das Ziel der Auseinandersetzung und der Argumentation ist daher nicht die Kircheneinheit im Sinne Augustins, sondern die Wiederherstellung der Einheit durch möglichst viele Übertritte von Gläubigen in die donatistische Kirche.

78 Vgl. u. Kap. 5.3.2.

79 Cresc. III 67. Möglicherweise bezieht sich Augustinus auf die Aussagen Parmenians (c. ep. Parm. I 11). 
marinos iudices a Caeciliano esse corruptos), kann aber als wahrscheinlich gelten. Die Donatisten und so auch Cresconius benötigten eine Erklärung für ihre Niederlage vor den Synoden in Rom und Arles. Die Unterstellung einer Befangenheit oder gar einer Korruption der Richter konnte eine solche Erklärung liefern, die auch für jeden gutgläubigen Anhänger der Donatisten eindeutig und leicht verständlich war.

Welche Vergehen Caecilianus konkret vorgeworfen worden waren, bleibt in den überlieferten Aussagen des Cresconius undeutlich. Höchstwahrscheinlich war die Anklage für Cresconius wie für Augustinus so offensichtlich, dass sie nicht näher erläutert werden musste. Fest steht: Die Anschuldigungen wurden von beiden Seiten unter dem Begriff traditio subsumiert, ohne dass der Wortsinn genau erläutert wurde. Cresconius sprach von der „Sünde wider den Heiligen Geist", die Caecilianus begangen habe (IV 10), ein Hinweis darauf, dass er ihm die Auslieferung oder Verbrennung der Bücher unterstellte. ${ }^{80}$ Diese Beurteilung deckt sich mit der donatistischen Überlieferung, die unter anderem auch Petilianus vertrat. ${ }^{81}$

Auch in Bezug auf Felix von Abthugni referierte Cresconius ganz offensichtlich bekannte donatistische Argumente. Unabhängig von der Frage, ob Caecilianus selbst ein Traditor war, galt bei den Donatisten seine Konsekration durch Felix von Abthugni als entscheidender Anklagepunkt gegen die Gültigkeit seiner Bischofsweihe. Während für die Katholiken ein Prozess gegen Felix von Abthugni klar erwiesen hatte, dass er in Bezug auf die traditio unschuldig sei, ${ }^{82}$ blieb Felix für die donatistische Seite stets die „Quelle allen Übels“ (fons omnium malorum), als solche er in Karthago bei der Absetzung Caecilians bezeichnet worden war. ${ }^{83}$ Auch im Jahre 411 beharrten die Donatisten darauf, dass Felix' Unschuld durch die Dokumente der Katholiken keinesfalls bewiesen sei. ${ }^{84}$ Den Schuldbeweis für die traditio des Felix entnahmen die Donatisten den Aussagen des Diakons Ingentius, der beim Prozess gegen Felix als Zeuge der Anklage auftrat. Seinem Bericht vertrauten sie mehr als dem Urteil des Prokonsuls Aelianus, durch den Felix offiziell freigesprochen worden war. Auf dieser donatistischen Überlieferung beruhten wohl auch Cresconius' Aussagen, wie die Erwähnung des Ingentius in der oben zitierten Äußerung zeigt.

Weitere Einzelheiten über Cresconius' Darstellung der Entstehungsgeschichte lassen sich nicht erschließen. Jedoch wird insgesamt deutlich, dass Cresconius eine recht große mündliche und schriftliche Überlieferung kannte,

80 Dieses donatistische Verständnis referiert Augustinus selbst in Cresc. IV 10.

81 C. litt. Pet. II 202.

$82 \mathrm{Zu}$ dem Prozess gegen Felix von Abthugni und der Rolle des Ingentius vgl. u. Kap. 6.1.3.

83 Augustinus zitiert diesen donatistischen Vorwurf gegen Felix sehr häufig, wodurch sich eine gewisse Aktualität ableiten lässt. Vgl. Cresc. III 67; un. bapt. 28; breuic. III 26; ep. 88, 3; vgl. Gesta conl. Carth. I 18, 55.

84 Cap. conl. Carth. III 553, 570; breuic. III 42. Vgl. Kap. 5.3.1. 
auf die er sich in seiner Argumentation stützen konnte und durch die er selbst überzeugt war, auf der richtigen Seite zu stehen. So schreibt er im Bezug auf die traditio:

„In dieser Sache ist das Gewissen beinahe des ganzen Erdkreises Zeuge [...]. Dies lernten unsere Vorfahren von ihren Vätern [...]. Jene sind noch nicht lange verstorben, die wussten, durch wen und an welchen Orten das Verbrechen der traditio begangen wurde. [...] Es sind auch noch Bücher vorhanden [...], in denen der Ablauf der Ereignisse zuverlässig und sorgfältig schriftlich festgelegt ist; es gibt Akten, es gibt Schriften, und auch das öffentliche Bekenntnis vieler Menschen wird bewahrt." ${ }^{85}$

Allem Anschein nach begnügte sich Cresconius mehrheitlich mit solchen Hinweisen, ohne tatsächlich aus den besagten Dokumenten zu zitieren, wie auch Augustinus bemängelt (III 29, 79). Nachweisbar ist lediglich ein wörtliches Zitat, die genannte Sentenz des Silvanus gegen Caecilianus. Es ist folglich nicht zu klären, inwiefern Cresconius selbst auf Grundlage schriftlicher Quellen arbeitete. Die Übereinstimmung seiner Argumente mit den Ansichten der Donatisten auf der Konferenz von 411 belegt jedoch die Existenz einer im Wesentlichen gleichlautenden Überlieferung einschließlich einiger passender Dokumente. Auch wenn Cresconius diese Dokumente nur im geringen Umfang selbst nutzen konnte, seine Abhängigkeit von der vermittelten Überlieferung ist eindeutig. ${ }^{86}$

Auf Grundlage dieser donatistischen Tradition, die auch Vorstellungen über die Geschichte des Schismas beinhalteten, konnte Cresconius selbstsicher auf die Argumentation antworten, die Augustinus über die historischen Beweise zur traditio in seinem Brief gegen Petilianus geltend gemacht hatte: ${ }^{87}$ Es gebe in dieser Frage vier Alternativen, so Augustinus in dieser Schrift, entweder seien alle Zeugnisse wahr, dann seien die Donatisten am Schisma schuldig, da auch sie nachweislich Traditoren in ihren Reihen hätten und dies nicht zugeben wollten. Oder alle Zeugnisse seien falsch, dann seien sie ebenfalls Schismatiker, weil sie die Katholiken unrechtmäßig angeklagt hätten. Wenn drittens nur die Beweise der Katholiken wahr seien, dann sei die Schuldfrage eindeutig. Schließlich, wenn die Donatisten Zeugnisse vorlegten, die Katholiken dagegen nicht, dann müssten sich die Donatisten aus Liebe zur Einheit der Kirche öffnen. Demnach hätten sie keinen Grund, im Schisma zu verharren. Cresconius' Antwort auf diese Ausführungen war eindeutig: Die Dokumente der Katholiken seien falsch,

85 Cresc. III 37: In hac re testis est [...] totius orbis paene conscientia. [...] hoc [...] maiores nostri a suis parentibus acceperunt. [...] non olim defuncti sunt, $[. .$.$] qui traditionis huius$ facinus per quos et quibus locis admissum sit cognouerunt. [...] extant [...] etiam libri, quibus ordo rerum gestarum fideliter ac diligenter adscriptus est; sunt acta, sunt litterae, multorum quoque tenetur manifesta confessio. Vgl. auch III 29.

$86 \mathrm{Zu}$ den donatistischen Traditionen s. u. Kap. 7.4.2.

87 C. litt. Pet. I 23-24. 
diejenigen der Donatisten seien richtig. Die von Augustinus geforderte Konsequenz hingegen lehnte er auf Grundlage des donatistischen Kirchenverständnisses ab (III 78-79, 84; IV 68). Jede andere Antwort hätte überrascht. Eine Anerkennung von Dokumenten, die die Heiligkeit der donatistischen Kirche infrage stellen, war für Cresconius unmöglich.

Die Geschichtsdarstellung bei Cresconius demonstriert, dass es unter den gebildeten Donatisten eine Form der Auseinandersetzung mit der Geschichte des Schismas gab. Diese Auseinandersetzung hatte freilich einen eindeutig apologetischen Charakter und zielte auf die Rechtfertigung der eigenen Position. Im Mittelpunkt stand der Nachweis von Traditoren unter den katholischen Bischöfen, der sich an den Personen von Caecilianus und dessen Konsekrator Felix von Abthugni verfestigte. Der Vorwurf der traditio, dies zeigt sich im Falle Caecilians sehr deutlich, wurde im Grunde nicht mehr allein im Sinne der „Bücherauslieferung“ verstanden, sondern wesentlich allgemeiner als Schuldanklage gegen Personen, die nicht mit der wahren Kirche übereinstimmten. In der causa Caeciliani argumentierten die Donatisten mit den Anklagen (des Ingentius) gegen Felix von Abthugni, der Verurteilung Caecilians durch ein ordentliches Konzil sowie mit dessen Verbannung durch den Kaiser. Das abweichende prokonsularische Urteil über Felix wurde als verfälscht zurückgewiesen, die Revisionen im Fall Caecilianus entweder als unrechtmäßig oder als Ergebnis von Korruption abgelehnt. Um auf die Anklagen Augustins im Buch gegen Petilianus zu antworten, ergänzte Cresconius diese Grundlagen donatistischer Apologetik um die Verteidigung des aus seiner Sicht unschuldigen Silvanus von Cirta.

Bei allen Themen wird Cresconius' Schlussfolgerung deutlich: Die Schuld der Kirchenspaltung liege bei den Katholiken, da sie nachweislich Traditoren in der Kirche belassen, die rechtmäßige Wahl des Maiorinus nicht anerkannt und auf diese Weise den Weg ins Schisma eingeschlagen hätten. Es ist auffällig, dass Cresconius an keiner Stelle die Tatsache des Urteils Konstantins über Caecilianus kritisierte oder die Zuständigkeit des Kaisers leugnete, obwohl doch die Ablehnung der kaiserlichen Einmischung in kirchliche Angelegenheiten ein Grundbekenntnis der Donatisten darstellte und im Zusammenhang mit der persecutio auch von Cresconius vertreten wurde. Insofern kann Augustinus Recht gegeben werden, wenn er Cresconius vorwirft mit zweierlei Maß zu messen: Cresconius akzeptierte das kaiserliche Urteil über Caecilianus, weil er es zu Gunsten der Donatisten deuten konnte. Maßnahmen gegen die Donatisten lehnte er dagegen als ungerechte Verfolgung ab.

Der Vergleich mit den Antworten, die Petilianus auf Augustins Brief (c. litt. Pet. I) gab, zeigt sehr deutlich, wie Cresconius sich selbstbewusst auf die historische Argumentation einließ, während es Petilianus bei allgemeinen Beschuldigungen beließ und die Geschichte weitgehend ignorierte. Hier zeichnen 
sich zwei Strategien donatistischer Argumentation ab: Petilianus führte die Diskussion auf einer theologischen Ebene und blendete - vielleicht im Wissen um die Anfechtbarkeit der donatistischen Beweise - die historischen Aspekte aus. Cresconius dagegen versuchte, die Angriffe Augustins zu entkräften, indem er auch Argumente zur Geschichte des Schismas benannte.

\subsection{Die Argumentation Augustins}

Angesichts der eingehenden Erörterung der historischen Ereignisse durch Cresconius erklärt sich die Ausführlichkeit und Gründlichkeit der Geschichtsdarstellung Augustins. Zwar wurde Augustinus nicht zum ersten Mal mit den donatistischen Interpretationen konfrontiert, ${ }^{88}$ jedoch scheint ihn Cresconius' Abhandlung in besonderer Weise $\mathrm{zu}$ einer Widerlegung herausgefordert $\mathrm{zu}$ haben, womöglich aufgrund einer breiten öffentlichen Wirkung. Bisher hatte Augustinus in seinen Schriften - ebenso wie Cresconius - lediglich auf die Existenz von Dokumenten zu den umstrittenen Fragen der Geschichte des Schismas hingewiesen. Nun ging er einen Schritt weiter: Er berichtet ausführlich über das Konzil von Cirta, über die Prozesse gegen Silvanus von Cirta und Felix von Abthugni sowie über die Urteile in der causa Caeciliani und untermauert seine Ausführungen mit zahlreichen Zitaten aus den Quellen, die ihm zur Verfügung standen. Augustins durchstrukturierte Argumentationsmethode soll im Folgenden dargestellt werden.

\subsubsection{Das Konzil von Cirta und die causa Silvani}

Im dritten Buch gegen Cresconius kommt Augustinus auf die Streitfrage der traditio zu sprechen und klagt namentlich Secundus von Tigisi und Silvanus von Cirta als Anstifter des Schismas an. Anlass für Augustins Darstellung über die Ereignisse des Konzils von Cirta ${ }^{89}$ ist der anticategoria-Vorwurf seines Gegners. Er weist diese Anschuldigung vehement zurück; es gehe schließlich nicht darum, die Streitfälle wie in der Schule in Kategorien von Gattungen (causa generibus) oder im Sinne eines Redegegenstandes (causa questionis) abzuhandeln, sondern es gehe um die Wahrheitsfrage. Auch bei einer Gegenklage müsse die Wahrheit vorgebracht werden, und Cresconius habe seine Anklagen bisher noch nicht beweisen können (III 29). Augustinus will darlegen, dass seine Anschuldigungen gegen die Urheber des Schismas nicht einer unbegründeten Gegenklage entspringen, sondern der Wahrheit entsprechen. Er zitiert in die-

88 Insbesondere ep. 43/44, vgl. u. Kap. 4.1.1.

89 Zum historischen Ablauf s. u. Kap. 7.1.1. Zu Secundus: Mandouze, PAC, 1052-154, s. v. Secundus 1. 
sem Zusammenhang erstmals einen längeren Abschnitt aus einem historischen Dokument, dem Protokoll der Bischofsversammlung in Cirta.

Aus dem Zitat geht hervor, dass am 4. März des Jahres 303 unter der Leitung des numidischen Primas Secundus von Tigisi einige Bischöfe zusammengekommen waren, um für Cirta einen neuen Bischof zu ordinieren. Auf Vorschlag des Secundus sollten zunächst alle Anwesenden auf ihr Verhalten in der Verfolgung hin überprüft werden, um die Würde der einzelnen Priester im Hinblick auf die Bischofsweihe festzustellen. Augustinus gibt nun drei Textabschnitte aus dem Protokoll wieder, in denen verschiedene Vergehen der Bischöfe aufgeführt werden:

Ein gewisser Bischof Donatus von Mascula war einer Vorladung zum Weihrauchopfer ausgewichen, doch hatte er offensichtlich heilige Bücher ausgeliefert, ${ }^{90}$ sein Kollege Marinus von Aquae Tibilitanae gab zu, einem Beamten irgendwelche Schriften (cartulae) übergeben zu haben. Bischof Donatus von Calama sprach von medizinischen Schriften, die er ausgehändigt habe und Victor von Russicade bestätigte, Evangelien verbrannt zu haben, die allerdings verderbt gewesen seien. Schließlich beschuldigte Purpurius von Liniata, selbst des Mordes angeklagt, den Vorsitzenden Secundus von Tigisi, sich durch die Auslieferung von Büchern und anderen Dingen freigekauft zu haben. Daraufhin schritt der jüngere Secundus, der Neffe des Bischofs, ein und warnte seinen Onkel auf die bisherige Weise weiter zu verfahren. Dieser lenkte ein und die Frage der Rechenschaft wurde Gott überlassen. Die bekennenden Traditoren unter den Bischöfen verblieben im Amt. ${ }^{91}$

Dieser Text ist das wichtigste Beweisstück für Augustins Anschuldigungen gegen die Ordinatoren Caecilians. Nach der Wiedergabe des Protokolls weist Augustinus seine Leser auf zwei wesentliche Konsequenzen hin: Erstens, die geständigen Traditoren von Cirta hätten später in Karthago zusammen mit anderen Bischöfen Caecilianus und seine Anhänger in Abwesenheit ohne Schuldeingeständnis verurteilt. Unter diesen Bischöfen habe sich nicht nur Secundus von Tigisi befunden, sondern auch Silvanus von Cirta, dessen traditio noch gesondert zu beweisen sei. Damit werde Cresconius' Argument hinfällig, dass einer, der zusammen mit anderen Bischöfen einen Traditor verdammt, selbst kein Traditor sein könne (III 31).

Zweitens, der Urteilsmaßstab in Karthago unterschied sich von den Kriterien in Cirta. Augustinus vergleicht die jeweiligen Entscheidungen, die Secundus zunächst in Cirta und später in Karthago getroffen hatte, und stellt die Ungleichheit in den Verfahrensweisen heraus. In Cirta habe Secundus die Geständnisse und Rechtfertigungen der Anwesenden angehört, in Karthago da-

90 Die traditio des Donatus wird zwar nicht ausdrücklich erwähnt, aber der Text impliziert, dass er zwar nicht geopfert, aber eine andere Schuld auf sich geladen habe.

91 Das Protokoll der Synode von Cirta: Cresc. III 30. 
gegen habe Caecilianus keine Gelegenheit zur Verteidigung erhalten (III 31). Während in Cirta kein Urteil über die Schuldigen gesprochen worden sei, seien in Karthago Männer verurteilt worden, die nicht geständig gewesen seien. In Cirta habe Secundus das iudicium Dei angerufen, um kein Schisma zu provozieren, in Karthago habe er trotz der ungewissen Schuldfrage darauf verzichtet und somit das Schisma hervorgerufen. In Karthago habe zudem der Einfluss der von Hass und Wut geprägten Lucilla zu der Spaltung beigetragen (III 32). Wenn auch Augustinus keinen direkten Vergleich herausstellt, so entgeht dem Leser jedoch nicht, dass implizit jener Lucilla der mäßigende Einfluss des jüngeren Secundus in Cirta, der seinen Onkel vor einer Spaltung warnte, gegenübersteht. $^{92}$

Mit diesen Erläuterungen lenkt Augustinus den Blick der Leser in eine vorgegebene Bahn: Das Protokoll von Cirta soll den von Cresconius angebrachten Zweifeln an der Glaubwürdigkeit der katholischen Anklagen einen doppelten Schuldbeweis entgegensetzen. Das Dokument bezeuge nicht nur die traditio der numidischen Bischöfe, sondern auch ihre Urheberschaft am Schisma. Trotz eigener Schuld und wider besseres Wissens habe insbesondere Secundus von Tigisi die Spaltung der Kirche in Kauf genommen. Augustinus betrachtet die Entscheidung von Cirta gewissermaßen als ein richterliches Präjudiz in der Auseinandersetzung über das crimen traditionis. Das dort gesprochene Urteil hätte als Messlatte für alle folgenden Urteile gelten sollen.

Obwohl Augustinus mit dem Protokoll von Cirta einen Nachweis für die traditio der numidischen Bischöfe führen konnte, so bleibt doch auffällig, wie dünn die Vorwürfe gegen die einzelnen Personen tatsächlich waren. Laut Protokoll gestand die Verbrennung heiliger Schriften explizit nur Victor von Russicade, alle anderen lieferten profane Schriften aus oder entgingen anderweitig einer direkten Verantwortung. Dieses Bild, in dem die Übergänge zwischen objektiver Schuld und Unschuld genauso fließend sind wie die subjektive Einstellung der Bischöfe zu ihren jeweiligen Vergehen, gibt (trotz seiner regionalen Einschränkung) ein anschauliches Zeugnis über die Probleme, die nach der Verfolgung die Kirche in der traditio-Frage zu lösen hatte und aufgrund derer sich die afrikanische Kirche spaltete. Die Fronten waren nicht klar umrissen und durch eigene Verwicklungen war kaum einer in der Lage, eine Regel vorzugeben, die von der gesamten Kirche akzeptiert werden konnte.

Den zweiten Teil der Anklage führt Augustinus gegen Silvanus von Cirta, dessen traditio-Schuld Cresconius vehement zurückgewiesen hatte. Seine Beweise gegen Silvanus schöpfte Augustinus aus dem Aktenmaterial der gesta

92 De Veer (BA 31, 329 Anm. 4) bemerkt zu Recht, dass in Cirta weniger die Warnung des jüngeren Secundus als vielmehr die Drohungen des Purpurius für die Entscheidung des Secundus entscheidend waren, die traditio-Anschuldigungen nicht weiter zu verfolgen. Zur Rolle der Lucilla s. u. Kap. 7.1.1. 
apud Zenophilum. ${ }^{93}$ Nach einem kurzen Hinweis über den Hintergrund des Prozesses gegen Silvanus gibt Augustinus mehrere ausgewählte Abschnitte aus den Prozessakten im Wortlaut wieder. Wie schon beim Protokoll von Cirta zitiert Augustinus zunächst die Einleitung mit der Angabe der Datierung und der Ausgangssituation, um einen eindeutigen Quellennachweis zu geben. Dann lässt er den für ihn wichtigsten Text ebenfalls mit Datierungsangabe folgen, nämlich das Protokoll über die traditio in der Stadt Cirta am 19. Mai des Jahres $303 .{ }^{94}$

Aus diesem Bericht stellt er die Szenen heraus, die Silvanus belasten. Er zitiert den Anfang des Dokumentes, in dem die Aufforderung an den Bischof Paulus von Cirta ergeht, die Kirchenschriften auszuliefern, bis zu der Textstelle, an dem die Anwesenheit des Subdiakons Silvanus genannt wird. Der nächste Abschnitt ist der entscheidende: Der Bericht bezeugt, dass Silvanus ohne ein Anzeichen von Widerstand eine silberne Kassette und einen silbernen Leuchter aus der Bibliothek an die Beamten übergeben habe. Aus den Prozessakten zitiert Augustinus anschließend eine weitere Aussage des Diakons Nundinarius, in der dieser Silvanus beschuldigt, nicht nur die traditio begangen $\mathrm{zu}$ haben, sondern auch von Lucilla für die Wahl des Maiorinus in Karthago mit 400 folles bestochen worden zu sein (vgl. Opt. App. I 6). Schließlich nennt Augustinus noch den Schuldspruch des Konsulars Zenophilus sowie den Nachweis, dass Silvanus zur Zeit der Verfolgung Subdiakon in Cirta gewesen sei (III 33; vgl. Opt. App. I 13).

Es ging Augustinus darum, mit diesen Dokumenten Silvanus eine Schuld nachzuweisen und seine Integrität zu untergraben. Für diesen Zweck genügte es, aus den Quellen die Silvanus betreffenden Aussagen auszuwählen und den Lesern dessen Vergehen vorzuführen. Silvanus wird an diesen Stellen als Traditor und als korrupter Bischof präsentiert, der rechtmäßig vor dem Gericht des Zenophilus verurteilt worden sei. Alle anderen Aussagen in den gesta apud Zenophilum übergeht Augustinus in diesem Zusammenhang. Die traditio von kirchlichen Kodizes durch die Lektoren von Cirta wird ebenso wenig erwähnt wie die Zeugenbefragungen und die Briefe bezüglich des Streits mit Nundinarius. Augustinus glaubte, alles entscheidende hinsichtlich der Schuld des Silvanus gesagt zu haben, so dass die Verteidigung durch Cresconius keine Basis mehr habe..$^{95}$

$93 \mathrm{Zu}$ dieser Quelle s. u. Kap. 6.2.2.

94 So die Datierung der Acta Munati Felicis in Opt. App. I 3 und bei Aug. Cresc. III 33. Die abweichende Angabe von Aug. ep. 53. 4 beruht wohl auf einem Irrtum.

95 Cresc. III 34: Man könne in Anlehnung an das Wort des Paulus sagen: „Du, der du predigst, keine traditio zu begehen, du begehst die traditio, und wo du einen anderen richtest, verdammst du dich selbst, denn du tust dasselbe, was du richtest." (qui praedicas non tradendum tradis et, in quo alium iudicas, temet ipsum condemnas; eadem enim agis qui iudicas); vgl. Rom. 2.1. 
Ebenso wie Cresconius' Begründungen für die Schuldlosigkeit des Silvanus lehnt Augustinus auch die Erklärung für die Exilstrafe des Silvanus ab. Silvanus sei lediglich nicht bereit gewesen, der Häresie abzuschwören, sondern habe in ihr verharrt, um höheres Ansehen zu erringen (III 34). Ob er damit die Exilstrafe als Folge des Prozesses vor Zenophilus betrachtet, bleibt an dieser Stelle offen. ${ }^{96}$ Jedoch wird deutlich, wie er Cresconius' Argumentation ins Gegenteil verkehrt: Silvanus sei gerade kein standhaftes Opfer, kein confessor in der Verfolgung gewesen, sondern als Traditor ein lapsus. Er sei kein Verteidiger des wahren Glaubens gewesen, sondern ein auf persönliche Ehren ausgerichteter Häretiker, der die Sünde des Schismas begangen habe. So zeigt sich am Beispiel Silvanus einmal mehr eine von Augustins zentralen Argumenten: Die Schuld der Schismatiker überwiege die der Traditoren bei weitem.

Augustinus beschließt seine Ausführungen zur causa Silvani mit einem Blick auf die Beweislage. Da Donatisten und Katholiken sich gegenseitig widersprüchliche Dokumente vorhielten, eröffne sich folgende Situation: Entweder gebe es auf beiden Seiten Traditoren oder die Dokumente beider Seiten müssten angezweifelt werden. Wenn es aber im menschlichen Streit keine Sicherheit gebe, dann bleibe nur die Einheit durch das Geschenk der Gnade Christi (III 34). Er erinnert Cresconius daran, was er selbst über Optatus von Thamugadi gesagt habe: Wenn keine Sicherheit besteht, sei er nicht in der Lage, ein Urteil zu fällen, sondern wo Zweifel bestehen, müsse man festhalten an dem sicheren Gut der Liebe und des Friedens Christi. ${ }^{97}$ In diesem Sinne ruft Augustinus zur Einheit auf. Er führt hier also seine historischen Darlegungen zu einer Schlussfolgerung, die letztlich die historische Argumentation nivelliert: Es zähle am Ende nicht, ob von beiden Seiten Anschuldigungen oder unterschiedliche Dokumente vorgelegt werden, ob die einen oder die anderen ihre Anklagen beweisen können. Die Schuld des einen könne nicht einen anderen belasten, die Sünden der Toten, selbst wenn sie bewiesen sind, können den Lebenden nichts anhaben, und so könne auch kein Traditor in Afrika die gesamte Christenheit verunreinigen (III 34-37).

Für die gesamte Thematik der Anschuldigungen gegen die Urheber des Donatismus lässt sich erkennen, dass Augustinus eine doppelte Anklage vorträgt. Die erste Anklage lautet auf crimen traditionis, im juristischen Sinne tatsächlich eine Gegenklage gegen den gleich lautenden Vorwurf der Donatisten. Um Secundus, Silvanus und die anderen numidischen Bischöfe ihrer Schuld zu überführen, zieht Augustinus öffentliche Akten als Beweismittel (probationes inartificiales) heran. Auf diese Weise kann er Cresconius' Vorwurf der Gegenklage entkräften, da seine Zeugnisse als stichhaltig gelten und nicht rein rhe-

96 Monceaux (IV 230 f.) und de Veer (BA 31, 336 Anm. 1) sehen in der Verbannung das Prozessurteil. Vgl. auch Grasmück, Coercitio, 87.

97 Cresc. III 37; vgl. III 16. 
torischer Natur sind. Die zweite Anklage lautet auf crimen schismatis. Wider besseres Wissen hätten die Beschuldigten eine Spaltung in Kauf genommen. Bei Secundus zeige sich dies in seinem widersprüchlichen Verhalten in Cirta und in Karthago, bei Silvanus in seinem Festhalten an der Häresie, obwohl er ein Traditor gewesen sei. Das Plädoyer, das Augustinus schließlich an seine Leser und Hörer richtet, lautet auf Anerkennung der Wahrheit. Entweder sei den vorgelegten Zeugnissen Glauben zu schenken, oder aber, falls dies nicht möglich sein sollte, sei die Wahrheit dort zu suchen, wo der Wunsch nach pax et unitas Christi ausgesprochen werde - in der katholischen Kirche.

\subsubsection{Die causa Caeciliani}

Die causa Caeciliani bildet das Zentrum der historischen Argumentation Augustins. Ebenso wie der Nachweis der traditio für die Begründer des Donatismus sollte die Verteidigung Caecilians und seines Konsekrators Felix von Abthugni den Erweis ihrer Unschuld erbringen und den donatistischen Vorwürfen den Boden entziehen. Augustinus geht in seiner Darstellung der causa Caeciliani auf zwei Argumente seiner Gegner ein. Zum einen behandelt er die quaestio factorum und reagiert damit auf die seines Erachtens falschen Vorstellungen der Donatisten über die Urteile gegen Caecilianus. Mit Hinweis auf historische Dokumente drängt er darauf, die verleumderischen Anklagen richtigzustellen (III 67-68), und im Vergleich mit dem Maximianistischen Schisma verdeutlicht er die Niederlage der Donatisten (III 16, 44; IV 7-9, 67). Zum anderen behandelt Augustinus die quaestio probationum. Ziel ist es, Cresconius' Behauptung zu widerlegen, die Dokumente der Katholiken seien falsch, während die der Donatisten wahr seien (III 78-83).

Nachdem Augustinus unter Verwendung von Aktenmaterial die Verfolgung der Maximianisten durch die Donatisten dargestellt hat, kommt er auf Cresconius' Beurteilung der causa Caeciliani zu sprechen:

„Nichts habt ihr in der Hand, womit ihr unwissenden Menschen finstere Lügen über längst vergangene Ereignisse andrehen könnt. Öffentliche Zeugnisse bezeugen, dass eure Leute Caecilianus bei Konstantin, der damals Kaiser war, anklagten. Die prokonsularischen Archive beweisen, dass der Fall [Caecilians] entschieden und zu einem gebührenden Ende geführt wurde, bis hin zu dem Freispruch des Felix von Abthugni, des Ordinators Caecilians, den sie auf dem Konzil in Karthago als ,Quelle allen Übels' bezeichnet und den sie bei Konstantin durch beständige Bittgesuche angeklagt haben, wie er selbst in seinen Schriften bemerkt. Ihr leugnet, ihr bestreitet und bekämpft die allzu sichtbare Wahrheit. Ihr sagt, dass auch die Richter aus Übersee von Caecilianus bestochen worden seien und dass selbst der Kaiser durch irgendeine Gefälligkeit verführt worden sei. Freilich ist dort ein besiegter Ankläger unverschämter, wo er auch zum Verleumder des Richters wird. Gleichwohl halten wir zwischen allen euren Lügen, mit denen ihr die Richter aus Übersee verleumdet, wenigstens daran fest, dass eure Vorfahren als erste jenen Fall 
dem Kaiser übertragen, als erste Caecilianus und seinen Ordinator angeklagt und als erste Caecilianus und seine Anhänger beim Kaiser verfolgt haben."

Augustinus fasst hier die Informationen jener Quellen zusammen, aus denen er später wörtlich zitiert. Sowohl Caecilianus als auch Felix von Abthugni seien von den Donatisten beim Kaiser angeklagt worden. Die Donatisten hätten als erste geklagt und behaupteten nun, die Richter und der Kaiser seien korrumpiert worden, da das Urteil nicht nach ihrem Geschmack ausgefallen war. Augustinus betont damit den Widerspruch zwischen der Anklageinitiative der Donatisten und ihrer Richterschelte, nachdem sie verloren hatten. Die weiteren Ausführungen verdeutlichen Augustins Intention an dieser Stelle: Anstatt den Freispruch Caecilians durch das bischöfliche Gericht in Übersee anzuerkennen, hätten die Donatisten die Richter angeklagt und darüber hinaus alle katholischen Christen weltweit beschuldigt, die entweder nie etwas von Caecilianus gehört hätten, oder, sollten sie etwas erfahren haben, dem Urteil der Richter geglaubt hätten (III 67-68). Augustinus hält dies seinen Lesern als Paradox vor Augen:

„O welch erstaunliches Geschick! Afrikaner beschuldigen Afrikaner des Verbrechens der traditio. Richter in Übersee sprachen die Angeklagten frei, und alle Völker werden zu Traditoren gemacht, weil sie den Richtern, die freigesprochen haben, eher glaubten als den Anklägern, die beschuldigt haben." 99

Die von ihm genannten historischen Zeugnisse stellt Augustinus in den Mittelpunkt seiner Beurteilung von jener Antwort, die Cresconius auf die vier Alternativen in der Beweisfrage zur traditio gegeben hatte. ${ }^{100}$ Zunächst deckt er die Widersprüche auf, in die sich Cresconius seiner Ansicht nach mit der Wahl der vierten Alternative verwickelt habe. Dazu stellt er ihn erneut vor verschiedene Antwortmöglichkeiten: Unter der Annahme, das Gericht in Übersee

98 Cresc. III 67: Nihil habetis iam unde caliginosa mendacia hominibus ignaris de rebus longe praeteritis ingeratis. quod uestri apud Constantinum tunc imperatorem accusauerunt Caecilianum, publica monumenta proclamant. dictam esse causam et ad debitum finem esse perductam usque ad purgationem Felicis Aptugnensis ordinatoris Caeciliani, quem in concilio Carthaginiensi 'malorum omnium fontem' dixerunt et apud eundem Constantinum, sicut scriptis suis ipse indicat, adsiduis interpellationibus accusarunt, proconsularia testantur archiua. resistitis reclamatis repugnatis apertissimae ueritati, dicitis etiam transmarinos iudices a Caeciliano esse corruptos, ipsum imperatorem nescio qua gratia deprauatum; eo quippe est inpudentior uictus accusator quo fit etiam iudicis calumniator. uerumtamen inter omnia illa uestra mendacia, quibus transmarinis iudicibus calumniamini, saltem hoc optinemus, quod primi maiores uestri ad imperatorem causam istam detulerunt, primi apud imperatorem Caecilianum et eius ordinatorem accusauerunt, primi apud imperatorem Caecilianum et eius socios persecuti sunt.

99 Cresc. III 68: o rem mirabiliter indignam! accusarunt Afri Afros crimine traditionis, accusatos transmarini iudices absoluerunt, et traditores facti sunt populi gentium, quia iudicibus absoluentibus potius quam accusatoribus criminantibus crediderunt. Vgl. II 45.

$100 \mathrm{Vgl}$. o. S. $90 \mathrm{f}$. 
habe mit wahren Dokumenten der Donatisten verhandelt, gebe es zwei Möglichkeiten, entweder die Donatisten hätten gesiegt oder verloren. Wenn sie die Sieger waren, dann stelle sich die Frage, warum sie heute nicht zu der Kirche gehörten, durch deren Urteil sie gesiegt hätten. Wenn sie die Verlierer waren, stelle sich die Frage, warum sie trotz der wahren Dokumente das Urteil abgelehnt und ein Schisma begangen hätten, anstatt sich den Siegern anzuschließen. Cresconius gehe aber davon aus, dass die Dokumente bei den Verhandlungen in Übersee nicht wahr gewesen seien. Dann aber sei zu fragen, auf welcher Grundlage die Donatisten alle Bischöfe weltweit verurteilten, die nichts von der traditio wussten (III 78). Die Dokumente der Donatisten, führt Augustinus weiter, hätten nicht ausgereicht, um die traditio der Angeklagten nachzuweisen. Daher habe Cresconius mit seiner Wahl nichts erreicht. Keiner, und erst recht nicht die gesamte Christenheit könnten durch die Schuld eines anderen belangt werden, wenn keine überzeugenden Beweise vorliegen. Daher bleibe die dritte Möglichkeit wahrscheinlicher: Die Beweise der Katholiken seien wahr, die der Donatisten falsch (III 79, 84).

Anhand von Zitaten aus mehreren Aktenstücken will Augustinus nun nachweisen, dass er im Gegensatz zu Cresconius tatsächlich glaubhafte Dokumente zur causa Caeciliani vorweisen kann. Es solle deutlich werden, dass alle Anklagen der Donatisten falsch seien: Caecilianus sei mitnichten verdammt, durch den Kaiser verurteilt und ins Exil nach Brescia geschickt, sondern in allen Punkten freigesprochen worden. Zunächst zitiert er die Sentenz des Prokonsuls Aelianus der bei Optatus von Mileve überlieferten acta purgationis Felicis, aus denen hervorgeht, dass Felix von Abthugni freigesprochen worden sei, die Anklagen gegen ihn aber durch die Fälschungen des Ingentius zustande gekommen seien, der dafür angeklagt werden solle. Den vollständigen Text könne man in den Archiven des Prokonsuls einsehen, ergänzt Augustinus. ${ }^{101}$ Als weiteres zieht Augustinus zwei Briefe Konstantins heran. Der erste Text ist ein Reskript des Kaisers an den Prokonsul Probianus, in dem der Hintergrund des Prozesses über Felix und dessen Freispruch erläutert wird. Entscheidend für die Widerlegung von Cresconius' Ansichten dürften darin zwei Aussagen gewesen sein:

„Da Caecilianus beschuldigt worden war, die Bischofswürde von jenem Felix übertragen bekommen zu haben, dem offenbar die Auslieferung und Verbrennung heiliger Schriften vorgeworfen wurde, führte [Prokonsul Aelianus] eine gerichtliche Anhörung durch, solange bis er feststellte, dass Felix hinsichtlich dieser Anklagen unschuldig sei." ${ }^{102}$

101 Cresc. III 80; vgl. Opt. App. II 10.

102 Cresc. III 81: [...], audientiam praebuit [Aelianus] conpetentem, adeo ut, cum Caeciliano fuisset obiectum, quod a Felice eidem episcopatus uideretur esse delatus, cui diuinarum scripturarum proditio atque exustio uideretur obiecta, innocentem de eo Felicem fuisse 
Der Freispruch des Felix findet also eine Bestätigung in dem kaiserlichen Brief. Außerdem wird ein Bezug zu den Verhandlungen gegen Caecilianus hergestellt. Beim Prozess gegen Felix sei die Fälschung des Ingentius aufgedeckt worden.

\begin{abstract}
„Daher wollen wir [Konstantin], dass du [Probianus] diesen Ingentius unter angemessenem Schutz an meinen, des Augustus Konstantins, Hof schickst, damit jenen, die gegenwärtig die Sache verhandeln und nicht ablassen, tagtäglich zu appellieren, durch seine Anhörung und persönliche Gegenwart beigebracht werden kann, dass sie vergeblich versuchten, Bischof Caecilianus Anfeindungen entgegenzubringen und sich gegen ihn gewalttätig zu erheben.“"103
\end{abstract}

Nach dem Willen Konstantins sollte der hartnäckige Widerstand der Gegner Caecilians gegen die bisherigen Urteile durch das Ergebnis des Prozesses gegen Felix und der Vorführung des Ingentius gebrochen werden. ${ }^{104}$ Der zweite Text ist ein Zitat aus einem Brief an den vicarius Africae Eumalius, in dem Konstantin den Freispruch Caecilians von den Anschuldigungen seiner Gegner bezeugt. $^{105}$

Nach diesen Aktenzitaten erläutert Augustinus wiederum die Konsequenzen für die Anschuldigungen des Cresconius. Dieser habe bezüglich der causa Caeciliani keine Dokumente vorlegen und seine Anklagen nicht beweisen können. Caecilianus sei auch nicht in Brescia im Exil gewesen, sondern, so die Begründung Augustins, er habe es vorgezogen, seine Kirche zu vernachlässigen anstatt den Frieden preiszugeben. Wenn Cresconius in Bezug auf die Exilstrafe Recht hätte, dann müsse er dies beweisen. Und selbst wenn er Recht hätte, dann könne man Caecilianus auch ein Opfer der kaiserlichen Verfolgung nennen ganz im Sinne des Cresconius. In den Akten ließen sich jedoch andere Tatsachen finden: Caecilianus sei zwar durch die Donatisten beim Kaiser verfolgt worden, allerdings habe es keine Verurteilung gegeben, sondern seinen Freispruch (III 83).

Augustinus demonstriert mit seinen Quellenzitaten, dass die Unschuld des Felix und Caecilians durch schriftliche Zeugnisse belegt werden könne. Die Beweisfrage war für ihn geklärt, da Cresconius keine entsprechenden Belege für

constiterit. - Augustinus zitiert den gleichen Wortlaut in ep. 88.4. Zum Dokument: Maier I, Nr. 24, 189-192; Soden Nr. 20, 32 f.; Duchesne Nr. 58, 639 f.; vgl. Seeck, ZKG 10, 534; 30, 188 f. Vgl. auch u. Kap. 6.1.3.

103 Cresc. III 81: unde uolumus eundem ipsum Ingentium sub idonea prosecutione ad comitatum meum Constantini Augusti mittas, ut illis, qui in praesentiarium agunt atque diurnis diebus interpellare non desinunt, audientibus et coram adsistentibus apparere et intimari possit frustra eos Caeciliano episcopo inuidiam conparare atque aduersus eum uiolenter insurgere uoluisse.

104 Zum historischen Kontext s. u. Kap. 7.4.1.

105 Cresc. III 82. In c. Don. 56 nennt Augustinus das Datum des Briefes: Constantinus ad Eumalium uicarium de purgatione Caeciliani scripsit Sabino et Rufinu consulibus IIII Idus Nouembres [= 10. November 316]. Ausführlich zu diesem Dokument und seiner Interpretation u. Kap. 7.4.1. 
seine Anschuldigungen vorgelegt hatte. Die Einengung der Argumentation an dieser Stelle auf die Schuldfrage der beiden Bischöfe lässt allerdings andere Fragen ohne Antwort. Die bischöflichen Urteile von Rom und Arles werden nur beiläufig erwähnt, und auf den tatsächlichen Inhalt der Verhandlungen vor dem Kaiser und dessen Urteilsspruch wird nur indirekt hingewiesen.

Ein Grund dafür ist, wie auch bei der Erörterung der causa Silvani, Augustins direkte Widerlegung der Aussagen seines Gegners. Er reagiert auf Cresconius' Anschuldigungen, der das Urteil des Konzils von Karthago durch das Urteil Konstantins bestätigt sah und den Anklagen des Ingentius gegen Felix von Abthugni glaubte. Augustinus betont entsprechend für beide Personen das entscheidende und endgültige Urteil Konstantins, nachdem die Donatisten selbst ihre Anklagen beim Kaiser vorgetragen hatten. Die Herausstellung der Appelle sollte außerdem die Gegner Caecilians als Verfolger und deren Urheberschaft des Schismas verdeutlichen. Durch die Ablehnung der selbst verlangten Urteile und die Verleumdung der Richter hätten die späteren Donatisten nach Meinung Augustins den Frieden aufs Spiel gesetzt und die Spaltung in Kauf genommen.

Ein weiterer Grund für die Zusammenstellung von Augustins Argumenten ist jedoch die Quellenlage: Augustinus kannte zwar einige weitere Einzelheiten über die Konzile von Rom und Arles, die er gegen Cresconius nicht heranzog, er verzichtete aber auf diese Details, da sein Argumentationsinteresse unter der Prämisse stand, die Tatsache der Freisprüche Caecilians zu verdeutlichen. Dennoch fehlten Augustinus Informationen, die sich für die Widerlegung des Cresconius geeignet hätten, vor allem über den genauen Ablauf des Verfahrens nach dem Konzil von Arles, insbesondere den Aufenthalt Caecilians in Brescia sowie über das Ergebnis der kaiserlichen Anhörung des Ingentius. Hierzu wusste Augustinus nicht mehr, als er den Briefen des Kaisers an Probianus und Eumalius sowie der Darstellung bei Optatus von Mileve entnehmen konnte. Die Abhängigkeit von Optatus wird insbesondere bei der Frage nach dem Grund für Caecilians Aufenthalt in Brescia deutlich: Augustinus konnte nicht mehr antworten, als ihm von der kurzen Anspielung bei Optatus (I 26) bekannt war. Gerade in dieser wichtigen donatistischen Anklage (Exilstrafe für Caecilianus) war Augustinus nicht in der Lage, ein schriftliches Dokument vorzulegen. Die Unsicherheit über das Verfahren nach Arles zeigt sich überdies in Augustins falscher Vorstellung vom zeitlichen Bezug des Prozesses über Felix von Abthugni und der Entscheidung des Kaisers über Caecilianus. Die Annahme, dass zuerst Caecilians Freispruch erfolgt sei, ${ }^{106}$ korrigierte Augustinus erst nach der Konferenz von 411. ${ }^{107}$ An diesen Beispielen zeigen sich die Grenzen für Augustins historische Argumentation.

106 So in Cresc. III 67; IV 9.

107 Retr. II 27-28. 
In dem Vergleich der causa Caeciliani mit dem Verlauf des Maximianistischen Schismas geht Augustinus auf einen weiteren Aspekt der Auseinandersetzung ein: die Rechtmäßigkeit der bischöflichen Urteile. Da er diese Frage im Laufe seiner Darstellung mehrmals wiederholt, scheint sie von entsprechend großer Bedeutung gewesen zu sein, zumindest für Augustinus und die katholische Position. Einen ersten Überblick über die Fragestellung gibt Augustinus im dritten Buch:

„Es wurde später in Übersee ein Urteil für Caecilianus gesprochen, weil eure Leute beim Kaiser Konstantin heftig darauf gedrängt hatten, dass dies geschehe. Wenn aber die kirchlichen Urteile, die vorher gesprochen worden waren, nicht für ungültig erklärt werden können, was werdet ihr dann mit Primianus tun, eurem Bischof von Karthago, gegen den zunächst einhundert [Bischöfe] urteilten - und damit mehr als über Caecilianus - und den sie seines Bischofsamtes enthoben und Maximianus an seine Stelle einsetzten? Verlässt sich Primianus etwa nicht auf das spätere Urteil, das zu seinen Gunsten in der Stadt Bagaï gesprochen wurde? Nach diesem Urteil wollte er nicht, dass man an ihm zweifelte, sondern er nötigte von euch allen ab, freigesprochen zu werden. Von daher sprechen wir Caecilianus ohne Einschränkung und Zögern frei, gemäß dem späteren Urteil über ihn.“"108

Noch detaillierter führt Augustinus diese Gegenüberstellung im vierten Buch aus: Er benennt die Urteilsschritte, die im Maximianistischen Schisma erfolgt waren, ${ }^{109}$ und stellt die Frage, welches der Konzile die größere Autorität in Anspruch nehmen könne. Cresconius und die Donatisten rekurrierten stets auf die Verurteilung Maximians auf dem Konzil von Bagaï. Augustinus rechnet vor, dass sowohl Primianus als auch Maximianus in Abwesenheit verurteilt worden seien. Die Maximianisten jedoch hätten Primianus dreimal aufgefordert, zu ihnen zu kommen. Da dieser nicht wollte, hätten sie ihm schließlich sogar angeboten, selbst zu ihm zu kommen. Primianus aber habe sie zurückgewiesen, woraufhin die Maximianisten noch kein endgültiges Urteil (ultimum iudicium), sondern nur ein vorläufiges (praeiudicium) gesprochen hätten, denn Primianus sollte die Gelegenheit erhalten, vor einem größeren Konzil (concilium celebrior) angehört zu werden und sich zu rechtfertigen. Da dies nicht geschehen sei, habe das Konzil von Cabarsussa Primianus ohne weitere Verzögerung verurteilt. Im Dekret des donatistischen Konzils von Bagaï hingegen finde sich kein Hinweis auf Boten, die zu Maximianus geschickt worden seien, um ihn einzuladen. Al-

108 Cresc. III 16: sed factum est pro Caeciliano posterius iudicium transmarinum, uestris apud Constantinum imperatorem ut fieret instantibus. aut ecclesiastica iudicia, quae prius facta fuerint, iam conuelli non possunt, quid de Primiano facturi estis uestro episcopo Carthaginiensi, contra quem primo centum, plures utique quam de Caeciliano, iudicauerunt eique abrogato episcopatu Maximianum pro illo constituerunt? nonne Primianus posteriore iudicio nititur, quod pro illo factum est in oppido Bagaiensi, secundum quod iudicium non uult de se dubitari, sed ab omnibus uobis se extorquet absolui? unde et nos secundum posterius de Caeciliano iudicium prorsus eum incunctanter absoluimus.

109 Vgl. o. S. $24 \mathrm{f}$. 
lerdings sei Maximianus Anstifter des Schismas und aufgrund dieses Verbrechens habe seine Verdammung und die seiner Ordinatoren nicht mehr länger aufgeschoben werden können (IV 8).

Augustinus hält ein Urteil, das in Abwesenheit des Beklagten ausgesprochen wird, für unrechtmäßig. Den Maximianisten billigt er ein rechtlich korrektes Verfahren zu, da sie in Abwesenheit Primians noch kein endgültiges Urteil gefällt und ihm die Möglichkeit zu einer Anhörung eingeräumt hätten. Da kein Einspruch und keine Verteidigung erfolgte, sei auf einem zweiten Konzil ein rechtskräftiges Urteil gesprochen worden. Entsprechend dieser Rechtsauffassung hält Augustinus das primianistische Verfahren gegen Maximianus für ungültig oder zumindest anfechtbar. Als entscheidend stellt $\mathrm{Au}$ gustinus jedoch heraus, dass trotzdem die Anhänger des Maximianus zu Recht verdammt worden seien, weil sie die Urheber des Schismas gewesen seien.

Auf dieser Grundlage steht Augustins folgende Darstellung über die causa Caeciliani: Im Gegensatz zur Verurteilung Primians habe es nur ein Konzilsurteil gegen Caecilianus gegeben. Caecilianus habe es auch nicht abgelehnt, seine Kollegen zu empfangen, sondern habe sie eingeladen zu ihm zu kommen, um ihr Urteil gegen ihn vorzutragen. In der Folgezeit seien nicht nur ein Urteil wie bei Primianus, sondern vier Urteile zu Caecilians Gunsten ausgefallen. In seiner Anwesenheit seien Caecilians Gegner widerlegt worden und zwar vor Richtern, zu deren Übernahme des Richteramtes die Donatisten selbst ihre Zustimmung gegeben hätten. Auch vom Kaiser Konstantin sei Caecilianus freigesprochen worden, bei dem die Donatisten zuerst Caecilianus angeklagt, bei dem sie später gegen das Urteil der Bischöfe Einspruch erhoben und an den sie schließlich nach einem zweiten bischöflichen Urteil nochmals appellierten hätten, so dass sie vom Kaiser selbst überwunden worden seien, nachdem dieser den Fall untersucht habe. Das vierte Urteil sei der Freispruch des Felix von Abthugni gewesen. Nachdem die Gegner Caecilians durch vielfache Eingaben (interpellationes) Felix der traditio angeklagt hätten, sei auf Befehl Konstantins der Fall verhandelt und Felix freigesprochen worden. Die Maximianisten seien nicht so oft besiegt worden, nicht in Gegenwart und auch nicht durch selbst gewählte Richter, aber sie hätten sich von der Gemeinschaft mit den Donatisten abgespalten (IV 9).

Der Vergleich mit dem Maximianistischen Schisma ändert nichts an $\mathrm{Au}-$ gustins Grundintention. Wie an den anderen Stellen der historischen Argumentation zielt er auf den Nachweis der Freisprüche Caecilians und Felix' sowie auf die Anerkennung dieser Urteile durch die Donatisten. Augustinus formalisiert den Verlauf der Prozesse noch weiter und spricht nunmehr von fünf Urteilen über Caecilianus, von denen vier zu dessen Gunsten ausgefallen seien. Die Betonung liegt eindeutig auf der Darstellung der immer neuen Appelle der Donatisten und nicht in der Erläuterung von Einzelheiten zum Prozessablauf. Entsprechend ergeben sich für den geschichtlichen Ablauf kaum neue Er- 
kenntnisse. Augustinus stellt allerdings stärker heraus, dass beim ersten Freispruch durch Bischöfe, also in Rom, Caecilianus anwesend war und die Richter von den Anklägern anerkannt worden seien. Später seien die bischöflichen Richter beim Kaiser angeklagt worden. Neu ist zudem die Erwähnung von den Boten der Gegenpartei, die Caecilianus zum Vortrag ihrer Anklagen eingeladen haben soll, eine Information, die Augustinus jedoch bei Optatus von Mileve finden konnte. ${ }^{110}$

Die bis ins Detail durchgeführte Parallelisierung des donatistischen und Maximianistischen Schismas im vierten Buch gegen Cresconius zeigt sich hier in der Gegenüberstellung der causa Primiani und der causa Caeciliani. Augustins Argumentationsaufbau gegen die Donatisten bildet ein durchstrukturiertes Gerüst: Wenn die Donatisten am Urteil gegen Caecilianus festhielten, dann müssten sie auch an der doppelten und rechtmäßigen Verurteilung Primians festhalten. Wenn sie das zweite Urteil über Primianus bevorzugten, d.h. seinen Freispruch in Bagaï, dann müssten auch das zweite und die weiteren Urteile für Caecilianus anerkannt werden (vgl. auch III 16). Wenn die Donatisten Primianus die Möglichkeit der Revision vor anderen Richtern einräumten, dann müssten sie dies auch Caecilianus einräumen. Wenn sie Bagaï wegen der Zahl von 310 Bischöfen dem Vorzug geben, dann sollten sie auch das Urteil der weltweiten Christen über Caecilianus anerkennen (vgl. auch IV 67). Wenn sie das Schisma des Maximianus verdammten, dann müssten sie auch Donatus verurteilen, der sich von der Einheit der katholischen Kirche getrennt habe. ${ }^{111}$

Diese Argumentation umfasst drei Rechtsebenen, mit denen sich Augustinus gegen alle denkbaren Widersprüche rüstet. Die erste Ebene betrifft die iudicia episcopalia und erstreckt sich somit auf das Kirchenrecht. Augustinus stellt die jeweiligen Synodalurteile gegen Primianus und Caecilianus gegenüber und beurteilt sie aus der kirchenrechtlichen Praxis. Seiner Ansicht nach sei (trotz einiger Verfahrensmängel) sowohl die Bevorzugung Primians gegen Maximianus gerechtfertigt als auch der Freispruch Caecilians. Denn in beiden Fällen sei ein erstes (negatives) Urteil durch ein zweites Urteil revidiert worden. Den jeweiligen zweiten Urteilen müsse der Vorzug gegeben werden, da ihnen ein höheres Maß an Autorität zukomme. Diese höhere Autorität sieht Augustinus im Falle Primians aufgrund der größeren Anzahl an Bischöfen gewährleistet, im Falle Caecilians aufgrund des Urteils europäischer Bischöfe, die als Repräsentanten der weltweiten Kirche die Entscheidung des karthagischen Provinzkonzils verwerfen durften.

110 Cresc. I 19; vgl. breuic. III 26.

111 Ein ähnlicher Argumentationsansatz in bapt. II 2-4; vgl. auch retr. II 35 (zur verlorenen Schrift Max.). 
Diese Argumentation Augustins ist anachronistisch. ${ }^{112}$ Zur Zeit Konstantins konnte ein Synodalurteil gegen einen Bischof grundsätzlich nicht durch eine weitere Instanz revidiert werden. Die Möglichkeit für einen verurteilten Bischof zu appellieren oder die Wiederaufnahme eines Verfahrens zu beantragen, erhielt erst im Laufe des vierten Jahrhunderts eine rechtliche Grundlage, vor allem auf der Synode von Serdica (342). Augustins Rechtfertigung der Folgeurteile über Caecilianus besitzt insofern keine historische Basis. In der Frage der Gewichtung bzw. höheren Autorität von Synoden finden sich Hinweise in den Beschlüssen der Konzile von Antiochien (328) und Konstantinopel (381/82), aus denen hervorgeht, dass Entscheidungen größerer Synoden kleineren übergeordnet wurden und Klerikern wohl die Möglichkeit eingeräumt wurde, von einer Provinzsynode an eine größere (Diözesan-)Synode zu appellieren. ${ }^{113}$ Auf einem Konzil in Karthago (419) wurde ausdrücklich die höhere Autorität einer größeren Synode in Bezug auf die Gerichtsbarkeit ausgesprochen. ${ }^{114}$ Augustinus beurteilt die Verurteilung Maximians im Jahre 394 somit im Verständnis der katholischen Praxis dieser Zeit. Er überträgt dieses Verständnis aber auch auf den Freispruch Caecilians in Rom und Arles, indem er eine höhere Autorität der europäischen Bischöfe postuliert und ihnen zubilligt, das Sprachrohr der gesamten Christenheit zu sein. Möglicherweise setzt Augustinus auch eine größere Autorität des römischen Bischofs voraus; jedoch findet sich in seinen Ausführungen kein derartiger Verweis. In jedem Fall geht Augustinus für die Situation zu Beginn der vierten Jahrhunderts von falschen Voraussetzungen aus. Es galt damals die Unwiderrufbarkeit der synodalen Entscheidung. Auf dieses Recht beriefen sich offensichtlich die Donatisten sowohl bei ihren Appellationen an den Kaiser als auch zur Zeit Augustins: In ihren Augen war das Urteil von Karthago über Caecilianus endgültig. ${ }^{115}$

Die zweite Argumentationsebene betrifft das iudicium imperatoris, erstreckt sich also auf das weltliche Zivilprozessrecht. Nach der Absetzung Caecilians in Karthago appellierte nicht die unterlegene Partei an eine weitere Synode, sondern die pars Maiorini wandte sich an den Kaiser und somit an die höchste

112 Zum Folgenden vgl. Girardet, Appellatio, Historia 23, 1974, 111-127; vgl. Bavaud, BA 29, 592-596.

113 Girardet, Historia 23, 1974, 123.

114 Vgl. Kanon XV des Konzils von Karthago 419 (Munier, CCL 149, 105): „Es wurde beschlossen, dass von allen bischöflichen Richtern an andere bischöfliche Richter appelliert werden dürfe, wenn diese eine größere Autorität besitzen." (Hoc etiam placuit, ut a quibuscumque iudicibus ecclesiasticis ad alios iudices ecclesiasticos, ubi est maior auctoritas, fuerit prouocatum etc.).

115 Die donatistische Kirche hatte selbstverständlich die Änderungen im Kirchenrecht des vierten Jahrhunderts nicht mitgetragen. Sehr wahrscheinlich folgten sie nach wie vor dem älteren Recht. Allerdings fehlen die Quellen, um das donatistische Verständnis der bischöflichen Gerichtsbarkeit zur Zeit Augustins genau zu erfassen. 
Instanz der weltlichen Gerichtsbarkeit. Augustinus stellt heraus, dass das erneute Verfahren auf ausdrücklichen Wunsch der Donatisten zustande gekommen sei. Zudem sei aufgrund ihrer Appelle an den Kaiser nach den Entscheidungen von Rom und Arles das endgültige Urteil des Kaisers gesprochen worden. Schließlich gehe auch der Prozess gegen Felix auf die Initiative der Donatisten zurück. Neben den bischöflichen Urteilen argumentiert Augustinus auch mit der Klage der Donatisten beim Kaiser. Das Ergebnis war das gleiche: Sowohl das letzte Urteil des Kaisers über Caecilianus als auch das Urteil über Felix von Abthugni sprachen gegen die Kläger. Indem die Donatisten keines dieser Urteile anerkennen, stellten sie sich gegen das geltende Recht und abermals gegen die Einheit der katholischen Kirche, die den Spruch des Kaisers akzeptierte.

Die dritte und letzte Argumentationsebene betrifft das iudicium Dei. In seiner Darstellung betont Augustinus das korrekte Verfahren der Maximianisten im Verhältnis zu dem anfechtbaren Verfahren der Primianisten, die Maximianus in Abwesenheit verurteilt hätten. Ganz gleich, wer nach irdischem Recht auf welche Weise auch immer verurteilt werde, die Schuld liege bei jenen, die die kirchliche Einheit zerbrechen. Deshalb stellt sich Augustinus demonstrativ auf die Seite der Donatisten gegen die Maximianisten, um dieses entscheidende Kriterium zu veranschaulichen. Denn die Donatisten selbst hätten sich von der Einheit der unschuldigen Völker getrennt, die entweder nicht selbst urteilen konnten, oder nicht wussten, dass es Richter und ein Urteil gab, oder dieses Urteil nicht kannten oder einfach diesem Urteil mehr vertrauten als den besiegten Anklägern (vgl. III 67). Damit führt Augustinus letztlich das theologisch begründete iudicium Dei ein, eine Lösung, die in allen Bereichen seiner Argumentation begegnet: Die Einheit sei das höchste Gut der Kirche, das Schisma stets das größere Verbrechen. Mit diesem Argument konnte Augustinus jene Angriffe seiner Gegner parieren, die nicht durch die ersten beiden Ebenen abgefangen werden konnten. Mit dieser dreifachen Struktur demonstrierte Augustinus nichts anderes als einen ,Sieg auf ganzer Linie'. Die Welt habe sich für Caecilianus als karthagischen Bischof ausgesprochen: Die Bischöfe, der Kaiser, die gesamte Christenheit und damit auch Gott. 


\section{Die antidonatistischen Briefe}

\section{Die Darstellung der donatistischen Kontroverse}

Die insgesamt 308 überlieferten Briefe der augustinischen Briefsammlung geben einen umfassenden Einblick in das Leben und Wirken Augustins. ${ }^{1}$ In vielen der Briefe wird das donatistische Schisma erwähnt. Darunter befinden sich Schreiben mit kurzen Notizen, Briefe, in denen konkrete Probleme angesprochen werden, aber auch ausführliche Abhandlungen, in denen unterschiedlichste Facetten des Donatismus erörtert werden. ${ }^{2}$ Innerhalb von Augustins Schriften sind die Übergänge zwischen den Gattungen fließend: Einige Briefe tragen deutlich den Charakter eines Traktates oder einer Predigt, umgekehrt finden sich zahlreiche Schriften, die der Form nach den Briefen zuzuordnen sind und trotzdem nicht in der Briefsammlung überliefert wurden. ${ }^{3}$

Von den uns heute erhaltenen Briefen schrieb Augustinus 18 an Donatisten. ${ }^{4}$ Die Adressaten waren zum einen donatistische Bischöfe, darunter $\mathrm{Au}-$ gustins Gegenbischöfe in Hippo Proculeianus (ep. 33) und später Macrobius (epp. 106, 108), ferner Crispinus von Calama (epp. 51, 66), Ianuarianus von Casae Nigrae (ep. 88) sowie Maximinus von Siniti (ep. 23), ein gewisser Honoratus (ep. 49) und Emeritus von Caesarea (ep. 87). Zum anderen schrieb Augustinus an einzelne donatistische Laien (epp. 43, 44, 52, 70), einen Brief an einen donatistischen Priester namens Donatus (ep. 173); drei Briefe richten sich an die Donatisten insgesamt (epp. 76, 105, 141). Eine Sonderrolle nimmt schließlich ep. 93 an Vincentius ein, den Führer der donatistischen Abspaltung der Rogatisten.

1 Edition: S. Aureli Augustini Hipponiensis episcopi epistulae, ed. A. Goldbacher, 4 Bde. Wien 1895-1923 (CSEL 34, 44, 57, 58); Epistulae ex duobus condicibus nuper in lucem prolatae, ed. Johannes Divjak, Wien 1981 (CSEL 88).

2 Ein knapper Überblick über Augustins Briefe im Zusammenhang mit dem Donatismus bei Monceaux VII, 129-146, 279-286. Ergänzend dazu: A. Schindler, Vermitteln die neuentdeckten Augustin-Briefe auch neue Erkenntnisse über die Donatisten?, in: Les Lettres de saint Augustin découvertes par Johannes Divjak, Paris 1983, 117-121. Eine Zusammenstellung aller Briefe mit kurzen Inhaltsangaben bietet F. Morgenstern (Die Briefpartner des Augustinus von Hippo, Bochum 1993), der allerdings Monceaux für die Datierung und inhaltliche Fragen unberücksichtigt lässt. Eine gute, vollständige Übersicht bei J. Divjak, AL 2, 893-1057, s. v. Epistulae.

3 Antidonatistische Traktate innerhalb der Briefsammlung sind ep. 76 und ep. 141; ein Brief außerhalb der Sammlung ist z. B. die Schrift cath. fr. Vgl. Monceaux VII, $142 \mathrm{f}$.

4 Vgl. Morgenstern, Briefpartner, 96-102. 
Während die Schreiben an die donatistischen Laien im Inhalt und Aufbau den antidonatistischen Traktaten und Abhandlungen sehr ähnlich sind, orientiert sich die Thematik der übrigen Briefe an konkreten Problemen, Anfragen oder Vorfällen. ${ }^{5}$ So war beispielsweise der Anlass für Augustins ersten Brief an einen Donatisten (ep. 23) der Bericht über die Wiedertaufe eines katholischen Diakons bei den Donatisten. Gegen die Wiedertaufe wendet er sich auch in den Briefen an Crispinus von Calama und Macrobius. ${ }^{6}$ In der Korrespondenz nach 405 finden sich vermehrt Berichte über donatistische Gewalttaten und Rechtfertigungen des kaiserlichen Eingreifens, so etwa in den Briefen an Ianuarianus (ep. 88) und Vincentius (ep. 93). ${ }^{7}$ Fast durchgängig - insbesondere in den Briefen vor 405 - äußert Augustinus gegenüber seinen donatistischen Briefpartnern den Wunsch, die Differenzen durch Gespräche oder Briefwechsel auf Grundlage der Heiligen Schrift auszuräumen oder auf einer allgemeinen Konferenz die Streitfragen zu schlichten. ${ }^{8}$ Nach der Konferenz von Karthago 411 sind nur noch zwei Briefe Augustins an Donatisten bekannt. In ihnen steht die Einladung zur Rückkehr in die Kircheneinheit im Vordergrund. ${ }^{9}$

In einigen Briefen an katholische Bischöfe und Laien findet das donatistische Schisma ebenfalls Erwähnung. ${ }^{10}$ Es ist auffällig, dass mit zwei Ausnahmen (epp. 53, 144) die Geschichte der Kirchenspaltung in diesen Schreiben kein Thema ist. Sowohl gegenüber Laien als auch Bischöfen und anderen Klerikern werden entweder theologische oder aktuelle kirchenpolitische Fragen abgehandelt. Oftmals ist der Donatismus nicht das Hauptthema, sondern die Bezüge sind eher beiläufig, wie etwa die Erwähnung von Gewalttaten der Circumcellionen (epp. 29, 35, 111). Häufig werden Fragen der Konversion angesprochen, seien es Probleme beim Übertritt von Klerikern oder aber positive Reaktionen

$5 \mathrm{Zu}$ Augustins Kontakten und Korrespondenzen mit donatistischen Bischöfen vgl. Poss. vita 9; ep. 43.1; dazu Crespin, Ministère, 144-155. - Die donatistischen Briefpartner reagierten häufig nicht auf Augustins Briefe (epp. 35.1; 87.6). In einigen Fällen bat Augustinus um Vermittlung durch Laien, so einen gewissen Naucellio (ep. 70.1), Eusebius (ep. 34, 35) oder Herotes (ep. 49.1); vgl. Crespin, aaO, 151. Bekannt ist indessen ein Brief des Bischofs Macrobius als Antwort auf Augustins ep. 106 (vgl. ep. 107).

6 Die umfangreiche ep. 108 an Macrobius enthält eine ausführliche theologische Erörterung des Schismas mit zahlreichen Verweisen auf das Maximianistische Schisma.

7 Vgl. die Ausführungen o. Kap. 2.2.

8 Epp. $23.6-7 ; 33.1-6 ; 34.5-6 ; 35.1 ; 44.6,14 ; 49.1,3 ; 51.1 ; 87.1,6,10 ; 88.10$.

9 Epp. 141, 173. Vgl. dazu u. Kap. 5.4.

10 Insgesamt 19 überlieferte epistulae: Epp. 29, 83 an Alypius; ep. 41 an Aurelius; ep. 53 an Generosus von Cirta; ep. 56, 57 an Celer; ep. 58 an den Senator Pammachius; ep. 61 an den Laien Theodorus; ep. 69 an Castorius; ep.78 an die Gemeinde von Hippo; ep. 85 an Bischof Paulus; ep. 111 an Victorianus; ep. 142 an zwei konvertierte Priester; ep. 144 an die konvertierten Donatisten von Cirta; ep. 208 an Felicia; ep. 209 an Papst Caelestius; ep. 245 an Possidius; ep. 28* an Bischof Novatus. Vgl. auch ep. 11* von Consentius an Augustinus über eine Anfrage hinsichtlich des Umgangs mit den Priscillianisten in Spanien. 
auf vollzogene Übertritte (epp. 58, 61, 69, 78, 245). Dagegen stehen politische Fragen, insbesondere die Umsetzung der antidonatistischen Gesetze nach 405 und 411 im Zentrum der Briefe zum Donatismus, die Augustinus an römische Beamte und Würdenträger schrieb. ${ }^{11}$ Meistens handelt es sich um eine Bestandsaufnahme der gegenwärtigen Situation, verbunden mit einer konkreten Bitte an die Adressaten. Nur in wenigen Schreiben weist Augustinus auch auf historische oder theologische Zusammenhänge hin, wie in ep. 89 an Festus oder in der Abhandlung über die correctio der Donatisten (ep. 185) an Bonifatius.

Im Folgenden werden jene Briefe betrachtet, die für die Darstellung der Geschichte des Schismas und die historische Argumentation Augustins von Bedeutung sind. ${ }^{12}$

\subsection{Im Gespräch mit Donatisten: Die Briefe 43 und 44}

Anfang des Jahres 397 schrieb Augustinus zwei Briefe ${ }^{13}$ an eine Gruppe von Donatisten aus der Umgebung der Stadt Thubursicum in Numidien. ${ }^{14}$ Augustinus befand sich auf einer Besuchsreise durch mehrere Städte, ${ }^{15}$ als er unter

11 Insgesamt 17 überlieferte Epistulae: Epp. 34, 35 an Eusebius, Beamter in Hippo; epp. 86, 151 an Caecilianus; ep. 89 an Festus; epp. 96, 97 an den MO Olympius; epp. 100, 112 an Donatus (Prokonsul 408/9); epp. 128, 129, 133, 139 an den Tribun Marcellinus; ep. 134 an Apringius (Prokonsul 411); ep. 155 an den vicarius Africae Macedonius; ep. 185 (= correct.) an den Tribun Bonifatius; ep. 204 an den Tribun Dulcitius; vgl. dazu Morgenstern, Briefpartner, 106-126.

12 Briefe, die für das Verhältnis Augustins zu den Donatisten und seinen Kampf gegen das Schisma relevant sind, wurden für die Entwicklung des Donatismus zur Zeit Augustins bereits ausgewertet. Vgl. o. Kap. 2.2. Diejenigen Briefe, die infolge der Konferenz von Karthago verfasst worden sind, werden ebenfalls an anderer Stelle betrachtet; s. u. Kap. 5.4.2.

13 Epp. 43, 44. Edition: Goldbacher, CSEL 34.2, 85-121. Zur Datierung vgl. Perler/Maier, $208 \mathrm{f}$.

14 Die colonia Thubursicum Numidarum lag etwa $87 \mathrm{~km}$ südlich von Hippo Regius und $40 \mathrm{~km}$ südöstlich von Thagaste auf einem Hochplateau; vgl. Perler/Maier, 210; Lepelley, Cités II, 210. - In ep. 43 wird kein Ortsname genannt, aber laut ep. 44.1 gehörten die Donatisten zur Diözese des Bischofs Fortunius von Thubursicum. - Die epp. 43 und 44 werden oftmals mit den Thiavensibus duas in Poss. Ind. VI 29 identifiziert. Demzufolge wären die Adressaten Bewohner der kleinen Ortsgemeinde Thiava. Für diese These spricht der inhaltliche Zusammenhang: Im Indiculus werden die Briefe unter der Überschrift Adversus Donatistas aufgeführt. Die geographische Nähe von Thubursicum und Thiava lässt ebenfalls auf eine Übereinstimmung schließen (vgl. Lepelley, Cités II, 210). Die Thiavensibus duas könnten auch verlorene Briefe aus einem anderen $\mathrm{Zu}-$ sammenhang sein (so Monceaux VII, 131), doch ist dies weniger wahrscheinlich. D. de Bruyne (Les anciennes collections et la chronologie des lettres de saint Augustin, RevBen 43, 1931, 284-295, hier: 295) hält die Identifizierung für sicher. Ihm folgen u.a. 
anderem auf einige donatistische Laien traf, die eine große Bereitschaft zur Diskussion zeigten (ep. 43.3). In ep. 43 berichtet Augustinus von zwei Gesprächen, in denen er mit diesen Donatisten Fragen zum Schisma erörterte und versuchte, sie zu einer Hinwendung zur katholischen Kirche zu bewegen. Einige Zeit später, während eines kurzen Aufenthalts in Thubursicum, kam es auf Wunsch Augustins zu einem Treffen mit dem dortigen donatistischen Bischof Fortunius, an dem von katholischer Seite unter anderem auch Alypius teilnahm, der sich unter Augustins Begleitern befand. ${ }^{16}$ Über den Verlauf dieses Gesprächs berichtet Augustinus in ep. 44. Beide Briefe geben somit ein eindrucksvolles Zeugnis über die Bemühungen Augustins zu Beginn seines Episkopats, mit Donatisten ins Gespräch zu kommen und die Gründe der Spaltung zu diskutieren. ${ }^{17}$ Zudem stellen die Briefe wertvolle Quellen sowohl für historische Einzelheiten als auch für Art und Weise der historischen Argumentation bei Augustinus dar.

Ep. 43 richtet Augustinus an die Donatisten Glorius, Eleusius, zwei mit Namen Felix und an Grammaticus, ${ }^{18}$ die sich an der Diskussion beteiligt hatten, darüber hinaus aber auch an alle anderen interessierten Leser. Seine Absicht ist es, die in der Diskussion vorgebrachten Argumente zusammenzufassen und den Gesprächspartnern schriftlich mitzuteilen, in der Hoffnung, diese würden sich endlich vom donatistischen Irrtum abwenden und zur katholischen Kirche zurückkehren. (43.1-3). Die allgemein gehaltene Adresse, die einleitenden Worte und die häufigen Appelle zur Umkehr zeigen den Pastoralcharakter des Briefes. Augustinus erwähnt, dass er früher bereits an führende Donatisten Briefe geschrieben habe, die allerdings nicht beantwortet worden seien. Er macht deut-

Mandouze, PAC, 336 f., s. v. Eleusis; Perler/Maier, 210 f. und Morgenstern, Briefpartner, 99, 244 Anm. 1394; vgl. Wilmart, Elenchus, $211 \mathrm{f}$.

15 Vgl. ep. 43.5 (Besuch der Kirche von Gelizitana). Die Reise fand wahrscheinlich im Jahr 396 statt.

16 Beide waren auf dem Weg nach Cirta (44.1), um dort einen neuen Bischof zu weihen (44.13). Perler/Maier (208 f.) setzen diese Reise vor die in ep. 43 beschriebene Fahrt. Monceaux (IV 276, 496; VII, 279) konstruiert aus der Aussage cum ei [Fortunius] renuntiaremus [Augustinus] uolentes eum uidere, non abnuit einen Brief Augustins an Fortunius mit der Bitte um eine Begegnung. Im Zusammenhang wird man jedoch eher an eine mündliche Übermittlung zur Vereinbarung eines Treffens denken.

17 Aufgrund dieser Beispielfunktion werden die Gespräche in der Literatur oft als positives Beispiel einer Annäherung beider Kirchen herangezogen. Vgl. Crespin, Ministère, 148-152; Lamirande, Studia canonica 32, 1998, 214-218; Lancel, Augustin, 267; van der Meer, Augustinus, 143 f. [mit stark antidonatistischer Färbung!]; Monceaux IV, 69, 275 279, VI; 297-303 [mit sehr großzügigen Interpretationen]; Grasmück, Coercitio, 180 183.

18 Keiner dieser Adressaten ist (abgesehen von ep. 44) anderweitig bekannt. Mandouze verzeichnet zwei der Adressaten namentlich: PAC, $336 \mathrm{f}$, s. v. Eleusis; $542 \mathrm{f}$., s. v. Grammaticus. 
lich, dass er die Sorge um die einzelnen Menschen als Ausgangspunkt seiner Tätigkeit ansieht (43.1).

Augustins Brief stellt zwar kein Protokoll der Diskussionen mit den Donatisten dar, aber sein Argumentationsaufbau und die Entgegnung auf einige Zwischenbemerkungen, die während des Gesprächs gefallen waren, geben den Inhalt des Treffens im Großen und Ganzen wieder. Durch die Sichtweise Augustins erfahren wir nur wenig über die Motivation der Donatisten und über ihre Urteile und Bemerkungen während des Gesprächs. Augustins Gesprächspartner waren aber offensichtlich dazu bereit, ohne dogmatische Vorbehalte die Gründe der Kirchenspaltung zu erörtern und eigene Positionen kritisieren zu lassen. Sie erwarteten vom Katholiken eine überzeugende Darstellung seiner Position, ${ }^{19}$ vielleicht teilten sie sogar sein Ansinnen, gemeinsame Lösungen für die Überwindung des Schismas zu finden.

Im Zentrum der Diskussion standen nicht die theologischen Fragen, sondern die Geschichte des Schismas. Nachdem die Donatisten auf die Absetzung Caecilians durch das karthagische Konzil hingewiesen hatten (43.3), referierte Augustinus seine Sicht der causa Caeciliani mit den bischöflichen und kaiserlichen Urteilen zu Gunsten der Katholiken. Da er jedoch keine schriftlichen Dokumente zum Beweis seiner Aussagen dabei hatte, ließ er sie beschaffen und in einem zweiten Treffen, zwei oder drei Tage später, den Donatisten vorlesen. Ausführlich wurden die Rolle des Secundus von Tigisi, das Konzil von Cirta, der Fall des Felix von Abthugni und die Urteile der Bischöfe in Übersee und des Kaisers abgehandelt (43.5). Inwieweit über die Dokumente kontrovers diskutiert wurde, lässt sich Augustins Darlegung nicht entnehmen. Wahrscheinlicher als eine lebhafte Auseinandersetzung scheint aber ein predigtähnlicher Vortrag Augustins zu sein, in dem er von einigen Nachfragen unterbrochen die Dokumente interpretierte. ${ }^{20}$

In jedem Fall hatte Augustinus den Eindruck gewonnen, dass seine Anstrengungen auf fruchtbaren Boden gefallen seien und sich eine Fortsetzung der Bemühungen lohnte. In Anknüpfung an die stattgefundenen Unterredungen räumt er der historischen Argumentation in ep. 43 den größten Platz ein. Er interpretiert ausführlich die seinen Adressaten nunmehr bekannten Dokumente, um ihr Verständnis von den Anfängen des Schismas zu widerlegen. ${ }^{21}$ Die Aussagen zur Geschichte münden schließlich in eine theologische Reflexion über das Unheil von Wiedertaufe und Schisma im Gegensatz zur christlichen

19 Vgl. ep. 43.5: Sed quia haec omnia dicebamus tantum, non etiam legebamus, minus profecto uobis agere uidebamur, quam de nostra expectabatis instantia.

20 Monceaux (VI, 299) übersieht den mit Sicherheit bestehenden Unterschied zwischen dem Gesprächsablauf und dem Predigtstil der ep. 43 (insbesondere am Schluss), wenn er folgert: „Le procès-verbal de la controverse se terminait par un sermon; et le sermon, par une mise en demeure de se convertir.“

21 Ep. 43.6-20. Vgl. u. Kap. 4.2.1. 
Einheit, in der gute und schlechte Menschen geduldet werden sollten (43.2124). Diese bekannten Formeln ergänzt Augustinus um Hinweise auf die Circumcellionen, Optatus von Thamugadi und andere Gewalttäter. Obwohl die Donatisten solche Menschen tolerierten, verharrten sie dennoch im Schisma (43.24). Nach einer Zusammenfassung (43.25), verweist Augustinus auf die Parallele des Maximianistischen Schismas (43.26) und ruft zur Einheit auf, in der Hoffnung auf Umkehr seiner Leser (43.27).

Im Gegensatz zu ep. 43 konzipierte Augustinus ep. 44 nicht als Hirtenbrief an Donatisten, sondern richtete ihn aus zwei Gründen direkt an vier seiner Gesprächspartner aus der Diözese Thubursicum. ${ }^{22}$ Zum einen wollte er seine ehemaligen Gesprächspartner über das abgehaltene Streitgespräch mit ihrem Bischof Fortunius ${ }^{23}$ informieren, an dessen Zustandekommen sie nicht unbeteiligt waren $(44.1,3)$. Zum anderen wollte Augustinus die begonnene Diskussion weiterführen, wie er es mit Fortunius vereinbart hatte, und wendet sich nun an die Adressaten mit der Bitte, Fortunius an sein Versprechen zu erinnern, den angefangenen Austausch zum Abschluss zu bringen (44. 2, 13). Offensichtlich hatte Augustinus seit seinem Besuch nichts mehr von dem Donatisten gehört, wünschte aber nach wie vor eine Fortsetzung des Disputs. ${ }^{24}$

Da während der Unterredungen nicht wie gewünscht ein vollständiges Protokoll angefertigt werden konnte, hatte Augustinus die entscheidenden Passagen im Nachhinein aufgezeichnet; und dieses Gedächtnisprotokoll übersandte er nun seinen Adressaten. Durch diesen Protokollcharakter der ep. 44 erhalten wir einen fast vollständigen Überblick über die einzelnen Diskussionspunkte und damit auch Einblick in einige Positionen der Donatisten.

Das Treffen zwischen Fortunius und Augustinus und seinen Begleitern fand im Haus des Donatisten statt. Offensichtlich sprach sich dieses Ereignis schnell herum, denn Augustinus berichtet von einer großen Menge Zuhörer, die herbeiströmten, um dem Disput beizuwohnen. Dabei ärgerte er sich über diejenigen, die nicht aus aufrichtigem Interesse, sondern aus Schaulust gekommen waren und durch Zwischenrufe und Lärmen die Unterredung störten. Nachdem die Katholiken die Anfertigung eines Protokolls verlangt hatten, wehrte sich Fortunius zunächst dagegen, stimmte dann aber doch zu. Die Schreiber gaben

22 Die Adresse von ep. 44 nennt Glorius, Eleusis und die beiden Felix, die aus ep. 43 bekannt sind. Es fehlt hier jedoch ein Zusatz für einen größeren Leserkreis.

23 Mandouze, PAC, 500-502, s. v. Fortunius 2.

24 Ep. 44.13: unde uos hortor et obtestor per domini sanguinem, ut eum [Fortunium] promissi sui commoneatis et gnauiter instetis, ut res coepta peragatur, quam prope ad finem peruenisse iam cernitis. - In ähnlicher Weise bat Augustinus den Laien Eusebius um Vermittlung eines Gespräches mit Proculeianus, dem donatistischen Bischof von Hippo (epp. 34, 35). - Lamirande (Studia canonica 32, 1998, 216) meint, Augustinus habe Fortunius selbst eine Kopie des Protokolls zukommen lassen. Es heißt aber eindeutig in ep. 44.2: potestis [die Adressaten] enim ei [Fortunius] litteras meas legere. 
jedoch aufgrund der immer größeren Unruhe und heftigeren Auseinandersetzung nach einiger Zeit auf (44.1-2). ${ }^{25}$ Diesen Mangel gedachte Augustinus mit der späteren Abfassung von ep. 44 auszugleichen.

Während in der Diskussion mit den Laien von Thubursicum die Geschichte des Schismas im Vordergrund stand, wurde dies im Gespräch mit Fortunius nur am Rande angeschnitten (vgl. 44.8). Im Zentrum standen Fragen zum Kirchenverständnis, zur Verfolgung und zum Taufsakrament. Fortunius, der bereits ein alter Mann war, hatte von Augustins Gesprächspartnern aus seiner Diözese lobende Worte über den Bischof von Hippo gehört und drückte zu Beginn des Gesprächs seinen Respekt vor Augustinus aus. Er akzeptierte ihn als Gesprächspartner (44.3), im Gegensatz zu den häufigen Verweigerungen oder polemischen Angriffen gegen Augustinus durch andere Donatisten.

Als erstes erörterten die beiden Bischöfe die Frage nach der wahren Kirche. Augustinus stellte die weltweite Verbundenheit der katholischen Kirche heraus, die auf der anderen Seite auch Fortunius für die Donatisten behauptete. Fortunius begründete die Rechtmäßigkeit der Donatisten durch ihre Rolle als verfolgte Kirche unter Heranziehung der biblischen Verheißung für diejenigen, die um der Gerechtigkeit willen verfolgt werden. ${ }^{26}$ Augustinus hielt dagegen, dass die Donatisten nur eine gerechte Verfolgung hätten erleiden können, wenn sie sich nicht zuvor von der Kirche des Erdkreises getrennt hätten, und forderte nunmehr, Fortunius solle klären, ob die Donatisten noch in der Kircheneinheit gelebt hätten, als die Verfolgung durch Macarius stattfand. Fortunius aber lenkte das Gespräch auf die Traditorenfrage und die Schuld der Katholiken durch die traditio (44.4). Augustinus lehnte diese Vorwürfe mit Hinweis auf die Gegensätzlichkeit der katholischen und donatistischen Dokumente ab und fragte, wie die Donatisten ihre Trennung von den schuldlosen Kirchen in anderen Provinzen rechtfertigten.

„[Fortunius antwortete], dass die Kirchen in den überseeischen Provinzen so lange unschuldig geblieben seien, bis sie zu jenen Bluttaten ihre Zustimmung gegeben hätten, die, wie er sagte, sich während der macarianischen Verfolgung zugetragen hätten. ${ }^{\text {‘27 }}$

Aus Augustins Sicht war diese Antwort eine Bestätigung für die Trennung der Donatisten von den Kirchen in Übersee. Interessant ist allerdings das Argument

25 Grasmück (Coercitio, 183) verallgemeinert in unzulässiger Weise, wenn er behauptet, aufgrund von „lärmenden Volksscharen“ hätten Gespräche „nie“ zu Ende geführt werden können, es sei denn, man habe sich „in aller Stille“ treffen können. - Zu den notarii vgl. Teitler, Notarii et exceptores, $191 \mathrm{f}$.

26 Ep. 44.3. Vgl. die Argumentation bei Cresconius (Kap. 3.3.4).

27 Ep.44.5: [Fortunius] respondit tam diu transmarinarum partium ecclesias mansisse innocentes, donec consensissent in eorum sanguinem, quos Macarianam persecutionem pertulisse dicebat. 
des Fortunius: Nicht die Schuldfrage der traditio sei für den Bruch mit den anderen Kirchenprovinzen entscheidend gewesen, sondern die offenkundige Parteinahme der dortigen Christen für die Verfolgung der Donatisten in Afrika. Damit argumentierte Fortunius nicht wie Cresconius mit einem Hinweis auf eine falsche, nichtcyprianische Taufpraxis der überseeischen Kirchen, durch die eine communio ausgeschlossen sei ${ }^{28}$ sondern mit einem anderen donatistischen Grundsatz: die alleinige Rechtmäßigkeit der verfolgten Kirche. Eine Kirche, die sich auf die Seite der Verfolger stellt, konnte für Fortunius nicht mehr die wahre Kirche sein. ${ }^{29}$

Als Augustinus einen weiteren Nachweis über die Verbindung der Donatisten mit anderen Kirchen vor der Verfolgung des Macarius forderte (44.5), ließ Fortunius eine Schrift heranbringen und daraus das Synodalschreiben der Bischöfe von Serdica verlesen, in dessen Adresse auch der Name Donatus als Bischof Karthagos auftauchte. Augustinus kannte diesen Brief noch nicht, äuBerte sich kritisch über die fehlende Datierung und zweifelte an der Identifizierung des Donatus mit dem gleichnamigen Begründer der Donatisten. Dann stellte er aber mit Hilfe des Alypius fest, dass es sich wohl um einen Brief des arianischen Teils der Synode von Serdica handelte. Zu Prüfungszwecken wollte Augustinus das Buch ausleihen, was ihm jedoch nicht gestattet wurde (44.6). ${ }^{30}$

Im weiteren Gesprächsverlauf wurde über gerechte und ungerechte Verfolgung diskutiert. Fortunius hielt dem donatistischen Verständnis gemäß jede Art von Verfolgung für ungerecht, während Augustinus anhand einiger Beispiele das Vorkommen gerechter Verfolgung nachweisen wollte. Er verwies auf biblische Exempel und auf das Vorgehen der Donatisten gegen die Maximianisten sowie auf die Gewalttaten, die von Donatisten an Katholiken wie auch an eigenen Leuten verübt worden seien. Fortunius leugnete derartige Gewalttaten und konfrontierte Augustinus umgekehrt mit einem Beispiel aus der Anfangszeit des Schismas, als Anhänger Caecilians angeblich einen Interimsbischof (interventor) der Donatisten ermordet hätten (44.7-9). ${ }^{31}$ Schließlich wurden noch einige Fragen gegenwärtiger Auseinandersetzungen besprochen. Augustinus betonte seinen Willen zum Dialog und lud auch Fortunius zu einer Fort-

28 Vgl. o. Kap. 3.3.3.

29 Crespin, Ministère, 162: „Pour certains, comme Fortunius de Thubursicu, ce grief est le plus grave: ce qui condamne l'Église catholique tout entière, ce n'est pas la communion avec Caecilianus, mais le consentement aux lois et aux poursuites du temps de Macarius.“ Für Fortunius jedoch scheint der Vorwurf der Verfolgung nicht per se der „schwerste“ gewesen zu sein. Der Diskussionszusammenhang (in ep. 44.4-5) zeigt, dass Fortunius, von Augustinus herausgefordert, eine weitere Begründung für die donatistische Abspaltung suchte, nachdem er mit der traditio-Beschuldigung nicht weitergekommen war.

30 Zum Synodalbrief aus Serdica vgl. o. Kap. 3.3.3.

31 Dazu ausführlich u. Kap. 7.1.2. 
setzung des fruchtbaren Gesprächs ein (44.11-14). Er zerstreute die Befürchtungen weiterer Verfolgungen der Donatisten ohne Einschränkung und betonte die Notwendigkeit von Liebe und Geduld zum Erlangen der Kircheneinheit.

Augustinus scheint einen positiven Eindruck von seinem Gesprächspartner mitgenommen zu haben, wohl auch, weil Fortunius am Ende des Gesprächs andeutete, dass er mit der inzwischen stets vollzogenen Wiedertaufe an Katholiken nicht einverstanden sei und letztlich doch zugab, dass von einzelnen Donatisten Gewalt verübt werde, der er ablehnend gegenüberstehe. Augustinus freute sich auch über das gemeinsame Ergebnis, sich die Gewalt anderer nicht gegenseitig zum Vorwurf zu machen (44.12). Am Ende seines Briefes stellt Augustinus nochmals deutlich den Wunsch heraus, durch eine Konferenz von Vertretern beider Parteien ungestört alle Fragen des Schismas zu erörtern (44.14). Der begonnene Dialog solle weitergeführt werden, denn er sei fast schon zum Abschluss gelangt (44.13).

Das Gespräch zwischen Fortunius und Augustinus scheint offenbar in einer guten Atmosphäre verlaufen zu sein, nicht zuletzt aufgrund Augustins moderaten Tonfalls. Dennoch entsprach der von Augustinus verbreitete Optimismus nicht den realen Voraussetzungen für zukünftige Gespräche. Auch wenn es am Ende zu Annäherungen gekommen war, wie zum Beispiel in der gemeinsamen Ablehnung von Gewalt, so wurden die grundsätzlichen Differenzen in keiner Weise überbrückt. Die unterschiedliche Beurteilung von Katholizität oder gerechter Verfolgung treten in dem Protokoll deutlich hervor und stehen genauso unversöhnlich gegenüber wie Augustins Positionen gegenüber denen eines Petilianus oder Cresconius. Nicht zu vergessen bleibt, dass die Fragen der traditio und der Entstehung des Schismas ausgeklammert wurden. ${ }^{32}$

\subsection{Auseinandersetzung mit donatistischen Bischöfen: Die Briefe 87 und 88}

Um das Jahr 403 versuchte Augustinus, einen Kontakt zu Emeritus, dem Bischof von Caesarea in Mauretanien und einem der führenden Donatisten, herzustellen. ${ }^{33}$ Auf einen ersten Brief, der nicht erhalten ist, hatte Augustinus keine

32 Monceaux (VI, 299f.) und ihm folgend van der Meer (Augustinus, $143 \mathrm{ff}$.) beurteilen Fortunius als naiven, ungelehrten, alten Mann, der gar nicht begriffen habe, worum es ging, und Augustinus nichts entgegenzusetzen hatte. Mag Fortunius auch nicht die Eloquenz eines Petilianus besessen haben, diese Deutung ist dennoch überzogen. Monceaux und van der Meer übersehen die einseitige Herausstellung der eigenen Positionen durch Augustinus und missverstehen die ekklesiologischen Grundlagen der donatistischen Argumente.

33 Emeritus war ein Wortführer des Konzils von Bagaï und 411 einer der offiziellen Vertreter der Donatisten in Karthago. Nach der Konferenz verfasste Augustinus eine Schrift gegen Emeritus, die nicht erhalten ist (retr. II 46; Poss. indic. VI 18). Am 20.09. 
Antwort erhalten (87.6). Nun unternahm er mit ep. 87 an den „geehrten und geliebten Bruder" einen weiteren Versuch, mit dem Donatisten ins Gespräch zu kommen. ${ }^{34}$ Augustinus schätzt Emeritus als einen sehr gebildeten Mann und macht aus seiner Hochachtung keinen Hehl. Geradezu begierig hofft er darauf, ihn kennenzulernen und mit ihm einen sachlichen Dialog führen zu können. ${ }^{35}$

Das Thema des Briefes ist die Frage, wie mit Sündern in der christlichen Kirche umgegangen werden soll. Augustinus setzt zwei bekannte Streitfragen in den Mittelpunkt seiner Ausführungen: zum einen das Verhältnis der donatistischen Partei zur weltweiten Kirche, zum anderen das Verständnis von Verfolgung. Bezüglich der ersten Frage erörtert Augustinus das Paradox, dass die Donatisten die gesamte Christenheit verurteilten, ohne ihre Anklagen zu beweisen, und umgekehrt nachweisliche Sünder in ihren eigenen Reihen duldeten. Er unterstreicht seine Position, dass kein Sünder die ganze Gemeinschaft der Christen verunreinigen könne und appelliert an Emeritus' Gelehrsamkeit, die Aussagen der Heiligen Schrift dahingehend zu überprüfen. Emeritus werde dadurch die Grundlosigkeit des Schismas erkennen (87.1-3). Im Anschluss

418 traf Augustinus mit Emeritus in Caesarea für einen Disput zusammen (vgl. Emer.; s. Caes. eccl. und retr. II 51; s. u. Kap. 5.4.4). Zur Person: Mandouze, PAC, 340-349, s. v. Emeritus 2; Monceaux VI, 145-189; Lancel, AL 2, 802-804, s. v. Emeritus.

34 Edition: Goldbacher, CSEL 34.2, 397-406. Beide Briefe verzeichnet Possidius (indic. VI 26). Zu ep. 87 vgl. Monceaux VI, 148-152; Mandouze, PAC, 340 f.; Grasmück, Coercitio, $205 \mathrm{f}$; Willis, Augustine, $64 \mathrm{f}$.

Die Datierung des Briefes ist schwierig. Goldbacher (CSEL 58, 26) und Monceaux (VII, 282) geben zu Recht das Jahr 411 als terminus ante quem an, da Augustinus Emeritus noch nicht persönlich kannte, als er den Brief schrieb (vgl. 87.10), ihm aber 411 in Karthago begegnete. Nicht stichhaltig sind Goldbachers und Monceaux' Datierungen nach 405 aufgrund der Anspielung auf kaiserliche Maßnahmen gegen Donatisten in ep. 87.8 (vgl. Monceaux VI, 148: „,vers 405“, dagegen VII, 282: „entre 405 et 411“!). Augustinus spricht an dieser Stelle nicht von dem Unionsgesetz, sondern sehr allgemein von den Maßnahmen der christlichen Kaiser. Außerdem verweist er auf den vicarius des Jahres 377 Flavianus und spricht von der Ablehnung unangemessener Gewalt. Diese Zusammenhänge entsprechen sehr stark der Argumentation zur Verfolgung in c. litt. Pet. Die Formulierung von 87.8 weist keinesfalls auf die Zeit der epp. 88, 93 oder 105, da ansonsten der Hinweis auf kaiserliche Legitimation deutlicher ausgefallen wäre. Allerdings wird dadurch eine Zeit bis etwa 406/7 nicht ausgeschlossen. Zudem deuten der sehr moderate Tonfall und Augustins Dialogwunsch auf eine frühere Abfassung, ebenso die Verwendung des Beispiels Optatus und die Argumentation zu den Maximianisten, da die Zuspitzungen der späteren Schriften (nach Cresc.) fehlen, in der vorliegenden Weise aber in ep. 51 an Crispinus (datiert zwischen 400 und 404) oder ep. 53 (datiert um 400, vgl. u. Kap. 4.1.5) vorkommen. Schließlich stellt Augustinus die Frage nach der Apostolizität der Kirche in den Mittelpunkt seiner Anfragen an Emeritus. Dies findet sich in dieser Form in ep. 49 an den Bischof Honoratus und in ep. 52 an Severinus, die beide sicherlich vor 405 datiert werden müssen. M. E. ist daher für ep. 87 eine Datierung um 403/4 am wahrscheinlichsten. 
verdeutlicht Augustinus seine Haltung anhand der Beispiele Optatus' von Thamugadi (87.4-5) und der Maximianisten (87.6).

Bezüglich der persecutio weist Augustinus auf die Unterscheidung von gerechter und ungerechter Verfolgung hin. Die entscheidende Frage sei, ob die Donatisten Schuld am Schisma trügen oder nicht, und ob sie um der Gerechtigkeit willen verfolgt würden oder nicht (87.7). Die Maßnahmen gegen die Donatisten seien demnach keine Verfolgung, sondern ein Schutz vor den Gewalttaten seitens der Donatisten. ${ }^{36}$ Unangemessene Härte und fehlende christliche Mäßigung, so Augustinus, missfielen ihm auch, seien aber kein Grund für eine Trennung von der katholischen Kirche (87.8). Die Katholiken akzeptierten trotz der Verurteilung des donatistischen Schismas deren Sakramente, weil diese von Gott gegeben und daher unveränderlich gültig seien (87.9). Schließlich äußert er seine Hoffnung auf eine Antwort und damit auf das Zustandekommen eines Dialogs (87.10).

Die Argumentation im Brief an Emeritus schließt inhaltlich an die Schriften gegen Petilianus an. Die donatistische These der Reinheit der Kirche nimmt Augustinus zum Ausgangspunkt und versucht ihr zunächst mit theologischen Argumenten entgegenzutreten. In einem verhältnismäßig nüchternen, teilweise sogar freundlichen Tonfall erläutert er das katholische Verständnis von Kirche, Taufe und Verfolgung und setzt die donatistischen Aussagen in Gegensatz zu Beispielen aus Bibel und Gegenwart. Man erkennt Augustins Taktik in Bezug auf den direkten Dialog mit Emeritus: Er beginnt mit einer Aufarbeitung der donatistischen Einwände und Vorbehalte gegen die Katholiken. Sein erstes Ziel ist es also, eine gemeinsame Grundlage zu schaffen, anhand derer dann - in einem zweiten Schritt - Ursprung und Anlass des Schismas überprüft werden können, um schließlich in Erkenntnis der wahren Begebenheiten zur Einheit zurückzufinden. Aus diesem Grund übergeht Augustinus in dieser ersten Kontaktaufnahme mit Emeritus die historischen Fragen und sucht Ansätze für eine gemeinsame Basis. Er hofft auf die gemeinsamen Feststellungen: Es gibt in beiden Kirchen Sündlose und Sünder, Verfolger und Verfolgte und die gleichen Sakramente Christi.

36 Ep. 87.8: „Da aber jene Kaiser bei jeder Gelegenheit die Ruchlosigkeit eures Schismas kennen lernen, so verfügen sie gegen euch gemäß ihrer Sorgfalt und Macht, was sie wollen. Denn sie tragen das Schwert nicht umsonst; sie sind Gottes Diener, Beschützer im Zorn gegen jene, die Böses tun." (sed illi principes qualibet occasione cognoscentes uestri schismatis nefas constituunt aduersus uos pro sua sollicitudine ac potestate, quod uolunt. non enim frustra gladium portant; dei enim ministri sunt. uindices in iram in eos, qui male agunt). 
Einen ganz anderen Charakter als der Brief an Emeritus trägt ep. 88 an den donatistischen Primas Numidiens, Ianuarianus von Casae Nigrae, ${ }^{37}$ der offenbar aufgrund der anhaltenden donatistischen Gewalttaten einige Zeit nach dem Unionsgesetz von 405 verfasst wurde. ${ }^{38}$ Absender des Briefes ist der Klerus von Hippo Regius, doch entsprechen die Gedanken und Argumente den Vorstellungen Augustins, der mit Sicherheit an der Abfassung maßgeblich beteiligt war. ${ }^{39}$

Die Verfasser des Briefes beklagen durchgängig, dass die Donatisten und Circumcellionen in bisher nicht bekannter Weise und mit unerhörter Grausamkeit gegen die Katholiken agitierten. Die emotionale Sprache lässt auf eine sehr aufgeheizte Atmosphäre zwischen den Donatisten und Katholiken in Hippo zu diesem Zeitpunkt schließen. Die Absender wollen eine Änderung der Situation und fordern Ianuarianus in seiner Funktion als donatistischer Primas auf, der Gewalt in der Diözese Hippo ein Ende zu setzen. Er solle Antwort geben und seine Position erklären, indem er den Boten dieses Briefes ein Rückschreiben mitgebe (88.11). Wenn er aber dies verweigere, solle entweder er selbst oder ein Beauftragter nach Hippo kommen oder sich zumindest schriftlich an die verantwortlichen Donatisten wenden, um ihnen in ihrer Gewalt Einhalt zu gebieten (88.12). ${ }^{40}$

Der Argumentationsaufbau ist dreigeteilt. An erster Stelle steht die historische Argumentation (88.1-5). Dem Adressaten werden Umstände der Entstehung des Schismas geschildert. Dabei wird besonders herausgestellt, dass die gegenwärtige antidonatistische Gesetzgebung lediglich die Konsequenz aus früheren Urteilen gegen die Donatisten sei ${ }^{41}$ Anschließend folgt eine Erläute-

37 Ianuarianus war wie Emeritus Teilnehmer des Konzils von Bagaï und der Konferenz von Karthago 411. Zur Zeit der Abfassung von ep. 88 war er bereits ein älterer Mann (ep. 88. 1). Zur Person: Mandouze, PAC, 579, s. v. Ianuarianus 1.

38 Edition: Goldbacher, CSEL 34.2, 407-419. Die Identifizierung des Briefes mit Poss. indic. VI 21 (Ianuariano primatui partis Donati) ist sehr wahrscheinlich. Ep. 88 gehört aufgrund seiner historischen Aussagen zu den meistbeachteten Briefen Augustins. Zum Inhalt vgl. Monceaux VI, 294-296; Grasmück, Coercitio, 205 f. - Datierung: Goldbacher (CSEL 58, 26 f.) datiert zu Recht zwischen 406-411, da der Brief nach dem Unionsedikt 405 und vor der Konferenz von Karthago 411 geschrieben wurde. Monceaux (VII, 282) datiert auf 406, da die antidonatistischen Gesetze als recens (88.6) bezeichnet und die donatistische Delegation nach Ravenna von Januar 406 erwähnt werden (88.10; vgl. o. Kap. 2.2). Die Formulierungen über die Gesetze und diese Reise deuten in der Tat auf verhältnismäßig junge Ereignisse, so dass ep. 88 wohl 406/07 geschrieben wurde.

39 Die Kleriker sprechen von Augustinus als „unserem Bischof“ in ep. 88.6-7. Ihre Verfasserschaft ist also nicht nur pro forma. Morgenstern (Briefpartner, 96) übergeht diese Frage und nennt Augustinus als Absender.

40 Im Gegensatz zu Monceaux (VI, 296) verstehe ich diese Vorschläge zur Beendigung der Gewalt in Hippo (88.11-12) nicht als Alternative zu dem grundsätzlichen Vorschlag einer allgemeinen Konferenz in 88.10.

41 Dazu ausführlich unten Kap. 4.2.2. 
rung zu der Gesetzgebung des Jahres 405 (88.6-7). Die Absender beschreiben anhand von Beispielen, wie Terror und Gewalt der Donatisten die ,Wiederbelebung" der Gesetze durch den Kaiser erzwungen hätten (in uos recoli et moueri $).{ }^{42}$ Im dritten Teil der Argumentation wird von der gegenwärtigen Gewalt berichtet, der es zu begegnen gelte (88.8-10). Während die Donatisten die Katholiken gewalttätig bekämpften, täten diese alles, um friedlich zur Einheit aufzurufen. Dennoch fühlten sich die Donatisten als Opfer einer Verfolgung, obwohl sie selbst verfolgten. Ein Ausweg aus dem derzeitigen Dilemma sei ein Zusammenkommen beider Seiten zu einer Konferenz. Die Absender appellieren eindringlich an Ianuarianus, einer solchen Konferenz zuzustimmen (88.10).

Wenn man sich die moderaten Töne Augustins im Gespräch mit Fortunius oder im Brief an Emeritus in Erinnerung ruft, wirken die Sätze in diesem Brief umso schärfer. Die Rechtfertigung der Katholiken für die antidonatistischen Gesetze und die Zwangsmaßnahmen sind nichts anderes als eine Schuldzuweisung auf die Donatisten: diese tragen die Schuld am Schisma, an der fortbestehenden Gewalt und an den Gesetzen. Die Gewalt und die neuen Gesetze dies macht das Schreiben deutlich - haben die Akzente der Argumentation maßgeblich verändert: Die historische Rechtfertigung überlagert hier die einzelnen theologischen Differenzen, die Augustinus in seinen Gesprächen und Korrespondenzen ursprünglich zu lösen gedachte. Gleichwohl bleibt ein Angebot zum Dialog bestehen. Die Idee einer allgemeinen Konferenz wird auch Ianuarianus unterbreitet, genauso wie die Möglichkeit einer schriftlichen Kontroverse. Man darf aber daran zweifeln, dass Ianuarianus in irgendeiner Form auf diesen Brief reagierte.

\subsection{Aufruf zur Umkehr: Die Briefe 76 und 105 an die Donatisten}

Die drei überlieferten Briefe, mit denen sich Augustinus an die donatistischen Laien richtete, geben einen sehr guten Einblick in Veränderungen von Augustins Argumentationsansätzen, da sie zu unterschiedlichen Phasen seines antidonatistischen Kampfes verfasst wurden, der erste Brief in der Zeit vor dem Unionsgesetz (ep. 76), der zweite einige Zeit danach (ep. 105) und schließlich der dritte nach der Konferenz von 411 (ep. 141). Formal handelt es sich um Traktate, knapp und übersichtlich, in einfacher Sprache und mit erläuternden Beispielen verfasst, die in möglichst vielen Exemplaren unter das Volk gebracht werden sollten. Es gab keine konkreten Empfänger, aber dort, wo es Augustinus und seinen katholischen Kollegen möglich war, sollten die Traktate abge-

42 Zur historischen Auswertung dieses Teils s. o. Kap. 2.2.1. 
schrieben und in Umlauf gebracht werden, sei es durch öffentliche Anschläge oder durch Weitergabe an lesekundige Laien in der Gemeinde. ${ }^{43}$

Ende des Jahres 403 wandte sich Augustinus mit der kurzen ep. 76 an die donatistischen Gläubigen. ${ }^{44}$ Das Schreiben trägt weder Adressat noch Absender, jedoch werden gleich im ersten Satz die Donatisten angesprochen (76.1), am Schluss konkret die Laien (76.4). Außerdem weisen Stil und Inhalt eindeutig auf ein weniger gebildetes Publikum aus theologischen Laien hin. Augustinus kleidet den gesamten Text in die rhetorische Figur einer Prosopopöie der katholischen Kirche an die Donatisten und trägt in einfachen, bildhaften Worten und fast lakonischer Kürze seine Thesen und Argumente gegen das Schisma vor: Die katholische Kirche sei nicht auf Afrika beschränkt, sondern umfasse den gesamten Erdkreis, und in dieser Kirche lebten „Weizen und Unkraut“ nebeneinander, bis Christus die Trennung vornehme. Die Donatisten aber hätten sich gegen die Einheit der Kirche gewandt und dieser Trennung vorgegriffen; als Unkraut klagten sie nun den Weizen an (76.1-2). Die Schuld zeige sich bei den Vorfahren der Donatisten. Sie hätten, obwohl selbst Traditoren, Caecilianus verurteilt und so Bischof gegen Bischof gestellt und Altar gegen Altar errichtet. Trotz der Urteile europäischer Bischöfe und des Kaisers gegen sie, seien diese Verleumder nicht von ihrem Frevel abgerückt (76.2). Schließlich sei die Furcht vor einer Vermischung von Guten und Bösen unbegründet, denn auch bei den Donatisten seien die Maximianisten nach ihrer Verurteilung wieder aufgenommen und ein Verbrecher wie Optatus von Thamugadi sei toleriert worden. Wie könnten also die Donatisten den Katholiken bis heute die traditio vorwerfen, aber die Maximianisten wieder aufnehmen, die Verfolgung anprangern, aber selber mit Hilfe des Kaisers die Maximianisten verfolgen, die Taufe ablehnen, aber die Taufe verurteilter und zurückgekehrter Maximianisten

43 Damit stehen diese Briefe in einer Reihe mit den verlorenen Traktaten zum Maximianistischen Schisma (retr. II 27-29). Insbesondere ep. 76 mit einem Umfang von nur vier Paragraphen war mit Sicherheit für eine große Vervielfältigung gedacht. - Monceaux (IV, 271; VII, 142, 145) bezeichnet die drei Briefe nicht zu Unrecht als „Manifeste“ und „Proklamationen“, weniger zutreffend dagegen ist m.E. die Bezeichnung „Avertissement“ (IV, 272; VI, 276). - Morgenstern (Briefpartner, 101 f., 246 Anm. 1418) geht mit keinem Wort darauf ein, wie die „Donatistae“ als „Briefpartner“ Augustins zu verstehen sind und in welcher Art die Verbreitung stattfand. - Zu ep. 141 vgl. u. Kap. 5.4.2.

44 Edition: Goldbacher, CSEL 34.2, 324-328; vgl. Monceaux IV, 271.

Datierung: Als terminus ante quem dürfte 405 sicher sein, da Augustinus ansonsten auf die kaiserlichen Maßnahmen nach dieser Zäsur eingegangen wäre und seine Argumente eine andere Zielrichtung eingenommen hätten. In 76.4 erwähnt Augustinus, dass die donatistischen Bischöfe nicht mit den Katholiken sprechen wollten. Monceaux (VII, 281) stellt diese Aussage zu Recht in Zusammenhang mit der Ablehnung des katholischen Gesprächsangebots vom August 403 und datiert ep. 76 auf Ende 403. So auch Goldbacher (CSEL 58, 23); Perler/Maier, 249. 
anerkennen (76.3-4)? Augustinus appelliert eindringlich an die Leser, sich vom gottlosen Schisma ${ }^{45}$ abzuwenden und zur Einheit zurückzukehren. Die Prosopopöie verstärkt den ermahnenden Charakter zusätzlich: Die Kirche selbst klagt über das verdammungswürdige Schisma und lobt im Gegensatz dazu den Frieden der Einheit. Das Schisma gehe auf menschliche Verleumdungen zurück, der Friede auf das Wort Gottes: Die Gläubigen sollen dem sermo dei vertrauen, nicht dem sermo hominum (76.1).

Alle entscheidenden Argumente Augustins gegen die Donatisten finden sich hier auf engem Raum versammelt: Dieser Traktat ist gleichsam eine Kurzlektion antidonatistischer Argumentation für den einfachen Gläubigen. Mit fünf Thesen sollten die donatistischen Laien überzeugt werden: 1. Die Kirche umfasst den gesamten Erdkreis und nicht nur Afrika, 2. Die Kirche umfasst Sünder und Gerechte, 3. Auch bei den Donatisten mischen sich Sünder und Gerechte, 4. Anders lautende Aussagen der Donatisten lassen sich leicht widerlegen, 5. Folglich ist das Schisma grundlos.

In Intention und Argumentation ähnelt ep. 76 stark dem Psalmus contra Partem Donati: Der Ruf zur Einheit und das Leitbild von Spreu und Weizen setzen auch hier den Hauptakzent, und auch im Psalmus spricht die Mutter Kirche den Schlussappell an die verlorenen Kinder. ${ }^{46}$ Der pastorale, ermahnende und ermutigende Charakter des Traktats hebt den versöhnenden Gestus hervor, mit dem Augustinus den Laien gegenübertritt. Die direkte Kritik gilt nicht den Gläubigen, sondern allein dem Zustand der Spaltung und den dafür Verantwortlichen, namentlich den donatistischen Bischöfen, die sich dem Gespräch verweigert hatten. Wenn die donatistischen Wortführer ihren Irrtum nicht einsehen wollten, so könne vielleicht der einfache Gläubige überzeugt werden.

Die Voraussetzungen hatten sich geändert, als Augustinus wohl um das Jahr 408 mit ep. 105 einen weiteren Brief an die donatistischen Laien richtete. ${ }^{47}$ Die

45 Es finden sich hier zahlreiche Wendungen: ep. 76.1: nefarium sacrilegium schismatis; 76.2: praecisio sacrilega; scelus; 76.3: scelus schismatis; nefarius furor; 76.4: sacrilegium schismatis.

46 Vgl. o. Kap. 1.1.

47 Edition: Goldbacher, CSEL 34.2, 595-610. Die Formulierungen presbyteri partis uestrae (105.1) und clerici uestri (105.3) bestätigen die donatistischen Laien als Adressaten. Zudem sprechen wiederum Inhalt und Argumentationsaufbau für diese Zielgruppe. Die Beispiele für donatistische Gewalt in ep. 105 deuten möglicherweise darauf, dass die Laien der Diözese Hippo besonders im Blickfeld Augustins standen. - Zu ep. 105 vgl. Monceaux IV, 272; VI 276; Grasmück, Coercitio, 212-214. - Datierung: Nach ep. 105. 3, 7, 10 dürfte der Brief nach dem Unionsgesetz von 405 (vgl. dazu o. Kap. 2.2.2) geschrieben worden sein. Monceaux (VII, 283) datiert auf Anfang 409 nach den verschärften Gesetzen von 408, Grasmück (Coercitio, 212 Anm. 257) auf Anfang 409. Es gibt allerdings keine sicheren Indizien für diese Spätdatierung. 
angespannte Situation in den donatistischen Gemeinden nach der Verkündigung der antidonatistischen Gesetze von 405 steigerte auch die Konfrontationshaltung gegenüber den Katholiken. Donatistische Priester hatten Augustinus unter Mordandrohung davor gewarnt, weiterhin mit donatistischen Gläubigen in Kontakt zu treten $(105.1-2,17)$. Augustinus antwortete auf diese Warnung mit dem Traktat an die Laien: „Die Liebe Christi erlaubt uns nicht zu schweigen“, beginnt er das Schreiben, auch gegen den Hass müsse der Frieden gepredigt werden. $^{48}$

Augustinus verfolgte nach wie vor das Ziel, Donatisten durch Überzeugungsarbeit zur Rückkehr in die katholische Kirche zu bewegen. Jedoch waren die Hürden für ihn höher geworden. Die Gesetze gegen die Donatisten bestärkten die Donatisten in ihrer Opferrolle und Märtyrermystik, und die Vorbehalte gegen die Katholiken und ihre Friedensappelle wuchsen. Ep. 105 zeigt deutlich das Bemühen Augustins, diese Vorbehalte auszuräumen und sich trotz dieser Situation bei den donatistischen Laien Gehör zu verschaffen.

Augustinus klärt mithilfe eines Bildes zwei Voraussetzungen für die donatistischen Laien: Zum einen beruft er sich auf das gemeinsame Taufsakrament, mit dem die Gläubigen stets mit der (katholischen) Kirche Christi verbunden seien. Zum anderen setzt er, wie bereits in ep. 76, die donatistischen Gläubigen deutlich von ihren Bischöfen und Priestern ab. Die Laien seien nur irregeführte Schafe, die nichts zu befürchten hätten, im Gegensatz zu ihren Verführern, die eine gerechte Strafe erhielten. Die Leser des Traktats, die einfachen Gläubigen, sollten durch die folgenden Ausführungen Augustins die Lügen der Verführer erkennen und sich selbst als Verführte begreifen, die jedoch ohne Furcht vor den antidonatistischen Gesetzen zur katholischen Einheit zurückkehren können. ${ }^{49}$

Entsprechend zieht sich die Gegenüberstellung von Wahrheit und Lüge als roter Faden durch den gesamten Text. Als Autorität für die Wahrheit greift Augustinus auf die Heilige Schrift zurück, da er deren Unantastbarkeit bei allen gleichermaßen anerkannt sah. Auf dieser gemeinsamen Grundlage hofft er, die Donatisten von der Notwendigkeit der Kircheneinheit überzeugen zu können. Seine Schlussfolgerungen demonstriert er im folgenden Syllogismus:

„Durch die Schriften lernen wir Christus kennen, durch die Schriften lernen wir die Kirche kennen. Wir haben die Schriften gemeinsam. Warum behalten wir nicht gemeinsam mit ihnen auch Christus und die Kirche? ‘50

48 Ep. 105.1: Caritas Christi [...] tacere nobis non permittit.

49 Vgl. auch die Exhortatio in 105.13.

50 Ep. 105.14: in scripturis didicimus Christum, in scripturis didicimus ecclesiam. has scripturas communiter habemus; quare non in eis et christum et ecclesiam communiter retinebus? - Sinngemäß wiederholt im Schlussappell (105.17): ecce scripturae communes, ecce ubi nouimus Christum, ecce ubi nouimus ecclesiam. 
Im Gegensatz dazu beruhe die donatistische Lehre von der Spaltung auf weitaus geringeren Autoritäten, nämlich allein auf menschlichen Denken und Handeln. ${ }^{51}$

Augustins Intention ist es nun, mit Hilfe der Heiligen Schrift die Grundpositionen der Donatisten zu erschüttern und als menschliche Lügen und Verleumdungen zu diskreditieren. Unter diesem Aspekt betrachtet er in ep. 105 die bekannten Themen: Er widerlegt die donatistischen Ansichten über die katholischen Traditoren (105.2), die ungültigen Taufen (105.12) und über die Reinheit der donatistischen Kirche in Afrika (105.14-16). Den mit Abstand größten Umfang nimmt allerdings die Frage der Verfolgung ein, die Augustinus zu einer ausgiebigen Apologie der antidonatistischen Gesetze ausweitet (105.311). Zweifellos handelte es sich zur Zeit der Abfassung um das aktuellste und drängendste Problem.

In der Konfrontation von Lüge und Wahrheit verwendet Augustinus Bibelzitate und Beispiele $\mathrm{zu}$ den einzelnen Themen, die auch aus anderen Schriften bekannt sind. ${ }^{52}$ In Bezug auf die Verfolgung treten die historische Argumentation und Beispiele gegenwärtiger Gewalt an die Seite der theologischen Aussagen. Augustinus möchte beweisen, dass die donatistische Selbstdarstellung als unverschuldet verfolgte Kirche der Märtyrer eine Lüge darstellt, dass in Wahrheit die Zwangsmaßnahmen von den Donatisten selbst verschuldet seien $(105.8-10) .^{53}$

Neben der Frage zur Ursache der Verfolgung ist Augustinus auch darum bemüht, die Differenz zwischen der donatistischen Gewalt und der Zwangsgewalt kenntlich zu machen. An erster Stelle steht wiederum die Berufung auf die Heilige Schrift, in der Christus verkündet wird, von dem die Kirche ihre Gewalt erhalte. Der Ursprung und die Legitimation der Gewalt sieht Augustinus also in der Autorität Christi. ${ }^{54}$ Er geht aber noch einen Schritt weiter, um zu beweisen,

51 Ep. 105.2, 6, 14, 17.

52 So stellt Augustinus die traditio-Anklage gegen die Katholiken der Verheißung Christi zur weltweiten Kirche gegenüber (105.2). Zur Verteidigung des katholischen Taufverständnisses beschwört er einmal mehr die Gültigkeit des Sakraments durch Gottes Gnade, unabhängig von der Würde des Priesters. Die biblischen Allegorien vom Spreu und Weizen sowie der Fische im Netz dienen ihm zur Darstellung der Mischung von Sündern und Gerechten in der Kirche (105.16). Mit einer Fülle von über zwanzig Zitaten aus dem Alten und Neuen Testament demonstriert Augustinus die Zusammengehörigkeit von Christus und der Kirche und ihre Verbreitung unter allen Völkern (105.14-15).

53 Zur historischen Argumentation u. Kap. 4.2.2.

54 Ep. 105.6: „Wir hoffen indessen auf keine menschliche Gewalt, auch wenn es wesentlich ehrenwerter ist, seine Hoffnung auf die Kaiser zu setzen als auf die Circumcellionen, seine Hoffnung auf die Gesetze zu setzen als auf Aufruhr, sondern wir erinnern uns, dass geschrieben ist: ,Verflucht ist jeder, der seine Hoffnung auf den Menschen setzt'.[...] Deswegen machen wir Gebrauch von dieser Gewalt der Kirche, die der Herr ihr ver- 
dass selbst die kaiserliche Gewalt keine menschliche Gewalt darstelle, sondern lediglich die potestas Christi in ihrer weltlichen Anwendung. Wenn ein Kaiser sich an die Wahrheit halte, dann seien seine Befehle auch zur Durchsetzung der Wahrheit da. ${ }^{55}$ Auf diese Weise werde es zur Aufgabe des christlichen Kaisers, Religion zu predigen und Gottlosigkeit zu verbieten (105.7). Mehr noch: Der Kaiser werde zum Sprachrohr Gottes und alle Gesetze beruhten auf der göttlichen Autorität (105.11-12).

Ep. 76 und ep. 105 weisen in der Argumentation große Übereinstimmungen auf. Augustinus verfolgte mit beiden Traktaten das gleiche Ziel, donatistische Laien zu überzeugen, in die katholische Kirche überzutreten. Es finden sich Parallelen in der Verwendung der Bibelzitate und Vergleiche sowie in der pastoralen Sprache, den Ermahnungen und Appellen. Auch die grundlegende Argumentationsstrategie ist gleich: Auf der Basis der Heiligen Schrift skizziert Augustinus sein Bild der katholischen Kirche und überprüft anschließend die historischen Taten und die Doktrin der Donatisten an diesem Ideal. Das Ergebnis dieser Überprüfung lautet: Der Exklusivismus der Donatisten steht im Widerspruch zur Heiligen Schrift und zu ihrem eigenen Handeln.

Trotz dieser Gemeinsamkeiten ist eine deutliche Akzentverschiebung sichtbar. Die Tauffrage wird in ep. 105 nur kurz angesprochen, und einige Beispiele über die Duldung von Sündern bei den Donatisten (Optatus, Maximianisten), die andernorts eine wichtige Rolle spielen, fehlen ganz. Stattdessen wird die Verfolgungsthematik in den Vordergrund gestellt und im Hinblick auf die neue Gesetzgebung in veränderter Form interpretiert. Entgegnet Augustinus in den früheren Schriften auf die Verfolgervorwürfe vor allem mit Gegenklagen (Verfolgung der Maximianisten) oder durch Leugnung der Verantwortung (im Falle der macarianischen Verfolgung), so rechtfertigt er in ep. 105 und anderen Schriften nach 405 die Zwangsmaßnahmen als Reaktion auf donatistische Gewalt und als Konsequenz aus dem donatistischen Widerstand gegen das kaiserliche Urteil in der Frage des Schismas.

sprochen und gegeben hat." (de nulla quidem nos hominis potestate praesumimus, quamuis utique multo sit honestius praesumere de imperatoribus quam praesumere de Circumcellionibus, praesumere de legibus quam praesumere de seditionibus; sed meminimus scriptum esse: maledictus omnis, qui spem suam ponit in hominem.[...] et ideo hac ecclesiae potestate utimur, quam ei dominus et promisit et dedit).

55 Augustinus zieht den persischen König Nebudkadnezar als Typus des bekehrten Herrschers heran (vgl. Dan. 3.1-18). Dieses Exempel findet sich auch in den epp. 88, 93. 


\subsection{Rechtfertigung des Zwangs: Der Brief 93 an den Rogatisten Vincentius}

Als ausführlichstes Beispiel einer solchen Rechtfertigung ist die ep. 93 überliefert. Bischof Vincentius von Cartenna war das Oberhaupt einer kleinen donatistischen Abspaltung, die nach ihrem inzwischen verstorbenen Gründer Rogatus „Rogatisten“ genannt wurde ${ }^{56}$ Er hatte Augustinus als jungen Mann in Karthago kennen gelernt, vielleicht in ihrer Studentenzeit, ${ }^{57}$ und wandte sich nun um das Jahr 408 in einem Brief an den alten Bekannten, der nunmehr Bischof von Hippo war. Vincentius verurteilte die Gewaltanwendung infolge der antidonatistischen Gesetzgebung $(93.1,5)$ und verteidigte sein Verständnis von der Katholizität der Kirche, die seiner Ansicht nach nicht auf einer erzwungenen Einheit, sondern auf der strengen Beachtung der Gebote und der Reinheit der Sakramente beruhe (93.23). Zur Begründung seiner Ausführungen zog er neben der Heiligen Schrift auch Cyprian und Hilarius von Poitiers heran (93.21, 31-35). Obgleich Vincentius sich allgemein gegen die Verfolgung der Kirche wandte, wollte er im Besonderen erreichen, dass seine friedliche Glaubensgemeinschaft nicht durch die geltenden Gesetze unterdrückt oder gar zerstört werde. Vielleicht hoffte er, Augustinus dahingehend überzeugen zu kön-

56 Nur wenige Textstellen geben Auskunft über den Rogatismus. Ausgehend von ep. 93.12 spaltete sich Rogatus in Mauretania Caesariensis nach der Regierungszeit Julians mit einigen Kollegen von den Donatisten ab. Auslöser waren vermutlich Gewalttaten von Circumcellionen, von denen sich Rogatus distanzierte (ep. 93.11). Es ist ferner bekannt, dass die Donatisten die Rogatisten mit Hilfe des Firmus gewaltsam bekämpften (c. ep. Parm. I 16-17; c. litt. Pet. II 184; vgl. o. Kap. 2.1.1-2). Die Rogatisten, die die Donatisten entsprechend „Firmiani“ nannten (ep. 87.10), versuchten, vor römischen Gerichten ihren Besitz zu verteidigen (ep. 93.11). Die Gruppe war wohl niemals groß und hatte nur in Mauretanien Anhänger. Zur Zeit des Vincentius, dem Nachfolger des Rogatus, gab es laut Augustinus nur noch elf Mitglieder (ep. 93.20), dessen Aussage allerdings kaum wörtlich zu verstehen sein dürfte (gegen Willis, Augustine, 21). Zu den Personen und dem Rogatismus vgl. Mandouze, PAC, 990 f., s. v. Rogatus 5; 1208 f., s. v. Vincentius 2; Monceaux IV, $128 \mathrm{f}$; VI 315-318. - Vincentius ist nicht mit Vincentius Victor zu identifizieren, der in Augustins de natura et origine animae erwähnt wird. Vgl. die Belege bei Mandouze, PAC, $1173 \mathrm{f}$, s. v. Vincentius Victor 62 und Monceaux VI, 325-327, gegen Willis (Augustine, 31), der aufgrund dieser Identifizierung fälschlicherweise das Ende der Rogatisten auf 420 datiert. - Irreführend ist die Darstellung bei Frend (Donatist Church, 197), der Augustins ironische Darstellungen in ep. 93.11 und 49 wörtlich interpretiert und meint, Rogatus habe sich aufgrund der Trinkgelage der Circumcellionen mit neun Bischöfen abgespalten, um die traditionelle Reinheit aufrecht zu erhalten.

57 Ep. 93.1. Möglicherweise waren sie Studienfreunde (in den Jahren 370-373), möglich ist aber auch ein späterer Zeitpunkt, als Augustinus bereits Rhetoriklehrer war (374-383); vgl. Perler/Maier, 128-130. Kritisch gegenüber diesen Interpretationen äußert sich Vössing, Schule und Bildung, 294 f. mit Anm. 1085. 
nen, dass dieser seinen Einfluss darauf verwende, bei den Verantwortlichen Fürsprache für die Rogatisten einzulegen. ${ }^{58}$

Augustinus antwortete dem Rogatisten mit ep. 93, einer ausführlichen Darlegung seiner Position. ${ }^{59}$ Die Bildung seines Adressaten erklärt das gehobene Niveau und die Ausführlichkeit der Argumente, aber auch die zum Teil beißende Ironie gegen den Absolutheitsanspruch der rogatistischen Gruppierung (vgl. 93.21-26). Augustinus hatte jedoch nicht nur Vincentius im Blick, sondern auch andere Leser, denen seine Ausführungen helfen sollten (93.53). So verfasste er einen Traktat, in dem er erstmals grundlegend seine Haltung zur Zwangsgewalt darlegte und theologisch rechtfertigte. Zweifellos sollte diese Schrift als Handreichung und Information gerade für katholische Bischöfe und Kleriker dienen, die selbst oder für ihre Gläubigen den staatlichen Zwang gegen die Donatisten verteidigen mussten. ${ }^{60}$

Der Brief kann in zwei Hauptteile untergliedert werden: Der erste Teil (93.1-20) umfasst eine Apologie der Zwangsmaßnahmen gegen die Donatisten. Augustinus erklärt die Herausbildung seiner eigenen gegenwärtigen Position und die Gründe für seine Zustimmung zur coercitio. Seine Leser versucht er mit den bisherigen praktischen Erfolgen von Übertritten, durch geschichtliche Bezüge und mit biblischen Argumenten von seinem Standpunkt zu überzeugen. Der zweite Teil (93.20-53) beinhaltet eine Weiterführung der theologischen

58 Ein Versuch, Vincentius' Brief inhaltlich zu rekonstruieren, bei Monceaux VI, 318-322. Seine Interpretationen sind allerdings z. T. sehr spekulativ.

59 Edition: Goldbacher, CSEL 34.2, 445-496. Possidius (VI 9) verzeichnet mit contra epistulam Vincenti Donatistae et Rogatistae liber unus zweifellos ep. 93. Unter den epistulae findet sich die Angabe Vincentio una (VI 24). Hierbei handelt es sich wohl um eine Doublette; vgl. de Bruyne (RevBen 43, 307) und D. Ludwig (Indiculus, 94). - Zum Inhalt vgl. Monceaux VI, 322-324; E. Herzog, Ein Schreiben Augustins über kirchenpolitischen Zwang (Ep. 93), Internationale kirchliche Zeitschrift 6, 1916, 1-26; Grasmück, Coercitio, 214-219. - Datierung: terminus post quem ist Februar 405, terminus ante quem 411. Ep. 93, 17-18 spricht für einen Zeitpunkt, an dem die antidonatistischen Gesetze Auswirkungen zeigten. Vgl. Monceaux (VII, 132, 282), der den Brief um 408 datiert, und Goldbacher (CSEL 58, 28 f.) mit einer Datierung von 407/8 (gefolgt von Grasmück, 214 Anm. 267 und Mandouze, PAC, 1209). Augustins Ausführungen über die Konversionen sind allerdings rhetorisch zugespitzt und daher kaum zur sicheren Eingrenzung des Abfassungszeitraums geeignet. Wahrscheinlich bleibt jedoch eine Datierung zwischen 406 und 409.

60 Augustins Rechtfertigung der Zwangsgewalt (coercitio), die außer in ep. 93 insbesondere in ep. 185 aus dem Jahre 417 thematisiert wird, ist in der Forschung vielfach behandelt worden. Brown, Religion and Society, 260-278; Crespin, Ministère, 164-168; Grasmück, Coercitio, 205-240, zu ep. 93: 214-218; R. Joly, Augustin et la intolérance, Revue Belge de Philologie et d'Histoire 33, 1955, 263-294; Lamirande, AL 1, 1038 1046, s. v. Coercitio (mit weiterer Literatur), hier: 1041 f.; W. Geerlings, Foris inveniatur necessitas nascitur intus voluntas, Augustins Rechtfertigung des Zwangs, in: Universalität und Toleranz, Der Anspruch des christlichen Glaubens, Essen 1989, 41-47, hier: 43-46; Willis, Augustine, 127-135; K. H. Chelius, AL 1, 1084 f., s. v. Compelle intrare. 
Argumentation zu den Fragen des Schismas und eine Widerlegung der Argumente des Vincentius. Dabei stellt Augustinus besonders die paradoxe Situation der Rogatisten als Splittergruppe zwischen Donatisten und Katholiken heraus.

Zur Rechtfertigung der coercitio versucht Augustinus, ein auf christlicher Basis begründetes Verständnis zu formulieren: Es stelle sich nicht die Frage, ob die Anwendung von Zwang erlaubt sei, sondern welchem Ziel der Zwang diene. Die Furcht vor Sanktionen befreie die Menschen aus ihrem Irrtum und lasse sie für die Wahrheit offen werden, die sie dann freiwillig annehmen könnten (93.16). Augustinus verweist auf die vielen Menschen, die bereits zur katholischen Kirche zurückgekehrt seien $(93.1-2,17)$ und die in unterschiedlicher Weise bezeugen könnten, wie heilsam sich die Furcht vor den Gesetzen (legum timor) auf sie ausgewirkt habe. ${ }^{61}$ Wahrhaft verfolgt seien dagegen immer nur jene, die für eine gerechte Sache verfolgt würden (93.8).

Vincentius hatte die Einbindung des Staates in eine kirchliche Angelegenheit scharf kritisiert, da es seines Erachtens keine biblischen Vorbilder dafür gebe. In seiner Entgegnung weist Augustinus unter anderem darauf hin, dass Vincentius' Vorgänger Rogatus vor weltlichen Gerichten um den Besitz der Rogatisten gestritten habe (93.11). Ebenso seien die Donatisten nachweislich unter Berufung auf antihäretische Gesetze gegen Rogatisten und Maximianisten vorgegangen. Bereits zuvor hätten sich die Donatisten an Julian gewandt, um von diesem Apostaten und Götzendiener Hilfe zu erhalten (93.12). Auch die Klage der Donatisten gegen Caecilianus lasse klar erkennen, dass sie sich zuerst an den Kaiser gewandt hätten, dessen Urteil sie damals wie heute ablehnten (93.13-14, 19). ${ }^{62}$ Augustinus appelliert an Vincentius, die Gewalt der weltlichen Mächte (terror temporalium potestatum) als Mahnung zu verstehen und umzukehren (93.20).

Die Leitgedanken dieser Argumentation sind dieselben wie auch in ep. 105 an die donatistischen Laien: die Stilisierung der weltlichen Herrscher zu Verteidigern der christlichen Wahrheit und die Legitimierung der Zwangsgewalt in ihrer Funktion als „heilsamer Schrecken“. Allerdings verzichtet er gegenüber dem Rogatisten auf die Exempel der Gewalt, sondern zieht nur die historischen Beispiele heran, wohl wissend, dass von den Rogatisten keine Gewalt ausge-

61 Augustinus hält vor Augen, dass die einen aus ihrer Erstarrung, Trägheit und Tradition aufgerüttelt worden seien, andere hätten nur aufgrund der donatistischen Verleumdungen über die Katholiken keinen Übertritt gewagt. Viele freuten sich, durch die Gewaltandrohung neu nach der Wahrheit geforscht zu haben und zu neuen Erkenntnissen gekommen zu sein. Wieder andere hätten erst nach ihrem Übertritt erkannt, dass die donatistischen Vorhalte gegen die Katholiken Lügen gewesen seien, und wiederum andere hätten geglaubt, es sei egal welcher Kirche man angehöre; diese freuten sich nun über das Ende des Schismas (93.17-18). Trotz dieser Ausführungen war sich Augustinus der Tatsache bewusst, dass der Zwang auch Heuchelei verursachte.

Zur historischen Argumentation ausführlich u. Kap. 4.2.2. 
gangen war. Der Schwerpunkt liegt jedoch eindeutig auf den biblisch-theologischen Argumenten. Wie in ep. 105 bilden die Zitate aus der Heiligen Schrift und die damit verbundenen Beispiele die oberste Autorität.

Im zweiten Teil des Briefes bringt Augustinus seine ekklesiologischen Positionen zur Sprache: der Glaube an die weltweite Kirche Christi, die Vermischung von Sündern und Gerechten in einer Kirche und die Wiederaufnahme von Häretikern. Augustinus greift Vincentius scharf an und polemisiert gegen den Anspruch der Rogatisten, Alleinvertreter der Wahrheit zu sein (93.20-27). Augustinus legt einige Bibelstellen aus, um seine Vorstellung einer über die Welt verbreiteten Kirche, in der Sünder und Gerecht ihren Platz haben, zu untermauern und die exklusive Haltung der Rogatisten zu widerlegen (93.2835). In der Tauffrage argumentiert Augustinus ausführlich auf Grundlage von Cyprian und Tyconius, um Vincentius von der katholischen Sicht zu überzeugen (93.36-48). Schließlich appelliert Augustinus an seinen Adressaten, zurück in die katholische Kirche zu kommen. Er gesteht ein, dass es bei der Umsetzung von Zwangsmaßnahmen Missbrauch gegeben habe, doch sollten alle in der Kirche ertragen werden (93.50-53).

Diese Argumente des zweiten Briefteils entsprechen den Ausführungen, die in Augustins großen Abhandlungen begegnen. Hervorzuheben ist hier der Bezug auf Tyconius und die Erwähnung von Parmenians Schrift gegen diesen Theologen (93.43-44). Augustinus kannte zwar schon zu Beginn seines Episkopats Teile von Tyconius' Werk ${ }^{63}$ und setzte sich später in contra epistulam Parmeniani intensiv mit Parmenians Kritik an Tyconius auseinander, verzichtete jedoch in den antidonatistischen Schriften auf direkte Bezüge. ${ }^{64}$ Zweifellos, dies lässt Augustinus selbst anklingen (93.44), war der bei den Donatisten diskreditierte Tyconius keine Autorität, dessen Aussagen sich für eine Polemik gegen Donatisten eignete.

Der Brief zeigt eindrücklich Augustins Gratwanderung zwischen Verteidigung von Zwangsgewalt und christlicher Verkündigung. Augustinus hatte sich von den sichtbaren Ergebnissen überzeugen lassen und suchte erst danach einen theoretischen Überbau. ${ }^{65}$ Vincentius' Brief war die notwendige Herausforderung für ihn, erstmals eine Apologie ausführlich zu formulieren. Er ging schließlich einen Weg, die vorgegebenen Umstände theologisch-heilsgeschichtlich zu rechtfertigen. Sollte Vincentius tatsächlich geglaubt haben, Augustinus würde ausgehend von der Heiligen Schrift und Cyprian in der Frage der

63 In ep. 41.2 an Aurelius (Bischof von Karthago) erwähnt Augustinus Tyconius' Liber Regularum und erbittet Aurelius' Meinung dazu.

64 Ausnahme ist ep. 249 an den Diakon Restitutus, den Augustinus zur Lektüre von Tyconius auffordert, aber auch auf Probleme und Differenzen hinweist. Zu Tyconius vgl. o. Kap. 2.1.2.

65 Im gleichen Sinne: Geerlings, Augustins Rechtfertigung, $43 \mathrm{f}$. 
Zwangsgewalt seinem Verständnis der Gewaltlosigkeit zustimmen, so hatte er sich getäuscht. $\mathrm{Ob}$ Augustinus mit seinem Sarkasmus und den Appellen an die Vernunft die augenscheinliche Realitätsferne des Rogatisten zu durchbrechen vermochte, darf bezweifelt werden.

\subsection{Widerstand gegen Donatisten: Die Briefe 53 und 89 an Katholiken}

Seine katholischen Briefpartner musste Augustinus grundsätzlich nicht davon überzeugen, dass Donatisten aus seiner Sicht falsche Ansichten vertraten. Entsprechend fehlen in den meisten Briefen an Katholiken längere antidonatistische Argumentationen und Polemiken. Die Briefe an Generosus (ep. 53) und Festus (ep. 89) stellen diesbezüglich Ausnahmen dar. In beiden Fällen wollte Augustinus den Adressaten Unterstützung in ihrem Widerstand bzw. Kampf gegen Donatisten zukommen lassen. Mit seinen Argumenten sollten sie eine Grundlage erhalten, um sich der Auseinandersetzung mit Donatisten zu stellen. $^{66}$

Augustinus schrieb ep. 53 um das Jahr 400 zusammen mit den Bischöfen Alypius von Thagaste und Fortunatus von Cirta an einen nicht weiter bekannten katholischen Gläubigen aus Cirta namens Generosus. ${ }^{67}$ Dieser hatte von einem donatistischen Priester einen Brief erhalten, in dem er unter Berufung auf eine Engelserscheinung aufgefordert wurde, sich der donatistischen Gemeinde anzuschließen. Generosus ließ sich jedoch nicht darauf ein, sondern leitete den Brief des Donatisten an die drei genannten Bischöfe weiter, die sowohl für ihn als auch für jenen donatistischen Priester eine Antwort schickten (53.1).

Die Absender geben Generosus einige Ratschläge: Sie weisen auf die biblische Vorhersage der weltweiten Ausbreitung der Kirche hin, die im Widerspruch zu dem auf Afrika beschränkten Donatismus stehe (53.1). Da in dem

66 Vgl. für die Zeit um 400 auch epp. 56, 57: Augustinus übergab dem Laien Celer, der mit dem Donatismus sympathisierte, einen codex zum Lesen (vermutlich einen oder mehrere seiner antidonatistischen Traktate, ep. 57.1) und beauftragte die jeweils überbringenden Priester, weitere Fragen zu beantworten (56.1, 57.2). Vgl. Mandouze, PAC, 202 f., s. v. Celer 1.

67 Edition: Goldbacher, CSEL 34.2, 152-158. Vgl. Poss. indic. X ${ }^{5}$ 40. Zum Inhalt: Monceaux VI, $305 \mathrm{f}$. - Datierung: In ep. 53.3 wird als gegenwärtiger römischer Bischof Anastasius genannt (399-401), so dass der Brief um das Jahr 400 zu datieren ist. Vgl. Monceaux VI, 305; VII, 131 f., 280; Mandouze, PAC, 532. Perler/Maier (230-232) folgern aus ep. 53 eine Reise Augustins und Alypius' nach Cirta im Jahre 400. Goldbacher (CSEL 58, 18) nimmt fälschlicherweise das Jahr 398 als Pontifikatsbeginn des Anastasius an und bestimmt als terminus ante quem den Tod des Praetextatus (vgl. 53.6), den er auf 400 datiert. Dieses Datum ist jedoch nicht zu halten. - Zu Generosus: Mandouze, PAC, 532 f., s. v. Generosus 1. Möglicherweise ist er mit dem gleichnamigen Konsular zu identifizieren, der in epp. 115/116 erwähnt wird. 
Brief der Donatisten an Generosus mit der Sukzession der Bischöfe von Cirta argumentiert worden war (53.1), zählen sie die Reihe aller römischen Bischöfe von Petrus bis Athanasius auf, um die Apostolizität der katholischen Kirche zu demonstrieren. Sie fügen hinzu, dass kein Traditor in den Reihen der Bischöfe die gesamte Kirche verunreinige (53.2-3). Damit Generosus nachweisen könne, wie unrecht die Donatisten selbst gehandelt hätten, dass sie sogar Traditoren in ihren Reihen geduldet hätten, empfehlen ihm die drei katholischen Bischöfe die Zuhilfenahme von historischen Dokumenten, die er den Gegnern vorlesen solle (53.4-5). Ebenso diene der Hinweis auf die Wiederaufnahme der Maximianisten Praetextatus und Felicianus nach ihrer Verurteilung zur Darstellung der donatistischen Inkonsequenz. Die Heilige Schrift schließlich bezeuge, dass in der weltweiten Kirche Gute und Schlechte ihren Platz hätten und diese Kirche niemals von irgendwelchen Schandtaten in Afrika befleckt werden könne (53.6-7).

Die Argumente, die Generosus hier an die Hand bekam und im Dialog anwenden sollte, entsprechen dem Katalog an Argumenten, mit denen Augustinus selbst seine Gespräche und Schriften vor dem Jahr 405 bestritt. Die Versatzstücke tauchen in ähnlicher Form in den epp. 34, 44 und 76 auf, ebenso wie in den Büchern gegen Petilianus. Durch den besonderen Anlass bedingt war lediglich die Aufzählung der römischen Bischöfe zum Nachweis der wahren Apostolizität und die Hervorhebung der causa Silvani.

Mit ep. 89 an Festus richtete sich Augustinus in der Zeit nach dem Einheitsgesetz von 405 an einen römischen Beamten, der mit der Durchführung der antidonatistischen Gesetze beauftragt worden war. ${ }^{68}$ Anlass des Briefes war die Bitte an Festus um konkrete Unterstützung im Kampf gegen die Donatisten von Hippo Regius. Die Durchsetzung der Gesetze gegen die Donatisten in Hippo war bisher an den Verantwortlichen gescheitert, weil sie angeblich selbst Donatisten gewesen seien. Festus sollte deshalb einen seiner Vertrauten nach Hippo schicken, um zunächst vertraulich Augustinus zu konsultieren, damit über das weitere Vorgehen beraten werden könne (89.8). Augustinus nutzte den Anlass, um einerseits Festus selbst über seine Beweggründe zu informieren, andererseits ihm Argumente an die Hand zu geben, mit denen er jene über-

68 Edition: Goldbacher, CSEL 34.2, 419-425. Vgl. Poss. indic. VI 33. Zum Inhalt vgl. Monceaux VII, 137, 140 f.; Grasmück, Coercitio, 205 f. - Datierung: Der Brief muss einige Zeit nach Verkündung des Unionsgesetzes verfasst worden sein. Monceaux (VII, 132, 282) datiert um 406; Goldbacher (CSEL 58, 27) legt sich nicht genauer fest. Insbesondere die historische Argumentation zeigt die Nähe zu epp. 88, 93, 105. Wahrscheinlich ist daher eine Abfassung um 406/7. - Auf den Rang des Adressaten deuten die Anrede (domino dilectissimo et honorabili ac suscipiendo filio Festo) sowie die Anspielungen im Text, vor allem ep. 89.8. Zur Person: Mandouze, PAC, 451, s. v. Festus 1; PLRE II, 466 f., s. v. Festus 1. 
zeugen könne, die die Zwangsmaßnahmen ablehnten oder behinderten (89.8). Augustinus hatte offenbar die Erfahrung gemacht, dass viele Beamte wenig Interesse an der Umsetzung der Gesetze gegen die Donatisten bekundeten oder sich sogar gegen die Anwendung der Gewalt aussprachen. Viele verstanden nicht, warum sie mit solch strengen Strafen gegen die Anhänger der Donatisten vorgehen sollten, obwohl sie keinen Unterschied zum Kult der Katholiken erkannten. Augustinus wollte entsprechend über den historischen und theologischen Hintergrund der Gesetzgebung informieren und die Notwendigkeit der strengen Durchsetzung der Maßnahmen begründen. ${ }^{69}$

Der Brief enthält eine kurze Darstellung der wichtigsten Argumente für die Zwangsmaßnahmen gegen die Donatisten. Im Gegensatz zu den an Donatisten gerichteten epp. 88 und 105 steht nicht die Aufzählung einzelner Gewalttaten im Vordergrund, sondern eine allgemeine Beurteilung des donatistischen Verhaltens und die Konsequenzen, die daraus zu ziehen seien. Die Donatisten, so Augustinus, verharrten in Irrtum und Schisma und wehrten sich nicht nur gegen die Berichtigung ihrer Fehler, sondern verdrehten noch die Tatsachen, indem sie sich rühmten, Opfer der Verfolgung zu sein, obwohl sie selbst die wahren Verfolger seien. Nach einem Abriss über die Entstehung des Schismas (89.3-4) erläutert Augustinus die Unterschiede des katholischen und donatistischen Taufverständnisses (89.5) sowie Absicht und Ziel der Zwangsmaßnahmen aus kirchlicher Sicht (89.6-7): Die Kirche und die weltlichen Gewalten seien lediglich in der Lage, den Weg zu bereiten, sei es mit Worten, sei es mit Zwang, die tatsächliche Veränderung müsse aber Gott überlassen werden.

Die Briefe 53 und 89 zeigen sehr deutlich die zwei Seiten des augustinischen Kampfes gegen die Donatisten: Auf der einen Seite die persuasio, die Überzeugungsarbeit auf Grundlage von Argumenten und Dokumenten, auf der anderen Seite die coercitio, die Anwendung des Zwanges gegen donatistische Gewalt und die Trägheit der Gewohnheit. Ep. 89 ist ferner ein Beispiel dafür, wie die katholisch-donatistischen Differenzen bei den Laien in Afrika auf Unverständnis stießen.

\section{Die historische Argumentation}

\subsection{Die Briefe vor dem Unionsgesetz von 405 (epp. 43, 53, 76)}

In den Briefen Augustins aus den Jahren vor 405 finden sich die ausführlichsten Darstellungen historischer Argumentation in den epp. 53 und 76, in denen jeweils die Entstehung des Schismas referiert wird, sowie in ep. 43 mit der Re-

69 Vgl. ep. 86 an Caecilianus und ep. 97 an den MO Olympius, in denen Augustinus zur Durchsetzung der Gesetze ermahnt. 
flexion des Gesprächs zwischen Augustinus und den donatistischen Laien. ${ }^{70}$ Gegenüber seinen donatistischen Bischofskollegen verweilt Augustinus wesentlich länger bei theologischen Erörterungen, insbesondere in der Frage des Rechts und Unrechts von Verfolgung. Gerne greift er hier zum Vergleich mit dem Maximianistischen Schisma, um die donatistische Sakramentenlehre anzugreifen. Der Disput Augustins mit Fortunius in Thubursicum Numidarum (ep. 44), seine Briefe an Emeritus (ep. 87), Honoratus (ep. 49) und Crispinus von Calama (ep. 51) bezeugen diese Akzentsetzung und stehen diesbezüglich in enger Bindung zur Argumentation in den Büchern gegen Petilianus. Die historische Argumentation wird dagegen nachrangig behandelt. So wird im Gespräch mit Fortunius deutlich, dass zunächst andere Themen angesprochen und diskutiert wurden und am Ende die Zeit nicht mehr reichte, die Geschichte des Schismas eingehender zu erörtern (vgl. 44.5, 12). Auch gegenüber Emeritus spricht Augustinus davon, bei einer Fortsetzung der Gespräche über die Ursachen des Schismas zu diskutieren (87.10). Gegenüber den Laien verzichtete Augustinus weitgehend auf die schwierigen theologischen Fragen. In der Geschichte des Donatismus sah er jedoch ein Instrument, die aus seiner Sicht falschen Ansichten der Donatisten anschaulich zu widerlegen.

Ebenso wie in den Büchern gegen Cresconius stellt Augustinus in den Briefen die Anfänge des Schismas dar, um die Schuldfrage der Kirchenspaltung zu klären. Die Essenz der historischen Argumentation findet sich in dem Traktat ep. 76. Im Verlauf weniger Sätze streift Augustinus die entscheidenden Stationen der causa Caeciliani und lässt sie in einem Appell zur Einheit münden:

„Einige von euren Vorfahren, in deren gottloser Abspaltung ihr verharrt, haben nämlich nach Ausweis städtischer Akten die heiligen Kodizes und Gegenstände der Kirche den Verfolgern ausgehändigt. Andere haben geständige [Traditoren] freigesprochen und mit ihnen Kirchengemeinschaft gepflegt. Beide Gruppen kamen in Karthago zu wütenden Umtrieben zusammen; sie verurteilten aufgrund des Vergehens der traditio andere [Bischöfe] ohne Anhörung, über die sie sich selbst zuvor abgestimmt hatten, und ordinierten Bischof gegen Bischof und errichteten Altar gegen Altar. Später schickten sie einen Brief an Kaiser Konstantin, damit Bischöfe aus Übersee zwischen den Afrikanern urteilen sollten. Den bestellten Richtern, die sie gefordert hatten und die in Rom ein Urteil sprachen, folgten sie nicht; sie klagten die Bischöfe beim Kaiser an, als ob sie schlecht geurteilt hätten; und von anderen Bischöfen, die nach Arles geschickt worden waren, appellierten sie wiederum an den Kaiser. Vom Kaiser selbst verhört und für Verleumder befunden, verharrten sie im gleichen Frevel. Erwachet zum Heil, liebet den Frieden, kehret

70 Ein kurzer Hinweis auf die bischöflichen Urteile über Caecilianus findet sich auch in ep. 52.2 an den donatistischen Laien Severinus, geschrieben wahrscheinlich um 400 (vgl. Monceaux VII, 280). 
um zur Einheit! Wenn ihr wollt, lesen wir euch dies alles vor, auf welche Weise das geschehen ist. “71

Augustinus beginnt diese Aufzählung mit seinen Kenntnissen über die traditio in Cirta und das spätere Konzil von Cirta, stellt dann den Zusammenhang zwischen den Traditoren von Cirta und dem Konzil von Karthago her. Ohne die Namen zu nennen, spricht er von der Unrechtmäßigkeit der Verurteilung Caecilians und anderer Bischöfe, die zum Schisma geführt habe. Schließlich belege das Urteil des Kaisers endgültig die Schuld der Donatisten, nachdem sie die bischöflichen Urteile nicht hätten akzeptieren wollen.

Im Brief an Generosus finden sich die gleichen Bausteine wieder. Augustins Ausführungen sind hier nicht in einem Referat über die Geschichte des Schismas zusammengefasst, sondern erschöpfen sich in einer Anweisung an Generosus, mit welchen Dokumenten er gegen die Donatisten argumentieren könne. Augustinus beginnt mit den Akten zu den Ereignissen aus Generosus' Heimatstadt Cirta. Wie im ersten Buch gegen Petilianus (c. litt. Pet. I 23) will Augustinus demonstrieren, dass sich gerade in Cirta Traditoren unter den Vorgängern des gegenwärtigen Bischofs Petilianus befunden hätten. Er weist Generosus auf die acta Munati Felicis hin, mit denen die traditio des Silvanus von Cirta, der in der donatistischen Bischofsliste genannt worden war, erwiesen werden könne. Aus dem Protokoll von Cirta zitiert Augustinus die Namen jener geständigen Traditoren, die zusammen mit Secundus von Tigisi Silvanus geweiht hätten, und nennt den Versammlungsort, das Haus des Urbanus Donatus. Möglicherweise rechnet Augustinus damit, dass Generosus mit dieser Angabe etwas anfangen kann, und durch eine genaue Identifizierung des Ortes seiner Darstellung mehr Glaubwürdigkeit verliehen wird. Schließlich weist er noch auf die gesta apud Zenophilum, in denen die Schuld des Silvanus ganz klar werde (53.4).

Nach diesen Hinweisen zu Silvanus ergänzt Augustinus summarisch die Prozessfolge gegen Caecilianus und macht Generosus wiederum auf Dokumente aufmerksam, in denen die Ereignisse und Urteile bezeugt seien: Die

71 Ep. 76.2: maiores enim uestri, in quorum sacrilega praecisione perseueratis, quidam gestis municipalibus codices sanctos et instrumenta ecclesiae persecutoribus tradiderunt, quidam eos fatentes dimiserunt et eis communicauerunt et utrique Carthaginem furiosa factione conuenerunt, de crimine traditionis, de quo ipsi inter se iam consenserant, inauditos damnauerunt, episcopum contra episcopum ordinauerunt, altare contra altare erexerunt. postea litteras ad imperatorem Constantinum, ut inter Afros episcopi transmarini iudicarent, miserunt; datis iudicibus, quos postulauerant, et Romae iudicantibus non obtemperauerunt; episcopos apud imperatorem, tamquam male iudicauerint, arguerunt; ab aliis rursus episcopis ad Arelatum missis ad ipsum imperatorem appellauerunt; ab ipso auditi et calumniatores inuenti in eodem scelere permanserunt. euigilate ad salutem, amate pacem, redite ad unitatem. haec uobis, quem ad modum gesta sint, quando uultis, omnia recitamus. 
preces der Donatisten an Konstantin, einen Brief des Kaisers zur Ladung der Bischöfe nach Rom, die römischen Konzilsakten sowie einen weiteren Brief Konstantins, in dem die Appelle der Donatisten, der Entschluss zum Konzil von Arles und der kaiserliche Entscheid über die Unschuld Caecilians nachzulesen seien. ${ }^{72}$ Auf eine weitergehende Interpretation der historischen Dokumente verzichten Augustinus und seine Mitverfasser. Die Aussagen dieser Zeugnisse sollten genügen, um die Argumente des donatistischen Priesters zu widerlegen, und es sollte Generosus überlassen bleiben, wie er mit diesen Hinweisen weiter verfahre.

Welche Möglichkeit zur Interpretation jene Quellen bieten konnten, die er Generosus zur Beweisführung vorschlägt, demonstriert Augustinus selbst in seiner ep. 43 an die Laien von Thubursicum Numidarum. Ausgangspunkt der gesamten Argumentation, sowohl im persönlichen Gespräch als auch in seinem Brief, war die These der Donatisten, dass die causa Caeciliani durch das Urteil der siebzig Bischöfe in Karthago unter der Führung des Secundus von Tigisi endgültig entschieden worden sei. Die donatistischen Gesprächsteilnehmer hatten die Konzilsakten mit den Verdammungssentenzen präsentiert und erwarteten von Augustinus eine Antwort auf die Frage, warum dieses eindeutige Urteil von den Katholiken nicht akzeptiert werde. Augustinus greift nun auf seine eigenen Dokumente zurück, um auf dieser Grundlage zu antworten und die These der Donatisten zu entkräften. Der Aufbau seiner Argumentation in

72 Ep. 53.5. - Das hier an zweiter Stelle genannte Schreiben ist zweifellos der Brief Konstantins an Eumalius. Der an erster Stelle genannte Brief ist schwieriger zuzuordnen (litteras etiam eiusdem imperatoris, ubi episcopos misit ad urbem Romam). Handelt es sich dabei um den Brief an Miltiades und Marcus, der bei Eusebius (HE X 5.18-20) überliefert ist? Dieser Brief scheint auf der Konferenz von 411 vorgelegen zu haben (breuic. III 24: tum deinde lectae sunt etiam litterae supradicti imperatoris [Constantini] ad episcopos datae, ubi eis causam Caeciliani iniunxit audiendam). Anhand dieser Formulierung könnte man auch vermuten, dass Augustinus nicht von einem Brief an Miltiades, sondern an mehrere Bischöfe spricht, und damit womöglich jenen Brief meint, durch den nach Konstantins eigenen Worten die gallischen Bischöfe nach Rom beordert wurden. Jedoch geht aus Cap. conl. Carth. III 318 klar hervor, dass der herangezogene Brief jener an Miltiades war. Dass Augustinus den Brief kannte, wird zudem in s. Denis 19.8 deutlich. Möglicherweise bezieht sich dennoch die Anspielung von ep. 53.5 nicht auf den Brief an Miltiades, sondern auf die in diesem Schreiben erwähnte Einberufung an die gallischen Bischöfe Reticius, Maternus und Marinus (vgl. Lancel, SC 194, 92 Anm. 2). Doch ist dies wenig wahrscheinlich: Warum sollte Augustinus ausgerechnet gegenüber seinem Adressaten Generosus auf ein Dokument hinweisen, das in der gesamten Auseinandersetzung nie wieder auftaucht, folglich nicht leicht zugänglich oder überhaupt nicht vorhanden war? Der Brief an Miltiades gehörte dagegen zur Aktensammlung der karthagischen Konferenz. Augustinus weist also mit hoher Wahrscheinlichkeit in ep. 53 auf den Brief Konstantins an Miltiades hin, der offensichtlich in mehrfachen Abschriften zur Verfügung stand. 
ep. 43 entspricht weitgehend der angegebenen Reihenfolge der im Gespräch vorgelesenen Dokumente (43.5). Von den jeweiligen Zeugnissen ausgehend entfaltet Augustinus seine Analysen und Schlussfolgerungen, jedoch stets mit Bezug auf die zu widerlegende These. ${ }^{73}$ An einigen Stellen bezieht sich $\mathrm{Au}-$ gustinus auf Einwände und Kritiken, die während des Gesprächs gefallen waren (43.10, 12-13), immer wieder macht er seine Adressaten auf die ihnen bereits bekannten Dokumente aufmerksam (43.14-15, 17, 20). Aufgrund der parallelen Abhandlung der Dokumente und den häufigen Bezugnahmen auf das Gespräch lässt sich davon ausgehen, dass die Ausführungen in ep. 43 weitgehend den Argumenten entsprechen, die Augustinus bereits mündlich vorgebracht hatte.

Zum besseren Verständnis der Argumentation Augustins ist es hilfreich, einige Grundanlagen der Struktur im Voraus $\mathrm{zu}$ verdeutlichen: Augustinus wertet die ihm vorliegenden historischen Dokumente stets mit dem Ziel aus, die donatistische These einer Verurteilung Caecilians in Karthago zu widerlegen. Gleichsam in der Funktion eines Verteidigers Caecilians sucht Augustinus in ihnen Beweise, um das Urteil der siebzig Bischöfe gegen Caecilianus als unrechtmäßig darzustellen. Dazu analysiert er das Motiv der Ankläger, die Zuständigkeit des Gerichts, die Integrität der Richter, die Beweise der Anklage und die Rechtmäßigkeit des Verfahrens. Zudem verteidigt er die Legitimität der Prozesse in Rom und Arles sowie das Handeln des Kaisers. Mit Hilfe zahlreicher Gegenüberstellungen polarisiert Augustinus Recht und Unrecht in den jeweiligen Verfahren. $\mathrm{Zu}$ den wichtigsten Gegenüberstellungen gehört zum einen der Vergleich der Entscheidung von Cirta mit der Entscheidung von Karthago, zum anderen der Vergleich der römischen mit der karthagischen Synode. Weitere Gegenüberstellungen sind auch aus anderen Texten Augustins bekannt, wie die Verurteilung Caecilians in Abwesenheit und ohne Anhörung im Gegensatz zu seinem Freispruch in Anwesenheit, oder der Gegensatz zwischen der Bedeutungslosigkeit des afrikanischen Streites im Verhältnis zur weltweiten Christenheit.

Augustins Quelleninterpretationen werden auf Grundlage dieses Argumentationsrahmens verständlich: Er beginnt mit dem Protokoll von Cirta und der Rolle des Secundus von Tigisi in Gegenüberstellung zum Konzil von Karthago (43.6-11), es folgt die Auswertung der acta purgationis Felicis zur Klärung der Schuldfrage (43.12-13), anschließend die Interpretation des Konzils in Rom auf Grundlage der Konzilsakten sowie der preces der Donatisten an den Kaiser und einem Brief Konstantins (14-18). In Ergänzung zu diesen Akten verweist

73 Monceaux (VI, 298) erwähnt die ausführliche Quellenkommentierung Augustins und zählt die wichtigsten Themen auf. Lamirande (Studia canonica 32, 1998, 214 f.) betont Augustins sorgfältige Dokumentation als Antwort auf die donatistischen Konzilsakten von 312, Beide verzichten jedoch darauf, die gezielte Interpretation der Quellen durch Augustinus näher zu beleuchten. 
er auch auf die gesta apud Zenophilum (43.17), die während des Gesprächs in Thubursicum nicht vorgelesen worden waren. Den Abschluss bildet eine erneute Rechtfertigung der bischöflichen Urteile von Rom und Arles sowie der Rolle des Kaisers in diesem Verfahren (43.19-20).

Zur Einführung in die Auseinandersetzung mit der causa Caeciliani hält Augustinus seinen Adressaten vor Augen, dass die historischen Zeugnisse eine eindeutige und klare Sprache sprächen: Obwohl eine ansehnliche Zahl von siebzig Bischöfen ein Urteil gesprochen habe, so bewiesen dennoch genügend Dokumente, dass dieses Urteil unrechtmäßig zustande gekommen sei, denn der Angeklagte sei nicht vor der Synode erschienen; außerdem hätten sich geständige Traditoren unter den Richtern befunden (43.6). Zum Nachweis interpretiert Augustinus das Protokoll von Cirta, wobei er sich auf die Person des Secundus von Tigisi konzentriert. Er lenkt die Aufmerksamkeit auf die Motivation des Secundus und dessen Verantwortung für die Vorgänge in Karthago. Ihm wirft er vor, aus persönlichem Interesse gehandelt zu haben, ohne Rücksicht auf die Folgen für die Kirche. Wie später gegen Cresconius kritisiert Augustinus keineswegs die Toleranz des Secundus gegenüber den geständigen Traditoren von Cirta, sondern ausdrücklich den Widerspruch zwischen dem Urteil in Cirta und dem Urteil in Karthago. Er verurteilt das Verhalten, das schließlich zum Verrat an der kirchlichen Einheit geführt habe. ${ }^{74}$

Das Scheitern einer Einigung begründet Augustinus ferner mit der fehlenden Rücksichtnahme auf die weltweite Kirchengemeinschaft. Secundus und seine Mitstreiter hätten beachten müssen, dass sich Caecilianus und die mitangeklagten Bischöfe aufgrund ihres Ranges an ein Gericht anderer Kollegen der apostolischen Kirche hätten wenden können. Doch in Kenntnis ihrer eigenen Vergehen und der Verfahrensfehler in Karthago hätten sie dies missachtet, wohl wissend, dass sie mangels Beweisen gegen die Angeklagten vor einem überseeischen Gericht nicht bestehen würden (43.9). Caecilianus jedoch sei sich dieser Möglichkeit sehr wohl bewusst gewesen und habe recht entschieden, nicht am Versammlungsort seiner Gegner zu erscheinen $(43.7-11) \cdot{ }^{75}$ Rhetorisch verpackt in einer „Friedensrede“, die er Secundus in den Mund legt, demon-

74 Secundus habe namentlich bekannten Traditoren verziehen, gleichzeitig werde durch die Anschuldigungen des Purpurius von Liniata klar, dass Secundus sich selbst der traditio schuldig gemacht habe. Er habe nicht um des Friedens, sondern um seiner selbst willen, aus Furcht vor der Offenlegung seiner Schuld, die ganz offenkundigen Vergehen der Bischöfe dem Urteil Gottes überlassen $(43.3,6)$. Dieses eigennützige Handeln bestätige sich durch das Verhalten in Karthago, wo Secundus mit Hilfe von geständigen Traditoren die traditio verurteilt habe, trotz Abwesenheit der Beklagten und mangelndem Erweis ihrer Schuld (43.7, 10-11). Zum Inhalt des Protokolls von Cirta vgl. auch o. Kap. 3.4.2.1.

75 Caecilianus hatte der Vorladung vor das Konzil des Secundus in Karthago keine Folge geleistet, vgl. Opt. I 19. 
striert Augustinus, auf welche Weise das Schisma hätte verhindert werden können (43.8): Geständige Traditoren hätten entweder dem Urteil Gottes überlassen oder aber vor Bischöfen anderer Kirchenprovinzen angeklagt werden sollen, wenn sich gegen die erste Lösung Widerspruch geregt hätte. Auch im Falle Caecilians hätte erst die Gemeinschaft aller Christen den Streit klären müssen, ehe es zur Wahl eines anderen Bischofs hätte kommen dürfen. Denn eigenmächtiges Handeln provoziere die Spaltung der Kirchen.

Beachtenswert sind an dieser Stelle die zwei Alternativen für den Umgang mit Traditoren, die Augustinus als gangbar und den Frieden erhaltend vorstellt. Zum einen akzeptiert er hier die Anrufung eines iudicium dei, wie sie in Cirta von Secundus durchgeführt wurde. Zum anderen plädiert er für die Austragung der Streitigkeiten vor unabhängigen Bischöfen anderer Provinzen und präsentiert so die Catholica als Schlichtungsinstanz für Auseinandersetzungen der afrikanischen Kirche. Beide Alternativen sind an dieser Stelle der Argumentation taktisch motiviert. Es kam Augustinus in erster Linie darauf an, die ungleiche Behandlung der Traditoren in Cirta und der vermeintlichen Traditoren in Karthago herauszustellen. Tatsächlich ist die Vorstellung anachronistisch, von einer bischöflichen Appellationsmöglichkeit an Kollegen anderer Provinzen auszugehen. ${ }^{76}$ Caecilians Motiv, das Konzil von Karthago abzulehnen, bestand folglich nicht in der Hoffnung, in Europa ein faires Urteil zu erhalten, wie Augustinus es seinen Lesern einreden wollte. Vermutlich glaubte Augustinus sogar, dass kirchenrechtlich ein europäisches Konzil in afrikanischen Angelegenheiten entscheiden durfte. Doch spielt seine eigene Überzeugung hier nur eine untergeordnete Rolle. Entscheidend ist Augustins Absicht, einerseits den später tatsächlich erfolgten Freispruch Caecilians durch ein iudicium transmarinum $\mathrm{zu}$ rechtfertigen und bereits in Vorausschau als selbstverständliche Instanz zur Wahrung des Kirchenfriedens zu etablieren, zum anderen auch an dieser Stelle die Notwendigkeit einer gesamtkirchlichen Perspektive darzustellen, die er den Donatisten grundsätzlich absprach. In seiner Interpretation des Entscheidungsablaufs von Karthago 312 verurteilte Augustinus insofern Verstöße der Donatisten gegen ein kirchliches Recht, das der Präzedenzfall Caecilianus erst schaffen sollte.

Nachdem er Ankläger und Richter des Konzils von Karthago abqualifiziert hat, wendet sich Augustinus der Überprüfung der Beweise der Anklage zu. Zentrale Frage war die Schuld des Felix von Abthugni. Während die Donatisten daran festhielten, dass Felix Traditor gewesen und deshalb die Weihe Caecilians zu Recht nicht anerkannt worden sei, verweist Augustinus auf die fehlenden Beweise für diese Anklage. Die Akten aus Karthago gäben keinen Hinweis, woher die Anklage ihre traditio-Anschuldigung genommen habe, und Felix selbst sei 
schließlich nicht verhört worden. Später jedoch, in dem Verfahren vor dem Prokonsul Aelianus, sei Felix nach einer sorgfältigen Untersuchung freigesprochen worden, wie die prokonsularischen Protokolle bewiesen (43.12). Einer der donatistischen Gesprächsteilnehmer in Thubursicum hatte diesen Beweis abgelehnt und angemerkt, dass ein Bischof nicht durch das Urteil eines Prokonsuls gerechtfertigt werden solle. Außerdem hatte er kritisiert, dass während des Verfahrens die Folter gegen Ingentius angewandt worden sei (43.13). Auch wenn diese Aussagen laut Augustinus das Missfallen anderer Gesprächsteilnehmer erregten, so sind sie dennoch bezeichnend für das grundsätzliche Kirchenverständnis der Donatisten. Felix war der traditio angeklagt und nach donatistischer Auffassung rechtmäßig und unwiderruflich durch ein Konzil verurteilt worden; der Freispruch durch ein weltliches Gericht besaß für sie keine Gültigkeit. Dass dieser Freispruch zudem durch das peinliche Verhör des Hauptbelastungszeugen zustande gekommen sei, bestätigte in den Augen des Donatisten in Thubursicum obendrein die Verwerflichkeit dieses Vorgehens. ${ }^{77}$

Augustinus geht auf die beiden Einwände ein und verteidigt den Prozess vor einem weltlichen Gericht, indem er auf die Klage der Donatisten beim Kaiser hinweist, mit der sie schließlich als erste den Fall seiner Sorge unterstellt hätten: „Wenn es aber kein Verbrechen ist an den Kaiser zu appellieren, dann ist es auch kein Verbrechen, vom Kaiser verhört zu werden oder von jenem, an den der Kaiser den Fall übertragen hat. ${ }^{\text {"78 }}$ Dem zweiten Einwand weicht Augustinus aus und verweist auf die Verantwortung des Prokonsuls für die Methode des Verhörs. Felix hätte nicht eingreifen können, ohne sich damit schuldig zu bekennen. Augustinus betont zudem, dass auch der Prokonsul niemals einen Abwesenden verurteilt hätte und schlägt damit nochmals einen Bogen zur Unrechtmäßigkeit des Verfahrens in Karthago im Gegensatz zur rechtmäßigen Durchführung des Verfahrens gegen Felix von Abthugni (43.13).

Nach der Gegenüberstellung der Konzile von Cirta und Karthago mit der Ergänzung um die causa Felicis beleuchtet Augustinus das Verfahren gegen Caecilianus aus einer weiteren Perspektive, indem er die Akten der Synode von Rom auswertet und der Entscheidung von Karthago gegenüberstellt (43.14-18). Zunächst verteidigt Augustinus das rechtmäßige Zustandekommen der römischen Synode unter Miltiades mit dem Hinweis auf das Bittgesuch der Donatisten und dem Brief des Kaisers. Daraus gehe klar hervor, dass der Kaiser auf

77 Die Aussage ist freilich nicht ganz richtig. Den acta purgationis Felicis (Opt. App. II 10) gemäß wurde Ingentius die Folter lediglich angedroht. Vgl. u. Kap. 6.1.3. Vgl. Girardet (Kaisergericht, 10-17) zum altkirchlichen Verständnis bei Streitigkeiten zwischen Christen: Vor einem weltlichen Gericht sollte keine Anklage erfolgen.

78 Ep. 43.13: Si autem criminis non est prouocare ad imperatorem, non est criminis audiri ab imperatore, ergo nec ab illo, cui causam delegauerit imperator. 
Wunsch der Donatisten die richterliche Untersuchung durch den römischen Bischof und dessen Kollegen angeordnet habe. Schon aus diesem Grund sei es kein Unrecht des Miltiades gewesen, das Verfahren nach dem Urteil der siebzig Bischöfe von Karthago an sich zu ziehen (43.14).

Anschließend erläutert Augustinus seinen Adressaten, was sich aus dem Protokoll der Verhandlungen in Rom ergebe: Die Untersuchung sei sorgfältig erfolgt mit der Absicht, den Frieden und die Einheit der Kirche zu bewahren und wiederherzustellen. Es sei festgestellt worden, dass die Ankläger und ihre Zeugen die Anschuldigungen gegen Caecilianus nicht hätten begründen können. Stattdessen hätten sie auf die Anhänger der Partei des Maiorinus im Kirchenvolk verwiesen. Dies bedeute also, folgert Augustinus, dass die Anklage auf eine aufgebrachte und dem Frieden feindliche Volksmenge zurückgehe; allein der Tumult und das Geschrei des Pöbels, die Beschuldigungen einer verführten und von Bestechung berauschten Menge habe die siebzig Bischöfe in Karthago veranlasst, unschuldige und abwesende Kollegen $\mathrm{zu}$ verdammen. ${ }^{79}$ Und jene Bischöfe hätten in Rom noch einmal den Pöbel zum Ankläger Caecilians erheben wollen, doch die Richter dort nicht von ihrem Irrsinn überzeugen können. ${ }^{80}$ Die Richter in Rom nämlich hätten sich nicht von einer anonymen Masse beeinflussen lassen, sondern Ankläger, Zeugen und andere Beteiligte befragen wollen, die aus Afrika mitgereist waren. Doch Donatus, so werde gesagt, habe diese Zeugen entfernt und nicht mehr vorgeführt, obwohl er es versprochen habe. Donatus selbst habe schließlich verweigert, zu den Verhandlungen zu erscheinen, anscheinend um nicht in Gegenwart verurteilt zu werden. Allerdings sei in seiner Anwesenheit seine Schuld hinreichend erwiesen worden (43.15).

Zum Abschluss seiner Interpretation der römischen Akten geht Augustinus auf das Argument der donatistischen Ankläger ein, demgemäß die Anzahl von siebzig urteilenden Bischöfen in Karthago eine schwerwiegende Autorität darstelle, die nicht einfach zu ignorieren sei. Die Richter in Rom, erwidert $\mathrm{Au}$ gustinus, hätten die Anzahl der Bischöfe nicht mehr beachtet, als sie sahen, in welch blindem Eifer diese überstürzt, ohne Anhörung und in Abwesenheit der Beklagten, ihre Kollegen verurteilt hätten. Miltiades habe dagegen ein unbestechliches, vorsichtiges und friedfertiges Schlussurteil gesprochen. Er habe allein Donatus verurteilt, den er als Urheber des ganzen Übels ansah, allen anderen habe er die Möglichkeit zur Umkehr gegeben. Er habe die Bereitschaft

79 Vgl. Kriegbaum, Kirche der Traditoren, 107 mit Anm. 41 zum Verständnis von ep. 43.14. Eventuell beruft sich Augustinus hier auf spätere Zeugenaussagen.

80 Ep. 43.14: quali enim turbae illi consenserant [septuaginta episcopi], ut aduersus innocentes non interrogatos proferrent sententias, a tali turba etiam rursus accusari Caecilianum uolebant, sed plane non tales inuenerant iudices, quibus illam dementiam persuaderent. Ich lese 'non tales inuenerant iudices'. Die von Goldbacher bevorzugte Lesart 'tales' gibt im Zusammenhang keinen Sinn. 
erklärt, Gemeinschaftsbriefe an die von Maiorinus geweihten Bischöfe zu senden und bestimmt, dass dort, wo bereits zwei Bischöfe nebeneinander existierten, der früher Geweihte die Gemeinde behalten solle. Auf diese Weise habe der Frieden gesiegt:

„Vergleichet nun diese kleine Zahl von Bischöfen mit jener großen Menge, vergleichet aber nicht Zahl um Zahl, sondern das jeweilige Gewicht ihres Ansehens: Hier Besonnenheit, dort Unbesonnenheit, hier Wachsamkeit, dort Verblendung! Hier zerstörte weder die Milde die Gerechtigkeit, noch standen Gerechtigkeit und Milde im Widerspruch zueinander; dort aber wurde mit Zorn die Furcht überdeckt und durch die Furcht wurde der Zorn angespornt. Diese nämlich waren zusammengekommen, um durch die Untersuchung der wahren Verbrechen die falschen zurückzuweisen, jene aber, um durch Verdammung der falschen Verbrechen die wirklichen zu verbergen." ${ }^{81}$

Die Analyse der Konzilsakten ergänzt Augustinus durch zwei weitere Anschuldigungen gegen die bischöflichen Richter in Karthago, mit denen Caecilians Weigerung, vor diesem Gremium zu erscheinen, zusätzlich gerechtfertigt werden soll. Erstens gehe aus den gesta apud Zenophilum hervor, dass Secundus und die anderen Bischöfe nicht nur von ihrer eigenen Schuld ablenken wollten, sondern außerdem von der reichen Lucilla bestochen worden seien, jener Frau, die Caecilianus noch als Diakon beleidigt habe, als er sie kirchendisziplinarisch zurechtweisen musste. Zweitens habe bei einigen Bischöfen auch verletzte Eitelkeit dazu beigetragen, dass sie Caecilianus gegenüber feindlich eingestellt gewesen seien, da sie bei dessen Ordination nicht berücksichtigt worden seien. Diese Motive der Bischöfe hätten es Caecilianus unmöglich gemacht, sich dem Urteil in Karthago zu unterwerfen, da er schließlich keinen aufrichtigen Richtern, sondern feindlich gesinnten und bestochenen Leuten hätte entgegengetreten müssen. Gleichzeitig habe Caecilianus gewusst, dass von den überseeischen Bischöfen, abseits von Feindschaft und Parteilichkeit, eine gerechte Untersuchung zu erwarten sei, der sich auch seine Gegner unterziehen müssten, wenn sie sich nicht von der weltweiten Gemeinschaft trennen wollten. ${ }^{82}$

81 Ep. 43.16: conferte nunc istam paucitatem cum illa multitudine episcoporum neque numerum numero sed pondus ponderi comparate: hinc modestiam, inde temeritatem; hinc uigilantiam, inde caecitatem; hic nec mansuetudo integritatem corrupit nec integritas mansuetudine repugnauit, ibi autem et furore timor tegebatur et timore furor incibatur; isti enim conuenerant cognitione uerorum criminum falsa respuere, illi falsorum damnatione uera celare.

82 Ep. 43.17-18, vgl. 25-26. Zum Inhalt der gesta apud Zenophilum s. u. Kap. 6.2.2. - Zu Recht sieht Kriegbaum (Kirche der Traditoren, 110 Anm. 52) bei Augustinus eine vorgeschobene Begründung: Der Hauptgrund für Caecilians Weigerung, vor dem Konzil zu erscheinen, sei die Beeinträchtigung seiner Rechtsposition durch das Verlassen der Kathedra gewesen. Andernfalls hätte Caecilianus die fehlende rechtliche Bindung seiner Wahl zugegeben. 
Zusammenfassend ist festzustellen, dass Augustinus in der Gegenüberstellung der Konzile von Karthago und Rom das Verfahren in Karthago mit drei Argumenten angreift: Das erste Argument betrifft das Zustandekommen des römischen Konzils. Die Bitte um ein neues Bischofsgericht sei von den Donatisten ausgegangen und dieses Gericht sei in Rom rechtmäßig durchgeführt worden. Ein Widerspruch gegen die Richter daher nicht möglich. Mit seinem zweiten Argument stilisiert Augustinus den parteiischen karthagischen Pöbel zum eigentlichen Ankläger Caecilians. Dieser habe sich in Karthago Gehör verschaffen können, in Rom jedoch hätten andere Zeugen nichts mehr zu sagen gewusst. Die Gegenüberstellung der Richter von Karthago und der Richter von Rom verdeutlicht für Augustinus, wessen Urteil das rechtmäßige gewesen sei. Das dritte Argument spitzt den Gegensatz zwischen den Richtern noch weiter zu. Die Anzahl der Bischöfe sei nicht entscheidend, wenn elementare christliche Tugenden ignoriert und in Verblendung und Rachsucht Urteile gesprochen werden. Damit bleibt Augustinus auch hier im Bezug zum Konzil von Karthago: Die Leser sollen die Personen und die Urteile abwägen, nicht die Anzahl der Richter zählen. Zur Verstärkung zieht er die Bestechungsvorwürfe sowie das unchristliche Motiv der gekränkten Eitelkeit heran, um die Richter endgültig zu diskreditieren.

Augustins Interpretationen der römischen Akten und seine Ausführungen über Hintergründe und Motive der Donatisten sind eine wichtige Quelle für die Rekonstruktion dieser Ereignisse. Da die Protokolle der Verhandlungen in Rom nicht erhalten sind, wird zu fragen sein, wie seine Angaben in ep. $43 \mathrm{zu}$ bewerten sind. Auf jeden Fall ordnete er seine Informationen seiner Argumentationsstrategie unter, um die Differenz zwischen den Verhandlungen in Rom und Karthago herauszustellen. Rom sollte als Beispiel des richtigen und rechtmäßigen Umgangs mit kirchlichen Streitigkeiten dienen, als Wiedergutmachung der Versäumnisse in Karthago. ${ }^{83}$

Bevor Augustinus zum Abschluss der historischen Argumentation die endgültige Entscheidung der causa Caeciliani durch Konstantin referiert, ergänzt er einige Erklärungen zu dem Bittgesuch der Donatisten an Kaiser Konstantin. Es war ihm daran gelegen, einen drohenden Widerspruch auszuräumen, der sich durch seine vorangegangenen Ausführungen andeutete. Auf der einen Seite hatte er von der Notwendigkeit eines unabhängigen Gerichts in Übersee gesprochen, auf der anderen Seite die Durchführung des römischen Verfahrens mit der Initiative der Donatisten begründet. Augustinus musste also darlegen, warum die Klage der Donatisten beim Kaiser nicht der richtige Weg gewesen sei, und er führt dies aus, indem er die donatistischen Kläger wiederum einer falschen Motivation bezichtigt (43.18-19). Augustinus beanstandet, dass der 
Fall Caecilians nicht sofort vor ein europäisches Gericht getragen worden sei. Vermutlich hätten die Donatisten so lange gewartet, damit sich vor einem Prozess ihre falschen Gerüchte über die Zeit verfestigen konnten. Wahrscheinlicher sei jedoch, dass die Donatisten gar nicht gewagt hätten die Sache dort zu verhandeln, wo die Wahrheit ans Licht gekommen wäre, während sie sich in der Heimat im Vertrauen auf ihre Anzahl ihrer Sache völlig sicher gewesen seien (43.18). Die Donatisten hätten sich erst an ein Gericht in Übersee gewandt, als das Schisma schon längst vollzogen gewesen sei und sie gemerkt hätten, dass die Christenheit nicht mit ihnen, sondern mit Caecilianus Gemeinschaft halte. Da man den Donatisten hätte vorwerfen können, sie akzeptierten ohne Widerspruch die Gemeinschaft der anderen Kirchen mit dem von ihnen verurteilten Bischof, hätten sie handeln müssen.

Diese Ausführungen erwecken den Anschein, dass die Donatisten nicht aus Einsicht, sondern aus Notwendigkeit ein erneutes Bischofsgericht gefordert hätten. Nachdem die anderen Kirchen der Christenheit in der Gemeinschaft mit Caecilianus verblieben seien, mussten die Donatisten zur Überwindung der Isolation die Anerkennung aus Übersee erlangen, um nicht als Sekte angesehen zu werden. Das Bittgesuch an den Kaiser sei so zwingend geworden, um den donatistischen Bischof von Karthago als den rechtmäßigen bestätigen zu lassen. Augustinus kann auf diese Weise demonstrieren, dass zum einen die weltweite Kirche nicht zu missachten sei, zum anderen aber die donatistischen Ankläger Caecilians sich nicht aus Erkenntnis dieser Tatsache, sondern aus Zwang beugen mussten.

Anhand eines Konstantinbriefes, der während des Gesprächs auch vorgelesen wurde, stellt Augustinus dar, auf welche Weise aus seiner Sicht der Fall endgültig entschieden worden sei. In der Beschreibung der Prozessfolge gegen Caecilianus stellt Augustinus heraus, dass es für den Kaiser nicht nötig gewesen wäre, das Verfahren fortzusetzen, jedoch habe dieser der Hartnäckigkeit der Ankläger nachgegeben, in dem Wunsche, ihre Dreistigkeit zu bändigen. Er habe aber nicht gewagt, selbst über das Urteil der Bischöfe zu richten und habe deshalb ein weiteres Bischofsgericht eingesetzt. Für sein eigenes Urteil habe der Kaiser später die Bischöfe um Verzeihung gebeten. Doch die Donatisten hätten nicht so rücksichtsvoll gehandelt wie der Kaiser. Sie hätten weder dem Urteil der Bischöfe noch dem Urteil des Kaisers Folge geleistet, obwohl sie nichts mehr hätten vorbringen können. Folgendermaßen sei die Sache entschieden worden:

„Der Kaiser nämlich befahl, dass die beiden Parteien zu ihm nach Rom kommen sollen, um den Fall zu verhandeln. Weil aus mir nicht bekannten Gründen Caecilianus dort nicht eintraf, ordnete er auf ihren [der Donatisten] Einspruch an, dass sie [ihm] nach Mailand folgen sollten. Darauf begannen einige der [donatistischen Partei] sich heimlich aus dem Staub zu machen, vielleicht aus Empörung, weil Konstantin sie nicht nachahmte, indem er Caecilianus sofort und schnell in Ab- 
wesenheit aburteilte. Als der vorausschauende Kaiser dies bemerkte, ließ er die anderen unter Bewachung nach Mailand bringen. Nachdem auch Caecilianus dort angekommen war, ermittelte der Kaiser auch selbst, wie er schreibt, und nach Untersuchung des Falles - mit welcher Sorgfalt, Achtsamkeit und Weitsicht er vorging, beweist sein Brief - erklärte er Caecilianus für vollkommen unschuldig, seine Gegner aber umfassend für schuldig. “ 84

Augustinus gibt an dieser Stelle wichtige Informationen über den Abschluss der causa Caeciliani vor den bischöflichen Gerichten und durch das kaiserliche Urteil. Umso wichtiger ist es, genau zwischen Augustins Kenntnissen der Fakten und seinen Interpretationen zu unterscheiden. Die Fakten, von denen Augustinus ausging und die er dem angegebenen Kaiserbrief entnahm, sind schnell aufgeführt: Die Anklage der römischen Richter beim Kaiser, der Entschluss ein erneutes Urteil durch Bischöfe in Arles fällen zu lassen, der Appell der Donatisten nach Arles, die Entscheidung des Kaisers, selbst zu urteilen, die Vorladung der Parteien nach Rom, das Ausbleiben Caecilians, die Verlagerung des Hofes nach Mailand, der Fluchtversuch einiger Donatisten und schließlich die Verhandlungen in Mailand mit der Entscheidung zu Gunsten Caecilians. ${ }^{85}$

Augustinus ist sichtlich bemüht, den Brief in einer Weise zu interpretieren, die dem Kaiser eine weitgehend passive Rolle bei der Lösung des Streites beimisst. Konstantin erhält von Augustinus den Nimbus des christlichen Kaisers, der sich unermesslich großzügig gegenüber dem Begehren der Donatisten gezeigt habe und demütig gegenüber der katholischen Kirche und ihren Bischöfen. Als treibende Kraft beschuldigt Augustinus dagegen wiederum die Donatisten. Anders als bei ihrer ersten Bitte um Richter hebt er an dieser Stelle nicht nur die Initiative heraus, sondern unterstellt gleichzeitig eine Verletzung kirchlichen Rechts. Die Donatisten hätten die Bischöfe nicht beim Kaiser anklagen, sondern allenfalls ein weiteres Bischofsgericht anrufen dürfen! Die Einberufung des Konzils von Arles durch den Kaiser verteidigt Augustinus entsprechend: Der christliche Kaiser habe gleichsam die Anklage an ein rechtmäßiges Gremium zurückverwiesen und es so (in vorbildlicher Weise) unterlassen, als weltlicher Herrscher über Bischöfe zu urteilen. Die Zulassung der Revision selbst beurteilt Augustinus bereits als Zeichen von Großmütigkeit, keinesfalls

84 Ep. 43.20: iussit enim ille [imperator], ut ei partes ad agendam causam Romam occurrerent. quo cum Caecilianus nescio qua causa non occurrisset, interpellatus ab eis praecepit, ut Mediolanum sequerentur. tunc se aliqui eorum subtrahere coeperant fortasse indignati, quia non est eos imitatus Constantinus, ut iam statim atque uelociter Caecilianum damnaret absentem. quod ubi cognouit prouidus imperator, reliquos ab officialibus custoditos fecit Mediolanum peruenire. quo cum etiam Caecilianus uenisset, ipsum quoque, sicut scripsit, exhibuit, cognitaque causa qua diligentia. qua cautela, qua prouisione, sicut eius indicant litterae, Caecilianum innocentissimum, illos inprobissimos iudicauit.

85 Augustinus zitiert aus dem Brief Konstantins an den Vikar Eumalius. Zur Identifizierung vgl. unten Kap. 7.4. 
als Notwendigkeit. Damit stellt er das Urteil von Rom an den Platz, den die Donatisten dem Urteil von Karthago einräumten. Die Folgeurteile von Arles und schließlich des Kaisers gelten ihm somit als Bestätigungen des ersten und einzig rechtmäßigen Verfahrens im Fall Caecilianus: das Verfahren in Rom.

Den Prozess vor dem Kaiser kann und will Augustinus dennoch nicht umgehen. Immerhin bezeugte gerade das Urteil Konstantins nichts anderes, als die Bischöfe vorher bereits entschieden hatten. Wiederum rechtfertigt er jedoch das Handeln des Kaisers. Er weist auf die Worte Konstantins, mit denen dieser selbst die donatistischen Appelle kritisiert habe, und er lässt sich sogar zu der Aussage hinreißen, dass Konstantin die Bischöfe um Verzeihung gebeten habe, weil er das Verfahren übernommen hatte. Während die überlieferten Quellen die Kritik Konstantins an den Donatisten durchaus bestätigen, gibt es für einen irgendwie gearteten Bittgang des Kaisers vor die Bischöfe keinerlei Anhaltspunkte. Es passte aber Augustinus für den Augenblick der Überzeugungsarbeit in ep. 43 besser ins Bild, die Demut Konstantins in besonderer Weise herauszustellen. Über die weiteren Hintergründe der Verzögerung der Untersuchung und dem Ablauf in Mailand scheint Augustinus nicht im Detail unterrichtet gewesen zu sein. Über Caecilians Ausbleiben in Rom will er nicht spekulieren und für die vermeintlichen Fluchtversuche der Donatisten zieht er den Gegensatz von Anwesenheit und Abwesenheit vor Gericht heran, ohne jedoch den Hintergrund dieser seltsamen Flucht vom kaiserlichen Hof damit aufzuklären. Das Ziel Augustins war es, als Hinführung auf den Freispruch Caecilians durch Konstantin klarzustellen, dass der Kaiser weder aus eigener Anmaßung noch aus Parteilichkeit über Caecilianus entschieden habe, sondern einzig und allein, weil die Donatisten permanent auf sein Urteil gedrängt hätten, nachdem sie die kirchlichen Entscheidungsinstanzen nicht hätten anerkennen wollen. ${ }^{86}$

Ep. 43 ist ein Glücksfall in der Überlieferung. Welche Absicht Augustinus für die Zeit vor 405 mit der historischen Argumentation verfolgte, wird zwar auch in den kurzen Darstellungen von ep. 53 oder ep. 76 sowie in anderen Notizen zur causa Caeciliani deutlich, jedoch findet sich in keiner anderen Schrift dieses Zeitraums mehr über Augustins zielgerichtete Auslegung der historischen Dokumente. Augustinus arbeitete mit geschickten Gegenüberstellungen, juristischen Feinheiten und klaren Schuldzuweisungen, alles vorgetragen in glänzender Rhetorik. Mit seinen Interpretationen war er in der Lage, den Freispruch Caecilians in allen Facetten als rechtskräftig begreifbar zu machen. Augustinus widersprach vor allem den donatistischen Anklagen der Vermischung von Kirche und Staat, indem er deutlich das römische Urteil der Bischöfe in den Vordergrund rückte, während er das kaiserliche Urteil über Caecilianus, wie auch den Prozess gegen Felix von Abthugni, als von den Donatisten erzwungenen Zusatz darstellte. Nach Augustins Verständnis waren

86 Zur Einordnung von Augustins Ausführungen in den historischen Kontext s. u. Kap. 7.4. 
kirchenrechtlich die Urteile von Rom und Arles bindend, da nur dort dem geltenden Recht entsprechend verhandelt worden sei. Zum Nachweis der Rechtmäßigkeit verwies Augustinus auf die Anwesenheit des Angeklagten, die Unbestechlichkeit und Unabhängigkeit der bischöflichen Richter, die Anhörung beider Parteien mit aufrichtigen Zeugen sowie die Möglichkeit des Appells an ein Bischofsgericht in Übersee. Die Konsequenz aus dieser Darstellung sollten die Leser von ep. 43 ziehen: die Ungültigkeit des Urteils von Karthago 312 und dadurch der Verlust einer Legitimation der donatistischen Partei.

2.2 Kontinuität der Gesetzgebung: Die Briefe nach 405 (epp. 88, 89, 93, 105)

Die Veränderung in der Argumentation Augustins nach dem Unionsgesetz vom Februar 405 ist bei der Betrachtung der einzelnen Briefe bereits dargelegt worden. ${ }^{87}$ Es stellt sich hier die Frage, welche Auswirkungen die geänderten Voraussetzungen auf die Verwendung der historischen Argumente hatten. Die causa Caeciliani wird in den Briefen an Ianuarianus (ep. 88), an den Rogatisten Vincentius (ep. 93), an Festus (ep. 89) und an alle Donatisten (ep. 105) thematisiert. Augustinus beabsichtigte in allen vier Briefen mit seiner Interpretation des Falles Caecilianus einen Beweis für zwei Thesen zu führen:

Erstens, die Donatisten hätten als erste und ohne Zwang den Streitfall vor das kaiserliche Gericht getragen. Diese These ist bereits aus früheren Briefen und Schriften bekannt, wird nach 405 jedoch wesentlich stärker in den Vordergrund gerückt.

Zweitens, die neuen Gesetze gegen die Donatisten seien nichts anderes als die Erneuerung und konsequente Anwendung des längst von Konstantin gefällten Urteils im Fall Caecilianus. Augustinus versucht also, zwischen Vergangenheit und Gegenwart eine rechtliche Kontinuität herauszustellen. Derartige Bezüge auf bereits vorhandene, von früheren Kaisern verkündete Gesetze, die lediglich „erneuert“ werden, sind vielfach aus Gesetzestexten bekannt. Nicht zuletzt beruft sich Honorius in der Präambel des Unionsgesetzes von 405 selbst auf bereits bestehende Gesetze. Augustinus adaptiert insofern die juristischen Formulierungen und führt sie in seiner Argumentation weiter aus. ${ }^{88}$

Im Vergleich zu den Briefen vor 405 ist besonders auffällig, dass Ausführungen zur causa Silvani fehlen. Außer zwei kurzen Notizen zum Konzil von Karthago (ep. 88.3, 5) und Hinweisen, dass es Beweise für die Unwahrheit der traditio-Anklagen gebe (105.16-17), findet sich nichts zum Konzil von Cirta, Silvanus von Cirta oder über den Ablauf der Absetzung Caecilians in Karthago. Augustinus verzichtet somit auf die Erörterung der historischen traditio-Schuld

87 S. o. Kap. $4.1 .2-3$.

88 Vgl. o. Kap. 2.2.2. 
und damit auf die „Gegenklage“, die er unter anderem gegenüber Petilianus ausgiebig behandelte und später gegen Cresconius nochmals verteidigte. Er stellt die vor allem in ep. 43 intensiv betriebene Schuldzuweisung im Bezug auf die Urheber des Schismas in den Hintergrund und konzentriert sich auf die Urheberschaft der Klage gegen Caecilianus, den technischen Ablauf des Verfahrens und die juristischen Folgen.

Zum Beweis seiner ersten These konnte Augustinus auf ein Dokument zurückgreifen, das ihm vor 405 noch nicht zur Verfügung gestanden hatte: der Bericht des Prokonsuls Anullinus, mit dem dieser am 15. April 313 die von der pars Maiorini entgegengenommene Anklage an den Kaiser weitergeleitet hatte ${ }^{89}$ Während Augustinus in dreien der Briefe auf diese relatio Anullini lediglich hinweist, ${ }^{90}$ enthält der Brief an Ianuarianus den vollständigen Text des Dokuments. Darin berichtet Anullinus, dass er die kaiserliche Anordnung, Bischof Caecilianus und dessen Kleriker von Abgaben zu befreien, umgesetzt habe. Dann seien jedoch Gegner Caecilians, begleitet von einer Volksmenge, bei ihm erschienen. Diese hätten ihm zwei Schriftstücke (libelli) zur Weiterleitung an Konstantin übergeben, ein versiegeltes und ein offenes. Das versiegelte Schriftstück trug den Titel: „Libellus der katholischen Kirche bezüglich der Vergehen Caecilians überreicht von der Partei des Maiorinus“.91

Zweifellos musste jeder Leser dieses Dokuments, vorausgesetzt, er glaubte an seine Authentizität, Augustins Schlussfolgerung nachvollziehen, die er allen Adressaten gegenüber formuliert: Die Vorfahren der Donatisten seien zuerst den Weg zu den staatlichen Instanzen gegangen, indem sie Caecilianus durch Anullinus beim Kaiser angeklagt hätten. Augustinus hebt sehr deutlich die Freiwilligkeit dieser Anklage hervor, keiner habe damals die Donatisten gezwungen, den Kaiser anzurufen, sondern freiwillig, von sich aus (ultro) seien sie vor das Gericht gezogen. ${ }^{22}$

Auf dieser Feststellung baute Augustinus die weitere Argumentation zur Begründung seiner zweiten These auf - die Darstellung einer Kontinuität der Gesetzgebung: Mit der donatistischen Anklage seien die Verfahren erst ins Rollen gekommen. Dann habe der Kaiser aufgrund der Anklage zunächst das Bischofsgericht in Rom zusammengerufen, in dem die Sache entschieden und Caecilianus freigesprochen worden sei. Infolge der Appelle der Kläger an den Kaiser gegen dieses Urteil seien das zweite Bischofsgericht und schließlich das Verfahren vor dem Kaiser selbst notwendig geworden $(88.3 ; 89.3 ; 93.13 ; 105.8)$.

89 Dies hat Girardet (Chiron 19, 1989, 200-203) überzeugend nachgewiesen. Vgl. dazu unten Kap. 7.2.

90 Ep. 89.3; 93.13 (mit kurzem Zitat); 105.10.

91 Ep. 88.2; vgl. u. Kap. 7.2.

92 Ultro accusavit Caecilianum (88.1); ultro per Anulinum [...] accusare ausi sunt Caecilianum (89.3); ultro accusantes (93.14); causam Caeciliani ultro detulerunt (105.10). 
Allen Adressaten gegenüber kritisiert Augustinus, dass die Donatisten Caecilianus nicht vor anderen Bischöfen, sondern vor dem Kaiser verklagt hätten (88.5; 89.3; 93.13). In Gegenüberstellung zu diesem falschen Handeln lobt er den Kaiser. Konstantin habe es nicht gewagt, selbst über Bischöfe zu richten und deshalb den Fall an Bischöfe delegiert (105.8). Damit habe er wesentlich ordnungsgemäßer gehandelt (longe ordinatius agente) als die Ankläger selbst (93.13). Nur wegen der weiteren hartnäckigen Eingaben auch nach dem zweiten Bischofsurteil sei Konstantin gleichsam gezwungen worden, letztlich selbst in die kirchliche Angelegenheit (causa episcopalis) einzugreifen und zu entscheiden (88.3).

Indem er die Geduld des Kaisers, sein Zögern selbst zu urteilen und seine Unterordnung unter bischöfliche Entscheidungen hervorhob, versucht Augustinus, ein positives Herrschaftsbild zu vermitteln. Konstantin habe keineswegs unbedacht in die kirchliche Streitfrage eingegriffen oder sich gar bischöfliche Macht angemaßt, sondern er habe dem Druck der Donatisten am Ende nachgegeben. Deshalb laufe die donatistische Kritik an der kaiserlichen Unterstützung für die katholische Kirche ins Leere. So kann Augustinus an Vincentius gerichtet fragen: „Warum werft ihr uns vor, worauf eure Leute zuerst ihre Hoffnung gesetzt haben?"93

Während in den meisten Aufzählungen der donatistischen Appelle an Konstantin lediglich allgemein von einer Klage der Donatisten über das Urteil oder die urteilenden Bischöfe die Rede ist, wird im Brief an Ianuarianus eine kurze Begründung für die Berufung nach der Entscheidung von Rom genannt. Die Ankläger hätten vorgebracht, dass weder das Urteil rechtmäßig zustande gekommen noch der ganze Fall angehört worden sei (88.3: non recte iudicatum neque omnem causam auditam esse). ${ }^{94}$ Außerdem behaupten die Absender, nach dem Urteil der Bischöfe von Arles seien viele Anhänger der pars Donati zur Kirchengemeinschaft zurückgekehrt, ${ }^{95}$ einige andere aber im Schisma verblieben, die dann erneut appelliert hätten (88.3).

Entscheidend für Augustins Argumentation ist nun die Information über ein Gesetz gegen die Partei der Donatisten, das Konstantin nach seinem Urteil über Caecilianus erlassen haben soll. Dieses Gesetz, teilt Augustinus mit, habe im Falle von anhaltendem Widerstand gegen die Kircheneinheit, die Konfiszierung von Besitztümern verfügt. ${ }^{96}$ Für Augustins Argumentation setzt diese kaiserli-

93 Ep. 93.13: quid nobis obicitis, quod uestrorum praesumptio primitus fecit?

94 In Karthago 411 begründeten die Donatisten ihre Kritik am römischen Urteil wesentlich grundsätzlicher, als in ep. 88 dargestellt wird. Sie versuchten, Miltiades das traditioVergehen nachzuweisen. Vgl. u. Kap. 5.1.3.

95 Grasmück (Coercitio, 64) übernimmt diese Aussage unkritisch.

96 Ep. 88.3: [Constantinus] primus contra uestram partem legem constituit ut loca congregationum uestrarum fisco uindicarentur; 93.14: imperator primus constituit in hac causa, ut res conuictorum et unitati peruicaciter resistentium fisco uindicarentur. - Weniger 
che Verfügung den Ausgangspunkt für eine Verbindung zur aktuellen Lage: $:^{97}$ Nachdem die Entscheidung im Fall Caecilians gefallen sei, sei es dem Kaiser gar nicht mehr möglich gewesen, von dem einmal eingeschlagenen Weg abzuweichen. Dieses Gesetz sei die notwendige Folge aus dem Urteil zu Gunsten Caecilians gewesen. Im Falle eines anderen Ausgangs des Prozesses hätten ebenso entsprechende Maßnahmen gegen Caecilianus und seine Anhänger verhängt werden müssen $(89.5$; 93.14). Von diesen ersten gesetzlichen Bestimmungen gegen die Donatisten schlägt Augustinus den Bogen zu den Zwangsmaßnahmen seiner Zeit:

„Welches andere als jenes Urteil des älteren Konstantin gegen eure Partei lebt heute noch? Das Urteil, das eure Vorfahren wählten, das sie mit fortwährenden Beschwerden erpressten und das sie dem bischöflichen Urteil vorzogen. “"

Dieses selbst gewählte, ja Konstantin abgenötigte Urteil sei stets in Kraft gewesen, durchgehend anerkannt und von allen Kaisern mit Ausnahme Julians geachtet worden. Besonders anschaulich schildert Augustinus diese Kontinuität gegenüber den donatistischen Laien in ep. 105:

„Darauf erließ Konstantin zum ersten Mal ein sehr strenges Gesetz gegen die Partei des Donatus. Seine Söhne verfügten in gleicher Weise solche Gesetze. Ihnen folgte Julian, ein Apostat und Feind Christi, der auf Antrag eurer Vertreter Rogatianus und Pontius der Partei des Donatus eine Freiheit zum Verderben gewährte. Am Ende gab er den Häretikern die Basiliken zu dem Zeitpunkt zurück, als er den Dämonen die Tempel [zurückgab]. Er glaubte, auf diese Weise das Christentum von der Erde vertilgen zu können, wenn er die Einheit der Kirche, von der er abgefallen war, bekämpfte und den gottlosen Abspaltungen die Freiheit gestattete. Dies war seine zu preisende Gerechtigkeit, mit der die Bittsteller Rogatianus und Pontius den Apostaten lobten, indem sie sagten, bei ihm allein habe die Gerechtigkeit ihren Platz. Diesem folgte Jovian, der nichts in diesen Angelegenheiten verordnete, da er bald gestorben ist. Darauf kam Valentinian: Lest, was er gegen euch befahl! Dann Gratian und Theodosius: Lest, wenn ihr wollt, welche [Maßnahmen] sie gegen euch beschlossen. Warum wundert ihr euch also über die Söhne des Theodosius, als ob sie in dieser Sache etwas anderem folgen sollten, als

formal in 105.9: tunc Constantinus prior contra partem Donati seuerissimam legem dedit. - Anspielungen auf dieses Gesetz finden sich ausschließlich bei Augustinus: vgl. auch c. litt. Pet. II 205; c. ep. Parm. I 13, 18. Aus einem Reskript des Jahres 321 an den Vikar Verinus (breuic. III 40, 42) lässt sich schließen, dass es zuvor Verbannungen von Bischöfen gegeben hatte. Wahrscheinlich gehen diese Maßnahmen auf das von Augustinus erwähnte Gesetz zurück; vgl. u. Kap. 6.3.1. Vgl. Grasmück (Coercitio, 84), der ohne nähere Begründung meint, dass sich CTh XVI 6.2 auf die bei Augustinus erwähnte lex beziehe.

97 Monceaux (VI, 295) stellt nur eine Absicht der Absender heraus, die Initiative der Donatisten beim Kaiser. Er übersieht die konkrete Anknüpfung an die Kontinuität der Gesetzgebung.

98 Ep. 88.5: et nunc quid aliud quam ipsius maioris Constantini iudicium contra uestram partem uiuit, quod maiores uestri elegerunt, quod assiduis interpellationibus extorserunt, quod episcopali iudicio praetulerunt? 
dem Urteil Konstantins, das von so vielen christlichen Kaisern strengstens beibehalten wurde?“99

Augustinus nennt die geschlossene Kette der Kaiser bis hin zu Honorius und Arcadius, die mit Ausnahme des von den Donatisten hofierten Julian den Verordnungen Konstantins gefolgt seien. Mit einem Satz fasst er nochmals zusammen: „Konstantin ist tot, aber das Urteil Konstantins gegen euch lebt."

Augustinus ließ keine Möglichkeit aus, um seine These noch weiter zu untermauern. An der zitierten Stelle wie auch gegenüber Vincentius (93.12) stellt Augustinus Kaiser Julian heraus und präsentiert ihn gleichsam als Antitypus zu Konstantin. Ausgerechnet an den Herrscher, der als einziger mit den Verordnungen des christlichen Kaisers Konstantin gebrochen hatte, hätten sich die Donatisten mit der Bitte um Hilfe gewandt und ihn anschließend für seine Unterstützung auch noch belobigt. Allein wegen dieses Handelns könne jeder Vorwurf gegen katholische Bitten an christliche Kaiser ad absurdum geführt werden. Auch die von ihm häufig herangezogene Gewalt der Donatisten gegen die Maximianisten verwendet Augustinus für den Nachweis gesetzlicher Kontinuität. Schließlich seien die Donatisten auf Grundlage der bestehenden und damit gültigen Gesetze gegen die Maximianisten und andere Abspaltungen vorgegangen $(88.11$; 93.12). Gegenüber Vincentius bezieht Augustinus bisher geschehene Konversionen ebenfalls auf die bereits seit Konstantin bestehende Gesetzgebung. Durch diese Gesetze seien die Donatisten aus ihrer Erstarrung, Trägheit oder ihrem Hochmut gerissen und auf den richtigen Weg aufmerksam worden (93.17). ${ }^{101}$

99 Ep. 105.9: Tunc Constantinus prior contra partem Donati seuerissimam legem dedit. hunc imitati filii eius talia praeceperunt. quibus succedens Iulianus, desertor Christi et inimicus, supplicantibus uestris Rogatiano et Pontio libertatem perditioni parti Donati permisit; denique tunc reddidit basilicas haereticis, quando templa daemoniis. eo modo putans Christianum nomen posse perire de terris, si unitati ecclesiae, de qua lapsus fuerat, inuideret et sacrilegas dissensiones liberas esse permitteret. haec erat eius praedicanda iustitia, quam supplicantes Rogatianus et Pontius laudauerunt dicentes homini apostatae, quod apud eum sola iustitia haberet locum. huic successit Iovianus, qui quoniam cito mortuus est, nihil de rebus talibus iussit. deinde Valentianus; legite, quae contra uos iusserit. inde Gratianus et Theodosius; legite, quando uultis, quae de uobis constituerint. quid ergo de filiis Theodosii miramini, quasi aliud in hac causa sequi debuerunt, quam Constantini iudicium per tot Christianos imperatores firmissime custoditum? - $\mathrm{Zu}$ den donatistischen Legaten Rogatianus und Pontius vgl. Opt. II 16; c. litt. Pet. II 184, 205, 224; Maier II, Nr. 39, 42 f.; Congar, BA 28, 730 f.; Quinot, BA 30, 797-799; Mandouze, PAC, 986, s. v. Rogatianus 5; 885 f., s. v. Pontius 1.

100 Ep. 105.10: defunctus est Constantinus, sed iudicium Constantini contra uos uiuit.

101 Die alttestamentliche Danielerzählung (Dan. 6.16-24) verwendet Augustinus als biblisches Vorbild gesetzlicher Konsequenz: Daniel wurde als Opfer einer falschen Anklage den Löwen vorgeworfen. Nachdem die Verlogenheit der Ankläger ans Licht gekommen war, wurden diese zu der gleichen Strafe verurteilt, die sie Daniel zugedacht hatten. Augustinus folgert daraus: „In gleicher Weise warfen eure Vorfahren Caecili- 
Während Augustinus gegenüber den donatistischen Adressaten die Sinnlosigkeit eines Aufbegehrens gegen die bestehenden Gesetze postuliert, da sie selbst von ihnen herausgefordert worden seien, so erläutert er mithilfe der gleichen Argumente gegenüber dem Katholiken und Beamten Festus, warum die Donatisten im Unrecht seien und bekämpft werden müssten. Festus sollte erkennen, dass die gegenwärtigen Maßnahmen gegen die Donatisten keine ungerechte Verfolgung seien, sondern nichts anderes als eine zwangsläufige Sanktion für den Verstoß gegen eine kaiserliche Verfügung. Diese Verfügung sei am Ende eines rechtmäßigen Verfahrens ergangen, nachdem dieses Verfahren auf juristisch korrektem Weg von den Donatisten selbst eingebracht worden sei. Die donatistische Haltung, sich selbst als Opfer der Verfolgung und als Märtyrer $\mathrm{zu}$ stilisieren, entbehre insofern jeglicher Grundlage. ${ }^{102} \mathrm{Im}$ Gegensatz dazu präsentiert Augustinus die katholische Seite als gesetzestreu und dem Willen

anus und seine Anhänger dem königlichen Zorn zum Verzehr vor. Nachdem dieser von den Königen wegen seiner Unschuld befreit worden war, erleidet ihr nun das, was eure Leute diesen antun wollten. Wie geschrieben steht: Wer dem nächsten eine Grube gräbt, wird selbst in sie hereinfallen." (similiter maiores uestri Caecilianum et eius societatem regiae irae consumendam obiecerunt, cuius innocentia liberata ab eisdem regibus eadem uos patimini, quae illos uestri pati uoluerunt, quoniam scriptum est: Qui parat proximo foueam, ipse incidet in eam [Eccl. 27, 29]), ep. 88.5; vgl. ep. 93.19.

102 Ep. 89. 3: „Wenn nämlich Caecilianus und seine Kollegen, nachdem sie von jenen angeklagt und besiegt worden wären, von ihren jeweiligen Bischofsitzen herunter gestoßen oder gar wegen Verbleibens in ihrer Verschwörung noch härter bestraft worden wären (die königliche Aufsicht konnte schließlich nicht hinnehmen, dass Besiegte auch noch Widerstand leisten), dann hätten sie sich dazu aufgeschwungen, in Lobeshymnen die Voraussicht und gewissenhafte Sorge [des Kaisers] für die Kirche zu verkünden. Nun aber, weil sie besiegt worden sind, da sie gegen jene, die sie zu richten suchten am wenigsten etwas beweisen konnten, nennen sie es Verfolgung, wenn sie irgendetwas für ihr Unrecht erleiden. Und sie halten ihre so große verderbliche Raserei kaum zurück, sondern suchen sogar die Ehre der Märtyrer, als ob gegen ihr so hartnäckiges Unrecht die wahren christlichen katholischen Kaiser irgendetwas anderes befolgen würden als das Urteil Konstantins, bei dem sie freiwillig Caecilians Ankläger waren und dessen Autorität sie allen Bischöfen in Übersee vorzogen, so dass sie eine Angelegenheit der Kirchen nicht [den Bischöfen], sondern [dem Kaiser] übertrugen und von diesem ein Bischofsgericht in der Stadt Rom bestellt wurde, vor dem sie zuerst besiegt wurden." (sed uidelicet si eis accusantibus atque superantibus Caecilianus eiusque collegae pellerentur sedibus, quas tenebant, uel etiam in sua conspiratione durantes grauius punirentur - neque enim poterat uictos et resistentes regia censura contemnere - tunc isti prouisionem suam et pro ecclesia sollicitam curam praedicandam laudibus uentilarent. nunc autem quia ipsi superati sunt, qui ea, quae intendebant, probare minime potuerunt, si quid pro sua iniquitate patiuntur, persecutionem uocant; nec tantum furorem perditum minime reprimunt, uerum etiam honorem martyrum quaerunt, quasi uero Christiani catholici imperatores aduersus eorum pertinacissimam iniquitatem aliud sequantur quam Constantini iudicium, apud quem ultro Caeciliani accusatores fuerunt, cuius auctoritatem omnibus transmarinis episcopis praetulerunt, ut non ad illos sed ad illum ecclesiae causam deferrent, ut ab eo datum in urbe Roma episcopale iudicium, in quo primum uiciti sunt, [...]). 
des Kaisers ergeben. Nach der Anklage beim Prokonsul sei den Anhängern Caecilians nichts anderes übrig geblieben, als dem Urteil zu gehorchen, und auch die gesamte Christenheit sei auf das Urteil der Richter angewiesen. Wenn man auch sagen könne, dass ein menschliches Urteil durch Einschmeichelung, Täuschung oder Bestechung beeinflusst werde, letztlich seien die Richter Gott verantwortlich und der Unwissende müsse denjenigen vertrauen, die das Urteil gesprochen haben (89.4). Diesem Urteil, so die Erwartung Augustins, solle sich auch Festus beugen und zur Umsetzung der Sanktionen beitragen.

Die Erörterung des Falles Felix von Abthugni war für die Darstellung der gesetzlichen Kontinuität entbehrlich. Dies dürfte der Grund sein, warum Augustinus gegenüber Festus und Vincentius auf eine Darlegung dieses Falls verzichtete. Dennoch kommt er in epp. 88 und 105 auf die causa Felicis zu sprechen, wobei nicht mehr die Frage im Zentrum steht, ob Felix der traditio schuldig gewesen sei oder nicht, sondern der Verfahrensablauf. So wird die causa Felicis zum zusätzlichen Argument für Augustins erste These: Gegen Felix sei wie bei Caecilianus aufgrund andauernder Beschwerden der Donatisten auf Befehl des Kaisers die Untersuchung durchgeführt worden, die mit dem Freispruch durch den Prokonsul Aelianus abgeschlossen worden sei $(88.3 ; 105.8,10)$. Augustinus hebt mit dieser Ergänzung die Erfolglosigkeit sämtlicher Beschwerden und Anklagen der donatistischen Partei und die Eindeutigkeit der kaiserlichen Urteile hervor. Die Betonung liegt wiederum auf der Initiative der Donatisten: Für das Verfahren gegen Felix seien sie ebenso verantwortlich wie für das Verfahren gegen Caecilianus.

In ep. 88 an Ianuarianus erhält die causa Felicis eine weitaus bedeutendere Funktion. So wie der eingefügte Anullinusbericht die Anklageinitiative der Donatisten gegen Caecilianus beweisen sollte, so sollte der vollständige Text des Briefes Konstantins an den Prokonsul Probianus Gleiches für den Prozess gegen Felix erweisen. ${ }^{103}$ Auf den ersten Blick scheint es eine gewichtige Stütze der Argumentation zu sein, dass dieses Dokument zitiert wird. Auf den zweiten Blick lässt sich erkennen, dass Augustins Interpretation der Aussagen Konstantins überzogen ist. Denn von einer donatistischen Anklage gegen Felix oder einem Drängen zu einem Urteil ist in diesem Brief explizit nicht die Rede. Es heißt lediglich, dass der damalige Prokonsul Aelianus in Vertretung des erkrankten Vikars Verus geglaubt habe, die Untersuchung im Fall Caecilianus an sich ziehen zu müssen und daraufhin die Anhörung bezüglich Felix von Abthugni durchgeführt habe. Zweifellos konnte Augustinus bei Optatus von Mileve lesen, dass der Auftrag zum Verfahren gegen Felix, durch donatistische Eingaben veranlasst, vom Kaiser erteilt worden sei, ${ }^{104}$ und Augustinus ging offensichtlich von dieser Darstellung aus. Jedoch war der herangezogene Brief an

103 Der Text des Briefes in ep. 88.4. Zum Inhalt vgl. auch o. Kap. 3.4.2.2.

104 Opt. I 27. 
Probianus kein Beweis für ein Verfahren in dieser Abfolge. Der Versuch war somit misslungen, Ianuarianus mithilfe dieses Briefes neben dem Bericht des Anullinus ein weiteres Zeugnis für eine donatistische Initiative beim Kaiser zu liefern. ${ }^{105}$

105 Der Brief an Probianus beinhaltet allerdings andere Aussagen, mit denen die Donatisten kaum weniger in ein schlechtes Licht gerückt wurden: Der Misserfolg ihrer traditio-Anschuldigungen gegen Felix wird ebenso deutlich wie Konstantins Beschwerde über die tagtäglichen Appelle der Donatisten (88.4). Doch diese Aspekte lassen die Absender beiseite. Entscheidend für ihre Intention ist allein der Nachweis, dass in allen Anklagen und Prozessen die Vorfahren der Donatisten die treibende Kraft gewesen seien. - Bezeichnenderweise präsentierten auf der Konferenz von 411 nicht die Katholiken, sondern die Donatisten diesen Brief als Beweisstück für ihre Geschichtsdarstellung! Vgl. u. Kap. 5.1.3 und 6.1.3. 


\section{Augustinus und die Konferenz von Karthago im Jahr 411}

Die Konferenz in Karthago im Jahre 411 war der vorläufige Höhepunkt in Augustins langjährigem Kampf gegen den Donatismus. Von Beginn seines Wirkens zielte er darauf, die Fragen des Schismas mit Vertretern der anderen Partei zu erörtern und durch Überzeugungsarbeit die kirchliche Einheit wiederherzustellen. Angesichts der Verschärfung der Auseinandersetzung in den Jahren nach dem Unionsedikt von 405 schien eine friedliche Lösung des Konflikts ferner denn je, gleichwohl hielt Augustinus den Wunsch und die Hoffnung aufrecht, durch ein allgemeines Religionsgespräch das Schisma zu überwinden. Nachdem der Kaiser eine Konferenz angeordnet hatte, ${ }^{1}$ setzte Augustinus alles daran, die geplante Konferenz auch zum Erfolg zu führen, und das bedeutete aus seiner Sicht, die Donatisten durch Argumente von der katholischen Wahrheit zu überzeugen.

Mit der Überlieferung eines Großteils der Konferenzakten ist eine herausragende Quelle erhalten, die über die Positionen und Denkweisen sowohl der Donatisten als auch der Katholiken Auskunft gibt. Zusammen mit den Schriften Augustins über Ablauf und Resultate der Konferenz lässt sich ein umfassendes Bild der Ereignisse gewinnen. ${ }^{2}$ Die folgende ausführliche Darstellung des Ablaufs und der Zusammenhänge der Konferenz ist notwendig, um die historische Argumentation in ihrem gesamten Kontext zu analysieren. Die Strategien und Argumente beider Parteien können nur so angemessen interpretiert werden. Zur Orientierung sollen daher zunächst die Voraussetzungen und der Ablauf der Konferenz generell betrachtet werden. Die Zusammenhänge der Argumentation werden anschließend durch die Analyse der Verhandlungsstrategien vertieft. Schließlich sollen die historische Argumentation und die Perspektive Augustins nach der Konferenz dargestellt werden.

1 Zur Einordnung vgl. o. Kap. 2.2.3.

2 Die Edition der Konzilsakten (Gesta conl. Carth.): S. Lancel, CCL 149 A. Vgl. zur Entstehung des Textes Lancel, CCL 149 A, VII-XIX; ders., SC 194, 357-375 sowie Tengström, Die Protokollierung der Collatio Carthaginensis, Göteborg 1962, 30-34. Die ausführlichste Darstellung über die Teilnehmer, Vorbereitung, Durchführung und Ergebnisse der Konferenz finden sich in der Edition der Sources Chrétiennes von Serge Lancel (SC 194, 195, 224, 373). Vgl. zum Ablauf Brown, Augustine, 331-334; Crespin, Ministère, 77-103; Frend, Donatist Church, 275-289; Lamirande, BA 32, 27-57; ders., La Conférence de Carthage (411) et les réactions de saint Augustin: un procès singulier, fatal aux donatistes, Studia canonica 32, 1998, 415-440; Lancel, Augustin, 417-423; Monceaux IV, 82-87 (Verlauf), 388-425 (Dokumente). 


\section{Der Verlauf der Konferenz}

\subsection{Vorbereitungen und Ausgangspositionen}

Die bischöflichen Gesandten des katholischen Konzils in Karthago vom 14. Juni $410,{ }^{3}$ Possidius, Praesidius und Benenatus, hatten unter anderem beim Kaiser ein Religionsgespräch zwischen gewählten Vertretern beider Parteien zur Beendigung des Streits erbeten. Am Hof war man nicht abgeneigt, diesem Wunsch $\mathrm{zu}$ entsprechen und Vorbereitungen für eine Konferenz einzuleiten. Durch ein kaiserliches Reskript vom 14. Oktober 410 wurde der vir inlustris Marcellinus, kaiserlicher Tribun und Notar, ${ }^{4}$ mit der Durchführung dieser Konferenz in Afrika beauftragt. Kaiser Honorius ließ keinen Zweifel aufkommen, dass er die Donatisten als Schuldige am Schisma ansah, aber unter Berufung auf seine christliche Verantwortung war er bereit, dem Vorschlag zu einer erneuten Entscheidung zu folgen, damit die Häresie widerlegt werde. ${ }^{5}$

Marcellinus, der noch Ende des Jahres 410 in Afrika eingetroffen war, veranlasste am 19. Januar 411 per Edikt die Einberufung der Konferenz nach Karthago. ${ }^{6}$ Im Gegensatz zum kaiserlichen Reskript wählte er wesentlich mildere Formulierungen in Bezug auf die Donatisten, um diese nicht von vornherein als Verurteilte erscheinen zu lassen. In der langen Präambel wird der Wunsch ausgesprochen, die Wahrheit herauszufinden, den Aberglauben zu besiegen und so der Unruhe und Zerstörung Afrikas durch die religiösen Streitigkeiten zu entgegnen. Marcellinus verweist darauf, dass sowohl Katholiken als auch Donatisten eine solche Versammlung gefordert hätten. Der kaiserlichen Anordnung gemäß sollten innerhalb von vier Monaten alle Bischöfe

3 Vgl. o. Kap. 2.2.2.

4 Zur Person: Mandouze, PAC, 671-688, s. v. Flauius Marcellinus 2; PLRE II, 711 f., s. v. Fl. Marcellinus 10; zum Titel vgl. Teitler, Notarii et exceptores, 16-21.

5 Text: Gesta conl. Carth. I 4; III 24; ein gekürztes Fragment in CTh XVI 11.3. Vgl. Lancel, SC 194, 25-31. Vgl. hier I 4 (Z. 25-33): „Und obwohl es die einhellige und offenkundige Meinung aller ist, dass die volle Wahrheit des katholischen Gesetzes durch den rechtmäßigen Kult der Menschen und das Urteil des Kaisers bestätigt ist, haben wir [Honorius] im Interesse von Frieden und Aussöhnung gerne die Gesandtschaft der ehrenwerten Bischöfe empfangen, die wünschen, dass die donatistischen Bischöfe zu einer Versammlung in der Metropole zusammenkommen, damit nach der Wahl von Priestern, die von der jeweiligen Partei beauftragt sind, eine Disputation abgehalten und der Aberglauben durch eine schlüssige Beweisführung widerlegt wird.“ (Et quamuis una sit omnium et manifesta sententia catholicae legis plenam ueritatem recto hominum cultu et caelesti sententia conprobatam, studio tamen pacis et gratiae uenerabilium uirorum episcoporum legationem libenter admisimus, quae congregari donatistas episcopos ad coetum celeberrimae desiderat ciuitatis, ut, electis sacerdotibus quos pars utraque delegerit, habitis disputationibus, superstitionem ratio manifesta confutet).

6 Text: Gesta conl. Carth. I 5; vgl. Lancel, SC 194, 31-34. 
beider Parteien eingeladen werden. Die Durchführung sollte den städtischen und kommunalen Autoritäten obliegen. Für diese Zeit wurde den donatistischen Bischöfen ein Entgegenkommen gewährt: Falls sie sich zur Teilnahme bereit erklärten, sollten ihnen ihre Kirchen und Güter zurückerstattet werden. Unabhängig vom Ausgang des Verfahrens erhielten alle Bischöfe die Zusicherung freier Rückkehr. Ferner bot Marcellinus an, seinen Richterplatz mit einem von den Donatisten berufenen gleichrangigen Richter zu teilen. Sicherlich war dies nur ein theoretisches Zugeständnis, denn in der Praxis war es für die Donatisten so gut wie unmöglich, einen Mann zu finden, der den Rang des Marcellinus gehabt hätte.

Die Prozedur der Einberufung der Konferenz entsprach formal der Prozesseinleitung eines nachklassischen Zivilprozesses: ${ }^{7}$ Kaiser Honorius wünschte die Klärung des Streits zwischen Donatisten und Katholiken in Afrika und ordnete durch sein Reskript die Durchführung eines Prozesses an. ${ }^{8}$ In Vertretung des Kaisers übernahm Marcellinus die Funktion des Richters (cognitor), sprach per Edikt die Einladung an die Prozessparteien aus und legte Zeit, Ort und Modus der Verhandlung fest. ${ }^{9}$ Diese prozessrechtliche Form der Konferenz und die juristische Beurteilung des Vorganges der Prozesseinleitung waren mitverantwortlich für langwierige Debatten während der Konferenz, da die Donatisten die rechtlichen Voraussetzungen anders interpretierten als Marcellinus und die Katholiken.

Ende Mai, kurz vor Eröffnung der Konferenz, erließ Marcellinus ein zweites Edikt, in dem er die genauen Regelungen für den Ablauf festlegte. ${ }^{10}$ Als Versammlungsort wurden die Thermen des Gargilius bestimmt. Die beiden Parteien sollten jedoch nicht mit allen Bischöfen an der Debatte teilnehmen, sondern von jeweils sieben Bischöfen als Wortführer (actores) vertreten werden, die wiederum jeweils einen weiteren Bischof als Berater (consiliarius) hinzuziehen durften. Synoden der beiden Parteien sollten diesen Anwälten und Beiständen Ermächtigungsurkunden (mandata) ausstellen, die in Gegenwart des Richters von allen Bischöfen bestätigt werden sollten, um die Arbeit der Mandatsträger anzuerkennen. Als Ausgleich für den Ausschluss der Öffentlichkeit von den Verhandlungen versprach Marcellinus die Veröffentlichung des

7 Vgl. Artur Steinwenter, Eine kirchliche Quelle des nachklassischen Zivilprozesses, in: Acta congressus iuridici internationalis II, Rom 1935, 123-144, hier: 126-129; Lancel, SC 194, 66-68; allgemein dazu Kaser/Hackl, Zivilprozessrecht, 517 ff.

8 Es handelte sich wohl um ein pragmaticum rescriptum, d.h. das Verfahren ging vom Kaiser selbst aus und bezog sich nicht auf die Klage einer Streitpartei. Vgl. Steinwenter, Kirchliche Quelle, 127; Lamirande, BA 32, 32 f.; Lancel, SC 194, 67 f.

9 Damit entsprach das Verfahren einer cognitio extraordinaria. Dazu Tilley, ChHist 60, 1991, $10 \mathrm{f}$.

10 Text: Gesta conl. Carth. I 10. Abgefasst zwischen dem 18. und dem 25. Mai; vgl. Lancel, SC 194, 38-41. 
Urteils und aller Protokolle. Um späteren Einsprüchen vorzubeugen, sollten zur Kontrolle alle Aussagen in den Protokollen durch die jeweiligen Sprecher gegengezeichnet werden. Ebenfalls zur Kontrolle sollten die beiden Parteien jeweils vier Notarii zur Unterstützung der staatlichen Schreiber benennen, außerdem je vier Bischöfe zur Beaufsichtigung des gesamten Ablaufs. Nach jedem Sitzungstag sollte ein Tag Pause eingelegt werden, damit genügend Zeit bestehe, unter Aufsicht dieser Personen die Reinschriften anzufertigen und unterzeichnen zu lassen. ${ }^{11}$ Ausdrücklich wurden die Maximianisten von den Verhandlungen ausgeschlossen, da es um die Entscheidung zwischen Katholiken und Donatisten ginge.

Die Verpflichtung zur Protokollierung, ebenso wie die Bevollmächtigung der Prozessvertreter (actores) durch ein Mandat waren dem Prozessrecht entlehnt und belegen wie bereits die Prozesseinleitung die gerichtliche Verfahrensweise der Konferenz. ${ }^{12}$ Angesichts der von Augustinus seit langem gehegten Idee, mit Vertretern beider Kirchen in einem offiziellen Rahmen zu disputieren, ist es aber wahrscheinlich, dass Marcellinus das Prozedere nicht allein aus juristischen Erwägungen entworfen hatte, sondern auch in enger Absprache mit Augustinus. Allzu deutlich spiegeln sich dessen Vorstellungen in den Bestimmungen wider, als dass eine solche Verbindung zu leugnen wäre. ${ }^{13}$

Die nach Karthago gereisten Bischöfe der katholischen Partei versammelten sich am 25. Mai zu einer ersten Zusammenkunft in der Basilika Restituta. Als Antwort auf das zweite Edikt verfassten sie ein Synodalschreiben an Marcellinus, in dem sie die Bedingungen für die Durchführung der Konferenz vorbehaltlos akzeptierten. ${ }^{14}$ Darüber hinaus umrissen sie ihre Intentionen und Diskussionsziele: Sollten die Donatisten nachweisen können, dass die Sünde einzelner Menschen der gesamten Kirche zum Schaden gereiche und dass ihre Partei allein frei von diesen Sündern sei, dann seien sie, die katholischen Bischöfe, bereit, auf ihre Ämter zu verzichten und den Siegern zu folgen. Im umgekehrten Falle seien sie aus christlicher Liebe bereit, die zur Einheit zurückkehrenden donatistischen Brüder in ihren bischöflichen Würden aufzu-

11 Zur Organisation und Verfahren der Protokollierung ausführlich Tengström, Protokollierung, passim; vgl. auch Lancel, SC 194, 342-353, 390 f.; Teitler, notarii et exceptores, 6-15; Steinwenter, Urkundenwesen, 11-15.

$12 \mathrm{Zu}$ diesem Verfahren der Bevollmächtigung im nachklassischen Zivilprozess vgl. Kaser/ Hackl, Zivilprozessrecht, 560 f., ferner Steinwenter, Kirchliche Quelle, 138 f.

13 Vgl. M. Moreau, Le dossier Marcellinus dans la correspondance de saint Augustin, Paris 1973, 109-112; Lamirande, Studia canonica 32, 1998, 420.

14 Text: Gesta conl. Carth. I 16 [= Aug. ep. 128]. Vgl. Lancel, SC 194, 41-43. Der Brief wird später in Emer. 5-7 vollständig zitiert. - Zum Versammlungsort s. gesta conl. Carth. III 4; vgl. Lancel, SC 194, 104 f. 
nehmen und gemeinsam mit ihnen die Kirchen und Gemeinden zu leiten. ${ }^{15}$ Dieses Ziel solle durch den Nachweis erreicht werden, dass die Kirche Christi unter allen Völkern verteilt sei und nicht durch einzelne Menschen verunreinigt werden könne. Sollten die Donatisten aber auf einer Diskussion über die von ihnen beschuldigten Menschen bestehen, dann werde man durch göttliche und menschliche Zeugnisse darlegen, dass jene unschuldig gewesen und ihre Fälle bereits durch den Kaiser entschieden worden seien.

Im Gegensatz zu ihren katholischen Kollegen reagierten die Donatisten, die am 18. Mai unter Führung des Primianus in einer aufwendigen Prozession demonstrativ in Karthago eingezogen waren und sich in der Basilika Theoprepia versammelt hatten ${ }^{16}$ verstimmt auf die Verhandlungsbedingungen. Sie richteten am 25. Mai eine Note (notoria) an Marcellinus und betonten darin das pünktliche Erscheinen aller reisefähigen Bischöfe am Konferenzort dem ersten Edikt vom Januar gemä $ß{ }^{17}$ Sie sahen im neuen Edikt eine Verletzung der bisherigen Bestimmungen. Es sei gegen die üblichen Prozessregeln, dass vor Beginn der Verhandlungen die Zustimmung für dieses Edikt verlangt werde. Daher solle das erste Edikt in Kraft bleiben und die Anwesenheit aller Bischöfe während der Debatte gestattet werden, denn nur durch die Feststellung der Anzahl könne die Wahrheit ans Licht gerückt werden. Während die Donatisten mit diesem Brief auf der einen Seite öffentlich ihre Ablehnung der Modalitäten demonstrierten, ließen sie sich auf der anderen Seite dennoch auf sie ein. Zur Vorbereitung auf die Sitzungen wählten sie die sieben Wortführer mit den jeweiligen Beratern und beauftragten sie in einer knappen Instruktion, die Kirche Gottes gegen die Traditoren und Persecutoren zu verteidigen. Alle donatistischen Bischöfe unterzeichneten dieses mandatum, allerdings nicht in Gegenwart des Marcellinus, wie es die Einhaltung des Ediktes gefordert hätte. ${ }^{18}$ Ebenso

15 Vgl. auch Aug. s. 359.5. - Zum schwierigen Textverständnis dieser Passage von Gesta conl. Carth. I 16 siehe die Diskussion bei É. Lamirande, L'offre conciliatrice des catholiques aux donatistes relativement à l'épiscopat (Gesta collationis Carthaginiensis I, 16), Église et théologie 2, 1971, 285-308; A.C. de Veer (Kritik an Lamirande), REAug 18, 1972, 321 -323 und S. Lancel, SC 373, 1557-1560. Vgl. auch Crespin, Ministère, 5460.

16 Gesta conl. Carth. I 14; c. Don. 43; vgl. Lancel, SC. 194, 36. - Zum Versammlungsort s. gesta conl. Carth. III 5; vgl. Lancel, SC 194, 104.

17 Text: Gesta conl. Carth. I 14; vgl. Lancel, SC 194, 40; Crespin, Ministère, 84.

18 Text des donatistischen Mandats: Gesta conl. Carth. I 148; vgl. Lancel, SC 194, 40 f.; Crespin, Ministère, 85. - Die donatistischen Mandatsträger waren in der von ihnen selbst genannten Reihenfolge: Primianus, Bischof von Karthago, Petilianus von Cirta und Primas Numidiens, Emeritus von Caesarea, Protasius von Tubunae in Numidien, Montanus von Zama Regia in der Byzacena, Gaudentius von Thamugadi und Adeodatus von Mileve. Vgl. Lancel, SC 194, 198-238, 105 f. (zu den donatistischen consiliarii). 
unterwarfen sie sich den Durchführungsbestimmungen, indem sie die angeforderten Schreiber für die Protokollierung designierten. ${ }^{19}$

Marcellinus selbst ließ sein Edikt und die Antworten der beiden Parteien sogleich in Karthago öffentlich anschlagen, um der Bevölkerung den Stand der Dinge zu präsentieren. ${ }^{20}$ In Reaktion auf die donatistische Kritik am Durchführungsedikt und ihre angedrohte Weigerung, den Bestimmungen nachzukommen, verfassten die katholischen Bischöfe einen weiteren Brief an Marcellinus. ${ }^{21}$ Darin drückten sie ihre Beunruhigung über die ablehnende Haltung ihrer Gegner zum Verfahren aus, unterstrichen gegenüber dem kaiserlichen Beauftragten ihren Wunsch nach Frieden und Einheit und wiederholten ihre Grundpositionen. Ihr Unmut über die Weigerung der Donatisten, Diskussionsziele oder -themen zu benennen, ist deutlich zu vernehmen: Wenn sie die Konferenz vorbereitet und die wichtigsten Fragen durchdacht hätten, dann hätten sie selbst herausfinden müssen, dass biblische und historische Argumente gegen sie sprächen. Die Anwesenheit aller Bischöfe bei der Konferenz lehnten die Katholiken ab, da sie glaubten, es gehe den Donatisten nur um Lärm und Störungen zur Beeinträchtigung der Diskussionen. Die Demonstration ihrer Anzahl sei lediglich ein vorgeschobener Grund, denn schließlich könne die Zahl auch durch die geforderten Unterschriften aller in Karthago anwesenden Bischöfe festgestellt werden, wie es im Durchführungsedikt vorgesehen sei.

Die katholischen Bischöfe selbst erteilten, wie es die Bestimmungen verlangten, auf einer Versammlung am 30. Mai sieben Vertretern ihre Bevollmächtigung, indem sie in Gegenwart von Marcellinus ein Mandat unterzeichneten. Dieses Mandat enthielt außer den Namen der Designierten auch eine ausführliche Darstellung der katholischen Positionen und detaillierte Anweisungen zur Verhandlungsführung. Neben den beiden Synodalbriefen der katholischen Bischöfe an Marcellinus gibt somit das Mandat Auskunft darüber, mit welcher Zielsetzung und welchen Plänen die katholische Partei in die Auseinandersetzung mit den Donatisten ging. ${ }^{22}$

19 In der Auflistung der anwesenden Personen vor Beginn der Sitzungstage werden jeweils ein gewisser Victor und ein Cresconius als donatistische Schreiber aufgeführt (Gesta conl. Carth. I 1 (Z. 19 f.); II 1 (Z. 19 f.); III 1 (Z. 22 f.)). Diese wurden während der jeweiligen Sitzungen durch zwei andere Schreiber abgelöst (Gesta conl. Carth. III 279 f.). Bekannt ist jedoch nur ein Name: Ianuarius aus Sitifis (Gesta conl. Carth. II 59). Vgl. Lancel, SC 194, 342-346.

20 Gesta conl. Carth. I 17; breuic. I 6.

21 Gesta conl. Carth. I 18 [= Aug. ep. 129]; vgl. breuic. I 7; Lancel, SC 194, 43-45; Lamirande, Studia canonica 32, 1998, $420 \mathrm{f}$.

22 Text: Gesta conl. Carth. I 55. Außer Aurelius und Augustinus sollten Alypius und Possidius sowie Fortunatus von Cirta, Vincentius von Culusi und Fortunatianus von Sicca die katholische Partei vertreten; vgl. Lancel, SC 194, 238-273; 105 f. (zu den consiliarii). Es fällt auf, dass Silvanus von Summa als Primas Numidiens kein Mandat erhielt. - Im Folgenden bezeichnen die Sammelbegriffe „Katholiken“ bzw. „Donatis- 
Zweifellos beruhte die Strategie der Katholiken auf den Ideen Augustins. Das Mandat und die Synodalbriefe tragen deutlich seine Handschrift. Es sind Augustins Argumentationsschritte, seine Vergleiche, seine Polemik und Rhetorik. Wer seine zahlreichen Traktate gegen die Donatisten aus den Jahren zuvor kannte, erlebte keine große Überraschung im Programm der Katholiken. $^{23}$

In der Präambel des Mandates wird die katholische Ausgangsposition für die Konferenz deutlich: Durch das Zeugnis der Heiligen Schriften sei die katholische Kirche gegen alle häretischen Irrtümer vollständig gerechtfertigt und die Angelegenheit der Donatisten sei bereits durch kirchliches und kaiserliches Urteil entschieden worden. Die Konferenz diene allein dazu, den unwissenden Menschen um ihres Heils Willen die Wahrheit klar und deutlich darzulegen. Die Katholiken präsentierten sich selbstbewusst und siegessicher. Göttliches und menschliches Urteil wussten sie auf ihrer Seite. Die Konferenz sollte jetzt als öffentliches Forum dienen, die donatistischen Lehren ein für alle Mal zu widerlegen. $^{24}$

Im Zentrum der katholischen Strategie stand die Unterscheidung der causa ecclesiae von der causa hominum (bzw. causa Caeciliani). Entsprechend sollten auch die Beweismittel unterschieden werden: Aus der Heiligen Schrift sollten die Argumente für das Kirchenverständnis gezogen, für die Verteidigung Caecilians und seiner Kollegen dagegen die offiziellen Dokumente gebraucht werden. Auf diese Weise wollten die Katholiken adäquat auf die Hauptanschuldigungen der Donatisten reagieren: zum einen die traditio-Anklagen gegen Caecilianus und andere Personen, zum anderen die Behauptung, dass die Kirche durch die Sünden Einzelner in ihrer Gesamtheit verunreinigt werden könne.

Die Frage des Schismas sahen die Katholiken bereits durch ihr Kirchenverständnis geklärt. Daher stellten sie die causa ecclesiae ins Zentrum ihrer Argumentation. Sie wollten gegen das donatistische Verständnis darlegen, dass die Kirche Jesu Christi aufgrund der Verheißungen Gottes unter allen Völkern verbreitet sei, dass dieser Kirche gute und schlechte Menschen angehörten und

ten“ jeweils die bestimmten Vertreter und Wortführer der beiden Parteien. - Zu Augustins Rolle auf der Konferenz vgl. Lamirande, BA 32, 44-48; Lancel, SC 194, $253-$ 273; Monceaux VII, 179-188; Willis, Augustine, 70-76.

23 Vgl. auch die stilistische Analyse Lancels (SC 194, 332-335). - Unmittelbar vor der Konferenz hielt Augustinus in Karthago zwei Predigten, in denen er den Gläubigen das Ziel der Konferenz dargelegte (s. 358 und 359). Augustinus hoffte auf die Wiederherstellung von Frieden und Einheit für die Kirche in Afrika, indem den Donatisten die Wahrheit verkündet werde. Diese Absicht findet sich ebenso in den Synodalbriefen und dem katholischen Mandat. Zu Augustins Predigten vgl. Lamirande, BA 32, 41-44; ders., Studia canonica 32, 1998, $418 \mathrm{f}$.

24 Gesta conl. Carth. I 55 (Z. 14-30). Vgl. zum Folgenden auch breuic. I 10; dazu Lancel, SC 194, 45-50; Crespin, Ministère, 86 f.; Lamirande, BA 32, 694-696. Im Folgenden die Zeilenangaben der SC-Edition im Text. 
dass die Sünden einzelner Menschen, auch wenn sie bekannt seien, niemals der gesamten Kirche zum Schaden gereichten. ${ }^{25}$ Augustins Intention tritt hier deutlich zutage: Sollte es auf der Konferenz gelingen, mit der katholischen Ekklesiologie die donatistischen Bischöfe zu überzeugen, dann würde jede weitere Debatte über Caecilianus oder die Traditoren hinfällig werden. Im Zentrum der donatistischen Anschauung stand schließlich die Abspaltung von der katholischen Kirche aufgrund der Sünden Caecilians. Wenn die Unabhängigkeit der Kirche von der Schuld Einzelner nachgewiesen werde, dann könne diese Anschauung nicht mehr greifen. ${ }^{26}$ Augustins Entscheidung, in dieser Frage auf die Heilige Schrift als Argumentationsgrundlage zu vertrauen, war mehr als nur ein taktisches Verhalten. Denn wie zuvor in seinen Gesprächen mit donatistischen Bischöfen, so hoffte er auch während der Konferenz, auf der gemeinsamen Grundlage der Heiligen Schrift zu Ergebnissen zu kommen. Seine Ausführungen verdeutlichen immer wieder, dass er an die Möglichkeit glaubte, die allgemein und theologisch hochgebildeten Vertreter der Donatisten durch das „Wort“ überzeugen zu können, ebenso wie er (theoretisch) zugestand, sich durch die Autorität der Heiligen Schrift korrigieren zu lassen. ${ }^{27}$

Wegen der entscheidenden Bedeutung der causa ecclesiae sollten die Themen Taufe, Verfolgung und Gewaltanwendung nur dann behandelt werden, wenn dies die Donatisten forderten. ${ }^{28}$ Auch die causa Caeciliani sollte ganz im Dienst der causa ecclesiae stehen. Nur wenn die Donatisten zuvor die Relevanz

25 Die Argumente dazu sind hinlänglich von Augustinus bekannt: Zitate aus dem Alten und Neuen Testament, die für die weltweite Verbreitung der Kirche und gegen Spaltungen sprechen (Z. 31-160). Zum Nachweis der Vermischung von Guten und Bösen innerhalb der Kirche sollten unter anderem die Allegorien von Spreu und Weizen sowie von den Fischen im Netz dienen (Z. 184-209). Als weitere Argumente sollten Cyprians Aussagen über die lapsi herangezogen sowie der Umgang der Donatisten mit den Maximianisten angesprochen werden (Z. 246-291).

26 Gesta conl. Carth. I 55 (Z. 218-224): „Wenn [die Donatisten] beweisen wollen, dass die Gemeinschaft der Christen, die in so vielen Ländern verbreitet ist, durch die Sünden Caecilians und seiner Anhänger vergiftet und zerstört werden konnte, dann genügt es nicht, dass sie darlegen, dass sie so waren wie sie in den Anklagen beschuldigt werden, es sei denn, sie belegen gleichzeitig, dass ihre nachgewiesenen Verbrechen allen bekannt geworden sind, von denen sie behaupten, dass sie durch diese Verunreinigung zugrunde gegangen sind." (Vnde si demonstrare uoluerint tam latam per tantas terras communionem gentium christianarum peccatis Caeciliani et sociorum eius contaminari ac perire potuisse, non sufficit ut ostendant tales eos fuisse quales accusando criminantur, nisi etiam ostendant uera crimina eorum omnibus innotuisse quos ipsa contagione perisse contendunt).

27 Zu Recht beurteilt Lancel (SC 194, 46 f.) die Trennung der kirchlichen von der historischen Debatte als Wunsch, der Emotionalität der Diskussion entgegen zu wirken und auf eine solide, von beiden Parteien akzeptierte Grundlage zu verlegen.

28 Bei allen Themen planten die Katholiken unter anderem die Donatisten mit dem Maximianistischen Schisma zu konfrontieren (Z. 292-344). 
der persönlichen Schuld für die Kirche haben nachweisen können, sei es sinnvoll die Geschichte des Schismas und die persönlichen Anschuldigungen aufzurollen (Z. 225 ff.). Caecilians Fall solle jedoch nicht als Kirchen-, sondern als Privatangelegenheit eines Bischofs behandelt werden, zudem nicht als offene Frage (causa finienda), sondern als entschiedener Streitfall (causa finita). Anders als in der Kirchenfrage sollte in der causa Caeciliani die Beweisführung mit öffentlichen Dokumenten bestritten werden. Es standen jene Zeugnisse zur Verfügung, die bereits in Augustins Schriften die gleiche Funktion erfüllt hatten: Einige wenige Schriftstücke sollten genügen, um die Unschuld Caecilians zu beweisen (Z. 345-367).

Mit diesen Vorhaben gingen Augustinus und seine Kollegen in die Verhandlungen; die Prioritäten waren klar gesetzt, die Argumentationslinien vorgegeben und das Ziel formuliert. Frieden und Einheit hatten sich die Katholiken auf die Fahnen geschrieben und sie wurden nicht müde dies zu betonen. Ihre Bereitschaft zum Gespräch und zur Aufteilung der Bischofssitze nach einer Vereinigung verstanden sie als Akt der christlichen Nächstenliebe, als Antwort des Friedens auf die bisher erlebte Gewalt. Die Verhandlungen sollten zeigen, welche Antworten die Donatisten bereithielten.

Es wäre falsch zu behaupten, die donatistischen Bischöfe seien im Gegensatz zu den Katholiken unvorbereitet in die Verhandlungen gegangen, nur weil sie im Vorfeld kein ausführliches Grundsatzpapier verfasst hatten. ${ }^{29}$ Ihre Ziele und Absichten wurden erst im Laufe der Verhandlungen deutlich, und es zeigte sich, dass die Donatisten durchaus mit durchdachten Mitteln versuchten, die Verhandlungen für sich zu entscheiden. ${ }^{30}$

\subsection{Die ersten beiden Sitzungstage}

Am 1. Juni 411 wurde die erste Sitzung der Konferenz durch Ursus, einen Beamten der Prätorianerpräfektur, eröffnet. ${ }^{31}$ Am Versammlungsort erschienen von der katholischen Partei allein die Abgeordneten, von der donatistischen Partei jedoch die gesamte Anzahl der in Karthago anwesenden Bischöfe. Diese Verletzung der Bestimmungen durch die Donatisten traf Marcellinus sicherlich nicht unerwartet. Sie hatte sich durch die schriftlichen Äußerungen der Donatisten angekündigt, und der Aufmarsch der Bischöfe vor Verhandlungsbeginn dürfte ihm sicher nicht entgangen sein. Die Donatisten lehnten es ab, sich zu setzen, und so blieben auch Marcellinus und die katholischen Bischöfe stehen. ${ }^{32}$

29 Gegen Lancel, SC 194, 50.

30 Zur Strategie der Donatisten ausführlich u. Kap. 5.2.

31 Gesta conl. Carth. I 1; zum Beamtenstab des Marcellinus Lancel, SC 194, 53-61.

32 Gesta conl. Carth. I 145, vgl. II 3-5. 
Marcellinus reagierte zunächst nicht auf die Provokation der Donatisten, sondern eröffnete die Sitzung formell mit einigen einleitenden Worten, in denen er das Ziel der Verhandlungen umriss: Unter den Augen Gottes solle die Wahrheit ans Licht kommen und die der christlichen Religion unwürdige Spaltung überwunden werden. ${ }^{33}$ Des Weiteren wurden zur Klärung von Intention, Gegenstand und Modus der Verhandlungen nacheinander das kaiserliche Reskript vom Oktober 410, die beiden Edikte des Marcellinus sowie die Antwortschreiben der beiden Parteien vorgelesen. Ausgehend von diesen Texten erinnerte Marcellinus nun die Donatisten an den Befehl, Sprecher aus ihren Reihen $\mathrm{zu}$ bestimmen und forderte sie auf, zu den Vorschriften eindeutig Stellung zu beziehen, wie es die Katholiken bereits getan hätten. ${ }^{34}$ Daraufhin ergriff Emeritus das Wort und skizzierte die grundlegenden Haltungen und Forderungen der Donatisten, die an allen Sitzungstagen immer wieder Gegenstand der Diskussion werden sollten. Entweder, erläuterte Emeritus, verlaufe die Konferenz nach den Regeln gerichtlicher Verfahren. Dann allerdings sei es notwendig, vor der eigentlichen Debatte die Prozessvoraussetzungen zu klären. Dazu gehöre eine Erklärung über die Verschiebung des Zeitpunktes der Konferenz (de tempore), über die Notwendigkeit der Erteilung eines Mandats (de mandato), über den Status von Ankläger und Angeklagten (de persona) sowie über den Verhandlungsgegenstand selbst (de causa). Oder aber - und dies sei zu bevorzugen - man verzichte auf das gerichtliche Prozedere und führe die Diskussion nach den Grundsätzen des kirchlichen Rechts, dann müsse auch der Richter nach christlichem Maßstab urteilen und unterliege dem gerechten Gott in seinen Entscheidungen. ${ }^{35}$

Die folgende Debatte geriet sogleich in Unordnung, da im gegenseitigen Unverständnis der Richter und die Donatisten verschiedene Ziele verfolgten. Marcellinus hielt an der Forderung fest, dass die Donatisten als Voraussetzung für den Beginn der ordentlichen Verhandlung ihre Sprecher wählen sollten, ${ }^{36}$ die Donatisten dagegen beharrten darauf, dass diese Wahl bereits auf Voraussetzungen beruhe, die zuerst geklärt werden müssten, und versuchten, ihre Ein-

33 Gesta conl. Carth. I 3.

34 Gesta conl. Carth. I 19.

35 Gesta conl. Carth. I 20: Si enim omnium negotiorum aduertamus instantiam, primo de tempore, de mandato, de persona, de causa, tum demum ad merita negotii ueniendum est. Quod si, praetermissis istis - secundum forenses fasces iactantiamque illius controuersiae quam tribunalia sibi uindicant - , semper legalis nobis ritus ac sermo seruandus est, iudica, uir sublimis, in negotio christiano, quia huic causae iudicat Deus, qui, et nostra merita et ueri iudicis sententiam aequa ponderans libra, ne inuergat adtendit. - Zum dem teilweise problematischen Verständnis der Aussagen von Emeritus siehe Lancel, SC 195, 618 f. Anm. 1. - Zum Hintergrund der Prozesseinreden als Teil des gerichtlichen Verfahrens, auf das sich Emeritus berief, vgl. u. Kap. 5.2.

36 Gesta conl. Carth. I 21, 23, 25, 30. 
reden vorzubringen. So thematisierten sie umgehend ihren Einspruch de tempore, der sich gegen die Festlegung des Konferenztermins auf den 1. Juni richtete. ${ }^{37}$ Der kaiserlichen Anordnung zufolge, so argumentierten Emeritus und Petilianus, hätte die Konferenz nach einer Frist von vier Monaten stattfinden müssen, dies wäre der 19. Mai gewesen, gerechnet ab der Einladung zur Konferenz durch das Edikt vom 19. Januar. Sie selbst seien fristgerecht am 18. Mai in Karthago eingezogen, während die Gegner am Tag darauf noch nicht verhandlungsbereit gewesen seien. Folglich solle Marcellinus die Katholiken gemäß der Verordnungen wegen Nichterscheinen am Verhandlungsort verurteilen. Marcellinus wehrte diesen Einspruch ab und verwies auf eine Konstitution des Kaisers, die eine Zugabe von zwei Monaten bei Fristen gestattete. Die Donatisten verlagerten die Diskussion daraufhin und sprachen die Rechtsgrundlage der Verhandlungen an. ${ }^{38} \mathrm{Im}$ Anschluss an seine erste Stellungnahme legte Emeritus dar, dass es nicht dem Brauch entspreche, zwischen Bischöfen in einer Frage des Glaubens und der Kirche nach der Gewohnheit von Gerichtsverhandlungen zu verfahren, sondern allein auf Grundlage der Heiligen Schriften des Alten und Neuen Testaments. Damit erzielten die Donatisten einen ersten Teilerfolg: Marcellinus ließ sich auf die Fragestellung ein und erklärte seine Zustimmung, auf Grundlage der göttlichen Schriften zu verhandeln, wenn beide Seiten dies wünschen sollten.

Offenbar missfiel aber den Katholiken die nun eingeschlagene Richtung und sie sahen sich genötigt, zum ersten Mal in die Debatte einzugreifen. Ärgerlich über die noch immer vollzählig anwesenden Donatisten konstatierte Aurelius kurz, dass die Katholiken auf Anordnung des Tribuns nur mit ihren Vertretern gekommen seien, und um der Diskussion eine neue Richtung zu geben, forderte er die Lesung des katholischen Mandats. Darin wiederum sahen die Donatisten bereits den Schritt in die inhaltliche Debatte und lehnten die Lesung vehement ab. Für sie war es eine entscheidende Frage, ob ein solches Mandat in einer kirchlichen Angelegenheit überhaupt zulässig sei. Die Sache des Glaubens, so formulierte Emeritus, könne auch ohne Mandat, nach den ihr eigenen Regeln verhandelt werden. Ein Mandat, ergänzte Petilianus, sei gegen den kirchlichen Brauch und die Lesung des katholischen Mandats bereits eine Vorentscheidung $\mathrm{zu}$ Gunsten einer gerichtlichen Verhandlung gegen das kirchliche Recht. ${ }^{39}$

Die Katholiken dagegen sahen in ihrem Mandat keinen Widerspruch zur Heiligen Schrift oder gar zum Kirchenrecht, sondern ein umfassendes Positionspapier und in der Wahl von Abgeordneten das Mittel, in Ruhe diskutieren zu können. Unter Berufung auf die bestehenden Gesetze folgte Marcellinus den

37 Gesta conl. Carth. I 22-30; vgl. Lancel, SC 194, 74-78.

38 Gesta conl. Carth. I 31-37.

39 Gesta conl. Carth. I 38-53. 
Katholiken und ordnete die Lesung des Mandats an, nicht aber ohne den Donatisten mehrfach versichert zu haben, dass dadurch keine Vorentscheidung bezüglich ihrer Einreden getroffen sei. Dieses Versprechen genügte den Donatisten, und Petilianus gab nun doch seine Zustimmung zur Lesung des katholischen Mandats. ${ }^{40}$ Im Anschluss an die Lesung stellte Marcellinus fest, dass die Katholiken unter Beachtung seines Ediktes den Heiligen Schriften als Basis der Verhandlung eindeutig den Vorzug eingeräumt hätten. ${ }^{41}$

Nun kam jedoch ein zweiter Einwand der Donatisten hinsichtlich des Mandates zum Tragen. Nachdem der Schreiber die Zahl der Unterzeichner mit 266 angegeben hatte, gab sich Petilianus mit diesen Unterschriften nicht zufrieden, sondern fragte nach der Präsenz dieser Bischöfe und forderte die Überprüfung aller Unterzeichner, da er fingierte Angaben vermutete. Es sei zu klären, ob die Anzahl der Bischöfe tatsächlich mit der Anzahl der Gemeinden übereinstimme und nicht irgendwelche Scheinbischöfe installiert worden seien; die vor dem Richter geleisteten Unterschriften genügten in diesem Zusammenhang nicht. ${ }^{42}$ Trotz Beschwerden der Katholiken über diese Verzögerungsmanöver der Donatisten und ihren Bedenken vor Unruhe und Tumulten, falls allen Bischöfen der Zutritt gewährt werde, entschied Marcellinus zu Gunsten der Donatisten und ordnete an, die katholischen Bischöfe aus der Stadt an den Verhandlungsort zu bringen und die Unterschriften zu prüfen. ${ }^{43}$

Nach weiteren Diskussionen einigte man sich schließlich auf ein zweifaches Verfahren, das die restliche Zeit des Tages in Anspruch nehmen sollte. Nachdem die katholischen Bischöfe hereingekommen waren, wurden zunächst der Reihe nach ihre Namen aus dem Mandat vorgelesen, und der jeweils genannte Bischof musste seine Anwesenheit bestätigen. Gab es einen donatistischen Gegenbischof, so hatte dieser zu bezeugen, ob die Angaben richtig waren. Nach ihrem Aufruf mussten die katholischen Bischöfe den Sitzungssaal verlassen, während die Donatisten vorerst blieben. ${ }^{44}$

Da die Katholiken nun die umgekehrte Überprüfung und die Ableistung der Unterschriften in Gegenwart des Marcellinus gefordert ${ }^{45}$ und die Donatisten

40 Gesta conl. Carth. I 48, 52-55.

41 Gesta conl. Carth. I 56: ex recitatione mandati [...] claruit diuina magis testimonia quam forensia uincula esse prolata et edicti pariter mei tenorem fuisse seruatum.

42 Gesta conl. Carth. I 57-65, 70, 77, 86.

43 Gesta conl. Carth. I 66, 68, 71-76, 78-85.

44 Gesta conl. Carth. I 97-99, 111-143. - Bei der Überprüfung der donatistischen Unterschriften waren allerdings wieder katholische Bischöfe anwesend, die nicht zu den Mandatsträgern oder Beratern gehörten. Offensichtlich sind sie also später nochmals hereingebeten worden und haben erst mit ihren donatistischen Kollegen schließlich die Sitzung endgültig verlassen. Zu dem nicht ganz klaren Ablauf vgl. Lancel, SC 194, $81 \mathrm{f}$. Anm. 5; SC 195, 702 f. Anm. 1.

45 Gesta conl. Carth. I 100, 150, 152, 154. 
ihrerseits zugestimmt hatten, nun doch in Gegenwart des Marcellinus ihr Mandat zu erteilen und anschließend allein mit den Wortführern weiter zu verhandeln, ${ }^{46}$ folgte im Anschluss an die bereits erfolgte Prozedur die Überprüfung der Anwesenheit der donatistischen Bischöfe. ${ }^{47}$ Während des gesamten Verfahrens kam es immer wieder zu Auseinandersetzungen zwischen den beiden Parteien. Die Donatisten verwiesen oftmals auf die an ihnen begangene Verfolgung, wenn sie in einer Stadt keinen Bischof vorweisen konnten, die Katholiken warfen den Donatisten vor, Bischöfe aus ländlichen Gebieten zu präsentieren, hinter denen gar keine Gemeinde stünde; Unregelmäßigkeiten traten zutage, sogar die Unterschrift eines verstorbenen Bischofs stand auf der donatistischen Liste. ${ }^{48}$ Am Ende der Prozedur notierten die Schreiber 285 Bischöfe auf Seiten der Donatisten und 286 Bischöfe auf Seiten der Katholiken. Beide Parteien reklamierten jedoch zusätzlich 120 abwesende Bischöfe für sich und verwiesen auf die zurzeit vakanten Bischofssitze. ${ }^{49}$ Am Ende des ersten

46 Gesta conl. Carth. I 104, 106, 108.

47 Gesta conl. Carth. I 157-212.

48 Gesta conl. Carth. I 200-203, 207-208. - Die Auflistung aller in Karthago anwesenden Bischofe, dazu die Aussagen über Vakanzen, konvertierte Bischöfe (vollständige Liste bei Lancel, SC 194, $121 \mathrm{f}$. mit Anm. 1) und die Verteilung von donatistischen und katholischen Bischofssitzen sind eine hervorragende Quelle und ergeben ein umfassendes Bild der Kirchenstrukturen in Afrika. Siehe dazu Lancel, SC 194, 107-190; SC 373, $1291 \mathrm{ff}$. (prosopographische und topographische Auswertung).

49 Gesta conl. Carth. I 212, 214-217. - Der Schreiber Rufinianus, der die Gesamtzahl der Bischöfe feststellen sollte, zählte im donatistischen Mandat 279 Unterschriften (Gesta conl. Carth. I 213). Unter Hinzunahme der donatistischen Mandatsträger, die mit Ausnahme des Primianus nicht in der Liste auftauchten (vgl. Gesta conl. Carth. I 149, 157), lag somit die offizielle Zahl der anwesenden Donatisten bei 285. Auf dem katholischen Mandat wurden zunächst 266 Unterschriften einschließlich der Mandatsträger gezählt. Nach einer Eingabe des Alypius gaben weitere sechzehn katholische Bischöfe, die aufgrund ihrer verspäteten Ankunft noch nicht unterzeichnet hatten, ihre Zustimmung zum Mandat. Weitere vier Bischöfe entschuldigte Alypius mit Krankheit. Unter Einbeziehung dieser 20 Bischöfe wurde die Gesamtzahl der Katholiken mit 286 festgehalten. Für beide Parteien bleibt die genaue Anzahl der anwesenden Bischöfe letztlich unklar, wodurch auch die abweichenden Zahlenangaben in der Forschungsliteratur bedingt sind. Ursache sind die Differenzen zwischen den offiziellen Zahlen und den namentlich genannten Bischöfen im Protokoll. So werden bei den Donatisten lediglich 277 Bischöfe aufgelistet; es fehlen jedoch in der Unterschriftenliste fünf donatistische Bischöfe, die ihre katholischen Gegner zuvor identifiziert hatten (vgl. Lancel, SC 194, 113 f. Anm. 1). Die Gesamtzahl der namentlich genannten katholischen Bischöfe liegt bei 267, einschließlich der Nachträge. Es ist ganz offensichtlich, dass beide Listen Unregelmäßigkeiten enthalten, etwa doppelte Nennungen und unsichere Zuordnungen. Ferner gab es Lücken und Fehler in der Übertragung des Protokolls, vor allem bei ähnlich klingenden Orts- und Personennamen. Die offizielle Zählung scheint jedoch sehr großzügig mit den umstrittenen Fällen verfahren zu sein. Dies bedeutet, die Anzahl der anwesenden Bischöfe dürfte etwas geringer als die der Mandatsunterzeichner gewesen sein. Ohne eine Zahl festlegen zu können, scheinen Katholiken und 
Sitzungstages konstatierte Marcellinus ernüchtert, dass fast der gesamte Tag vergangen sei, nur um sich über die Verhandlungsweise zu verständigen. Nach Festlegung des neuen Termins und der Anordnung, die Protokolle zu veröffentlichen, wurde die Sitzung geschlossen. ${ }^{50}$

Am folgenden Tag beantragten die Donatisten bei Marcellinus die Ausfertigung einer Abschrift des katholischen Mandates, um sich für die kommende Debatte vorbereiten zu können. Der Richter gestattete dies in der Hoffnung, weiteren Verzögerungen in den Verhandlungen zu entgehen. ${ }^{51}$ Wenn Marcellinus geglaubt hatte, dass nunmehr die Grundfragen geklärt seien und der zweite Sitzungstag am 3. Juni zum Beginn der Hauptverhandlung führen würde, sollte seine Erwartungshaltung bald einer neuerlichen Enttäuschung weichen: Auf seine Aufforderung an die Vertreter beider Parteien, ihre Aussagen im Protokoll der ersten Sitzung mit ihrer Unterschrift zu bestätigen, weigerten sich die Donatisten, dieser Forderung nachzukommen. Petilianus berief sich auf das Versprechen des Marcellinus, alle Akten öffentlich zugänglich zu machen, und beantragte die vollständige Aushändigung der Protokolle vor einer Abzeichnung der Redebeiträge. ${ }^{52}$ Es stellte sich heraus, dass es die Schreiber während des vergangenen Tages nicht geschafft hatten, das in Kurzschrift vorliegende Protokoll vollständig in Reinschrift zu übertragen und nun am zweiten Sitzungstag vorzulegen. ${ }^{53}$ Dies bedeutete einen Vorteil für die Donatisten. Emeritus und Petilianus beharrten darauf, dass es nur recht und billig sei, ausreichend informiert zu sein; daher müssten die Protokolle eingehend geprüft werden. Jedoch könnten sie die stenographischen Notizen nicht lesen und deshalb auch nicht unterschreiben, da sie den Inhalt ja nicht nachvollziehen könnten. Marcellinus solle deshalb die Konferenz bis zur Fertigstellung der Protokolle vertagen..$^{54}$

Während die Katholiken in der Forderung der Donatisten nichts anderes sahen als ein weiteres, unsachliches Verzögerungsmanöver, ${ }^{55}$ versuchte Marcellinus, die Donatisten von der Unverfälschtheit der Protokolle zu überzeugen, indem er auf die von ihnen gestellten Sekretäre verwies, die schließlich den

Donatisten sich in etwa gleicher Zahl versammelt zu haben, wobei die Donatisten möglicherweise eine geringe Mehrheit besaßen. - Zur Problematik der Anzahl mit einigen Erklärungsansätzen vgl. Lancel, SC 194, 110-118.

50 Gesta conl. Carth. I 220-223.

51 Gesta conl. Carth. II 12.

52 Gesta conl. Carth. II 13, 15-16, 20, 25. Vgl. auch zum Folgenden Lancel, SC 194, 82-84; Crespin, Ministère, 88 f.; Tengström, Protokollierung, 18-21.

53 Gesta conl. Carth. II 37-38.

54 Gesta conl. Carth. II 28, 33, 35, 39, 43, 46, 48, 55, 61. - Bei der Forderung der Donatisten handelte es sich juristisch um den Antrag einer dilatio instrumentorum causa, eine Vertagung zur Beschaffung von Beweismitteln. Vgl. Lancel, SC 194, 82-84; Steinwenter, Kirchliche Quelle, 139; allgemein dazu Kaser/Hackl, Zivilprozessrecht, 596.

55 Gesta conl. Carth. II 26, 29. 
gesamten Vorgang kontrolliert hätten. Er befahl sogar die versiegelten Kodizes heranzubringen, um die Richtigkeit zu untermauern. ${ }^{56}$ Verärgert über die sture Haltung der Donatisten ließ er dreimal den Abschnitt aus dem Protokoll vorlesen, in dem die Donatisten ihre Zustimmung zur Fortführung der Konferenz am 3. Juni geäußert hatten, um sie zur Beachtung ihrer eigenen Aussagen zu zwingen. ${ }^{57}$ Diese Zustimmung, so Marcellinus, sei unumkehrbar, und eine Vertagung komme nicht in Frage. ${ }^{58}$

Die festgefahrenen Positionen zwischen Richter und Donatisten durchbrach kein anderer als Augustinus. Er hatte erkannt, dass die Donatisten mit ihrer Forderung nach Fertigstellung der Protokolle prinzipiell im Recht und nicht zum Einlenken bereit waren. Daher bat er Marcellinus, der Forderung der Donatisten nachzukommen und die Sitzung zu vertagen. ${ }^{59}$ Dieser gab den Forderungen schließlich nach und legte in Absprache mit den Schreibern den nächsten Termin auf den 8. Juni. Beide Parteien stimmten zu und erklärten sich bereit, zuvor die Protokolle gemäß Anordnung abzuzeichnen. Damit endete die zweite Sitzung, ohne dass irgendeine Sachfrage diskutiert worden wäre. ${ }^{60}$

\subsection{Der dritte Sitzungstag}

Der am 8. Juni anberaumte dritte Sitzungstag sollte die Konferenz zu einer Entscheidung führen. Nachdem die Formalitäten diesmal reibungslos vonstatten gegangen waren, ${ }^{61}$ entwickelte sich von Beginn an eine Debatte mit heftigen Auseinandersetzungen und starken Emotionen. Häufige Unterbrechungen, Wiederholungen und sprunghafte Argumentationen sowie nicht zuletzt die Länge des Protokolls erschweren es, die Übersicht zu wahren und den Lauf der Diskussion zu folgen. Unter dem Vorbehalt der Vielschichtigkeit der Debatte, aller Verschränkungen und fließenden Übergänge lässt sich der Sitzungsverlauf in fünf Phasen einteilen. ${ }^{62}$ Erstens: Die Diskussion über den Status des An-

56 Gesta conl. Carth. II 19, 47, 49, 51, 53; vgl. Tengström, Protokollierung, 17, 19 f.

57 Gesta conl. Carth. II 32, 44, 59; vgl. I 220-222.

58 Gesta conl. Carth. II 24, 45, 49.

59 Gesta conl. Carth. II 56.

60 Gesta conl. Carth. II 60-70.

61 Gesta conl. Carth. III 1-5. - Die Protokolle der Vortage waren dieses Mal rechtzeitig fertig gestellt und am 6. Juni beiden Parteien übergeben worden (vgl. Gesta conl. Carth. III 4-5; Lancel, SC 194, 277-279).

62 Die Einteilung dient der Orientierung und grenzt die einzelnen Themen nicht exakt ab. In der ersten Edition der Konzilsakten, der auch Augustins Breviculus zugrunde lag (vgl. u. Kap. 5.3.1), wurde das Protokoll des 8. Juni ebenfalls in fünf loci gegliedert, ganz offensichtlich aus inhaltlichen Gründen. Folgende Zäsuren werden gesetzt: Gesta conl. Carth. III 6 (Beginn des 2. Teils), III 220 (3. Teil), III 258 (4. Teil), Cap. conl. Carth. III 
klägers (qualitas personae) ${ }^{63}$ zweitens: die Fortsetzung dieser Debatte unter Hinzuziehung älterer Dokumente ${ }^{64}$ darin eingefügt findet sich, drittens, die Debatte über die Rechtsnorm der Konferenz, ${ }^{65}$ viertens, die Diskussion über die kirchenrechtliche Beurteilung von traditio und persecutio einschließlich der Debatte über das donatistische Grundsatzpapier, ${ }^{66}$ fünftens und letztens: die umfassende Diskussion über die causa Caeciliani, veranlasst durch die Wiederaufnahme der Lesung historischer Dokumente zur Feststellung des locus petitoris. ${ }^{67}$

Während die Katholiken mit denselben Zielsetzungen wie an den Vortagen zur Verhandlung erschienen, hatten die Donatisten in der Zwischenzeit eine ausführliche theologische Entgegnung auf das Mandat der Katholiken abgefasst, mit der sie die Hauptverhandlung bestreiten wollten. Zunächst kamen Emeritus und Petilianus jedoch auf die bereits am ersten Sitzungstag angesprochenen principia negotii zu sprechen, die sie noch längst nicht vollständig geklärt sahen; sie brachten nunmehr die Prozesseinrede über die Festlegung von Kläger und Beklagten vor (praescriptio de persona) und stellten damit die Weichen für die erste Phase der Diskussion. ${ }^{68}$ Die Donatisten sahen eindeutig die Katholiken in der Rolle des Klägers und begründeten ihre Behauptung aus dem Wortlaut des kaiserlichen Reskripts. Sie verstanden die Petition, mit der die Legaten des katholischen Konzils vom Juni 410 vor den Kaiser getreten waren (sog. mandatum legatorum), als offizielle Anklageschrift (supplicatio) gegen ihre Kirche. ${ }^{69}$ Die Donatisten forderten nun vehement die Veröffentlichung dieser Supplik, damit der Inhalt der Anklage deutlich werde und eine entsprechende Verteidigung formuliert werden könne. Sie vermuteten eine Reihe von Aussagen in dieser Schrift, die sie als Verleumdungen und Lügen und damit als falsche Anklagen entlarven wollten. ${ }^{70}$ Zudem wollten die Donatisten durch einen Vergleich der Inhalte das vorliegende Mandat der Katholiken aushebeln. So wie am ersten Sitzungstag das katholische Mandat gegen die

315 (5. Teil). Die Zäsuren III 220 und 315 stimmen mit der folgenden Gliederung überein.

63 Gesta conl. Carth. III 15-120; vgl. breuic. III 2-5.

64 Gesta conl. Carth. III 120-180; breuic. III 5-7; Gesta conl. Carth. III 215-220; breuic. III 8.

65 Gesta conl. Carth. III 149-56, 181-214; breuic. III 6-7.

66 Gesta conl. Carth. III 221-281; Cap. conl. Carth. III 282-313; breuic. III 8-23.

67 Cap. conl. Carth. III 314-583; breuic. III 24-43.

68 Vgl. Gesta conl. Carth. I 20; vgl. Lancel, SC 194, 84-88.

69 S. o. Kap. 2.2.2 und 5.1.1.

70 Gesta conl. Carth. III 37-89. - Die Donatisten intendierten durch diese praescriptio mendaciorum den Nachweis, dass das kaiserliche Reskript auf unwahren Darstellungen der Kläger beruhte und damit als ungültig anzusehen sei. Vgl. Kaser (Zivilprozessrecht, 523) mit Angaben für vergleichbare Fälle. Zu den Einreden im nachklassischen Zivilprozess vgl. Kaser/Hackl, Zivilprozessrecht, 582-586. 
Heilige Schrift gesetzt wurde, so forderte Emeritus nun, dass die Katholiken entweder die Vereinbarkeit ihres Mandates mit der Petition der Legaten darlegen müssten, oder aber auf eines der Dokument zu verzichten hätten, wenn darin unterschiedliche Forderungen enthalten seien. ${ }^{71}$

Auf der Gegenseite hielten sich die Katholiken strikt an die Vorgaben ihres Mandates. Sie wollten auf Basis der bestehenden Anordnungen und in Ausführung ihres Mandatsprogrammes die Streitfragen des Schismas behandeln. ${ }^{72}$ Folglich forderten sie die Donatisten auf, ihre Anklagen gegen die Kirche zu beweisen und die Inhalte ihrer Instruktionen offen zu legen. ${ }^{73}$ Bezüglich der Anklage betonten die Katholiken, dass die Konferenz zwar auf ihren Wunsch zurückgehe, aber dennoch letztlich auf Anordnung des Kaisers zur Aufdeckung der Ursachen der Spaltung und des Irrtums einberufen und von beiden Parteien akzeptiert worden sei. ${ }^{74}$ Eine weitere Diskussion über die Supplik und die Legaten sei unnötig und nur ein weiteres Verzögerungsmanöver. ${ }^{75}$

Die Donatisten konnten sich mit ihren Argumenten nicht durchsetzen. Sie scheiterten nicht nur am Widerstand der Katholiken, auch Marcellinus lehnte die Debatte über Petition und Legation des Jahres 410 ab. Er berief sich auf seine Verpflichtung, den Anordnungen des kaiserlichen Reskripts Folge zu leisten, und dementsprechend sei die causa primi erroris zu untersuchen, nicht aber der locus petitoris. Zusammen mit den Katholiken forderte er die Donatisten auf, auf Grundlage der Positionspapiere beider Parteien die Sachthemen anzusprechen. ${ }^{76}$

Nachdem sich aber die Streitgespräche ohne Fortschritte in die Länge zogen, versuchte Marcellinus doch, sich über die gegenseitigen Vorwürfe ein Bild zu machen, um auf diese Weise den locus petitoris zu klären. ${ }^{77}$ Augustinus deklarierte daraufhin die Donatisten als Ankläger, da diese die weltweite Kirche ohne Beweise der traditio beschuldigten, und sie diesen Beweis nun zu führen hätten. Überdies hätten sich auch die Donatisten mit Anklagen an staatliche Gewalten gewandt und Verhandlungen erbeten. ${ }^{78}$ Emeritus und Petilianus dagegen wiederholten die Forderung nach Offenlegung der Anklageschrift, denn nur so könne eine angemessene Verteidigung stattfinden: Entscheidend sei, wer den Prozess vor dem Kaiser erbeten habe. ${ }^{79}$ Daraufhin konstatierte Marcellinus, dass beide Parteien die Konferenz gefordert hätten,

71 Gesta conl. Carth. III 43, 46, 49, 159.

72 Gesta conl. Carth. III 50, 68-69, 74.

73 Gesta conl. Carth. III 7, 12.

74 Gesta conl. Carth. III 20, 41, 53, 55, 72, 74, 80.

75 Gesta conl. Carth. III 41, 57, 62, 82, 88.

76 Gesta conl. Carth. III 36, 38, 45, 51, 64, 70, 77, 79, 84, 86, 90, 92, 94, 140, 164, 194.

77 Gesta conl. Carth. III 98-99, 107, 111, 113, 115.

78 Gesta conl. Carth. III 98, 100-101, 108, 110.

79 Gesta conl. Carth. III 97, 99, 104, 106, 109. 
die Position des Anklägers im gegenwärtigen Verfahren folglich anderweitig gefunden werden müsse, und zwar sei diejenige Partei Bittsteller, die als erste Anklage erhoben habe (qui crimen intendit).$^{80}$ Damit setzte er einen Einschnitt, der weitreichende Folgen für den Verlauf der Debatte hatte. Marcellinus verfolgte von nun ab konsequent das Ziel, mit Hilfe der von beiden Parteien vorgelegten historischen Dokumente die Herkunft der Anklage zu ermitteln und läutete damit die zweite Phase der Verhandlung ein.

Zunächst präsentierte Fortunatianus für die Katholiken Akten aus der Prätorianerpräfektur in Ravenna des Jahres 406, mit denen bewiesen werden sollte, dass auch die Donatisten bei säkularen Gewalten um eine Konferenz gebeten hätten. ${ }^{81}$ Offenbar fürchteten die Donatisten eine Diskreditierung durch dieses Dokument. Daher verwies Petilianus auf ältere Dokumente, die nach der Ordnung vorher gelesen werden müssten, nämlich Akten über eine Petition katholischer Bischöfe bei den Provinzstatthaltern aus dem Jahr 403, in der sie baten, Religionsgespräche in Städten und Gemeinden unter staatlicher Aufsicht durchzuführen. ${ }^{82}$ Diese Aussage Petilians bedeutete eine weitere entscheidende Zäsur: Er hatte sich auf das Spiel eingelassen, zur Feststellung des Klägers mit den Gegnern um die Vorlage der ,ältesten“ Dokumente wetteifern zu müssen. Für Augustinus stand fest, welches Dokument die älteste Anklage enthielt, nämlich die relatio Anullini, mit der die donatistische Partei Caecilianus bei Konstantin verklagt hatte; und er nutzte den Augenblick, den Richter auf dieses Dokument hinzuweisen. ${ }^{83}$ Um Ordnung in die Debatte zu bringen, entschied Marcellinus endgültig, dass alle vorgelegten Dokumente nach chronologischer Ordnung vorzulesen seien. ${ }^{84} \mathrm{Er}$ ebnete damit den Weg für den weiteren Fortgang der Konferenz. Denn die Suche nach dem petitor und die daraus entstehenden Diskussionen über die historischen Dokumente bildeten den roten Faden für den restlichen Verlauf der Debatte.

Zuvor lenkten die Donatisten die Auseinandersetzung jedoch zurück auf ihre Forderung nach Klärung der Rechtsnorm. Obwohl Marcellinus bereits am

80 Gesta conl. Carth. III 117, 120. Vgl. Lancel, SC 224, 1078 f. Anm. 1: „Cet interlocutoire de Marcellinus marque un tournant majeur dans le débat: à partir de ce moment, à la controverse de jure sur le point de savoir qui est demandeur se substitue une enquête de facto sur les positions historiques prises par les deux parties.“ - Marcellinus' Aussage war trotz seiner Wichtigkeit für die Debatte keineswegs eine neue Erkenntnis. In seinem ersten Edikt hieß es bereits (Gesta conl. Carth. I 5 (Z. 19-24): Consona siquidem utriusque partis petitio ad hanc principem sententiam prouocauit. Nam sicut a catholicis nuper conlatio postulata est, sic ante breuissimum tempus donatistarum episcopos in iudicio inlustrium potestatum conlationem postulasse non dubium est. - Mit großer Wahrscheinlichkeit ist dieser Passus auf das Einwirken Augustins zurückzuführen.

81 Gesta conl. Carth. III 124, 128.

82 Gesta conl. Carth. III 141.

83 Gesta conl. Carth. III 144.

84 Gesta conl. Carth. III 147, 150. 
ersten Sitzungstag die übereinstimmende Bereitschaft der Parteien festgestellt hatte, auf Grundlage der Heiligen Schrift zu verhandeln, insistierten Emeritus und Petilianus auf einer klaren Entscheidung in dieser Frage. ${ }^{85}$ Sie hatten gemerkt, dass eine weitere Prüfung der historischen Dokumente unweigerlich zu einer inhaltlichen Debatte führen würde, und zwar nicht auf Basis der Heiligen Schrift, sondern menschlicher Zeugnisse. Diese langsame Verlagerung der Themen in die Sachdebatte auf der falschen Grundlage wollten sie verhindern. ${ }^{86}$ Petilianus forderte daher die Katholiken auf, vor Eintritt in die Hauptverhandlung über die Rechtsquelle zu entscheiden. Falls sie mit historischen Dokumenten argumentierten, verließen sie die Grundlage der Heiligen Schrift. ${ }^{87}$

Augustinus hielt diese Ausschlussforderung für unangebracht, solange die Donatisten an ihrer traditio-Anklage gegen einzelne Personen festhielten. Er offerierte den Gegnern, auf die historischen Zeugnisse zu verzichten, wenn sie derartigen Anschuldigungen entsagten. ${ }^{8}$ Als aber die Donatisten auf ihrem Standpunkt verharrten, gab Augustinus der Debatte einen entscheidenden Impuls, indem er von den Gegnern eine kurze und deutliche Antwort auf die Frage verlangte, ob sie ihre üblichen Anklagen gegen Caecilianus und dessen Kollegen aufrecht erhielten oder nicht. ${ }^{89}$ Emeritus wich dieser direkten Frage in einer langen Antwort aus und berief sich wiederum darauf, dass zunächst die principia geklärt werden müssten, ehe er zur Anklage gegen Caecilianus Stellung beziehen könne. ${ }^{90}$ Für Augustinus war indessen klar, dass bei Aufrechterhaltung der donatistischen traditio-Anschuldigungen kein Verzicht auf die historischen Dokumente möglich sei. Seine Argumente überzeugten auch Marcellinus, der deshalb die donatistische Forderung, allein die Heilige Schrift als Rechtsgrundlage anzuerkennen, zurückwies. ${ }^{91}$

Parallel zur Diskussion über die Rechtsquelle setzte Marcellinus die Lesung weiterer historischer Dokumente durch. Gegen den Protest der Katholiken entschied er, zunächst die von den Donatisten vorgeschlagenen Dokumente über die Petition der Katholiken beim Prokonsul Septiminus anzuhören. Nach der Lesung bestätigte Marcellinus, dass auf Grundlage dieser Dokumente die

85 Gesta conl. Carth. III 149, 153, 181, 183, 185, 188, 191, 193.

86 Petilianus (Gesta conl. Carth. III 151 vgl. III 193): sensim in causam inducimur!

87 Gesta conl. Carth. III 153.

88 Gesta conl. Carth. III 155, 183, 186-187, 189, 197.

89 Gesta conl. Carth. III 199: Ergo ad interrogata respondete. Receditis a criminibus traditionis? Respondeant ad breue interrogatum nostrum: facitis iacturam criminum quae soletis obicere Caeciliano et collegis eius, an in eadem criminatione persistitis?

90 Gesta conl. Carth. III 200.

91 Gesta conl. Carth. III 156, 194, 202, 215. 
Katholiken die Bittsteller seien. ${ }^{92}$ Konnten an dieser Stelle die Donatisten noch hoffen, dass der Richter ihnen tatsächlich den Verteidigerstatus zubilligen würde, so traf es sie umso mehr, als der Richter nun doch der Forderung der Katholiken nachkam und die relatio Anullini vortragen ließ. ${ }^{93} \mathrm{Um}$ eine Diskussion dieses Dokumentes zu verhindern, stießen sie eine theologische Grundsatzdiskussion an, in deren Verlauf die unterschiedlichen ekklesiologischen Positionen aufeinander trafen.

Petilianus stellte seinem Gegner Augustinus die Frage, ob er ein „Sohn Caecilians" sei und forderte ihn auf, den Namen seines Ordinators zu nennen. ${ }^{94}$ Er wollte damit vor der Öffentlichkeit feststellen lassen, dass Augustinus und die anderen „Ankläger“ der katholischen Partei als Nachfolger der Traditoren selbst schuldig seien. Augustinus behauptete dagegen, dass er von der Schuld Caecilians oder der Kirche unabhängig sei. ${ }^{95}$ Die Donatisten sahen den Zeitpunkt gekommen, ihre Widerlegung des katholischen Mandates vorzulegen, um mit den dort genannten Argumenten ihre These zur Heiligkeit und Unbeflecktheit der Kirche zu begründen und ihre Verfolgung anzuprangern. ${ }^{96} \mathrm{Au}-$ gustinus, der auf die Gelegenheit der theologischen Auseinandersetzung nur gewartet hatte, begann nach der Lesung mit einer Analyse des Textes. Er konzentrierte sich vor allem darauf, die donatistische Auslegung der Heiligen Schrift zu widerlegen. In der Diskussion zeigten sich die unversöhnlichen Standpunkte und das gegenseitige Unverständnis. Während Augustinus seine These von der Mischung guter und schlechter Menschen innerhalb der zeitlichen Kirche darlegte, verwarfen Emeritus und Petilianus dieses Kirchenverständnis und betonten die Trennung der Kirche der Heiligen von der sündigen Welt und die Pflicht, nach allen Kräften die Reinheit der Kirche zu wahren. ${ }^{97}$

92 Gesta conl. Carth. III 166-177. Zu diesen gesta proconsularia (Petition der Bischöfe vom 13.9.403 und Reskript des Prokonsuls Septiminus, vgl. o. Kap. 2.2.1 (historische Einordnung); zur Quelle im donatistischen Dossier u. Kap. 6.3.1.

93 Gesta conl. Carth. III 215-220.

94 Gesta conl. Carth. III 221, 227, 231, 234, 236, 238, 243.

95 Gesta conl. Carth. III 222, 226, 228, 230, 233, 235, 237, 242, 247.

96 Gesta conl. Carth. III 249-258.

97 Gesta conl. Carth. III 261-281; Cap. conl. Carth. III 282-288. Die überlieferten Protokolle brechen während der Debatte über die causa ecclesiae mit III $281 \mathrm{ab}$; für den weiteren Verlauf stehen nur noch die Kapitelüberschriften und Augustins Berichte zur Verfügung. - Zur Debatte der causa ecclesiae s. J. Alexander, A Note on the Interpretation of the Parable of the Threshing Floor at the Conference of Carthage of A.D. 411, JThS 24, 1973, 512-519; Lamirande, BA 32, 720-725; ders., Augustine and the Discussion on the Sinners in the Church at the conference of Carthage (411), AugStud 3, 1972, 97-112; ders. Studia canonica 32, 1998, 423-426; Lancel, SC 194, 89-91; W. Wischmeyer (ZNW 70, 1979, 68-85) stellt das unterschiedliche Verständnis gleicher Begriffe heraus, wodurch eine Verständigung nahezu ausgeschlossen wurde. - M. Tilley (ChHist 60, 1991, 16-18) betont zu Recht, dass die Donatisten die Kirchen außerhalb Afrikas nicht pauschal verurteilten und in ihrem Verständnis auch die Heiligkeit nicht 
Marcellinus setzte den Ausführungen nach einer Weile ein Ende und behielt sich die Entscheidung in der Kirchenfrage vor, obwohl beide Parteien ein Zwischenurteil forderten. ${ }^{98}$ In der offenbar sehr aufgeheizten Atmosphäre beschuldigten die Donatisten Marcellinus, er dürfe gar nicht über Bischöfe richten, und warfen den Katholiken die Verfolgung vor, die ihrerseits aufgebracht die Verfolgungen der Donatisten brandmarkten. ${ }^{99}$

Auf Anordnung des Richters kehrte man zur Lesung der Dokumente zurück, womit die letzte Phase der Debatte begann: die Auseinandersetzung mit den Anfängen des Schismas. ${ }^{100}$ Zunächst kamen die Katholiken zum Zuge, die mit verschiedenen Dokumenten nachweisen wollten, dass die Donatisten als erste Klage vor einem weltlichen Gericht eingereicht hätten und der Fall zu Gunsten des Beklagten entschieden worden sei. ${ }^{101}$ Die Donatisten unterbrachen die Lesung aus dem Protokoll der römischen Synode des Jahres 313, als sich darin der Freispruch Caecilians abzeichnete, und forderten erneut, dass eine Anklage vorgebracht werde. ${ }^{102}$ Marcellinus gestattete es daraufhin den Donatisten, den Einwand zu rechtfertigen und ihre Dokumente vorzulegen. ${ }^{103}$

Die Donatisten begannen mit einem Referat über die Ursachen des Schismas. Sie kamen auf die Situation der karthagischen Kirche zur Zeit der Verfolgung zu sprechen und beschuldigten Mensurius, den Vorgänger Caecilians, der traditio. Als Beweis legten sie zwei Briefe vor, deren Authentizität und Inhalt die Katholiken jedoch anzweifelten. ${ }^{104}$ Im Anschluss präsentierten die Donatisten die Protokolle des karthagischen Konzils mit den Anschuldigungen und Verurteilungssentenzen gegen Caecilianus und einige andere Bischöfe. ${ }^{105}$ Im Gegenzug legte Augustinus das Protokoll des Konzils von Cirta vor. Es entwickelte sich eine ausgedehnte und scharfe Kontroverse über Echtheit und Bewertung des Protokolls von Cirta und dessen Bedeutung für die juristische Beurteilung des Konzils von Karthago. ${ }^{106}$ Die Donatisten zogen eine Stelle bei Optatus von Mileve heran, um zu beweisen, dass Caecilianus selbst zugegeben

durch versteckte Sünder befleckt werden konnte. Augustinus stellt dies nicht richtig dar. Vgl. die Aussagen Petilians und Cresconius' o. Kap. 3.3.

98 Cap. conl. Carth. III 289-292, 312-313; breuic. III 21.

99 Cap. conl. Carth. III 295-303; breuic. III 21-23.

100 Zum Folgenden Lamirande, Studia canonica 32, 1998, 426 f.; Lancel, SC 194, 91-103. Die historischen Argumente werden hier nur kurz skizziert. Die ausführliche Analyse erfolgt in Kap. 5.3.

101 Cap. conl. Carth. III 314-320; breuic. III 24.

102 Cap. conl. Carth. III 321-328, 331; breuic. III 24.

103 Cap. conl. Carth. III 329-332.

104 Cap. conl. Carth. III 333-342; breuic. III 25; c. Don. 18.

105 Cap. conl. Carth. III 343-346; breuic. III 26; c. Don. 3, 38.

106 Cap. conl. Carth. III 350 ff.; breuic. III 27. - Abgesehen von einigen Einschüben und unter Einschluss der durch die Cirta-Diskussion herangezogenen Dokumente zog sich dieser Teil der Debatte von III 350 bis III 470 in der Kapitelordnung des Marcellus, nahm also etwa ein Fünftel des Sitzungstages in Anspruch. 
habe, von einem Traditor ordiniert worden $\mathrm{zu}$ sein, ${ }^{107}$ doch konnten sie auch damit weder Marcellinus noch ihre Gegner überzeugen.

Das Interesse des Marcellinus richtete sich wieder auf die Anklage Caecilians vor Konstantin und er ließ die unterbrochene Lesung der römischen Protokolle fortsetzen. ${ }^{108}$ Die Donatisten hingegen nahmen ihre Kritik am Protokoll von Cirta wieder auf; sie wiederholten ihre Zweifel an der Authentizität mit dem Argument, das Konzil von Cirta könne gar nicht stattgefunden haben, da zur Zeit der Verfolgung eine Versammlung nicht möglich gewesen sei. ${ }^{109}$ Die unergiebige Diskussion über diese These beendete Marcellinus, indem er feststellte, dass sich grundsätzlich Bischöfe hätten versammeln können. Er gab jedoch kein Zwischenurteil über die Authentizität des Protokolls ab, wie es die Donatisten mehrmals gefordert hatten. ${ }^{110}$

Marcellinus verlangte nun entschlossen und zielstrebig eine klare Stellungnahme der Donatisten zur angeblichen Verurteilung Caecilians durch Miltiades. ${ }^{111}$ Jene beabsichtigten die Autorität des Miltiadesurteils zu unterwandern, indem sie zum einen dem außerafrikanischen Konzil die Zuständigkeit absprachen, zum anderen Miltiades selbst der traditio anklagten. ${ }^{112}$ Mit den vorgelegten Dokumenten und ihren Argumenten konnten die Donatisten aber wiederum nicht überzeugen ${ }^{113}$ und Marcellinus drängte auf die Lesung der restlichen Dokumente, um die Umstände des Urteils über Caecilianus zu klären. Die Katholiken legten den Brief Konstantins an den vicarius Eumalius vor, in dem aus ihrer Sicht der kaiserliche Freispruch Caecilians klar hervorging. Es wurde offensichtlich, dass Marcellinus diesem Urteil ein entscheidendes Gewicht für seine Entscheidung beimessen würde, und die Donatisten gerieten in erhebliche Beweisnot. Dennoch argumentierten sie weiter, indem sie sowohl das Konstantinurteil selbst als auch die Echtheit des Eumaliusbriefes anzweifelten. ${ }^{114}$ Erneut mit Berufung auf Optatus glaubten die Donatisten nachweisen zu können, dass Konstantin später in Wahrheit zu ihren Gunsten entschieden hätte. $^{115}$

107 Cap. conl. Carth. III 371, 374; breuic. III 29. - Zu Opt. I 19 s. auch Kap. 5.3.1 u. 7.1.1.

108 Cap. conl. Carth. III 376, 379, 386, 388, 390, 392, 397, 400-402; breuic. III 30-31.

109 Cap. conl. Carth. III 403, 407, 409; breuic. III 32.

110 Cap. conl. Carth. III 405-470; breuic. III 31-33.

111 Cap. conl. Carth. III 461, 463, 465, 467, 470.

112 Cap. conl. Carth. III 471.

113 Cap. conl. Carth. III 489-514; breuic. III 34-35.

114 Cap. conl. Carth. III 515-528; breuic. III 37.

115 Cap. conl. Carth. III 529-539; breuic. III 38. - Bereits in der Diskussion über Miltiades wollten die Donatisten den Optatustext vorbringen, doch wurde er auf Anordnung des Marcellinus zurückgestellt (Cap. conl. Carth. III 476-488). 
In dieser Phase erklärte Petilianus überraschend seinen Rückzug von der Diskussion mit der Begründung, er sei heiser und könne nicht mehr reden, ${ }^{116}$ so dass wohl von nun an vor allem Emeritus für die Donatisten das Wort führte. Diese präsentierten ein Gesuch ihrer Vorfahren an Konstantin mit einer Bitte um freie Religionsausübung, was der Kaiser auch durch ein Reskript, gerichtet an den Vikar Verinus, gewährt habe. Die Katholiken sahen in beiden Texten ihre eigene Position bestätigt, nämlich die donatistische Opposition zu Caecilianus und die Verurteilung der schismatischen Donatisten durch Konstantin. Marcellinus folgte dieser Beurteilung und lehnte die donatistische Forderung ab, er solle Konstantins Gewährung der Toleranz bestätigen. Die derzeitige Konferenz, so Marcellinus, solle ja schließlich auf Anweisung des jetzigen Kaisers Honorius über den Fall Caecilianus entscheiden. ${ }^{117}$

Nach diesem erneuten Fehlschlag legten die Donatisten ihr letztes Dokument vor: Der Brief Konstantins an den Prokonsul Probianus sollte ebenfalls ihre These stützen, dass ein letztgültiges Urteil des Kaisers gegen Caecilianus ausgefallen sei. Wiederum interpretierten die Katholiken die Situation gegenteilig und zogen dafür die Akten des Prozesses gegen Felix von Abthugni heran. Marcellinus hielt diese Akten für überzeugend und forderte von den Donatisten, gleichwertige, aussagekräftige Zeugnisse vorzulegen. ${ }^{118}$ Dieser Aufforderung konnten die Donatisten nicht mehr nachkommen. Sie wiederholten ihre bisherigen Argumente, forderten nochmals ein Zwischenurteil des Marcellinus und, da dieser ablehnte, taten sie kund, dass durch ihre Aussagen der Gegner vollständig unterlegen sei. Die Katholiken hielten alle Sachfragen für geklärt und erbaten das Urteil. ${ }^{119}$ Als Marcellinus merkte, dass die Donatisten keine neuen Beweise vorlegten, erklärte er die Sitzung für geschlossen. Nach der Beratungsunterbrechung verkündete er sein Urteil: Die Dokumente hätten die Donatisten widerlegt. Die katholische Einheit sei wieder herzustellen. ${ }^{120}$

Die donatistischen Bischöfe, die noch am folgenden Tag ihre Aussagen im Protokoll abzeichnen mussten, taten dies in einer Haltung, die keine Akzeptanz des Urteils verrät: sie unterschrieben nur vorbehaltlich eines Widerspruchs salua appellatione!

116 Cap. conl. Carth. III 540-542.

117 Cap. conl. Carth. III 543-552; breuic. III 39-40.

118 Cap. conl. Carth. III 553-570; breuic. III 41-42.

119 Cap. conl. Carth. III 567-582; breuic. III 43.

120 Cap. conl. Carth. III 583-585; breuic. III 43. 


\section{Verhandlungsstrategien}

Bis heute findet man in den Beurteilungen über die Konferenz von Karthago mehrheitlich ein negatives Bild der Donatisten, die nichts anderes beabsichtigt hätten, als durch juristische Finessen, unklare Aussagen und sprunghaftes Argumentieren die Verhandlungen in die Länge zu ziehen, die Diskussion der „Sache“ zu verhindern und die Konferenz zum Scheitern zu bringen, während auf der Gegenseite Augustinus und die Katholiken sich durchgängig um eine sachliche Debatte bemüht hätten. ${ }^{121}$ Zweifellos drängt sich eine derartige Einschätzung schnell auf; man denke nur an die endlose Prozedur des persönlichen Erscheinens aller Bischöfe vor dem Richter oder die Prozesseinreden, die zu ausufernden Debatten führten. Bereits während der Konferenz äußerten die Katholiken immer wieder ihren Unmut über die dilatorischen Prozesseinreden (praescriptiones moratoriae) und die überflüssigen Forderungen ihrer Gegner. Später verbreitete und verfestigte sich dieses Bild der Donatisten durch Augustins Schriften, die er im Anschluss an die Konferenz verfasste. ${ }^{122}$

Dieses Bild wird den Donatisten nicht gerecht und verklärt die Rolle der Katholiken. In jüngster Zeit ist es deshalb zu Recht korrigiert worden: Bei genauerer Betrachtung des Verhandlungsverlaufs unter juristischen und ekklesiologischen Gesichtspunkten lassen sich die Grundpositionen der Donatisten erkennen, die zu vielschichtig und durchdacht waren, als dass man sie mit einem Pauschalurteil abstempeln sollte. ${ }^{123}$

Die im Mandat und den Synodalbriefen verankerte Strategie der Katholiken ist bereits ausführlicher dargestellt worden. ${ }^{124}$ Im Verlauf der Debatte kamen Augustinus oder seine Mitstreiter immer wieder auf ihre zentralen Argumente zu sprechen. Die Strategie der Donatisten ist dagegen auf den ersten Blick verwirrend und leicht kommt der Gedanke auf, sie hätten gar keine gehabt. Wenn überhaupt, trifft eine solche Einschätzung lediglich auf die letzte Phase der Debatte zu, als Marcellinus und die Katholiken die donatistischen Zeugnisse zerpflückten und diese letztlich keine Antworten mehr geben

121 Vgl. in der älteren Forschung Seeck, Untergang III, 372: „Sie treiben die unwürdigste Obstruktion, verstecken sich hinter juristischem Formelkram und suchen durch elende Advokatenkniffe das Eingehen auf die wesentlichen Fragen zuerst ganz zu verhindern, dann wenigstens nach Möglichkeit zu verschleppen.“ Monceaux (IV 84-86, 422 f.): „une perpétuelle obstruction“. In neuerer Zeit Frend, Donatist Church, 279; Grasmück, Coercitio, 224 f.; van der Meer, Augustinus, 123 f.; Ch. Pietri, Geschichte des Christentums, 518-521; zuletzt noch Lamirande, Studia canonica 32, 1998, 421; Lancel, SC 194, 74; ders., Augustin, 420-423. Differenzierter dagegen Crespin, Ministère, $81 \mathrm{ff}$.

122 Vgl. u. Kap. 5.4.

123 Vor allem Maureen Tilley bemüht sich um eine differenziertere Sicht des Donatismus. Im Bezug auf die Konferenz vgl. Dilatory Donatists or Procrastinating Catholics: The Trial at the Conference of Carthage, ChHist 60, 1991, 7-19.

124 Vgl. o. Kap. 5.1.1. 
konnten. Bis es aber zu dieser Situation kam, waren bereits eine Reihe von Vorentscheidungen gegen die Donatisten gefallen, die ihnen in dieser letzten Phase keine Möglichkeit mehr ließen, ihren ursprünglichen Argumentationsaufbau sinnvoll einzusetzen. Eine Rekonstruktion der donatistischen Motive und Ziele im Vorfeld der Debatten sowie die Gründe ihres Scheiterns sollen im Folgenden dargelegt werden.

$\mathrm{Zu}$ Beginn der Konferenz verfolgten die donatistischen Bischöfe eine Doppelstrategie. Sie akzeptierten einerseits die prozessrechtlichen Regeln und nutzten ihre juristischen Möglichkeiten, das Verfahren zu ihren Gunsten zu beeinflussen. Andererseits stellten sie die vorgegebene Verfahrensweise permanent infrage und forderten ein Plenarkonzil aller Bischöfe, bei dem nach kirchlichem Recht und auf auf Grundlage der Heiligen Schrift verhandelt werde. ${ }^{125}$ Die Grundgedanken beider Verfahrensweisen finden sich bereits in der notoria vom 25. Mai und stehen im Zentrum der Worte von Emeritus, mit denen er die Debatte eröffnete. ${ }^{126}$

Zweifellos bevorzugten die Donatisten die Durchführung der Konferenz als kirchliches Konzil und eine Verhandlung auf Basis des ius divinum. ${ }^{127}$ Bei einer Bischofssynode sind alle Bischöfe der Provinz geladen und gleichermaßen stimmberechtigt; es gibt keine Mandate und keinen Richter, sondern die Entscheidung wird gemeinsam getroffen und von allen unterzeichnet. ${ }^{128}$ Die Formulierungen im ersten Edikt des Marcellinus hinsichtlich des geplanten Religionsgesprächs waren uneinheitlich ${ }^{129}$ und es wurde eine Einladung an alle Bischöfe ausgesprochen, so dass es trotz prozessrechtlicher Verfahrenseinleitung nicht von vornherein abwegig war, die Prozedur als Auftakt eines Konzils zu interpretieren, zumindest aber die Formfrage als unentschieden zu betrachten. ${ }^{130}$ Deshalb beriefen sich die Donatisten bei ihrer Ablehnung des zweiten Ediktes auf die Bestimmungen vom 19. Januar: Alle eingeladenen Bischöfe

125 Die Formulierungen variieren: Gesta conl. Carth. I 20: in negotio christiano; I 31: regula episcopalis moris; I 53: consuetudo ecclesiastica.

126 Gesta conl. Carth. I 20; vgl. I 47.

127 Gesta conl. Carth. I 20, 31, 44, 47.

128 Die Verfahrensweisen von Konzilien waren noch nicht einheitlich geregelt; es herrschten weitgehend gewohnheitsrechtliche Regeln. Für die Donatisten bildeten die Konzilien des 3. Jh., vor allem die afrikanischen Synoden unter Cyprian die Orientierungsgrundlage, während die Entscheidungen der großen Konzilien des 4 . Jh. für sie keine Berechtigung mehr hatten. Vgl. J. Gaudemet, Formation du droit, 143-159.

129 Es ist die Rede von in unum congregari (gesta conl. Carth. I 5, Z. 14), concilium (Z. 25, 33) und conlatio (Z. 21, 23). Auch im zweiten Edikt wird sowohl von concilium (Gesta conl. Carth. I 10, Z. 111, 125) als auch von conlatio/collatio (Z. 28, 97, 100) gesprochen.

130 Die Vorbereitungen der Donatisten zeigen, dass sie von einem offenen Verfahren ausgingen. Anders Tilley (ChHist 60, 1991, 9f.), die glaubt, die Donatisten hätten fest mit einem Konzilsverfahren gerechnet und nach Ankunft in Karthago überraschend veränderte Bedingungen vorgefunden. 
sollten nun auch teilnehmen können, wie es nach kirchlichem Brauch üblich sei. Die scharfen Einwände gegen die Mandatserteilung zu Beginn der ersten Sitzung unterstrichen diese Forderung, denn eine Bevollmächtigung für Prozessvertreter existierte im konziliaren Recht nicht. ${ }^{131}$ Neben den verbalen Attacken auf das Mandat offenbart sich die praktische Konsequenz der Strategie im Erscheinen aller Bischöfe vor Gericht am ersten Sitzungstag. Die Donatisten demonstrierten ihre Konzilsstärke und glaubten, durch ihre Anzahl der Forderung Nachdruck verleihen zu können, dem kirchlichen Brauch entsprechend weiter zu verfahren. Die Katholiken stellten sie vor die Alternative, die Rechtsnorm frei zu wählen; der Ton indessen zeigt deutlich, dass sie eine Entscheidung zu Gunsten eines weltlichen Prozesses als eines Bischofs unwürdig betrachteten. ${ }^{132}$

Was erwarteten die Donatisten von einem Konzilsverfahren? In der Hoffnung, tatsächlich die zahlenmäßig größere Gruppe auf der Konferenz zu stellen, wollten sie durch ihre Mehrheit ihre theologischen Positionen in der Diskussion durchsetzen. Möglicherweise glaubten sie sogar an einen Erfolg ohne eine Überlegenheit in der Anzahl. Die donatistischen Bischöfe waren von der Richtigkeit ihrer Ekklesiologie fest überzeugt; sie konnten auf die afrikanische Tradition, insbesondere auf Cyprian bauen und sahen ihre Standpunkte durch die Heilige Schrift bestätigt. ${ }^{133}$ Das Selbstbewusstsein der Donatisten darf diesbezüglich keinesfalls unterschätzt werden. Im Wissen um die bescheidenen Erfolgsaussichten vor einem katholischen Richter, theologische Interpretationen durchzusetzen, zielten die Donatisten auf die Chance, die ein Konzilsverfahren ohne Richter eröffnen würde. Sie konnten den Gläubigen in Afrika und den Kirchen des Erdkreises die Fehlentwicklung der katholischen Kirche in Afrika vor Augen stellen und mit Berufung auf das unwandelbare ius divinum sich als wahre Katholiken präsentieren.

Es zeugt von einer realistischen Einschätzung der gegebenen Umstände, dass die Donatisten nicht allein auf die Konzilsforderung gesetzt, sondern einen weiteren strategischen Zweig entwickelt hatten. Sie hatten sich entschieden, die prozessrechtlichen Regeln vorbehaltlich der Entscheidung über die Rechtsnorm zu akzeptieren, zunächst um überhaupt die Möglichkeit zu haben, vor Marcellinus und den Katholiken ihre Einwände vorzubringen. Des Weiteren präparierten sie sich aber für den Fall, dass sich der Wunsch nach einem Konzil nicht erfüllen und letztlich der Richter über die causa entscheiden würde. Sie fertigten

131 Gesta conl. Carth. I 14 (Z. 25-30), 20, 31, 33, 47, 53.

132 So z.B. Petilianus (Gesta conl. Carth. I 53): ,[...] wenn [mein Gegner] sich vom [göttlichen] Gesetz trennt, zeigt er, dass er kein Bischof ist; wenn er allerdings das göttliche Gesetz heranzieht, dann muss ich ihm antworten, wie einem, der wünscht ein Christ zu sein." ([...], si a lege discesserit, episcopum se non esse demonstret; si uero legem tenuerit, tunc ei ut illi qui christianus esse desiderat debeam respondere).

133 Vgl. die Diskussion in der causa ecclesiae und insbesondere die donatistische Widerlegung des katholischen Mandats. 
ihr Mandat aus und erarbeiteten die Prozesseinreden, mit denen sie zwar keine Konzilsform, wohl aber bestmögliche Ausgangspositionen für die Hauptverhandlung über die causa schismatis erreichen wollten. ${ }^{134}$ Der häufige Wechsel zwischen diesen Einreden und der Grundsatzforderung nach Klärung der Rechtsnorm in den ersten Beiträgen der Donatisten war insofern taktisches Verhalten, um in beiden Bereichen ihrer Doppelstrategie die Möglichkeiten auszuloten. ${ }^{135}$

Die erste Phase in der Verhandlungsführung der Donatisten endete mit ihrer Akzeptanz des Mandates als Prozessvoraussetzung bzw. der Bereitschaft, ihr eigenes Mandat öffentlich ratifizieren zu lassen, nachdem Marcellinus eindeutig erklärt hatte, dass die Mandate aus Rechtsgründen nicht verworfen werden könnten. ${ }^{136}$ De facto bedeutete dies den Verzicht auf eine Durchführung der Konferenz als Konzil und damit die Aufgabe der Doppelstrategie für die Donatisten. Von nun an konzentrierten sie sich auf den zweiten Aspekt: die Ausnutzung der Möglichkeiten des Zivilprozessrechtes.

Die Konferenz wurde in Anlehnung an das nachklassische Zivilprozessrecht eingeleitet und durchgeführt. ${ }^{137}$ Die gelernten Advokaten unter den donatistischen Bischöfen, vor allem Emeritus und Petilianus, bewegten sich auf bekanntem Terrain, als sie planten, den rechtlichen Rahmen für ihre Zwecke auszuschöpfen. Ihr Ziel war es, keinen Eintritt in die Hauptverhandlung (negotium principale) zuzulassen, bevor nicht alle Prozessvoraussetzungen (principia negotii) geklärt seien. ${ }^{138}$ Es bleibt zu klären, welche Erwartungen die

134 Die eindeutige Gegenüberstellung der Alternativen und die juristisch korrekte Aufzählung der Prozesseinreden durch Emeritus gleich zu Beginn der ersten Sitzung (Gesta conl. Carth. I 20; vgl. die Aussagen Petilians in I 9) belegen die gründliche Vorbereitung der Donatisten in den Tagen vor der Konferenz.

135 Vgl. Lancel, SC 194, $73 \mathrm{f}$.

136 Petilianus gestattete unter Vorbehalt die Lesung des katholischen Mandats (Gesta conl. Carth. I 53): „Er soll [das Mandat] lesen ohne ein Präjudiz gegen uns, vorbehaltlich der Tatsache, dass die Anklageform gerichtlich ist und nicht dem Kirchenrecht entspringt. Denn die Verwendung eines Mandates lässt nicht auf eine Form nach kirchlichem Brauch schließen, sondern nach gerichtlicher Spielart und Auseinandersetzung, und damit nach jener Praxis, die oftmals mehr auf Argumenten als auf einer Überzeugung beruht." (Sine praeiudicio nostro legat [mandatum], saluo eo quia haec causatio forensis est, non legalis. Nam uti mandato, his formulis praesumere non est ecclesiasticae consuetudinis sed forensis ludi atque certaminis, et illius exercitii quod magis argumentis quam fide aliqua saepe subsistit). Später erklären Primianus, Emeritus und Petilianus ihre Bereitschaft, vor dem Richter die Bevollmächtigung der Donatisten zu erteilen (Gesta conl. Carth. I 104, 106, 108).

137 Vgl. o. S. 155 mit Anm. 7.

138 Im klassischen und nachklassischen Kognitionsverfahren war es üblich, die Prozessvoraussetzungen zu klären (vgl. für die Rhetorik der Gerichtsrede etwa Quint. III 6.69; VII 5.3). Auf diesem Grundsatz beriefen sich sowohl Donatisten als auch Marcellinus. Für letzteren stellte die Erteilung des Mandates eine notwendige Prozessvoraussetzung 
Donatisten ursprünglich mit den Prozesseinreden (praescriptiones) verknüpften und ob sich diese Erwartungen während der Konferenz erfüllten.

Das Gesamtbild der Argumentation verdeutlicht, dass sich die Donatisten an den Regeln zivilrechtlicher Verfahren orientierten und Verstöße gegen übliche Verfahrensgrundsätze aufzeigen wollten. So lag es für die Donatisten nahe, nachdem im kaiserlichen Reskript eine Viermonatsfrist bis zum Beginn der Konferenz vorgegeben war, ${ }^{139}$ dies als Analogie zu den Fristbestimmungen der durch litis denuntiatio eingeleiteten Prozesse aufzufassen, ein verspätetes Eintreffen der Katholiken als Klägerpartei festzustellen (lapsus temporis) und daraus einen Antrag auf Prozessverlust zu formulieren. ${ }^{140}$ Die praescriptio de tempore der Donatisten zielte somit auf ein schnelles Ende der Konferenz mit einem Urteil zu ihren Gunsten. Marcellinus wehrte diese Einrede mit Verweis auf eine mögliche Fristverlängerung juristisch korrekt ab, ohne allerdings die Gründe für die Differenzen zu nennen. ${ }^{141}$

Die praescriptio de mandato, die prozessrechtliche Einrede gegen das Mandat, muss von der bereits erörterten kirchenrechtlich motivierten Ablehnung des Mandates unterschieden werden. ${ }^{142}$ Die prozessrechtliche Einrede betraf nicht mehr die Forderung nach einem Konzilsverfahren, sondern vielmehr die verfahrensrechtliche Frage, zu welchem Zeitpunkt des Prozesses die schriftliche Zustimmung zum formalen Ablauf erfolgen musste bzw. ob das Verfahren der Bevollmächtigung korrekt abgelaufen war. Für Marcellinus war die Ausstellung und Unterzeichnung der Mandate seinem Edikt gemäß die notwendige Vor-

dar, für die Donatisten dagegen die Klärung ihrer Einreden. Vgl. Kaser/Hackl, Zivilprozessrecht, 587 f.; Steinwenter, Kirchliche Quelle, $136 \mathrm{f}$.

139 Gesta conl. Carth. I 4 (Z. 34): intra quattuor menses.

140 Insoweit sich aus den Quellen eine Systematik ableiten lässt, mussten sich beim sog. Litisdenuntiationsprozess Kläger und Beklagte innerhalb einer Frist (in der Regel von vier Monaten) nach Zustellung der Klageschrift am vorgegebenen Prozessort einfinden (cursus temporis). Bei Nichterscheinen nach Ablauf der Frist wurde der Beklagte wegen contumacia verurteilt. Bei Ausbleiben des Klägers - worauf die Donatisten hier abhoben - erfolgte Prozessverlust, also eine Entscheidung zu Gunsten des Beklagten. Allerdings war auf richterliche Anordnung eine Wiedereinsetzung des Prozesses möglich. Vgl. Kaser/Hackl, Zivilprozessrecht, 566-570; Steinwenter, Kirchliche Quelle, 130 f.; ders., Versäumnisverfahren, $156 \mathrm{ff}$. (mit den z.T. problematischen Quellenbelegen).

141 Es ist erstaunlich, dass im Edikt vom 19. Januar gleichzeitig die Viermonatsfrist angekündigt und der 1. Juni als Prozesstermin festgelegt wird (Gesta conl. Carth. I 5 [Z. 30]), obwohl etwaige Verzögerungen noch gar nicht ermessen werden konnten. Ein sicherer Grund für diese Verschiebung lässt sich nicht finden (verschiedene Vermutungen bei Lancel, SC 194, 77 f.). Deutlich wird allerdings, dass Marcellinus weitgehende Organisationsfreiheit für die Ladung besaß. Zur praescriptio de tempore vgl. Lancel, SC 194, 74-78; Steinwenter, Kirchliche Quelle, 133-136. - Steinwenters Vermutung, die Terminnennung „1. Juni“ im ersten Edikt sei möglicherweise interpoliert (ebd., 135), widerlegt Lancel (SC 194, 75 f. Anm. 4) mit Verweis auf Gesta conl. Carth. II 50; III 206.

142 Vgl. o. S. $177 \mathrm{f}$. 
aussetzung für einen Eintritt in die Verhandlungen, ${ }^{143}$ für die Donatisten dagegen konnte eine Bevollmächtigung erst nach den Vorverhandlungen ratifiziert werden, hinsichtlich einer legitimen Prozessvertretung in der Hauptverhandlung.

Diese Ansicht wird bereits vor der Konferenz in der notoria sichtbar, als die Donatisten unter Berufung auf den mos publicus und die iudicum consuetudo, und gerade nicht mit Verweis auf das kirchliche Recht - ablehnten, den Verfahrensvorschriften des Marcellinus vorab zuzustimmen. ${ }^{144}$ Auch dieser Einwand findet eine Parallele in den Regelungen des Litisdenuntiationsprozesses, in denen für die Zustimmung beider Parteien zum modus procedendi der Abschluss der Vorverhandlungen mit Klärung aller Prozessvoraussetzungen vorgesehen war. ${ }^{145} \mathrm{Da}$ noch gar keine Verhandlungen stattgefunden hatten, geschweige denn Prozessvoraussetzungen geklärt worden waren, sahen die Donatisten neben ihrer theologischen Kritik am Mandat auch juristisch keinen Anlass, den Forderungen des Marcellinus nachzukommen. Zwar bestimmten sie ihre actores, aber sie unterließen das vorgeschriebene Verfahren der Unterzeichnung in Gegenwart des Richters, so dass ihr Mandat vorerst nur eine interne Absprache darstellte.

Nach Aufgabe der Doppelstrategie und mit der Konzentration auf die Prozesseinreden wurden folgerichtig die juristischen Argumente der notoria wieder aufgegriffen und weitergeführt. Nachdem sie das Mandat als Verhandlungsbasis vorbehaltlich akzeptiert hatten, ging es den Donatisten nun nicht mehr um die Debatte über das Mandat, die gerade stattgefunden hatte, sondern um die Überprüfung des Bevollmächtigungsverfahrens. Sie forderten eine Mandatserteilung in Gegenwart aller und die Aufnahme des Verfahrens ins Protokoll (apud acta). Sie begründeten ihre Forderung eindeutig prozessrechtlich, indem sie den korrekten Ablauf der außergerichtlichen Mandatsunterzeichnung in Zweifel zogen und mit der Wiederholung des Verfahrens in Gegenwart aller Prozessparteien die Angaben verifizieren wollten. ${ }^{146}$ Sie gaben

143 Gesta conl. Carth. I 32: Marcellinus, uir clarissimus, tribunus et notarius, dixit: 'Ne quid inordinate fieri uideatur, quoniam hoc et ipsum ueritatis regula continetur, et legum dictat auctoritas, prius est ut personarum numerus designetur; tum demum ea quae partibus conpetunt per eos qui firmati fuerint rectius peragentur, ne haec inter incertas personas uideantur infirma.'

144 Gesta conl. Carth. I 14 (Z. 20).

145 Vgl. Kaser/Hackl, Zivilprozessrecht, 587-595; Steinwenter, Kirchliche Quelle, 136 f.

146 Nach der Beschwerde des katholischen Bischofs Fortunatianus über diese „überflüssige" donatistische Forderung, nachdem doch die Heilige Schrift als gemeinsame Basis festgestellt worden sei (Gesta conl. Carth. I 68), legt Petilianus explizit dar, dass die Katholiken seine Forderung nicht verstanden hätten: Natürlich werde er, da auch die Katholiken sich zu einer Diskussion auf Grundlage der Heiligen Schrift bereit erklärt hatten, ebenfalls auf diese Grundlage verpflichtet antworten. Zuerst aber sei die Feststellung der Anzahl der Mandatsgeber nötig (I 70). Entscheidend ist hier die Betonung 
sich weder mit Marcellinus' Versicherungen über die Zuverlässigkeit des Verfahrens zufrieden noch akzeptierten sie seinen Kompromissvorschlag, nur in verdächtigen Fällen die Unterschrift zu prüfen,${ }^{147}$ so dass dem Richter letztlich nichts anderes übrig blieb, als dem Wunsch der Donatisten zu entsprechen, um sich nicht dem Vorwurf einer unkorrekten Verfahrensweise auszusetzen. ${ }^{148}$

Welchem Zweck diente die letztlich erfolgreiche Einrede? Die offizielle Begründung, der auch Marcellinus folgte, war juristischer Natur: Die Unterschriften der Mandatsgeber sollten kontrolliert werden. Zweifellos lag es in der Absicht der Donatisten, wie bereits in der praescriptio de tempore, Unregelmäßigkeiten und Verfahrensfehler aufzudecken. ${ }^{149}$ Da die Donatisten ihre Gegner als Ankläger betrachteten, sollte dies für die weiteren Verhandlungen Vorteile schaffen: Nachgewiesene Fehler in der Form der Anklageführung sollten zum Vorteil der Beklagten gereichen. Allerdings verfolgten die Donatisten einen weiteren, nicht juristischen Hintergedanken: Sie wollten trotz Akzeptanz des paritätischen Verhältnisses der Mandatsträger nicht auf eine Präsentation ihrer Gesamtanzahl verzichten. Es blieb für sie von größter Bedeutung, ihre Ausbreitung in Afrika sichtbar werden zu lassen und gleichzeitig die vermeintliche Stärke der Gegner als Schein und Lüge zu entlarven. Die Donatisten waren stolz auf ihre Kirche, die allen Anfeindungen und Verfolgungen zum Trotz ihre innere Reinheit und äußere Größe bewahrt hatte. Vor dem Richter und der Öffentlichkeit wollten sie die Verhältnisse richtigstellen. ${ }^{150}$ Die Gegenüberstellung aller Bischöfe brachte zwar weder juristisch verwertbare Unregelmäßigkeiten ans Licht (vielmehr zeigten sich Vorteile für die Katholiken) noch die erhoffte Überlegenheit in der Gesamtzahl, dennoch blieb ein Gewinn für die Donatisten: Sie hatten einerseits ihre Größe eindrücklich darstellen können und andererseits die Möglichkeit erhalten, einzelne Bischöfe als ihre Verfolger und als Nachfolger der Traditoren zu brandmarken. Nach ihren theologischen Beurteilungskriterien gab ihnen dies die Möglichkeit, diesen Bischöfen Amt und Würde abzusprechen. ${ }^{151}$

des „zuerst“: Es ging Petilianus immer noch um die Klärung der Prozessvoraussetzungen - also um einen prozessrechtlichen Vorgang. Fortunatianus hatte diesen Unterschied nicht begriffen.

147 Gesta conl. Carth. I 69, 73, 85, 87.

148 Gesta conl. Carth. I 98 - Marcellinus sah offenbar eine rechtliche Verpflichtung, die cautio ratam rem habiturum überprüfen zu lassen (vgl. Lancel, SC 194, 80). Es war also nicht allein ein großzügiges Entgegenkommen des Richters, wie Steinwenter (Kirchliche Quelle, 139) meint.

149 So sieht auch Augustinus die donatistische Absicht (breuic. I 11).

150 Dieser Gedanke wird explizit in der notoria formuliert (Gesta conl. Carth. I 14 (Z. $22-$ 24): exhortamur ut prioris edicti fide seruata [...], ut quamprimum de numero nostro constet, quos aduersarii paucos esse saepe mentiti sunt) und später in den Wortbeiträgen Petilians angedeutet (Gesta conl. Carth. I 59, 61, 65, 96).

151 Vgl. Tilley, Ch Hist 60, 1991, 15. 
Die praescriptio de mandato erfolgte somit aus einer doppelten Motivation, sowohl theologisch als auch juristisch. Ihrer Form gemäß wurde sie jedoch allein auf prozessrechtlicher Grundlage von den Donatisten vorgetragen, von Marcellinus akzeptiert und schließlich mit der zweifachen Gegenüberstellung der Bischöfe zum Abschluss gebracht. ${ }^{152}$

Ein weiterer rein juristischer Vorgang war der Antrag auf Vertagung der Konferenz am zweiten Sitzungstag. Da die Protokolle nicht vorlagen, war aus Sicht der Donatisten die Arbeitsfähigkeit des Gerichts eingeschränkt, vor allem, weil sie sich als Beklagte sahen, fühlten sie sich in der Argumentationsfähigkeit behindert. Dem Prozessrecht entsprechend beantragten sie eine dilatio instrumentorum causa, die Marcellinus schließlich bewilligte, obwohl es juristisch wohl eine Ermessensfrage darstellte, ob der donatistischen Forderung der Vorzug eingeräumt werden musste oder der Position des Richters, der sich auf die Einhaltung der donatistischen cautio, sich am 3. Juni zu versammeln, berufen konnte. ${ }^{153}$

Zum Auftakt des dritten Sitzungstages wurde die dritte Prozesseinrede der Donatisten vorgetragen: Die praescriptio de persona sollte dazu führen, den Katholiken die Klägerrolle und damit die Beweispflicht aufzuerlegen. Die Motivation der Donatisten war durch ihr Kirchenverständnis vorgegeben und hatte insofern Grundsatzcharakter. Sie verteidigten die Reinheit der Kirche gegen die Verschmutzung durch traditio und persecutio und klagten keinesfalls die katholische Kirche an, wie es die Gegner darzustellen pflegten. Dennoch waren auch bei dieser Einrede die donatistischen Argumente auf den Prozess bezogen und juristisch formuliert.

Ganz offensichtlich gingen die Donatisten davon aus, dass der laufende Prozess mit dem mandatum legatorum von 410 als Anklageschrift eingeleitet worden sei. Wiederum in Analogie zu ihnen bekannten zivilrechtlichen Verfahren erwarteten sie nun offenbar eine Zustellung der Anklageschrift, um als

152 Den rein juristischen Aspekt der Durchführung betont zu Recht Steinwenter (Kirchliche Quelle, 138 f.). Er ignoriert indessen die theologische Motivation der Einrede und sieht in ihr fälschlicherweise ein „reines Verschleppungsmanöver“. Lancel (SC 194, 7981) dagegen benennt beide wesentlichen Motive der Donatisten, übersieht aber, dass in der Verhandlung allein die juristische Begründung zählte. Tilley (ChHist 60, 15, 18 f.) stellt die theologische Motivation heraus und interpretiert die Einrede gegen das Mandat als Möglichkeit, die zentrale Frage der Heiligkeit der einzelnen Person, im Prozessrahmen zur Sprache zu bringen. Sie sieht somit völlig zu Recht, dass die Donatisten die Umsetzung der ekklesiologischen Ziele durch das Prozessrecht zu erlangen suchten. Dabei entgeht ihr allerdings der juristische Aspekt der Motivation.

153 Vgl. Lancel, SC 194, 82-84; Kaser/Hackl, Zivilprozessrecht, 596; Steinwenter, Kirchliche Quelle, 139. 
Beklagte entsprechend mit einer Gegenschrift darauf antworten zu können. ${ }^{154}$ Sie sahen ihre Rechte nicht gewahrt, solange ihnen der Inhalt des mandatum legatorum und die Namen der Legaten vorenthalten wurden. Ohne diesen formalen Vorgang jedoch konnten keine Hauptverhandlungen stattfinden. Primär diente diese Forderung der Festlegung des locus petitoris, indessen intendierten die Donatisten auch eine praescriptio mendaciorum. Sollte sich erweisen, dass mit dem mandatum legatorum falsche Anklagen vor den Kaiser gebracht worden seien, konnte die Anklage der Katholiken unterhöhlt oder gar zu Fall gebracht werden. ${ }^{155}$

Als Folge der Zuweisung des Anklägerstatus auf die Katholiken sahen die Donatisten ein weiteres Problem: Die juristische Bedeutung des katholischen Mandats im Verhältnis zu der ihrer Ansicht nach offiziellen Anklageschrift des mandatum legatorum. Sie forderten die Veröffentlichung der supplicatio auch mit der Begründung, den Inhalt beider Dokumente miteinander vergleichen zu können. Welche Funktion haben die Aussagen des katholischen Mandates, wenn doch das mandatum legatorum die Klageschrift darstellt? Gleich nach dem ersten Verhandlungstag hatten die Donatisten eine Kopie des katholischen Mandates angefordert und bis zur dritten Sitzung ihre Entgegnung zu diesem Text verfasst. Aus donatistischer Perspektive war es folglich keine überflüssige Anfrage zu klären, ob in dem Inhalt des Mandates die katholischen Anklagen vollständig erfasst worden waren, oder ob es weitere Anklagen gab, mit denen die Katholiken die Konferenz beim Kaiser gefordert hatten. ${ }^{156}$ Denn ihre Verteidigungsschrift sollte sich rechtlich korrekt auf die richtige Anklageschrift beziehen. So tritt in der praescriptio de persona neben den Wunsch, die Klägerrolle festzulegen und eventuell eine obreptio precum nachzuweisen, der Wunsch, in den Hauptverhandlungen nicht plötzlich mit überraschenden An-

154 Vgl. z. B. Gesta conl. Carth. III 62: „Der [donatistische] Bischof Montanus sagte: ,Da die gegnerische Partei Zuflucht bei dem allermildesten Kaiser gesucht hat, ist es nötig, dass sie sowohl das Mandat bekannt machen als auch die Legation selbst, damit wir, nachdem wir uns damit haben beschäftigen können, vor dem Gericht Deiner Nobilität wissen, was wir antworten können.'“ (Montanus episcopus dixit: quoniam pars aduersa ad clementissimum imperatorem confugit, oportet eandem et mandatum edere et legationem ut, cum haec potuerimus aduertere, in iudicio nobilitatis tuae nouerimus quid possimus respondere). - Beim Litisdenuntiationsprozess erhielt der Beklagte vorab die Anklageschrift, die gleichzeitig die Ladung vor Gericht darstellte (litis denuntiatio), so dass dieser eine Gegenschrift (contradictorii libelli) verfassen konnte. Vgl. Kaser/Hackl, Zivilprozessrecht, 566-568.

155 Dieser Vorgang zeigt eine Anlehnung an das Reskriptverfahren: Stellte sich heraus, dass der Bittsteller falsche Angaben gemacht hatte (obreptio precum), wurden die Verordnungen ungültig. Kaser/Hackl, Zivilprozessrecht, 636. - Vgl. zur praescriptio de persona Lancel, SC 194, 84-88; Steinwenter, Kirchliche Quelle, 139-141; Tilley, ChHist 60, 11 13.

156 Explizit dargestellt von Emeritus (Gesta conl. Carth. III 43). 
schuldigungen konfrontiert zu werden, die den zuvor festgelegten Rahmen widersprächen. ${ }^{157}$

Neben den Prozesseinreden geben die Debatten über die Rechtsquelle und über die causa ecclesiae am dritten Sitzungstag weitere Informationen zu den Zielen der Donatisten: Nach dem langen juristischen Gefeilsche um den locus petitoris erfolgte die Wiederaufnahme der Forderung nach der lex divina als Rechtsquelle durch Petilianus fast überraschend. Aus Sicht des Donatisten war dieser Einwand jedoch begründet. Die Katholiken hatten wiederholt die Vorlage des ältesten Anklagedokuments gefordert, und Marcellinus schien diesem Wunsch entsprechen zu wollen. Petilianus sah in dieser Entwicklung einen Übergang in die Hauptverhandlungen auf der Grundlage öffentlicher Dokumente. Dies widersprach seiner Ansicht nach den Vereinbarungen der ersten Sitzung: Nur aufgrund der Zusage, die Verhandlungen auf Basis der Heiligen Schrift zu führen, hätten die Donatisten Abstand von ihren ursprünglichen Einwänden genommen. In Einhaltung der Vereinbarung dürften jetzt die historischen Dokumente nicht gelesen werden; wenn die Katholiken dies trotzdem verlangten, dann sollten sie die Heilige Schrift verwerfen. Dies hätte bedeutet, eine neue Ausgangsbasis schaffen zu müssen. ${ }^{158}$

157 Die in Emeritus' Eingangserklärung aufgeführte praescriptio de causa (Gesta conl. Carth. I 20; vgl. o. Kap. 5.1.1) wurde im Gegensatz zu den anderen Einreden in den Verhandlungen nicht mehr explizit aufgenommen. Sie bezog sich jedoch höchstwahrscheinlich auf das heftig diskutierte Anliegen, die vorgegebene Streitsache (causa schismatis) als Kirchenfrage (causa ecclesiae) zu verhandeln. Im Gegensatz zu den katholischen Vorstellungen umfasste für die Donatisten die causa ecclesiae auch die causa traditorum bzw. die causa Caeciliani. Die praescriptio de causa steht somit im engen Zusammenhang mit der Auseinandersetzung über die Rechtsquelle. Da es für die Donatisten keine getrennte causa traditorum gab, benötigte man auch keine Beweismittel neben der Heiligen Schrift. - Anders Kaser (Zivilprozessrecht, 474 f.), der die praescriptio de causa für eine Einrede bezüglich der Zulässigkeit des Verfahrens hält. Steinwenter (Kirchliche Quelle, 136-141) nennt diese Einrede in der Aufzählung, ohne auf den möglichen Inhalt einzugehen. Ebenso übergeht Lancel (SC 195, 618 f.) die Frage, was mit der Einrede de causa gemeint sein könnte.

158 Gesta conl. Carth. III 153; 149: „Wenn dies von Deiner Potestas angeordnet worden ist [sc. die Lesung der relatio Anullini], wenn sie sich von dem entfernt haben, was sie kurz zuvor noch versprochen hatten, die Verpflichtung, der [göttlichen] Gesetze gemäß zu verhandeln, dann wende dich wieder jenem ersten Einwand von uns zu, den wir aufgrund dieser Annahme in gewisser Weise aufgegeben zu haben scheinen." (Si hoc potestati tuae mandatum est, si recesserunt ab his quae iam dudum promiserant, se legaliter agere oportere, redde nobis illam primam obiectionem, cuius uisi quodam modo sumus sub huius exceptionis ratione fecisse iacturam) [Ich folge der Konjektur Lancels, das non vor recesserunt zu tilgen.]. - Petilianus kehrt hier zur Basisfrage zurück, ob im Rahmen eines Konzils verhandelt werden soll oder nicht. Die Donatisten sind den Durchführungsbestimmungen lediglich gefolgt, da ihnen die Hauptverhandlung auf Grundlage der Heiligen Schriften zugesagt worden war. - Anders Lancel (SC 224, 1102 f. Anm. 1), 
An dieser Stelle wird deutlich, dass die Donatisten trotz Verzicht auf das Konzilsverfahren keinesfalls auch auf die Heilige Schrift als alleinige Rechtsquelle für die Hauptverhandlungen verzichtet hatten. Durch das Insistieren der Katholiken auf jenen Dokumenten, die in die Anfangszeit des Schismas führten, sahen sie eine bereits erzielte Verständigung untergraben. Die wiederholte Forderung an die Katholiken, sich doch für eine Rechtsnorm zu entscheiden, die sich nach Petilians erstem Einwurf neben der Debatte über den locus petitoris weiter durch die Verhandlung zog, ${ }^{159}$ beruhte somit auf der Überzeugung der Donatisten, dass beide Parteien und der Richter die Heilige Schrift bereits als alleinige Rechtsquelle für die Hauptverhandlungen anerkannt hätten. Die Heilige Schrift und historische Dokumente, wie es die Katholiken forderten, lehnten die Donatisten ab: Ambo enim tenere non poterunt $!^{160}$

Dieser Ausgangspunkt der Donatisten für den dritten Sitzungstag findet sich auch festgelegt in ihrer schriftlichen Widerlegung des katholischen Mandates. ${ }^{161}$ Die katholische Unterscheidung der beiden causae wird in diesen Instruktionen ignoriert und die historischen Bereiche werden ausgeklammert. Die Ausführungen konzentrieren sich allein auf die umstrittene Ekklesiologie: In den Verhandlungen solle aus der Heiligen Schrift die theologische Notwendigkeit

der Petilians Verweis auf die prima obiectio der Donatisten auf die praescriptio de tempore bezieht. Im Zusammenhang der Debatte kann mit dem „ersten Einwand“ jedoch nur die Frage der Rechtsnorm gemeint sein. In der Auflistung des Emeritus (I 20) steht zwar de tempore an erster Stelle, aber ausdrücklich unter der Prämisse, dass die Katholiken sich zuvor für das prozessrechtliche Verfahren entschieden hätten. Insofern hat Petilianus Recht, die Forderung nach Klärung der Rechtsnorm als prima obiectio zu bezeichnen.

Angesichts der Tatsache, dass Emeritus (III 159) und Adeodatus (III 161, 163) ihre Argumentation zum locus petitoris wie bisher fortsetzten, obwohl Petilianus die leges divinae wieder ins Spiel brachte, lässt eher auf eine Uneinigkeit der Donatisten schließen als auf ein gezieltes Manöver. Ein ähnlicher Gegensatz zeigt sich wenig später: Petilianus führt mit mehreren Beiträgen die donatistische Debatte an (III $181 \mathrm{ff}$.), Emeritus kommt ohne Bezug auf die Aussagen seines Kollegen wieder auf den juristischen Sachverhalt zu sprechen (III 200).

159 Gesta conl. Carth. III 155, 181, 183, 185, 191, 193, 203, 207, 209, 213.

160 Gesta conl. Carth. III 155 (in fine).

161 Gesta conl. Carth. III 258. - Die Donatisten verfassten den Text als Gegenschrift der Beklagten zur Anklageschrift der Katholiken, wie die juristischen Formulierungen im einleitenden Teil deutlich zeigen (Z. 5-23). Mit dem Vortrag der Gegenschrift (responsio) gaben sie gemäß des zivilrechtlichen Verfahrens ihre Zustimmung zur Eröffnung der Hauptverhandlung bzw. zum Eintritt in das Beweisverfahren (Z. 21 f.: Quare igitur hanc epistulam nostram petimus accipi atque inseri iubeas [sc. Marcellinus], tunc deinde causam audire digneris); vgl. Kaser/Hackl, Zivilprozessrecht, 592-595. Emeritus betonte nach der Lesung, dass nun zuerst ausschließlich die biblischen Zeugnisse mit ebensolchen Zeugnissen widerlegt werden müssen (Gesta conl. Carth. III 260: Prius testimoniis testimonia reuincant). 
einer ecclesia immaculata erwiesen werden. ${ }^{162}$ Auf dieser Grundlage müsse deutlich werden, dass Traditoren und Persecutoren als Sünder die Kirche verunreinigen. Die Trennung von diesen Sündern in der Vergangenheit sei folglich theologisch geboten und gerechtfertigt.

Der tatsächliche Verlauf der Debatte am dritten Sitzungstag verdeutlicht nochmals die Strategie der Donatisten: Grundlegend blieb für sie die Unterscheidung von Vorverhandlungen und Hauptverhandlung. Mithilfe der Prozesseinreden verfolgten sie das Ziel, in den Vorverhandlungen die bestmögliche Ausgangsposition zu erzielen. Dazu gehörte, den Katholiken die Klägerrolle zuzuweisen und das mandatum legatorum von 410 als Anklageschrift definieren zu lassen. Zudem versuchten die Donatisten, Verfahrensfehler bei der Anklage offenzulegen und so ein Ende des Prozesses zu ihren Gunsten herbeizuführen. Von zentraler Bedeutung für die Donatisten war jedoch, dass in der Hauptverhandlung allein auf Grundlage der Heiligen Schrift verhandelt werde. Dann sollte gezeigt werden, dass die traditio der entscheidende Aspekt der Auseinandersetzung sei, folglich die Katholiken als „Kirche der Traditoren“ keinesfalls die wahre Kirche Afrikas darstellen könnten. Um diesen entscheidenden Argumentationsschritt zu vollziehen, hatten die Donatisten auch ein historisches Dossier vorbereitet. Die historischen Argumente bezogen sich ausschließlich darauf, den Schlüsselfiguren der Auseinandersetzung - wie Caecilianus, Mensurius, Miltiades und Felix von Abthugni - die Schuld der traditio nachzuweisen. Auf dieser Grundlage sollte der Richter Marcellinus die donatistische Kirche letztlich als wahre Kirche Afrikas anerkennen. ${ }^{163}$

Im Gesamtblick zeigt sich zweifellos ein durchdachtes Konzept der Donatisten. Ganz offensichtlich waren die „Juristen“ Petilianus und Emeritus die Hauptverantwortlichen für die Ausarbeitung der Strategie, denn sie gaben auch in der Debatte den Ton an; während ihre Kollegen sich mit wenigen Redebeiträgen begnügten. ${ }^{164}$ Ihr Ausgangspunkt vor der ersten Sitzung war eine Doppelstrategie: Innerhalb des vorgegebenen Rahmens stritten sie parallel um die Durchsetzung eines Konzilsverfahrens einerseits und um Vorteile für eine et-

162 Gesta conl. Carth. III 258 (Z. 29-31): „Wir zeigen, dass die Kirche des Herrn überall in den göttlichen Schriften als heilig und unbefleckt verkündet wird.“ ([...] ostendimus ecclesiam domini in scripturis diuinis sanctam et immaculatam fore ubique nuntiatam).

163 Zur historischen Argumentation vgl. ausführlich u. Kap. 5.3.

164 Auffällig ist das Schweigen Primians von Karthago am 2. und 3. Sitzungstag, nachdem von ihm 13 Wortmeldungen am ersten Tag verzeichnet sind. Die Gründe können nur vermutet werden. Vielleicht gab es einen Dissens über den einzuschlagenden Weg? Möglicherweise hielt er sich aber bewusst zurück, um keine unbequemen Angriffe gegen seine Person wegen des Maximianistenstreites zu provozieren. Die Donatisten kannten schließlich die üblichen Argumente Augustins. Vgl. Mandouze, PAC, 910-913; keine Erklärung bei Lancel, SC 194, $210 \mathrm{f}$. 
waige Fortsetzung des richterlichen Verfahrens andererseits. Die Strategie der Donatisten war insofern zielgerichtet: Die Kritik an den Durchführungsbestimmungen sowie die Prozesseinreden waren notwendig zur Durchsetzung der eigenen Argumentation. Für die Donatisten sollte es keine Konferenz als „Religionsgespräch" geben, sondern entweder eine Konzilsentscheidung oder eine richterliche Entscheidung zu ihren Gunsten. Entsprechend verhinderten die Einreden zwar ein schnelles Vordringen zur „Sache“, juristisch aber (d.h. im Sinne der von allen Parteien akzeptierten Verfahrensweise) waren sie gerechtfertigt. Explizit erklärten die Donatisten, dass sie nach Abschluss der Vorverhandlungen in die Hauptverhandlungen treten wollten. Sie wollten die Hauptverhandlungen nicht verhindern, sondern unter den für sie am besten geeigneten Bedingungen durchführen.

Der Vorwurf, die Donatisten hätten die Konferenz zum Scheitern bringen wollen, trifft also nur teilweise zu. Zum einen wollten sie das von Augustinus geplante Religionsgespräch verhindern, zum anderen waren sie aber bereit, ein Urteil des Richters zu ihren Gunsten in jeder Phase des Prozesses zu akzeptieren. Die Donatisten konnten auf die Hauptverhandlungen verzichten, wenn durch nachgewiesene Unrechtmäßigkeiten seitens der Katholiken als Kläger der Prozess bereits in den Vorverhandlungen ein Ende gefunden hätte.

Auch die Aussage, die Donatisten hätten die historischen Dokumente gefürchtet und die historische Debatte verhindern wollen, trifft nur bedingt zu. Die Donatisten waren, wie ihre Dokumente zeigen, auf eine historische Debatte gut vorbereitet. Die Bedingungen für eine historische Debatte in ihrem Sinne musste jedoch zuvor in den Vorverhandlungen sowie in der Debatte über die causa ecclesiae geklärt sein: Die historische Argumentation der Donatisten war abhängig vom Ergebnis der ekklesiologischen Diskussion. ${ }^{165}$

Vergleicht man nun die Ausgangspositionen von Katholiken und Donatisten mit dem Ablauf der drei Sitzungstage, kristallisieren sich die Ursachen und Umstände heraus, an denen die Donatisten scheiterten und die zu der Entscheidung des Marcellinus führten.

Am ersten Sitzungstag konnten die katholischen Bischöfe keine Diskussion über die in ihrem Mandat niedergelegten Themen beginnen, den Donatisten hingegen gelang es, das Geschehen zu dominieren. Allein schon durch ihre

165 Vgl. die These von Tilley (ChHist 60, 1991, 18): „Procedural motions made by the Donatists at the Conference have been characterized as dilatory, but this is not the case. Rather they were, in the main, attempts to raise the issue of personal holiness in the only way it could be raised, procedurally." Tilley erkennt zu Recht, dass die entscheidende Motivation für das forensische Taktieren ekklesiologisch bedingt ist. Ihre Fokussierung auf die Frage der Heiligkeit der Person stellt zwar einen zentralen Punkt der donatistischen Strategie heraus, dadurch werden aber die übrigen Aspekte von Motivation und Zielsetzung der Donatisten vernachlässigt. 
Massenpräsenz und wegen des fehlenden Mandates für die donatistischen $a c$ tores blieb Marcellinus gar nichts anderes übrig, als die Einwände der Donatisten anzuhören. Doch Marcellinus trotzte den unterschiedlichen Kritiken, entgegnete den Einreden gegen die Fristbestimmungen und gegen das Mandat mit Hinweisen auf seine Bindung an die gesetzlichen Vorschriften. Seiner Konsequenz mussten sich die Donatisten beugen und ihre Konzilsidee aufgeben. ${ }^{166}$ Die durch die Umstände erzwungene Akzeptanz der Konferenz unter den vom Kaiser und Marcellinus vorgegebenen Bestimmungen nahm im Grunde das spätere Urteil schon voraus. Denn allein als innerafrikanische und innerkirchliche Angelegenheit hätten die Donatisten die causa schismatis für sich entscheiden können.

Dennoch bescherte der erste Sitzungstag den Donatisten Teilerfolge, die ihren geplanten Vorhaben entgegen kamen. Sie hatten ihre zahlenmäßige Größe vorgeführt und vor allem von den Katholiken und vom Richter das Zugeständnis erhalten, auf Basis der heiligen Schriften zu verhandeln. ${ }^{167}$ Auch die Vertagung der Konferenz am zweiten Sitzungstag kann als ein weiterer Teilerfolg für die Donatisten verstanden werden. Nicht nur hatten sie sich mehr Zeit zur Vorbereitung und zum Ausarbeiten ihrer Positionen für die folgenden Debatten erstritten, das Ergebnis des zweiten Tages ließ sie auch auf weitere Erfolge mit den vorbereiteten Prozesseinreden hoffen.

Für die Katholiken bedeuteten die Ergebnisse der ersten Sitzung trotz aller Kritik am Verhalten der Gegner keinen Nachteil. Schließlich hatte sich letztlich die Verhandlung mit actores durchgesetzt und die Heilige Schrift als Rechtsquelle zu nutzen, entsprach der Absicht, die causa ecclesiae in den Mittelpunkt der Debatte zu stellen.

Der dritte Sitzungstag zeigt - abgesehen von einigen retardierenden Momenten - eine kontinuierliche Demontage der donatistischen Strategie. Es gelang den Donatisten nicht, ihre Gegner in den Klägerstatus zu drängen. Das Insistieren auf dem mandatum legatorum brachte keine Anerkennung dieser Schrift als Anklageschrift, so dass weder eine obreptio precum nachgewiesen noch der locus petitoris durch dieses Dokument schnell und eindeutig festgestellt werden konnte. Marcellinus' Beurteilung der praescriptio de persona zeigt deutlich: Die Donatisten hatten die rechtliche Lage falsch eingeschätzt. Marcellinus besaß die kaiserliche Vollmacht zur Leitung und Durchführung der Konferenz. Er war insofern an keine gerichtlichen Vorschriften gebunden, die nicht im Reskript des Kaisers verankert waren. ${ }^{168}$ Folglich hatten jene Einwände der Donatisten

166 Gesta conl. Carth. I 30, 49, 54. - Zu diesem Einschnitt vgl. o. S. 179.

167 Gesta conl. Carth. I 36, 54-55.

168 Vgl. Gesta conl. Carth. III 36, 45, 51. Für Marcellinus gab es keine Prozessvoraussetzungen außer den im Reskript und den Durchführungsedikten verankerten Bestim- 
keine Chance, die sich auf die formaljuristischen Abläufe des Zivilprozessrechtes stützten. Mit ihren Forderungen nach Feststellung des Anklägers bzw. Offenlegung der Instruktion von 410 wären sie nur im Recht gewesen, wenn es sich tatsächlich um einen Litisdenuntationsprozess gehandelt hätte. Da dieser donatistische Ausgangspunkt falsch war, scheiterte die Einrede; Marcellinus war nicht gezwungen, von den Katholiken die Vorlage des mandatum legatorum zu fordern. Weil der Kaiser den Prozess angeordnet hatte, gab es keinen Ankläger und keine Anklageschrift; folglich hatte jenes Dokument mit der Sache nichts $\mathrm{zu}$ tun und alle folgenden Versuche, es wieder in die Diskussion einzubringen, ${ }^{169}$ wurden durch Marcellinus und Augustinus zurückgewiesen. ${ }^{170}$

Mit der Forderung nach dem mandatum legatorum hatten die Donatisten auch einen anderen Fehler begangen. Gegen ihren Willen wurde dieses Dokument der Ausgangspunkt zur Vorlage anderer öffentlicher Zeugnisse und der Entscheidung des Marcellinus, den ersten Ankläger durch diese Zeugnisse feststellen zu lassen. ${ }^{171}$ Die Donatisten waren somit gezwungen, auf andere Art und Weise die für sie notwendigen Vorausentscheidungen zu erreichen, denn das erste Dokument, das nicht mehr die offizielle supplicatio darstellte, bedeutete für sie den Eintritt in die Hauptverhandlungen. Ohne vorherige Entscheidung über die causa ecclesiae konnten sie allerdings keinen Eintritt in die Hauptverhandlungen oder eine Diskussion über historische Zeugnisse dulden.

Die Donatisten versuchten durch Wiederaufnahme der Rechtsquellenfrage wieder an Boden zu gewinnen. Sie erinnerten ihre Gegner an das Versprechen vom ersten Tag, allein auf Grundlage der Heiligen Schriften zu diskutieren. ${ }^{172}$ Doch wiederum hatten sie sich verrechnet: Weder interpretierten der Richter und die Katholiken den jetzigen Verhandlungsstand als Eintritt in die Hauptverhandlungen, noch deuteten sie ihre Zusage, auf Basis der Heiligen Schrift zu verhandeln, in gleicher Weise wie die Donatisten. Die Donatisten nämlich hatten das Übereinkommen, legaliter zu verhandeln, als eine ausschließliche Entscheidung über die Rechtsquelle verstanden: sola scriptura. Marcellinus

mungen, d.h. vor allem die Wahl der actores durch die Abfassung von Mandaten. Der Verhandlung auf Basis der Heiligen Schriften stimmte er wahrscheinlich zu, da auch Augustinus und die Katholiken dies wünschten. Hinsichtlich des mandatum legatorum wollte Marcellinus zwischenzeitlich der donatistischen Bitte nachkommen (III 66), hielt dies dann jedoch für unnötig (III 70) und bezog sich auf das Reskript. Dies zeugt ebenfalls von seiner Entscheidungsfreiheit in dieser Frage.

169 Gesta conl. Carth. III 129, 138, 140, 146, 153, 157, 159, 161, 163, 165, 188, 191.

170 Gesta conl. Carth. III 160, 162, 164, 194. Vgl. Lancel, SC 194, 66-68; Tilley, ChHist 60, 1991, $11 \mathrm{f}$.

171 Gesta conl. Carth. III 120.

172 Gesta conl. Carth. I 53-55. 
hingegen folgte den Katholiken, die in der Heiligen Schrift lediglich eine geeignete Rechtsquelle für die theologischen Differenzen sahen. ${ }^{173}$

In der Tat war das donatistische Verständnis für die anderen Parteien kaum nachvollziehbar. Es hätte ein völliges Umdenken beim Richter und den Katholiken erfordert, die donatistische Schlussfolgerung zu ziehen, dass ein Traditor per se Ankläger der wahren Kirche sei. So brachte der Rückverweis auf den Konsens über die Rechtsquelle die Donatisten nicht näher an ihr Ziel. Im Gegenteil: Nachdem Augustinus mit der Lesung der relatio Anullini sein entscheidendes Beweismittel hatte vortragen können (III 220), standen sie mit dem Rücken zur Wand. Überdeutlich offenbarte das Dokument eine Anklage Caecilians beim Kaiser durch die Donatisten. Eher aus dem Augenblick heraus als wohl überlegt versuchten die Donatisten nun, auf einem direkten Weg ihren Standpunkt über die Verbindung von traditio und Anklage vorzubringen. In dieser Phase, in der noch im Protokoll die Spannung spürbar ist, stellte Petilianus Augustinus die donatistische Gretchenfrage: Filius es Caeciliani, an non ${ }^{174}$ An der Person Caecilians und seiner Nachfolger entschied sich für die Donatisten die Frage der wahren Kirche. Da Augustinus diese Verbindung ablehnte, mussten die Donatisten nun ihr Verständnis theologisch begründen. Emeritus war jetzt bereit, die donatistische Widerlegung des katholischen Mandats vorlesen zu lassen und die causa ecclesiae zu diskutieren. Dies bedeutete aber, dass

173 Aufschlussreich ist folgender Disput (Gesta conl. Carth.III 213-214): „Bischof Adeodatus sagte: ,Wenn nämlich ein Konsens besteht und wir unseren Konsens einhalten sollen, dann schulden auch sie uns, treu zu ihrem Konsens zu stehen, die versprochen haben auf Grundlage der göttlichen Gesetze zu verhandeln' [...]. Augustinus, Bischof der katholischen Kirche, sagte: ,Aber nur die Sache der Kirche, nicht aber den Fall des Caecilianus und seiner Kollegen, gegen die ihr Anklagen erhebt. Seht, wir versprechen es, und wir versprechen es genauso so oft, wie es von uns verlangt wird, und wenn es nicht verlangt wird, dann bieten wir es an: Wir beweisen, wir lehren, wir zeigen die Sache der Kirche nur mit göttlichen Zeugnissen, den Fall des Caecilianus aber und welcher Menschen auch immer, mit keinen anderen Dokumenten als denen, mit denen solche Dinge gewöhnlich bewiesen oder widerlegt werden' [...].“ (Adeodatus episcopus dixit: „Si enim consensus est et retinendi sumus ad consensum nostrum, debent etiam nobis ipsi fidem sui consensus, qui se legibus diuinis acturos esse promiserunt. “ [...] Augustinus, episcopus ecclesiae catholicae, dixit: „Sed causam ecclesiae, non causam Caeciliani et conlegarum eius, quibus crimina intenditis. Ecce pollicemur, et totiens pollicemur quotiens exactum fuerit a nobis, et cum non exigitur, offerimus: ecclesiae causam non nisi testimoniis diuinis firmamus, docemus, ostendimus; Caeciliani autem et quorumlibet hominum non nisi his documentis quibus solent ista uel demonstrari, uel purgari. " $[\ldots])$.

174 Gesta conl. Carth. III 227; vgl. III 221. Vgl. Tilley (ChHist 60, 1991, 15): „This ad hominem argument about who ordained Augustine reveals the centrality of the personal for Donatists." - Wischmeyer (ZNW 70, 1979, 72-76) betont, wie hier deutlich werde, dass Petilianus die „Garantie der reinen Kirche“ in der „Sukzession der reinen Bischöfe" sah. 
sich die Donatisten auf die Hauptverhandlungen einließen, die sie eigentlich erst nach Abschluss der Vorverhandlungen, nach Feststellung der Anklage zulassen wollten. Da sie jedoch keinen Spielraum mehr besaßen, mussten sie ohne diese Bedingungen die causa ecclesiae diskutieren.

Aber auch diese Debatte brachte keine Wende zu Gunsten der Donatisten. Marcellinus' erneute Ablehnung einer Zwischenentscheidung, diesmal in der Frage des Kirchenverständnisses bedeutete das endgültige Aus für das Anliegen der Donatisten. ${ }^{175}$ Ohne eine Bestätigung, dass die Sünde der traditio maßgeblich für die Aufrechterhaltung der Trennung von der katholischen Kirche sei, ohne die eindeutige Entscheidung zu ihren Gunsten, konnte ihre Strategie nicht mehr greifen und keine sinnvolle Verteidigung mehr erfolgen. Da die theologische Basis nicht gelegt worden war, mussten die geplanten traditio-Nachweise für Katholiken und Marcellinus konstruiert wirken und die Diskussion über die Geschichte des Schismas geriet zur Farce.

Damit stand fest: Obwohl sich die Auseinandersetzungen über die historischen Zeugnisse noch lange hinzogen und die Donatisten alles taten, um ihre Sichtweise des Schismas überzeugend darzustellen, war mit dem Ende der Diskussion über die causa ecclesiae die donatistische Strategie gescheitert. Sie scheiterte an der unterschiedlichen Rechtsauffassung von Marcellinus und Donatisten; sie scheiterte an der Weigerung des Marcellinus, Zwischenentscheidungen über den locus petitoris, die Rechtsquelle und die causa ecclesiae zu treffen, so dass niemals eine klare Trennung zwischen Vor- und Hauptverhandlungen bestand und den Donatisten dadurch notwendige Verhandlungsgrundlagen entzogen wurden. Sie scheiterte letztlich an ihrer leichten Verwundbarkeit: Zum Erreichen des Sieges hätte kein Glied in der Argumentationskette fehlen dürfen, aber die Gegner und der Richter waren stark genug, um keine Verbindung der Einzelteile zuzulassen. Die fragmentierten Argumente der Donatisten ließen sich leicht widerlegen.

Die Katholiken trugen zwar am Ende der Konferenz den Sieg davon, doch ihre ursprüngliche Strategie konnten sie nicht in allen Teilen umsetzen. ${ }^{176}$ In den Debatten nahm Augustinus unangefochten die geistige Führungsrolle unter seinen Kollegen ein. Bei den entscheidenden Phasen der Debatte griff er ein, gab die Impulse und setzte die inhaltlichen Akzente durch seine Ausführungen. Aus den juristischen Streitigkeiten der ersten beiden Sitzungen hielt sich Augustinus weitgehend heraus und überließ es seinen Mitstreitern, die Verzögerungstaktik der Donatisten zu kritisieren oder auf die Sachverhandlungen zu drängen. Am dritten Tag wollte Augustinus seinen Vorstellungen gemäß mit den donatistischen Vertretern diskutieren. Doch bereits sein Grundanliegen, mit den donatistischen Kollegen auf einer Ebene die causa schismatis zu erörtern,

175 Cap. conl. Carth. III 289-292, 312-313.

176 Vgl. o. Kap. 5.1.1. 
erwies sich als Utopie. Die Donatisten akzeptierten die Katholiken niemals als „Gesprächspartner“, sondern sahen in ihnen stets die Traditoren und Verfolger, deren falsche Anklagen sie zu widerlegen hatten. Sie teilten auch nicht die übereinstimmende Auffassung der Katholiken und Marcellinus', dass beide Parteien die Konferenz gefordert hätten.

Die Entwicklung der Debatte über den locus petitoris widersprach gewiss nicht den Vorstellungen Augustins. Es war ihm zwar durchaus daran gelegen, die Donatisten als Ankläger vorzuführen, wie auch sein Insistieren auf der Lesung der relatio Anullini zeigt. Wie im Mandat vorgesehen, wurden diese Argumente als Teil der causa Caeciliani lediglich in Reaktion auf die donatistischen Forderungen vorgetragen. Wäre es jedoch nach dem Willen der Katholiken gegangen, hätte zuerst der Versuch erfolgen sollen, auf theologischer Grundlage die Differenzen in der Kirchenfrage auszuräumen. Als die Donatisten endlich bereit waren, diese Frage zu diskutieren, ging Augustinus eifrig darauf ein und legte seine Positionen dar. Es entsprach aber ganz und gar nicht seinem Interesse, dass die Debatte über die causa ecclesiae keinerlei Annäherung der unterschiedlichen Standpunkte brachte, vielmehr der große Graben zwischen den Parteien deutlicher wurde. Obgleich die Kontroverse über die causa ecclesiae letztlich nur eine Parenthese ${ }^{177}$ zwischen den anderen Themen darstellte, so demonstriert sie im Nachhinein allerdings die Sprachlosigkeit zwischen den beiden Kirchen. Das ekklesiologische Missverständnis bedeutete das Scheitern des Dialogs.

Die strenge Trennung der causa Caeciliani von der causa ecclesiae konnten die Katholiken bei Marcellinus durchsetzen, und sie brachte am Ende auch den Erfolg. Denn anders als ihre Gegner benötigten die Katholiken kein Zwischenurteil über das Kirchenverständnis, um in der causa Caeciliani ihre Argumente vorzubringen. Ihre Beweismittel waren im Gegensatz zu denjenigen der Donatisten unmissverständlich und für den Richter nachvollziehbar. Der Freispruch Caecilians konnte eindeutig in den Akten aus Rom und durch die Briefe Konstantins bezeugt werden, so wie es im katholischen Mandat vorgesehen war. Die Demontage der Donatisten durch die historischen Dokumente bedeutete aus katholischer Sicht die Offenlegung der Wahrheit: Die Donatisten hätten grundlos ein Schisma verursacht und sich weder durch bischöfliches noch durch kaiserliches Urteil gegen sie korrigieren lassen. Dies war gleichzeitig eine eindeutige Antwort auf die Anfrage des Kaisers: Der Urheber des Schismas konnte durch die historischen Dokumente eindeutig ermittelt werden.

Augustinus und die Katholiken hatten damit ein Ziel erreicht, dessen sie sich vorher bereits sicher waren. Marcellinus hatte nach drei Sitzungstagen zu Gunsten der katholischen Einheit entschieden. Trotz aller Zugeständnisse an die Donatisten während der Verhandlung: Seine Autorität reichte nicht aus, um

177 So Lancel, SC 194, 91. 
eine von Augustinus abweichende theologische Haltung einzunehmen, die notwendig gewesen wäre, um der donatistischen Argumentation Folge zu leisten.

Augustinus besaß nun das eindeutige Ergebnis, das er der afrikanischen Öffentlichkeit präsentieren wollte, das den Gläubigen die Wahrheit über das Schisma und über die Lehre der Donatisten vor Augen stellen sollte. Das übergeordnete Ziel, Frieden und Versöhnung mit den donatistischen Brüdern herzustellen, blieb allerdings ein unerfüllter Wunsch.

Der Einblick in die Verhandlungen der Konferenz von 411 zeigt, dass beide Parteien gleichermaßen die Möglichkeit hatten, ihre Anliegen vorzutragen und diskutieren zu lassen. In dieser Hinsicht erscheint der Prozess unvoreingenommen geführt worden zu sein. Jedoch konnte Marcellinus am Ende kein anderes Urteil fällen als das, was er fällte. Trotz seiner weitgehenden Entscheidungsfreiheit und aller förmlichen Objektivität war er in mehrfacher Hinsicht gebunden. Das kaiserliche Reskript hatte schon keinen Zweifel aufkommen lassen, welche der beiden Parteien als Urheberin des Schismas zu gelten habe. Marcellinus' häufige Verweise auf das Reskript und die Anordnung, nach den Gründen des Schismas zu forschen, zeigen, dass den historischen Gegebenheiten von vornherein sehr großes Gewicht beigemessen wurde. Wie die Katholiken es beabsichtigten, ging es um nichts anderes als die Bestätigung der causa finita. Nachdem die offiziellen Dokumente die Freisprüche für Caecilianus und Felix erwiesen hatten, sprach Marcellinus seine Sentenz, ein Urteil, das selbstverständlich nicht anders lautete als das Urteil des sakrosankten Konstantin. ${ }^{178}$

Die theologischen Argumente spielten entgegen den Ankündigungen und Willen beider Parteien eine untergeordnete Rolle. Für die Katholiken, besonders für Augustinus, dürfte dies enttäuschend gewesen sein, doch war es für sie nicht entscheidend. Für die Donatisten hingegen bedeutete die stillschweigende Akzeptanz der katholischen Ekklesiologie den Anfang vom Ende ihrer Argumentation. Hier offenbart sich eine weitere Bindung des Richters. Marcellinus war als katholischer Laie gar nicht in der Lage, an den theologischen Interpretationen Augustins zu zweifeln. Ein theologisch begründetes Urteil gegen die Katholiken ist schwer vorstellbar. Auch den Donatisten dürfte klar gewesen sein, dass ein umfassender Erfolg für sie lediglich durch Umstimmung der katholischen Bischöfe möglich gewesen wäre, nicht aber durch das Überzeugen

178 Vgl. in diesem Sinne u. a. Frend, Donatist Church, 275; Lamirande, Studia canonica 32, 1998, 428. Lancel (SC 194, 64 f.; ders., Augustin, 423 f.) hält derartige Kritik an Marcellinus für unangemessen. Jedoch geht es nicht um einen Angriff auf die Ehrenhaftigkeit des Richters, sondern es ist schlicht zu konstatieren, dass Marcellinus aus seiner Perspektive und unter den gegebenen Umständen letzthin keine Alternative für die Entscheidung besaß. - Vgl. zum Ergebnis der Konferenz das edictum cognitoris vom 26. Juni 411 (CCL 149 A, 177-179); M. Moreau, Le dossier Marcellinus, 112 f. 
des Richters. Juristische Teilerfolge für die Donatisten lagen vielleicht im Bereich des Möglichen; sie hätten aber im günstigsten Falle zu einem Abbruch der Konferenz und somit zur Beibehaltung des status quo geführt.

\section{Die historische Argumentation}

Die Konferenz von Karthago wurde auf Grundlage der historischen Argumentation entschieden. Die Dokumente der Katholiken gaben den Ausschlag für das Urteil des Marcellinus, nachdem die Forderungen der Donatisten nach anderen Bedingungen für den Prozessverlauf abgelehnt worden waren. Obwohl zahlreiche Dokumente und Argumente in einer Vielzahl von Wortmeldungen und Randdebatten vorgetragen wurden, ging es stets um nur eine Frage: Welche über Caecilianus gefällte Entscheidung besitzt Gültigkeit? Der Mandatsforderung der Katholiken entsprechend ${ }^{179}$ wurde nicht primär darüber entschieden, ob Caecilianus irgendwelcher Vergehen schuldig war oder nicht, sondern ob es in der Vergangenheit eine rechtmäßige Verurteilung oder einen rechtmäßigen Freispruch gab. Keine causa finienda, sondern eine causa finita stand zur Debatte. Die Verhandlungen waren von zwei großen Auseinandersetzungen geprägt, die im Folgenden betrachtet werden sollen. Zum einen der Streit um das Protokoll der Synode von Cirta, zum anderen der Streit über die europäischen Urteile in der causa Caeciliani.

\subsection{Das Konzil von Karthago gegen das Konzil von Cirta}

Nachdem Marcellinus die Lesung der historischen Dokumente gefordert hatte, begannen die Katholiken mit der Vorlage ihrer Zeugnisse über die Anklage Caecilians beim Kaiser und über die Durchführung und Entscheidung des Konzils von Rom. Damit sollte bewiesen werden, dass die Donatisten die Anklageinitiative ergriffen hätten und Caecilianus in den folgenden Urteilen freigesprochen worden sei. ${ }^{180}$ Die Donatisten forderten dagegen, dass zunächst der Inhalt der Anklage gegen Caecilianus vorgetragen werde. ${ }^{181}$ Aus dieser Forderung entwickelte sich die Diskussion über die Bedeutung der traditio für den Fall Caecilians.

Die Donatisten waren durchaus bereit, den geschichtlichen Hintergrund für das Schisma aus ihrer Sicht zu verdeutlichen und eröffneten ihre Darstellung

179 Gesta conl. Carth. I 55 (Z. 345-367); vgl. o. Kap. 5.1.1.

180 Cap. conl. Carth. III 314-320; breuic. III 24. - Zu diesem Teil der Argumentation vgl. u. Kap. 5.3.2.

181 Cap. conl. Carth. III 328. 
mit einem Abriss über die Vorgänge in Karthago zur Zeit der Verfolgung. Ihr Ausgangspunkt war das Fehlverhalten von Caecilianus und Mensurius während der Verfolgung und der daraus resultierende Verlust der Würde für ein geistliches Amt. ${ }^{182}$ Zur Bekräftigung ihrer Anklagen legten die Donatisten einen Briefwechsel zwischen Mensurius und Secundus vor, durch den sie den karthagischen Bischof belastet sahen. ${ }^{183}$ Als entscheidendes Dokument präsentierten sie anschließend ein decretum de Caeciliani damnatione, die Akten und Sentenzen des Konzils von Karthago gegen Caecilianus. In dem Beschluss dieser Synode - Caecilianus aufgrund seiner Vergehen und der traditio seiner Ordinatoren abzusetzen - sahen die Donatisten die einzig entscheidende historische Grundlage zur Klärung der Debatte. Ausgehend von dieser Grundlage sollte Marcellinus urteilen; er sollte bestätigen, dass das Konzil in Karthago rechtmäßig zustande gekommen und durchgeführt worden sei, folglich die Sentenzen gegen Caecilianus und damit seine Absetzung gültig seien. ${ }^{184}$

Den Katholiken fiel es nicht leicht, dieser Auffassung schlagkräftige Argumente entgegenzusetzen. Für die Donatisten besaß das Urteil von Karthago höchste Priorität, da ein afrikanisches Konzil über die Schuld eines afrikanischen Bischofs eine eindeutige Entscheidung getroffen hatte. Dies war kirchenrechtlich von Gewicht, denn Provinzialsynoden besaßen traditionell grundsätzlich das Recht über die Anklage gegen Bischöfe abschließend zu entscheiden. ${ }^{185}$ Augustinus wusste, dass dieses Argument für das Urteil des Marcellinus keine entscheidende Bedeutung haben würde. Er nahm jedoch die Herausforderung an und griff zu einer bewährten Argumentation: Ein Vergleich des Protokolls der Synode von Cirta mit den Namen der Bischöfe des karthagischen Konzils sollte zeigen, dass sich unter den numidischen Gegnern Caecilians selbst Traditoren befunden hätten. ${ }^{186}$ Wie bereits in früheren Schriften, so forcierte Augustinus damit eine Gegenklage gegen die traditioAnklagen der Donatisten. Vor allem der Schuldnachweis gegen den numidischen Primas Secundus als einem der entscheidenden Protagonisten im Absetzungsverfahren gegen Caecilianus sollte zeigen, dass in der Frage der Traditoren mit zweierlei Maß gemessen worden sei und immer noch gemessen werde. Während Secundus das eine Mal im Angesicht seiner eigenen Schuld das Urteil über die Traditoren Gott überlassen habe, so habe er das andere Mal eigenmächtig entschieden und das Schisma bewirkt. ${ }^{187}$

182 Cap. conl. Carth. III 333; breuic. III 25.

183 Cap. Conl. Carth. III 336-341; breuic. III 25. Eine ausführliche Auswertung dieser Quelle und der donatistischen Argumentation u. Kap. 6.1.1.

184 Cap. conl. Carth. III 367, 369, 401, 457.

185 S. dazu Girardet, Historia 23, 1974, 111-127.

186 Cap. Conl. Carth. III $350 \mathrm{ff}$.

187 Vgl. die Argumentation in ep. 43 (o. Kap. 4.2.1) und u. Kap. 6.2.1. 
In seinen Schriften nach der Konferenz ${ }^{188}$ behandelt Augustinus den Fall des Secundus wesentlich ausführlicher als dies nach Informationen der Capitula auf der Konferenz geschah. Er greift nochmals auf Secundus' Brief zurück, den die Donatisten vorgelegt hatten, und vergleicht die Selbstaussagen dort mit den Vorwürfen des Purpurius von Liniata gegen Secundus auf dem Kozil zu Cirta. Die Aussagen des Purpurius macht sich Augustinus zu eigen: Von einem mutigen Bekenntnis des Secundus und der Weigerung, Schriften auszuliefern, könne gar keine Rede sein. Im Gegenteil: Mit Purpurius sei zu fragen, wie denn Secundus hätte ungeschoren davonkommen können, wenn er nicht in irgendeiner Form mit den Behörden kooperiert hätte. ${ }^{189}$ Für Augustinus war dadurch erwiesen, dass Secundus sich nicht anders verhalten habe als Mensurius oder Caecilianus.

Augustins argumentativer Gebrauch des Protokolls erweist sich somit als zielgerichtet, aber auch als einseitig. Ihm ist nicht daran gelegen, mögliche Hintergründe der Synode von Cirta zu klären oder den Umgang mit den Traditoren differenziert zu betrachten. Augustinus unterlässt es geflissentlich, näher auf die Vorwürfe gegen Purpurius einzugehen, der in Cirta immerhin als „Mörder“ beschuldigt wurde. Er gibt zwar zu, dass dessen Anschuldigungen gegen Secundus aus einer Verteidigungshaltung heraus entstanden sind, aber Augustinus sieht darin keinen Grund, diese Anschuldigungen anzuzweifeln.

Die Donatisten indessen wiesen die Anschuldigungen scharf zurück, indem sie das vorgelegte Protokoll als Fälschung deklarierten. Als ersten Grund nannten sie die Datierung des Protokolls, die ihrer Ansicht nach dem kirchlichen Brauch widerspreche. Trotz mehrfacher Versuche schafften sie es aber nicht, sich mit diesem Argument bei Marcellinus Gehör zu verschaffen. ${ }^{190}$ Ausführlich debattiert wurde dagegen der zweite Einwand der Donatisten: Das Datum des Protokolls wies in die Zeit der Verfolgung, und die Donatisten postulierten, dass während der Verfolgung eine derartige Versammlung von Bischöfen nicht hätte stattfinden können. ${ }^{191}$ Die Katholiken widersprachen und zogen Beispiele auch aus der Bibel heran, in denen von Versammlungen während Verfolgungen die Rede war. Im Gegenzug präsentierten die Donatisten Berichte von Märtyrern aus Abitina, um die Härte der Verfolgung zu beweisen, die Katholiken legten jedoch ebenfalls Märtyrerakten vor, aus denen das Gegenteil hervorging. ${ }^{192}$

188 Vgl. u. Kap. 5.4.

189 Breuic. III 27; c. Don. 18-19; Gaud. I 47.

190 Cap. conl. Carth. III 352 ff., breuic. III 27, 32.

191 Cap. conl. Carth. III 386 ff.; breuic. III 31-33.

192 Cap. conl. Carth. III 432-448; breuic. III 32-33. - Die Donatisten verwendeten wahrscheinlich eine frühere Redaktion der heute bekannten Akten der Abitinischen Märtyrer (vgl. dazu u. Kap. 6.1.1). Die von den Katholiken vorgelegten Akten sind unbekannt. 
Ein Vergleich der Datierungen des Protokolls von Cirta und den Märtyrerakten hatte zuvor Gewissheit bringen sollen, ob das Konzil tatsächlich während der Verfolgung stattgefunden habe. Es entstanden Irritationen, da die Schreiber bei der Kontrolle der Daten zu Ergebnissen kamen, die von den Angaben der Katholiken abwichen. Die Katholiken akzeptierten jedoch das Resultat der Schreiber, das von einem Monat Differenz zwischen dem Konzil von Cirta und der in den Akten beschriebenen Verfolgung ausging. ${ }^{193}$ Der Termin war für ihre Argumentation letztlich unerheblich. Marcellinus stimmte mit den Katholiken überein, dass eine Zusammenkunft von zwölf Bischöfen in einem Privathaus auch während der Verfolgung möglich gewesen sei. Damit bestätigte er indirekt die Echtheit des Protokolls und schloss sich der katholischen Argumentation an. ${ }^{194}$ Der letzte Einwand der Donatisten gegen das Protokoll war zuvor ungehört verhallt: Caecilianus hätte sich doch mit diesem Dokument verteidigt, wenn es authentisch gewesen wäre. ${ }^{195}$

Die scharfe Diskussion um das Protokoll von Cirta verdeutlicht die Brisanz dieses Dokuments in der Auseinandersetzung. Trotz der wenig konkreten Aussagen über die traditio ging Augustins Strategie auf, mit diesem Dokument das Urteil des karthagischen Konzils gegen Caecilianus zu diskreditieren. Dies gelang vor allem deshalb, weil die Donatisten keinen Schritt von ihrer Grundhaltung abwichen, der zufolge jene Bischöfe frei von jeder Schuld sein mussten, die in Karthago Caecilianus abgesetzt und Maiorinus gewählt und geweiht hatten. Insbesondere auf eine Persönlichkeit wie Secundus durfte kein Schatten fallen. Aus dieser Haltung heraus konnten die Donatisten gar nicht anders verfahren, als die Authentizität des Protokolls anzuzweifeln. Es war daher nicht nur eine Frage der Verteidigung vor Gericht, sondern auch eine Frage des Selbstverständnisses, dass die Donatisten auf der generellen Ablehnung beharrten und nicht - was vielleicht Erfolg versprechender gewesen wäre - versuchten, die inhaltlichen Schwächen des Dokuments für ihre Zwecke auszunützen.

193 Cap. conl. Carth. III 434-439. Augustinus versuchte nach der Konferenz die Datierungsfrage zu klären (breuic. III 32). Zu diesem Problem vgl. u. Exkurs: Zur Datierung des Konzils von Cirta.

194 Cap. conl. Carth. III 458, 461: Marcellinus hielt eine Entscheidung über das Protokoll von Cirta für irrelevant, solange keine anderen Argumente gegen die Verurteilung Caecilians vorgebracht worden seien.

195 Cap. conl. Carth. III 452. Vgl. Lancel, SC 195, 533 Anm. 2. - Selbst wenn dieser Einwand diskutiert worden wäre, hätten die Donatisten kaum an Boden gewonnen. Sollte Caecilianus Informationen über die Vorgänge in Cirta besessen oder gar das Protokoll in Händen gehalten haben, eine Verteidigung wäre wenig erfolgreich gewesen. Die Vorgänge in Cirta und in Karthago, die aus späterer Perspektive Parallelen aufweisen, betrachtete Secundus in der jeweiligen Situation unterschiedlich. Vgl. u. Kap. 6.2.1. 
Im Verlauf der Debatte zitierten die Donatisten aus dem Werk des Optatus von Mileve, um zu bekräftigen, dass Caecilianus von einem Traditor ordiniert worden sei. Bei Optatus - so die Interpretation - werde deutlich, dass Caecilianus die Schuld seiner Ordinatoren selbst zugegeben habe. Auf der Konferenz ging man auf diese Wortmeldung nicht ein. Erst Augustinus bezieht sich später auf dieses Argument und schreibt, dass Optatus im Sinne der Unschuld des Felix zu verstehen sei. ${ }^{196}$ Tatsächlich findet man zwar bei Optatus die Aussage, dass Caecilianus angeboten habe, sich nochmals weihen $\mathrm{zu}$ lassen, jedoch rechtfertigt dies nicht die umgekehrte Schlussfolgerung, Caecilianus habe die traditio seiner Ordinatoren zugegeben. ${ }^{197}$ Bezeichnenderweise lässt Augustinus die Frage der tatsächlichen Schuld offen. Er kann anscheinend in seinen Quellen keine eindeutige Aussage finden. Während aber die Klärung dieser Frage für die katholische Seite letztlich unwichtig war, zeigt der Versuch der Donatisten, jedes kleine Indiz gegen Caecilianus zu verwenden, wie zentral ihnen der Nachweis einer traditio erschien.

Die Katholiken ergänzten ihre Ausführungen zur Verurteilung Caecilians durch ein juristisches Argument. Sie unterließen es zwar, die Rechtmäßigkeit des Konzils anzufechten, aber sie sprachen dem Urteil die Gültigkeit ab, da Caecilianus bei den Verhandlungen nicht anwesend gewesen sei. Sie verwiesen zudem auf das Maximianistische Schisma und die Verurteilung Primians in Abwesenheit, die von den Donatisten auch nicht anerkannt werde. ${ }^{198}$ Augustinus fügt später noch ein weiteres Argument hinzu: Seiner Ansicht nach hätten die numidischen Bischöfe gar kein Recht gehabt, den karthagischen Bischof zu ordinieren, sondern lediglich die benachbarten Bischöfe, wie im Falle Caecilians geschehen. So werde es schließlich auch in Rom praktiziert. Die Donatisten ließen diese Argumente nicht gelten: Ihrer Meinung nach treffe Caecilianus selbst die Schuld, da er sich dem zuständigen Tribunal verweigert hätte. Der Streit um Primianus sei ein völlig anderer gewesen. Außerdem gingen sie davon aus, dass nach der Gewohnheit der Kirche Caecilianus als Primas von Africa proconsularis nur durch einen Primas hätte ordiniert werden können. ${ }^{199}$ Hinsichtlich dieser Auseinandersetzung gaben weder die donatistische noch die katholische Seite die rechtliche Situation um 310 n. Chr. richtig wieder. Die Donatisten projizierten offenbar ihr Gewohnheitsrecht auf die Anfangszeit des Schismas, die Katholiken argumentierten mit kirchenrechtlichen Verhältnissen, die sich erst im Laufe des 4. Jahrhunderts entwickelt hatten. ${ }^{200}$

196 Cap. conl. Carth. III 374; breuic. III 29.

197 Opt. I 19.2: iterum a Caeciliano mandatum est ut, si Felix in se sicut illi arbitrabantur nihil contulisset, ipsi tamquam adhuc diaconum ordinarent Caecilianum. Vgl. auch u. Kap. 7.1.1.

198 Cap. conl. Carth. III 370-373; breuic. III 29.

199 Cap. conl. Carth. III 370-373; breuic. III 29.

200 Vgl. Lamirande, BA 32, 729-731; u. Kap. 7.1.1. 
Die historische Debatte über die Rechtmäßigkeit der Ordination Caecilians blieb auf der Konferenz ohne Ergebnis. Beide Parteien hielten an ihren Auffassungen fest. Die Donatisten verteidigten die Legitimität der Absetzung Caecilians. Die Katholiken ließen sich nicht auf die Frage ein, ob das Konzil des Secundus kirchenrechtlich legitim war oder nicht. Sie beschränkten sich darauf zu zeigen, dass Secundus und die numidischen Bischöfe mit zweierlei Maß gemessen hätten, ebenso wie später die Donatisten im Maximianistischen Schisma. Diese katholische Anklage traf die Donatisten allerdings im Zentrum ihrer Argumentation, da die theologische Grundfrage nach der traditio berührt wurde. Die Donatisten mussten konsequenterweise die Echtheit des CirtaProtokolls abstreiten und Secundus als confessor und Kämpfer für die Heiligkeit der Kirche präsentieren. Ein Schuldeingeständnis hätte ihre Argumentationsbasis zerstört.

\subsection{Der Streit um die Urteile von Miltiades und Konstantin}

Die Auseinandersetzung fand ihre Fortsetzung in der Verhandlung über die europäischen Urteile in der causa Caeciliani, nachdem Marcellinus auf die Rückkehr der Debatte zum Urteil des Miltiades gedrängt hatte. Die Katholiken argumentierten auf Grundlage der von Augustinus bekannten Strategie: Caecilianus sei von zwei bischöflichen Gerichten und schließlich vom Kaiser selbst freigesprochen worden, nachdem die Donatisten selbst durch ihre Klage das Verfahren eingeleitet hätten.

Bereits zu Beginn der historischen Debatte hatten sie vier Texte vorgelegt, mit denen die Anklageinitiative der Donatisten und das Urteil des römischen Bischofs Miltiades bezeugt werden sollten. Dazu gehörten die beiden Berichte des Prokonsuls Anullinus an den Kaiser. Außerdem wurde ein Brief Konstantins an Miltiades vorgelesen sowie die Akten der Synode von Rom mit dem iudicium Miltiadis. ${ }^{201}$ Es kann kein Zweifel daran bestehen, dass diese Dokumente die katholische Darstellung untermauerten: Durch die pars Donati in Karthago sei Caecilianus beim Kaiser angeklagt worden. Konstantin habe eine Untersuchung angeordnet und Miltiades beauftragt, in diesem innerkirchlichen Streit ein Urteil zu fällen. Unter dem Vorsitz des römischen Bischofs habe diese Synode nach Anhörung der Parteien entschieden, dass Caecilianus der rechtmäßige Bischof Karthagos sei. Darüber hinaus unterstellten die Katholiken, dass die Donatisten beim Kaiser geklagt hätten, da sie offenbar selbst das Urteil von Karthago als ungenügend angesehen hätten. ${ }^{202}$

201 Cap. conl. Carth. III 315-320, 402; breuic. III 24.

202 Cap. Conl. Carth. III 375; breuic. III 30. 
Die Donatisten kannten die Argumente Augustins; sie waren auf die Auseinandersetzung über das Urteil vom Rom vorbereitet, obwohl sie versuchten, einer konkreten Stellungnahme möglichst lange $\mathrm{zu}$ entgehen, indem sie weiterhin Einwände gegen das Protokoll von Cirta vortrugen. Nach mehrfacher Aufforderung durch Marcellinus begründeten sie jedoch schließlich ihre Ablehnung der römischen Synode mit zwei Argumenten: Erstens hätte Caecilianus in Afrika gerechtfertigt werden müssen und nicht in Übersee, zweitens hätte Miltiades kein Urteil fällen dürfen, da er selbst Traditor gewesen sei. ${ }^{203}$

Das erste Argument nahm nochmals die vorangegangene juristische Auseinandersetzung auf. Es unterstreicht das kirchenrechtliche Verständnis, nach dem allein das karthagische Urteil gültig sein könne. Mit diesem Argument konnten die Donatisten auf keinen Erfolg mehr hoffen. Der Verlauf hatte gezeigt, dass Marcellinus über das Ergebnis des karthagischen Konzils nicht entscheiden wollte, ohne die folgenden Prozesse berücksichtigt zu haben. Die Anschuldigungen gegen Miltiades hingegen konnten vielleicht etwas gegen die Zeugnisse der Katholiken ausrichten. Sollte der Nachweis gelingen, dass Miltiades als Traditor gleichsam als befangener Richter über Caecilianus geurteilt hätte, könnten die Donatisten wieder an Boden gutmachen. Doch auch mit diesem Argument scheiterten sie letztlich, da ihre Beweismittel gegen Miltiades weder Marcellinus noch den Katholiken ausreichend erschienen.

Mangels besserer Alternativen legten sie Akten vor, die offenbar aus den Archiven des römischen Stadtpräfekten stammten und in denen von der traditio in Rom berichtet wurde. ${ }^{204}$ Anschließend präsentierten sie noch andere Akten, möglicherweise aus kirchlichen Archivbeständen, die beinhalteten, dass sich Miltiades um Rückgabe von Kirchengütern bemüht habe. ${ }^{205}$ Im ersten Text war unter anderem von der traditio eines gewissen Straton die Rede, dem zweiten Text zufolge war es ein Diakon namens Straton, der im Auftrag des Miltiades einen Brief des Maxentius an den Stadtpräfekten und den Prätorianerpräfekten überbrachte. Die Donatisten schlossen auf die übereinstimmende Identität der

203 Cap. conl. Carth. III 471: Prosecutio donatistarum, Caecilianum in Africa, ubi damnatus fuerat, debuisse purgari, Miltiadis autem pro eo sententiam non ualere, quia simili etiam crimine tenebatur.

204 Cap. conl. Carth. III 474, 489-490; breuic. III 34. c. Don. 17. Diese gesta quaedam prolixissima apud praefectum sind anderweitig nicht bekannt. Auch auf der Konferenz blieb die Herkunft ungeklärt und die Katholiken verlangten einen entsprechenden Eintrag in die Akten (Cap. conl. Carth. III 496-497). Augustinus bemerkt, dass der Text weder den Präfekten genau benenne noch den Ort, an dem sich das Berichtete ereignet haben soll (breuic. III 34).

205 Cap. conl. Carth. III 498; breuic. III 34; c. Don 17. Die Bezeichnung gesta alia verrät nichts über die Herkunft dieser Akten, doch lässt der Inhalt auf eine kirchliche Quelle schließen. 
beiden Personen und beurteilten Miltiades' Umgang mit dem Traditor Straton als hinreichendes Argument, den Bischof ebenfalls als Traditor zu bezeichnen. ${ }^{206}$

Die Katholiken und Marcellinus bezweifelten die Übereinstimmung beider Personen, da nur im zweiten Text von einem Diakon die Rede war. In den Akten des Präfekten wurde Straton dagegen als hortator uanissimae superstitionis bezeichnet. Während Augustinus anmerkt, dass diese Bezeichnung allen Traditoren gegeben worden sei, vertraten die Donatisten die Auffassung, es handele sich um einen Begriff der heidnischen Verfolger, mit dem sie sowohl Priester als auch Diakone der christlichen Religion bezeichnet hätten. Anscheinend konnte man diese Frage nicht klären, ${ }^{207}$ doch blieb dies unerheblich, da ohnehin nirgends Miltiades' Schuld explizit bewiesen worden war und Marcellinus das vorgetragene Argument der Donatisten als bloße Verdächtigung zurückwies. ${ }^{208}$

Die Donatisten dürften sich darüber im Klaren gewesen sein, dass die vorgelegten Dokumente nur im Hinblick auf ihr Kirchenverständnis ausreichende Beweiskraft besaßen. Auch in diesem Fall zeigt sich, wie der unterschiedliche ekklesiologische Ansatz die historische Argumentation beeinflusste. Allein die geistliche Verunreinigung des Miltiades durch Straton galt den Donatisten als Verurteilungsgrund. Mit welchem Ernst sie ihren Beweis verfolgten, verdeutlicht die Tatsache, dass die Donatisten nach der Konferenz Miltiades durch einen weiteren Traditor, den Diakon Cassianus, belasten wollten. ${ }^{209} \mathrm{Au}-$ gustinus sieht in dem neuen Namen keinen neuen Beweis. Für die Donatisten indessen bekräftigte der Verdacht auf einen zweiten Traditor in der Gemeinschaft des Miltiades ihre Überzeugung von dessen Schuld.

Nachdem Marcellinus die Diskussion über Miltiades beendet und Stellungnahmen zum Urteil Konstantins gefordert hatte, ${ }^{210}$ präsentierten die Katholiken den Brief des Kaisers an den vicarius Africae Eumalius aus dem Jahr 316, in dem sowohl die Entscheidung des Konzils von Arles als auch Konstantins Bestätigung von Caecilians Unschuld Erwähnung findet. ${ }^{211}$ Die Donatisten zweifelten aufgrund der fehlenden Datierung die Authentizität des Dokumentes an. Jedoch dürfte dies ein taktischer Schachzug gewesen sein, denn auf Nach-

206 Cap. conl. Carth. III 509: Wortmeldung der Donatisten [...], dass man Miltiades aufgrund seiner Gemeinschaft mit Straton als befleckt beurteilen müsse. (Prosecutio donatistarum [...] de Miltiade oportere iudicari Stratonis consortio maculatum); vgl. Cap.conl. Carth. III 511, 517.

207 Cap. conl. Carth. III 500-510; breuic. III 34-35.

208 Cap. conl. Carth. III 514.

209 Breuic. III 36; c. Don 17.

210 Cap. conl. Carth. III 514.

211 Cap. conl. Carth. III 515; breuic. III 37; c. Don. 56. Zu diesem Dokument s. Cresc. III 82; vgl. o. Kap. 3.4.2.2. und u. Kap. 7.4. 
frage gingen sie nicht soweit, den Brief als Fälschung zu deklarieren. ${ }^{212}$ Aufschlussreicher für die donatistische Beurteilung des Verfahrens ist dagegen die inhaltliche Kritik am Urteil Konstantins. Dieses, so die donatistischen Bischöfe, sei nicht rechtmäßig zustande gekommen, sondern falsche Informationen und Ratschläge hätten den Kaiser zu dieser Entscheidung geführt. ${ }^{213}$ Zwar entgegnete Marcellinus, dass das Urteil nach einem ordentlichen Verfahren (inter partes) gefällt worden sei, aber als Beweis stand den Katholiken nichts weiter zur Verfügung als jenes Reskript an Eumalius und lediglich die dort formulierte Sentenz konnte nochmals vorgelesen werden. Den Donatisten genügten diese Aussagen nicht, um die Umstände des kaiserlichen Verfahrens als geklärt anzusehen. Sie gingen in die Offensive und stellten ihre Sichtweise dar. ${ }^{214}$

Die Katholiken besaßen mit dem Reskript an Eumalius lediglich ein Dokument, das die letzte Phase der causa Caeciliani erhellen sollte, dies aber nur in begrenztem Umfang konnte. Die Donatisten hingegen präsentierten gleich mehrere Zeugnisse, die allerdings nicht das beweisen konnten, was sie beweisen sollten. Ihre Absicht war es, Marcellinus und den Katholiken folgendes Bild zu vermitteln: Das Reskript an Eumalius sei ebenso wie die vorangegangenen Urteile der europäischen Bischöfe hinfällig, weil Caecilianus in einem endgültigem Verfahren verurteilt und nach Brescia in die Verbannung geschickt worden sei. Konstantin habe seine Meinung revidiert, nachdem er infolge des Prozesses gegen Felix von Abthugni in Karthago den Hauptzeugen Ingentius nach Mailand beordert hätte. Der Kaiser habe aufgrund der Aussagen des Ingentius am Hofe den Freispruch des Felix nicht bestätigen können und dies habe auch zu einer neuen Sachlage in der causa Caeciliani geführt. ${ }^{215}$ Donatus von Casae Nigrae und seine Begleiter, die die Klage gegen Caecilianus beim Kaiser vertreten hätten, seien freigesprochen worden. Schließlich sei den Donatisten die freie Religionsausübung gestattet worden, nachdem diese sich nochmals mit einer entsprechenden Bitte an den Kaiser gewandt hätten. ${ }^{216}$

Die von den Donatisten vorgelegten Dokumente enthielten jedoch wenig zur Untermauerung dieser Version der Ereignisse. Es ist daher nicht verwunderlich, wenn Augustinus nach der Konferenz spöttisch kommentiert, die Donatisten hätten mit ihren Dokumenten den Freispruch Caecilians selbst aufs

212 Cap. conl. Carth. III 523-532; breuic. III 37-38.

213 Cap. conl. Carth. III 519: „Als die Donatisten sagen, dass das Urteil falsch sei, welches Konstantin berichtet worden sei." (Vbi dicunt donatistae falsum esse iudicium Constantini auribus intimatum); breuic. III 37: „Die Donatisten antworteten auch, dass falsche Ratschläge an die kaiserlichen Ohren gedrungen seien.“ (responderunt [donatistae] etiam imperatorias aures prauis suggestionibus inflatas).

214 Cap. conl. Carth. III 520-522; breuic. III 37.

215 Cap. conl. Carth. III 553.

216 Cap. conl. Carth. III 530 ff.; breuic. III 38-42; c. Don. 54; ep. 141.8-9. 
Beste bewiesen. ${ }^{217}$ Denn als Beleg für Caecilians Verbannung nach Brescia hatten die Donatisten nichts anderes vorzuweisen als ein mehrdeutiges Textzitat aus dem Werk des Optatus von Mileve, das lautete:

„Dann wurde dem Kaiser von Filumenus, einem Anhänger des Donatus, geraten, dass Caecilianus um das Gut des Friedens willen in Brescia festgehalten werde; und so geschah es.“218

Obwohl die Katholiken nicht leugnen konnten, dass Caecilianus aus irgendwelchen Gründen in Brescia bleiben musste, so wurde doch deutlich, als der Text im Zusammenhang vorgelesen wurde, dass Optatus in diesem Abschnitt eindeutig von einem Freispruch Caecilians berichtet; und dies war für Marcellinus die entscheidende Aussage. Die Katholiken quittierten entsprechend die donatistische Interpretation des Optatus mit Lachen. Es war auch nicht hilfreich, dass die Donatisten postulierten, Optatus habe die historischen Tatsachen bewusst schöngeredet. Marcellinus forderte einen überzeugenderen Beweis. ${ }^{219}$

Ähnlich scheiterte der Versuch der Donatisten, durch die Unterscheidung eines Donatus von Casae Nigrae von jenem Donatus, der später Bischof von Karthago werden sollte, die Verantwortung für die Aussagen in Rom nicht ihrem Namensgeber Donatus zu geben. ${ }^{220}$ Des Weiteren wollten die Donatisten nachweisen, dass Konstantin die causa Caeciliani letztgültig zu Gunsten der Donatisten entschieden und ihnen Religionsfreiheit gewährt hätte. Dazu legten sie eine Bittschrift (libellus) ihrer Vorgänger und das dazugehörige Reskript Konstantins an den Vikar Verinus vor. Dieses Vorhaben war im Rahmen der Debatte taktisch klug, da es Marcellinus auf die kaiserliche Autorität ankam und eine Anknüpfung an ein Urteil Konstantins durchaus sachgemäß war. Zudem überraschten sie mit diesen Dokumenten, da sie Augustinus und den Katholiken bis zu diesem Zeitpunkt unbekannt waren. Allerdings war der Verweis auf diese Texte sehr gewagt. Denn es ging zwar aus dem Reskript

217 C. Don. 57; ep. 141.8.

218 Breuic. III 38: recitatus est et Optatus recitantibus Donatistis, ubi ait: „[...] tunc a Philomeno suggestore eius [sc. Donati] imperatori suggestum est, ut bono pacis Caecilianus Brixae teneretur, et factum est." Vgl. Opt. I 26: tunc a Filumeno suffragatore eius imperatori suggestum est, ut bono pacis Caecilianus Brixiae retineretur. et factum est. $-\mathrm{Zu}$ den Lesarten und der Interpretation des Zusammenhangs ausführlich u. Kap. 7.4.2.1.

219 Cap. conl. Carth. III 532-536; breuic. III 38; c. Don. 54; ep. 141.9.

220 Cap. conl. Carth. 538-539. Trotz einiger Stimmen, die von der tatsächlichen Existenz zweier Donati ausgehen (vgl. de Veer, BA 31, 757 f.), halte ich diese Unterscheidung für sehr unwahrscheinlich. Wie J. Alexander (The Motive for a Distinction between Donatus of Carthage and Donatus of Casae Nigrae, JThS 31, 1980, 540-547) deutlich gezeigt hat, ist es gerade die aus der Not geborene Situation auf der Konferenz von 411, die die Donatisten zu dieser Unterscheidung brachte. Wahrscheinlich hat sich auch Augustinus täuschen lassen. Vgl. zur Diskussion auch Mandouze, PAC, 292 f., s. v. Donatus 5; Lancel, SC 194, 100 f, Anm. 2.; Monceaux V, 103. 
hervor, dass Konstantin den Streitfall nicht weiter verfolgen wollte, den noch exilierten Donatisten die Rückkehr gestattete und den Donatisten in Afrika eine freie Betätigung zubilligte, aber ansonsten enthielt sowohl die Bittschrift als auch das Reskript genügend Aussagen gegen die vorgetragene Darstellung der Donatisten. ${ }^{221}$ Augustinus sah im donatistischen libellus den deutlichsten Beweis gegen eine Verbannung Caecilians nach Brescia. Denn die Donatisten hätten darin erklärt, dass sie mit Caecilianus, den sie „Konstantins Taugenichts an Bischof" genannt hätten, niemals Gemeinschaft pflegen wollten und bereit wären, alles zu ertragen, was ihnen vom Kaiser auferlegt werden sollte. Wenn Caecilianus zuvor vom Kaiser verurteilt worden wäre, so die durchaus plausible Schlussfolgerung Augustins, wären solche Worte wohl kaum gefallen. ${ }^{222}$ Konstantins Antwort demonstriere den Unmut über die Donatisten in so eindeutiger Weise, dass keinesfalls von einer Verurteilung Caecilians auszugehen sei. ${ }^{223}$ In diesem Sinne interpretierte auch Marcellinus die beiden vorgelegten Zeugnisse.

Das letzte Dokument der Donatisten verband schließlich die causa Caeciliani mit dem Prozess gegen Felix von Abthugni und der Person des Ingentius. Sie präsentierten mit dem Brief Konstantins an den Prokonsul Probianus ein Schriftstück, auf das Augustinus häufig zurückgegriffen hatte, um seine Sicht der causa Felicis darzustellen. Dieses Schreiben sollte nun sowohl die entscheidende Rolle des Ingentius im kaiserlichen Verfahren beweisen als auch vom zeitlichen Verlauf klarstellen, dass das Verfahren gegen Caecilianus noch nicht entschieden worden sei, wie es die Katholiken durch den Eumaliusbrief hatten belegen wollen. ${ }^{224}$

Auf die causa Felicis waren aber auch die Katholiken gut vorbereitet. Sie hielten die Akten des prokonsularischen Verfahrens bereit, in dem Felix freigesprochen worden war. ${ }^{225}$ Die Donatisten machten deutlich, dass sie das Urteil

221 Cap. conl. Carth. III 543-550; breuic. III 39-40; c. Don. 54; ep. 141.9; vgl. Lamirande, BA 32, 734; Seeck, ZKG 10, 1889, 533-535; ZKG 30, 1909, 191; vgl. auch Monceaux IV, 198, 203, 208 f.; 211-213. - Zur donatistischen Deutung einer „Toleranz Konstantins“ vgl. u. Kap. 7.4.2.1.

222 Breuic. III 39: in quo libello satis aperteque monstrarunt, quam falsum dixerint de damnatione Caeciliani apud Brixam; idem quippe libellus ostendit, quemadmodum contra eos senserit Constantinus. nam ibi dicunt nullo modo se communicaturos antistiti ipsius nebuloni paratosque esse perpeti quidquid eis facere uoluisset; [...]. quomodo ergo eum Constantini antistitem dicebant, cui se contra Constantinum loquentes non communicare confirmabant, si eum apud Constantinum superauerant, ita ut ab illo Brixae scirent esse damnatum?

223 Breuic. III 40; c. Don. 54; ep. 141.9.

224 Breuic. III 41: hoc autem imperiale praeceptum ideo Donatistae se recitare dicebant, ut quasi ostenderent Caeciliani causam adhuc fuisse suspensam etiam post illud iudicium, quo se Constantinus inter partes omnia terminasse iam scripserat, $[\ldots]$.

225 Die Acta purgationis Felicis; vgl. Opt. App. II; zu dem Verfahren u. Kap. 6.1.3. 
des Prokonsuls über Felix nicht akzeptierten. Sie polemisierten heftig gegen den Richter und die Zeugen und kritisierten vor allem die Abwesenheit des Felix während des Verfahrens. ${ }^{226}$ Der Brief an Probianus und die Prozessakten der causa Felicis förderten allerdings ein klares Ergebnis gegen die donatistische Darstellung zutage und Marcellinus beendete die Sitzung, als die Donatisten seiner Forderung nach weiteren stichhaltigen Zeugnissen nicht nachkamen. ${ }^{227}$

In der Tat beinhaltete das letzte Beweisstück der Donatisten keine Aussagen, aus der sich eine Revision der Fälle Felix und Caecilianus folgern ließe. Der Brief an Probianus, der durch Augustinus überliefert ist, verrät nichts in Bezug auf irgendeinen Einfluss des Ingentius bei den Verhandlungen über Caecilianus. Vielmehr wird in dem kurzen Bericht über den Prozess gegen Felix deutlich, dass dieser mit einem Freispruch abgeschlossen worden war und Ingentius an den Hof beordert werden sollte, um gegen die beständig appellierenden Ankläger Caecilians auszusagen und die Vergeblichkeit weiterer Anschuldigungen klarzustellen. ${ }^{228}$ Interessanterweise forderten im Verlauf der Diskussion die Donatisten von den Katholiken eine Darstellung des Verfahrens, nachdem Ingentius zum Kaiser gekommen war. Offenbar gingen sie davon aus, dass über die Verhandlungen Konstantins mehr bekannt sei als die Katholiken zugeben wollten. Aber auch die Katholiken besaßen keine weiteren Informationen über Einzelheiten des kaiserlichen Verfahrens. Es ließ sich nicht einmal feststellen, ob Ingentius tatsächlich jemals am Hofe eingetroffen war. ${ }^{229}$ Für die Katholiken waren die vorliegenden Dokumente jedoch vollkommen ausreichend, um sowohl die Unschuld Caecilians als auch die Unschuld des Felix zu beweisen. ${ }^{230}$

Das Argument der Donatisten, dass der Brief an Probianus nach dem Brief an Eumalius geschrieben worden sei, wurde während der Konferenz weder weiter diskutiert noch nachgeprüft. Augustinus versuchte erst nach der Konferenz, die Chronologie der Ereignisse zu klären, aber für den Probianusbrief konnte auch er kein Datum eruieren. Er folgerte allerdings aus dem Zusammenhang, dass Konstantin zu keiner Zeit ein Urteil gegen Caecilian gefällt habe. ${ }^{231} \mathrm{Da}$ aber kein eindeutiger Beweis vorlag, blieb den Donatisten die Annahme erhalten, dass der Brief an Probianus später zu datieren sei als der Brief an Eumalius, den Augustinus auf den 10. November 316 datierte. Erst heute lässt sich mit großer Sicherheit sagen, dass der Brief an Probianus vor diesem Datum geschrieben wurde. ${ }^{232}$

226 Cap. conl. Carth. III 562-573; breuic. III 42.

227 Breuic. III 43; c. Don. 55.

228 Vgl. den Text des Briefes Konstantins an Probianus in Cresc. III 81, ep. 88.4.

229 Cap. conl. Carth. III 561; breuic. III 42; c. Don. 55-56.

230 Cap. conl. Carth. III 562.

231 C. Don. 56; breuic. III 42.

232 Augustinus prüfte anhand einer Prokonsulnliste die Reihenfolge der Ereignisse. In der Aufzählung der Dokumente lässt er den Probianusbrief allerdings aus, wahrscheinlich, 
Im Streit um die Urteile von Militiades und Konstantin hatte sich die katholische Darstellung durchgesetzt. Marcellinus betrachtete es als erwiesen, dass Caecilianus sowohl durch das Konzil in Rom als auch im kaiserlichen Verfahren freigesprochen worden sei. Er sah aufgrund der donatistischen Zeugnisse keinen Anlass, das Urteil des Miltiades in Frage zu stellen, und er verwarf die Ansicht, es habe ein Revisionsurteil Konstantins gegen Caecilianus gegeben. Marcellinus fasste sein Urteil zur causa Caeciliani finita nach der gegebenen Aktenlage, die zweifellos die katholische Darstellung stützte.

\subsection{Zusammenfassung: Argumentation und Beweisführung}

Der Diskussionsverlauf über die causa Caeciliani auf der Konferenz bestätigt die Gegensätzlichkeit der Argumentationsansätze bei Katholiken und Donatisten, die zuvor bereits im Streit über die causa ecclesiae deutlich geworden waren. ${ }^{233}$ Dem unterschiedlichen Verständnis für traditio folgte eine vollkommen unterschiedliche Vorstellung von den Anfängen des Schismas und eine unterschiedliche Interpretation der zur Verfügung stehenden Quellen.

Dem Mandat der Katholiken zufolge sollte die Geschichte des Schismas nur eine untergeordnete Rolle spielen. Dass es dennoch zu ausgedehnten Debatten über die Anfänge des Schismas kam, lag daher nicht in der Verantwortung der katholischen Bischöfe: Nachdem die Donatisten die Frage nach dem Status des Klägers angestoßen hatten, war es vor allem Marcellinus, der mit seiner Forderung zur Feststellung des ersten Anklägers, die Debatte der causa Caeciliani forcierte. Die Katholiken reagierten allerdings den Forderungen des Richters entsprechend. Sie wählten aus ihrem historischen Dossier die jeweils geeigneten Akten aus, um begründete Antworten bereit zu halten. So sollte die relatio Anullini die Anklageinitiative der Donatisten beweisen, die römischen Akten den Freispruch Caecilians durch ein Bischofskonzil, das Protokoll von Cirta die traditio-Schuld der numidischen Bischöfe und schließlich der Brief an Eumalius den Freispruch Caecilians durch den Kaiser. Diese Art und Weise der Aktenauswertung entsprach der Methode Augustins in seinen vorangegangenen antidonatistischen Werken. Die reagierende Haltung der Katholiken änderte

weil er kein Datum gefunden hat (vgl. c. Don. 19, 56). Probianus ist von August 315 bis August 316 als Prokonsul in Afrika nachweisbar. Der Brief Konstantins an ihn datiert höchstwahrscheinlich in den Sommer des Jahres 315; vgl. Maier I, 189; Barnes (New Empire, 170, $243 \mathrm{f}$.) datiert den Brief mit Verweis auf die Chronologie Chr. Habichts (Hermes 86, 1958, 373 Anm. 1) auf Anfang Mai 315; vgl. u. Kap. 7 Anm. 138 - Der Brief an Eumalius wurde zunächst von einer Kopie ohne Datum vorgelesen, doch fanden kurz darauf die Katholiken in ihren Unterlagen eine Abschrift mit Datum (Cap. conl. Carth. III 523-528, 534; c. Don 19; breuic. III 37-38).

233 Vgl. o. Kap. 5.1.2-3. 
nichts daran, dass sie letztlich das von Augustinus bekannte Schema vortragen konnten: Einspruch gegen das Konzil des Secundus auf der einen Seite und Nachweis der Urteilsfolge zu Gunsten Caecilians auf der anderen.

Ganz anders der Ausgangspunkt und die Absicht der Donatisten: Ihr Ziel der historischen Argumentation war es, die traditio bei Caecilianus und den anderen entscheidenden Personen zu Beginn des Schismas nachzuweisen. Nachdem in der causa ecclesiae die notwendige Vorausentscheidung, dass die persönliche traditio-Schuld einzelner die gesamte Kirche belaste, nicht getroffen worden war, hatten Augustinus und die Katholiken eines ihrer Argumentationsziele erreicht, während die Donatisten in ein Dilemma geraten waren. Selbst wenn ein traditio-Nachweis gelingen sollte, konnten sie nicht sicher sein, dass der Richter dies als ausreichende Begründung des Schismas beurteilen würde. Sie versuchten dennoch, ihre jeweiligen Anschuldigungen gegen Caecilianus, Miltiades und schließlich auch Felix von Abthugni zu bekräftigen, aber mit Ausnahme Caecilians, in dessen Fall immerhin die Verurteilung durch ein Konzil vorgelegt werden konnte, missglückten die Beweisführungen vollständig. Die Dokumente erwiesen sich als ungeeignet, die Interpretationen als umständlich und insgesamt kaum nachvollziehbar. Insbesondere bei der Widerlegung des Protokolls von Cirta verloren sich die Donatisten in Nebensächlichkeiten, die letztlich ohne Einfluss blieben.

Als sich in der Schlussphase der Debatte alles auf die Frage konzentrierte, wie denn das endgültige Urteil über Caecilianus ausgefallen sei, zeigte sich, dass sich die Donatisten auch über ihre eigenen traditio-Anschuldigungen hinaus mit dem geschichtlichen Ablauf beschäftigt hatten. Sie versuchten eine eigene, plausible und strukturierte Version der Ereignisse zu präsentieren, an deren Ende die Verurteilung Caecilians und Felix' von Abthugni stand, und hofften, dass Marcellinus die von Konstantin gewährte Freiheit nach diesen Verurteilungen bestätigen würde. Allerdings kann man sich kaum des Eindrucks erwehren, dass die vorgelegte Geschichtsdarstellung ein für den Anlass der Konferenz gebildetes Konstrukt war, das in dieser Form - im Gegensatz zu den Anschuldigungen gegen einzelne Personen - in der donatistischen Tradition keine Verankerung hatte. ${ }^{234}$

Sowohl die donatistische als auch die katholische Geschichtsdarstellung waren schematisch. Dies lag zum einen Teil an der Konzentration und Herausstellung bestimmter inhaltlicher Aspekte, zum anderen Teil aber an fehlenden Informationen. Den Katholiken mangelte es an Quellen, die genaue Auskunft über die Entscheidungsfindung in den Verhandlungen von Arles und vor dem Kaiser gaben. Sie hatten zudem weder genaue Vorstellungen über die zeitlichen Abläufe noch über die genaue Identität der beteiligten Personen. Donatus und Maiorinus, auch Caecilianus und Felix von Abthugni waren kaum

234 Dazu ausführlich u. Kap. 7.4.2.1. 
als Persönlichkeiten zu greifen; viele andere Vertreter der pars Maiorini blieben ohnehin anonym.

Insbesondere bei den Donatisten fällt aber die Diskrepanz zwischen ihren Behauptungen und den tatsächlichen Beweisen auf. Abgesehen von den Akten des Konzils von Karthago waren ihre historischen Dokumente wenig zum Nachweis ihrer eigenen Ausführungen geeignet. Es ist bezeichnend, dass sie auf „katholische“ bzw. augustinische Beweismittel, wie etwa Optatus von Mileve oder den Brief an Probianus, zurückgriffen, um ihre Thesen zu untermauern. Auf der anderen Seite ist es beachtenswert, wie die gleichen Dokumente aus einer anderen Perspektive völlig anders interpretiert werden konnten. Letztlich waren jedoch die donatistischen Akten zu unpräzise und die Interpretationen zu umständlich, als dass eine eindeutige Beweisführung hätte erfolgen können. Niemals, resümierte Augustinus später in zugespitzter Form, habe es Beweise für das gegeben, was die Donatisten gegen Caecilianus behaupteten. ${ }^{235}$

Abschließend sei nochmals ein wichtiger Aspekt betont: Die Geschichtsargumentationen beider Parteien unterlagen ekklesiologischen Prämissen, und nur im Zusammenhang mit diesen Vorgaben sind die Argumentationsstrategien, die Präsentationen und letztlich Sieg und Niederlage zu verstehen. Für die Katholiken waren zwei Voraussetzungen wesentlich: zum einen die Bedeutungslosigkeit persönlicher traditio-Vergehen für die Kirche, zum anderen das Recht eines europäischen Konzils, über einen Streitfall der afrikanischen Kirchebzu urteilen. Die Prämisse der Donatisten dagegen war die kompromisslose Bewertung der traditio, die eine umfassende Schuld für die gesamte Kirchengemeinschaft bedeutete.

\section{Die Schriften Augustins nach der Konferenz}

Die Konferenz von 411 sollte nach dem Willen des Kaisers und Augustins die Wahrheit ans Licht bringen, und das Urteil des Marcellinus hatte die Wahrheit über das Schisma im Sinne der Katholiken festgelegt und die Einheit per Zwang verordnet. Augustinus war mit dem Versuch gescheitert, durch die Diskussion mit den donatistischen Bischöfen in Karthago eine friedliche Vereinigung der beiden Kirchen herbeizuführen. Er sah es nun als seine Aufgabe an, mit dem ambivalenten Ergebnis der Konferenz im Rücken, seinen Kampf gegen den Donatismus fortzusetzen.

Trotz des „bitteren Beigeschmacks“ (LANCEL) für Augustinus präsentierte dieser das Ergebnis der Konferenz als Triumph der Wahrheit und des Friedens. In allen den Donatismus betreffenden Schriften nach 411 bezog er sich auf die Verhandlungen, demonstrierte die vollständige Niederlage der donatistischen

235 C. Don. $20-21$. 
Partei und rechtfertigte das Urteil des Marcellinus. In einer Situation, in der sich relative Erfolge bei der Wiedereingliederung donatistischer Gemeinden und Bischöfe in die katholische Kirche und hinsichtlich des Zwangsvollzugs bei widerstrebenden Donatisten zeigten, ${ }^{236}$ war es das seelsorgerische Anliegen Augustins, auf der neu geschaffenen Grundlage die Argumente für die Kircheneinheit weiterhin vorzutragen, um einer rein äußerlichen Bekehrung vieler donatistischer Gläubiger die innerliche Umkehr folgen zu lassen. ${ }^{237}$ Vor allem sollten die Laien überzeugt werden; sie sollten verstehen, warum die Einheit der Kirche so entscheidend sei, dass der staatliche Zwang gerechtfertigt werden könne. Mit dem Urteil von 411 war auch Augustins Position endgültig geklärt: Eine Veränderung der Argumentation gegen die Donatisten fand nicht mehr statt: Zentraler Punkt der Verkündigung war und blieb, dass der „Irrtum“ der Donatisten endgültig widerlegt und damit die Sache auch endgültig beendet sei. Augustins Darstellung und Auseinandersetzung mit der Konferenz und seine Akzentsetzungen sollen im Folgenden anhand der wichtigsten Schriften dieser Zeit betrachtet werden: der Breviculus, der Traktat an die Donatisten und die Epistula (141) an alle Donatisten.

\subsection{Der Kurzbericht über die Konferenz mit den Donatisten (breuic.)}

Der breuiculus conlationis cum donatistis ist ein kommentiertes Exzerpt aus den Protokollen der Konferenz von 411. ${ }^{238}$ Augustinus schrieb dieses Werk bald nach seiner Rückkehr aus Karthago, wahrscheinlich noch Ende 411. ${ }^{239}$ Alle Gläubigen sollten Verlauf und vor allem Ergebnis der Konferenz kennen lernen und sich von der Richtigkeit des Urteils überzeugen. Da die ebenfalls veröffentlichten Akten der Konferenz sehr umfangreich und ermüdend zu lesen waren, sah Augustinus die Notwendigkeit, eine vereinfachte Version herzustellen, die einem größeren Publikum zugänglich sein sollte. ${ }^{240}$ Um vergleichen zu können und Parallelen zu finden, verwandte Augustinus für sein Breviarium die gleiche

236 Zur politischen Umsetzung des Konferenzurteils s. o. Kap. 2.2.3.

237 Auf die gängige Formel gebracht: Foris inueniatur necessitas, nascitur intus uoluntas; vgl. u. a. s. 112.8; Emer. 2; correct. 30 .

238 Edition: Lancel, CCL 149 A, 261-306; Petschenig, CSEL 53, 39-92; vgl. retr. II 39; Poss. indic. VI 15; Monceaux VII, 118 f.; Lamirande, BA 32, 58-79; ders., Studia canonica 32, 1998, 426-430; Lancel, AL 1, 681-684, s. v. Breuiculus conlationis cum Donatistis.

239 Datierung: Terminus ante quem ist ep. 139, die spätestens Februar 412 geschrieben worden ist. Vgl. Lamirande, BA 32, 77; Lancel, SC 194, 353 f.; Monceaux VII, 277.

240 Breuic. I praef.; retr. II 39. 
Gliederung, die der ersten Aktenedition zugrunde lag, ${ }^{241}$ drei Bücher, den drei Sitzungstagen entsprechend, mit insgesamt 23 Kapiteln, wobei 15 auf das erste Buch entfallen, drei auf das zweite und lediglich fünf auf das umfangreiche dritte Buch. Augustinus gibt diese Unterteilung im Breviculus mit der Bezeichnung loci wieder. Von nachhaltig historischem Wert ist Augustins drittes Buch, da mit diesem die verlorenen Teile des Protokolls ergänzt werden können. ${ }^{242}$ Ein formales Defizit dieser Arbeit ist aber, dass nicht zwischen den einzelnen Redebeiträgen differenziert wird, sondern stets von „Katholiken“ und „Donatisten“ als Parteien die Rede ist.

Durch den Vergleich zwischen dem erhaltenen Teil der Protokolle und der Kurzfassung lassen sich einige Kennzeichen der Arbeitsweise Augustins feststellen. Im Großen und Ganzen gibt Augustinus den Verhandlungsverlauf wahrheitsgetreu wieder. Da jeder Leser zumindest theoretisch die Möglichkeit hatte, die Kurzfassung anhand der Originale zu kontrollieren, wären schwerwiegendere Änderungen auch äußerst ungeschickt gewesen. Allerdings setzt Augustinus deutliche Akzente auf bestimmte Themen, die sich besonders gut für seine Propaganda auswerten ließen; er kürzt die seines Erachtens überflüssigen Längen und ergänzt an anderen Stellen Erläuterungen und Argumente. ${ }^{243}$

Bei der Wiedergabe des ersten Sitzungstages kritisiert Augustinus die Verhinderungs- und Verwirrtaktiken der Donatisten, die die Sachdebatte hinausgezögert hätten. Die Überprüfung der Mandatsunterschriften referiert Augustinus verständlicherweise nicht im Einzelnen, er greift jedoch einige Beispiele heraus, mit denen er die Donatisten diskreditieren kann. So fügt er eine kurze Erklärung über das Maximianistische Schisma ein, als der Name Felicianus von Musti genannt wird, und gibt einen kritischen Kommentar zur donatistischen Diözese Turris ab, die - wie er glaubt - eine spätere Hinzufügung zur alten Diözese von Musti sei. ${ }^{244}$ Hinsichtlich der donatistischen Unterschriften betont Augustinus, dass viele Fehler und Unregelmäßigkeiten festgestellt worden seien. ${ }^{245}$ Außerdem zweifelt Augustinus an den Angaben der Donatisten über

241 Vgl. breuic. I preaef.; retr. II 39; ep. 139.3. - Diese erste Edition der Akten ist nicht erhalten. Die heutige Gliederung ist jene aus der Edition des Marcellus. Zur Vorlage Augustins siehe Lancel, SC 194, 354 f.

242 Eine Inhaltsangabe von breuic. erübrigt sich, da sie dem Verhandlungsverlauf der Konferenz entspricht (s. o. Kap. 5.1.2-3).

243 Lancel, SC 194, 356: „Résumé fidèle, pour l'essentiel, le Breuiculus est aussi une œuvre de combat,...". Gewohnt enthusiastisch äußert sich Monceaux (VII, 119): „cet ouvrage où il résumait les débats, au lendemain de la Conférence, avait la netteté, la plénitude, l'éloquence impérieuse et brève, d'un bulletin de victoire."

244 Breuic. I 12; vgl. Gesta conl. Carth. I 123-125.

245 Ausführlich kritisiert Augustinus die widersprüchlichen Erklärungen der Donatisten zum Fall des Quodvultdeus, der, obgleich verstorben, in der Liste der Unterschriften auftauchte. Breuic. I 14; vgl. Gesta conl. Carth. I 207 (Z. 28 ff.). 
ihre Vakanzen und die 120 nicht erschienenen Bischöfe. Es sei daher offensichtlich, dass die Katholiken die Mehrheit gestellt hätten, die Donatisten aber mit Lügen ihre Zahl vergrößern wollten. So präsentiert Augustinus die Katholiken als Vertreter der Wahrheit. Die Unregelmäßigkeiten bei den katholischen Mandatsunterschriften übergeht er mit Schweigen. ${ }^{246}$

Das umfangreiche Aktenmaterial des dritten Sitzungstages kürzt Augustinus an jenen Stellen ab, an denen die Donatisten ihre Einreden begründen, während er zu den katholischen Positionen zum Teil sehr ausführliche Erklärungen hinzufügt. So findet die für die Donatisten wichtige Forderung nach dem mandatum legatorum vergleichsweise wenig Raum und wird von Augustinus als unnötig abgetan, ebenso wie die wiederholten Anfragen bezüglich der Verhandlungsgrundlage. ${ }^{247}$ Augustinus legt einen Schwerpunkt auf die Widerlegung der donatistischen Schriftauslegung. Er referiert nicht nur ausgiebig die katholischen Positionen aus der Debatte über die Kirche (breuic. III 15-20), sondern kommentiert zuvor die donatistische Antwort zum katholischen Mandat (breuic. III 10-14). Darin kritisiert Augustinus, dass die Donatisten zu jenen vielen Bibelstellen schweigen, die die weltweite Ausbreitung der Kirche prophezeiten, und dass sie die Allegorie von den Fischen im Netz falsch interpretiert hätten (breuic. III 10,16). Außerdem bemängelt er, dass jegliche Erwiderungen zu den Parallelen des donatistischen und des Maximianistischen Schismas und zu den Zitaten Cyprians zur Tolerierung der Sünder fehlten (breuic. III 11). Gegen die Verurteilung seiner Position durch die Donatisten begründet Augustinus, warum die Katholiken Häretiker ohne eine erneute Taufe wieder in ihre Gemeinschaft aufnehmen (breuic. III 12). Schließlich wehrt Augustinus die Vorwürfe einer Verfolgung ab und beanstandet, dass die Donatisten keine Beweise zur Schuld Caecilians vorgelegt hätten. ${ }^{248} \mathrm{Da}$ er in dieser Argumentation nach wie vor das Schema der Unterteilung der zwei causae verfolgte, blieben Augustins Ausführungen zwangsläufig eine Darstellung der bekannten Argumente. Die Debatte über die causa ecclesiae auf der Konferenz hatte Augustins Verständnis für die Hintergründe donatistischer Ekklesiologie offensichtlich nicht erweitert.

Dem Grundschema entsprechend legt Augustinus den zweiten Schwerpunkt auf die Diskussion über die Anfänge des Schismas. Da der Verhandlungsverlauf ohnehin das gewünschte Ergebnis gebracht hatte, referiert Augustinus ohne viel Polemik diesen letzten Teil der Konferenz. Zur Erklärung für die Leser und Hörer erläutert Augustinus jedoch die angesprochenen historischen Zeugnisse

246 Breuic. I 14; vgl. I 12: ita factum est, ut omnino nullius catholici recitaretur subscriptio, de cuius praesentia dubitarent.

247 Breuic. III 2-7.

248 Vgl. zum Verständnis den Inhalt des katholischen Mandats (Gesta conl. Carth. I 55) und die donatistische Widerlegung (Gesta conl. Carth. III 258). 
an der einen oder anderen Stelle ausführlicher als die Katholiken in der Debatte. Ebenso wie bei den theologischen Argumenten ist ihm daran gelegen, die katholischen Beweise in den Vordergrund zu rücken und die unsichere Herkunft, die Fehlerhaftigkeit und mangelnde Stringenz der donatistischen Dokumente und Interpretationen vor Augen zu halten. So betont Augustinus die Anschuldigungen gegen die Person des Secundus, die auf der Konferenz nicht in dieser Ausführlichkeit besprochen worden waren. ${ }^{249}$ Dagegen fehlt der Versuch der Donatisten, die Verurteilung Caecilians auf dem Konzil von Karthago als wahr anerkennen zu lassen, obwohl Augustinus erwähnt, dass dieses Konzil durch die Donatisten vehement verteidigt wurde, und sie einen falschen rechtlichen Ausgangspunkt kritisierten. ${ }^{250}$ Die von den Donatisten herangezogene Optatusstelle (I 19) ergänzt Augustinus um eine kurze Erläuterung, ${ }^{251}$ die undurchsichtig gebliebene Datierung des Protokolls von Cirta versucht er im Nachhinein zu klären, ${ }^{252}$ ebenso fügt er eine Erklärung für die offen gebliebene Chronologie der Urteile gegen Felix und Caecilianus hinzu. ${ }^{253}$

Auf den Vergleich, den die Katholiken zwischen dem Fall Caecilianus und der Verurteilung Primians durch Maximianus anstellten, hatten die Donatisten im Verlauf der Debatte geantwortet, dass eine Sache mit der anderen nichts zu tun habe. ${ }^{254}$ Während auf der Konferenz selbst die Verhandlung schnell eine andere Richtung genommen hatte und der Satz weitgehend unkommentiert geblieben war, bedeutete diese Äußerung für Augustinus nach der Konferenz einen hervorragenden Anknüpfungspunkt für seine Polemik. ${ }^{255} \mathrm{Im}$ Breviculus kommentiert er die Stelle:

249 Breuic. III 27. In Cap. conl. Carth. III 351-365 ist nichts von einem Vergleich der Aussagen über Secundus im Protokoll von Cirta und den von den Donatisten vorgelegten Briefen erwähnt. - M. E. irrt Lancel (SC 194, 93 Anm. 6), wenn er glaubt, die Katholiken hätten eine der im Protokoll von Cirta genannten Personen namens „Donatus“ für den Gründer des Schismas gehalten. Beide Donati im Protokoll sind mit ihrem Herkunftsort versehen. An erster Stelle steht dort ein Donatus von Mascula und als dritter Name taucht ein Donatus von Calama auf (Cresc. III 30). Auf der Konferenz ging es den Katholiken lediglich um den Nachweis, dass bekennende Traditoren auf dem Konzil von Cirta die Verurteilung Caecilians in Karthago mitgetragen hätten. Wahrscheinlich ist daher, dass in Cap. conl. Carth III 355 der an erster Stelle aufgeführte Donatus von Mascula gemeint war, der nun als erster in den Konzilsakten der Donatisten gesucht werden sollte.

250 Breuic. III 29; vgl. Cap. conl. Carth. III 369-370.

251 Breuic. III 29; vgl. Cap. conl. Carth. III 374.

252 Breuic. III 32. Zu diesem Datierungsproblem s. u. Exkurs: Zur Datierung des Konzils von Cirta.

253 Breuic. III 42. Vgl. o. Anm. 232 und u. Kap. 7 Anm. 138.

254 Cap. conl. Carth. III 371.

255 Zugespitzt in c. Don.; vgl. u. Kap. 5.3.2; vgl. auch ep. 141.6-7; ep. 142.3; ep. 173.7-8 (an den donatistischen Priester Donatus). 
„Diese Aussage liegt normalerweise allen Katholiken als Kommentar auf der Zunge, wenn die Donatisten ihre Abspaltung verteidigen, indem sie die Vergehen der einen anderen vorwerfen und den christlichen Erdkreis mit irgendwelchen Vergehen der Afrikaner anklagen. Und alles, was die Katholiken auf jener Konferenz verfolgten, dass sie die causa ecclesiae von der causa Caeciliani trennten, indem sie erklärten, dass die der Kirche untergemischten Schlechten weder den Guten schaden noch mit ihren Sünden die Guten beschmutzen. Dieses alles verfolgten sie, damit weder die eine Sache ein Präjudiz für die andere schaffe noch die eine Person für die andere. Dies ist von den Gegnern in anderem Zusammenhang mit deutlichster Stimme bestätigt worden. “256

Die Unbedarftheit der mit Sicherheit spontanen Aussage des donatistischen Bischofs (vielleicht Petilians) lieferte Augustinus somit eine Stütze seiner eigenen Thesen. Jede weitere Diskussion sei hinfällig, da die Donatisten dem katholischen Verständnis zugestimmt hätten. Die Donatisten freilich hatten ihre Äußerung ganz und gar nicht als Bestätigung der katholischen Position verstanden, sondern lediglich darlegen wollen, dass die von den Katholiken verübte traditio und persecutio in der Sache nicht vergleichbar sei mit dem Verfahren in der Abspaltung der Maximianisten. ${ }^{257}$ Augustinus jedoch nutzt diesen einen Satz als Anlass, eine Überlegenheit der katholischen Argumentation zu demonstrieren.

Abgesehen von den genannten Kürzungen, Erläuterungen und subjektiven Fokussierungen, die in den meisten Fällen auch als solche erkennbar waren und sind, bleibt der Breviculus im Wesentlichen auf die Darstellung des Konferenzverlaufs beschränkt. Besonders auffällig ist der Verzicht Augustins auf jegliche Kommentierung des Urteils und auf Exhortationen und Einheitsappelle am Ende des Textes, die sich ansonsten fast immer finden lassen. Augustinus gibt die Schlussverhandlungen und das Urteil des Richters nahezu lakonisch wieder. Dies ist ein Zeichen für seine sichere Überlegenheit, mit der er die katholischen Beweise und das Urteil des Marcellinus vor den Gläubigen vertrat.

256 Breuic. III 28: quam sententiam in ore habere solent omnes catholici, cum Donatistae aliorum crimina aliis obicientes suam separationem defenderent et orbem christianum nescio quibus Afrorum criminibus accusarent. nam et ista collatione totum quod egerant catholici, ut ecclesiae causam a causa Caeciliani distinguerent, asserentes in ecclesia permixtos malos non obesse bonis nec eos suis maculare peccatis, hoc utique egerant, $u t$ nec causa causae praeiudicaret nec persona personae. quod ab aduersariis, dum aliud ageretur, uoce apertissima confirmatum est.

257 Vgl. ihre diesbezüglichen Äußerungen in ihrer Widerlegung Gesta conl. Carth. III 258 (Z. 269 ff.). 
Nur kurze Zeit nach der Abfassung des Breviculus schrieb Augustinus einen Traktat an die donatistischen Laien, ${ }^{258}$ um auf Anschuldigungen der donatistischen Bischöfe gegen den Ablauf der Konferenz, das Urteil und Marcellinus selbst zu reagieren und sie als Verleumdungen $\mathrm{zu}$ kritisieren. ${ }^{259}$ Für diesen Zusammenhang griff Augustinus nochmals auf die Hauptaussagen und Streitpunkte der Konferenz zurück und unterstrich die Wahrheit und Richtigkeit der katholischen Aussagen. Dasselbe Ziel verfolgte Augustinus mit einem kurzgefassten Schreiben, das er zunächst auf einem Konzil im numidischen Zerta seinen Kollegen vorlegte und von dort als Synodalbrief an die Donatisten gerichtet wurde. ${ }^{260}$

Ausgangspunkt für beide Schriften waren donatistische Angriffe auf die Konferenz von Karthago und es wird deutlich, dass die Donatisten eine rege Propagandatätigkeit entfaltet hatten; Augustinus spricht explizit von donatistischen Schriften, die in Umlauf gebracht worden waren. ${ }^{261}$ Einerseits übten die Donatisten heftige Kritik am Ablauf des Verfahrens. Vor allem warfen sie

258 Edition: Petschenig, CSEL 53, 97-162. In retr. II 40 wird die Schrift unter dem Titel post conlationem contra Donatistas liber unus aufgeführt, vgl. Possidius. (indic. VI 16): post conlationem contra supra scriptos Donatistas liber unus. Augustinus schreibt in retr. II 40 von Librum [...] ad [...] Donatistas post collationem. Diese Titulierungen werden zu Recht bevorzugt gegenüber Petschenigs Titel contra partem Donati post gesta. - Zum Text vgl. Monceaux VII, 119-122; Lamirande, BA 32, 79-90; ders., Studia canonica 32, 1998, 431-434; Lancel, Al 2, 639-644, s. v. Donatistas (Contra - ); Willis, Augustine, 79. - Datierung: Terminus post quem ist die Abfassungszeit von breuic. Terminus ante quem ist laut retr. II 40 die ep. 141, die am 14.06. 412 geschrieben wurde. Wahrscheinlich ist auch, dass der in ep. 139.3 an Marcellinus erwähnte Brief c. Don. bezeichnet, vgl. Monceaux (VII, 277, 284) und die Argumente bei Lamirande (BA 32, 87 f.) und Crespin (Ministère, 95 f. Anm. 7) gegen Goldbacher (CSEL 58, 38), der glaubt, Augustinus rekurriere in ep. 139.3 auf ep. 141. Demnach ließe sich der terminus ante quem auf Ende Februar 412 vorziehen. Die Abfassungszeit von c. Don. lag folglich Ende 411/Anfang 412.

259 Vgl. c. Don. 1; retr. II 40.

260 Ep. 141. Edition: Goldbacher, CSEL 44, 235-246; vgl. retr. II 40. - Datierung: 14.06 .412 (ep. 141.13: XVIII Kal. Julias piissimo Honorio Augusto VIIII cons.). - Das Provinzialkonzil, dessen Akten nicht überliefert sind, fand laut Adresse von ep. 141 und retr. II 40 in einem Ort namens Zerta statt. Durch Gesta conl. Carth. I 187 (Z. 84) ist dieser Ort belegt (vgl. Lancel. SC 373, 1534 f.). Gegen Monceaux (IV, 383 f.) und Lamirande (BA 32,88 ) gibt es keinen Grund, die Überlieferung zu ändern und das Konzil in Cirta zu lokalisieren. Dazu Perler/Maier, 307-309 und Lancel, SC 194, 274 f. Der Synodalbrief nennt namentlich acht Bischöfe als Absender. An erster Stelle steht Silvanus als Primas von Numidien (senex), an siebter Stelle Augustinus. Der an dritter Stelle genannte Aurelius ist Bischof von Macomades in Numidien (vgl. Gesta conl. Carth. 226, Z.4-5), nicht Aurelius von Karthago; vgl. Lancel, SC 194, 274.

261 C. Don. 25. 
Marcellinus Befangenheit und Bestechlichkeit vor. ${ }^{262}$ Sie behaupteten aber auch, durch den Kaiser zur Teilnahme gezwungen worden zu sein (c. Don. 1), und verwarfen zudem das Urteil des Richters, da es erst nach Einbruch der Nacht gesprochen worden sei, so wie auch Judas Christus bei Nacht verraten hätte (c. Don. 16, 58). Ähnlich wie Augustinus verteidigten die Donatisten aber auch ihre Argumentation auf der Konferenz und erweiterten sie teilweise. So erwähnt Augustinus wie bereits im Breviculus, dass beim donatistischen traditioNachweis gegen Miltiades ein neues Argument aufgetaucht sei (c. Don. 17; vgl. breuic. III 36) und dass hinsichtlich der causa ecclesiae die Donatisten nun mit dem Propheten Haggai argumentierten (c. Don. 26).

Um diesen Darstellungen zu entgegnen, wendet sich Augustinus mit c. Don. und ep. 141 an die gläubigen Laien. Wie bereits in den epp. 76 und 105 vor der Konferenz ruft er sie auf, sich nicht von ihren Bischöfen länger verführen zu lassen, da doch die Wahrheit auf der Konferenz klar ans Licht getreten sei. Er beschwört und ermutigt sie immer wieder, zur Einheit zurückzukehren und dem Frieden zu folgen. ${ }^{263} \mathrm{Im}$ Aufbau orientieren sich beide Schriften nicht mehr wie der Breviculus vollständig am Verhandlungsablauf, sondern Augustinus knüpft an die genannten donatistischen Anschuldigungen nach der Konferenz an und widerlegt sie durch seine Interpretation von Verhandlungsablauf und Urteil.

Im Traktat gegen die Donatisten (c. Don.) betont Augustinus nach einer Polemik gegen die donatistischen Bischöfe zunächst die Freiwilligkeit, mit der die Donatisten an der Konferenz teilgenommen hätten. Wenn sie nun ihr Erscheinen bei der Konferenz mit dem Zwang der kaiserlichen Anordnung rechtfertigten, sei dem entgegenzuhalten, dass die Donatisten doch auch nicht etwa mit dieser Entschuldigung die traditio während der Verfolgung verteidigen wollten. Schließlich basierte diese ebenfalls auf einen kaiserlichen Befehl. Wollten die Donatisten etwa sagen, man dürfe Schlechtes tun, nur weil der Kaiser es befiehlt (c. Don. 1)?

Für die anschließende Darlegung orientiert sich Augustinus an den genannten Anklagen der Donatisten. Seine Argumente sind nicht neu, sie entsprechen den Ausführungen im Breviculus bzw. den Beiträgen auf der Konferenz. Allerdings erweckt die rhetorisch geschickte Einbettung und eine zum Teil beißende Ironie das eine oder andere Argument zu neuem Leben. Stärker als andernorts stellt Augustinus die Absurdität donatistischer Argumente und Anschuldigungen in den Vordergrund:

262 C. Don. 1, 6, 39, 46; ep. 141.1, 12; vgl. Emer. 2.

263 C. Don. 1: „Warum, ihr Donatisten, lasst ihr euch von euren Bischöfen immer noch verführen, deren betrügerische Finsternis durch strahlendes Licht vertrieben, deren Irrtum offenbar und deren Starrsinn überwunden worden ist?" (Quid adhuc, Donatistae, seducimini ab episcopis uestris, quorum fallaces tenebrae clara luce discussae sunt, quorum error apparuit, quorum pertinacia superata est?). vgl. c. Don. 21, 24, 48, 58; ep. $141.1,12-13$. 
Der erste Bezugspunkt ist die Äußerung der Donatisten, „, dass weder ein Fall einen anderen Fall verurteilt noch eine Person eine andere Person" (c. Don. $2-15) .{ }^{264}$ Diese Aussage, so Augustinus, müssten die Donatisten auch bezüglich des Maximianistischen Schismas berücksichtigen. Sowohl in der causa Caeciliani als auch in der causa ecclesiae hätten die Donatisten mit dieser Aussage ihre eigenen Argumente konterkariert und entwertet. Die Schuld Caecilians beschmutze nicht die Kirche (c. Don. 2-5), wie auch durch die Heilige Schrift und Cyprian belegt sei (c. Don. 6-15).

Zur Veranschaulichung und Affektsteigerung verwendet Augustinus innerhalb seiner ekklesiologischen Darlegungen die bei ihm beliebte rhetorische Figur der Prosopopöie. Zunächst lässt er jene Kirchen zu den Donatisten sprechen, die bei den Aposteln Petrus, Johannes und Paulus erwähnt werden, und fügt dann eine Prosopopöie der afrikanischen Kirche hinzu ${ }^{265}$ Er demonstriert damit, dass die Donatisten getrennt von den Gemeinden lebten, auf denen göttliche Verheißungen liegen. Zudem stellt er die Grundlosigkeit der Trennung heraus: Die katholischen Kirchen beklagen die Abspaltung der Donatisten, obwohl sie doch nichts mit der Schuld Caecilians zu tun hätten und die Donatisten diese Aussage selbst unterzeichnet hätten. Warum könne Felicianus, der Ordinator Maximians, den Donatisten keinen Schaden zufügen, aber Caecilianus der gesamten Kirche ${ }^{266}$

Wie bereits im Breviculus verwendet Augustinus viel Zeit auf die Widerlegung der donatistischen Gegenschrift zum katholischen Mandat, um Unzulänglichkeiten des donatistischen Kirchen- und Schriftverständnisses aufzuzeigen. Ironisch entgegnet er auf die Auslegung der biblischen Gleichnisse: Die Donatisten hätten ihre Vorstellung der ,,versteckten Sünder“ in der Kirche mit der Allegorie von den Fischen im Netz begründet. Solange das Netz unter Wasser sei, könnten die Fischer die schlechten Fische nicht sehen, das hieße, die verborgenen Sünden könnten nicht geahndet werden. ${ }^{267}$ Urteilt selbst, ruft Augustinus seine Leser auf: Wie sieht denn Entsprechendes für die Allegorie von Spreu und Weizen aus? Ist etwa die Tenne unter Wasser oder unter der Erde, oder ist es etwa Nacht beim Dreschen oder der Bauer blind, dass er die Spreu nicht sehen kann? Man könne nicht für jeden einzelnen Fall einen anderen Vergleich heranziehen; für die versteckten Sünder das Netz und für die offenbaren Sünder die Tenne. ${ }^{268}$ Auch an anderer Stelle zeigt sich Augustinus als spitzfindiger Exeget, der den donatistischen Theologen Unverständnis für die Heilige Schrift nachweisen möchte. In Karthago hatten die Donatisten ihre

264 Vgl. Cap. conl. Carth. III 371 und oben zu breuic. III 28.

265 C. Don 4-5.

266 C. Don 5; vgl. 25, 52.

267 Vgl. Gesta conl. Carth. III 258 (Z. 90-105).

268 C. Don. 14; vgl. breuic. III 10 mit ähnlicher Argumentation. 
Weigerung, sich zu setzen, mit einem Psalmwort begründet (breuic. III 18). Augustinus entgegnet nun, die Donatisten hätten gar nicht erst kommen dürfen, denn es stehe dort geschrieben „ich werde nicht zusammen mit den Feinden eintreten" (Ps. 25.4). Damit zeigten die Donatisten, dass sie die Schrift nicht verstünden und nach menschlichem Ermessen die Einheit zerrissen hätten (c. Don. 7).

Der zweite Bezugspunkt für Augustins Ausführungen ist die donatistische Anfechtung des Urteils, da es in der Nacht gesprochen worden sei. Augustinus verwendet diesen Vorwurf für ironische Anspielungen mit einer Tag- und Nachtsymbolik. So wiederholt er mehrmals die rhetorische Formel, „es war noch Tag" (adhuc dies erat), als die Donatisten mit ihren Dokumenten nichts hätten beweisen können. Am helllichten Tage seien die Donatisten gescheitert mit ihrer Einrede gegen die Frist (c. Don. 16), ihren Zeugnissen gegen Miltiades (c. Don. 17) und mit ihrer Anfechtung der Protokolle von Cirta (c. Don. 18-19). Tiefste Nacht sei es dagegen in den Köpfen der donatistischen Bischöfe gewesen. Diese hätten sich nicht dem Licht der Wahrheit zugewandt, sondern in ihrer Blindheit nur Aussagen vorgetragen, die sich gegen sie selbst richteten (c. Don. 16, 19, 25). Dem formalen Einwand der Donatisten gibt Augustinus eine theologisch-symbolische Antwort: Auch wenn das Urteil in der Nacht gesprochen worden sei, so erstrahlt es dennoch im Licht der Wahrheit, denn der Nacht des Irrtums sei ein Ende gesetzt (c. Don. 58). An die Leser gerichtet fordert er, die Augen zu öffnen und der Finsternis der Nacht zu entkommen, in denen sich die donatistischen Bischöfe noch befänden (c. Don. 19).

Der dritte Bezugspunkt ist der Bestechungsvorwurf gegen Marcellinus. Augustinus zählt dagegen auf, in wie vielen Fragen der Verhandlung die Donatisten gegen sich selbst gesprochen und Zeugnisse zu Gunsten der katholischen Position vorgelegt hätten. Seine Ausführungen leitet er jeweils mit der ironischen Frage ein, wie viel Bestechungsgeld denn notwendig gewesen wäre (quanti emere debuimus), um von den donatistischen Vertretern diese Selbstwiderlegung zu erhalten (c. Don. 39-56). Mit seiner Aufzählung demonstriert Augustinus, dass die Verhandlungsweise der Donatisten eigentlich „unbezahlbar" gewesen sei. ${ }^{269}$ Zum Ende steigert Augustinus die Menge des notwendigen „Bestechungsgeldes“ ins Groteske: „Berge von Gold“ hätten gezahlt werden müssen, um von den Donatisten zur causa Maximiani den Satz zu hören, dass eine Sache nichts mit der anderen zu tun habe (c. Don. 52), und schließlich, welche Schätze, Reichtümer und angehäufte Edelsteine wären nötig gewesen, um von den Donatisten zu hören, dass ihre Vorfahren selbst Caecilianus beim Kaiser verfolgt und sich noch gerühmt hätten, er sei verurteilt worden, obwohl nichts davon bewiesen werden konnte (c. Don. 53). Wenn der Richter bestochen

269 Vgl. Lamirande, Studia canonica 32, 1998, 431-434. 
worden sei, dann lediglich, um seine Autorität zu schwächen, die ihn so nachsichtig gegenüber den Donatisten werden ließ (c Don 57).

Außerhalb dieser drei Bezugspunkte, in denen die donatistischen Anklagen gegen Richter und Urteil verarbeitet werden, polemisiert Augustinus gegen das donatistische Verständnis von Verfolgung. Er wirft die Frage nach dem wahren Verfolger auf und legt dar, dass nach donatistischer Lehre Caecilianus als verfolgter Märtyrer zu gelten habe, denn dieser sei schließlich von Donatus verfolgt worden. Augustinus verweist ferner auf die Verfolgung der Maximianisten und die Gewalt der Circumcellionen und greift das falsche Märtyrerverständnis der Donatisten an (c. Don. 20-23). Anschließend widerlegt Augustinus nochmals einige von den Donatisten vorgebrachte Interpretationen der Heiligen Schrift (c. Don. 24-38), wobei er ausgiebig auf das neu vorgebrachte Exempel des Propheten Haggai eingeht, um die Mischung von Guten und Bösen in der Kirche nachzuweisen (c. Don. 30-32). Am Ende von c. Don. fasst er die Argumente nochmals zusammen und appelliert an die Hörer und Leser, der Kircheneinheit zu folgen (c. Don. 57-58).

Der Inhalt, Aufbau und die glänzende Rhetorik dieser Schrift zeigen, dass Augustinus offensiv in die neue Phase der Auseinandersetzung nach der Konferenz von 411 ging. Das Ergebnis sollte nicht unterhöhlt und die Argumente nicht durch Ausreden verwässert werden. Allen Gläubigen in Afrika sollte die Eindeutigkeit der donatistischen Niederlage in allen Themenbereichen eindrücklich vor Augen gestellt werden. Mit dieser umfassenden Darstellung, in der die entscheidenden historischen und theologischen Argumente unter Bezug auf die Konferenzdebatten und die späteren Anklagen der Donatisten thematisiert und durch eine bildhafte Sprache, Ironie und Polemik veranschaulicht werden, stellte sich Augustinus der selbst auferlegten Herausforderung, den Wissens- und Glaubensdefiziten in breiten Schichten der Bevölkerung entgegen zu wirken.

Der argumentative Gehalt von ep. 141 ist dem von c. Don. sehr ähnlich. Allerdings fehlen die ausfallende Polemik und wegen des weitaus geringeren Umfangs die langen theologischen Ausführungen. Ausgehend vom Bestechungsvorwurf gegen Marcellinus bezichtigt Augustinus die donatistischen Bischöfe der Lüge, indem er auf die offengelegten Fehler bei ihrer Mandatsunterzeichnung verweist (141.1). Um die Glaubwürdigkeit seiner Aussagen zu unterstreichen, erläutert Augustinus die Formalien der Konferenz und verteidigt die Sorgfalt der Protokollierung (141.2). Nachdem er die Verweigerungshaltung der Donatisten kritisiert hat (141.3), erläutert Augustinus im Folgenden mit Bezug auf die Debatten die vollständige Niederlage der Donatisten auf der Konferenz. Die Anknüpfungspunkte sind dieselben wie in c. Don.: Die Donatisten hätten die weltweite Verbreitung der Kirche bestätigt (141.4) und, konfrontiert mit dem Maximianistischen Schisma, zugegeben, dass die Schuld eines 
Einzelnen einem anderen nicht schade (141.5-6). Sie hätten keine ihrer Anschuldigungen beweisen können, sondern ihre eigenen historischen Dokumente hätten gegen sie gesprochen, sowohl in der causa Caeciliani (141.7-9) als auch in der causa Felicis (141.10-11). Die Akten der Konferenz bewiesen folglich, dass es keine Bestechung gegeben habe, sondern dass die Donatisten gegen sich selbst argumentiert hätten (141.12). Mit einem Einheitsappell endet der Brief (141.13).

Mit seiner inhaltlichen Prägnanz, den Aufforderungen zur Umkehr an die Gläubigen und den stets eingestreuten Hinweisen auf das Erbarmen und Barmherzigkeit Gottes, der Herausstellung der Wahrheit gegen die Lüge der donatistischen Verführer $(141.7,8)$ und den rhetorischen Fragen (141.3), erinnert der Brief insbesondere an die ep. 105. Hier wie dort sollten die Laien dazu gebracht werde, die Aussagen ihrer Bischöfe zu hinterfragen und zu überprüfen (vgl. ep. 105.1; 141.1). Ging es vor der Konferenz jedoch um die allgemeinen Standpunkte zum Schisma, so zeigt sich in ep. 141 der neue Ausgangspunkt: Augustinus brauchte sich nicht mehr auf Dokumente aus den Archiven zu stützen, sondern er konnte auf die ordnungsgemäß protokollierten Aussagen der donatistischen Vertreter zurückgreifen. Aus dieser Wortmasse die geeigneten Sätze auswählen, einzeln widerlegen oder gegeneinander ausspielen zu können, war der größte Gewinn für Augustins Überzeugungsarbeit nach der Konferenz.

\subsection{Augustins Beurteilung der Konferenz}

Den Verhandlungsverlauf und das Ergebnis der Konferenz von Karthago verbreitete Augustinus als katholischen Sieg, und dementsprechend sind seine Schriften angelegt. In den überlieferten Texten findet sich keine kritische Analyse der Konferenz, wenngleich sicherlich nicht alles nach Augustins Wunsch verlaufen war. Er beschränkt sich auf gelegentliche Kommentare zum Verhalten der Donatisten oder gibt erläuternde Informationen zu den Beiträgen der Katholiken.

Durchgängig beurteilt Augustinus die Verhandlungsführung der Donatisten als eine Kombination von bewussten Obstruktionen und Unvermögen in der Beweisführung. Die Prozesseinreden, die Anfechtung der Mandatsunterschriften und das Verwirrspiel um die Verhandlungsgrundlage seien lediglich Verzögerungs- und Verhinderungstaktiken gewesen, um die Sachdebatte über die Fragen des Schismas zu verhindern. ${ }^{270}$ Die Katholiken hätten dagegen stets versucht, die Debatte abzukürzen und die Kernfragen zu behandeln. Als zen-

270 Diese Ansicht findet sich bereits im Vorwort des breuic. und wird in den Texten häufig wiederholt. Vgl. etwa breuic. III 1, 2, 3, 4, 5, 6, 7, 30, 31; c. Don. 44. 
trales Motiv der Donatisten stellt Augustinus ihre Furcht heraus: Sie hätten Angst davor gehabt, vor dem Gericht zu verhandeln und sie hätten sich vor den Argumenten und Dokumenten der Katholiken gefürchtet. ${ }^{271}$ So kommentiert Augustinus die Abwehr der Donatisten, die relatio Anullini lesen zu lassen und in die Hauptverhandlungen zu treten mit folgendem Ausruf:

„O welch große, aber keinesfalls erstaunliche Verwirrung! Wann hat jemals ein Dämon einen Exorzisten so gefürchtet wie [die Donatisten] fürchteten, dass jene Relation gelesen werde? ‘272

Die Furcht vor den Dokumenten sei auch die Ursache der donatistischen Entscheidung gewesen, die Heilige Schrift als Grundlage zu akzeptieren. Weil sie aber nicht bei dieser Entscheidung geblieben seien, sondern gegen ihr Versprechen auf andere Dokumente zurückgriffen hätten, nur deshalb hätten es die Katholiken genauso getan (c. Don. 47). Auf diese Weise präsentiert Augustinus im Nachhinein stolz das Gelingen der katholischen Taktik: Die Donatisten konnten ohne die historischen Dokumente die Katholiken nicht mit der traditioSchuld Caecilians belasten und so auch nicht die Spaltung begründen. Sie standen vor dem Dilemma, entweder auf die alleinige Grundlage der Heiligen Schrift oder auf die causa Caeciliani verzichten zu müssen (c. Don. 47).

Dass trotz der vermeintlichen Obstruktionen die Hauptverhandlungen schließlich erreicht wurden, bezeichnet Augustinus als wunderbare Tat Gottes. Ohne Zutun habe die Debatte über die Person des Klägers zu den entscheidenden Fragen geführt (breuic. III 7; c. Don. 43). In dieser Debatte waren es dann die Donatisten selbst, die mit Hilfe ihrer Dokumente, die Augustinus zum Teil unbekannt waren, den Weg zur Entscheidung ebneten. Der vorgelegte Text von Optatus, mit der sie Caecilians Verbannung beweisen wollten, sei doppeldeutig gewesen, und ihre Supplik an Konstantin sowie der Brief an Verinus hätten klar für die Katholiken gesprochen, ebenso wie der Probianusbrief für die causa Felicis (c. Don. 55; breuic. III 40). Augustinus zieht einen Vergleich zwischen den Donatisten in Karthago und den Anklägern des Propheten Daniel: In beiden Fällen fielen ihre Anschuldigungen auf sie selbst zurück (c. Don. 54).

Erwartungsgemäß beurteilte Augustinus die Konferenz nicht nach juristischen Gesichtspunkten, sondern er richtete den Blick nach vorne und wollte mithilfe des Urteils die Einheit der Kirche voranbringen. Seine Schriften waren auf die Überzeugung der Gläubigen ausgerichtet, so dass es für Augustinus nicht angebracht war, darüber nachzudenken, ob gewisse Einreden der Donatisten prozessrechtlich rechtens waren oder ob die Taktik der Donatisten aus ihrer

271 Breuic. I 8; c. Don. 39, 43.

272 C. Don. 44: o magna, sed non miranda confusio! quando enim daemon sic exorcistam timeret, quomodo timuerunt ne illa legerentur, [...] ?; vgl. breuic. III 5-6, 30. 
Sicht nachvollziehbar war: Augustinus interpretierte die donatistische Zustimmung zum Mandat und zur biblischen Grundlage der Verhandlungen bei gleichzeitiger Verwendung gerichtlicher Einreden lediglich als Verwirrspiel und übersah damit die Aussagen der Donatisten, die auf die Trennung der Vor- und Hauptverhandlungen abhoben. Indem er das gerichtliche Vorgehen der Donatisten stets dem katholischen Willen einer Sachdebatte auf Grundlage der Heiligen Schrift gegenüberstellt, weist er den Donatisten eine doppelt negative Rolle zu: Sie seien die Verweigerer der theologischen Auseinandersetzung und Schuldige am langen Prozedere. Augustinus sieht im Urteil der Konferenz das Urteil Gottes, an dem es nichts mehr zu kritisieren gibt. Entsprechend kann er die Einwände der Donatisten nur als nichtig betrachten: Die Katholiken stellt Augustinus als Partei des Gotteswortes dar, die Donatisten dagegen als Verfechter menschlicher Gedanken; so stehen sie auf verlorenem Posten.

\subsection{Ein Epilog: Die Zusammenkunft mit Emeritus in Caesarea}

Sieben Jahre nach der Konferenz von Karthago befand sich Augustinus in Begleitung von einigen Kollegen, darunter Possidius und Alypius, in Caesarea in Mauretanien, der Stadt des donatistischen Wortführers Emeritus. ${ }^{273}$ Dieser war nach wie vor donatistischer Bischof, wenngleich eines Großteils seiner Gemeinde beraubt und offenbar ohne Residenz innerhalb Caesareas, sondern außerhalb der Stadt lebend. Nachdem Emeritus von der Anwesenheit Augustins erfahren hatte, begab er sich in die Stadt, um seinen Gegner zu treffen. Augustinus traf Emeritus am 18. September in den Straßen Caesareas und lud ihn ein, mit in die katholische Kirche zu kommen; und zu seiner Freude willigte Emeritus ein. ${ }^{274}$

Nachdem er in die von Menschen gefüllte Kirche eingetreten war, sprach Emeritus den rätselhaften Satz: Non possum nolle quod uultis, sed possum uelle quod uolo und schwieg anschließend. ${ }^{275}$ Augustinus wandte sich mit einer Predigt an die versammelten Gläubigen, in der er diese Aussage des Emeritus mit auslegte: ${ }^{276}$ Wir Katholiken, so Augustinus, wollen, was der Herr will, der sagt:

273 Emer. 1; ep. 190.1; 193.1; Poss. vita 14. 3-4. Zu den Zusammenhängen der Reise vgl. Lancel, Augustin, 489-494; Perler/Maier, 345-350. Zur Person s.o. Kap. 4.1.2 mit Anm. 33.

274 Emer. 1-2; c. Gaud. 15; vgl. Lancel, Augustin, 494 f.; Mandouze, PAC, 347-349; Anscheinend lebte Emeritus auf dem Land in der Umgebung von Caesarea. Ob im Versteck, wie Monceaux (VI, $174 \mathrm{f}$.) annimmt, dürfte fraglich sein.

275 S. Caes. eccl. 1.

276 Der sog. sermo ad Caesariensis ecclesiae plebem. Edition: Petschenig, CSEL 53, $167-$ 178. Der Titel ist nicht in der Überlieferung verankert, sondern geht auf die Edition der 
,Ich gebe euch meinen Frieden, meinen Frieden lasse ich euch' (Joh. 14.27). Wenn aber Emeritus außerhalb der katholischen Kirche im Schisma verharren wolle, dann stehe er gegen Gottes Willen. Er könne aber, wenn er es wolle, in seiner Würde als Bischof zur Einheit zurückkehren. ${ }^{277}$ Im Anschluss erklärt Augustinus die katholische Position zur Wiederaufnahme der Donatisten. Er unterstreicht die Zugehörigkeit zur katholischen Kirche, in der allein die Taufe Christi, der Glaube und Sakramente durch den inneren Wandel des Gläubigen und die caritas zum Heil gereichen könnten. So wie Gott der Vater sei, so solle die katholische Kirche auch den Donatisten als Mutter gelten, auf der der Segen Gottes und die Prophezeiungen liegen. Wenn aber Emeritus glaube, er sei ein Märtyrer vor Gott, weil er der Einheit widerstehe und verfolgt werde, so täuscht er sich. Denn außerhalb der Kirche werde er als ein Feind Christi verfolgt, dem die Krone des Märtyrers nicht zustehe. ${ }^{278}$

Daran anschließend erläutert Augustinus die Frage der Verfolgung und rechtfertigt den Zwang zur Einheit. Mit dem Hinweis auf die Geschichte fordert er auf zu beurteilen, wer denn die wahren Verfolger seien. Auch Emeritus habe durch seine Unterschrift in Karthago bestätigt, dass seine Vorfahren Caecilianus verfolgt und versucht hätten, ihn vom Kaiser verurteilen zu lassen. Daher dürfe sich Emeritus nicht über die Verfolgung beklagen. Die Verfolgung von Feinden der Kirche sei dagegen gerechtfertigt. ${ }^{279}$ Zum Schluss seiner Predigt äußert Augustinus die Hoffnung auf die Bekehrung des Emeritus und aller, die der Einheit widerstehen wollen, jetzt oder bald mit der Hilfe Gottes. ${ }^{280}$

Auch wenn sich Augustinus in der konkreten Situation an Emeritus und das Kirchenvolk in Caesarea wandte, die angesprochenen Themen verraten etwas über die generelle Lage und die Haltung von Donatisten und Konvertiten. Es herrschte nach wie vor Unsicherheit, zum Teil auch Unverständnis bei den Gläubigen über die Art und Weise des Umgangs mit den Donatisten und die theologischen Begründungen der Katholiken: Was rechtfertigt die gewaltsame

Mauriner zurück (PL 43, 689-698). Vgl. Lamirande, BA 32, 408-410; Monceaux VI, 175-178; Zum Datum: Emer. 1; dazu Perler/Maier, 346 Anm.3.

277 S. Caes. eccl. 1.

278 S. Caes. eccl. 2-6. Am Beispiel Emeritus verdeutlicht Augustinus (ebd. 6): „Außerhalb der katholischen Kirche kann er alles besitzen, ausgenommen das Heil: Er kann Würde besitzen, er kann die Sakramente besitzen, er kann das Allelujah singen und 'Amen" antworten, er kann das Evangelium verstanden haben, er kann im Namen des Vaters, des Sohnes und des Heiligen Geistes den Glauben besitzen und verkündigen, jedoch nirgends, nur innerhalb der katholischen Kirche wird er Heil finden können." (extra catholicam ecclesiam totum potest praeter salutem: potest habere honorem, potest habere sacramenta, potest cantare alleluia, potest respondere, amen', potest euangelium tenere, potest in nomine patris et filii et spiritus sancti fidem habere et praedicare, sed nusquam nisi in ecclesia catholica salutem poterit inuenire).

279 S. Caes. eccl. 7-8.

280 S. Caes. eccl. 9. 
Bekämpfung der Donatisten, wenn doch Taufe und Liturgie in der einen wie anderen Kirche gleich sind? Augustinus suchte immer wieder nach verständlichen Formeln, um die Katholizität der Kirche als notwendig darzustellen. Nach den Jahren der Anwendung von Zwangsgewalt waren aber seine Aussagen im Verhältnis schärfer geworden. Dies schlägt sich in der Predigt von Caesarea nieder: keine gerechte Verfolgung, kein Martyrium und kein Seelenheil auBerhalb der Catholica. Diese deutliche Botschaft sollten alle hören, die noch glaubten, es sei gleichgültig, zu welcher Kirche man gehöre. Augustinus griff in seiner Rede jene Haltung an, die Emeritus bei dieser ersten Begegnung demonstrierte: Den Stolz eines um der Wahrheit willen verfolgten Christen. ${ }^{281}$

Zwei Tage nach dieser Predigt, am 20. September 418, fand in Gegenwart mehrerer Bischöfe, darunter Deuterius, Bischof von Caesarea, ferner Alypius und Possidius sowie einer großen Anzahl von Klerikern und Laien ein weiteres Treffen zwischen Emeritus und Augustinus statt. ${ }^{282}$ Sieben Jahre nach ihrer Begegnung in Karthago standen sich somit die Wortführer beider Parteien noch einmal zu einem Streitgespräch gegenüber. Nach dem Willen Augustins sollte Emeritus bei dieser Debatte seine Einwände und Anschuldigungen gegen die Konferenz von Karthago öffentlich vortragen, und er selbst wollte diese Anschuldigungen widerlegen und so jene überzeugen, die nach wie vor den Donatisten Gehör schenkten, das Ergebnis der Konferenz anzweifelten und die Einheit ablehnten (Emer. 1-2). Nach seinen einleitenden Worten sagte Augustinus:

„,Bruder Emeritus, du bist hier anwesend. Du hast mit uns an der Konferenz teilgenommen. Wenn du besiegt worden bist, warum bist du gekommen? Wenn du

281 Obwohl Augustins Auslegung nicht die seltsame Aussage des Emeritus beim Eintritt in die Kirche vollständig entschlüsselt, so weist sie dennoch den richtigen Weg. Denn wahrscheinlich wollte Emeritus, der bereits auf der Konferenz in Karthago mit zum Teil unverständlichen Reden auffiel, lediglich zwei Aussagen rhetorisch zusammenfügen: Erstens: Das Anliegen der Kirche Christi sei natürlich Frieden und Einheit, diesem könne nicht der persönliche Wille entgegengesetzt werden ('non possum nolle quod uultis'). Doch dürfe dieses Anliegen nicht von der katholischen Position vereinnahmt werden, wie es in der gegenwärtigen Situation geschehe. Deshalb, zweitens, bliebe die persönliche Überzeugung der Wahrheit bestehen, auch gegen die Übermacht der Gegner. Diesen Willen könne ihm keiner nehmen ('possum uelle quod uolo').

282 Die Unterredung wurde mitstenographiert und ist heute als Gesta cum Emerito Donatistarum episcopo [Emer.] überliefert. Edition: Petschenig, CSEL 53, 181-196. Vgl. retr. II 51; vgl. auch c. Gaud. I 15 und den Bericht des Possidius (Poss. vita 14) über die Treffen der beiden Bischöfe. Vgl. Monceaux VI, 145-189; Lamirande, BA 32, 397-414; ders., Studia canonica 32, 1998, 435 f.; Lancel, Augustin, 494-497; ders., AL 2, 801 f., s. v. Emeritum episcopum Donatistarum post conlationem (Ad-); Frend, Donatist Church, $294 \mathrm{f}$. Willis, Augustine, $81 \mathrm{f}$. . Ungenau ist die Darstellung von van der Meer (Augustinus, 133), der die Begegnungen vom 18. und 20.09. miteinander vermischt. 
jedoch glaubst, dass du nicht besiegt worden bist, erzähle, warum du meinst, der Sieger zu sein. Du bist nämlich dann besiegt, wenn du durch die Wahrheit besiegt bist. Wenn du aber glaubst, du seiest durch die weltliche Gewalt besiegt worden, obwohl du durch die Wahrheit besiegt worden bist, wirst du erkennen, dass hier keine weltliche Gewalt ist, durch die du glaubst besiegt zu sein. Deine Mitbürger sollen hören, warum du annimmst, du seiest der Sieger. Wenn du hingegen weißt, dass die Wahrheit gegen dich die Siegerin war, warum verschmähst du noch immer die Einheit?'

Emeritus, Bischof der donatistischen Partei, sagte: ,Die Akten zeigen, ob ich besiegt worden bin oder ob ich gesiegt habe, ob ich durch die Wahrheit besiegt oder durch die weltliche Gewalt unterdrückt worden bin.'

Augustinus, Bischof der katholischen Kirche, sagte: ,Warum also bist du gekommen?'

Emeritus, Bischof der donatistischen Partei, sagte: ,Um dir zu sagen, was du verlangst!'

Augustinus, Bischof der katholischen Kirche, sagte: ,Ich frage, warum du gekommen bist. Ich würde dies nicht fragen, wenn du nicht gekommen wärst.'

Emeritus, Bischof der donatistischen Partei, sagte zu dem protokollierenden Schreiber: ,Schreibe!'،283

Anschließend verfiel Emeritus in Schweigen. Da er keine Antwort mehr erhielt, knüpfte Augustinus an die Aussage des Emeritus an und erklärte, dass aus den Konferenzakten von 411 die Wahrheit erwiesen werden solle. Er entschied, den katholischen Synodalbrief an Marcellinus vorlesen zu lassen, in dem die wichtigsten Ziele der Katholiken und die Vorschläge über die Umsetzung einer Kircheneinheit nach der Konferenz unterbreitet werden. ${ }^{284}$ Alypius las aus dem Brief und Augustinus kommentierte die entscheidenden Stellen (Emer. 5-7). Er betonte, dass fast alle katholischen Bischöfe Bereitschaft gezeigt hätten, ihre Sitze mit den donatistischen Brüdern zu teilen, und unterstrich diese demütige Haltung, die nach dem Vorbild Christi dem Frieden und der Einheit diene. Ausgehend von den Maximianisten, die in dem Brief erwähnt werden, erläuterte Augustinus anschließend die wichtigsten Fakten der causa Maximiani und die Widersprüchlichkeit der Donatisten in diesem Fall (Emer. 8-11). Noch nie, auch nicht auf der Konferenz von 411, hätten die Donatisten die Frage beantworten können, warum die verdammten Ordinatoren des Maximianus wieder

283 Emer. 3: Frater Emerite, praesens es. collationi nobiscum interfuisti. si uictus es, quare uenisti? si autem te uictum esse non putas, loquere unde tibi uictor esse uidearis. tunc enim uictus es, si ueritate uictus es. si autem uideris uictus potestate et uicisti ueritate, non est hic potestas qua uictus uideris; audiant ciues tui unde te uictorem praesumis esse. at si nosti aduersus te uictricem fuisse ueritatem, quid adhuc respuis unitatem? Emeritus episcopus partis Donati dixit: Gesta indicant si uictus sum aut uici, si ueritate uictus sum aut potestate oppressus sum. Augustinus episcopus ecclesiae catholicae dixit: Quare ergo uenisti? Emeritus episcopus partis Donati dixit: Ut hoc dicerem quod requiris. Augustinus episcopus ecclesiae catholicae dixit: Requiro quare ueneris. hoc non quaererem, si non uenisses. Emeritus episcopus partis Donati dixit notario qui excipiebat: Fac.

284 Emer. 4; vgl. Gesta conl. Carth. I 16 [= Aug, ep. 128]; vgl. o. Kap. 5.1.1. 
aufgenommen, ihre Taufe anerkannt worden sei und den Donatisten nicht schadeten, während die Schuld Caecilians noch heute die Kirche verunreinige. Augustinus beendete seine Ausführungen mit einem Appell für den Frieden und in der Hoffnung, dass Gott die verstockten Herzen noch bewegen möge (Emer. 12).

So mündete der letzte bekannte Dialog Augustins mit einem Donatisten in einen Monolog. Die vorangegangenen Begegnungen und Korrespondenzen zwischen Augustinus und Donatisten sowie die Konferenz von Karthago zeigten sich stets als argumentative Einbahnstraßen ohne einen gemeinsamen Ausgangspunkt. Die letzte Begegnung in Caesarea gibt der Geschichte des Unverständnisses eine dramatische Pointe:

Auf der einen Seite Emeritus. Sein Verhalten bei den beiden Begegnungen mit dem großen katholischen Gegner Augustinus darf keinesfalls als Schwäche, Unvermögen, Trotz oder Eingeständnis der Niederlage verstanden werden. ${ }^{285}$ Seine ausdrückliche Bereitschaft für diese Zusammentreffen, die wenigen Worte und anschließend sein demonstratives Schweigen setzten deutliche Zeichen mit hoher Symbolkraft. Emeritus demonstrierte seinen Stolz und seine ungebrochene Überzeugung, ein Vertreter der wahren Kirche zu sein. Die Akten der Konferenz von 411 waren für Emeritus der Beweis für die Unterdrückung der Donatisten, dem nichts hinzuzufügen war. Jetzt, da Augustinus neue Beweise für die donatistischen Anklagen von ihm forderte, wiederholte sich im Kleinen die Situation von 411: Emeritus sollte Ankläger sein, obwohl er doch aus seiner Perspektive Opfer war und die Verteidigerrolle zu übernehmen hatte. Er ließ sich nicht mehr auf eine Debatte ein und gab doch eine Antwort: Seine Worte belegen dies: „Ich bin gekommen, um dir zu antworten.“ Seine Antwort war das Schweigen und seine schweigende Anwesenheit war beredter als manche Worte. Emeritus folgte dem Vorbild Christi, auf die falschen Anklagen nichts mehr zu antworten, ${ }^{286}$ und zeigte so seine Verachtung vor dem weltlichen Tribunal. Sein Auftritt war eine Demonstration donatistischen Selbstverständnisses und Selbstbewusstseins: als Verfolgter der Menschen, allein Christus verpflichtet, bereit zum Martyrium. ${ }^{287}$

Auf der anderen Seite Augustinus. Auch dieser Gesprächsversuch war gescheitert und deutlicher als zuvor lassen sich die Gründe dafür erkennen. Im Kern bedeutete ein Gespräch für Augustinus nichts anderes als Mission, die Darstellung seiner Überzeugungen nach vorgefertigten Beweismustern. Das

285 In diesem abwertenden Tenor urteilte bereits Augustinus selbst; vgl. Emer. 4; Gaud. I 15; retr. II 51; Possidius, vita 14.5-6, ebenfalls Monceaux VI, 156, 178 f., 184-189.

286 Vgl. Mk. 14. 53-65; 15.1-5.

287 Lamirande, BA 32, 404: „Le silence et la retraite d'Emeritus n'en eurent pas moins une grande portée apologétique.“ Ders., Studia canonica 32, 1998, 436: „Les catholiques étaient assurés de leur bon droit, mais leurs adversaires savaint aussi défendre leur tradition avec l'opiniâtreté de gens traqués.“ 
Rezitieren des alten katholischen Synodalbriefes veranschaulicht den Rückgriff Augustins auf die bekannten Stereotype. Mögen sie in ihrem Anliegen auch aufrichtig und in ihrer Darstellung wahrheitsgetreu sein, sie verfehlten eine gemeinsame Grundlage mit den Donatisten. Augustins Argumente konnten überzeugen, aber sie konnten keine Ausgangsbasis für ein Religionsgespräch bilden. Emeritus scheint dies nach den Erfahrungen von 411 erkannt zu haben. ${ }^{288}$

288 Vgl. Lancels Kommentar zu Augustins Gespräch mit Emeritus (Augustin, 497): „De l'évêque d'Hippone les intentions généreuses et la charité n'étaient pas douteuses, mais sa pédagogie avait parfois la pesanteur d'un rouleau compresseur.“ 


\section{Donatistische Geschichtsbilder und Augustins Entgegnung}

In den drei vorangehenden Kapiteln ist gezeigt worden, in welcher Weise Augustinus und seine donatistischen Widersacher historische Informationen und Dokumente in der Kontroverse einsetzten und interpretierten. In den beiden folgenden Kapiteln sollen diese Informationen und Dokumente in ihrem historischen Kontext betrachtet werden. Auf dieser Grundlage lässt sich genauer erfassen, wie die Geschichte des donatistischen Schismas von Donatisten und Augustinus verstanden wurde, welche Informationen ihnen zur Verfügung standen und wie sie ihre Kenntnisse auswerteten und deuteten. Die geschichtliche Darstellung einzelner Ereignisse dient in diesem Zusammenhang dem besseren Vergleich zwischen den Geschichtsbildern in der Zeit Augustins und den historischen Abläufen, wie sie sich heute aus den Quellen erschließen lassen.

Innerhalb der historischen Argumentation beider Seiten treten stets zwei Hauptaspekte zutage, die im Folgenden betrachtet werden sollen: zum einen die Auseinandersetzung über die traditio und persecutio, zum anderen der Streit um die die Darstellung der causa Caeciliani. In diesem Kapitel (6) soll der erstgenannte Aspekt behandelt werden. Die Frage der causa Caeciliani wird im anschließenden Kapitel (7) thematisiert.

\section{Donatistische traditio-Anschuldigungen}

Die Überzeugung, dass einzelne Bischöfe die Schuld der traditio auf sich geladen hatten, bildete für die Donatisten stets das Zentrum der Anschuldigungen gegen die Katholiken und den Rechtfertigungsgrund für das Schisma: In der wahren Kirche konnten keine Traditoren geduldet werden; die Aufhebung der Kirchengemeinschaft mit den Traditoren und ihren Anhängern war das oberste Gebot für alle Donatisten.

Anhand der Schriften Augustins und den Akten der Konferenz von Karthago lässt sich nachvollziehen, wie sich in der donatistischen Überlieferung die Anschuldigung der traditio gegen fast alle wichtigen Personen der katholischen Kirche aus der Anfangszeit des Schismas verbreitete: Dass Caecilians Ordinator, Felix von Abthugni, die Verfehlung der traditio begangen hätte, bildete bereits den Kern der Anklage und die Urteilsbegründung in dem Verfahren gegen Caecilianus auf dem Konzil des Secundus in Karthago. Doch schon bald galten den Donatisten nicht mehr nur Felix von Abthugni, sondern auch Cae- 
cilianus selbst sowie dessen Vorgänger Mensurius als Traditoren, ebenso die römischen Bischöfe dieser Zeit, insbesondere Miltiades. So greift Petilianus in seinem Brief an die Priester und Diakone den römischen Bischof Marcellinus sowie Mensurius und Caecilianus als Weihrauchopferer und Bücherverbrenner an. ${ }^{1}$ Ähnliche Anschuldigungen brachte er in seiner Schrift über die Taufe vor. In der Entgegnung auf diesen Traktat schreibt Augustinus, Petilianus habe ohne irgendwelche Beweise und Zeugnisse unglaubwürdige Verleumdungen geäußert und dem römischen Bischof Marcellinus sowie dessen Priestern Miltiades, Marcellus und Silvester die Auslieferung heiliger Schriften und Weihrauchopferung vorgeworfen. ${ }^{2}$ Falsche Anklagen habe er außerdem gegen Mensurius und Caecilianus und andere erhoben. ${ }^{3}$ Die gleichen Aussagen finden sich in der donatistischen Version des Liber Genealogus vom Beginn des 5. Jahrhunderts wieder:

„Marcellinus von Rom und Mensurius von Karthago, Straton und Cassianus, Diakone in Rom, und Caecilianus, als sie Diakone der wahren Kirche waren, verbrannten von [den Kaisern] gezwungen Weihrauch und die Evangelien öffentlich auf dem Kapitol.“4

Auf der Konferenz von Karthago war es wiederum Petilianus, der Mensurius und Caecilianus in einem Atemzuge als verdammungswürdige Personen beschuldigte. ${ }^{5}$ Innerhalb der donatistischen Argumentation nahm die Beweisführung über die traditio des Mensurius, des Miltiades und des Felix von Abthugni einen gewichtigen Teil ein; und auch nach der Konferenz hielten die Donatisten ihre Anschuldigungen aufrecht. ${ }^{6}$

Es stellt sich nun zum einen die Frage, welche Quellen und historischen Ereignisse den donatistischen Überlieferungen zugrunde lagen, zum anderen, wie der Tatbestand der traditio zu verstehen ist, ob etwa konkrete Vergehen vorliegen mussten, um als Traditor zu gelten. Bei den einzelnen beschuldigten Bischöfen ist sowohl die Quellenlage als auch die Argumentationsweise der Donatisten unterschiedlich. Zunächst soll daher die traditio der beiden afrika-

1 C. litt. Pet. II 202; vgl. III 29.

2 Un. bapt. 27: quid ergo iam opus est ut episcoporum Romanae ecclesiae, quos incredibilibus calumniis insecatus est, obiecta ab eo crimina diluamus? Marcellinus et presbyteri eius Miltiades, Marcellus et Siluester traditionis codicum diuinorum et turificationis ab eo crimine arguuntur.

3 Un. bapt. 30: prorsus, qualescumque fuerint Marcellinus, Marcellus, Siluester, Miltiades, Mensurius, Caecilianus atque alii, quibus obiciunt pro sua dissensione quod uolunt, [...].

4 Lib. Gen. 626: Ab his coacti Marcellinus Vrbis et Mensurius Carthaginis, Strathon et Cassianus diaconi Vrbis et Caecilianus, dum essent ueritatis ecclesiae diacones, publice in Capitolio tura et euangelia concremauerunt. Vgl. Maier II, Nr. 82, $148 \mathrm{f}$.

5 Gesta conl. Carth. III 34.

6 Vgl. o. Kap. 5.3 und 5.4. 
nischen Bischöfe Mensurius und Caecilianus, dann die des Felix von Abthugni und schließlich die Anklagen gegen die römischen Bischöfe betrachtet werden.

\subsection{Mensurius von Karthago}

Auf der Konferenz von 411 begannen die Donatisten die historischen Ausführungen mit einer Darlegung der Ereignisse in Karthago zur Zeit der Verfolgung. Darin beschuldigten sie den damaligen karthagischen Bischof Mensurius ${ }^{7}$ der traditio und bezeichneten sein Handeln als Ursache der späteren Kirchenspaltung. ${ }^{8}$ Zum Beweis ihrer Anklage legten sie einen Brief des Mensurius an Secundus von Tigisi und anschließend dessen Antwortschreiben vor. ${ }^{9}$ Abgesehen von einer Erwähnung in Petilians Schrift über die Taufe, von der Augustinus erst kurze Zeit vor Beginn der Konferenz erfahren hatte, ${ }^{10}$ scheint dieser Briefwechsel in den Auseinandersetzungen zuvor keine Rolle gespielt zu haben. Wahrscheinlich war er gar nicht bekannt. ${ }^{11}$ Die beiden Briefe sind heute nicht mehr erhalten, jedoch gibt Augustinus im Breviculus eine kurze Zusammenfassung des Inhalts: $:^{12}$

Die Korrespondenz zwischen Mensurius und Secundus fand höchstwahrscheinlich kurze Zeit nach den Ausführungen des ersten Edikts Diokletians gegen die Christen in Afrika statt, da es offensichtlich um die Aufarbeitung noch recht aktueller Ereignisse ging. ${ }^{13}$ In seinem Brief an Secundus berichtete

7 Zur Person: Mandouze, PAC, 748 f., s. v. Mensurius 1; Monceaux IV, 8-17.

8 Cap. conl. Carth. III 333: „Darlegung der Donatisten, in der sie über den Beginn des Streitfalles berichteten, dass sich der Grund der Spaltung aus dem ergab, was Mensurius, Bischof der Kirche in Karthago, zur Zeit der Einheit während der Verfolgung getan hat." (Prosecutio donatistarum, initium referens causae, quid Mensurius Carthaginiensis ecclesiae episcopus unitatis tempore in persecutione effecerit, unde extitit causa discidii). Vgl. breuic. III 25.

9 Cap. conl. Carth. III 334-341; breuic. III 25, 27; c. Don 18; Gaud. I 47. - Zu den Dokumenten: von Soden Nr. 4; vgl. Seeck, ZKG 10, 1889, 532 f.; Monceaux IV, 204.

10 Un. bapt. 29. Diese Schrift ist höchstwahrscheinlich in das Jahr 410 zu datieren; vgl. de Veer, BA 31, 649-653.

11 Optatus kennt den Briefwechsel offenbar nicht. Es ist unwahrscheinlich, dass er ihn bewusst verschwiegen hätte. Soweit ersichtlich argumentierte Parmenianus nicht mit diesen Briefen, da sich weder bei Optatus noch bei Augustinus Entgegnungen darauf finden.

12 Zum Folgenden breuic. III 25; vgl. Kriegbaum, Kirche der Traditoren, 74-83; Frend, Donatist Church, 13 f.; Lamirande, BA 32, 728; Monceaux IV, 11 f.; V, $9 \mathrm{f}$.

13 Terminus post quem ist Mai/Juni des Jahres 303 (Publikation des Ediktes in Afrika). Eine genauere Datierung ist jedoch kaum möglich. Ein Bezug zum Konzil von Cirta lässt sich nicht herzustellen. Seeck (ZKG 10, 1889, 533) spricht sich für die Jahre 305/6 aus, Monceaux (IV, 204) vermutet das Jahr 304. Frend (Donatist Church, 13) datiert auf 305; Kriegbaum (Kirche der Traditoren, 74) hält 304/5 für wahrscheinlich. 
Mensurius über den dies traditionis in Karthago und sein Verhalten hinsichtlich der Verfolgung. Er erklärte, dass die Heiligen Schriften von ihm sicher verwahrt worden seien, wohingegen er in der Basilika Novarum häretische Schriften hinterlassen habe, die von den Verfolgern gefunden worden seien. Mehr sei von ihm auch nicht verlangt worden. Obwohl Prokonsul Anullinus erfahren habe, dass sich im Hause des Bischofs noch weitere Schriften befänden, habe dieser seine Zustimmung verweigert, diese Schriften zu verbrennen. Zudem informierte Mensurius seinen Kollegen darüber, dass er es missbillige, wenn Christen ohne Zwang die Verfolger herausfordern, und dass er verboten habe, solche Leute als Bekenner zu verehren. Unter diesen Provokateuren befänden sich auch Leute, die finanzielle Schulden hätten und nun glaubten, dass ihnen durch ihre öffentlichen Bekenntnisse ein Schuldenerlass oder gar materielle Unterstützung zukäme.

In seinem Antwortschreiben äußerte sich Secundus offenbar nicht direkt zu den Ausführungen seines Amtsbruders. Er berichtete stattdessen seinerseits von der Verfolgung in Numidien, bei der die Bekenner, die sich der traditio verweigert hätten, schwerste Folter und sogar den Tod hätten erleiden müssen. Diese Märtyrer sollten die ihnen zustehenden Ehren erhalten. Secundus stellte sich selbst als Bekenner dar, der nicht einmal wertlose Schriften ausgeliefert habe, um gar nicht erst den Anschein einer Schwäche zu erwecken. Demgegenüber erwähnte er aber, dass Bischof Paulus von Cirta Schriften ausgeliefert habe. $^{14}$

Die Katholiken auf der Konferenz von 411 äußerten zunächst Zweifel an der Authentizität der Briefe, jedoch verfolgten sie dies nicht weiter, da sie ihre Beweiskraft offenbar als gering einschätzten. ${ }^{15}$ In der Tat findet sich im Brief des Mensurius kein eindeutiges traditio-Vergehen des Bischofs und schon gar nicht das Eingeständnis einer öffentlichen Weihrauchopferung. Es ist daher auch heute von der Echtheit der Dokumente auszugehen. ${ }^{16}$ Augustinus wird in seiner inhaltlichen Skizze die wesentlichen Fakten richtig wiedergegeben haben. Es muss freilich offen bleiben, ob Mensurius und Secundus noch weitere Themen oder Einzelheiten angesprochen haben.

Mensurius selbst präsentierte sich in seinem Brief als Mann mit pragmatischer Haltung. Er lehnte es zwar ab, die Heiligen Schriften auszuliefern, gleichzeitig wollte er aber auf Provokationen der Verfolger verzichten. Anscheinend hatte er mit seinem Verhalten Erfolg, da der Prokonsul ihn nicht

14 C. Don. 18: [...] episcopus [Cirtensis] cum clero lapsus per epistulam Secundi, quae ab illis [Donatistis] allegata est, monstrabatur. Der Name Paulus geht aus den acta Munati Felicis hervor; Opt. App. I 3-5.

15 Cap. conl. Carth. III 337, 350.

16 Die Begründung bereits bei Seeck, ZKG 10, 1889, 532 f.; vgl. Kriegbaum, Kirche der Traditoren, 75. 
weiter belangte. Die gleiche Zurückhaltung forderte Mensurius auch von seinen Gemeindegliedern. Falschen Martyriumseifer lehnte er ab, womit er in Tradition zu seinem Vorgänger Cyprian stand. ${ }^{17}$ Wahrscheinlich informierte er Secundus über die Ereignisse, um vom numidischen Primas eine Bestätigung oder Unterstützung für sein Handeln zu erreichen. Schließlich waren Mensurius' Maßnahmen gegen eifernde Bekenner nicht unumstritten. Die Unterstützung blieb jedoch aus: Secundus kritisierte seinen Kollegen zwar nicht direkt, aber gut hörbar, indem er zum Lob der Märtyrer anhob und seine eigene weiße Weste herausstellte. ${ }^{18}$

Die Interpretation dieser Briefe durch die Donatisten im Jahre 411 gibt einen guten Einblick in das donatistische Verständnis: Mensurius' Brief galt ihnen als klares Eingeständnis der Schuld. Aus ihrer Perspektive war bereits das Auffindenlassen häretischer Schriften eine Bücherauslieferung, eine Sichtweise, die sich im Antwortschreiben des Secundus bereits andeutete. Ferner musste es äußerst verdächtig sein, dass Anullinus trotz einer Anzeige Mensurius nicht weiter verfolgte. Dies konnte man als Kollaboration mit den Verfolgern deuten. $\mathrm{Zu}$ dieser verwerflichen Haltung gesellte sich noch das anmaßende Vorgehen gegen die confessores. Mensurius war nicht nur einem mutigen Bekenntnis aus dem Weg gegangen, sondern versagte martyriumsbereiten Bekennern die Anerkennung und unterstellte ihnen auch noch eine falsche Motivation. Damit hatte er sich in den Augen der Rigoristen eindeutig auf die Seite der Verfolger gestellt.

Trotz der vagen Formulierungen im Brief des Mensurius, die sie als Verschleierung der Schuld deuteten, hielten die Donatisten diesen Brief als Beweismittel für vollkommen ausreichend und konnten selbstsicher vertreten, dass Mensurius Kodizes ausgeliefert habe. Der Brief war für sie ein Zeugnis aus erster Hand, ein Schuldeingeständnis, das die Verschmutzung der katholischen Kirche durch einen Traditor offenlegte, und damit ein Zeitdokument, aus dem begründet werden könnte, warum Caecilianus als Nachfolger des Mensurius unhaltbar gewesen sei.

In der mündlichen Überlieferung der Donatisten konkretisierten sich jene Vorwürfe, die aus dem Brief des Mensurius interpretiert wurden. Zur Zeit Augustins, vermutlich erst nach der Konferenz von 411, entstand eine polemische Schrift, in der das Verhalten des Bischofs Mensurius sowie seines Diakons Caecilians während der Verfolgungszeit angeprangert wurde: In der Passio

17 Vgl. Cypr. ep. 81 in Bezug auf die Verfolgung unter Valerian.

18 Mit Kriegbaum, Kirche der Traditoren, $76 \mathrm{f}$. Es ist aber unwahrscheinlich, dass Mensurius versuchte, „eine gesamtafrikanische Diskreditierung der Enthusiasten unter den Christen“ und ein „einmütiges Vorgehen der afrikanischen Bischöfe“ zu erreichen, wie Kriegbaum interpretiert. Augustins Aussagen zeigen recht deutlich, dass es Mensurius allein um die Verhältnisse in Karthago gegangen sein dürfte, die er gegenüber Secundus rechtfertigte. 
sanctorum Dativi, Saturnini presbyteri et aliorum (die sog. „Akten der abitinischen Märtyrer") ${ }^{19}$ wird berichtet, dass Mensurius Schriften ausgeliefert habe, und, was noch viel schlimmer sei, anstatt für die Märtyrer einzutreten, sich gegen sie erhoben habe. Er habe seinen Diakon Caecilianus als Helfer für seine Verbrechen erwählt und ihn als Wächter, bewaffnet mit Peitschen und Ruten, vor dem Gefängnistor postiert, damit die Märtyrer im Gefängnis nicht besucht und versorgt werden könnten. Caecilianus habe die Besucher brutal niedergeschlagen. Im Epilog der Akten werden Mensurius und Caecilianus schließlich für den Tod der Märtyrer mit verantwortlich gemacht. ${ }^{20}$

Es zeigen sich in diesem Bericht offensichtliche Parallelen zu Mensurius' Brief, allerdings wird auch die donatistische Zuspitzung deutlich, in der ein scharfer Gegensatz zwischen den standhaften Märtyrern und den Verrätern hergestellt wird. In den Augen des Verfassers war Mensurius eindeutig ein Traditor und nur mit Abscheu kann er über dessen Umgang mit den Märtyrern sprechen. Eindrücklich beschreibt er die Gewalt des Bischofs und Caecilians

19 Edition: Maier I, Nr. 4, 57-92. Diese passio eines unbekannten Verfassers handelt von einer Gruppe Christen, die während der Verfolgung unter Diokletian in Abitina, einer Ortschaft in der Nähe Karthagos, verhaftet und anschließend in Karthago vom Prokonsul Anullinus verhört und gefoltert wurden (passio Dat. 2-3). Der Hauptteil des Textes (passio Dat. 4-18) beinhaltet ein Protokoll der Anhörung vor Anullinus, der Schlussteil (passio Dat. 19-23) berichtet von dem Gefängnisaufenthalt der Bekenner und in diesem Zusammenhang von den „Verbrechen“ der Traditoren, die sich gegen die Bekenner gestellt hätten. Auch in der Einleitung (passio Dat. 1) wird deutlich, dass der Verfasser die passio schreibt, um die Traditoren zu verdammen. Dieser Aufbau legt nahe, von einer donatistischen Bearbeitung der ursprünglichen Verhörprotokolle auszugehen (dazu bereits Monceaux III, 143-147, V, 53-59; vgl. Tilley, Donatist Martyr Stories, 25-49; Bible, 57-59, 61-64). A. Dearn (JEH 55, 2004, 1-18, hier: 6-13) geht noch weiter und legt überzeugend dar, dass die Redaktion des Textes nicht nur eine Umrahmung vermeintlich authentischer Märtyrerakten des Jahres 304 umfasst, sondern den gesamten Text betrifft. Folglich könne nicht von einer exakten Wiedergabe der Ereignisse gesprochen werden, wie sie z. B. Frend (Donatist Church, 8-10) oder Maier (I, Nr. 4) suggerieren. - Für eine Datierung der passio auf Beginn des 5. Jahrhunderts plädierte bereits F. de Cavalieri (Studi et testi 65, 1935, 4-6), Dearn zeigt mit guten Argumenten, dass die passio in der vorliegenden Form vermutlich erst als Antwort auf die Herausforderungen der Konferenz von 411 geschrieben wurde (JEH 55, 2004, 1 18). Die Debatte während der Konferenz (vgl. o. Kap. 5.3) bestätigt Dearns Einschätzung, dass sich die von den Donatisten vorgelegten Dokumente zur Verfolgung in Karthago (breuic. III 32) zwar auf die abitinischen Märtyrer bezogen, es sich aber keinesfalls um die passio in der vorliegenden Form handelte (Dearn, aaO, $10 \mathrm{f}$.). - F. Dolbeau (La ,passion' des martyrs d'Abitnia: remarques sur l'etablissement du texte, AB 121, 2003, 273-296, hier: 293-285) belegt mit hinreichenden textkritischen Argumenten, dass der Epilog (ab 23,4) erst im 15. Jahrhundert dem Text zugefügt wurde und somit keine historische Aussagekraft hat. 
gegen die Bekenner unter den Christen und appelliert an die Leser, daraus Konsequenzen zu ziehen:

„Also soll man fliehen und die verdorbene Bande aller Beschmutzten verfluchen; und ein jeder soll in allem die ruhmreiche Nachfolge der gesegneten Märtyrer anstreben, welche die eine, heilige und wahre Kirche ist, aus der die Märtyrer entspringen und deren heilige Sakramente die Märtyrer bewahren. “21

Der Verfasser will mit seinen Ausführungen den Lesern beweisen, dass sich Caecilianus und Mensurius zweifelsfrei der traditio schuldig gemacht haben, und er appelliert an sie, der donatistischen Kirche mit ihren Wurzeln bei den Mätyrern der Verfolgung zu folgen.

Die Frage, ob Mensurius ein Traditor im Wortsinne war oder nicht, ist folglich durch den Standpunkt des Betrachters bedingt. Auf der einen Seite machte sich Mensurius durch sein Handeln der traditio und der Kollaboration mit den Behörden zumindest verdächtig, auf der anderen Seite gibt es in den frühen Zeugnissen keinen Hinweis auf eine öffentliche traditio oder gar turificatio des Mensurius. Derartige Aussagen sind zweifellos spätere donatistische Erfindungen. Die Bezeichnung des Mensurius als Traditor beruhte somit auf einer rigoristischen Einschätzung seines Handelns während der Verfolgungszeit. Eine Bewertung, die von den Katholiken nicht geteilt wurde. So zeigt sich gerade in der Diskussion über die Person des Mensurius auf der Konferenz von 411, wie die unterschiedlichen Voraussetzungen der beiden Parteien das Urteil über die Geschichte beeinflussten.

\subsection{Caecilianus von Karthago}

Ebenso wie Mensurius galt Caecilianus den Donatisten als Traditor. Dies zeigt sich vor allem in den Aussagen Petilians und auf der Konferenz von 411. ${ }^{22}$ Eine deutliche Aussage findet sich ferner in der Schrift contra Fulgentium. Dort wird der Donatist Fulgentius mit den Worten zitiert, die er gegen Augustinus richtete:

„Ich sage, dass Caecilianus dein Vater ist. Er selbst ist Traditor und er selbst hat Weihrauch geopfert, er selbst hat alle Übel begangen." ${ }^{23}$

21 Passio Dat. 23,1: Fugienda est ergo et exsecranda pollutorum omnium congregatio uitiosa et appetenda omnibus beatissimorum martyrum successio gloriosa quae est ecclesia una, sancta et uera catholica, ex qua martyres profecti sunt et cui martyres mysteria diuina seruarunt.

22 Bei Cresconius findet sich lediglich eine Andeutung (Cresc. IV 10).

23 C. Fulg. II 20 (ed. Maier II, 281 f.): Fulgentium dixit: Patrem tuum dico Caecilianum. Ipse tradidit, ipse turificauit, ipse omnia mala commisit. 
Anders als im Falle des Mensurius, bei dem sie den Briefwechsel mit Secundus vorlegten, unterließen es die Donatisten im Jahre 411, Caecilians traditio zu beweisen. Zwar stand die Person Caecilianus zumeist im Mittelpunkt der historischen Argumentation, jedoch stets im Zusammenhang mit dem Konzil von Karthago und den späteren Prozessen in Rom, Arles und vor dem Kaiser. Die donatistische Beweisführung richtete sich dabei auf die Verteidigung des Urteils in Karthago, Augustinus und der katholischen Seite ging es dagegen um den Nachweis, dass die späteren Urteile gegen Caecilianus anerkannt werden müssten. ${ }^{24}$

Wie im Fall des Mensurius existieren keine historischen Dokumente, die eine traditio oder turificatio Caecilians explizit bezeugen. Die Beschuldigungen, er habe Weihrauch geopfert und aktiv heilige Schriften ausgeliefert, dürften insofern unbegründete spätere Topoi der Donatisten sein. Unabhängig davon waren es offensichtlich unterschiedliche Berichte über Vergehen Caecilians, die später in der Summe zu der Beurteilung als „Traditor“ führten.

Aus den bereits erwähnten Akten der abitinischen Märtyrer wird deutlich, dass zur Zeit Augustins Caecilianus den Donatisten als brutaler und williger Handlanger des Mensurius galt, der während der Verfolgung in Karthago die Gefangenenversorgung und die Verehrung der Märtyrer gewaltsam verhindert habe. ${ }^{25}$ Eine weitere Überlieferung, in der Caecilianus Gewaltanwendung vorgeworfen wird, ist der sermo de passione Donati, in der von der ersten Verfolgung der Donatisten unter Kaiser Konstantin die Rede ist. ${ }^{26}$ Außer diesen Überlieferungen spielte seine enge Verbindungen $\mathrm{zu}$ anderen Traditoren eine entscheidende Rolle: Caecilianus war zum einen der Nachfolger des „Traditors“ Mensurius und hatte seine Bischofsweihe durch den „Traditor“ Felix von Abthugni empfangen. Dies genügte in den Augen der Donatisten, um ihn ebenfalls als „Traditor“ anzusehen. Der Fall Caecilians zeigt somit sehr anschaulich, wie wenig die spätere Bezeichnung „Traditor“ an die Tat einer tatsächlichen Bücherauslieferung geknüpft war.

Es ist bemerkenswert, dass Augustinus die Frage der tatsächlichen traditioSchuld Caecilians offen ließ. ${ }^{27}$ Die Unschuld bekräftigte er lediglich juristisch, indem er auf die Freisprüche durch bischöfliches und kaiserliches Gericht verwies oder die Irrelevanz persönlicher Schuld für die Kirche darlegte. Mangels Beweisen unterließen es auch die Donatisten zur Zeit Augustins, Caecilianus eine aktive Bücherauslieferung vorzuwerfen. Sie argumentierten kirchenrechtlich mit der Entscheidung des Konzils von Karthago und konzentrierten sich somit auf die traditio des Felix von Abthugni, die aus ihrer Sicht klar ersichtlich

24 Vgl. u. Kap. 7.

25 Passio Dat. 20-21, 23.

26 S. pass. Don. 2, 8, 10-11; vgl. u. Kap. 6.3.1.

27 Vgl. c. Don. 37. 
war. ${ }^{28}$ Die Beantwortung der Frage, ob Caecilianus ein Traditor war oder nicht, unterliegt insofern den gleichen Kriterien, die bereits bei Mensurius deutlich wurden: Nach donatistischem Verständnis gab es keinen Zweifel an der Schuld Caecilians; eine aktive Auslieferung von Büchern musste dafür nicht nachgewiesen werden. Für das katholische Kirchenverständnis war die Beantwortung der Frage nicht relevant, so dass Augustinus auf eine Klärung verzichtete.

\subsection{Felix von Abthugni}

Die traditio-Anklage gegen Felix von Abthugni ist die älteste und bestbezeugte aller Anschuldigungen gegen afrikanische Bischöfe. Felix war für die Donatisten der „Urheber allen Übels“, wie es schon auf dem Konzil des Secundus hieß. ${ }^{29}$ Die Überzeugung, dass Felix als Traditor Caecilianus geweiht habe, war dort die Begründung, Caecilians Bischofswürde für nichtig zu erklären. ${ }^{30}$ Vielleicht noch Ende des Jahres 313 klagten die Donatisten Felix von Abthugni beim Kaiser an, nachdem die Bischöfe in Rom Caecilianus freigesprochen hatten. ${ }^{31}$ Eine Ver-

$28 \mathrm{Zu}$ den donatistischen Argumenten im Jahre 411 vgl. o. Kap. 5.2.

29 Cresc. III 67; un. bapt. 28; breuic. III 26; ep. 88.3; vgl. Ps. c. Don. 57.

30 Vgl. u. Kap. 7.1.1. - Außer der Hauptfigur Felix von Abthugni galten in der donatistischen Überlieferung auch die anderen Ordinatoren Caecilians als Traditoren (vgl. cath. fr. 5: ordinatores [...] fuisse traditores; Cap. conl. Carth. 374; breuic. III 26: nominati sunt etiam quidam collegae Caeciliani, qui traditores asserebantur publicis gestis, quae tamen gesta non legebantur). Augustinus nennt in c. Don. 38 namentlich Novellus von Thizica und Faustinus von Thuburbo. Aus seiner Aussage ist nicht zu schließen, dass alle Ordinatoren Caecilians bereits auf dem Konzil des Secundus angeklagt wurden, wie etwa Monceaux (IV, 329) und Grasmück (Coercitio, 22) meinen. Mit großer Wahrscheinlichkeit stand dort nur der Fall des Felix von Abthugni zur Debatte. Die traditioAnklagen gegen die übrigen Ordinatoren reihen sich in die Zahl derjenigen Personen ein, die aufgrund ihrer Gemeinschaft mit Caecilianus bzw. ihrer Unterstützung der pars Caeciliani von den Donatisten pauschal als Traditoren bezeichnet wurden. So zu Recht Kriegbaum, Kirche der Traditoren, 117. Vgl. auch Lamirande, BA 32, 342 f. Anm. 1; Maier I, 128 Anm. 5.

31 Möglicherweise wurde die Anklage auch nach der Entscheidung der Untersuchungskommission durch Eunomius und Olympius (Opt. I 19; vgl. u. Kap. 7.4.2.1) im Frühjahr 314 eingereicht. Die Chronologie des Prozessverlaufes ist nicht ganz klar, da widersprüchliche Daten überliefert sind. Augustinus datiert in c. Don. 56 die Schlussverhandlung auf den 15.02. 314, während in den überlieferten Akten von einer Voruntersuchung vor dem duumvir Karthagos Didymus Speretius am 19.08. 314 berichtet wird (Opt. App. II 4). Im Frühsommer des Jahres 315 ist der Prozess nachweislich beendet, wie aus dem Brief Konstantins an den Prokonsul Probianus hervorgeht (ep. 88. 4). Bereits Seeck (ZKG 10, 1889, 516-518; 30, 1909, 188) plädierte für eine Korrektur der augustinischen Datierung auf den 15. Februar 315 und begründete dies mit der Verwechslung des Konsulats mit dem Postkonsulat. Diese Umdatierung wird in der Forschung weitgehend anerkannt, da sie die vergleichsweise beste Lösung der Chronologie 
urteilung des Felix, so hofften sie, sollte zu einer Revision dieses Freispruchs führen. Konstantin delegierte das Verfahren zunächst an den Vikar Aelius Paulinus, der aber wegen Erkrankung im Hauptprozess durch den Prokonsul Aelianus vertreten wurde. ${ }^{32}$

Dank der teilweise erhaltenen Prozessakten des prokonsularischen Verfahrens gegen Felix im Jahre 314/15, die im Dokumentenanhang des Optatus überliefert sind, werden die Hintergründe der donatistischen traditio-Anklage gegen Felix verhältnismäßig gut deutlich. ${ }^{33}$

Ausgangspunkt der Anklage war ein Brief, den ein gewisser Ingentius, ehemals ein Stadtschreiber in Abthugni, an die Öffentlichkeit gebracht hatte, und durch den offenbar viele Bischöfe in Numidien und Mauretanien gegen ihren Kollegen in Abthugni aufgehetzt worden waren. ${ }^{34}$ Dieser Brief, den ein duumvir von Abthugni namens Alfius Caecilianus ${ }^{35}$ an Bischof Felix geschrieben hatte, enthielt einen Bericht über den Vorgang der Bücherauslieferung am dies traditionis in der Stadt während der diokletianischen Verfolgung.

Zunächst wird kurz berichtet, dass ein Christ namens Galatius „Grußbriefe“ (epistulae salutatoriae) $^{36}$ aus der Basilika weggebracht habe, die verbrannt worden seien. Anschließend wird aus einem Gespräch zwischen Felix und Alfius Caecilianus zitiert, bei dem der Bischof zu dem Stadtschreiber gesagt habe, dieser solle den Schlüssel der Basilika nehmen und dort alle Bücher beschlagnahmen, die er auf der Kathedra und dem Stein finde; das dort aufbewahrte Öl und den Weizen solle er jedoch verschonen. Alfius Caecilianus habe darauf geantwortet, dass auch das Haus zerstört werden müsse, in dem man die Schriften fände. Daraufhin hätten beide vereinbart, dass die Bücher auf den Friedhof gebracht und dort von den Beamten gefunden werden sollten. ${ }^{37}$

bietet (vgl. Grasmück, Coercitio, 68 Anm. 300; Maier I, 171-173); sie liegt auch meiner Darstellung zugrunde. Anders Monceaux IV, 219 f. und Mandouze; PAC, 44 Anm. 5.

32 Mandouze, PAC 1, 44, s. v. Aelianus; 838, s. v. Aelius Paulinus.

33 Acta purgationis Felicis (Opt. App. II); vgl. Opt I 27. Zu den Akten des Prozesses vgl. die detaillierte Studie von Y. Duval, Chrétiens d'Afrique à l'aube de la paix constantinienne. Les premiers échos de la grande persécution, Paris 2000; vgl. auch von Soden, Nr. 19; Maier I, Nr. 22, 171-187; Seeck, ZKG 10, 1889, 516-522. - Der Prozess gegen Felix ist in der Forschung eingehend behandelt worden und soll hier nur kurz skizziert werden: Vgl. Y. Duval, aaO; Girardet, Kaisergericht, 40-43; Grasmück, Coercitio, 6571; Kriegbaum, Kirche der Traditoren, 91-95; Lamirande, BA 32, 698 f.; Lepelley, Cités I, 338-341; Mandouze, PAC, 409 f., s. v. Felix 2; Monceaux IV, 216-228; Mühlsteiger, ZRG KA 85, 1999, 39-44.

34 Acta purgationis Felicis 10. (Die Einteilung in Paragrafen nach Maier I, Nr. 22).

35 Zu den Personen: Mandouze, PAC, 599 f., s. v. Ingentius; 175 f., s. v. (Alfius) Caecilianus 2.

36 Vielleicht handelte es sich um Gemeinschaftsbriefe anderer Gemeinden, sog. formatae (vgl. ep. 44.3: epistulae communicatoriae), sicher nicht um die Paulusbriefe, wie Kriegbaum (Kirche der Traditoren, 92) vermutet.

37 Acta purgationis Felicis 5. 
Sollte der Bericht zutreffen, dann bedeutete dies zweifellos eine schwere Belastung für Felix: Der Unterredung zufolge hatte Felix ohne Zögern der Übergabe der Heiligen Schriften zugestimmt und außerdem in Absprache mit dem Verfolger die Modalitäten der Auslieferung geklärt, um das Kirchengebäude, materiellen Besitz und sein Leben zu schützen. In den Augen der späteren Donatisten waren diese Vorkommnisse mehr als ausreichend, um Felix als Traditor anzusehen. Entsprechend ist davon auszugehen, dass dieser Brief bereits während des Konzils von Karthago sowie für die späteren Prozesse gegen Caecilianus und Felix beim Kaiser eine entscheidende Rolle für die Beweisführung der Ankläger spielte. ${ }^{38}$

In den Verhandlungen der causa Felicis vor dem duumvir Didymus Speretius und dem Prokonsul Aelianus wurde allerdings diesem für die Donatisten so wichtigen Dokument die Beweiskraft entzogen. Der als Zeuge geladene Alfius Caecilianus erklärte, dass er lediglich den ersten Teil des Briefes geschrieben habe, der zweite Teil nach der Grußformel, der die kompromittierenden Sätze des Felix beinhaltete, sei hingegen eine spätere Hinzufügung, mit anderen Worten eine Fälschung des Ingentius. ${ }^{39}$ Durch weitere Zeugenaussagen wurde folgender Sachverhalt ermittelt: Bischof Felix von Abthugni hatte in der Stadt Utica den Bischof Maurus wegen Simonie absetzen lassen. ${ }^{40}$ Ingentius, der während der Verfolgung in Utica bei Maurus Zuflucht gefunden hatte, klagte aus Verdruss darüber im Gegenzug Felix als Traditor an und versuchte anschließend, Beweise für diese Anklage zu sammeln. In Abthugni erreichte Ingentius durch ein gefälschtes Empfehlungsschreiben des Bischofs Felix ${ }^{41}$ und mit Hilfe des zweiten duumvir Augentius, dass Alfius Caecilianus den besagten

38 Vgl. die Aussage des donatistischen Advokaten Maximus in der Anhörung des Falles vor dem duumvir A. Didymus Speretius in Karthago (Acta purgationis Felicis 4): „Ich spreche im Namen der seniores des christlichen Volkes in der katholischen Lehre. Vor den allerhöchsten Kaisern soll der Fall gegen Caecilianus und Felix verhandelt werden, die mit aller Kraft versuchen, die Vorherrschaft über diese Lehre an sich zu reißen. Gegen sie werden Dokumente über seine [sc. Felix'] Verbrechen zusammengesucht.“ (Loquor nomine seniorum christiani populi catholicae legis. apud maximos imperatores causa agenda erit contra Caecilianum et Felicem qui principatum eiusdem legis omni ui conantur inuadere. contra ipsos documenta criminum eius conquiruntur). Anschließend begründet Maximus die Anklage gegen Felix mit dem Inhalt des von Ingentius vorgelegten Briefes. - Zur Person des Maximus vgl. Mandouze, PAC, 732 f., s. v. Maximus 1.

39 Acta purgationis Felicis 6, 9.

40 Kriegbaum (Kirche der Traditoren, 92) vermutet aufgrund dieser Amtsvollmacht, dass Felix zur Zeit der Abwesenheit des Mensurius die Aufgaben des Primas von Afrika kommissarisch ausgeübt habe und deshalb wohl auch Caecilians Ordinator gewesen sei. Diese Annahme erscheint plausibel, wenngleich sie sich nicht nachweisen lässt.

41 Acta purgationis Felicis 7. 
Brief an Felix formulierte, in dem er über den Ablauf des dies traditionis in Abthugni berichtete. ${ }^{42}$

Alfius Caecilianus schilderte vor dem Gericht des Prokonsuls nochmals seine Sicht der Ereignisse am dies traditionis, um zu zeigen, dass der zweite Briefteil tatsächlich eine Fälschung darstelle. Demnach sei er in Begleitung des Gemeindemitglieds Galatius zum Haus des Bischofs gegangen. Dort habe man die Kathedra und „Grußbriefe“ genommen, die später verbrannt worden seien; ebenso seien die Türen der Basilika niedergebrannt worden. Bischof Felix jedoch sei an diesem Tag gar nicht in Abthugni gewesen. ${ }^{43}$

Nach dieser Aussage und nachdem Aelianus die Folter angedroht hatte, gab Ingentius zu, den Brief durch den Zusatz verfälscht zu haben. Der Prokonsul akzeptierte die Aussagen des Alfius Caecilianus, Ingentius wurde in Haft genommen und der Prozess gegen Felix endete mit dem Freispruch des Bischofs von der Anklage der traditio. ${ }^{44}$

Für die Katholiken war mit dem Urteil des Aelianus der Fall Felix geklärt. Die Unschuld des Bischofs von Abthugni wurde stets mit dem Hinweis auf die Prozessakten unterstrichen. Für die Donatisten bedeutete dieses Urteil indessen eine herbe Niederlage in dem Kampf, für die Rechtmäßigkeit ihrer Kirche eine offizielle Bestätigung zu erhalten. Verständlicherweise akzeptierten sie die Entscheidung des Aelianus nicht, sondern hielten die traditio-Anschuldigung gegen Felix vehement aufrecht. Noch Cresconius und die Donatisten auf der Konferenz von 411 beriefen sich auf den Brief bzw. die Aussagen des Ingentius. ${ }^{45}$

An dem Prozessverlauf der causa Felicis übten die Donatisten scharfe Kritik. Die Androhung der Folter gab den Donatisten Anlass, den überlieferten Aussagen des Ingentius vor Gericht keinen Glauben zu schenken. Es konnte sich offenbar die Meinung durchsetzen, dass das Geständnis der Fälschung von Ingentius erpresst worden sei. Zudem wurde der gesamte Prozess gegen Felix in Frage gestellt, da sich Felix als Kleriker anstatt vor einem weltlichen Gericht vor anderen Bischöfen hätte rechtfertigen lassen müssen. ${ }^{46}$ Auf der Konferenz von Karthago griffen die Donatisten die Person des Richters an und kritisierten die Abwesenheit des Angeklagten Felix beim Prozess. Unter diesen Umständen hätte kein Urteil gesprochen werden dürfen. ${ }^{47}$ Im Zusammenhang mit dem kaiserlichen Urteil über Caecilianus versuchten die Donatisten darüber hinaus zu erweisen, dass nach dem Verhör des Ingentius vor dem Kaiser der Fall Felix

42 Acta purgationis Felicis 8.

43 Acta purgationis Felicis 4.

44 Acta purgationis Felicis 10-11.

45 Vgl. bei Cresconius (Cresc. III 80, vgl. o. Kap. 3.4.1) und die Aussagen der Donatisten auf der Konferenz von 411 (breuic. III 41-42).

46 Beide Vorwürfe traten im Gespräch Augustins in Thubursicum zutage, ep. 43.13; vgl. o. Kap. 4.2.1.

47 Cap. conl. Carth. III 570; breuic. III 42; vgl. o. Kap. 5.3.2. 
neu entschieden worden sei und zwar zu Gunsten des Ingentius und gegen Felix. ${ }^{48}$ Der vorgelegte Konstantinbrief an Probianus konnte diese Version jedoch nicht bestätigen und die Donatisten waren auch nicht in der Lage, ihre Aussagen durch andere Dokumente zu untermauern. ${ }^{49}$

Unabhängig von ihrer festen Überzeugung, dass Felix ein Traditor gewesen sei, bedeutete dies für die traditio-Anklage gegen Felix, dass sich die Donatisten lediglich auf den umstrittenen Brief des Ingentius als schriftliches Dokument stützen konnten. Sie versuchten, die Beweiskraft des Briefes zu erhalten, indem sie zum einen mit üblichen Topoi das Gerichtsverfahren angriffen (Unzuständigkeit des Gerichts, befangene Richter), zum anderen das Urteil des Aelianus entwerteten, indem sie ein Revisionsurteil postulierten. Ob und in welcher Form Felix von Abthugni tatsächlich Traditor war, lässt sich heute genauso wenig beurteilen wie im Prozess 314/15 oder auf der Konferenz von Karthago. Sicher ist, dass die Katholiken die Urteile des Prokonsuls und des Kaisers auf ihrer Seite hatten, die von der Unschuld des Felix ausgingen. Die Donatisten hingegen schenkten ihrer Überlieferung mehr Glauben als diesen Urteilen. Ganz offensichtlich hatte sich Felix jedoch ähnlich verhalten wie Mensurius in Karthago: Unwichtige Schriften wurden von den Beamten „gefunden“, während Felix selbst gar nicht in der Stadt war. Wie bereits bei Mensurius und Caecilianus festgestellt, reichte aber jeder kleine Verdacht auf traditio, Kollaboration oder Agitation gegen Bekenner aus, um unter die Traditoren gerechnet zu werden. Ingentius nutzte diesen „Anfangsverdacht“ aus, wohl auch unter Verwendung der nachgewiesenen unlauteren Mittel, um Felix nachhaltig in Verruf zu bringen. Zusammengefasst gilt indessen über die Person des Felix in der Geschichte wie über viele andere Personen aus der Anfangszeit des Schismas das Urteil von Mandouze: „Felix apparaît dans l'histoire de la naissance du donatisme plus comme un argument que comme un personnage. “50

\subsection{Die römischen Bischöfe}

Die traditio-Anklagen gegen die römischen Bischöfe Marcellinus, Marcellus, Miltiades und Silvester standen niemals im Zentrum der donatistischen Argumentation. Mit Ausnahme des Miltiades, dessen traditio die Donatisten auf der Konferenz von 411 beweisen wollten, ist auch nichts über irgendwelche Dokumente bekannt, die zur Rechtfertigung dieser Beschuldigungen von den Donatisten vorgelegt wurden, so dass sich die Frage stellt, auf welchen Gerüchten oder Tatsachen die Anschuldigungen der Donatisten basierten.

48 Cap. conl. Carth. III 553, 555, 561, 570; breuic. III 41. Vgl. u. Kap. 7.4.2.1.

49 Breuic. III 41-42.

50 Mandouze, PAC, 410. 
Die Situation in Rom zur Zeit der Verfolgung ist anhand der überlieferten Quellen nur in Ansätzen zu rekonstruieren. ${ }^{51}$ Die Nachrichten über die Bischöfe Marcellinus und Marcellus sind spärlich, zum Teil widersprüchlich und gründen sich auf wenig verlässliche Zeugnisse. ${ }^{52}$ Marcellinus war von Juni 295 bis zum Herbst 303 (?) römischer Bischof. Wahrscheinlich kam er unter der Herrschaft Diokletians gewaltsam zu Tode; ob er ein Martyrium erlitt, bleibt dagegen sehr zweifelhaft. ${ }^{53}$ Sowohl der Liber Pontificalis als auch die gefälschten Akten der Synode von Sinuessa enthalten allerdings die Nachricht, dass Marcellinus sich der turificatio bzw. auch der traditio schuldig gemacht habe. ${ }^{54}$ Es stellt sich die Frage, ob es sich bei diesen Informationen um die Rezeption einer unabhängigen Überlieferung handelt ${ }^{55}$ oder um eine spätere Verwendung bzw. Übernahme der donatistischen Anklage in die katholische Tradition. ${ }^{56}$ Die erste Möglichkeit ließe darauf schließen, dass die donatistischen Anklagen einen gewissen Wahrheitsgehalt besaßen, die zweite Möglichkeit dagegen, dass der Topos „Traditor" ohne geschichtlich erweisbaren Hintergrund angewandt wurde.

51 Zum Folgenden: E. Caspar, Geschichte des Papsttums 1, 95-102; A. Amore, Il preteso „Lapsus“ di Papa Marcellino, Antonianum 32, 1957, 411-426; ders., È esistito Papa Marcello?, Antonianum 33, 1958, 57-75; E. H. Röttges, Marcellinus - Marcellus, Zur Papstgeschichte der diokletianischen Verfolgungszeit, ZKTh 78, 1956, 385-420; R. Davis, Pre-Constantinian Chronology: the Roman Bishopric from AD 258 to 314, JThS 48, 1997, 439-470; Kriegbaum, Kirche der Traditoren, 151 f.; Quinot, BA 30, 795 f.; de Veer, BA 31, 845-847; Monceaux IV, 205.

52 Eine Zusammenstellung und kritische Betrachtung aller Quellen zu den beiden Bischöfen bei Röttges, ZKTh 56, 1956, 387-409. Zu den Datierungen der Amtszeiten s. Davis, JThS 48, 1997, 461-465. Vgl. auch J. N. D. Kelly, The Oxford Dictionary of Popes, s. v. Marcellinus, s. v. Marcellus I; Enßlin, RE XIV 2, 1930, Sp. 1448 f., s. v. Marcellinus 32; Sp. 1494, s. v. Marcellus 34 u. 35.

53 Das in Lib. Pontif. 30 berichtete Martyrium geht wohl auf eine im 5. Jh. entstandene passio Marcellini zurück, jedoch fehlt der Name des Marcellinus in den Märtyrerkalendern des 4. Jahrhunderts; vgl. Caspar, Geschichte des Papsttums, $98 \mathrm{f}$.

54 Lib. Pontif. 30: de qua re [sc. persecutione] et ipse Marcellinus ad sacrificium ductus est, ut turificaret, quod et fecit. - Die Akten des vermeintlichen Konzils von Sinuessa, das im Jahre 303 stattgefunden haben soll, sind vermutlich im 6. Jh. nach dem SymmachusProzess entstanden und dienten dazu, den Grundsatz der Nichtjudizierbarkeit des Papstes zu verfestigen. Man kann aber davon ausgehen, dass die Fälscher hinsichtlich der turificatio des Marcellinus auf eine mündliche oder schriftliche Überlieferung zurückgreifen konnten (vgl. Röttges, ZKTh, 78, 1956, 399-401).

55 So Caspar (Geschichte des Papsttums, 98 f.) und Enßlin (RE XIV 2, 1448 f.); Frend, Donatist Church $22 \mathrm{f}$.

56 So Röttges (ZKTh 78, 1956, 403-405), der vermutet, dass die turificatio des Marcellinus eine donatistische Erfindung nach 370 gewesen und dann über Augustinus und andere Notizen in die katholisch-kirchliche Tradition eingegangen sei. Motiv der Donatisten sei die Beschuldigung des Miltiades gewesen, der durch Marcellinus indirekt belastet gewesen wäre. Gegen Amore, Antonianum 32, 1957, 419-421. 
Marcellus wurde im Jahr 305/6, wohl noch vor dem Herrschaftsantritt des Maxentius, Bischof von Rom. ${ }^{57}$ Bei ihm findet sich in der Überlieferung kein Hinweis auf eine Opferung oder traditio in der Verfolgung. In einem Epitaph des Papstes Damasus I. heißt es indessen, dass Marcellus einem Gefallenen eine strenge Buße auferlegt habe, wodurch es zu Streitigkeiten in der römischen Kirche gekommen sei ${ }^{58}$ Diese Streitigkeiten veranlassten wiederum Kaiser Maxentius, Marcellus ins Exil zu schicken, ebenso wie wenig später dessen Nachfolger Eusebius. ${ }^{59}$ Die Weihrauchopferung oder traditio des Marcellus findet insofern keinen Rückhalt in den Quellen.

Abgesehen von der Beschuldigung durch Petilianus ist nichts über das Verhalten des Bischofs Silvester, den Nachfolger des Miltiades, während der Verfolgung bekannt. ${ }^{60}$ Ohnehin sind die Informationen zu seiner Person sehr gering. Seine lange Amtszeit (314-335) und die Berichte über seine Tätigkeiten und seinen Einsatz für die Kirche ${ }^{61}$ zeigen jedoch, dass er innerhalb der katholischen Kirche eine angesehene Position innehatte. Sollte er sich während der Verfolgung etwas zu Schulden haben kommen lassen, spielte dies jedenfalls in der römischen Kirche nach 313 keine Rolle mehr. Eine vita Silvestri aus dem 5. Jahrhundert erwähnt jedoch, dass Silvester von Miltiades zum Priester geweiht worden sei. ${ }^{2}$ Möglicherweise war den Donatisten diese Weihe Silvesters durch einen ebenfalls der traditio beschuldigten Bischof bekannt.

Eine andere denkbare Traditionslinie ist die Entscheidung der Synode von Arles im Jahr 314. Auch wenn der Synodalbrief der Bischöfe aus Arles an Silvester, der heute im Anhang des Optatus überliefert ist, ${ }^{63}$ den Donatisten zur Zeit Augustins nicht bekannt war, steht dennoch außer Frage, dass sie den

57 Aufgrund des ähnlichen Namens mit seinem Vorgänger und unstimmigen Quellenangaben zu den Pontifikaten vertrat ein Teil der älteren Forschung die Ansicht, bei Marcellinus und Marcellus handele es sich um dieselbe Person (Bereits Mommsen, Libri Pontificalis, LIII-LV, zuletzt Röttges, ZKTh 78, 1956, 411-415). Gegen diese These und zur Diskussion vgl. Caspar, ZKG 46, 1927, 321 ff. - Enßlin unterscheidet fälschlicherweise den römischen Bischof von dem Priester Marcellus, der nach Augustinus (un. bapt. 27, 29) von den Donatisten der traditio beschuldigt wurde. Petilians Anschuldigung richtet sich allerdings eindeutig gegen Marcellinus und die drei späteren römischen Bischöfe Miltiades, Marcellus und Silvester.

58 Damasus epigr. 48 (ed. M. Ihm, S. 51). Eine standhafte Haltung des Marcellus gegenüber Kaiser Maximian überliefern die Acta Marcelli aus dem späten 5. Jh. (ed. Mombritius, Vitae Sanctorum II, 169-173). Das von dieser Legende abhängige Kapitel im Liber Pontificalis (Lib. Pontif. 31) bezeugt sogar eine confessio gegenüber Maxentius.

59 Vgl. D. Decker, La politique religieuse de Maxence, Byzantion 38, 1968, 472-562; Kriegbaum, Die Religionspolitik des Kaisers Maxentius, AHP 30, 1992, 7-54.

60 Zur Person: Pietri, PIC 2, 2071, s. v. Silvester 1; Caspar, Geschichte des Papsttums 2, 122-130.

61 Vgl. Lib. Pontif. 34.

62 Vita Silvestri (ed. Mombritius, Vitae Sanctorum II, 508-531, hier: 509, Z. 6 ff.).

63 Opt. App. IV. 
Namen des Papstes mit der negativen Entscheidung von Arles in Verbindung brachten. Wie bereits festgestellt, genügten aus donatistischer Sicht bereits wenige Hinweise, um Personen als Traditoren zu bezeichnen. Bei Silvester lieBen sich folglich zwei Gründe anführen, die ihn in den Augen der Donatisten zum Traditor werden ließen: Zum einen die Weihe durch Miltiades, zum anderen seine Amtszeit als römischer Bischof in einer Zeit, in der die Gesamtheit der katholischen Kirche den Forderungen der Donatisten eine Absage erteilte.

Die traditio-Anklage gegen Miltiades ${ }^{64}$ steht im direkten Zusammenhang mit dem römischen Konzil von 313 und dem Urteil zu Gunsten Caecilians. Diese argumentative Verknüpfung der Donatisten thematisiert Augustinus in seiner Schrift gegen Parmenianus sowie in de unico baptismo und sie bestätigt sich durch die Ausführungen der donatistischen Bischöfe im Jahr 411. Die Donatisten versuchten auf unterschiedliche Weise, das Urteil von Rom anzufechten und dazu gehörte neben den Vorwürfen der Bestechung oder des ungültigen Verfahrens auch der Angriff auf die Person des Vorsitzenden Miltiades. Augustinus sah in diesem Vorwurf nichts anderes als den Versuch der Donatisten, der Entscheidung des römischen Konzils im Nachhinein die Berechtigung zu entziehen. Wenn die Schuld des Miltiades so offenbar gewesen wäre, schreibt er, dann hätten sich die Ankläger Caecilians doch unmittelbar nach der Synode an den Kaiser wenden können, um darzulegen, dass das Urteil eines Traditoren und Weihrauchopferers nicht zu akzeptieren sei. ${ }^{65}$

In den Quellen findet sich kein Hinweis auf ein traditio-Vergehen des Miltiades, und aller Wahrscheinlichkeit nach existierten bereits im 4. Jahrhundert keine entsprechenden Belege. Denn auch die Donatisten besaßen keine Dokumente, mit denen sie ihre Anschuldigung eindeutig beweisen konnten. Die gewagten Querverbindungen der donatistischen Vertreter auf der Konferenz von 411 sind heute nicht überzeugender als damals, so dass aus ihnen eine Schuld des Miltiades nicht nachweisbar ist. ${ }^{66}$

Davon abgesehen verdeutlicht das Beispiel Miltiades nochmals das Verständnis der Donatisten: Für eine traditio-Anschuldigung waren keine Beweise vonnöten. Miltiades' Parteinahme für Caecilianus genügte vollkommen, um ihn selbst als Traditor zu verleumden. Als auf der Konferenz von 411 Beweise vorgelegt werden mussten, hielten es die Donatisten für ausreichend, die Gemeinschaft des Miltiades mit einem einzigen Traditor unter seinen Klerikern nachzuweisen, um ihre Anklage zu begründen. Darin zeigt sich, wie umfassend

64 Miltiades war römischer Bischof vom 2. Juli 310 bis zum 10. Januar 314. Zur Person: Pietri, PIC 2, 1513, s. v. Miltiades.

65 Un. bapt. 28; vgl. auch c. ep. Parm. I 10. - Congar (BA 28, 725 f.) meint, Parmenianus sei der erste gewesen, der die traditio-Vorwürfe gegen Miltiades erhoben hätte. Dies kann jedoch nur spekulativ sein. Vgl. auch Kriegbaum, AHP 28, 1990, $41 \mathrm{f}$.

$\mathrm{Zu}$ ihrer Argumentation vgl. ausführlich o. Kap. 5.3.2. 
das Wort „Traditor“ in der Vorstellung der Donatisten zu diesem Zeitpunkt verstanden wurde.

Die Notwendigkeit, ihre Anklagen gegen Miltiades auch zu beweisen, sahen die Donatisten erst im Hinblick auf diese Konferenz. Es ist daher sehr wahrscheinlich, dass das Aktenmaterial aus Rom erst zur Vorbereitung der Konferenz herangezogen wurde. ${ }^{67}$

Als Ergebnis lässt sich festhalten: Die donatistischen traditio-Anklagen gegen römische Bischöfe konnten zu keiner Zeit mit stichhaltigen Zeugnissen belegt werden. Es ist zudem wahrscheinlich, dass keiner der genannten Bischöfe eine traditio dem Wortsinn nach begangen hat. Allerdings ist anzunehmen, insbesondere bei Marcellinus, dass bereits Verständigungsversuche mit den Behörden oder Kompromisse bei der Bücherauslieferung von einigen Rigoristen als lapsus gewertet wurden, ähnlich wie bei Felix und Mensurius in Afrika. Auf diese Weise wurden belastende Aussagen weitergegeben, die später von den Donatisten aufgegriffen werden konnten.

Obwohl es erst bei Petilianus und den Donatisten zur Zeit Augustins nachweisbar ist, so ist es wahrscheinlich, dass schon sehr bald nach den antidonatistischen Entscheidungen von Rom und Arles die römischen Bischöfe Ziel donatistischer Anschuldigungen wurden. Es spielte schon früh keine Rolle mehr, was tatsächlich in der Verfolgungszeit geschehen war, sondern die Gemeinschaft mit anderen Traditoren galt als erstes Kriterium. Die Anklage gegen eine Person zog die Anklage gegen eine andere nach sich, und in der Summe galten alle als Traditoren und Weihrauchopferer. Gerüchte und Legenden über irgendwelche Bücherauslieferungen fanden offene Ohren und ergänzten bestenfalls noch die bereits gefällten Urteile über die römischen Bischöfe.

Unter den schriftlichen Zeugnissen der Donatisten befanden sich keine aussagekräftigen Beweise über die traditio in Rom, doch gab es vielleicht hier und dort Anspielungen in Märtyrerakten und Leidensgeschichten, die heute nicht mehr erhalten sind. ${ }^{68}$ Während die donatistische Kritik an Miltiades ein-

67 Da die Donatisten die Verbindung des Militades zum Diakon Straton erstmals auf der Konferenz vortrugen, diejenige zum Diakon Cassianus Augustins Aussage zufolge erst nach der Konferenz (vgl. o. Kap. 5.4.2), ist es äußerst unwahrscheinlich, dass die Passage im Liber Genealogus über die traditio von Straton und Cassianus (Lib. Gen. 626-627, vgl. o. Anm. 4) noch vor der Konferenz eingefügt wurde, wie Monceaux (IV 101 f., 501) und Maier (II, 147-149) annehmen, und eine erste „donatistische Redaktion“ des Buches auf 406-410 datieren. Die ansonsten völlig unbedeutenden Diakone werden eindeutig nur zur Belastung des Miltiades aufgeführt. Ihre Namen dürften also erst nach 411 hinzugefügt worden sein (vgl. de Veer, BA 31, 847). Das in Lib. Gen. 627 genannte Datum (26. Juni 405) ist lediglich terminus post quem einer ersten donatistischen Überarbeitung des Textes, dient also nicht der weiteren Präzisierung.

68 Es ist beispielsweise gut möglich, dass die Nachrichten über die traditio des Bischofs Marcellinus in irgendeiner Form in jenen römischen Akten erwähnt waren, die von den 
deutig durch dessen Urteil zugunsten Caecilianus motiviert wurde und diese Motivation auch zu einer gründlicheren Auseinandersetzung mit seinem Fall im Jahre 411 führte, beschränkt sich der Grund für die Anklage der übrigen römischen Bischöfe auf ihre bloße Zugehörigkeit und führende Rolle in der „Kirche der Traditoren“. Die Aufzählung dieser Bischöfe bei Petilianus weist in diese Richtung. Umgekehrt wollte dieser vielleicht auch die Notwendigkeit der von den Donatisten installierten Bischöfe in Rom rechtfertigen. ${ }^{69}$ Die Diskreditierung der römischen Bischöfe lag jedenfalls im Interesse der Donatisten, um mit einem zusätzlichen Argument ihre Abgrenzung auch von den europäischen Kirchen zu untermauern. Alle traditio-Anklagen der Donatisten müssen auBerdem im Zusammenhang mit ihren anderen Angriffen auf Personen betrachtet werden: Die erste Generation ihrer katholischen Gegner galten den Donatisten pauschal als Traditoren, die folgenden Generationen pauschal als Persecutoren. Andere unliebsame Personen, wie Augustinus oder die Bischöfe Fortunatus und Profuturus von Constantina, wurden von Petilianus und anderen Donatisten als Manichäer verleumdet. ${ }^{70}$ Diese Parallelen verdeutlichen, dass es sich in den meisten Fällen um Stereotype handelte.

Augustinus selbst sah in den Beschuldigungen der römischen Bischöfe nichts anderes als völlig aus der Luft gegriffene Behauptungen. Es seien niemals Beweise vorgelegt worden, außerdem hätten bereits die ersten Donatisten diese Beschuldigungen vorgebracht, wenn sie denn existiert hätten. ${ }^{71}$ Einzelheiten zu den Bischöfen Marcellinus oder Silvester nennt Augustinus jedoch nicht in seiner Entgegnung. Wahrscheinlich mangelte es ihm ebenso an konkreten Informationen wie seinem Gegner Petilianus. ${ }^{72}$

\section{Augustins Antwort: traditio-Anschuldigungen gegen donatistische Bischöfe}

\subsection{Das Protokoll des Konzils von Cirta}

Um den traditio-Anschuldigungen der Donatisten entgegenzutreten, versuchte Augustinus im Rahmen seiner historischen Argumentation nachzuweisen, dass sich unter den Gründern der Donatisten selbst Traditoren befunden hätten. Das

Donatisten 411 gegen Miltiades herangezogen wurden. De Veer (BA 31, $846 \mathrm{f}$.) und Quinot (BA 30, 796) gehen davon aus, dass die Donatisten 411 auch die Schuld des Marcellinus erweisen wollten. Allerdings lässt sich dies weder aus den Cap. conl. Carth. noch aus Augustins Aussagen schließen.

69 So de Veer, BA 31, 846.

70 Vgl. c. litt. Pet. III 11, 30; un. bapt. 29; vgl. Quinot, BA 30, 769-771.

71 Vgl. c. litt. Pet. II 208, III 29; un. bapt. 28.

72 Vgl. Quinot, BA 30, 796. 
Protokoll des Konzils von Cirta war dafür eines der wichtigsten Dokumente in seinen Händen. ${ }^{73}$ Mithilfe dieses Protokolls wollte Augustinus die donatistische Selbstdarstellung als unbefleckte, reine Kirche als Mythos entlarven und so den Grund des Schismas als hinfällig erweisen.

Bereits in seinen ersten Schriften verwendet Augustinus traditio-Beschuldigungen als Argumente gegen die gleichlautenden Vorwürfe der Donatisten. So schreibt er im Psalmus contra Partem Donati, dass die numidischen Bischöfe, die in Karthago Caecilianus abgesetzt hätten, Traditoren gewesen seien. ${ }^{74}$ Gleiches behauptet Augustinus in allen späteren Schriften, in denen er sich mit der Geschichte des Schismas auseinandersetzt. Häufig verweist er auf „kirchliche Akten", die seine Behauptung belegen sollten. Diese Akten sind indessen nicht mehr als jenes Protokoll der Synode aus Cirta. ${ }^{75}$ Auch auf der Konferenz von 411 war dieses Dokument eines der Hauptzeugnisse der Katholiken, mit dem die Gültigkeit der Absetzung Caecilians durch das Konzil von Karthago widerlegt werden sollte. ${ }^{76}$

Aufgrund seiner Brisanz in der Auseinandersetzung zwischen Donatisten und Katholiken ist das Protokoll von Cirta auch ein wichtiges Dokument für die Entstehungsgeschichte des Schismas. Sollten die Aussagen authentisch sein, ist zumindest die später von den Donatisten behauptete theologische Begründung des Schismas, die Reinheit der Kirche aufrechtzuerhalten, in Frage zu stellen. $\mathrm{Ob}$ jene Synode in Cirta in der berichteten Form tatsächlich stattgefunden hat und mit welchem Recht Augustinus das überlieferte Protokoll für seine Argumentation verwendet, ist folglich eine der zentralen Fragen für das Schisma.

Der Text des Protokolls ist im Wortlaut nur bei Augustinus im dritten Buch gegen Cresconius überliefert. ${ }^{77}$ Allerdings gibt er den ihm vorliegenden Text nicht vollständig wieder. An zwei Stellen weist Augustinus selbst auf Auslassungen hin (et alio loco). Offensichtlich kürzte er im Protokoll die Befragung der Bischöfe durch Secundus ab, um nur Antworten der tatsächlich von der traditio betroffenen Bischöfe wiederzugeben. Allerdings dürften die Auslassungen nicht sehr groß gewesen sein. Außer den befragten Personen werden am Ende nur noch drei weitere Bischöfe genannt, die anscheinend keine Schuld auf sich geladen hatten; die Gesamtzahl der anwesenden Bischöfe betrug demzu-

73 Edition: Maier I, Nr. 7, 112-118; von Soden, Nr. 5; Duchesne Nr. 5, 629; Seeck, ZKG 10, 524-532; 30, 182 f.; vgl. Barnes, JThS 26, 13-22; Fischer, AHC 18, 1986, 281-292; Tilley, Bible, 51 f.; de Veer, BA 31, 796-799; Monceaux III, 100-102; IV 325 f. - Eine kurze Inhaltswiedergabe des Protokolls s. o. Kap. 3.4.2.1.

74 Ps. c. Don. 49-50.

75 C. litt. Pet. I 23; II 20; c. ep. Parm. I 5; Cresc. III 30; cath. fr. 73; epp. 43.6-11; 53.4; 76.2; un. bapt. 31; un. eccl. 5, 46; s. Dolbeau 2.22.

76 Cap. conl. Carth. III 350 ff.; breuic. III 27, 31-33; c. Don. 18; Gaud. I 47.

77 Cresc. III 30. Vgl. o. Kap. 3.4.2.1. 
folge wahrscheinlich zwölf. ${ }^{78}$ Es ist daher anzunehmen, dass Secundus alle anwesenden Bischöfe befragte und ursprünglich alle Namen im Protokoll vermerkt worden waren. Dies bedeutet, Augustinus kürzte den Text um drei oder vier der Dialoge, die für seine Intention unerheblich waren.

Anlass der Synode war die Wahl und Weihe eines neuen Bischofs für die Stadt Cirta. Es stellt sich daher die Frage, warum Augustinus den zitierten Textausschnitt nach Secundus' Entscheidung zu Gunsten der Traditoren abbrechen ließ und nicht noch einen Ausschnitt über die Ordination des Silvanus anfügte. Schließlich war es ein Hauptanliegen Augustins zur Widerlegung des Cresconius, Silvanus die traditio nachzuweisen. Entweder konnte der restliche Text des Protokolls nichts mehr zur Diskussion beitragen, oder aber Augustins Vorlage endete bereits mit der Sentenz des Secundus und Silvanus' Name fand gar keine Erwähnung mehr. Da im Zusammenhang mit dem Protokoll von Cirta immer nur auf die oben genannten Geständnisse der Bischöfe verwiesen wird, ist die zweite Möglichkeit wesentlich wahrscheinlicher. Sollte es einen weiteren Teil des Protokolls gegeben haben, war dieser offenbar zu keiner Zeit in der Auseinandersetzung zwischen Donatisten und Katholiken bekannt.

Augustinus rechnet das Protokoll von Cirta zu den kirchlichen Akten; er macht aber keine genauen Angaben über die Herkunft des Textes. Gegenüber Cresconius erwähnt er lediglich, dass durch die Sorgfalt gewisser Leute das Dokument überliefert worden sei. Eine ähnliche Formulierung findet sich im Breviculus. Möglicherweise spielt er hier auf den Diakon Nundinarius an, von dem Optatus im Zusammenhang mit dem Protokoll spricht: ${ }^{79}$ Optatus von Mileve befand sich ebenfalls im Besitz einer Abschrift des Protokolls, die er für seine Darstellung verwandte. Er gibt an, dass das Dokument zu den Schriften des Diakons Nundinarius (scripta Nundinarii) gehöre, die er seinem Werk angefügt habe. ${ }^{80}$ Dieser Nundinarius war der Ankläger des Silvanus in dem Prozess vor dem Konsular Zenophilus im Jahre 320 und die Akten dieses Prozesses sind - allerdings unvollständig - im Dokumentenanhang bei Optatus erhalten. Gerade das Protokoll von Cirta fehlt jedoch heute in diesem Aktenmaterial.

Es bleibt daher zu klären, ob mit der Bezeichnung scripta Nundinarii die gesamten Prozessakten, die gesta apud Zenophilum (Opt. App. I), gemeint

78 Der Text in Cresc. III 30 nennt insgesamt 10 Namen: Secundus von Tigisi, seinen Neffen, den jüngeren Secundus, vier geständige Traditoren sowie Purpurius und die drei unbelasteten Bischöfe. Nach der Konferenz von Karthago 411 spricht Augustinus von zwölf teilnehmenden Bischöfen (breuic. III 32; c. Gaud. I 47). Optatus nennt zudem einen gewissen Menalius als Teilnehmer, der ebenfalls der traditio beschuldigt wurde (Opt. I 13). Schließlich ist anzunehmen, dass der zu weihende Bischof, Silvanus von Cirta, ebenfalls anwesend war. - Vgl. Fischer, AHC 18, 1986, 289.

79 Cresc. III 31; breuic. III 32: dictum est etiam a catholicis episcopalia gesta illa Cirtensia, qui diligentia maiorum usque ad haec tempora seruari et inueniri potuerint.

80 Opt. I 13-14; vgl. I 19-20. 
waren, oder ob sie einen eigenständigen Teil der Appendizes bei Optatus bezeichneten, der heute nicht mehr erhalten ist, etwa eine gesonderte Sammlung der Beweisdokumente des Nundinarius für den Prozess gegen Silvanus. Mit anderen Worten: Gehörte das Protokoll von Cirta ursprünglich zu den gesta apud Zenophilum oder wurde es unabhängig überliefert?

Seit Duchesne, Seeck und von Soden nimmt die Forschung durchgängig an, dass das Protokoll von Cirta durch die Prozessakten des Zenophilus in die Hände des Optatus und Augustins geraten sei. ${ }^{81}$ Der Befund bei Augustinus spricht jedoch zunächst gegen diese Annahme: In seinem Brief an Generosus führt Augustinus das Protokoll von Cirta getrennt von den gesta apud Zenophilum auf. Allerdings nennt er auch die acta Munati Felicis gesondert, die heute noch immer Teil der gesta apud Zenophilum sind. Eine deutliche Abgrenzung beider Texte findet sich jedoch in ep. 43: Seinen Gesprächspartnern in Thubursicum, so Augustinus, habe er das Protokoll von Cirta vorgetragen, nicht aber die Akten des Zenophilus. Ganz offensichtlich betrachtete Augustinus das Protokoll von Cirta als eigenständiges, kirchliches Dokument, getrennt von den anderen weltlichen Prozessakten im Zusammenhang mit der causa Silvani. ${ }^{82}$

Daraus lässt sich folgern, dass Augustinus zwar den darstellenden Bericht des Optatus und dessen Aussage über die scripta Nundinarii kannte und diese Kenntnisse zur Herkunft gegenüber Cresconius andeutete, das Protokoll von Cirta selbst konnte aber schon Augustinus nicht mehr in dem von Optatus überlieferten Anhang finden. Er griff auf eine andere Quelle, vermutlich ein kirchliches Archiv in Numidien, zurück und benützte somit eine von Optatus unabhängige Abschrift des Protokolls, die er konsequenterweise nicht zu den gesta apud Zenophilum rechnete. Für die Verwendung unterschiedlicher Kopien sprechen auch die abweichenden Datierungen bei Augustinus und Optatus. Letzterer nennt den 13. Mai als Termin der Synode in Cirta, Augustinus überliefert dagegen den 4. März. ${ }^{83}$

Bedeutet dies nun, dass das Protokoll von Cirta niemals zu den gesta apud Zenophilum gehörte oder dass es Augustinus nur aus einem anderen Zusammenhang kannte? Die Verwendung der Bezeichnung scripta Nundinarii bei Optatus ist der einzige Hinweis auf die Überlieferung des Textes. Sie legt zwar nahe, dass das Protokoll als Beweismittel des Nundinarius im Silvanus-Prozess eine Rolle spielte, es ist jedoch ungewiss, ob der Text in den offiziellen Prozessakten auftauchte. Zumindest in der unvollständigen Fassung, die Optatus

81 Duchesne, Dossier, 629, gefolgt von Seeck (ZKG 30, 182 f.), der seine erste Einschätzung, dass die scripta Nundinarii die Konzilsakten aus Cirta selbst seien, die möglicherweise Nundinarius als Protokollführer angefertigt habe, widerrief (ZKG 10, 1889, 528 f.). Von Soden, 7; ebenso Fischer, AHC 18, 1986, 284; Kriegbaum, Kirche der Traditoren, 134; Labrousse, SC 412, 59 f.; Maier I, 112 f.; Monceaux IV, 232 f.

82 Vgl. epp. 43.5, 17; 53.4; gegen Seeck, ZKG 30, 1909, 183 mit Anm. 1.

83 Zur Datierung s. u. Exkurs: Zur Datierung des Konzils von Cirta. 
und Augustinus vorlag, war das Protokoll von Cirta als Beweisdokument untauglich, da dort über Silvanus gar keine Aussagen gemacht werden. Dennoch kann nicht ausgeschlossen werden, dass beim Prozess eine vollständige Fassung des Textes vorlag, aus der nur einzelne Teile herangezogen wurden. Relativ sicher scheint dagegen, dass Optatus das Protokoll von Cirta in seinem Dokumentenanhang mit anderen Zeugnissen zur causa Silvani zusammenfasste und diese Sammlung als scripta Nundinarii deklarierte. Insofern gehörte das Protokoll von Cirta in jene Aktensammlung des Optatus, die heute unter der Bezeichnung gesta apud Zenophilum teilweise erhalten ist. $\mathrm{Ob}$ es Teil der ursprünglichen Prozessakten war, bleibt dagegen fraglich. Die Hinweise bei Augustinus zeigen indessen, dass die Zusammenstellung des Optatus nicht die einzige Überlieferung des Protokolls darstellte.

Der ungewissen Herkunft entsprechend wurden an der Echtheit des Dokumentes immer wieder Zweifel geäußert. Nicht nur die Donatisten lehnten das Protokoll von Cirta als Fälschung ab, die Authentizität wurde auch später von einigen Historikern infrage gestellt. Während die Donatisten auf der Konferenz von 411 vor allem mit der Datierung argumentierten, ${ }^{84}$ wurden später inhaltliche Gründe angeführt: Das Dokument entstamme zum einen aus dem Dunstkreis des wenig vertrauenswürdigen Nundinarius, der mit einem falschen Beweis den Prozess gegen Silvanus für sich entscheiden wollte, zum anderen liefere das Protokoll auf engstem Raum zahlreiche Argumente für die katholischen Propaganda. Es enthalte die traditio-Geständnisse gleich einer ganzen Reihe von numidischen Bischöfen, eingeschlossen die Verdächtigungen gegenüber dem Primas Secundus von Tigisi und als Spitze der Anklage ein ungesühnter Mord des Bischofs Purpurius an seinen Neffen. Diese Häufung lasse den Text bedenklich erscheinen. ${ }^{85}$

Nachdem sich aber sowohl SEeck als auch Duchesne und MonceAux für die Echtheit ausgesprochen haben, ${ }^{86}$ wird dies in der neueren Forschung fast durchgängig akzeptiert. Ernsthafte Zweifel an den Aussagen des Protokolls von Cirta hegt indessen T.D. BARnES. Er leugnet zwar nicht die Existenz einer kleinen, informellen Bischofsversammlung in Cirta, hält es aber für unmöglich, über die Worte oder Taten der Bischöfe etwas Sicheres auszusagen, da das Dokument auf den zweifelhaften Aussagen des Nundinarius basiere. Die überlieferten Geständnisse der Bischöfe seien, so BARNES, nichts anderes als eine vorsätzliche Erfindung des Nundinarius. ${ }^{87}$

Für die Echtheit des Dokumentes sprechen jedoch gute Gründe: Die Ansicht, das Protokoll sei eine Fälschung des Nundinarius, ist in zweifacher Hin-

84 Vgl. o. Kap. 5.3.1 und unten Exkurs: Zur Datierung des Konzils von Cirta.

85 Völter, Ursprung, 94-96; Thümmel, Beurtheilung, $17 \mathrm{ff}$.

86 Seeck, ZKG 10, 1889, 524-532; Duchesne, Dossier, 629; Monceaux IV, 326; V, 6 f.

87 Barnes, JThS 26, 1975, 14-16. 
sicht zu widerlegen. Zum einen lässt sich, wie oben dargestellt, die Herkunft des Textes durch die Aussage des Optatus allein nicht sicherstellen, zum anderen spricht der Inhalt des Protokolls bei näherer Betrachtung eher für die Authentizität des Textes als dagegen. SeEck betont zu Recht, dass bei einer Fälschung wesentlich direkter und konkreter die Schuld der angeklagten Bischöfe angesprochen worden wäre. ${ }^{88} \mathrm{Im}$ vorliegenden Text sind mit Ausnahme des Purpurius die Anschuldigungen sehr vage und das Verhalten der Bischöfe kaum eindeutig zu beurteilen. Der Vergleich mit anderen Quellen zur traditio zeigt Übereinstimmungen, die - wenngleich mit Vorsicht - auf den Wahrheitsgehalt der in Cirta angesprochenen Fälle schließen lassen. ${ }^{89}$ Bei einer Fälschung durch Nundinarius sollte man zudem erwarten, dass die traditio des Silvanus von Cirta an exponierter Stelle genannt würde. Dass dies in einem nicht überlieferten Teil des Protokolls geschehen ist, kann nicht ausgeschlossen werden, ist jedoch unwahrscheinlich.

Dem gesamten Ablauf der Versammlung ist eine inhaltliche Stringenz nicht abzusprechen. Es ging bei der Synode um die Wahl und Ordination eines neuen Bischofs, und Secundus befragte die Bischöfe vor der anstehenden Weihe, ob sie für dieses Sakrament aufgrund ihres persönlichen Verhaltens in der Verfolgung würdig seien. Ungeachtet der späteren Auseinandersetzungen über die traditio ist dies ein logisches Verfahren: Secundus wollte die Heiligkeit der Sukzession erhalten und daher vermeiden, dass unwürdige Priester die Weihe spendeten. Die Frage, wie die Schuld der amtierenden Bischöfe zu sühnen sei, wurde in Cirta offensichtlich zurückgestellt, da sich eindeutige Schuldzuweisungen als unmöglich erwiesen. Für eine bewusste Fälschung zu Gunsten katholischer Propaganda scheint dieser Vorgang jedoch zu wenig akzentuiert.

Letztlich spricht auch die Unklarheit über die Datierung gegen eine Fälschung des Protokolls. Optatus' Abschrift trug sehr wahrscheinlich keine oder nur eine unvollständige Datierung, Augustins Kopien trugen eine Datierung, die nicht richtig sein konnte. Eine frühe Fälschung (etwa des Nundinarius) aber hätte mit hoher Wahrscheinlichkeit ein vollständiges und glaubwürdiges Datum getragen, um authentisch zu wirken.

Folglich ist davon auszugehen, dass unter der Leitung des Secundus von Tigisi in Cirta eine Synode stattgefunden hat und grundsätzlich von der Echtheit des überlieferten Protokolls auszugehen ist. Demzufolge kamen aus Anlass der Ordination des Silvanus ein Dutzend Bischöfe in einem Privathaus zusammen. Der Vorsitzende führte eine Befragung der Anwesenden bezüglich ihres Verhaltens in der Verfolgung durch, um die Gültigkeit des zu spendenden Sakraments der Weihe nicht zu gefährden. Diese Befragung ist in Ausschnitten im

88 Seeck, ZKG 10, 1889, 531.

89 Vgl. insbesondere den Brief des Mensurius an Secundus mit dem Bericht über die traditio in Karthago (breuic. III 25); dazu o. Kap. 6.1.1. 
Protokoll wiedergegeben. Die einzelnen Aussagen und Geständnisse geben einen Einblick in Verhaltensformen der Kleriker während der Verfolgung, und die Vertagung der Schuldfrage vermittelt einen Eindruck von dem noch ungeklärten Umgang mit unterschiedlichen Formen der Kooperation von Bischöfen mit den Behörden.

Das Datum des Konzils lässt sich heute ebenso wenig sicher ermitteln wie zur Zeit Augustins. Es fand nach dem dies traditionis in der Stadt Cirta statt. Wahrscheinlich ist auch, dass die Christen die Zeit der Verfolgung als beendet ansahen. In welchen historischen Kontext dies zu setzen ist, bleibt allerdings trotz ambitionierter Datierungsversuche offen. ${ }^{90}$

Jahrzehnte nach dieser Synode erhob Augustinus das Protokoll in den Status eines Hauptzeugnisses gegen die Absetzung Caecilians und damit gegen die Abspaltung der Donatisten. In seiner Argumentation fokussiert er den Blick der Hörer und Leser auf die Schuld der Bischöfe, insbesondere auf die Rolle des Secundus. Sein erster Vorwurf betrifft das Verfahren: Secundus habe in den Bischofswahlverfahren von Cirta einen anderen Maßstab angelegt als bei der Absetzung Caecilians in Karthago. Hier sei Caecilianus die Anhörung verweigert und als Nichtgeständiger verurteilt worden. Dort seien geständige Bischöfe dem iudicium dei überlassen worden. Sein zweiter Vorwurf trifft die Person: Secundus müsse laut Aktenlage selbst Traditor gewesen sein, wodurch er sich als Richter disqualifiziert habe. ${ }^{91}$

Beide Vorwürfe Augustins erweisen sich für den Zweck seiner Argumentation als dienlich, in der historischen Begründung jedoch als fraglich: Hinsichtlich der Argumentation begründet sich der Erfolg Augustins dadurch, dass sich die Donatisten (Cresconius und die Bischöfe im Jahr 411) auf die von ihm vorgegebene Grundlage einließen. Denn die Donatisten gingen selbstverständlich von dem dogmatischen Grundsatz aus, dass die urteilenden Bischöfe in Karthago frei von Schuld gewesen sein mussten. Dass dies nicht der Fall war, konnte Augustinus mit dem Protokoll von Cirta beweisen. Selbst wenn die Anklagen gegen Secundus auf unsicherem Fundament stehen, die Schuld einiger anderer Bischöfe ist durch das Schriftstück offensichtlich.

Doch ungeachtet der Polemik und Auseinandersetzung zwischen Augustinus und den Donatisten zeigt sich die historische Situation in einem anderen Licht. Der Vergleich des Konzils von Cirta mit dem Konzil in Karthago lässt nicht zwangsläufig darauf schließen, dass Secundus verschiedene Beurteilungsmaßstäbe gesetzt hätte, wie es Augustinus unterstellt. Vielmehr agierte Secundus in den beiden unterschiedlichen Situationen durchaus mit einem einheitlichen Anliegen:

90 Zur Datierungsfrage s. u. Exkurs: Zur Datierung des Konzils von Cirta.

91 Cresc. III 31; breuic. III 27; c. Don. 18-19; Gaud. I 47. Die schärfste Polemik gegen Secundus findet sich in ep. 43. 6-8. Vgl. o. Kap. 4.2.1. 
In Cirta ging es um die Wahl und Weihe eines neuen Bischofs, in Karthago ging es darum, eine durch einen Traditoren vollzogene Ordination zu annullieren. In Cirta diente die Befragung der Bischöfe dazu, das zu vermeiden, was in Karthago bereits geschehen war, nämlich die Weihe durch einen unwürdigen Priester. In dieser Hinsicht ist kein Widerspruch in den Verfahrensweisen von Cirta und Karthago zu sehen. In beiden Fällen achtete Secundus auf die Integrität des neuen Bischofs und auf die Rechtmäßigkeit von Wahl und Weihe; in beiden Fällen beabsichtigte er, den Verlust der kirchlichen Heiligkeit durch belastete Ordinatoren zu vermeiden. Silvanus in Cirta wurde schließlich nach Ermessen des Secundus rechtmäßig von dazu befugten Bischöfen ernannt und geweiht. Der Ordinator Felix von Abthugni hielt dagegen diesem Maßstab nicht stand, woraufhin das Konzil des Secundus Caecilians Weihe mit allen bekannten Konsequenzen für ungültig deklarierte. Aus der Sicht des Secundus ging es in beiden Fällen nicht primär um die Frage, welche der bereits amtierenden Bischöfe Schuld auf sich geladen hatten, sondern um die Würde neu berufener Bischöfe. Deshalb war es aus der Sicht des Secundus nicht entscheidend, ob sich unter den Konzilsteilnehmern in Cirta potenzielle Traditoren befanden; es ging um die Heiligkeit der Sukzession, nicht um die Buße und Korrektur gefallener Kollegen, es ging um die Zukunft der Kirche, nicht um einen blinden Rigorismus gegen Traditoren. Erst die dogmatische Erstarrung in der traditio-Frage stellte die späteren Donatisten vor das Problem, dass alle ihre Vorväter und damit auch alle Teilnehmer des Konzils von Karthago unbelastet sein mussten. Jedes Anzeichen, das eine Versündigung andeutete, mussten sie entsprechend vehement bekämpfen, wie in der Debatte um das Protokoll von Cirta sichtbar wird. Die Offenheit in der traditio-Frage vor dem Schisma von Karthago sahen zur Zeit Augustins weder Katholiken noch Donatisten.

Augustinus traf insofern mit dem historischen Dokument des Protokolls von Cirta einen wunden Punkt der Donatisten, indem er völlig zu Recht zeigte, dass geständige Traditoren bei der Absetzung Caecilians beteiligt waren. Damit waren seine Gegner einer dogmatischen Grundlage beraubt. Augustinus verkannte jedoch die historischen Gegebenheiten und ignorierte das ekklesiologisch durchaus „,ehrenwerte“ Anliegen des Secundus, indem er in seiner Polemik die traditio-Frage ohne den Kontext der Bischofsweihe thematisierte. Die Frage nach der Rechtmäßigkeit von Bischofsweihen, die sich Secundus gestellt hatte, geriet dadurch in den Hintergrund.

\subsection{Die traditio-Anklage gegen Silvanus von Cirta}

In engem Zusammenhang mit Augustins Anschuldigungen gegen Secundus steht die traditio-Anklage gegen Bischof Silvanus von Cirta. In seinen Auseinandersetzungen mit Petilianus konfrontiert Augustinus seinen Gegner mit der 
Person des Silvanus, um zu verdeutlichen, dass ein direkter Vorgänger auf dem Bischofsstuhl von Cirta ein Traditor gewesen sei. Gegenüber Cresconius, der diese Anschuldigungen anzweifelte, führt Augustinus dies nochmals aus. Generosus, einem katholischen Christen aus Cirta, gibt Augustinus ebenfalls den Hinweis, anhand des Beispiels Silvanus den Donatisten einen Makel in ihrer Bischofssukzession aufzuzeigen. ${ }^{92}$ In anderen Traktaten oder Briefen verwendet Augustinus dieses Beispiel allerdings nicht; ebenso wenig spielte es auf der Konferenz von 411 eine Rolle.

Insofern war Silvanus für Augustinus ein exemplum de choix, wie MANDouze zu Recht bemerkt, ${ }^{93}$ doch war diese Wahl durch die Quellen vorgegeben. Zweifellos wäre Augustinus für Bischöfe aus anderen Städten nicht in der Lage gewesen, derartige Beweise vorzulegen wie gegen Silvanus. Im Fall des Bischofs von Cirta konnte Augustinus auf die Prozessakten des Konsulars Zenophilus zurückgreifen, die ihm aussagekräftige Dokumente zur Verfügung stellten und seiner Interpretation dienlich waren.

Die gesta apud Zenophilum sind im Anhang des Optatus überliefert. Diese Aktensammlung enthält das Protokoll der Gerichtsverhandlung gegen Silvanus, eingeschlossen einige schriftliche Zeugnisse, die der Ankläger Nundinarius vorgelegt hatte. Das Protokoll ist unvollständig; das Ende mit dem Urteilsspruch und der Urteilsbegründung fehlt. Darüber hinaus existieren keine weiteren Quellen zum Vergleich; alle späteren Erwähnungen, etwa bei Augustinus stützen sich auf das gleiche Aktenmaterial des Prozesses. ${ }^{94}$

Anlass für den Zivilprozess vor dem numidischen Konsular Zenophilus, der am 13. Dezember des Jahres 320 in Cirta stattfand, ${ }^{95}$ waren Streitigkeiten zwischen Silvanus und dessen Diakon Nundinarius. Über die Ursachen der Auseinandersetzung ist nichts bekannt. Jedenfalls versuchte Nundinarius zunächst Silvanus bei Nachbarbischöfen in Misskredit zu bringen, indem er ihnen ein Dossier mit Schriftstücken über die Verbrechen des Silvanus zusandte, das er zuvor zusammengestellt hatte. Seine Vorwürfe lauteten auf traditio, Korruption und Unterschlagung sowie Diebstahl öffentlichen Eigentums. Silvanus exkom-

92 Vgl. c. litt. Pet. I 23; III 69; Cresc. III 31-34; ep. 54.3.

93 Mandouze, PAC, 1078.

94 Gesta apud Zenophilum (Opt. App. I). Auf eine ausführliche Darstellung des Prozessgeschehens soll hier verzichtet werden. Vgl. vor allem Y. Duval, Le gouverneur de Numidie en sa capitale. Le lieu et les acteurs du procès de l'évêque de Cirta en 320, Antiquité tardive 6, 1998,193-207; dies., Chrétiens d'Afrique, passim; vgl. auch Maier I, Nr. 29, 211-239; Monceaux IV, 228-239; Mandouze, PAC, 1078-180, s. v. Silvanus 1; de Veer, BA 31, 802-805.

95 Zur Datierung vgl. Gesta apud Zenophilum (Opt. App. I) 1. Der Text ist aufgrund einer Lücke nicht ganz eindeutig. Gegen die Emendation Monceaux' (IV 231 Anm. 6), die auf den 8. Dezember führt, vgl. die Erläuterungen Maiers (I, S. 214 f. mit Anm. 27). 
munizierte daraufhin seinen Diakon und dieser wiederum leitete mit seiner Zivilklage den Prozess ein.

Es ist bemerkenswert, dass ähnlich wie im Prozess gegen Felix von Abthugni der Statthalter sich der innerkirchlichen Auseinandersetzungen annahm. Für Zenophilus konnte der Nachweis einer traditio oder der unrechtmäßigen Wahl eines Bischofs allein kein Anlass für einen Prozess sein, vielmehr dürften die Korruptionsvorwürfe ausschlaggebend gewesen sein, vor allem aber die Beteiligung des Silvanus bei der Wahl des Maiorinus und damit seine Unterstützung für die Schismatiker der donatistischen Partei sowie möglicherweise die Sorge um die öffentliche Ruhe, die durch den umstrittenen Bischof gefährdet schien. ${ }^{96}$ Von einem „katholischen“ Bischof in Cirta ist nicht die Rede und man darf mit Sicherheit davon ausgehen, dass es im Jahr 320 noch keine Doppelbesetzung in den numidischen Städten gegeben hat, sondern lediglich Bischöfe der pars Caeciliani auf der einen und der pars Donati auf der anderen Seite. Die Durchführung des Prozesses ist insofern auch ein Beleg für das Bestreben der römischen Behörden, der Spaltung der Kirche entgegenzuwirken und somit den Anweisungen des Kaisers Folge zu leisten.

Welche Berechtigung hatten die Anklagen gegen Silvanus? Die Prozessakten enthalten Zeugenaussagen und Beweisdokumente, die Silvanus eindeutig belasten, Zeugen der Verteidigung kommen dagegen nicht vor und auch Silvanus selbst scheint vor Gericht nicht präsent gewesen zu sein. Der Konsular Zenophilus nahm die von Nundinarius aufgebotenen Zeugen nacheinander ins Verhör, wobei er sich häufig bei Nundinarius zur Klärung der Personen und ihrer Rollen informierte. ${ }^{97}$

Von diesen Zeugen trat als erster ein Grammatiklehrer namens Victor auf, ${ }^{98}$ ein Lektor der Gemeinde von Cirta, der den Acta Munati Felicis zufolge am dies traditionis zwei Kodizes und vier Hefte (quiniones) an die Behörden ausgeliefert hatte. Victor leugnete zunächst seine eigene traditio, behauptete, nicht in der

96 Insofern beurteilt Augustinus gegenüber Cresconius die Prozessentscheidung zutreffend, wenn er sagt, Silvanus sei aufgrund seines Verharrens im Schisma verurteilt worden (Cresc. III 34).

97 In dem erhaltenen Teil der Prozessakten werden insgesamt sechs Zeugen genannt: Der Grammatiklehrer Victor (Opt. App. I 5-6, 13), der (Friedhofs- ?) Gräber (fossor) Saturninus (I 14) und der Handwerker (artifex) Victor, Sohn des Samsuricus (I 14-15). Gegen Mandouze (PAC, 1035-1037) und mit Maier (I, 233 Anm. 117) handelt es sich m.E. lediglich um einen Saturninus. Dies geht aus der Sentenz des Zenophilus (Opt. App. I 17) eindeutig hervor. Dass in I 15 plötzlich vom „Diakon“ Saturninus die Rede ist, kann ein Überlieferungsfehler sein. Weitere Zeugen sind der Diakon Castus (I 18), der Subdiakon Crescentianus (I 19-20) und schließlich der Subdiakon Ianuarius (I 20). Offenbar anwesend, aber im erhaltenen Teil der Akten nicht zum Verhör geladen war auch jener Donatus, den die Bürger von Cirta als Gegenkandidat zu Silvanus gefordert hatten (I 16).

98 Zur Person: Mandouze, PAC, 1152, s. v. Victor 1. 
Stadt gewesen zu sein und gab an, auch nichts über die traditio des Silvanus zu wissen. ${ }^{99}$ Nach Konfrontation mit den schriftlichen Zeugnissen erklärte er jedoch, dass Silvanus Traditor gewesen sei und dass es deshalb auch bei der Bischofswahl zu Unruhen gekommen sei. ${ }^{100}$

Die weiteren Zeugen des Nundinarius wurden suggestiv befragt. Es ging neben der traditio um die Korruptionsvorwürfe. Letztlich bestätigten alle vorgeladenen Zeugen, dass Silvanus nach Augenzeugenberichten bzw. nach eigener Aussage einen Silberleuchter und eine silberne Kassette ausgeliefert habe, dass er in Karthago von Lucilla ein Bestechungsgeld in Höhe von 400 folles angenommen sowie einen Tuchwalker namens Victor für 20 folles zum Priester erhoben habe. Diese Gelder habe Silvanus persönlich angenommen und nicht an die Gemeinde weitergegeben. Ferner wurde bezeugt, dass Silvanus aus einem Tempel der Serapis gemeinsam mit zwei Priestern und einem Diakon Acetum gestohlen habe, das als Steuer vom Fiskus eingezogen worden war. Sein Kollege Purpurius habe bei der gleichen Aktion Fässer mitgehen lassen. Schließlich bestätigten die Zeugen die Aussagen des Nundinarius, dass Silvanus sich von zwielichtigen Anhängern aus dem Milieu von Gladiatoren und Prostituierten zum Bischof habe ausrufen lassen, während das Kirchenvolk in einem Haus auf dem Friedhof eingeschlossen worden sei.

Durch die vorgelegten schriftlichen Zeugnisse findet von diesen Vorwürfen lediglich die Auslieferung der kirchlichen Mobilien eine Bestätigung. Zentrales Beweisdokument waren jene Akten, die über die Ausführung des diokletianischen Ediktes zur Auslieferung heiliger Schriften am 19. Mai des Jahres 303 in der Stadt Cirta durch den Priester und curator civitatis Munatius Felix Zeugnis ablegen. ${ }^{101}$ In diesen Acta Munati Felicis wird ausführlich berichtet, wie Silvanus in seinem damaligen Amt als Subdiakon ohne Widerstand mit den Behörden kooperierte und die besagten Gegenstände aus der Kirche auslieferte. Allerdings handelte er damit nicht anders als sein Bischof Paulus und eine Anzahl weiterer namentlich genannter Kleriker der Stadt, die kaum Widerstand gegen die Auslieferung zeigten. ${ }^{102}$

Ferner wurden als schriftliche Beweise Briefe der Bischöfe Purpurius von Liniata (App. I 7-8) und Fortis (App. I 9-10) sowie ein Briefwechsel zwischen Silvanus und Sabinus (App. I 11-12) verlesen, in denen die Anschuldigungen des Nundinarius gegen Silvanus thematisiert werden. Diese Briefe enthalten aber keine Details über die Anklagen; sie bezeugen lediglich, dass die numidischen Bischöfe von den Vorwürfen des Nundinarius in Kenntnis gesetzt worden waren und ihnen auch weitgehend Glauben schenkten. Allerdings

99 Gesta apud Zenophilum (Opt. App. I) 5-6.

100 Gesta apud Zenophilum (Opt. App. I) 13.

101 Zur Person: Mandouze, PAC, 407, s. v. Munatius Felix; Maier I, 30 f.

102 Acta Munati Felicis (Opt. App. I) 3-5; vgl. o. Kap. 3.4.2.1. 
wollten sie daraus keine Konsequenzen ziehen und Schritte gegen Silvanus einleiten. Einhellig beschworen sie die Einheit und den Frieden der Kirche: Der Disput in der Kirche von Cirta solle friedlich beigelegt werden; nichts sei schlimmer als die kirchlichen Streitigkeiten nach außen zu tragen und so ein schlechtes Bild abzugeben. Diese Standpunkte lassen erkennen, wie sensibel die Kirche auf neue Auseinandersetzungen im Inneren reagierte. Angesichts der angespannten Situation nach der Doppelwahl in Karthago sollten weitere Meinungsverschiedenheiten auf jeden Fall vermieden werden.

Während die numidischen Bischöfe nichts gegen Silvanus unternahmen, sprach Zenophilus aufgrund der vorgelegten Beweise Silvanus schuldig in allen Punkten der Anklage und verhängte offensichtlich die Exilstrafe gegen ihn. ${ }^{103}$ Es ist heute nicht möglich, den Wahrheitsgehalt der einzelnen Zeugnisse zu beurteilen. Es ist zu berücksichtigen, dass bereits während des Prozesses die behandelten Ereignisse über 15 Jahre zurücklagen; die Glaubwürdigkeit und Aufrichtigkeit der von Nundinarius aufgebotenen Zeugen bleibt anfechtbar. So erscheint die Anklage, Silvanus sei auf den Schultern des Gladiators Mutius zum Bischof erhoben worden, geradezu als Topos einer Diskreditierung. Ebenso wirken die Vorwürfe auf Diebstahl und Korruption konstruiert. Der Verlauf des Prozesses zeigt, dass die Zeugen im Kreuzverhör schwerlich etwas anderes hätten sagen können, als die Anklagen zu bestätigen.

Abgesehen von den sehr fragwürdigen Vorwürfen in der Verhandlung bleibt die Anklage der traditio bestehen, die sich auf ein glaubwürdiges, schriftliches Dokument stützen konnte. Demnach lieferte Silvanus Gegenstände aus der Kirche von Cirta aus. Diese Tatsache wurde ihm offensichtlich bei seiner Wahl zum Bischof nicht angelastet. So wie anderen amtierenden Bischöfen auf der Synode von Cirta Verfehlungen zugestanden wurden, konnte auch Silvanus Bischof werden, trotz dieser Art von traditio.

Allein auf diesen eindeutigen Nachweis der traditio kam es Augustinus an, wenn er die Anschuldigungen vortrug. Er interessierte sich nicht für den persönlichen Kleinkrieg des Nundinarius gegen Silvanus, sondern lediglich für die Tatsache der Fehlbarkeit eines von den Donatisten anerkannten Bischofs. Damit erfüllte Augustins traditio-Nachweis gegen Silvanus die gleiche Funktion wie das Protokoll von Cirta. Es diente als Angriff auf die dogmatische Maßgabe der Donatisten seiner Zeit. Gleichzeitig zeigt sich aber auch die gleiche Problematik in der Argumentation wie mit dem Protokoll von Cirta. Das tatsächliche Vergehen des Silvanus hatte im Jahre 320 für die numidische Kirche keine weiterreichende Bedeutung; die Einheit der Kirche stand auch für nachmalige Donatisten im Vordergrund. Erst die Donatisten späterer Generationen mussten die Historizität der traditio leugnen, um ihr ekklesiologisches Selbstverständnis nicht zu gefährden.

103 Cresc. III 34; vgl. Grasmück, Coercitio, 87. 


\section{Donatistische Traditionen über Verfolgung und Martyrium}

Die Geschichte der Kirche war für die Donatisten auch nach der Konstantinischen Wende eine Geschichte der Unterdrückung und Verfolgung. Nach den „Heiden“ waren es nun die Traditoren und ihre Verbündeten, die gegen die Christen vorgingen. Entsprechend prägten Berichte von Bekennern und Märtyrern die Erinnerung und das Selbstverständnis der Donatisten. In allen bekannten, von Donatisten verfassten Schriften wird die Verfolgung als zentrales Thema angesprochen.

Augustins Schriften enthalten keine ausführlichen historischen Berichte über die Verfolgung der Donatisten. Verständlicherweise lag es nicht im Interesse Augustins, die Vorwürfe der Donatisten im Detail zu zitieren. Eine Ausnahme bildet der von Augustinus vollständig wiedergegebene erste Brief Petilians, der somit ein wichtiges Zeugnis hinsichtlich des donatistischen Verständnisses von Verfolgung darstellt. ${ }^{104}$ Obwohl die Vorwürfe der persecutio häufig schlagwortartig fallen, zeichnen sich dennoch in der Menge der pauschalen Anklagen zwei Schwerpunkte in der donatistischen Überlieferung ab: Die Verfolgung unter Konstantin und die Verfolgung unter Constans, die so genannte macarianische Verfolgungszeit. ${ }^{105}$

\subsection{Die Verfolgung unter Konstantin}

Hinsichtlich einer Verfolgung unter Konstantin sind konkrete Hinweise auf donatistische Traditionen rar in Augustins Schriften. Es lässt sich allerdings erschließen, dass Parmenianus von ersten Verfolgungen der Donatisten unter Konstantin sprach. Seiner Ansicht nach war Ossius von Cordova der Anstifter gewaltsamer Maßnahmen und Verurteilungen von Donatisten. ${ }^{106}$ Cresconius dagegen erwähnt im Zusammenhang mit dem Prozess gegen Silvanus von Cirta eine Verfolgung: Silvanus sei während der Verfolgung unter Ursacius und Zenophilus ins Exil verbannt worden. ${ }^{107}$ Petilianus schließlich nennt in einer Aufzählung von Verfolgern ebenfalls den Namen Ursacius in einem Atemzug mit Macarius und anderen comites auf Seiten der katholischen Partei. ${ }^{108}$

Bei Optatus von Mileve finden sich einige weitere Informationen über den Vorwurf gegen Ursacius. Gemeinsam mit dem comes Leontius, so die donatis-

104 C. litt. Pet. II 171-223; III 29.

105 Die Gesetzgebung seit 405 galt den Donatisten als neue Verfolgungszeit; vgl. o. Kap. 2.2.2.

106 C. ep. Parm. I 13-14, 18.

107 Cresc. III 34; vgl. o. Kap. 3.4.1.

108 C. litt Pet. II 202; III 29. 
tische Anschauung, habe dieser einer großen Menge Menschen Schaden zugefügt. ${ }^{109}$ Diese Verfolgung unter Ursacius, so Optatus an anderer Stelle, sei die früheste Aktion gegen Donatisten gewesen. ${ }^{110}$ In der Auflistung der Verfolgernamen, die in der donatistischen Widerlegung des katholischen Mandats auf der Konferenz von 411 enthalten ist, werden ebenfalls Ursacius sowie Leontius an den ersten beiden Stellen noch vor Macarius genannt. ${ }^{111}$ Die Donatisten verbanden also die erste Welle der Verfolgung mit den Namen Ursacius und Leontius.

Von katholischer Seite sind die Maßnahmen des Kaisers gegen die donatistische Kirche, die schon bald nach dem Urteil Konstantins in der causa Caeciliani eingeleitet worden waren, nur durch Augustinus bezeugt. Dieser spricht mehrfach von einem Gesetz Konstantins, das die Rückgabe der Basiliken und die Wiederherstellung der Kircheneinheit forderte und die Konfiszierung des Eigentums androhte. ${ }^{112}$ Das Reskript an Verinus vom Jahr 321 erlaubte die Rückkehr von Bischöfen aus dem Exil, die folglich zuvor aufgrund ihres Widerstandes verbannt worden waren. ${ }^{113}$ Weitere Einzelheiten über die Umsetzung der kaiserlichen Verfügung finden sich aber weder bei Optatus noch bei Augustinus.

Die Hintergründe der stereotypen Anklagen der Donatisten gegen die Personen Ursacius und Leontius bis in die Zeit Augustins lassen sich jedoch dank einer erhaltenen donatistischen Predigt erschließen. In dem sermo de passione sanctorum Donati et Aduocati eines unbekannten Autors wird ein Ereignis beschrieben, das sich in die Zeit Konstantins einordnen lässt: ${ }^{114}$ Der Verfasser bekundet die Absicht, mit seiner Predigt die Erinnerung an die Opfer jener Verfolgung zu wahren, die unter dem Deckmantel der christlichen Reli-

109 Opt. III 4.12: Querelam per ordinem deponitis sub Leontio, sub Vrsacio iniuriatus esse quam plurimos, [...].

110 Opt. III 10.9: Fuit primo tempestas sub Vrsacio.

111 Gesta conl. Carth. III 258 (Z. 285-287).

112 Ep. 105.9; 88.3; 93.14; vgl. o. Kap. 4.2.2; c. litt. Pet. II 205; c. ep. Parm. I 13, 18.

113 Breuic. III 40, 42; c. Don. 54, 56; ep. 141.9; vgl. u. Kap. 7.4.1. Vgl. Grasmück, Coercitio, $84 \mathrm{f}$; Monceaux IV, $197 \mathrm{f}$.

114 Edition: Migne, PL 8, 752-758; Maier I, Nr. 28, 198-21; englische Übersetzung und Kommentar bei Tilley, Donatist Martyr Stories, 51-60. Vgl. Monceaux V, 60-69; Frend, Donatist Church, $159 \mathrm{f}$., Tilley, Bible, $60 \mathrm{f}$. Zum Folgenden vgl. insbesondere die gründliche Analyse des Textes (mit deutscher Übersetzung) von Knut Schäferdiek (Der Sermo de passione sanctorum Donati et Aduocati als donatistisches Selbstzeugnis, in: Oecumenica et Patristica, Stuttgart 1989, 175-198). Schäferdiek hält den Zeitpunkt der Abfassung für nicht eindeutig bestimmbar (Sermo, $176 \mathrm{f}$.), sieht jedoch eine Nähe zu den erwähnten Ereignisse und spricht sich für eine Datierung vor der Verfolgung unter Macarius aus. Monceaux (IV, 490) datiert auf um 320 und postuliert ohne weitere Argumente, dass Donatus der Verfasser der Predigt gewesen sei (V, 61 f.). 
gion geführt worden sei. ${ }^{115}$ Allgemein spricht er davon, dass mit Hilfe der weltlichen Macht Zwang ausgeübt und Strafandrohungen gegen jene ausgesprochen würden, die sich noch nicht haben verführen lassen. ${ }^{116}$ Es werden eine Anzahl von Untaten aufgezählt: Raub, Plünderungen, Vergewaltigungen und Misshandlungen, die hätten erduldet werden müssen. ${ }^{117}$

Im Zentrum der Predigt steht jedoch die Darstellung eines Ereignisses, das sich in Karthago noch zur Amtszeit Caecilians abgespielt haben soll: Auf Betreiben Caecilians hätten der comes Leontius, der dux Ursacius sowie ein Tribun namens Marcellinus ${ }^{118}$ eine große Gruppe von Christen, die sich in einer Basilika versammelt hatten, angegriffen und ohne Rücksicht auf Alter oder Geschlecht niedergeknüppelt. Es habe zahlreiche Tote und Verletzte gegeben. Marcellinus habe dabei dem anwesenden Bischof von Sicilibba das Schlüsselbein verletzt, der Bischof aus Avioccala habe das Martyrium erlitten, ebenso ein Katechume. ${ }^{119}$ Das versammelte ,Volk Gottes“ aber habe sich ohne Furcht den Angreifern gestellt; so seien diese Christen Bekenner und Märtyrer in der Nachfolge Jesu Christi geworden. ${ }^{120}$

In seiner Bewertung der Ereignisse verdeutlicht der Verfasser, dass Caecilianus und die Traditoren die Urheber und Anstifter der Gewalt seien. Er stellt die Unheiligkeit dieser vermeintlichen Christen und ihre Verführung durch den Teufel heraus und warnt seine Hörer davor, den Gegnern zu glauben, nur weil

115 S. pass. Don. 1. - Der Anlass für die Predigt ist vermutlich eine Gedächtnisfeier zum Jahrestag der Märtyrer der im Folgenden beschriebenen Verfolgungsmaßnahmen (s. pass. Don. 9). Das am Beginn des Textes überlieferte Datum, der 12. März, wäre dann sowohl Datierung für die Predigt als auch für die erwähnten Martyrien.

116 S. pass. Don. 3.

117 S. pass. Don. 5.

118 S. pass. Don. 2. - Dieser Marcellinus ist kaum mit dem Marcellinus des Jahres $411 \mathrm{zu}$ identifizieren, wie Seeck (Geschichte III, 517 f.) glaubt. Vgl. Mandouze, PAC, 671, s. v. Marcellinus 1.

119 S. pass. Don. 7-9, 11-12. Möglicherweise beziehen sich die in der Überschrift genannten Namen Donatus und Advocatus auf die beiden im Text nicht namentlich erwähnten bischöflichen Märtyrer. Vgl. Schäferdiek, Sermo, 175. Anders Maier (I, 201 Anm. 29), der die Auffassung Monceaux' (V, 64 f.) übernimmt, dass der Name „Advocatus" auf eine Fehlinterpretation des Wortes Avioccalensis zurückgehe, folglich der erwähnte Bischof aus Avioccala Donatus hieß. Vgl. auch Mandouze, PAC, 303, s. v. Donatus 6. - Da bei der Versammlung in Karthago auch auswärtige Bischöfe anwesend waren, könnte es sich um ein überregionales Treffen von Donatisten gehandelt haben (Schäferdiek, Sermo, 179). Beide erwähnten Orte liegen in Africa proconsularis; vgl. Lepelley, Cités II, 162 f. (zu Sicilibba, ca. 45 km westlich von Karthago); Lancel, SC 373, 1461. - Tilley (Bible, 60) meint, die Soldaten hätten die Donatisten unter dem Vorwand eines Gottesdienstes zusammengetrieben, die Basilika verriegelt und anschließend die Menge exekutiert. Für diese Darstellung sehe ich keine Grundlage im Text.

120 S. pass. Don. 6-14. 
sie vorgäben, katholisch zu sein und für die Kircheneinheit zu kämpfen. ${ }^{121}$ In dem Traditor Caecilianus sieht er den wahren Mörder, der für das Blut der Märtyrer verantwortlich sei und der nicht gezögert hätte, nach dem Blutbad die Basilika für sich zu beanspruchen. ${ }^{122}$ Die nur kurz namentlich genannten Verantwortlichen der Militäraktion sind für den Verfasser lediglich Statisten, ${ }^{123}$ während er im Zusammenhang mit dem Märtyrergedenken in aufschlussreicher Formulierung von der „caecilianischen Verfolgung“ spricht. ${ }^{124}$

Da der Verfasser ganz offensichtlich mit Stereotypen und Topoi in den Angriffen gegen die Katholiken arbeitet, gezielt gegen Caecilianus und seine Kirche polemisiert und die Predigt rhetorisch ausgestaltet, ${ }^{125}$ bleiben zwar Zweifel am Wahrheitsgehalt der Darstellung, doch dürfte sie auf einer historischen Grundlage beruhen. Außerdem gibt die Quelle Einblick in die Art und Weise der Donatisten, einschlägige Erfahrungen von Verfolgung und Unterdrückung zu interpretierten und polemisch zu nutzten. ${ }^{126}$

Unverkennbar war es dieser Einsatz in Karthago, der Ursacius und Leontius den zweifelhaften Ruhm bei den Donatisten einbrachte, auch wenn sie in der Predigt nur beiläufig als verantwortliche Militärs genannt werden. ${ }^{127}$ Darüber hinaus kann man nur vermuten, dass es ähnliche Berichte über Einsätze militärischer Gewalt gab, die zusätzlich zur Kritik an Leontius und Ursacius führten, wie es sich etwa in Cresconius' Darstellung in Bezug auf die causa Silvani widerspiegelt. Es ist aber unwahrscheinlich, dass über diese „Verfolger“ viele unterschiedliche Informationen bekannt waren. Die Anspielung bei Optatus

121 S. pass. Don. 1-3, 5, 12. - Schäferdiek (Sermo, 180-184) betont zu Recht die Absicht des Autors, die eigene Kirche (der Märtyrer) von der Kirche der Traditoren abzugrenzen, zur Stärkung und Vergewisserung der eigenen Identität.

122 S. pass. Don. 10.

$123 \mathrm{Ob}$ es sich beim comes Leontius um den comes Africae oder um einen Sonderbeauftragten handelte, ist nicht sicher zu sagen. Leontius ist in keinem anderen Zusammenhang in den Quellen erwähnt. Ebenso fehlen zu Ursacius, der als dux offensichtlich den Befehl über die eingesetzten Soldaten führte, weitere Zeugnisse. Zu den Personen: PLRE I, 984, s. v. Vrsacius 1; 499 f., s. v. Leontius 4; Mandouze, PAC, 632, s. v. Leontius 2; 1235 , s. v. Vrsacius.

124 S. pass. Don. 2, 8-11.

125 Maßgeblich ist, wie Schäferdiek (Sermo, 183) richtig bemerkt, dass „für das donatistische Selbstverständnis dauerhaft wirksame Feindbildstereotyp des traditor und persecutor", das hier auf Caecilianus projiziert wird. Zu der Verwendung von Bibelstellen und alttestamentlichen Bildern vgl. Tilley, Bible, $64 \mathrm{f}$., $67 \mathrm{f}$.

126 Zur Kritik am Text vgl. Grasmück, Coercitio, 85 Anm. 403; Maier I, 198-200. Schäferdiek (Sermo, 175) wendet sich gegen eine pauschale Verurteilung der Quelle (etwa durch Seeck, Geschichte III, 517 f.) und verweist mit Recht auf den Quellenwert als donatistisches Selbstzeugnis.

127 Erstaunlicherweise wird der Tribun Marcellinus in den späteren Anschuldigungen nicht mehr erwähnt, obwohl seine Gewalttätigkeiten in Gegensatz zu den anderen Befehlshabern zweimal herausgestellt werden (s. pass. Don. 7, 13). 
von Mileve bezieht sich eindeutig auf die in der Predigt beschriebenen Vorgänge. Zudem war es in der polemischen Literatur allgemeiner Brauch, einmalige Ereignisse zu verallgemeinern und aufzubauschen, so dass tatsächlich lediglich das berichtete Ereignis in Karthago jene donatistische Tradition begründete, die Ursacius sowie Leontius in die Reihe der Christenverfolger stellte. ${ }^{128}$ Ebenso wie bei den Anklagen gegen die Traditoren fokussierten die Donatisten ihre Anklagen gegen Verfolger auf bestimmte Personen, deren Namen pars pro toto für die Verfolgungen standen. Und diese Namen verfestigten sich in der donatistischen Tradition.

Auch wenn die Überlieferung der Namen lediglich auf ein einziges Ereignis zurückgeht, so bedeutet dies nicht, dass es keine weiteren Verfolgungsmaßnahmen gegen Donatisten gegeben hätte. Die Aufzählung unterschiedlicher Gewalttaten gegen Donatisten in dem sermo belegt, dass es andere Erfahrungen mit Zwangsmaßnahmen und gewaltsamen Vorgehen gab - zu welchem Zeitpunkt und unter welchen Umständen auch immer -, die im Bewusstsein der Donatisten verankert waren.

So lässt sich zwar weder aus diesem Zeugnis noch aus den anderen vorhandenen Quellen eine blutige Verfolgung der Donatisten unter Konstantin ableiten, aber es ist sicher, dass ausgehend von dem Gesetz Konstantins zur Wiederherstellung der Kircheneinheit sowohl mit zivilen Rechtsmitteln als auch mit Unterstützung des Militärs einzelne Maßnahmen gegen donatistische Bischöfe und Gemeinden durchgeführt wurden. Gewaltsames Vorgehen gegen donatistische Versammlungen dürften indes nicht die Regel gewesen sein. Gerade die Herausstellung von Leontius und Ursacius lassen auf die Ausnahmestellung des Ereignisses in Karthago schließen. Vielmehr gab es gezielte Prozesse und Verbannungen donatistischer Bischöfe sowie Maßnahmen gegen öffentlichen Widerstand, in ähnlicher Form wie sie nach dem Unionsedikt von 405 zum Tragen kamen. Im Hinblick auf die weitere Ausbreitung der Donatisten ist es kaum vorstellbar, dass donatistische Gemeinden und Basiliken in den Jahren 317 bis 321 in größerem Umfang katholisch wurden. Nicht zuletzt war auch die Aufgabe der Einheitsbemühungen im Mai 321 das Eingeständnis eines Misserfolgs. $^{129}$

128 Vgl. etwa Augustins Verallgemeinerung der Taten des Optatus von Thamugadi oder der Fall des Crispinus von Calama; o. Kap. 2.2.1. Vgl. Alexander, ZAC 2, 1998, $252 \mathrm{f}$.

$129 \mathrm{Zu} \mathrm{Recht} \mathrm{vorsichtig} \mathrm{interpretierend} \mathrm{Grasmück} \mathrm{(Coercitio,} 85$ f.); Frend (Donatist Church, 160) vermutet richtig, dass außerhalb Karthagos die Verfolgung nicht sehr streng gewesen sein konnte. 


\subsection{Die Verfolgung durch Macarius}

Die Zeit des Kaisers Constans verbanden die Donatisten mit dem Namen Macarius. Die gewaltsamen Übergriffe auf ihre Kirchen und Anhänger, die von Macarius durchgeführt worden sein sollen, prägten das Vokabular der Donatisten: Sie sprachen von der Macariana persecutio oder Macariana tempora ${ }^{130}$ ihre katholischen Gegner bezeichneten sie von nun an auch als pars Macarii und die katholische Kirche als Macariana ecclesia. ${ }^{131}$

Augustinus musste sich in seinen Gesprächen und Briefwechseln mit Donatisten häufig gegen Angriffe verteidigen, dass die Katholiken durch ihre Unterstützung des Macarius selbst zu Verfolgern geworden seien. Bereits in seinen ersten Schriften zum Donatismus tauchen die Anklagen über die Verfolgung des Macarius auf, wodurch die Brisanz dieser Frage für das Schisma verdeutlicht wird. ${ }^{132}$ Cresconius erwähnte den Märtyrer Marculus, der ein Opfer der blutigen Verfolgung des Macarius geworden sei, außerdem noch drei weitere Opfer, die Augustinus allerdings nicht namentlich wiedergibt. ${ }^{133}$ Selbstverständlich findet sich Macarius in den Verfolgerlisten bei Petilianus und im Jahr 411. ${ }^{134}$ Alles in allem wird deutlich, dass die Vorkommnisse der macarianischen Verfolgung für die Donatisten einen tiefen Einschnitt in den Beziehungen zwischen den beiden Kirchen bedeutete: Mit Macarius sind die katholischen Traditoren endgültig auch zu Persecutoren geworden. ${ }^{135}$

Im Wesentlichen geben drei schriftliche Quellen nähere Auskunft über die Ereignisse der macarianischen Verfolgung: Auf katholischer Seite berichtet Optatus von Mileve, dessen Darstellung jedoch sehr stark apologetisch ausgerichtet ist, so dass sie ebenso vorsichtig betrachtet werden muss wie die beiden erhaltenen Märtyerberichte aus der donatistischen Überlieferung. Die Widersprüchlichkeit der Texte erschwert die Rekonstruktion des Geschehens und viele Fragen sind bis heute nicht geklärt. Unabhängig davon stellt sich hier jedoch die Frage nach den Hintergründen der späteren donatistischen Anklagen. ${ }^{136}$

130 Ep. 23.6; 44.4-5; 93.43; en. Ps. X 5; vgl. gesta conl. Carth. I 187, Z. 33 f. (tempora Macarii).

131 C. litt. Pet. II 92, 94, 108; ep. 49.3; 87.10.

132 Ps. c. Don. 144, 151-153, 164-165; ep. 23.6; 44.4-5.

133 Cresc. III 54. - Vielleicht bezog sich Cresconius auf Donatus von Bagaï und die Märtyrer Isaac und Maximianus, die bei den Donatisten zu den Opfern des Macarius gezählt wurden (vgl. dazu unten).

134 C. litt. Pet. II 202; III 29; gesta conl. Carth. III 258 (Z. 286).

135 Vgl. die Argumentation von Fortunius (ep. 44.5) und Petilianus (c. litt. Pet. II 92).

136 Eine vollständige Darstellung der Ereignisse führt an dieser Stelle zu weit. Vgl. dazu Grasmück, Coercitio, 112-132; Frend, Donatist Church, 177-182; Monceaux IV 33-38, $241 \mathrm{f} ., 246-248$. 
Wahrscheinlich waren es immer wieder aufflammende Unruhen zwischen Anhängern der Donatisten und Katholiken, darunter auch Übergriffe der Circumcellionen, die Kaiser Constans dazu bewogen, in Afrika religionspolitisch tätig zu werden. Spätestens im Frühjahr des Jahres 347 erließ er ein Gesetz, in dem erneut die Wiederherstellung der Kircheneinheit in Afrika gefordert wurde. ${ }^{137}$ Auf Anweisung des Constans begaben sich die Sonderbeauftragten Macarius und Paulus in die afrikanischen Provinzen, um für die Umsetzung der Bestimmungen zu sorgen. ${ }^{138}$ Zunächst sollte dies mit friedlichen Mitteln geschehen. Die Gesandten zogen durch die afrikanischen Städte und versuchten, mit Geld für die Armen und Geschenken für die Kirchen den Donatisten die Einheit schmackhafter zu machen. Allerdings stießen sie bei den Donatisten auf Widerstand. Donatus, noch immer Bischof in Karthago, entlarvte das Ansinnen der kaiserlichen Beamten als perfiden Bestechungsversuch und wies sie radikal zurück. Er schrieb einen Brief an seine Kollegen, in dem er vor Macarius und Paulus warnte und zur Standhaftigkeit aufrief. ${ }^{139}$

Dies ist die Ausgangssituation für jene drei Ereignisse, die die donatistische Überlieferung prägen sollten. Das erste Ereignis berichtet Optatus von Mileve: Der donatistische Bischof der numidischen Stadt Bagaï namens Donatus, offenbar ein besonderer Glaubenseiferer, beabsichtigte, den kaiserlichen Gesandten keinen Zutritt in seine Kirche zu gewähren. Er organisierte mit seiner Gemeinde den Widerstand und zog auch Gruppen von Circumcellionen zu diesem Zweck zusammen. Macarius und Paulus, denen dies zu Ohren gekom-

137 Dieses Gesetz ist nicht überliefert, aber mehrfach indirekt bezeugt: Ps. c. Don. 151-152; Cresc. III 56-57; ep. 105.9; Conc. Carth. $348 / 49$ exord. (Munier, CCL 149, S. 3); Opt. II 15; III 1; Passio Max. et Isaac 3; Passio Marculi 3-4, 11. Vgl. Monceaux IV, 241 f.; Tengström, Donatisten und Katholiken, $93 \mathrm{f}$ - - Gegen die oftmals vertretene Ansicht, dass vor Erlass des Gesetzes Donatus von Karthago bei Constans die Anerkennung als rechtmäßiger Bischof von Karthago gefordert habe (vgl. etwa Seeck, Geschichte III, 336; Frend, Donatist Church, 177; zuletzt noch Tilley, Bible, 69), wendet sich zu Recht Grasmück (Coercitio, 113 Anm. 569).

$138 \mathrm{Zu}$ den Personen: PLRE I, 524 f., s. v. Macarius 1; 683, s. v. Paulus 2; Mandouze, PAC, $655-658$, s. v. Macarius 1; 839-841, s. v. Paulus 2. - Über den offiziellen Rang der beiden Sonderbeauftragen ist nichts bekannt. Vielleicht waren sie notarii. - Eine genaue Datierung ist nicht möglich: Terminus post quem ist nach ep. 44.6 das Konzil von Serdica des Jahres 343, Terminus ante quem das katholische Konzil von Karthago unter der Leitung des Bischofs Gratus, das spätestens im Jahr 348, vielleicht aber schon 345 stattfand (vgl. Munier, CCL 149, XIX; Maier I, 291 f.). Die überlieferten Märtyrerakten weisen in das Jahr 347 (Passio Isaac 12; vgl. Alexander, ZAC 2, 1998, 253 f.; Maier I, 256 Anm. 4; Mandouze, PAC, 655, 839 f.; Monceaux IV, 491 f.). - Zur folgenden Darstellung vgl. Monceaux IV 33-38, 241 f., 246-248.

139 Opt. III 3; vgl. auch c. ep. Parm. I 18. - Gegen Grasmück (Coercitio, 112 f.) halte ich es für unwahrscheinlich, dass Paulus und Macarius tatsächlich den Kirchen nur Geschenke überbringen sollten. Dies ist eine Beschönigung des Optatus aus apologetischen Gründen; s. auch Anm. 141. 
men war, hatten entsprechend eine verstärkte militärische Unterstützung vom comes Silvester angefordert und erhalten. Nachdem ein Vorauskommando der Soldaten in Bagaï misshandelt worden war, fielen deren erzürnte Kameraden in die Stadt ein und übten blutige Rache. ${ }^{140}$ Auch Donatus von Bagaï wurde getötet und galt den Donatisten seither als Märtyrer. ${ }^{141}$

Das zweite Ereignis berichtet die donatistische passio Maximiani et Isaac. ${ }^{142}$ Der Verfasser erzählt eine Begebenheit, die sich im August des Jahres 347 in Karthago zugetragen haben soll: Der donatistische Laie Maximianus habe auf

140 Opt. III 4. - Vgl. Mandouze, PAC, 304 f., s. v. Donatus 8. - Silvester ist ansonsten nicht bekannt. Wahrscheinlich war er comes Africae. Vgl. PLRE I, 842, s. v. Siluester; Mandouze, PAC, 1083, s. v. Silvester.

141 Opt. III 6. Die Donatisten verbreiteten die Nachricht, Donatus sei in einen Brunnen geworfen worden; vgl. Aug. Io. eu. tr. XI 15. - Optatus' Darstellung dieser Ereignisse ist aufgrund ihrer Polemik sehr kritisch zu betrachten. Denn Optatus verteidigt sich in Buch III gegen Parmenians Anschuldigung, die katholische Kirche habe das militärische Eingreifen gegen die Donatisten aktiv gefordert (III 1, vgl. IV 1). Er behauptet dagegen, dass zum einen die katholische Kirche nichts mit dem Handeln der kaiserlichen Beauftragten zu tun hätte, zum anderen die Bischöfe Donatus von Karthago und Donatus von Bagaï die in friedlicher Absicht operierenden Gesandten Macarius und Paulus derart provoziert hätten, dass die Situation eskalierte. Die Gewalt der Militärs sei also von den Donatisten selbstverschuldet gewesen (III 1). Zweifellos hatte der gewaltsame Widerstand des Donatus in Bagaï die Auseinandersetzung verschärft, aber auf der anderen Seite zeigt die feste Absicht des Macarius und Paulus, trotz des Widerstandes mit einer verstärkten Eskorte nach Bagaï zu ziehen, dass es nicht, wie Optatus behauptet, allein um das Verteilen von Almosen ging, sondern von vornherein um die Wiederherstellung der Kircheneinheit, notfalls auch mit Gewalt. - Vgl. dazu ausführlich: G. A. Cecconi, Elemosina e propaganda. Un' analisi della Macariana persecutio nel III libro di Ottato di Milevi, REAug 36, 1990, 42-66; vgl. auch Alexander, ZAC 2, 1998, 259-261; Labrousse, SC 413, 42-66; Monceaux V, 282-296.

Ein Teil der Forschung geht davon aus, dass Constans das Gesetz zur Kircheneinheit erst erlassen hätte, nachdem Paulus und Macarius auf gewaltsamen Widerstand gestoBen seien (vgl. Grasmück, Coercitio, 117 f.; Maier I, 257). Unter Berücksichtigung der Argumentationsabsichten des Optatus trifft dies nicht zu. Optatus erwähnt jenes Gesetz des Constans an keiner Stelle explizit, aber er bezeichnet die Beauftragten des Kaisers als operarii unitatis (III 1.1; 4.13; 5.1), und es kann kein Zweifel bestehen, dass Paulus und Macarius die Kircheneinheit im Auftrag des Kaisers herstellen sollten. Optatus unterschlägt das kaiserliche Gesetz, um in seiner Darstellung den friedlichen Charakter der Gesandtschaft herauszustellen. Doch ist dies eine Verzerrung der Situation: Die Donatisten sollten zunächst mit Geldmitteln gelockt werden, bei anhaltendem Widerstand gegen die Einheit wurden die üblichen Strafen verhängt: Konfiszierungen und vor allem Verbannung der Bischöfe.

142 Edition: Maier I, Nr. 36, 259-275; vgl. Tilley, Donatist Martyr Stories, 61-75; Bible, 70-76; Monceaux V, 82-96. Zum Folgenden vgl. Grasmück, Coercitio, 118-122; Mandouze, PAC 609 f., s. v. Isaac 1; 718 f., s. v. Maximianus 2. - Die Passio ist in die Form eines Briefes gekleidet. Als Verfasser wird ein Macrobius genannt, der vielleicht mit dem gleichnamigen donatistischen Bischof von Rom zu identifizieren ist. Vgl. Opt. II 4; Mandouze, PAC, 662, s. v. Macrobius 1. 
einen Platz der Stadt, wo das Edikt des Prokonsuls zur Umsetzung des kaiserlichen Erlasses der Kircheneinheit veröffentlich worden war, den Anschlag heruntergerissen und zerstört. Daraufhin sei er festgenommen und öffentlich gefoltert worden. ${ }^{143}$ Unter den Zuschauern habe sich auch ein gewisser Isaac befunden, der das Geschehen mit den Worten kommentiert habe: „Traditoren, kommt, rettet den Wahnsinn eurer Einheit!"144 Wegen dieser Provokation sei auch er verhaftet und gefoltert worden. Schließlich seien Maximianus und Isaac gemeinsam zu Märtyrern ihres Glaubens geworden. ${ }^{145}$

Das dritte Ereignis aus dieser Zeit ist das Martyrium des numidischen Bischofs Marculus. ${ }^{146}$ Gemeinsam mit neun anderen Kollegen, so die Darstellung in der Passio Marculi, sei Marculus von einem numidischen Konzil zu Macarius und Paulus gesandt worden, um gegen die erzwungene Kircheneinheit zu protestieren. ${ }^{147}$ Die Gesandten seien von Macarius verhaftet, an Säulen gebunden und geschlagen worden. Anschließend habe man die Gefangenen auf der Reise durch Numidien mitgeführt und zur Demütigung öffentlich vorgeführt. ${ }^{148}$ An der Festung Nova Petra schließlich sei Marculus am 29. November 347 hingerichtet und von einem Felsen gestoßen worden. ${ }^{149}$

So unterschiedlich diese drei Schlaglichter auf die macarianische Verfolgung sind, so bezeichnend sind sie dennoch für das Selbstverständnis und die darauf aufbauende Tradition der Donatisten: Eine tiefe Furcht, zur Einheit mit den Traditoren gezwungen zu werden, lässt sich als Grundhaltung bei den Donatisten feststellen. Diese Furcht führte zu einer Abwehrhaltung, die sich zum Teil in offenem Widerstand äußerte. Was den Katholiken und Obrigkeiten lediglich als Maßnahme gegen öffentliche Provokation und Aufruhr galt, bedeutete für die Donatisten eine Zwangsvollstreckung zur Einheit mit gewaltsamen Mitteln. In ihren Augen führten die weltlichen Obrigkeiten Krieg gegen die Kirche, und die Kirche der Traditoren sahen sie als Urheber dieser neuen Verfolgung der wahren Kirche. ${ }^{150}$

143 Passio Max. et Isaac 4-5.

144 Passio Max. et Isaac 6: Traditores, uenite, saluate uestrae unitatis insaniam!

145 Passio Max. et Isaac 6-17. In der Passio wird ausführlich dargestellt, wie Maximianus und Isaac zunächst deportiert werden sollten, dann ihre Leichname im Meer versenkt, schließlich ihre Körper wundersam am Ufer angespült wurden, damit sie von ihren Brüdern bestattet werden konnten.

146 Edition der passio benedicti martyris Marculi: Migne, PL 8, 760-766; Maier I, Nr. 37, 275-291; vgl. Tilley, Donatist Martyr Stories, 77-87; Monceaux V, 69-81. Zum Folgenden vgl. Grasmück, Coercitio, 123-126; Mandouze, PAC, 696 f., s. v. Marculus; Tilley, Bible, $71 \mathrm{f}$.

147 Passio Marculi 3.

148 Passio Marculi 4-6.

149 Passio Marculi 7-13.

150 Passio Marculi 1: „Wie das Wüten der Heiden, die dem Teufel gehorchten, jene [Märtyrer] für das Königreich [Gottes] auserwählte, so sandte auch das Wüten der 
Das Martyrium des Marculus und das Massaker von Bagaï, die die Willkür von Gewalt demonstrieren, waren der Grund für den Hass und den Zorn der Donatisten auf Macarius. Es spielte keine Rolle, ob Donatus von Bagaï und die Circumcellionen den Einsatz der Soldaten provoziert hatten, wie Optatus von Mileve betont; es spielte keine Rolle, ob Marculus tatsächlich ermordet oder nicht doch Selbstmord begangen hatte, wie Augustinus später die katholische Sicht wiedergibt ${ }^{151}$ und es spielte keine Rolle, ob es nur diese Einzelfälle waren, oder ob auch andernorts Gewalt angewandt wurde: Für die Donatisten war entscheidend, dass Christen ihrer Kirche Folter und Tod um des Glaubens willen erlitten und dass die Katholiken dies gefordert und unterstützt hatten. ${ }^{152}$ Diese Deutung vertiefte die Kluft zwischen Katholiken und Donatisten und führte zu den Klagen über die macarianische Verfolgung, die sich in Augustins Schriften wiederfinden.

Sowohl Optatus als auch Augustinus gestehen in Auseinandersetzung mit den donatistischen Vorwürfen indirekt ein, dass Macarius durch sein Vorgehen Schuld auf sich geladen hatte. Sie wehren sich aber gegen die Schlussfolgerung der Donatisten, dass die katholische Kirche für diese Taten verantwortlich sei. Das unterschiedliche Verständnis über die Bedeutung von persönlicher Schuld und Kirche wird hier ebenso deutlich wie in der Frage der traditio.

Außer den bereits genannten Personen, werden in den Verfolgerlisten der Donatisten noch die Namen Taurinus und Romanus angeführt. ${ }^{153}$ Allerdings sind die Hintergründe für ihre Nennungen wenig klar. Romanus war comes Africae zur Zeit des Firmusaufstandes. ${ }^{154}$ Möglicherweise verbanden die Donatisten eine Verschärfung ihrer Situation nach der Entspannungsphase unter Julian mit dem Namen Romanus. Vielleicht spielte auch der allgemein schlechte Ruf des Romanus in Afrika eine Rolle. Denkbar ist ferner ein einzelnes, heute nicht mehr bekanntes Vorkommnis, das ähnlich wie bei Ursacius und Leontius, zur Aufnahme des Romanus in die Liste der Verfolger führte.

Traditoren, die im Dienst des Antichristen stehen, diese [neuen Märtyrer] in den Himmel." (sicut enim illos gentilis saeuitia diabolo parens destinauit ad regnum, sic et hos traditorum rabies Antichristo seruiens misit ad caelum). Passio Marculi 3: „,[Vom Hof des Constans] wurden zwei Bestien nach Afrika gesandt, nämlich Macarius und Paulus, und man erklärte der Kirche einen vollkommen zu verfluchenden und schrecklichen Krieg, damit das christliche Volk zur Einheit mit den Traditoren gezwungen werde, durch die bloßen Schwerter der Soldaten, die Zeichen der Standartenträger und das Kriegsgeschrei der Menge." ([...] duabus bestiis ad Africam missis, eodem scilicet Macario et Paulo, exsecrandum prorsus ac dirum ecclesiae certamen indictum est populus christianus ad unitatem cum traditoribus faciendam nudatis militum gladiis et draconum praesentibus signis et turbarum uocibus cogeretur).

151 C. litt. Pet. II 46; vgl. Cresc. 54; Io. eu. tr. XI 15.

152 Vgl. Quinot, BA 30, 771-773.

153 C. litt. Pet. III 29; Gesta conl. Carth. III 258 (Z. 286).

154 Zur Person: PLRE I, 768, s. v. Romanus 3; Mandouze, PAC, 997 f., s. v. Romanus 1. Vgl. Alexander, ZAC 2, 1998, 254 f. - vgl. o. Kap. 2.1.1. 
Über Taurinus gibt Optatus von Mileve einen kurzen Bericht. ${ }^{155}$ Demnach sei Taurinus als comes Africae noch vor der Mission des Macarius von donatistischen Bischöfen gebeten worden, gegen Ausschreitungen radikaler Circumcellionen vorzugehen. Er habe diesem Gesuch entsprochen und in zahlreichen Städten Verdächtige aufgespürt. Bei einem Einsatz seien dann in der numidischen Ortschaft Octava viele Circumcellionen von den Soldaten des Taurinus getötet worden. ${ }^{156}$

Der Grund für die Donatisten, Taurinus unter die Verfolger zu zählen, waren zweifellos die Todesopfer der Militäraktion in Octava. Fraglich ist indessen, ob Optatus' Aussagen über Zeitpunkt und Anlass dieser Aktion der Wahrheit entsprechen. Denn Optatus fügt den Bericht in seine Polemik gegen den Bischof Donatus von Bagaï ein, um die Gewalt der Soldaten dort zu rechtfertigen. Donatus, so seine Argumentation, habe mit jenen Circumcellionen zusammen gekämpft, gegen deren Gewalttätigkeiten andere donatistische Bischöfe zuvor schon einmal freiwillig die weltliche Unterstützung angefordert und begrüßt hätten.

James Alexander hat darauf hingewiesen, dass die Verfolgerlisten und die wenigen anderen Hinweise entgegen der Darstellung des Optatus für eine chronologische Einordnung des Taurinus nach Macarius sprechen, und zu Recht gefolgert, dass Optatus die zeitliche Folge zum Zwecke seiner Argumentation umgestellt habe. Gegen die bislang vorherrschende Meinung dürfte also die Amtszeit des Taurinus als comes Africae erst nach dem Wirken des Macarius, vielleicht in den 350er Jahre anzusetzen sein. ${ }^{157}$

Weil aber die Geschichte von Taurinus Optatus so gut in den Zusammenhang passte, ist anzunehmen, dass die donatistischen Bischöfe tatsächlich bei Taurinus Unterstützung gefordert hatten. ${ }^{158}$ Die Zuhilfenahme staatlicher Strukturen durch die Donatisten begegnet immer wieder und muss kein Wi-

155 Opt. III 4.5-8. Zur Person: PLRE I, 878 f., s. v. Taurinus; Mandouze, PAC, 1100, s. v. Taurinus.

156 Vgl. die Darstellungen bei Monceaux IV, 247 f.; V, 278 [datiert auf um 340]; Grasmück, Coercitio, $108 \mathrm{f}$; Frend, Donatist Church, $176 \mathrm{f}$.

157 Alexander, ZAC 2, 1998, 247-267. Folgende Argumente sind ausschlaggebend: 1. Optatus erwähnt, dass auch Nachfolger von Paulus und Macarius von Donatisten angeklagt worden seien (Opt. III 4.12; vgl. III 10.7 und c. litt. Pet. II 202; gesta conl. Carth. III 258 (Z. 286-288). 2. Die Reihenfolge bei Petilianus (c. litt. Pet. II 202) ist offensichtlich chronologisch. 3. Optatus ändert die Reihenfolge aus Propagandagründen: Er will den Widerspruch zwischen der Bitte um Hilfe und der Verdammung desselben als Verfolger aufzeigen. Er will grundsätzlich zeigen, dass Donatisten die Schuld an der militärischen Gewalt haben, und Donatus von Bagaï die Schuld aufgrund der Circumcellionen. Um die Gewaltbereitschaft der Circumcellionen zu demonstrieren und zu belegen, dass die Donatisten einstmals vor den Katholiken militärische Hilfe angefordert hatten, erwähnt Optatus Taurinus' Hilfe gegen die Circumcellionen.

158 Anders Alexander (ZAC 2, 1998, 264 f.), der dies für wenig plausibel hält. 
derspruch zu der späteren Tradition der Donatisten sein, die Taurinus unter die Verfolger zählte. Unter Taurinus' Führung hatte es Opfer gegeben; und diese Opfer galten für einige Gruppen der Donatisten als Märtyrer der Verfolgung, für andere zunächst nicht. Optatus selbst deutet diesen Gegensatz an. Er erwähnt den Streit zwischen einem donatistischen Priester und dessen Bischof über die Frage, ob ein getöteter Circumcellione in der Kirche bestattet werden solle oder nicht. Der Vergleich mit den oben behandelten donatistischen Märtyrergeschichten zeigt somit, wie Erzählungen von einzelnen Aktionen gegen Donatisten tradiert wurden und sich im Bewusstsein einschließlich der Namen der verantwortlichen Verfolger verfestigten. Dies konnte auch eine Geschichte über Taurinus und die Märtyrer von Octava bewirken.

\subsection{Zusammenfassung: Die donatistischen Traditionen über Verfolgung}

Die donatistischen Traditionen über Verfolgungen, die uns bei Augustinus lediglich in Namen und Schlagworten begegnen, haben ihren Ursprung stets in konkreten Einzelfällen. Die Opfer von Gewalt zeigten den Donatisten die andauernde Feindschaft der Welt gegenüber der Kirche. Die Erinnerung an die Märtyrer bestärkte sie in ihrem Verständnis, zu den wenigen Auserwählten in einer gottlosen Umwelt zu gehören, auch in Zeiten ohne Verfolgung. ${ }^{159}$ Das Selbstverständnis als verfolgte Kirche wurde ebenso ritualisiert wie die pauschale Verurteilung der Katholiken als Traditoren. Beides diente dazu, eine klare Grenze zwischen den beiden Kirchen zu ziehen.

Die Donatisten sahen die Verfolgungen ihrer Kirche in Kontinuität zu den Verfolgungen der heidnischen Kaiser. Dies spiegelt sich in der Fortsetzung der Verfolgerlisten wider. Der Verzicht, in den Aufzählungen Kaisernamen zu nennen und stattdessen afrikanische Befehlshaber einzusetzen, lässt allerdings auf eine veränderte Perspektive schließen: Zur Zeit Augustins wollten weder Petilianus noch seine Kollegen, die Kaiser direkt für die Verfolgungen verantwortlich machen. Sie stellten die Befehlshaber in Afrika in Verbund mit den Traditoren in den Vordergrund, da es nicht opportun erschien, die Kaiser anzugreifen und gleichzeitig selbst etwas von den Kaisern zu erwarten. Hier wird wiederum deutlich, dass die Donatisten niemals in einer Fundamentalopposition zu den weltlichen Gewalten verharrten, sondern stets darauf hofften - nicht

159 Diesen Aspekt betont Tilley, Sustaining Donatist Self-Identity: From the Church of the Martyrs to the Collecta of the Desert, JECS 5, 1997, 21-35. 
zuletzt auch auf der Konferenz von Karthago -, dass ein Kaiser zu ihren Gunsten entscheiden werde. ${ }^{160}$

Blickt man auf die Märtyrerberichte, zeigen sich weitere Aspekte in der donatistischen Beurteilung der Kaiser. Die ersten Maßnahmen gegen Donatisten werden in dem sermo de passione Donati nicht in direkten Zusammenhang mit Kaiser Konstantin gebracht und auch später wird Konstantin nicht als Urheber verantwortlich gemacht, sondern als Opfer falscher Ratgeber dargestellt. Die Person Konstantins galt offenbar auch bei den Donatisten als nicht oder kaum angreifbar. Deutlich anders fiel jedoch die Beurteilung des Kaisers Constans aus. Dessen Gesetz zur Einheit wird ohne Umschweife als Ursache der macarianischen Verfolgung benannt und entsprechend verurteilt. ${ }^{161}$ Diese Verfolgungszeit markiert einen klaren Bruch der bisherigen Einstellung der Donatisten zu Kaiser und Staat. Nach einer Generation faktischer Toleranz der Donatisten wirkte das Einheitsgesetz besonders einschneidend. Das gewachsene Arrangement beider Kirchen wurde zerstört. Der Schock war ausschlaggebend für die spätere Gewichtung der macarianischen Verfolgung innerhalb der donatistischen Tradition.

Die Herrschaft Julians bewirkte bei den Donatisten wieder eine Änderung der Haltung gegenüber den Kaisern. Sie konnten auf eine Zukunft ohne Unterdrückung hoffen und ihre Anliegen frei artikulieren. Das Beispiel Julians demonstrierte den Donatisten, dass eine andere Politik möglich war, in der die Traditoren an Einfluss verloren. In der Folgezeit beließen sie es dabei, die unmittelbar Verantwortlichen der Verfolgung zu benennen, nicht aber die Kaiser. So wird auch in den Verfolgerlisten der Donatisten die Ambivalenz ihrer Haltung deutlich. Neben dem Verständnis der verfolgten Kirche, das beispielhaft in Karthago 411 vorgetragen wurde, ${ }^{162}$ standen stets pragmatische Überlegungen zur Verbesserung der eigenen Lage. Wenn auch die Einstellung gegenüber den Kaisern Änderungen unterworfen war, stets gleichbleibend galten den Donatisten die Traditoren der katholischen Kirche als Schuldige und Urheber ihrer Verfolgung.

160 So auch Alexander, ZAC 2, 1998, 250 f. - Diese ambivalente Haltung der Donatisten entspricht dem Verhalten der frühen Christen in den Verfolgungszeiten des 1.-3. Jahrhunderts.

161 Vgl. Schäferdiek, Sermo, 184-187.

162 Gesta conl. Carth. III 258. 


\section{Die Entstehung des donatistischen Schismas: Historische Argumente zur causa Caeciliani}

In den Auseinandersetzungen über die traditio und die persecutio lassen sich Ursachen und Hintergründe des Schismas erschließen. Im Streit um die causa Caeciliani zeigen sich Anlass, Umstände und die frühen Entwicklungen, die zur Spaltung der Kirche und zur Verfestigung der gegensätzlichen Auffassungen führten. Die unterschiedlichen historischen Argumente, die von Donatisten und Augustins zur causa Caeciliani zusammengetragen und verwendet wurden, sollen im Folgenden dargestellt werden. Wie im vorangehenden Kapitel sollen dabei sowohl die historischen Zusammenhänge als auch die Argumentationsstrukturen verdeutlicht werden. Der Verlauf dieses Kapitels folgt der Chronologie der Ereignisse: Ausgangspunkt der causa Caeciliani ist das Konzil von Karthago, an dem Caecilianus abgesetzt und mit Maiorinus ein erster „donatistischer" Gegenbischof ernannt wurde. Anschließend wird die Abfolge der Anklagen und Verfahren gegen Caecilianus betrachtet: die Verhandlungen des Falles vor den Bischofsgerichten in Rom und Arles, und schließlich das Urteil des Kaisers Konstantin. Im jeweiligen Zusammenhang wird beleuchtet, wie die Ereignisse durch die beiden Parteien zur Zeit Augustins dargestellt und interpretiert wurden.

\section{Das Konzil von Karthago und die Absetzung Caecilians}

\subsection{Die Akten des Konzils von Karthago}

Die heute nicht mehr erhaltenen Akten des Konzils von Karthago waren zur Zeit Augustins die wichtigsten historischen Dokumente in den Händen der Donatisten. ${ }^{1}$ In ihren Augen erbrachten diese Akten den entscheidenden Beweis für die Schuld Caecilians und damit für die Rechtmäßigkeit ihrer eigenen Kirche. Unter Berufung auf die Konzilsakten argumentierten Cresconius, ${ }^{2}$ die

1 Zu den Quellenfragmenten siehe von Soden, Nr. 6; Maier I, Nr. 10, 128-135; Monceaux IV, 18-20, 326-332; V, 8 f. - Seeck (ZKG 10, 1889, 535-542) hielt die Akten zunächst für eine Fälschung, revidierte diese Meinung jedoch später (ZKG 30, 1909,182).

2 Unter Heranziehung der Sentenz des Silvanus, Cresc. III 16, 31, 34; IV 66-67; vgl. o. Kap. 3.4.1. 
Gesprächspartner Augustins in Thubursicum Numidarum ${ }^{3}$ sowie die donatistischen Bischöfe auf der Konferenz im Jahr 411. ${ }^{4}$ Die zahlreichen Anspielungen Augustins auf dieses Konzil und seine Versuche, die Rechtmäßigkeit des Urteils gegen Caecilianus in Frage zu stellen, bezeugen zudem, welchen Stellenwert diese Dokumente für die Donatisten und die gesamte Auseinandersetzung besaßen. ${ }^{5}$

Die Akten enthielten die Verhandlungsprotokolle mit den Anklagen gegen Caecilianus und seiner Ordinatoren sowie die Sentenzen aller anwesenden Bischöfe. Zudem wurde zum Abschluss des Konzils ein Synodalschreiben verfasst, in dem das Ergebnis allen Kirchengemeinden in Afrika mitgeteilt wurde. ${ }^{6}$ Dieser Brief war mit Sicherheit ebenfalls im Aktenmaterial erhalten und gehörte zu den Dokumenten, die Optatus seinem Werk beifügte. ${ }^{7}$ Möglicherweise geht auf diesen Brief der in den Capitula der Konferenzakten von 411 verwendete Begriff decretum de Caeciliani damnatione zurück. ${ }^{8}$ Vom Wortlaut des gesamten Aktenmaterials sind heute lediglich zwei kleine Fragmente in der pseudoaugustinischen Schrift contra Fulgentium überliefert, darunter die Sentenz eines Bischofs namens Marcianus. ${ }^{9}$ Für die näheren Umstände und den Ablauf des Konzils steht nur die Darstellung bei Optatus zur Verfügung, ${ }^{10}$ ergänzt um wenige weiterführende Hinweise bei Augustinus. Viele Einzelheiten des Verhandlungsverlaufs und der Motivation der Bischöfe sowie der genaue Zeitpunkt der Synode bleiben jedoch im Dunkeln.

Vielleicht um die Jahre 309/10 ${ }^{11}$ versammelten sich etwa siebzig mehrheitlich numidische Bischöfe unter der Leitung des numidischen Primas Secundus

3 Ep. 43.3; vgl. o. Kap. 4.2.1.

4 Cap. conl. Carth. III 343-346, 367-369; breuic. III 26, 29; c. Don. 38; vgl. o. Kap. 5.1.3 u. 5.3.1.

5 Vgl. Ps. c. Don. 73-84; c. ep. Parm. I 5; cath. fr. 46, 73 (Synodalbrief); en. Ps. 36, 2, 19; s. 46. 39; Cresc. II 45, III 44, 67; IV 9, 66; un. bapt. 28; epp. 43.3, 14, 18; 88.3; breuic. III 26, 28-32; c. Don. 3, 38; ep. 141.6.

6 Cath. fr. 73; Opt. I 20.

7 Vgl. Opt. I 20.

8 So Monceaux IV, 331; vgl. Cap. Conl. Carth. III 346.

9 C. Fulg. 5, 24 (ed. Lambot, RevBen 58, 148, 117-221); vgl. Maier I, 134 f.

10 Vgl. auch zum Folgenden Opt. I 18-20.

11 Die Datierung des Konzils von Karthago ist wie die gesamte Chronologie der Entstehungsphase des Schismas sehr schwierig und bis heute umstritten. Bereits die auf der Konferenz im Jahre 411 vorgelegten Akten enthielten kein Datum, lediglich eine Tagesangabe (Cap. conl. Carth III 350; breuic. III 26, 30; c. Don. 19). In der Forschung werden zwei gegensätzliche Positionen vertreten: Für eine Frühdatierung um 307 plädierte bereits Seeck (ZKG 30, 1909, 224 f.; Geschichte III, 323, 509), mit anderen Argumenten später u. a. Barnes (JThS 26, 1975, 18-20) und Lancel (REAug 25, 1979, 226 229). Eine Datierung in die Jahre 311/12 vertraten dagegen Duchesne (Dossier, $597 \mathrm{f}$, 626) und Monceaux (IV, 18 f., 327). Ihnen folgten u.a. Frend (Donatist Church, 19 f.; JThS 28, 1977, 104-109), Congar (BA 28, 713 f.), de Veer (REAug 22, 1976, 353-355) 
von Tigisi in einem Privathaus in Karthago. ${ }^{12}$ Ziel der Bischöfe war es, den neu gewählten und ordinierten Bischof der Stadt Caecilianus seines Amtes zu entheben. Caecilianus wurde zur Anhörung vorgeladen, doch weigerte er sich zu kommen und ließ übermitteln, dass seine Ankläger Beweise gegen ihn vorlegen sollten. Ohne einen weiteren Versuch der Vorladung verhandelten die Bischöfe den Fall in Abwesenheit Caecilians. Ob tatsächlich eine aufgewühlte Stimmung herrschte und die Bischöfe durch eine anwesende Volksmenge gegen Caecilianus aufgehetzt und beeinflusst wurden, wie Augustinus später behauptet (ep. 43.14), ist sehr fraglich. Fest steht jedoch, dass persönliche Anschuldigungen gegen Caecilianus vorgebracht wurden, darunter der Vorwurf, er habe während der Verfolgung die Besuche und Versorgung von Christen in den Gefängnissen gewaltsam verhindert, möglicherweise auch die Anschuldigung, er habe bei der traditio mit den Behörden kollaboriert. ${ }^{13}$ Bei diesen Anklagen spielten Caecilians Gegner in der karthagischen Gemeinde eine entscheidende Rolle. Optatus spricht von drei Parteien, die gegen Caecilianus agitiert hätten:

und Maier (I, 129-134). Mit der Datierung des Konzils in die Jahre 309/10 folge ich der Darstellung Kriegbaums (Kirche der Traditoren, 135-149). Wenngleich Kriegbaums chronologische Rekonstruktion aufgrund der Quellenlage nicht zwingend ist, so ist sie dennoch die bessere Alternative im Vergleich zu den übrigen Erklärungsansätzen: Entscheidend für die Chronologie ist die bei Optatus (I 17) überlieferte sog. „Affäre Felix“. Der Diakon Felix hatte ein Pamphlet gegen einen „tyrannus imperator“ geschrieben, wurde daraufhin verfolgt und erhielt Asyl bei Mensurius, dem Bischof von Karthago. Mensurius musste sich deswegen am Hofe verantworten, verließ Karthago und kehrte nicht wieder zurück. Die weiteren Umstände und Hintergründe liegen völlig im Dunkeln. Es scheint aber am wahrscheinlichsten, dass mit jenem „Tyrannen“ Kaiser Maximian gemeint war (so auch Barnes und Lancel). Ausgehend von der politischen Situation folgert Kriegbaum, dass die Vorladung des Mensurius in die Zeit des Machtkampfes zwischen Maxentius und seinem Vater gefallen sei, d.h. in das Jahr 308. Nachdem sich Maxentius durchgesetzt hatte, sei die Anklage gegen Mensurius hinfällig geworden, der aber aufgrund der Revolte des Domitius Alexander nicht nach Afrika hätte zurückkehren können und bald darauf gestorben sei. In der gleichen Zeit sei auch das Toleranzedikt des Maxentius gegenüber den Christen promulgiert worden. Die Wahl und Weihe Caecilians als Nachfolger des Mensurius sowie seine Absetzung und die Ernennung des Maiorinus fielen somit in die Zeit nach Mai 308. - Ein indirektes Tyconius-Zitat bei Augustinus (ep. 93.43) besagt, dass Donatus mit einem gewissen Deuterius und anderen mauretanischen Bischöfen Kirchengemeinschaft gehalten hätte, „über 40 Jahre hinweg bis hin zur Verfolgung des Macarius“. Seeck verwendete diese Zeitangabe, um den Beginn des Schismas auf $307 \mathrm{zu}$ datieren. Abgesehen von einem Fehler in der Überlieferung (vgl. die Vermutungen bei Maier I, 130) sind die besagten 40 Jahre jedoch allenfalls als eine gerundete Jahresanzahl zu verstehen und somit für eine Datierung des Konzils von Karthago wertlos.

12 Die ausführlichste Darstellung der Ereignisse bei Kriegbaum, Kirche der Traditoren, 96-129. Vgl. ferner Congar, BA 28, 713 f.; Frend, Donatist Church, 18-21; Grasmück, Coercitio, 21-26; Mandouze, PAC, 1052-1054, s. v. Secundus 1; Mühlsteiger, ZRG KA 85, 1999, 11-13.

13 Vgl. breuic. III 26. Zur Quellengrundlage s. o. Kap. 6.1.2. 
Die Kleriker Botrus und Celestius aus persönlicher Missgunst heraus, da sie sich ebenfalls Hoffnung auf das Bischofsamt gemacht hätten, die reiche Lucilla, die von Caecilianus wegen einer dubiosen Märtyrerverehrung zurechtgewiesen worden sein soll und viele Bischöfe des Konzils bestochen habe, und schließlich einige Gemeindeälteste (seniores laici), die ihnen anvertrautes Kirchenvermögen nicht an Caecilianus hätten übergeben wollen. ${ }^{14}$ Wenngleich diese niederen Beweggründe, die Optatus und später Augustinus in ihrer Polemik herausstellen, sicher nicht den tatsächlichen Gegebenheiten entsprachen, ${ }^{15}$ ist dennoch die Existenz einer starken Opposition gegen Caecilianus unbestreitbar, die im Zusammenwirken mit den numidischen Bischöfen dessen Absetzung betrieb.

Die entscheidende Anklage, die auf dem Konzil gegen Caecilianus erhoben wurde, bezog sich indessen nicht auf irgendwelche persönlichen Verfehlungen, sondern auf den Akt seiner Bischofsweihe. Man behauptete, dass Caecilianus von Traditoren geweiht worden und deshalb seine Weihe unwirksam sei. Vor allem Felix von Abthugni wurde der traditio angeklagt. ${ }^{16}$ Zur Feststellung der Schuld wurden vermutlich Zeugen gehört, schriftliche Dokumente hingegen nicht vorgelegt. Nachdem die Schuld der Ordinatoren als erwiesen angesehen wurde, erklärten die anwesenden Bischöfe die Wahl und Weihe Caecilians für nichtig. Caecilianus hatte sich zuvor noch bereit erklärt, eine neuerliche Weihe durch die numidischen Bischöfe zu akzeptieren, wenn seine Würde allein aufgrund der Schuld des Felix angezweifelt würde. Doch dieses Angebot wurde zurückgewiesen. ${ }^{17}$ Die Bischöfe wählten den Lektor Maiorinus - einen domesticus der Lucilla, wie Optatus vermerkt - zum Bischof von Karthago. Jeder der anwesenden Bischöfe kündigte in einer eigenen Sentenz die Gemeinschaft mit Caecilianus auf. Die Begründungen betrafen die ungültige Weihe durch Traditoren, wenngleich die Berichte über Caecilians „Fehlverhalten“ während der Verfolgungszeit einen bestärkenden Einfluss gehabt haben dürften. ${ }^{18}$ Die in

14 Opt. I 18-19. Zur Bedeutung der seniores laici vgl. Frend, JThS 12, 1961, 280-284; Kriegbaum, Kirche der Traditoren, 127-129. Zu Lucilla: Mandouze, PAC, 649, s. v. Lucilla 1.

15 Augustins zugespitzte Darstellung in ep. 43.14-18 diente der Gegenüberstellung des Verfahrens in Rom (s. o. Kap. 4.2.1). Vgl. auch Kriegbaum, Kirche der Traditoren, 100102.

16 Augustinus nennt namentlich ferner Novellus von Thizica und Faustinus von Thuburbo (Maius oder Minor) als weitere Ordinatoren, denen allerdings die traditio nicht nachgewiesen werden konnte (c. Don. 38). Vgl. o. Kap. 6.1.3.

17 Opt. I 19.

18 In breuic. III 26 gibt Augustinus eine kurze Zusammenfassung der Urteilsbegründungen. Auf der Konferenz 411 wurden alle Sentenzen der Bischöfe vorgelesen. - Kriegbaum (Kirche der Traditoren, 114-118) verweist zu Recht auf die cyprianische Tradition und betont, dass die traditio der Ordinatoren der entscheidende Punkt gewesen sein müsse, um Caecilians Bischofswürde als null und nichtig zu beurteilen. Der Weiheakt war ungültig, da er wegen der traditio der Ordinatoren nach Verständnis der pars 
contra Fulgentium überlieferte Sentenz vermittelt einen Eindruck von den Urteilsbegründungen. Die Sentenz des Marcianus endet mit den Worten:

„So wie die unfruchtbaren Zweige abgeschnitten und weggeworfen werden, so können auch die Weihrauchopferer und die Traditoren, die sich von Gott losgesagt haben, nicht in der Kirche Gottes bleiben, es sei denn, sie werden durch Buße wieder aufgenommen, wenn ihr Bußruf bekannt geworden ist. Deshalb soll mit Caecilianus keine Gemeinschaft gepflegt werden, weil er im Schisma von Traditoren ordiniert worden ist." ${ }^{\text {19 }}$

Die Argumentation der Donatisten zur Zeit Augustins war entscheidend auf das Urteil des Konzils von Karthago ausgerichtet. Die näheren Umstände, die zu dem Konzil und dem Schisma führten, fanden bei den Donatisten wenig Interesse, so dass es keine Hinweise darauf gibt, wie sie die Situation der karthagischen Kirche im Vorfeld der Auseinandersetzung über die Wahl Caecilians einschätzten, welche Rolle sie etwa der Lucilla beimaßen. Alle Berichte über diese kirchlichen Streitigkeiten in Karthago, die Intrigen und gegenseitigen Anschuldigungen, finden sich allein in der katholischen Überlieferung. ${ }^{20}$

Auf der Konferenz von 411 verteidigten die Donatisten die Rechtmäßigkeit dieses Urteils, indem sie behaupteten, numidische Bischöfe hätten zur Weihe Caecilians hinzugezogen werden müssen. ${ }^{21}$ Bereits Augustinus kommentiert dies mit der Bemerkung, dass die Donatisten diesen Vorwurf doch Caecilianus sofort gemacht hätten, wenn es tatsächlich ein derartiges kirchliches Gewohnheitsrecht gegeben hätte. Aber von solchen Anschuldigungen war offenbar in den Akten von Karthago nirgends die Rede. Vermutlich bestanden für die Wahl und Weihe des karthagischen Bischofs zu Beginn des 4. Jahrhunderts keine eindeutigen Richtlinien, so dass der Anspruch des numidischen Primas auf Mitwirkung der eigenen Einschätzung entsprang. ${ }^{22}$

Um den rechtmäßigen Ablauf des Konzils zu bekräftigen, wiesen die Donatisten im Jahre 411 auch auf das Angebot Caecilians an die Konzilsteilnehmer hin, sich nochmals ordinieren zu lassen, falls die Weihe durch Felix von Abthugni unwirksam gewesen sein sollte. Dieses Zugeständnis, von dem bei Op-

Maiorini nicht innerhalb der Kirche stattgefunden hatte. Demzufolge hatte Caecilianus die Bischofswürde niemals besessen.

19 C. Fulg. 24 (RevBen 58, 1948, 221; Maier II, S. 284): sicut ergo palmites infructuosi amputati proiciuntur, ita turificati, traditores, abhorrentes deo manere in ecclesia dei non possunt, nisi, cognito ululatu suo, per paenitentiam reconcilientur. unde Caeciliano in schismate a traditoribus ordinato non comunicare oportet.

20 Insbesondere bei Optatus von Mileve (I 16-20), dessen Ausführungen Augustinus in seinen Schriften vor 405 aufnimmt und für seine Argumentation interpretiert (vgl. o. Kap. 4.2.1; 6.2).

21 Breuic. III 29.

22 Es gibt keine weiteren Quellen, die über die kirchenrechtliche Situation sicher Auskunft geben könnten. Vgl. dazu Kriebaum, Kirche der Traditoren, 98 f.; Grasmück, Coercitio, $23 \mathrm{f}$. 
tatus die Rede ist, werteten die Donatisten jedoch nicht nur als Anerkennung des Konzils durch Caecilianus, sondern auch als sein Schuldeingeständnis: Caecilianus hätte zugegeben, von Traditoren ordiniert worden zu sein. ${ }^{23}$

Tatsächlich scheint Caecilianus einen Versuch unternommen zu haben, mit den numidischen Bischöfen zu einer Einigung zu kommen, indem er seine Weihe zur Disposition stellte. Caecilianus bekannte sich insofern zur afrikanisch-cyprianischen Tradition, der zufolge die Sakramente eines unwürdigen Spenders nicht galten. Offenbar war er bereit, sich von Felix zu distanzieren, um sein erworbenes Amt zu verteidigen. Das Scheitern dieses Angebots zeigt indessen, dass es den Gegnern Caecilians nicht allein um die vermeintlich ungültige Weihe ging, sondern auch jene Ursachen zur Ablehnung seiner Person geführt hatten, von denen Optatus einen Eindruck vermittelt. Das Angebot Caecilians zeigt darüber hinaus, dass die theologischen Positionen in dieser ersten Phase des Schismas keineswegs so festgelegt waren, wie es aufgrund der späteren Darstellungen oftmals den Anschein hat. Ein Eingeständnis seiner eigenen Schuld oder ein Beweis für die traditio der Ordinatoren, wie die Donatisten 411 glauben machen wollten, war das Handeln Caecilians freilich nicht, wie bereits Augustinus in seinem Kommentar bemerkt. ${ }^{24}$

Die Argumentation der Donatisten im Jahre 411 macht deutlich, dass sie durchaus gewillt waren, die Rechtmäßigkeit des Konzils von Karthago zu begründen. Leider fehlen Quellen, in denen außer den genannten weitere Argumente ersichtlich werden könnten. Ausgehend von den Aussagen des Cresconius lässt sich jedoch feststellen, dass den Donatisten im Grunde nicht daran gelegen war, Hintergründe und Motive der Situation der Kirche in Karthago aufzudecken. Sie beriefen sich allein auf das Protokoll und die Sentenzen, um zu konstatieren, dass Caecilianus und seine Ordinatoren nachweislich Traditoren gewesen seien, folglich Caecilians Wahl und Ordination zum Bischof Karthagos rechtmäßig durch das Konzil des Secundus annulliert worden seien, eine Entscheidung, die als eindeutig und unanfechtbar anerkannt werden müsse. ${ }^{25}$

23 Cap. conl. Carth. III 374; breuic. III 29; vgl. Opt. I 19.

24 Breuic. III 29. Vgl. Grasmück, Coercitio, 24; ausführlich Kriegbaum (Kirche der Traditoren, 107-112), dessen Interpretation über die Motivation der beiden Parteien allerdings teilweise spekulativ ist. - Vgl. auch oben Kap. 5.3.1.

25 Vgl. Cresc. III 31, 34; IV 9. Dieses Verständnis der Donatisten wird auch deutlich in der Forderung im Jahre 411, aufgrund der Sentenzen des Konzils, die de jure Verurteilung Caecilians anzuerkennen (Cap. conl. Carth. III 367). 


\subsection{Der interventor von Karthago}

Einen der seltenen Hinweise auf mündliche donatistische Überlieferungen aus der Entstehungsphase des Schismas gibt Bischof Fortunius von Thubursicum Numidarum. ${ }^{26}$ Dieser erzählte Augustinus und den anderen katholischen Gesprächspartnern, dass seine Vorfahren zu Beginn der Auseinandersetzung durchaus bereit gewesen seien, die Schuld Caecilians auf sich beruhen zu lassen, um ein Schisma zu verhindern. Daher hätten sie noch vor der Ordination des Maiorinus einen interventor für ihre Gemeinde in Karthago eingesetzt. Dieser Mann sei jedoch inmitten seiner Gemeinde von den Gegnern ermordet worden. ${ }^{27}$ Augustinus selbst bemerkte, diese Geschichte noch niemals zuvor gehört zu haben, obwohl er viele Anklagen und Vorwürfe der Donatisten gegen die Katholiken kenne. Offensichtlich hielt er diese Darstellung für unglaubwürdig. ${ }^{28}$

In einer späteren Predigt erwähnt Augustinus jedoch, dass Secundus von Tigisi zunächst Kleriker nach Karthago geschickt hätte, die einen visitator eingesetzt und mit den Anhängern der Lucilla eigene Gottesdienste gefeiert hätten. ${ }^{29}$ Hier bezog sich Augustinus ganz offensichtlich auf Informationen, die Optatus von Mileve nicht besessen bzw. nicht für erwähnenswert gehalten hatte. Geht man nun davon aus, dass sich beide Aussagen auf dieselbe Person beziehen, bleibt zunächst die Frage, wie sie in den historischen Kontext einzuordnen sind. Augustins Notiz erscheint im Zusammenhang durchaus plausibel: Caecilians Gegner in Karthago brauchten Unterstützung und wandten sich an den einflussreichen numidischen Primas Secundus. Da aus Sicht der späteren pars Maiorini Caecilianus und seine Kleriker ihre Ämter unrechtmäßig ausübten, sandte Secundus vor seiner eigenen Reise numidische Kleriker nach Karthago. Diese wiederum ernannten einen Bistumsverweser, dem bis zur offiziellen Neuwahl eines Bischofs die provisorische Leitung der anticaecilianischen Gemeinde oblag. ${ }^{30}$

26 Ep. 44; vgl. o. Kap. 4.1.1.

27 Ep. 44.8: [Fortunius] Narrauit etiam in ipsa schismatis nouitate maiores suos, cum cogitarent culpam Caeciliani, ne schisma fieret, quoquo modo uelle sopire, dedisse quendam interuentorem populo suae communionis apud Carthaginem constituto, antequam Maiorinus aduersus Caecilianum ordinaretur. hunc ergo interuentorem in suo conuenticulo a nostris dicebat occisum.

28 Ep. 44.8 .

29 S. 46.39: de Numidia nata est pars Donati. ipsi missi sunt primo in dissensionem et tumultum et scandalum, quaerentes ingenium uulneri. Numidae miserunt. Secundus Tigisitanus misit. ubi sit Tigisi, notum est. qui missi sunt clerici, extra congregauerunt ab ecclesia, et clericos Carthaginis accedere noluerunt, uisitatorem posuerunt, a Lucilla excepti sunt. auctor totius huius mali Numida haereticus fuit. - Monceaux (VII, 289) datiert die Predigt mit guter Begründung auf Mitte des Jahres 410.

30 Zur Rekonstruktion des Verlaufs in Karthago vgl. Kriegbaum, Kirche der Traditoren, 100-104. 
Während die Existenz dieser Person unzweifelhaft sein dürfte ${ }^{31}$ stellt sich weiterhin die Frage nach ihrer Bedeutung. Die Bemerkung des Fortunius zeigt, dass die Donatisten später im interventor eine Vermittlerfigur zwischen den beiden Parteien sahen, dessen Ermordung aber eine Einigung unmöglich gemacht hätte. Zweifellos war einerseits vor der Verurteilung Caecilians durch das Konzil des Secundus die Situation der karthagischen Kirche ungeklärt und grundsätzlich offen. Andererseits waren die Abgrenzungen bereits soweit fortgeschritten, dass eine Einheit der Kirche mit einem Bischof Caecilianus kaum mehr zu erreichen gewesen sein dürfte. Sollte der interventor tatsächlich versucht haben, die zerstrittene Gemeinde zu vereinen, so konnte dies nur durch Überzeugung der Gläubigen geschehen. Caecilianus selbst war für die Rigoristen untragbar. Fortunius' Andeutung, dass seine Vorfahren die „Schuld Caecilians“ irgendwie ,einschläfern“ (sopire) wollten, ist allerdings unklar. Entweder ist sie als euphemistische Darstellung einer Absetzung Caecilians zu verstehen oder als eine Umschreibung, dass Caecilians Anhänger zu einer Abkehr von ihrem Bischof bewegt werden sollten. ${ }^{32}$

Unglaubwürdig ist dagegen die Behauptung, der interventor sei ermordet worden. Dass ein solch einschneidendes Vorkommnis bei Optatus fehlt, könnte noch mit Hinweis auf die tendenziöse Darstellung begründet werden. Jedoch wäre dieser Fall von den Donatisten selbst weitaus häufiger zur Sprache gebracht worden, nicht zuletzt bei der Konferenz von Karthago, wenn diese donatistische Überlieferung der Wahrheit entsprochen hätte. Abgesehen davon gehört der Vorwurf von Mord, ebenso wie andere Arten der Gewaltausübung oder Bestechung zu den gängigen Topoi in der Auseinandersetzung. Hier liegt offenbar ein Beispiel für die Herausbildung eines solchen Topos vor, mit dem die eigene Geschichte gerechtfertigt und die Schuld an den Gegner verwiesen werden sollte. ${ }^{33}$

31 Dies ist weitgehend communis opinio in der Forschung. Anders Seeck (Geschichte III, 329, 514) und Grasmück (Coercitio, 22 f. Anm. 45). - Zur Bedeutung der Wörter visitator / interventor vgl. Gaudemet, Église, $366 \mathrm{f}$.

32 Vgl. Kriegbaum, Kirche der Traditoren, 103 f. und 124: Mit der Entsendung des Vermittlers „konnte Secundus beabsichtigt haben, den Gläubigen von Karthago die Möglichkeit zu bieten, sich von dem in seinen Augen schismatischen Caecilian loszusagen und so die Einheit der Gemeinde zu bewahren."

33 Die donatistische Überlieferung des Mordes wurde unkritisch übernommen u.a. von Frend (Donatist Church, 19: „The first action Secundus took, therefore, was to consider Caecilian's election as unconfirmed, and to appoint an interim administrator (an interventor) to look after the see until the dispute was settled. The interventor was murdered in his church allegedly by the Caecilianists.") und Piétri (Geschichte, 247: „provisorischer Bistumsverweser“, der ermordet wurde). 


\section{Die Anklage der Donatisten gegen Caecilianus}

Indem der Streit über die Bischofswahl von Karthago vor den Kaiser getragen wurde, vollzog sich ein bedeutsamer Schritt, der langfristige Auswirkungen auf das Verhältnis zwischen Kirche und Staat haben sollte. ${ }^{34}$ Die Umstände, die dazu führten, werden bei Augustinus an zahlreichen Stellen mit klaren Worten zusammengefasst: Die Donatisten selbst hätten die causa Caeciliani vor Konstantin gebracht und somit eine Entscheidung des Kaisers gefordert. So eindeutig diese Aussage auch sein mag, so schwierig ist es, unter Einbeziehung aller Quellen den genauen Vorgang und die Motive der Anklage vor dem Kaiser zu rekonstruieren. Die in der Forschung vielfach diskutierte Frage soll hier vor allem unter dem Aspekt aufgegriffen werden, inwiefern Augustinus und die Donatisten den geschichtlichen Verlauf kannten und wie sie ihn in ihren Argumentationen verarbeiteten.

Bereits Optatus von Mileve argumentiert gegen die donatistische Anfrage, „was die Christen mit den weltlichen Herrschern zu tun hätten“, mit einem Zitat, das angeblich jener Petition (preces) der Donatisten entstammte, mit der diese sich schon kurz nach dem Schisma in Karthago an Kaiser Konstantin gewandt und um sein Eingreifen gebeten hatten. ${ }^{35}$ Augustinus verfolgt in seinen antidonatistischen Schriften das gleiche Argumentationsziel: Die Donatisten dürften sich über das Eingreifen der staatlichen Gewalt in den Auseinandersetzungen zwischen den beiden Parteien nicht beschweren, denn sie selbst hätten sich zuerst mit einer kirchlichen Angelegenheit an Konstantin gewandt. Augustinus verteidigte mit diesem Argument die Inanspruchnahme weltlicher Institutionen durch die Katholiken, sei es die Hilfe von Soldaten gegen Circumcellionen und donatistische Gewalttaten, sei es die Nutzung zivilrechtlicher Mittel, um gegen Donatisten vorzugehen.

Die Zäsur in der Beweisführung Augustins um das Jahr 405 ist im Zusammenhang mit der historischen Argumentation in den Briefen dargelegt worden. ${ }^{36}$ In seinen Schriften vor dem Jahr 405 berief sich Augustinus ganz offensichtlich auf die Darstellung des Optatus und dessen Zitat aus besagter Petition: Von Konstantin, so der stereotype Vortrag, hätten die Donatisten Bischöfe als Richter erbeten, woraufhin dieser das Konzil von Rom einberufen habe. ${ }^{37}$ Seinen Aussagen zufolge hatte Augustinus den Gesprächspartnern in Thubursicum den Wortlaut jener preces vortragen lassen und seinen Briefpartner Generosus weist er ebenfalls ausdrücklich auf dieses Zeugnis hin. ${ }^{38} \mathrm{Da}$ aber ansonsten diese

34 Allgemein dazu Instinsky, Kaiserstuhl, 47-82; Girardet, Kaisergericht, 6-51.

35 Opt. I 22.

36 Vgl. o. Kap. 4.2.2.

37 Ps. c. Don. v102; epp. 43.14; 53.5; 76.2; cath. fr. 46; retr. I 21.3.

38 Epp. 43.4-5; 53.5. 
preces als eigenständiges Dokument niemals genannt werden - weder in späteren Augustinusschriften noch auf der Konferenz von 411 - ist davon auszugehen, dass Augustinus lediglich das bei Optatus überlieferte Fragment kannte und an entsprechender Stelle daraus zitierte. ${ }^{39}$

Die Wende in der Argumentationsweise erfolgte um das Jahr 405: In den Archiven des Prokonsuls in Karthago entdeckte Augustinus den Bericht des Prokonsuls Anullinus an Konstantin, ${ }^{40}$ mit dem die Petition der Donatisten seinerzeit übermittelt worden war. Diese relatio Anullini avancierte fortan zu dem entscheidenden historischen Dokument in den Händen Augustins, auf das er an zahlreichen Stellen explizit hinwies. Mit Hilfe der relatio Anullini führte er den Beweis, dass sich die Donatisten als erste und vollkommen freiwillig an den Kaiser gewandt und Caecilianus bei Konstantin angeklagt hätten. Diese Anklage habe zu den folgenden Prozessen geführt, die allesamt zu Gunsten Caecilians ausgefallen seien. ${ }^{41}$ Diese juristische Terminologie beherrschte auch die Konferenz von 411, bei der die Katholiken eine Bestätigung des Freispruchs Caecilians in der causa Caeciliani erreichen wollten. ${ }^{42}$ Nach der Konferenz verzichtete Augustinus bezeichnenderweise wieder auf diese Formulierungen und betonte nunmehr die Verfolgung Caecilians durch die Donatisten. Damit griff er den Sprachgebrauch der Donatisten auf, die ihrerseits von der Verfolgung durch die Katholiken und den weltlichen Mächten sprachen. ${ }^{43}$ Augustinus berief sich also zu verschiedenen Zeiten auf unterschiedliche Quellen und variierte entsprechend seine Interpretation des geschichtlichen Vorgangs.

Wenden wir uns als erstes der relatio Anullini zu, die am deutlichsten über die Ereignisse Auskunft gibt und daher auch von Augustinus bevorzugt wurde: Der Text der relatio Anullini ist durch Augustinus und die Konferenzakten von Karthago überliefert. An der Echtheit und Glaubwürdigkeit des Dokumentes

39 Girardet, Chiron 19, 1989, 199 f. - Dass Augustinus im Gegensatz zu Optatus deutlich von „bischöflichen Richtern“ aus Gallien spricht, ist als eine Interpretation ex eventu zu verstehen. Insbesondere im Kontext von ep. 43 wird deutlich, wie Augustinus spätere Entwicklungen und Ereignisse heranzieht, um die aus seiner Sicht falsche Motivation der Donatisten herauszustellen; vgl. die Darstellung o. Kap. 4.2.1.

40 Als auf der Konferenz von 411 nach der Herkunft des Dokumentes gefragt wurde, verwies Augustinus auf das Archiv des Prokonsuls (gesta conl. Carth. III 220; breuic. III 8). Vgl. Girardet, Chiron 19, 1989, 196; Kriegbaum, AHP 28, 1990, 28 f.

41 Vgl. epp. 88.1-3; 89.3; 93.13-14; 105.8; Cresc. III 16, 67; IV 9; un. bapt. 28; s. Denis 19.8; s. Dolbeau 2.22; breuic. III 21, 24, 30; Gaud. I 53; gesta conl. Carth. I 16, 18 , 55 (SC 195, S. 668 Z. 351-358). Diese Veränderung ist besonders an den Briefen mit historischer Argumentation sichtbar (vgl. o. Kap. 4.2.2). Zur Argumentation im Jahre 411 vgl. o. Kap. 5.2.2. Vgl. auch Girardet, Chiron 19, 1989, 196-203.

42 Gesta conl. Carth. III 144, 176, 215-220; vgl. auch gesta conl. Carth. I 18, 55 (Z. 353); breuic. III 8, 24; vgl. o. Kap. 5.3.2.

43 Gaud. I 21; s. Caes. eccl. 7; c. Don. 53. 
ist nicht zu zweifeln. ${ }^{44}$ Augustinus verweist auf das Archiv des Prokonsuls in Karthago als Herkunftsort, die Datierung ist korrekt, nachprüfbar und selbst von den Donatisten ist kein Versuch überliefert, die Authentizität in Abrede zu stellen: Parmenianus bekannte sich laut Augustinus ausdrücklich zu der Anklageinitiative seiner Vorgänger ${ }^{45}$ und auch auf der Konferenz von 411 sprachen die Donatisten der relatio Anullini die Echtheit nicht ab. ${ }^{46}$

In dieser relatio, die auf den 15. April 313 datiert, berichtet Anullinus dem Kaiser zunächst, dass die Anordnung umgesetzt worden sei, die karthagische Kirche des Bischofs Caecilianus von den Abgabenpflichten (munera) zu befreien. Anschließend schreibt er:

„Nach wenigen Tagen aber erschienen, begleitet von einer Volksmenge, einige Leute, die glaubten, Caecilianus widersprechen zu müssen. Sie übergaben mir ein in Leder gebundenes und versiegeltes Päckchen sowie ein schriftliches Gesuch ohne Siegel und sie bitten mich dringend, diese an den heiligen und verehrungswürdigen Hof eurer kaiserlichen Hoheit weiterzureichen. Meine Wenigkeit hat dafür Sorge getragen, dass sie - während Caecilianus in seinem Stand verbleiben

44 Ep. 88. 2; Gesta conl. Carth. III 220; vgl. Maier I, Nr. 14, 144-146; von Soden, Nr. 10; vgl. Monceaux IV, 200; Seeck, ZKG 10, 1889, 515; Girardet, Chiron 19, 1989, 185 f; Barnes, New Empire, 240 f.; Corcoran, Empire, 155 f. - Mandouze unterscheidet den Verfasser dieses Berichts (PAC, $80 \mathrm{f}$, , s. v. Anulinus 2) von dem gleichnamigen Prokonsul, der zur Zeit der Verfolgung in Afrika amtierte (PAC, 78-80, s. v. Anulinus 1). Vgl. PLRE I, 79, s. v. Annius Anullinus; 78, s. v. Anullinus 2.

45 C. ep. Parm. I 10: ultro fassus est ipsos suos adisse etiam Constantinum et eius arbitrio a iudicibus episcopis causam esse cognitam, quibus praefuit Miltiades Romanae urbis episcopus.

46 Augustinus zufolge hatten die Donatisten die „Verfolgung“ Caecilians beim Kaiser zugegeben (c. Don. 53; vgl. breuic. III 30). Dies deutet ebenfalls darauf, dass sie die Anklage gegen ihn nicht leugneten, freilich ohne das Wort „Verfolgung“ zu gebrauchen. - Die Diskussion über die relatio Anullini auf der Konferenz von 411 stellt einen Sonderfall dar und lässt daher kaum Rückschlüsse auf den allgemeinen Umgang der Donatisten mit diesem Dokument zu. Zweimal lenkten sie von diesem Dokument ab, das erste Mal, indem sie die Grundsatzdebatte über die traditio begannen, das zweite Mal, als sie thematisch weit ausholten und ihre Ausführungen über Mensurius und die traditio in Karthago vortrugen. Diese Obstruktionen entsprangen taktischen Überlegungen: Im Gesamtzusammenhang der Debatte mussten die Donatisten der relatio Anullini entgegentreten, um nicht doch plötzlich in den Status des Anklägers zu geraten, was sie unbedingt vermeiden wollten. Dennoch wird auch der inhaltliche Hintergrund ihrer Argumentation deutlich: Aus ihrer Sicht war der entscheidende Aspekt der Anklage nicht die formale Supplik beim Kaiser, sondern der Angriff der katholischen Traditoren auf die Reinheit der Kirche. Die Anrufung des Kaisers verstanden sie entsprechend als ein Akt der Verteidigung der Kirche, nicht als Verfolgung Caecilians. Auch wenn die Donatisten es nicht aussprachen: Sie wussten, dass ihre Vorfahren die Option einer Petition an den Kaiser hatten wahrnehmen müssen, wenn sie als wahre Kirche anerkannt werden wollten. Hundert Jahre später jedoch mussten die Donatisten dieser Tatsache ausweichen, um nicht von den Gegnern, insbesondere Augustinus, in eine Argumentationsfalle zu geraten. Vgl. auch o. Kap. 5.2. 
sollte - unter Beifügung der Akten geschickt werden, damit eure Majestät alles zur Kenntnis nehmen könne. Zwei Schriften wurden versandt: eines in Leder mit der Überschrift: ,Klageschrift der katholischen Kirche bezüglich der Vergehen Caecilians übergeben von der Partei des Maiorinus', außerdem eine andere Schrift ohne Siegel, die mit der in Leder verbunden ist. Geschrieben in Karthago an den 17. Kalenden des Mai im III. Konsulat unseres Herren des Augustus Konstantin." ${ }^{* 47}$

Aus diesem Bericht lassen sich einige Informationen ableiten: ${ }^{48}$ Konstantin hatte der Kirche in Afrika Privilegien eingeräumt, darunter die Befreiung von munera. Anullinus trat daraufhin in Kontakt mit Caecilianus und informierte ihn über diese Privilegien, gleichzeitig mahnte er, für die Einheit der Kirche einzutreten. Gegen diese Zuwendung an die pars Caeciliani legten die Anhänger des Maiorinus Widerspruch ein, indem sie eine Petition an Konstantin verfassten und den Prokonsul baten, diese weiterzuleiten. Gleichsam als Begründung ihres Einspruchs fügten sie eine Schrift hinzu, in der offenbar die Verstöße Caecilians gegen kirchliches Recht aufgelistet wurde. Eindeutig bestätigt die relatio Anullini Augustins Darstellung, dass die Donatisten sich freiwillig in der causa Caeciliani an den Kaiser gewandt hätten. Aus welchen Motiven und mit welcher Intention sie handelten, wird später zu fragen sein. Zunächst soll noch die Schilderung des Optatus von Mileve betrachtet werden: $:^{49}$

Im 22. Kapitel des ersten Buches leitet Optatus einen neuen Abschnitt seiner historischen Darstellung ein, indem er die Glaubwürdigkeit donatistischer Schriften infrage stellt und demgegenüber die Zuverlässigkeit der katholischen Dokumente unterstreicht. Als Beispiel für die unwahren Aussagen der Donatisten führt Optatus die beliebte Anfrage der Donatisten an: „Was haben die Christen mit den Herrschern zu tun, was die Bischöfe mit den Palästen?" Diese Aussage, so Optatus, sei falsch, da die Gründer der pars Donati sich selbst an den Kaiser mit einer Petition gewandt hätten. Anschließend zitiert er aus dieser Petition mit den Worten:

„Wir wenden uns an dich, Konstantin, bester Kaiser, da du aus einem gerechten Geschlecht bist, dessen Vater unter all den anderen Kaisern keine Verfolgung

47 Ep. 88.2: uerum post paucos dies extiterunt quidam adunata secum populi multitudine, qui Caeciliano contradicendum putarent quique fasciculum in aluta signatum et libellum sine signo obtulerunt dicationi meae atque impendio postularunt, ut ad sacrum ac uenerabilem comitatum numinis uestri dirigerem, quae manente Caeciliano in statu suo subiectis eorundem actis, quo cuncta maiestas uestra possit dinoscere, paruitas mea dirigere curauit. transmissi libelli duo, unus in aluta suprascriptus ita: 'Libellus ecclesiae catholicae criminum Caeciliani traditus a parte Maiorini', item alius sine sigillo cohaerens eidam alutae, datus die XVII Kalendas Maias Carthagine domino nostro Constantino Augusto III.

48 Vgl. Girardet, Chiron 19, 1989, 185; ders., Historia 41, 1992, 105 f.; Kriegbaum, AHP 28, 1990, 28-30.

49 Vgl. Girardet (Chiron 19, 1989, 188-196) und Kriegbaum (AHP 28, 1990, 35-38) mit Analysen des literarischen Kontextes von Opt. I 22. 
durchführte. Von dieser Untat ist Gallien frei, denn in Afrika herrscht Streit zwischen uns und anderen Bischöfen. Wir bitten dich, deine Frömmigkeit möge verordnen, dass uns aus Gallien Richter gegeben werden. Eingereicht von Lucianus, Dignus, Nasutius, Capito, Fidentius und den übrigen Bischöfen der Partei des Donatus. “50

Optatus führt seine Darstellung fort, indem er eine abweisende Reaktion Konstantins zitiert und dann die Einberufung der Bischöfe zur römischen Synode beschreibt (I 23).

Aufgrund der zahlreichen sprachlichen Unebenheiten und sachlichen Ungereimtheiten in diesem Text ist sein Quellenwert bis heute in der Forschung umstritten. ${ }^{51}$ Der überwiegende Teil der Historiker geht davon aus, dass diese von Optatus zitierte Bittschrift entweder wörtlich, zumindest aber dem Sinn nach jener unversiegelten Petition entspreche, von der in der relatio Anullini die Rede ist. ${ }^{52}$ Ein geringerer Teil hält die preces für eine Fälschung ${ }^{53}$ oder bezweifelt zumindest den Zusammenhang mit der relatio Anullini. ${ }^{54}$

Wenngleich die Quellenlage wohl kein abschließendes Urteil zulässt, so scheinen mir doch die Argumente eindeutig zu überwiegen, die gegen eine Verbindung der relatio Anullini und der bei Optatus überlieferten preces sprechen. Insbesondere K. M. GiRARDET hat die Widersprüche herausgestellt und zu Recht gefolgert, dass „Optatus kein im Wortlaut oder wenigstens der Sache nach authentisches Zeugnis für die donatistische Petition im Frühjahr 313 überliefert hat. ${ }^{\text {"55 }}$ Daraus ergeben sich Konsequenzen sowohl für die Interpre-

50 Opt. I 22: rogamus te, Constantine, optime imperator - quoniam de genere iusto es, cuius pater inter ceteros imperatores persecutionem non exercuit et ab hoc facinore immunis est Gallia, nam in Africa inter nos et ceteros episcopos contentiones sunt - petimus, ut de Gallia nobis iudices dari praecipiat pietas tua. datae a Luciano, Digno, Nasutio, Capitone, Fidentio et ceteris episcopis partis Donati. - Zur Übersetzung vgl. Labrousse, SC 412, 222 Anm. 2.

51 Zur Problemstellung allgemein siehe Girardet (Chiron 19, 1989, 185-206) und Kriegbaum (AHP 28, 1990, 23-25; Mazzucco, Ottato di Milevi, 112-117.

52 So u.a. Barnes, Constantine, 56 f.; New Empire, 238-241; Corcoran, Empire, 156 f.; Drake, Constantine and the Bishops, 216 f.; Frend, Donatist Church, 147 f.; Grasmück, Coercitio 33 mit Anm. 107; Instinsky, Bischofsstuhl, 70 f.; Keresztes, Constantine, 61; Maier I, 146-148; Millar, Emperor, 584-590; Monceaux IV, 200 f.; Piétri, Geschichte, 248; Schindler, TRE 1, 656 (,[...] wahrscheinlich teilweise echte Schreiben“).

53 Zuerst Voelter (Donatismus, 136-144) gefolgt von Seeck (ZKG 10, 1889, 550 f.; 30, 1909, 196-198, 214-216).

54 Girardet; Kaisergericht, 17-26; Chiron 19, 1989, 188-196; ders., Historia 41, 1992, 104 116 bes. 109; Kriegbaum, AHP 28, 1990, 23-49.

55 Girardet, Historia 41, 1992, 109. - Es erübrigt sich hier, sämtliche Argumente ausführlich zu diskutieren; vgl. dazu die Übersicht bei Mazzucco (Ottato di Milevi, 112 117) und die genannten Darstellungen von Voelter, Seeck, Girardet und Kriegbaum (o. Anm. 53/54). Entscheidend sind folgende Feststellungen: 1. Die Bezeichnung pars Donati steht im Widerspruch zu der Angabe pars Maiorini in der relatio Anullini. 2. 
Keinesfalls hätten die Donatisten nach der Absetzung Caecilians von einem „Streit mit anderen Bischöfen" gesprochen, denn Caecilianus war in ihren Augen kein Bischof mehr. 3. Eine explizite Bitte um Richter aus Gallien ist nur schwer zu erklären. Geht man von bischöflichen Richtern aus, so steht dies im Widerspruch zu der endgültigen Synodalentscheidung von Karthago, von denen die Donatisten stets sprachen, geht man von weltlichen Richtern aus (wie zuerst Instinsky, Bischofsstuhl, 70), so findet dies keine Entsprechung im Prozessrecht. Warum sollten sich die Donatisten an den Kaiser wenden, um dann ein mehrfach besetztes Tribunal gegen Caecilianus zu fordern? (Girardet, Chiron 19, 1989, 192-196). 4. In den späteren Äußerungen Konstantins ist niemals von der Bitte um gallische Richter die Rede, und die Donatisten beschwerten sich - trotz zahlreicher anderer Einwände - niemals, dass ihre Bitte um gallische Richter missachtet worden sei. 5. Die unklare Chronologie in der Darstellung des Optatus: Anhand des vorhandenen Quellenmaterials versuchte Optatus zwar eine Ordnung zu schaffen, aber einerseits wusste er zu wenig Einzelheiten, andererseits war ihm die Polemik wichtiger als die historische Genauigkeit. Seine Unkenntnis über das Konzil von Arles sowie das aus dem Zusammenhang gerissene Konstantinzitat (in Opt. I 23) sind nur zwei Beispiele, die gegen einen vertrauenswürdigen Umgang mit dem vorliegenden Textfragment sprechen.

Kriegbaum (AHP 28, 1990, 49-58) geht davon aus, dass es sich bei dem Text der preces nicht um eine Fälschung handele, sondern Optatus seine vorliegende Quelle einem falschen Kontext zugeordnet habe. Ausgehend von den in den preces genannten Personen, die ähnlich in Opt. App. VIII genannt werden, vermutet Kriegbaum, dass der vorliegende Text eine zusammenfassende Notiz einer Petition sei, die von den Donatisten nach der Entscheidung von Rom eingereicht worden sei. Nachdem ihnen deutlich geworden sei, dass Konstantin nicht selber urteilen wollte, hätten sie um ein erneutes Bischofsgericht gebeten, das ohne die befangenen italischen Bischöfe abgehalten werden sollte. Da Optatus über das Konzil in Arles nicht informiert war, habe er seine Vorlage als Nachweis der ersten Anklage Caecilians verwendet. - Diesem interessanten Lösungsvorschlag stehen jedoch einige Einwände gegenüber, die Girardet (Historia 41, 1992, 114-116) in seiner Replik auf Kriegbaums These zu Recht geltend macht: 1. Die Donatisten sprachen dem Konzil von Rom die Berechtigung ab, in einer afrikanischen Kirchenangelegenheit zu entscheiden (Aug. ep. 43.14; Eus. HE X 5.22; vgl. u. Kap. 7.3). Eine Bitte, nun gallische Bischöfe entscheiden zu lassen, ist daher kaum vorstellbar. 2. In den Äußerungen Konstantins ist weder vor noch nach der Synode von Arles davon die Rede, dass die Donatisten dieses Konzil selbst gefordert oder eine schriftliche Petition eingereicht hätten. - Es ist daher äußerst unwahrscheinlich, dass Kriegbaums Hypothese zutrifft. Gleichwohl stimme ich mit Kriegbaum überein, dass kaum anzunehmen ist, Optatus habe den Text der preces gefälscht. Wenn man aber eine Fälschung (auch vor Optatus) ausschließt und Optatus auf eine historische Quelle zurückgreifen konnte, welche Möglichkeiten bleiben für den historischen Kontext? Eine denkbare Alternative wäre von einem Text aus dem unmittelbaren Vorfeld des römischen Konzils auszugehen. Auch Girardet gibt zu, dass sich die Donatisten zu einem bestimmten Zeitpunkt vor den dortigen Verhandlungen ,wohl oder übel“ auf das Bischofsgericht und die neue Sachlage eingestellt hätten (Historia 41, 1992, 112). Möglicherweise entwickelte die in den „preces“ genannte Gruppe Donatisten in dem kurzen Zeitraum zwischen der Entscheidung Konstantins, ein Bischofsgericht einzuberufen, und der tatsächlichen Einberufung (Brief an Miltiades, Eus. HE X 5.18-20) den Gedanken, den Kaiser zu bitten, gallische Richter (Bischöfe) hinzuzuziehen, da sie sich von den Galliern Zustimmung erhofften. Die „preces“ wären dann ein informelles Gesuch, das an 
tation des historischen Ereignisses als auch für das Verständnis der Argumentation Augustins.

Der Hintergrund der donatistischen Petition an den Kaiser wird durch zwei Briefe Konstantins an den Prokonsul Anullinus sowie einen an Bischof Caecilianus erhellt, die in der Kirchengeschichte des Eusebius überliefert sind. ${ }^{56}$ In dem ersten Brief an Anullinus, der vielleicht noch Ende 312 geschrieben wurde, weist Konstantin den Prokonsul an, der katholischen Kirche das konfiszierte Eigentum zurückzugeben. ${ }^{57}$ Mit dem zweiten Brief veranlasste der Kaiser die Befreiung der Kleriker von allen öffentlichen Verpflichtungen in der Provinz des Anullinus. ${ }^{58}$ Ausdrücklich wird Caecilianus als Vorsteher der Kirche genannt. Dass Konstantin inzwischen über die Spaltung in der Kirche Karthagos informiert worden war, geht eindeutig aus dem Schreiben an Caecilianus selbst hervor. ${ }^{59}$ Hier ist die Rede von Irrlehrern, die das Kirchenvolk verführten. Caecilianus solle sich bedenkenlos an die weltlichen Richter wenden, wenn diese Leute in ihrem Wahnsinn verharrten. Konstantin verfügt außerdem, dass Caecilianus eine große Geldsumme (3000 folles) erhalte, die er anhand einer vorgefertigten Namensliste an Kirchen der afrikanischen Provinzen verteilen

den Kaiser gestellt wurde. Freilich gilt auch bei dieser Möglichkeit der Einwand, dass von derartigen Forderungen in keiner Äußerung des Kaisers die Rede ist. Allerdings erklärt sich mit dieser Einordnung die Bezeichnung pars Donati und die Chronologie bei Optatus. Zu dem früheren Termin passt zudem die Hoffnung des gerade erst als Nachfolger des Maiorinus geweihten Donatus, doch noch die Anerkennung der überseeischen Kirchen zu erhalten.

56 Zur Sammlung konstantinischer Briefe bei Eusebius vgl. B. H. Warmington, The Sources of Some Constantinian Documents in Eusebius' Ecclesiastical History and Life of Constantine, Studia Patristica 18, 1985, 93-98; T. D. Barnes, The Constantinian Settlement, in: Eusebius, Christianity and Judaism, Leiden/New York/Köln 1992, 635 657. - E. Carotenuto (Six Constantinian Documents (Eus. H. E.10, 5-7), VChr 56, 2002, 56-74, hier: $67 \mathrm{f}$.) vermutet, dass die sechs Briefe in einem „antidonatistischen Milieu“ vor 315/16 zusammengestellt worden seien. Mit den Dokumenten sollte verdeutlicht werden, dass nur die katholische Kirche der Partei Caecilians Empfänger der kaiserlichen Zuwendungen sei und nicht die Donatisten. Eusebius habe später diese Zusammenstellung - vielleicht über einen Kontaktmann aus Rom - erhalten, ohne die $\mathrm{Zu}$ sammenhänge zu kennen. Für Carotenutos Vermutungen sprechen sowohl die Thematik der überlieferten Briefe als auch der Kontext bei Eusebius. Sicherheit lässt sich hierin aber kaum erlangen.

57 Eus. HE X 5.15-17; Maier I, Nr. 11, 138 f.; von Soden Nr. 7; vgl. Barnes, Constantine, 56; New Empire, 240 f.; Corcoran, Empire, 153; Dörries, Selbstzeugnis, 16; Monceaux IV, 200.

58 Eus. HE X 7.1-2; Maier I, Nr. 13, 142-44; Soden Nr. 9; vgl. Barnes, New Empire, 169 f., 240 f.; Corcoran, Empire, 155; Dörries, Selbstzeugnis, 18 f.; Monceaux IV, 200; Seeck, ZKG 10, 1889, 511. - Zur Privilegierung der Kleriker vgl. CTh XVI 2.1-2 (Befreiung der Kleriker von munera in Italien), dazu Corcoran, Empire, 155, 162.

59 Eus. HE X 6.1-5; Maier I, Nr. 12, 140-142; Soden Nr. 8; vgl. Barnes, New Empire, 240 f.; Corcoran, Empire, 153; Dörries, Selbstzeugnis, 17 f.; Monceaux IV, 200; Seeck, ZKG 10, 1889, $510 \mathrm{f}$. 
solle. Vermutlich war auch diese Zuwendung zur Förderung der kirchlichen Einheit gedacht.

Wie bereits dargestellt bestätigte Anullinus in seinem Bericht an den Kaiser die Durchführung der an ihn ergangenen Verfügungen und sah sich daraufhin den Protesten der Donatisten ausgesetzt.

Das Motiv der Donatisten, sich über den Prokonsul an den Kaiser zu wenden, wird durch diese zusätzlichen Quellen evident: Die pars Donati sah sich selbst als die wahre Vertreterin der katholischen Kirche und sie forderte nun, dass die Vergünstigungen und die finanzielle Unterstützung an ihre Adresse mit ihrem Bischof Maiorinus zu gehen hätten. Caecilianus war vom Kaiser offensichtlich als Vertreter der afrikanischen Kirche anerkannt worden. Dies konnten die Donatisten nicht akzeptieren. In ihren Augen war Caecilianus kein Bischof mehr und daher auch nicht berechtigt, die afrikanische Kirche zu vertreten. Deshalb begründeten sie ihren Einspruch mit einem Dossier, das sich allein auf die Person Caecilians bezog, jenem libellus criminum Caeciliani. ${ }^{60}$

Handelte es sich bei diesem Vorgang im juristischen Sinne um eine Anklageerhebung, eine förmliche Prozesseinleitung gegen Caecilianus? Die Mehrheit der Historiker vertritt diese Ansicht oder lässt die Frage offen, die aufgrund der mangelnden Kenntnisse über den Inhalt der beiden libelli nicht leicht $\mathrm{zu}$ beantworten ist. ${ }^{61}$ Die pars Maiorini war in einer für sie schwierigen Lage: Welche Argumente könnten Konstantin überzeugen, dass nicht Caecilianus, der rechtmäßig exkommuniziert worden war, sondern Maiorinus als Bischof von Karthago gelten müsse und daher Anspruch auf die Privilegien hätte? K. M. Girardet geht davon aus, dass die Anklagen, die zur Absetzung Caecilians geführt hatten, nicht mehr Gegenstand der Anklage beim Kaiser gewesen seien, da die ,kirchlich zu ahndenden crimina durch die allein zuständige Instanz", nämlich durch das Konzil von Karthago, endgültig erledigt worden seien. Die pars Maiorini hätte daher eine Zivilklage erhoben, mit der Begründung, Caecilianus habe - da er ja kein Bischof gewesen sei - rechtswidrig Kirchenbesitz, Privilegien und Geldzuwendungen des Kaisers in Anspruch genommen.

60 Kriegbaum, AHP 28, 1990, 30 f.; Grasmück, Coercitio, 32.

61 So etwa Seeck, Geschichte III, 328 („Anklageschrift gegen Caecilianus“); insbesondere aber Girardet, Kaisergericht, 17-20, 26 f.; Chiron 19, 1989, 204-206; und Grasmück, Coercitio, 32-39 (,Zivilklage gegen Caecilian“). - Ein Teil der Forschung geht indessen aufgrund von Opt. I 22 (fälschlicherweise) von dem Wunsch nach weltlichen iudices dati aus, so Instinsky, Bischofsstuhl, 70; Frend, Donatist Church, 146-148; Maier I, 147. Anders urteilen zwangsläufig jene, die von dem Wunsch nach einem Bischofsgericht ausgehen, etwa Monceaux IV, 21; Barnes, JThS 26, 1975, 20 f.; Constantine, 57; Congar, BA 28, 15 f.; Drake, Constantine and the Bishops, 57; Keresztes, Constantine, 58-61; Piétri, Geschichte, 24. - Zur Rechtsgrundlage der Litisdenuntiation vgl. Kaser/Hackl, Zivilprozessrecht, 566-570. 
Möglicherweise sei ihm auch gewaltsame Amtsanmaßung und Mord vorgeworfen worden. ${ }^{62}$

Im Gegensatz zu dieser Deutung ist es allerdings ebenso möglich, dass die pars Maiorini zunächst den Kaiser grundsätzlich über den Sachverhalt des Schismas, die Lage in Karthago und auch über die Person Caecilians aufklären wollte. Die crimina Caecilians umfassten demnach nicht nur die Vorwürfe der Amtsanmaßung, sondern die auch später noch stereotyp vorgetragenen Anklagen gegen Caecilianus: Seine traditio, seine Kollaboration während der Verfolgung, seine Weihe durch einen Traditor und die daraus resultierende Absetzung auf einem ordentlichen Konzil in Karthago. Trifft diese Vermutung $\mathrm{zu}$, dann beinhaltete der libellus criminum Caeciliani die Sammlung aller bestehenden Vorwürfe gegen Caecilianus, die dem Kaiser übermittelt werden sollte, verbunden mit der Bitte, diese Anschuldigungen zur Kenntnis zu nehmen. Die pars Maiorini erwartete vom Kaiser keinen Prozess gegen Caecilianus und auf keinen Fall die Einberufung einer Synode, sondern lediglich eine Revision seiner bisherigen Entscheidung, nachdem er über die wahren Sachverhalte aufgeklärt worden war. ${ }^{63}$

Der weitere Verlauf der Ereignisse unterstützt die letztgenannte Möglichkeit und spricht somit gegen eine förmliche Anklage. Wenn nämlich Konstantin eine zivilprozessrechtliche Anklage gegen Caecilianus mit säkular justiziablen Anschuldigungen erhalten hätte, dann wäre dies wahrscheinlich auch in entsprechender Form durchgeführt und entschieden worden. Der Kaiser oder ein Stellvertreter (iudex datus) hätten ein Urteil gefällt, wie es im Falle des Felix von Abthugni geschah. Genau das ist aber nicht geschehen, sondern Konstantin berief ein kirchliches Gremium ein und beauftragte es, zwischen Donatus und Caecilianus zu entscheiden. Dieses Vorgehen erklärt sich am besten, wenn man von einem grundsätzlichen Protest und generellen Anschuldigungen der pars Maiorini gegen Caecilianus ausgeht. Konstantin sah sich offensichtlich nicht in der Lage, die von Anullinus weitergereichten Anschuldigungen zu beurteilen, da es um Kirchenfragen ging. Er war zwar daran interessiert, die Spaltung zu überwinden und Unruhen zu vermeiden, doch wollte er die Entscheidung über kirchenrechtliche Fragen der Kirche selbst überlassen. ${ }^{64}$ Es war somit Kon-

62 Girardet, Kaisergericht, 19 f.; Chiron 19, 1989, 205. Girardet betont allerdings den hypothetischen Charakter seiner Interpretation.

63 Vgl. Kriegbaum, AHP 28, 1990, 33-35, insbesondere Anm. 40 u. 41. - Girardet (Chiron 19, 1989, 204) ist der Meinung, diese Interpretation stehe im Widerspruch zu dem bereits gefällten Urteil des Konzils von Karthago. Dies ist aber nicht der Fall, denn die Donatisten wollten schließlich kein neues Urteil über Caecilianus, sondern lediglich eine Bestätigung ihrer Entscheidung durch den Kaiser. Sollte Konstantin ihren Ausführungen folgen, erübrigte sich ein Prozess gegen Caecilianus.

64 Diese Tendenz zeigt sich in den Äußerungen Konstantins gegenüber Miltiades (Eus. HE X 5.18-20) und Aelafius (Opt. App. III). Zu diesen Texten vgl. u. Kap. 7.3. 
stantin, der ein Verfahren gegen Caecilianus einleitete, indem er erstmals aufgrund kaiserlicher Gewalt eine Bischofssynode einberief, die an seiner statt urteilen sollte. ${ }^{65}$

Sollte diese Annahme richtig sein, dann stellt sich die Frage, warum in den Schriften Augustins nach 405 und auf der Konferenz von 411 stets von „Anklage“ die Rede ist. GiRARDET sieht darin eine Bestätigung für den juristischen Vorgang der Prozesseinleitung. ${ }^{66}$ Tatsächlich formuliert Augustinus seine Aussagen im Zusammenhang mit der relatio Anullini stets mit den juristischen Termini accusare oder accusatio. ${ }^{67}$ Mit welcher Intention aber spricht er von dieser Anklage? Der Blick auf das Argumentationsgefüge zeigt, dass Augustinus an den entsprechenden Stellen ohne Ausnahme die spätere Durchführung von Prozessen bzw. die Anwendung von staatlicher Gewalt gegen Donatisten rechtfertigen will. Er begründet die antidonatistische Gesetzgebung seiner Gegenwart mit der Konstruktion einer rechtlichen Kontinuität, die in der Anklage der pars Maiorini ihren Ausgangspunkt genommen haben soll. Er wird nicht müde $\mathrm{zu}$ wiederholen: Vos imperatoris iudicium flagitastis ! ${ }^{68}$ Augustins juristische Formulierungen sind daher kein Beleg für eine Prozesseinleitung. Seine Wortwahl ist vielmehr einer Argumentationsabsicht unterworfen, in der die späteren rechtlichen Konstellationen in erheblichem Maße auf die Vorgänge des Aprils 313 projiziert werden. ${ }^{69}$

Die juristischen Formulierungen, die in den Texten aus dem Umfeld der Konferenz von $411 \mathrm{zu}$ lesen sind, lassen sich ebenfalls aus dem Argumentati-

65 Vgl. Girardet (Chiron 19, 1989, 205 f.), der (trotz der m.E. falschen Annahme einer Prozesseinleitung durch die pars Maiorini) zu Recht davon ausgeht, dass Konstantin selbst entschied, die causa Caeciliani als causa ecclesiastica zu behandeln und daraufhin das Bischofsgericht berief. Zu Girardets Verständnis des Prozesses in Rom vgl. u. Kap. 7.3.

66 Girardet, Chiron 19, 1989, $202 \mathrm{f}$.

67 Augustins verwendet entweder die Wörter accusare / accusatio oder eine Formulierung mit (ad Constantinum) deferre. Vgl. die Stellenangaben o. Anm. 41.

68 S. Denis 19.8. Zur Darstellung der gesetzgeberischen Kontinuität in der Argumentation Augustins vgl. o. Kap. 4.2.2.

69 Wenngleich Augustinus einer wahrheitsgetreuen Wiedergabe der Geschichte einen hohen Stellenwert einräumt, so hält er sich in seiner Polemik einen Interpretationsrahmen offen. Im Bezug auf die Prozesse gegen Caecilianus lässt sich dies gut erkennen, wenn man seine Vergleiche mit den Maximianisten heranzieht: Obwohl er den gleichen Sachverhalt wiedergibt und zum Teil die gleichen Vorwürfe der Donatisten bekämpft (nämlich die „Verfolgung“ der Donatisten), ist an diesen Stellen (auch mit Kenntnis der relatio Anullini) von juristischen Formulierungen nichts mehr zu lesen. Weder unterscheidet er die Verurteilung Caecilians in Karthago von den Urteilen in Europa noch die Urteile der Bischöfe von dem des Kaisers. Die „Prozesseinleitung“ spielt bei seiner Gegenüberstellung Primianus - Caecilianus keine Rolle. Vgl. Cresc. III 16; IV 9; Emer. 9; c. Don. 37; explizit in Cresc. IV 9: pro quo [sc. Caeciliano] non unum, sicut pro Primiano, sed quattuor posteriora iudicia recitantur. Dazu o. Kap. 3.4.2.2. 
onszusammenhang erklären: Zum einen trug die gesamte Struktur der historischen Argumentation der Katholiken die Handschrift Augustins mit den genannten Implikationen, ${ }^{70}$ zum anderen unterstand die Debatte einer klaren juristischen Forderung, da Marcellinus explizit den Nachweis der „ersten Anklage" gefordert hatte. Beide Parteien mussten dieser Forderung nachkommen. ${ }^{71}$ Verständlicherweise zogen die Katholiken die relatio Anullini heran und wiesen es als Dokument der ersten Anklage aus. Es ist jedoch zu berücksichtigen, dass von Donatisten und Katholiken auch Aktenstücke vorgelegt wurden, die eindeutig keine Anklageschriften im juristischen Sinne darstellten, die aber genauso die „erste Anklage“ belegen sollten. ${ }^{72}$ Aufgrund der verwendeten Formulierungen lässt sich insofern nicht folgern, dass die relatio Anullini eine formelle Anklageschrift gewesen sei. ${ }^{73}$

Außer der relatio Anullini existierten im Jahre 411 weitere Dokumente, die heute nicht erhalten sind, damals aber zusätzliche Informationen über den Weg der Anklageerhebung liefern konnten. So waren die Katholiken im Besitz einer weiteren relatio des Anullinus, in der über die Entsendung von Vertretern beider Parteien nach Rom Auskunft gegeben wurde, ${ }^{74}$ darüber hinaus standen die gesamten Akten der römischen Synode zur Verfügung, einschließlich der Urteilssprüche. ${ }^{75}$ Über die Form der Anklageerhebung konnten die Protokolle aus Rom keine weiterführenden Auskünfte geben, da ein völlig anderer Pro-

70 Vgl. Gesta conl. Carth. I 14, 16, 55 (SC 195, Z. 332 ff.). Die katholische Strategie ist folgende: Wenn die Donatisten sich über Gewalt und Verfolgung beschweren, dann antworten die Katholiken (neben dem biblischen Zeugnis) auch mit den menschlichen Dokumenten, die zeigten, dass die Donatisten zuerst beim Kaiser geklagt hätten. Vgl. oben Kap. 5.1.2.

71 Gesta conl. Carth. III 117, 120.

72 Die Akten über eine donatistische Gesandtschaft nach Ravenna im Jahr 406 (gesta conl. Carth. III 124, 128) und die Petition katholischer Bischöfe mit Bitte um Religionsgespräche aus dem Jahr 403 (gesta conl. Carth. III 141). - Die Zusammenhänge sind o. Kap. 5.3. ausführlich dargestellt worden.

73 Vgl. auch die Argumente Kriegbaums (AHP 28, 1990, 30-35), der zu Recht darauf hinweist, dass die erste Instanz eines Zivilprozesses der Prokonsul hätte sein müssen. Gleichwohl könnte man in diesem Fall auch eine Ausnahme annehmen (Girardet, Historia 41, 1992, 106). Kriegbaum hält es für möglich, dass die Klagen gar „keine prozessuale Relevanz" besaßen. Ebenso sei denkbar, dass zunächst die Katholiken die pars Maiorini beim Prokonsul angeklagt und daraufhin die Donatisten eine Klageerwiderung (libellus contradictoribus) abgefasst hätten. Aufgrund von Überforderung in der Sache hätte Anullinus die Sache dann an den Kaiser weitergeleitet. Gegen die letzte Einschätzung spricht jedoch die ausdrückliche Forderung der pars Maiorini um Weiterleitung in der relatio Anullini. Vgl. auch Girardet, Historia 41, 1992, 105-107.

74 Breuic. III 24; vgl. Monceaux IV, 201; Seeck, ZKG 10, 1889, 515 f.; Grasmück, Coercitio, 39.

75 Cap. conl. Carth. III 315-320, 402; breuic. III 24; vgl. o. Kap. 5.3.2. 
zessrahmen gesteckt worden war, als die Donatisten gefordert hatten. ${ }^{76}$ Die zweite relatio Anullini scheint in dieser Frage ebenfalls nicht weiterführend gewesen zu sein. Wenn aus diesem Dokument klar hervorgegangen wäre, dass Caecilianus zivilrechtlich verklagt worden war, dann wäre dies mit Sicherheit auf der Konferenz thematisiert worden. Die Donatisten hätten mit ganz anderen Argumenten die Unzuständigkeit der römischen Synode anprangern können, als sie es taten. Die zusätzlichen Dokumente konnten also die Kenntnisse der Parteien über den Inhalt der Anklageschrift nicht erweitern. Die Argumentationen erfolgten auf der gleichen Basis und mit den gleichen Intentionen wie zuvor.

Das Wort „Anklage“ im Zusammenhang mit der relatio Anullini wird folglich sowohl bei Augustinus als auch auf der Konferenz von 411 entweder nicht im juristischen Sinne oder mit einer eindeutigen, auf die Gegenwart bezogenen Argumentation, verwendet. Es lässt sich entsprechend kein sicherer Rückschluss über die tatsächliche Form der Anklage der pars Maiorini ziehen. Am wahrscheinlichsten bleibt die Möglichkeit, dass der libellus criminum eine Sammlung von Vorwürfen gegen Caecilianus enthielt, ohne dass die Einleitung eines Zivilprozesses intendiert war.

Für Augustinus war die Frage nach der juristischen Intention der Anklagen zu keinem Zeitpunkt entscheidend. Auch er kannte nicht den genauen Inhalt der donatistischen Eingaben und ging von einer wie auch immer gearteten Anklage Caecilians beim Kaiser aus, die er mit der relatio Anullini begründete. Für seine Argumentation betonte er, dass die Donatisten als erste und freiwillig den Kaiser um Unterstützung in einer kirchlichen Angelegenheit ersucht hätten. Seine historische Darstellung ist somit richtig im Hinblick auf den äußeren Vorgang des donatistischen Bittgesuchs. Es ist jedoch bemerkenswert, dass Augustinus niemals auf die vorangegangenen finanziellen Zuwendungen Konstantins an die katholische Kirche eingeht. Damit unterschlägt er den tatsächlichen Grund des donatistischen Protestes und rückt die persönlichen Vorwürfe gegen Caecilianus in den Vordergrund; er übergeht geflissentlich, dass die Katholiken bereits vom Kaiser bevorzugt wurden und mit ihm kooperierten, indem sie finanzielle Zuwendungen entgegennahmen. Dadurch gelingt es ihm, die Widersprüche in der donatistischen Argumentation noch deutlicher zu kennzeichnen. Es bleiben aber jene historischen Hintergründe blass, die Augustinus aufgrund seiner Quellenbasis ausführlicher hätte darstellen können.

Aus den wenigen Stellen, die Aussagen von Donatisten enthalten, geht nicht hervor, ob und in welcher Weise die Petition an den Kaiser in der donatistischen Tradition eine Rolle spielte, ob Hintergründe und Motive überliefert wurden. Sicher ist allerdings, dass es den Donatisten zur Zeit Augustins nicht gelegen 
kam, mit den Verbindungen ihrer Vorgänger zu Kaiser Konstantin konfrontiert zu werden. Es passte nicht zu ihrem grundsätzlichen Verständnis der verfolgten Kirche. Gleichwohl mussten die Donatisten in der konkreten Auseinandersetzung reagieren, vor allem auf Augustins Versuche, mit Verweis auf die relatio Anullini die aktuellen staatlichen Eingriffe gegen die Donatisten zu rechtfertigen. Allerdings versuchten sie erst gar nicht, den Inhalt dieses Dokuments in Zweifel zu ziehen, sondern sie verlagerten die Debatte und setzten einen anderen Akzent. Während Augustinus stets den Zusammenhang zwischen jener ersten Anklage gegen Caecilianus im Jahre 313 und den gegenwärtigen Auseinandersetzungen betonte, beurteilten die Donatisten die Ereignisse getrennt voneinander: Ihre traditio-Anklagen gegen Felix und Caecilianus vor weltlichen Instanzen betrachteten sie als eine notwendige Maßnahme zur Verteidigung der Kirche. Ihre Verfolgung durch die Katholiken und den Kaiser dagegen stellte aus donatistischer Perspektive einen abzulehnenden Angriff auf die wahre Kirche dar. Auf diese Weise konnten die Donatisten ausweichen, wenn Augustinus ihnen vorwarf, mit zweierlei Maß zu messen, indem sie einerseits selbst säkulare Hilfe in Anspruch nähmen, andererseits gegen die staatlichen Entscheidungen aufbegehrten. Ihre Ekklesiologie erlaubte es den Donatisten, nach diesem eklektizistischen Prinzip zu verfahren: Die Reinheit der Kirche konnte auch mit Hilfe weltlicher Mittel verteidigt werden, ohne dass damit eine generelle Anerkennung weltlicher Verfügungen einhergehen musste.

\section{Die Konzile von Rom und Arles}

Der Verlauf der Konzile in Rom und Arles spielte in der historischen Argumentation beider Seiten bis auf wenige Ausnahmen eine untergeordnete Rolle. Entscheidend waren lediglich die Urteile dieser Synoden in der causa Caeciliani. Die Weigerung der Donatisten, die in Rom und Arles gefällten Freisprüche Caecilians anzuerkennen, nahm Augustinus zum Anlass, scharf gegen das Schisma und die Verletzung der Kircheneinheit durch die Donatisten zu polemisieren. $^{77}$

Über den Verlauf des Konzils von Rom berichtet Augustinus ausführlicher nur in dem Brief an seine Gesprächspartner von Thubursicum (ep. 43), obwohl er über die Vorgänge sehr gut informiert war. Augustinus kannte nachweislich die gesamten Konzilsakten, darüber hinaus einen Brief Konstantins an den römischen Bischof Miltiades und den Bericht des Anullinus über die Entsendung

77 Ps. c. Don. 105-107; c. litt. Pet. II 205; III 29; c. ep. Parm I 10-11; II 30; cath. fr. 46; Cresc. III 44; IV 9; un. bapt. 28; c. Iul. 7; epp. 43. 4-5, 14-16; 53.5; 76.2; 88.3; 89.3; 93.13; 105.8; breuic. III 24, 31, 37; c. Don. 17, 19, 56; correct. 47; s. Denis 19.8; vgl. auch bapt. II 14 . 
der beiden Streitparteien nach Rom. Da heutzutage von den genannten Quellen nur noch der Brief an Miltiades existiert, kommt der Interpretation von $\mathrm{Au}-$ gustins ep. 43 eine besondere Bedeutung zu.

Neben Augustinus geben nur wenige Quellen Auskunft über die römische Synode: Optatus von Mileve erwähnt in einem kurzen Bericht den Versammlungsort und das Datum; zudem listet er die Namen der Teilnehmer auf. ${ }^{78}$ Einige Rückschlüsse lassen sich aus den erhaltenen Briefen Konstantins ziehen, die vor und nach der Synode geschrieben worden sind, und schließlich geben die Konferenzakten von 411 bzw. Augustins Breviculus zusätzliche Hinweise. ${ }^{79}$ Die Rekonstruktion der Ereignisse bleibt jedoch aufgrund der wenigen Anspielungen und Fragmente problematisch.

Das Konzil von Rom, das in der causa Caeciliani entscheiden sollte, fand Ende September und Anfang Oktober 313 auf dem Lateran statt. ${ }^{80}$ Außer dem römischen Bischof Miltiades waren noch 18 weitere Bischöfe als Richter anwesend, drei von Konstantin ausgewählte Bischöfe aus Gallien ${ }^{81}$ sowie 15 Bischöfe aus Italien, die Miltiades wohl eigenständig hinzugezogen hatte. Aus dem Brief Konstantins an Miltiades, der durch die Kirchengeschichte des Eusebius erhalten ist, gehen einige Motive und Erwartungen des Kaisers hervor ${ }^{82}$ Kon-

78 Opt. I 23-24.

79 Cap. conl. Carth. III 317-320, 402, 404; breuic. III 24, 31; vgl. c. Don. 56.

$80 \mathrm{Zu}$ diesem Konzil vgl. Girardet, Kaisergericht, 26-35; Historia 41, 1992, 104-116; Grasmück, Coercitio, 39-49; Instinsky, Bischofsstuhl, 74-82; Lietzmann, Geschichte III, 72-74; Maier I, Nr. 17, 151 f.; Monachino, AHP 2, 1964, 11-16; Roethe, Synoden, 51-81; Mühlsteiger, ZRG KA 85, 1999, 21-30. - Die wichtigsten Quellen versammelt von Soden, Nr. 13, 14-16. - Zur Identifizierung des Versammlungsortes vgl. Ernest Nash, Convenerunt in domum Faustae in Laterano S. Optati Milevitani I, 23, RQA 71, 1976, 1-21. - Zum Datum vgl. Roethe (Synoden, 64 f. mit Anm. 44), der zu Recht ausgehend von c. Don. 56 den 2. Oktober als letzten Tag der Synode mit Urteilsverkündung zählt. So auch Mandouze (PAC, 169 Anm. 38) und Mühlsteiger (aaO, 24); gegen die weit verbreitete Datierung 2.-4. Oktober etwa bei Monceaux (IV 22, 338) und Seeck, Geschichte III, 329 f.; vgl. auch Maier I, 151 Anm. 3.

81 Reticius von Autun, Maternus von Köln und Marinus von Arles. Alle drei Bischöfe sind auch Teilnehmer des Konzils von Arles ein Jahr später (vgl. Gaudemet, SC 241, 56-60). Roethe (Synoden, 55 f.) vermutet wohl zu Recht, dass diese Bischöfe Konstantin persönlich bekannt waren und sein Vertrauen besaßen.

82 Eus. HE X 5.18-21; Maier I, Nr. 16, 148-150; von Soden Nr. 12; vgl. Monceaux IV, 201; Seeck, ZKG 10, 1889, 512 f.; Dörries, Selbstzeugnis, 20 f.; Barnes, New Empire, 241; Corcoran, Empire, 160. - Das Datum des Briefes ist nicht überliefert; er dürfte jedoch in einem nicht allzu großen Abstand nach der relatio Anullini geschrieben worden sein, im Frühjahr oder Sommer 313 (von Trier aus). - Die Adresse nennt neben Miltiades einen gewissen Marcus als zweiten Adressaten. Eine Identifizierung dieser Person ist schwierig. Seeck (aaO, 512) vermutet einen Übertragungsfehler: der ursprüngliche zweite Adressat sei vermutlich Merocles, der Bischof von Mailand gewesen, der am Konzil in Rom teilnahm. Doch Augustinus überliefert ebenfalls den Namen Marcus (s. 
stantin lässt erkennen, dass ihm die Kirchenspaltung in der erst kürzlich erworbenen Provinz sehr große Sorgen bereitete; eine Ausweitung des Streites sollte unbedingt verhindert werden. Er informierte Miltiades über die Anklagen gegen Caecilianus und über seine Anordnungen, die drei gallischen Bischöfe sowie je zehn Bischöfe der beiden Parteien nach Rom zu beordern. Den Konzilsteilnehmern übersandte er Kopien der beiden donatistischen libelli, damit sie sich vorab ein Bild über die Sachlage machen konnten. Vom römischen Bischof forderte der Kaiser eine gewissenhafte Untersuchung und auf jeden Fall eine Beendigung des Schismas. Unter Beachtung des kirchlichen Rechts überließ er jedoch Miltiades die Entscheidung über die weitere Verfahrensweise. ${ }^{83}$

Konstantin verstand den Fall als innerkirchlichen Streit über die Rechtmäßigkeit des Bischofsamtes Caecilians. Er sah sich aber auch dem Gott der Christen gegenüber verpflichtet, derartige Streitigkeiten zu unterbinden und die rechte Ausübung des christlichen Kultes zu gewährleisten. ${ }^{84}$ Daher delegierte er die Aufgabe an ein kirchliches Gremium, das ihm geeignet schien, den Konflikt möglichst schnell, und zum Wohl von Staat und Kirche zu schlichten. ${ }^{85}$

Nachdem sich das Konzil offenbar ohne Schwierigkeiten konstituiert hatte und die beiden Parteien in Rom eingetroffen waren, begannen die Verhandlungen. Im Breviculus der Konferenz von 411 gibt Augustinus auf Grundlage der römischen Akten ein kurzes Resümee über den Verlauf des ersten Verhandlungstages. Demnach hätten die Ankläger Caecilians verweigert, zu den Anklagen Stellung zu nehmen. Außerdem sei Donatus von Casae Nigrae in Anwesenheit überführt worden, in Karthago ein Schisma verursacht zu haben, zu der Zeit, als Caecilianus noch Diakon war. ${ }^{86}$ Optatus von Mileve spricht ebenfalls von dem „Eingeständnis“ der donatistischen Zeugen, nichts gegen

Denis 19.8). Möglicherweise handelte es sich um einen Diakon (so auch Kraft, Entwicklung, 168 f.); vgl. Maier I, 149 Anm. 4 und Pietri, PIC 2, 1389, s. v. Marcus 1.

83 Vgl. Roethe, Synoden, $59 \mathrm{f}$.

$84 \mathrm{Zu}$ diesem Motiv s. Konstantins Brief an den Vikar Aelafius, Opt. App. III (hier: ed. Ziwsa, S. 206 Z. 9 ff.); Maier I, Nr. 18, 153-158; von Soden Nr. 14. Der Brief ist nur in einer schlechten Handschrift überliefert und der Text teilweise unverständlich. Die Authentizität wurde häufig angezweifelt. Zur Problematik vgl. Kraft, Entwicklung, 172 183; Grasmück, Coercitio, 51 f. Anm. 226; Dörries, Selbstzeugnis, 21-24; Monceaux IV, 202; Seeck, ZKG 30, 1909, 200-207.

85 Es ist unergiebig, darüber zu spekulieren, ob und in welcher Weise Ossius von Cordova den Kaiser gegen die Donatisten beeinflusst haben könnte. So u.a. bei Maier I, 148 Anm. 1; Girardet, Kaisergericht, 29 f.; Instinsky, Bischofsstuhl, 72; Seeck, ZKG 10, 1889, 513. - Vgl. u. Kap. 7.4.2.2.

86 Breuic. III 24: atque inde ex ordine legi coepit etiam episcopale iudicium Miltiadis Romani episcopi et aliorum cum illo Gallorum et Italorum episcoporum in eadem urbe Romae factam, cuius iudicii prima parte, id est gestis primi diei recitatis, ubi accusatores Caeciliani qui missi fuerant negauerunt se habere quod in eum dicerent, ubi etiam Donatus a Casis Nigris in praesenti conuictus est adhuc diacono Caeciliano schisma fecisse Carthagine [...]. 
Caecilianus in der Hand zu haben. Donatus dagegen habe „gestanden“, wiedergetauft und gefallenen Bischöfen die Hand aufgelegt zu haben. ${ }^{87}$

Diese Aussagen lassen erkennen, dass Donatus zum Auftakt des ersten Verhandlungstages die Rolle eines Anklägers gegen Caecilianus übernommen hatte und das Plädoyer der Anklage hielt. Darin erläuterte er dem Gericht die Situation der Kirche in Karthago und Afrika. Er legte dar, dass seiner Ansicht nach Traditoren als Bischöfe nicht ohne Buße in ihrem Amt verbleiben könnten und deshalb Wiedertaufen praktiziert worden seien. Ausgehend von dieser Grundlage dürfte Donatus die bekannten Beschwerden gegen Caecilianus (vor allem die Weihe durch Traditoren) vorgebracht haben. ${ }^{88}$ Im Anschluss daran sollten weitere Zeugen die Anklagen bestätigen, was laut Auskunft der Protokolle aber nicht geschah.

Zur Feststellung weiterer Einzelheiten führen die Aussagen Augustins in ep. 43 weiter. Dort schreibt er über die Verhandlungen in Rom:

„Seht, mit welcher Sorge um die Bewahrung und Wiederherstellung von Frieden und Einheit alles besprochen wurde, auf welche Weise die Person der Ankläger untersucht wurde und aufgrund welcher Mängel etliche von ihnen zurückgewiesen wurden; und dass aufgrund der Aussagen der Anwesenden mit Gewissheit festgestellt wurde, dass [die Ankläger] nichts hatten, was sie gegen Caecilianus sagen konnten, sondern dass sie die ganze Sache den Anhängern der pars Maiorini - das heißt einem aufrührerischen und vom Frieden der Kirche entfremdeten Pöbel zuschieben wollten, damit nämlich Caecilianus von dieser tobenden Menge angeklagt werden sollte. Sie, so glaubten sie, werde allein mit tumultartigem Geschrei, ohne den Beweis von Dokumenten und ohne eine Untersuchung der Wahrheit, die Herzen der Richter zu ihren Gunsten verdrehen können, [...]." ${ }^{89}$

Es folgen eine Polemik gegen das Konzil von Karthago und ein Vergleich der Urteile von Secundus und Miltiades. In Rom, so betont Augustinus nochmals, hätten die Richter nicht zugelassen, dass Caecilianus durch die anonyme Masse der pars Maiorini anstatt durch einen ordentlichen Kläger angeklagt werde.

Diese Aussagen Augustins beziehen sich zwar eindeutig auf die vorliegenden Konzilsakten von Rom, jedoch erscheint die Darstellung offensichtlich übertrieben. Augustins primäres Argumentationsziel in diesem Brief war es, die

87 Opt. I 23: [...] quod confessus sit se rebaptizasse et episcopis lapsis manum inposuisse, quod ab ecclesia alienum est.

88 Vgl. Roethe, Synoden, 66.

89 Ep. 43.14: uidete, quanta cura pacis atque unitatis conseruandae uel restituendae cuncta discussa sint, quem ad modum accusatorum persona tractata et quorundam eorum quibus maculis inprobata sit praesentiumque uocibus liquido constiterit nihil eos habuisse, quod in Caecilianum dicerent, sed totam causam in plebem de parte Maiorini, hoc est seditiosam et ab ecclesiae pace alienatam multitudinem transferre uoluisse, ut ab ea uidelicet turba Caecilianus accusaretur, quam solis tumultuosis clamoribus nulla documentorum adtestatione, nullo ueritatis examine ad suam uoluntatem animos iudicum detorquere posse arbitrabantur, [...]. 
Legitimität der europäischen Urteile zu bekräftigen. Er stellt die sorgfältige Untersuchung in Rom dem vom Pöbel geforderten Urteil in Karthago gegenüber. Dies spiegelt sich in seiner Auslegung wider, die zugespitzt lautet: Die Donatisten hätten auf die Fragen des Gerichts nicht geantwortet und anstelle einer sorgfältigen Untersuchung wiederum ein tumultartiges Verfahren haben wollen. $^{90}$

Die historische Grundlage für Augustins Interpretation zeichnet sich zwischen den Zeilen ab: Offensichtlich wurden gegen Donatus und seine Mitstreiter Vorwürfe erhoben, die überprüft und als wahr angesehen wurden. Sie selbst wurden zu Angeklagten, wie es auch das spätere Urteil verdeutlichte. Jene Aussage, die Augustinus mit „der pars Maiorini zuschieben“ bezeichnet, bezieht sich auf jenes donatistische Argument, das genauso noch im Jahre 411 vorgetragen wurde: Die Donatisten verwiesen auf das in ihren Augen kirchenrechtlich bindende Urteil des Konzils von Karthago und forderten die Anerkennung dieser Entscheidung anstelle einer neuen Untersuchung der Anklagen gegen Caecilianus. ${ }^{91}$ Die römischen Richter lehnten diese Forderung als Grundlage des Prozesses ab und erwarteten von Donatus einen Vortrag der Beschuldigungen gegen Caecilianus und Zeugen, die dies im Einzelnen bestätigen konnten. ${ }^{92}$ Dieses wiederum verweigerte Donatus, eine Entscheidung, die zu den späteren Formulierungen beitrug, die Zeugen hätten gestanden, nichts gegen Caecilianus sagen zu können.

Für die Verhandlung des ersten Tages lässt sich also zusammenfassen, dass Donatus in seinem Plädoyer zunächst das Verständnis seiner Kirche in der Häretikertaufe darlegte, sodann die Gründe für die Aberkennung der Weihe Cecilians nannte und schließlich die Unzuständigkeit des bischöflichen Gerichts mit der bereits gefällten Entscheidung von Karthago begründete. Allen weiteren Forderungen verweigerte er sich.

Die Weigerung der pars Donati, das Gericht anzuerkennen, setzte sich im weiteren Prozessverlauf fort. Am zweiten und dritten Verhandlungstag, so Augustins Angabe im Breviculus, seien Donatus und die anderen Ankläger nicht mehr erschienen, obwohl sie zuvor noch versprochen hätten, andere Zeugen vorzuführen. ${ }^{93}$ In ep. 43 erwähnt Augustinus die Vermutung, Donatus habe die Zeugen wegbringen lassen und so an der Aussage gehindert. Augustinus deutet dieses Verhalten in seinem Sinne aus: Donatus sei nicht mehr erschienen, da er wohl einer Verurteilung entgehen wollte, doch sei seine Schuld bereits in seiner Gegenwart festgestellt worden. Dies entsprach Augustins po-

90 Zur historischen Argumentation in ep. 43 vgl. o. Kap. 4.2.1.

91 Auch der Kontext in ep. 43.14-16 zeigt deutlich, dass das Konzil des Secundus ein Hauptargument des Donatus in Rom war.

92 Vgl. Grasmück, Coercitio, 44 Anm. 177; Roethe, Synoden, 70.

93 Breuic. III 24. 
lemischen Ansatz, die Ungültigkeit von Caecilians Verurteilung in Abwesenheit zu unterstreichen. ${ }^{94}$ Tatsächlich beabsichtigte Donatus wohl gezielt, die Handlungsfähigkeit des Gerichtes zum Erliegen zu bringen, indem er seine Zeugen nicht vorführte und selbst nicht mehr erschien. Wahrscheinlich spekulierte er zu diesem Zeitpunkt bereits mit einer erneuten Beschwerde beim Kaiser. ${ }^{95}$

Während die Bischöfe, nunmehr in Abwesenheit der Klägerpartei, über die causa Caeciliani berieten, wurde nochmals in schriftlicher Form eine Klageschrift gegen Caecilianus eingereicht, die Anlass für erneute Diskussionen gab. Leider überliefert Augustinus weder Genaueres über den Inhalt noch über die Verfasser dieser Anklageschrift. ${ }^{96}$ Es scheint aber, dass nicht Donatus selbst, sondern eine Gruppe seiner Anhänger mit diesem libellus einen erneuten Versuch unternahm, ihr Anliegen zu verdeutlichen und die Anklagen gegen Caecilianus zu begründen. Möglicherweise handelte diese Gruppe in Dissens zu Donatus und seiner Strategie, das Gericht nicht anzuerkennen. Wie auch immer, die enthaltenen Anklagen wurden ebenso verworfen wie zuvor die Ausführungen des Donatus. ${ }^{97}$

Am dritten Tag wurden die Urteile gefällt. Caecilianus wurde durch die Urteilssprüche aller 19 Bischöfe freigesprochen, mit der Begründung, es seien keine Anklagen vorgetragen worden. Donatus dagegen wurde in Abwesenheit als Urheber des Schismas verurteilt und damit exkommuniziert. Optatus zitiert das Schlussurteil des Miltiades:

„Da es feststeht, dass Caecilianus von denen, die mit Donatus gekommen sind, ihrer eigenen Erklärung gemäß nicht angeklagt wird, und ebenfalls feststeht, dass

94 Vgl. o. Kap. 4.2.1.

95 Von vorsätzlichen Obstruktionen gehen auch Roethe (Synoden, 70), Girardet (Kaisergericht, 35) und Mühlsteiger (ZRG KA 85, 1999, 28) aus. Roethe (aaO, 70-72) und ihm folgend Girardet (aaO, $35 \mathrm{f}$.) glauben, die Donatisten wollten eine Verlagerung des Prozesses nach Karthago bzw. ein erneutes Urteil einer afrikanischen Synode erreichen. Gegen diese Annahme spricht jedoch der Kontext von ep. 43.14-15 (s.o. Kap. 4.2.1): Schon die Formulierung pars Maiorini weist darauf, dass Augustinus von dem bereits gefällten Urteil in Karthago spricht und nicht von einem neuen Prozess in Karthago.

96 Ep. 43.15: accessit aliud, ut quibusdam aduersus Caecilianum denuntiationis libellus daretur. Post quod factum quem ad modum sit rursus agitata cognitio et quae personae illum libellum dederint quoque modo nihil Caecilianum probari potuerit, quid dicam, cum et audieritis omnia et, quotiens uolueritis, legere possitis? - Die Formulierung lässt keinen Zweifel daran, dass die römischen Akten über diesen Vorgang Auskunft gaben.

97 Anders die Überlegungen Girardets (Kaisergericht, 36 f.), der ausgehend von seiner Hypothese, der erste libellus habe zivilrechtliche Anklagen beinhaltet, nunmehr von kirchlichen Anklagen ausgeht, die taktisch geschickt eingesetzt worden seien. Roethe (Synoden, 73 f. mit Anm. 78) und Grasmück (Coercitio, 43) halten es für möglich, dass der libellus criminum Caeciliani eingereicht wurde, da er zuvor noch nicht verlesen worden sei. 
er in keiner Weise von Donatus überführt worden ist, urteile ich, dass er verdientermaßen unangetastet in der kirchlichen Gemeinschaft verbleiben soll.“"98

Das Urteil fiel eindeutig auf Grundlage der theologisch-dogmatischen Vorentscheidung, dass eine Wiedertaufe von lapsi nicht notwendig sei. Indem Donatus vor der Synode ein Bekenntnis zur Wiedertaufe abgelegt hatte, hatte er sich in den Augen der Richter selbst überführt und galt als Verursacher des Schismas. ${ }^{99}$ An der Wahl und Weihe Caecilians war folglich nichts auszusetzen, entsprechende Einreden des Donatus wurden ebenso zurückgewiesen wie das Urteil des Konzils von Karthago. Caecilianus wurde als rechtmäßiger Bischof Karthagos bestätigt. Die Bischöfe in Rom formulierten auch Regelungen für die Wiederherstellung der Kircheneinheit in Afrika. Allein Donatus sollte aus der Kirche ausgeschlossen bleiben. Alle anderen donatistischen Bischöfe sollten Gemeinschaftsbriefe erhalten und ihre Gemeinden behalten, sofern sie früher geweiht worden waren als ihre katholischen Kollegen. Die Übrigen sollten andere Gemeinden übernehmen. ${ }^{100}$

Der Verlauf und das Urteil verdeutlichen sowohl die Parallelen als auch die Ambivalenz von weltlicher und kirchlicher Gerichtsbarkeit. Auf der einen Seite entsprach der Prozess vor dem bischöflichen Gremium einer Synode mit der kirchenrechtlich relevanten Exkommunizierung des Donatus und der Anerkennung Caecilians. Auf der anderen Seite entsprach der Prozess einem zivilrechtlichen Kognitionsverfahren. Miltiades übernahm dabei formal die Funktion eines Einzelrichters, seine Kollegen bildeten das beratende consilium. Am Ende der Verhandlungen gaben alle 19 Mitglieder ihre Sentenzen ab, zuletzt

98 Opt. I 24: cum constiterit Caecilianum ab his, qui cum Donato uenerunt, iuxta professionem suam non accusari nec a Donato conuictum esse in aliqua parte constiterit, suae communioni ecclesiasticae integro statu retinendum merito esse censeo. - Vgl. breuic. III 31; ep. 43.16.

99 Die Aussage in breuic. III 24, Donatus habe in Karthago ein Schisma verursacht, bevor Caecilianus Bischof geworden sei, kann daher nur bedeuten, dass Donatus bereits nach Beendigung der Verfolgung in Karthago wirkte und die Taufe von Gefallenen praktizierte. Es ist dagegen auszuschließen (vgl. Mandouze, PAC, $293 \mathrm{f}$.), dass Donatus unter den Gegnern Caecilians zu Beginn der Auseinandersetzung bereits eine herausragende Stellung einnahm. Ansonsten wäre sein Name sicher schon vor dem Konzil in Rom genannt worden. Vgl. auch Roethe, Synoden, 74.

100 Ep. 43.16. - Trotz der rhetorischen Überhöhung des ,vorausschauenden und friedfertigen“ Urteils des Miltiades, dürften Augustins Informationen über diese Regelungen den Akten entnommen sein. Sie entsprechen zudem den Anweisungen Konstantins, ein schnelles Ende der Spaltung herbeizuführen. - Für seine Darstellung des Konzils von Rom übernimmt Grasmück (Coercitio, 41-45) völlig unkritisch die Aussagen Augustins aus ep. 43, wodurch ein verzerrtes Bild von den Absichten der pars Donati in Rom entsteht. 
Miltiades, durch dessen Urteil die Entscheidung Rechtsgültigkeit erhielt (iudicium Miltiadis). ${ }^{101}$

Das gesamte Verfahren, die Beauftragung durch den Kaiser, die Durchführung durch die Bischöfe und schließlich die Anerkennung des Ergebnisses durch den Kaiser, war ein Novum in der Geschichte der Kirche. Insofern war das Konzil von Rom Auftakt und Modell für nachfolgende Konzile und kirchenpolitische Entscheidungen in ihrer Verquickung von Staat und Kirche. ${ }^{102}$

Es stellt sich die Frage, warum Augustinus so wenig aus den Akten des Konzils zitiert, obwohl ihm die Dokumente bekannt waren. Es ist kaum anzunehmen, dass er etwas über bestimmte Vorgänge verschweigen wollte, dann hätte er schließlich ganz auf das Dokument verzichtet und nicht seinen Gegnern daraus vorlesen lassen. Vielmehr konzentrierte er sich aufgrund der ekklesiologischen Perspektive in seiner Argumentation auf das Urteil des Miltiades. Die Entscheidung der europäischen Bischöfe wollte er als Entscheidung der $\mathrm{Ca}$ tholica vermitteln. Ganz im Sinne Cyprians stellte er die Einheit der Kirche über die unterschiedlichen theologischen Ansichten. Die Donatisten sollten am römischen Urteil sehen, dass sie sich von der kirchlichen Einheit und damit von der Wahrheit abgetrennt hatten und nicht umgekehrt. Die einzigen bekannten Ausnahmen von dieser Argumentation sind die Ausführungen über das römische Konzil in ep. 43 und während der Konferenz von 411. In beiden Fällen verfolgte Augustinus jedoch bestimmte Ziele: In dem Brief ging es um die Kontrastierung des Prozesses in Rom mit den Vorgängen in Karthago und der Absetzung Caecilians. Auf der Konferenz sollte durch die Verlesung der Protokolle von Rom die Unanfechtbarkeit des iudicium Miltiadis bekräftigt werden. ${ }^{103}$

Für die Donatisten bedeuteten die Akten des Konzils lediglich eine Bestätigung ihrer Auffassung über die Kirche der Traditoren. In Karthago 411 deklarierten die Donatisten die römische Synode als ungültig, da sie für die afrikanische Angelegenheit nicht zuständig gewesen und das Urteil durch den

101 Dazu ausführlich Girardet, Kaisergericht, 27-35; vgl. Instinsky (Bischofsstuhl, 77 f.) und Roethe (Synoden, 74-79). Girardet postuliert allerdings, dass letztlich der Kaiser als iudex, nachdem er über die Entscheidung in Rom informiert worden sei, das eigentliche Urteil gesprochen habe. Gleichwohl, so Girardet (aaO, 33), war Konstantin gewillt, ,seinem consilium aus Bischöfen eine höhere Autorität zuzuerkennen als einem Sachverständigenrat." Diese umständliche Argumentation ist nicht überzeugend. Die Reaktionen Konstantins nach den bischöflichen Entscheidungen (vgl. Opt. App. III und V) zeigen deutlich, dass er den Bischöfen das Urteil für diese kirchliche Angelegenheit überlassen hatte und zunächst nicht selbst urteilen wollte (vgl. Gaudemet, Église, 457). Nochmals anders beurteilen Grasmück (Coercitio, 45-48) und Mühlsteiger (ZRG KA 85, 1999, 25) den Prozess. Sie gehen davon aus, dass Miltiades nicht als Vorsitzender, sondern als primus inter pares in einem bischöflichen Kollegialgericht geurteilt habe.

102 Roethe, Synoden, $53 \mathrm{f}$.

103 Vgl. o. Kap. 4.2.1. und 5.3.2. 
Traditor Miltiades gesprochen worden sei. Dabei betonten sie, dass aus diesem Grund bereits ihre Vorfahren das Urteil abgelehnt hätten. ${ }^{104}$ Doch erweist sich diese Aussage als sehr gewagt, wenn man den weiteren Verlauf der Ereignisse betrachtet, wie er sich aus den Quellen ergibt. Denn die traditio des Miltiades spielte bei den donatistischen Appellen gegen die Entscheidung von Rom ganz offensichtlich keine Rolle. ${ }^{105}$ In donatistischen Quellen vor der Konferenz von 411 fehlen entsprechende Hinweise. Bei Cresconius und Parmenianus findet sich lediglich der Vorwurf, die Bischöfe seien bestochen worden. Damit verwendeten beide einen üblichen Topos zur Diskreditierung eines Urteils. ${ }^{106}$ Demzufolge ist es wahrscheinlich, dass die Ablehnung des römischen Urteils aufgrund von traditio-Vorwürfen gegen Miltiades entgegen der donatistischen Behauptungen erst zur Zeit Augustins aufkam und sich verfestigte. ${ }^{107}$

Über das Konzil von Arles waren die Kenntnisse bei Donatisten und Katholiken zur Zeit Augustins gering. Im Gegensatz zur römischen Synode waren weder Akten bekannt noch jene Briefe Konstantins, die im Zusammenhang mit dem Konzil von Arles geschrieben wurden und heute erhalten sind. Da auch Optatus von Mileve nichts über Arles berichtet, war die einzige Quelle offenbar der Brief Konstantins an den Vikar Eumalius vom November 316, den Augustinus für die Auseinandersetzung heranzog. Diesem Schreiben entnahm er Informationen über die Appelle der Donatisten bei Konstantin, die Einberufung der Synode von Arles und den erneuten Freispruch Caecilians durch die Bischöfe. ${ }^{108}$ Für seine Argumentation verarbeitete Augustinus diese wenigen Angaben, indem er das zweifache Urteil der Bischöfe für Caecilianus dem einfachen Urteil gegen Caecilianus in Karthago entgegenstellte. Die Entscheidung von Arles wie das spätere Urteil des Kaisers sollten die eindeutige Klärung des Streites demonstrieren..$^{109}$

Zur genaueren Klärung der Umstände stehen heute einige weitere Quellen zur Verfügung: Die Briefe Konstantins an den Vikar Aelafius ${ }^{110}$ und an den

104 Cap. conl. Carth. III 471; vgl. breuic. III 34; un. bapt. 28; vgl. o. Kap. 5.3.2.

105 Vgl. u. S. 299 - Auch Augustinus macht deutlich, dass er die Anschuldigungen gegen Miltiades für haltlos erachtet (un. bapt. 28).

106 Cresc. III 67; c. ep. Parm. I 11; vgl. o. Kap. 3.4.1; u. Kap. 7.4.2.2.

107 Zur traditio des Miltiades vgl. auch o. Kap. 6.1.4.

108 Breuic. III 37. - Augustins Gegner Parmenianus erwähnte die Synode von Arles in seinen Schriften (vgl. c. ep. Parm. I 11). Wie ausführlich er darüber berichtete, lässt sich nicht sagen; möglicherweise zog aber Augustinus Informationen zu Arles aus den Aussagen Parmenians. - Maier (I, S. 16 mit Anm. 28) meint, Augustinus habe seine Kenntnisse über das Konzil von Arles nicht aus den Briefen Konstantins. Dabei übersieht er, dass Augustinus schon in frühen Briefen das Schreiben an Eumalius explizit heranzieht.

109 Vgl. die Stellenangaben o. Anm. 77.

110 Opt. App. III; zum Text s. o. Anm. 84. 
Bischof Chrestus von Syrakus ${ }^{111}$ geben Auskunft über die Beschwerden der Donatisten nach der Entscheidung von Rom und über die Einberufung der Synode nach Arles. Die Konzilsakten selbst sind nur noch fragmentarisch erhalten. So ist im Anhang des Optatus ein Schreiben der versammelten Bischöfe an Silvester von Rom überliefert. ${ }^{112}$ Darüber hinaus existieren noch einige Beschlüsse sowie eine Unterschriftenliste aller Teilnehmer. ${ }^{113}$

Aus den vorhandenen Quellen ergibt sich folgendes Bild: Nachdem die Synode in Rom ihr Urteil gefällt hatte, wurden Konstantin die Ergebnisse mitgeteilt. Vermutlich waren es die von ihm bestimmen gallischen Bischöfe, die zu ihm nach Trier kamen, die Akten am Hof übergaben und Bericht erstatteten, in dem sie die rechtmäßige und gründliche Durchführung des Prozesses in Rom hervorhoben. ${ }^{114}$ Die Donatisten indessen ließen das Urteil von Rom nicht lange auf sich beruhen. Wahrscheinlich noch Ende des Jahres 313 reichten sie beim Kaiser Beschwerde ein und forderten, Konstantin möge, wie ursprünglich erbeten, sich selbst mit dem Fall beschäftigen. Gegen das Konzil von Rom wandten sie ein, es hätten nur wenige Bischöfe ihr Urteil abgegeben, und es sei ohne vollständige Prüfung aller Fragen $\mathrm{zu}$ schnell geurteilt worden. Sie behaupteten zudem, die Richter hätten sich eingeschlossen und dann nach ihrem Gutdünken geurteilt. Caecilianus aber, darauf insistierten die Donatisten, sei des Bischofsamtes unwürdig. ${ }^{115}$ Zum einen argumentierten die Donatisten also kirchenrechtlich, indem sie wie zuvor die Absetzung Caecilians durch das afrikanische Konzil als Grundlage betrachteten, zum anderen kehrten sie ihre eigenen Obstruktionen gegen das Gericht, indem sie ihre Weigerungen auszusagen als nicht erfolgte Anhörung interpretierten. ${ }^{116}$

111 Eus. HE X 5.21-24; Maier I, Nr. 19, 158-160; von Soden, Nr. 15; Dörries, Selbstzeugnis, 24-28; Kraft, Entwicklung, 169-172; vgl. Monceaux IV, 202; Grasmück, Coercitio, $56 \mathrm{f}$.

112 Opt. App. IV; Gaudemet, SC 241, 40-45; Maier I, Nr. 20 A, 160-165; von Soden, Nr. 16; vgl. Monceaux IV, 345-348; Grasmück, Coercitio, 60-62; Mühlsteiger, ZRG KA 85, 1999, 36-38.

113 Zusammengestellt bei Gaudemet, SC 241, 46-67.

114 Konstantins Brief an Aelafius (Opt. App. III, von Soden, Nr. 14, Z. 13 ff.); vgl. Roethe, Synoden, $57 \mathrm{f}$.

115 Opt. App. III (von Soden, Nr. 14, Z. 33-35): nam id quoque te scire conuenit, quod ex hisdem uenerunt, adserentes, quod minus dignus idem Caecilianus cultu sanctissimae religionis habeatur, [...].

116 Brief an Aelafius (Opt. App. III); Brief an Chrestus (Eus. HE X 5.22); vgl. ep. 88.3. Vgl. Girardet, Historia 41, 1992, 110-113. Girardet beurteilt die Einwände der Donatisten in juristischer Hinsicht als Versuch, eine Nichtigkeitserklärung des Urteils herbeizuführen. Da das Urteil von Rom bereits ein Kaiserurteil gewesen sei, sei es inappellabel gewesen; daher dürfe man nicht von einer Appellation der Donatisten sprechen Gegen diese Einschätzung spricht jedoch die Feststellung, dass Konstantin sich gerade nicht als oberster Richter eines bischöflichen consilium verstanden hatte, sondern zunächst den Fall an die Kirche delegierte. Von dieser Grundlage ausgehend lässt sich 
Konstantin reagierte zwar mit deutlicher Missbilligung auf die erneute Klage der Donatisten, entschied aber dennoch, den Fall nochmals untersuchen zu lassen. Wahrscheinlich hatte er den Donatisten nach dem Urteil von Rom untersagt, nach Afrika zurückzukehren. ${ }^{117}$ Möglicherweise hatte er bereits zu diesem Zeitpunkt von neuen Unruhen zwischen den Kirchen in Afrika gehört und suchte nun nach weiteren Lösungswegen. ${ }^{118}$ Nachdem entschieden worden war, auch Caecilianus die Rückkehr nach Karthago zu untersagen, setzte Konstantin eine Untersuchungskommission ein, die in Afrika vor Ort die Lage klären sollte. Die beiden beauftragten Bischöfe bestätigten zwar das Urteil des Miltiades, jedoch beugten sich die Donatisten dieser Entscheidung ebenso wenig wie zuvor. ${ }^{119}$

Nach dem Scheitern dieses Versuchs entschied sich Konstantin im Frühjahr 314, erneut ein Bischofskonzil mit der Untersuchung der causa Caeciliani zu beauftragen. Mit Berücksichtigung der donatistischen Einwände sollte diesmal eine möglichst große Anzahl von Bischöfen beteiligt sein. Alle Beschwerden sollten gründlich angehört werden, um eine Lösung zur Wiederherstellung der Kircheneinheit zu finden. Offensichtlich erwartete Konstantin, dass ein solcher Prozess ein unanfechtbares Urteil hervorbringen werde, dem sich die beiden Parteien beugen würden. Er selbst verordnete den Bischöfen aus seinem Herrschaftsgebiet, zum 1. August 314 nach Arles zu kommen. ${ }^{120}$ Zum festgesetzten Termin traten die geladenen Bischöfe und Diakone in Arles unter

auch von einem Appell sprechen. Untechnisch verwendet Augustinus auf der Basis seiner Quelle (Konstantin an Eumalius) das Wort appellatio (vgl. s. Denis 19.8) Vgl. auch Grasmück (Coercitio, $48 \mathrm{f}$.), der von der falschen Annahme ausgeht, es habe ein „Appellationsgerichtsverfahren“" stattgefunden.

117 Konstantin an Aelafius (Opt. App. III). Aufgrund der problematischen Textüberlieferung ist die Stelle mit Unsicherheit behaftet. Turner (JThS 27, 1926, 286) spricht sich dafür aus, statt prohiberent, d.h., die Bischöfe in Rom untersagten die Rückkehr, prohiberem zu lesen, d.h. der Kaiser selbst verbot die Rückkehr, was wesentlich wahrscheinlicher ist. Ebenso Dörries, Selbstzeugnis, 21 Anm. 3; Kraft, Entwicklung, $180 \mathrm{f}$. Siehe auch Maier I, 155 Anm. 11; Monceaux IV, 343; von Soden, 17 Anm. 1; Grasmück, 52 f. Anm. 231; Kriegbaum, AHP 28, 1990, 57.

118 Über diese Unruhen in Afrika berichtete Aelafius in einem nicht erhaltenen Schreiben an den Kaiser bzw. einem gewissen Nicasius (dessen Identifizierung ist unklar, vgl. Kraft, Entwicklung, 181; Mandouze, PAC, 789, s. v. Nicasius 1; Corcoran, Empire, 168 Anm. 217). Vgl. die Antwort Konstantins, Opt. App. III.

119 Opt. I 26. Zur chronologischen Einordnung und zur Problematik der „Brescia-Episode“ bei Optatus vgl. u. Kap. 7.4.2.1.

120 Vgl. die Anordnungen in dem Brief Konstantins an Chrestus von Syrakus (Eus. HE X 5.21-24). - Nach Auskunft der Unterschriftenliste (vgl. SC 241, 56-63) waren aus allen westlichen Diözesen (Italien, Gallien, Viennensis, Britannien, Pannonien, Spanien und Afrika) Vertreter in Arles. Die genaue Zahl der Teilnehmer ist jedoch unsicher, da die Quellenmanuskripte unterschiedlich Auskunft geben. Vgl. Gaudemet, SC 241, 36. Zu Chrestus (Crescens) vgl. Pietri, PIC 1, 431 f., s. v. Chrestus 1. 
Vorsitz des dortigen Bischofs Marinus zusammen Die beiden Streitparteien waren wiederum mit Delegationen ihrer Anhänger vertreten. ${ }^{121}$

Über den Verlauf der Verhandlungen ist wenig bekannt. Aus dem Synodalbrief an den römischen Bischof Silvester, der zu Beginn des Jahres die Nachfolge des verstorbenen Miltiades angetreten hatte, geht hervor, dass die Bischöfe erneut den Ausführungen der Donatisten nicht folgten, ein klares Urteil zu Gunsten Caecilians sprachen und dessen Ankläger als Feinde von Glauben und Tradition verurteilten. ${ }^{122}$ Zudem wurden die theologischen und ekklesiologischen Grundfragen des Schismas debattiert. Die Wiedertaufe von Häretikern wurde abgelehnt; stattdessen sollten einem bereits getauften Häretiker die Hände aufgelegt werden. ${ }^{123}$ Hinsichtlich der Traditoren wurde beschlossen, durch Dokumente der traditio überführte Kleriker aus ihrem Amt zu entlassen. Verleumdungen und falschen Anklagen sollte dagegen keinesfalls Gehör geschenkt werden. Gegen das donatistische Verständnis bekräftigten die Bischöfe, dass von Traditoren vollzogene Weihen ihre Gültigkeit nicht verlieren sollten. ${ }^{124}$ Auf dieser Grundlage blieb den Gegnern Caecilians notwendigerweise ein Erfolg verwehrt.

121 Zum Konzil von Arles vgl. Congar, BA 28, 726 f.; Girardet, Kaisergericht, 37-39; Grasmück, Coercitio, 51-65; Kraft, Entwicklung, 37-41; Lamirande, BA 32, 732 f.; Lietzmann, Geschichte III, 74-76; Maier I, Nr. 20, 160-167; Mandouze IV, 343-349; Monachino, AHP 2, 1964, 16-21; Mühlsteiger, ZRG KA 85, 1999, 30-39; von Soden, Nr. 17. - Unter anderem Seeck (ZKG 10, 1889, 508-510; Regesten, 162) und in neuester Zeit wieder Barnes (New Empire, 72; Constantine, 58) vertreten aufgrund einer allgemeinen Notiz des Eusebius zum Verhältnis Konstantins zur Kirche (VC I 44) die Ansicht, dass Konstantin persönlich am Konzil in Arles teilgenommen habe. Gegen diese Interpretation sprechen jedoch die zur Verfügung stehenden Quellen zur Synode von Arles. - Zur Bedeutung von Arles als Residenzstadt Konstantins vgl. Grünewald, Constantinus, 35-38.

122 Opt. App. IV. Maier I, Nr. 20, 161-165; Gaudemet, SC 241, 40-45; von Soden, Nr. 16. Während Seeck (ZKG 10, 1889, 542-545) von der Echtheit des Schreibens ausging, hält Kraft (Entwicklung, 38-41) den Brief für ein literarisches Produkt: „Es handelt sich um einen für den historischen Bericht komponierten Brief.“ Der Sachverstand lasse aber auf einen Konzilsteilnehmer als Verfasser schließen. - Zu Bischof Silvester: Pietri, PIC 2, 2971, s. v. Silvester 1. Aus welchen Gründen Silvester der Synode in Arles ferngeblieben war, lässt sich nicht beantworten. Vgl. die Diskussion bei Monachino, AHP 2, 1964, 17 f.; Grasmück, Coercitio, 60 f.; Mühlsteiger, ZRG KA 85, 35.

123 Canon VIII (bzw. IX); Opt. App. IV; vgl. von Soden, Nr. 16 Z. 33 ff.; Gaudemet, SC 241, S. 44 u. 50.

124 Canon XIII (bzw. XIV); von Soden Nr. 17; Gaudemet, SC 241, 52-54: de his qui scripturas sanctas tradidisse dicuntur uel uasa dominica uel nomina fratrum suorum, placuit nobis ut quicumque eorum ex actis publicis fuerit detectus, non uerbis nudis, ab ordine clerici amoueatur. nam si idem aliquos ordinasse fuerint depraehensi et de his quos ordinauerunt ratio subsistit, non illis obsit ordinatio. et quoniam multi sunt qui contra ecclesiam repugnare uidentur et per testes redemptos putant se ad accusationem admitti debere, omnino non permittantur, nisi ut supra diximus, actis publicis docuerint. 
Die Synode von Arles besaß in rechtlicher Hinsicht keinen anderen Charakter als das Verfahren in Rom. Zwar sprach man niemals von einem iudicium Marini, doch dürfte dies an dem übereinstimmenden Ergebnis mit dem vorhergehenden iudicium Miltiadis liegen. Die Bischöfe in Arles überprüften nicht nur die donatistischen Vorwürfe gegen das römische Verfahren, sondern verhandelten die causa Caeciliani neu, freilich mit dem gleichen Ergebnis. Damit bestätigten sie das einmal gefällte Urteil und formulierten nochmals die theologischen Grundlagen, die zu der Verurteilung der Donatisten geführt hatten. Auf der einen Seite erfüllten sie somit den Auftrag Konstantins, durch eine neue Verhandlung die donatistischen Einwände gegen die Rechtmäßigkeit des römischen Verfahrens auszuräumen, auf der anderen Seite legten sie als Gesamtsynode kirchenrechtlich verbindliche Leitlinien für die Zukunft fest. ${ }^{125}$

Die Entscheidung von Arles blieb in Afrika nicht ohne Wirkung. Augustinus zufolge gab es einige donatistische Bischöfe, die sich wieder der katholischen Kirche anschlossen. ${ }^{126}$ Die Mehrheit der Anhänger des Donatus akzeptierte jedoch das Ergebnis von Arles ebenso wenig wie jenes von Rom. Sie wollten nach wie vor vom Kaiser als katholische Kirche Afrikas anerkannt werden. Diese erneuten Appelle bei Konstantin stellt Augustinus in seiner antidonatistischen Polemik heraus. Er deutet die Ablehnung des Urteils von Arles als Zeichen der Unbelehrbarkeit und Hartnäckigkeit der Donatisten, die allein dazu geführt habe, dass Konstantin selbst zu einem Urteil gezwungen worden sei.

In der Argumentation der Donatisten spielte die Synode von Arles keine Rolle. Anders als zum Urteil des Miltiades wurden auch keine konkreten Vorwürfe gegen die in Arles versammelten Bischöfe laut. Dies bestätigt die Annahme, dass die tatsächlichen Kenntnisse zum Ablauf und zum Ergebnis sehr gering waren. Auch auf der Konferenz von 411 blieb das Konzil von Arles mit der Bestätigung des Urteils von Rom lediglich eine Randnotiz. Nur durch den Eumaliusbrief wurde diese Entscheidung überhaupt ins Gedächtnis gerufen. ${ }^{127}$ Die Donatisten scheinen auf die Aussagen des Briefes nicht eingegangen zu sein, sondern stellten sogleich das spätere Urteil des Kaisers in den Mittelpunkt. Es bleibt somit unklar, wie sie das Ergebnis des Konzils von Arles im Einzelnen deuteten, jedoch dürfte sicher sein, dass sie diese Synode ebenso wie die römische als unzuständig ansahen.

$125 \mathrm{Zu}$ diesem ambivalenten Charakter vgl. Grasmück, Coercitio, 57 f. Anm. 250.

126 Ep. 88.3; breuic. III 37.

127 Cap. conl. Carth. III 515; breuic. III 37. 


\section{Das Urteil Konstantins}

Das Urteil Konstantins begegnet bei Augustinus als Schlussstrich unter dem Fall Caecilianus. Während das iudicium Miltiadis und die Bestätigung dieses Urteils durch die Bischöfe in Arles seine Grundlage für das Plädoyer zur Kircheneinheit bildete, nahm Augustinus die Entscheidung des weltlichen Herrschers zu Gunsten Caecilians gleichsam als komplementäres Urteil, um damit die Unterstützung der katholischen Kirche durch weltliche Gewalten zu rechtfertigen. Gegen die donatistische Theorie der vom Staat verfolgten Kirche entwickelte er nach und nach seine Theorie des christlichen Staates. In dem Ergebnis des kaiserlichen Prozesses lag für Augustinus die entscheidende Bedeutung. Das Urteil Konstantins, so stellt er stets den Zusammenhang klar, sei die notwendige Konsequenz der donatistischen Appelle an den Kaiser gewesen. Jede Kritik am Eingreifen der Kaiser sei folglich unbegründet, da die Donatisten selbst dieses Eingreifen gefordert hätten. Auf diese Weise bildete das Urteil Konstantins in der Argumentation Augustins die Gelenkstelle zwischen Vergangenheit und Gegenwart. ${ }^{128}$

Bei den Donatisten zeigt sich einmal mehr ein fragmentarisches sowie uneinheitliches Bild. Parmenianus ging davon aus, dass Konstantin zwar ein Urteil gegen Donatus und damit gegen die wahre Kirche gefällt hätte, jedoch von donatistischen Gegnern bestochen und beeinflusst gewesen sei. ${ }^{129}$ Dagegen erklärten Cresconius und später die Donatisten auf der Konferenz von 411, es hätte entgegen der Darstellung der Katholiken ein Konstantinurteil gegen Caecilianus gegeben. Außerdem behaupteten sie, Konstantin hätte eine Religionsfreiheit für die Donatisten verkündet, und forderten, diese Tatsache in die aktuelle Auseinandersetzung einzubeziehen. ${ }^{130}$

Um die unterschiedlichen Aussagen und Interpretationen beider Seiten besser beurteilen zu können, soll im Folgenden zunächst der chronologische Verlauf der Ereignisse rekonstruiert werden, wie er sich aus den zur Verfügung stehenden Quellen ergibt. Auf dieser Grundlage können anschließend die Interpretationen der Donatisten und Augustins dargestellt und im Hinblick auf ihre Aussagekraft überprüft werden.

128 Vgl. c. litt. Pet. II 205; III 29; c. ep. Parm. I 11, 13, 15-16; Cresc. III 16, 67, 82; IV 9; cath. fr. 46, 50; epp. 43.4, 20; 53.5; 76.2; 88.3; 89.3; 93.13; 105.8; 141.11; s. Denis 19.8; s. Dolbeau 2.22; breuic. III 37-38, 41; c. Don. 19-20, 56; dazu o. Kap. 4.2.2.

129 C. ep. Parm. I 10-11; vgl. u. Kap. 7.4.2.2.

130 Vgl. zum Verlauf der Debatte o. Kap. 5.3.2. 


\subsection{Vom Konzil von Arles zum Urteil Konstantins in Mailand}

Wie bei dem Konzil von Rom sind es vor allem Augustins ep. 43 und der Breviculus der Konferenz von 411, die wichtige Informationen über die letzte Phase im Prozess gegen Caecilianus enthalten. Außer diesen Quellen stehen nur wenige Dokumente aus dem Anhang bei Optatus zur Verfügung, die Auskunft über die Zeit zwischen dem Urteil von Arles im August 314 und dem Urteil Konstantins im Herbst 315 geben. ${ }^{131}$ Aufgrund zum Teil widersprüchlicher Aussagen und fehlender Datierungen ist es sehr problematisch, eine stringente Abfolge der Ereignisse zu rekonstruieren. Folglich weichen die Interpretationen der Historiker zu dieser Phase der Geschichte zum Teil erheblich voneinander ab. Die nachfolgende Darstellung ist ein neuer Versuch, den vorhandenen Informationen einen schlüssigen Ereignisverlauf abzugewinnen. ${ }^{132}$

Auch nach dem Konzil von Arles wandte sich die unterlegene Partei mit Einsprüchen an den Kaiser. ${ }^{133}$ Konstantins wiederholter Versuch, die causa Caeciliani als Kirchenangelegenheit durch ein bischöfliches Gremium zu einem Ende zu bringen, war damit gescheitert. Bereits vor der Einberufung zur Synode nach Arles war Konstantin einer der donatistischen Anschuldigungen gezielt nachgegangen: dem traditio-Vorwurf gegen Felix von Abthugni. Inzwischen war es sowohl allen beteiligten europäischen Bischöfen als auch den Verantwortli-

131 Der Brief Konstantins an die katholischen Bischöfe nach dem Konzil von Arles (Opt. App. V), ein Brief an donatistische Bischofe (App. VI), ein Brief an den Vikar von Afrika Celsus (App. VII) sowie der Brief an den Prokonsul Probianus (Aug. Cresc. III 81; ep. 88.4).

132 Die neuere Forschung beruft sich im Wesentlichen auf Grasmück (Coercitio, 70-80), der einen recht gelungenen und ausführlichen, wenngleich nicht widerspruchsfreien Rekonstruktionsversuch vorgelegt hat. Grasmück hat u. a. richtig erkannt, dass die bei Optatus überlieferte „Brescia-Episode“ nicht in den Rahmen der Ereignisse des Jahres 315 einzupassen ist. Allerdings kann sein Lösungsansatz nicht überzeugen, den Bericht des Optatus zeitlich nach das Kaiserurteil zu setzten. Die geschilderten Ereignisse passen wesentlich besser in das Frühjahr des Jahres 314 (s. u. Anm. 163). - Ältere und z.T. abweichende Darstellungen der Entwicklungen der Jahre 315/316 bei Lietzmann, Geschichte III, 74-77; Monceaux IV, 24 f.; Seeck, Geschichte III, 332-335; Frend, Donatist Church, 155-159, die zum Teil auch für neuere Darstellungen übernommen wurden.

133 Vgl. den Brief Konstantins an die Bischöfe von Arles (Opt. App. V). Maier I, Nr. 21, 167-171; von Soden, Nr. 18. Ebenso wie der Brief an Aelafius ist dieser Text in seiner Authentizität umstritten und gilt zumindest als redaktionell bearbeitet. Den Grundtenor dieses Briefes wird man jedoch nicht in Abrede stellen können. Vgl. die Textanalysen von Dörries (Selbstzeugnis, 28-33) und Kraft (Entwicklung, 185-191). Grasmück (Coercitio, 254-256) vermutet, dass Konstantin einen Kleriker mit der Abfassung des Schreibens betraut habe. Zuletzt für die Glaubwürdigkeit des Schreibens: C. Odahl, Constantine's Epistle to the Bishops of the Council of Arles, JRH 17, 1993, 274-289. Vgl. auch E. D. Digeser, Lactantius and Constantine's Letter to Arles, Dating the Divine Institutes, JECS 2, 1994, 33-52. 
chen am Hofe deutlich geworden, dass der Streit um die Weihe Caecilians den Anlass zum Schisma gegeben hatte. Der Prozess gegen Felix, den der Kaiser an den Vikar Aelius Paulinus delegiert hatte, sollte folglich durch die Klärung des Hauptvorwurfs einen entscheidenden Beitrag zur Überwindung der Spaltung leisten. Der Freispruch des Felix in diesem Prozess am 15. Februar 315 trug dazu bei, dass Konstantin in den folgenden Monaten seine Bemühungen um ein Ende des Streites verstärkte. ${ }^{134}$

Ganz offensichtlich beabsichtigte Konstantin nicht, sofort ein eigenes Urteil zu fällen, nachdem wiederum Beschwerden der Donatisten über die Richter und die Entscheidung von Arles eingetroffen waren. Vielmehr belegen die überlieferten Aussagen, dass er zunächst andere Versuche unternahm, die Donatisten zum Einlenken zu bewegen und auf diese Weise die Einheit der Kirche wiederherzustellen. Als erstes beorderte Konstantin die donatistischen Vertreter, die nach dem Konzil von Arles appelliert hatten, in seine Residenz nach Trier. Den amtierenden vicarius Africae Aelius Paulinus wies er außerdem an, renitente donatistische Bischöfe $\mathrm{zu}$ ihm zu schicken, damit diese ihren Widerstand in Afrika nicht fortsetzen könnten. ${ }^{135}$ Es ist weder bekannt, auf welche Weise diesen Donatisten die Rückkehr zur katholischen Kirche nahegelegt wurde, noch, ob tatsächlich auf Befehl des Statthalters weitere Donatisten nach Gallien geschickt wurden. Vermutlich waren aber Kleriker am Hofe beauftragt worden, die Donatisten fernab von Afrika mit allen Mitteln von ihrem „Irrweg“ abzubringen.

Überliefert ist ein Informationsschreiben der Prätorianerpräfektur in Trier an den vicarius Africae Celsus vom 28. April 315. ${ }^{136}$ Daraus geht hervor, dass vier donatistische Bischöfe und ein Priester die kaiserliche Genehmigung erhalten hatten, nach Arles zu reisen und von dort zurück nach Afrika zu segeln. Folglich waren sie in den vorangegangenen Monaten tatsächlich am kaiserlichen Hof festgehalten worden. ${ }^{137} \mathrm{Ob}$ Donatus sich $\mathrm{zu}$ diesem Zeitpunkt noch in Gallien befand, lässt sich wiederum nicht sicher sagen. Es ist aber durchaus wahrscheinlich, dass ihm nach wie vor die Rückkehr verweigert wurde und er mit einigen Anhängern am Hof verbleiben musste.

134 Zum Prozess gegen Felix vgl. o. Kap. 6.1.3.

135 Brief an die katholischen Bischöfe (Opt. App. V); vgl. Grasmück, Coercitio, $64 \mathrm{f}$.

136 Opt. App. VIII; Maier I, Nr. 23, 187-189; von Soden, Nr. 22. - Zum Datum vgl. Habicht, Hermes 86, 1958, 367-373; gegen Seeck (ZKG 30, 1909, 211-213), der das Dokument auf das Jahr 316 datiert und in Zusammenhang mit App. VII nach dem Konstantinurteil einordnet.

137 Mit Grasmück (Coercitio, 70) ist das Dokument zu diesem Zeitpunkt einzuordnen, und zwar unabhängig von den Bitten der Donatisten um Rückkehr in Opt. App. VI, wie etwa Barnes (New Empire, 243) postuliert. Es ist denkbar, dass die Erlaubnis zur Rückkehr mit dem Urteil im Prozess gegen Felix im Zusammenhang stand; vgl. Habicht, Hermes 86, 1958, $372 \mathrm{f}$. 
Auf jeden Fall gab es donatistische Vertreter, die noch (oder wieder) im Frühjahr und Sommer 315 bei Konstantin ihre Kritik an den bisherigen Entscheidungen vorbrachten, wie aus dem Reskript des Kaisers an den Prokonsul Probianus hervorgeht. ${ }^{138} \mathrm{Um}$ diese Donatisten von der Zwecklosigkeit ihrer Appelle zu überzeugen, verfügte Konstantin, dass Ingentius, der überführte Fälscher im Prozess gegen Felix von Abthugni, an seinen Hof kommen solle. Damit unternahm er einen weiteren Versuch, die Donatisten durch die bereits bestehenden Urteile zur Kircheneinheit zu bewegen. Vermutlich hoffte er, dass außer den beiden bischöflichen Urteilen zu Gunsten Caecilians nun durch das prokonsularische Urteil zu Gunsten des Felix der entscheidende Anklagepunkt der Donatisten ausgeräumt werden könnte: Ingentius sollte allen demonstrieren, dass Felix kein traditio-Vergehen nachgewiesen werden konnte.

Konstantin, der sich noch bis ins Frühjahr 315 in Trier aufhielt, begab sich im frühen Sommer auf den Weg nach Rom, wo er am 21. Juli zur Feier seiner Decennalien eintraf. ${ }^{139}$ Möglicherweise kam es in Rom zu der Begegnung des Ingentius mit den donatistischen Anklägern. Obwohl nichts über die Durchführung dieses Vorhabens bekannt ist, lässt sich aus dem weiteren Verlauf erkennen, dass die Donatisten nicht von ihrer Position abwichen, ob sie nun mit Ingentius konfrontiert worden waren oder nicht.

In dieser Zeit erhielt Konstantin wiederholt Nachrichten aus Afrika über aufrührerisches Treiben, das mit dem Kirchenstreit im Zusammenhang stand. Einem Bericht des afrikanischen Vikars Celsus konnte er entnehmen, dass ein gewisser Menalius, wahrscheinlich ein numidischer Bischof, mit anderen Donatisten Unruhen schürte und, obwohl Celsus auf Befehl des Kaisers Maßnahmen ergriffen hatte, anhaltend Widerstand leistete. Inzwischen sprach man bei den donatistischen Anhängern bereits von Märtyrern und Verfolgung. ${ }^{140}$ Derartige Vorkommnisse mussten alarmierend wirken, da das Schisma die öffentliche Ruhe zu gefährden drohte, und sie veranlassten den Kaiser zu neuen

138 Brief an Probianus, Aug. ep. 88.4; vgl. o. Kap. 3.4.2.2. Monceaux (IV, 490) datiert dieses Reskript bereits auf Anfang des Jahres 315. Demnach hätte die Vorladung des Ingentius noch vor der in Opt. App. VIII beschriebenen Rückreise gelegen. Sachlich fügte sich diese Datierung sehr gut ein. Allerdings ist der Vorgänger des Probianus, Aelianus Paulinus, durch CTh XI 36.3 noch für den 26. April 315 als Prokonsul recht sicher nachweisbar. Probianus' Amtsantritt und somit der terminus post quem für seinen Brief an Konstantin sind folglich frühestens in den Mai 315 zu datieren. Barnes, New Empire, 170; Seeck, Regesten, 161, 163; vgl. auch o. Kap. 5 Anm. 232.

139 Seeck, Regesten, 163; Barnes, New Empire, 72; Grünewald, Constantinus, 104, 107; Grasmück (Coercitio, 71 f.) vermutet, dass die Donatisten den Kaiser in Rom erwarteten und dort mit neuen Anklagen bestürmten.

140 Der Brief des Celsus an Konstantin ist bezeugt durch das Reskript des Kaisers (Opt. App. VII). Vgl. Monceaux IV, 202; Grasmück, Coercitio, $74 \mathrm{f}$. Zur Datierung s. u. Anm. 143 - Menalius war möglicherweise jener numidische Bischof, der an der Bischofsweihe des Silvanus (Opt. I 13) beteiligt war. Mandouze, PAC, 747, s. v. Menalius. 
Überlegungen, die Probleme zu lösen: In seinem Reskript an Celsus ${ }^{141}$ erwähnt Konstantin, dass nach seinem Entschluss, die Sache einer neuerlichen Untersuchung zu unterziehen, die Donatisten aus seiner Umgebung geflohen seien. ${ }^{142}$ Ferner äußert Konstantin den Gedanken, selbst nach Afrika zu kommen, um vor Ort die causa Caeciliani zu klären und so zu demonstrieren, welche Verehrung der höchsten Gottheit gebühre und welcher Kult sie erfreue. Den Vikar wies er an, bis zu dieser Entscheidung Nachsicht gegenüber den Unruhestiftern zu üben. ${ }^{143}$

Die Konsequenzen, die eine Reise Konstantins nach Afrika für die Geschichte des Donatismus und sicherlich auch darüber hinaus gehabt hätte, sind

141 Der Brief Konstantins an Celsus (Opt. App. VII). Maier I, Nr. 26, 194-196; von Soden, Nr. 23; vgl. Monceaux IV, 202 f.; Dörries, Selbstzeugnis, 35-37; Kraft, Entwicklung, $193-195$.

142 Opt. App.VII: [...] cum statuissem inter ipsos atque Caecilianum plenissime super allegationibus diuersis requirere, praesentiae meae susceptam fugam subtrahere laborarunt.

143 Opt. App. VII: at cum constet minime unumquemque propria penitus delicta lucrari, etiamsi paulisper eorum fuerit coercitio dilata, mandandum grauitati tuae duxi ut interim quidem eosdem omittas et dissimulandum super ipsos esse cognoscas. uerum lecta hac epistula, tam Caeciliano quam hisdem palam facias quod, cum fauente pietate diuinam Africam uenero, plenissime uniuersis, tam Caeciliano quam his qui contra eum agere uidentur, lecto dilucido iudicio demonstraturus sum quae et qualis summae diuinitati sit adhibenda ueneratio et cuiusmodi cultus delectare uideatur. - Das Reskript an Celsus ist nicht datiert, wird jedoch von den meisten Historikern in den Herbst 315 oder erst in das Jahr 316 gelegt. Begründet wird dies zum einen mit der Erwähnung eines „Fluchtversuchs" der Donatisten am Hof, der mit jenem Fluchtversuch identifiziert wird, den Augustinus in ep. $43.20 \mathrm{im}$ Zusammenhang mit dem Mailänder Urteil erwähnt. Zum anderen werden die besagten Unruhen für das Ausbleiben Caecilians in Rom verantwortlich gemacht, von dem ebenfalls in ep. 43.20 die Rede ist (vgl. die Argumente bei Grasmück, Coercitio, 74 Anm. 341 und Barnes, New Empire, 244 f.). Demgegenüber halte ich eine frühere Einordnung und eine Datierung des Reskriptes in den Juli 315 für wesentlich sinnvoller: 1. Caecilianus hielt sich dem Brief zufolge in Afrika auf. Von einer Vorladung, die verhindert worden sei, ist aber nicht die Rede. Die angesprochenen Unruhen fanden nicht in Karthago, sondern in der numidischen Provinz statt und stehen in keinem Zusammenhang mit Caecilianus. Folglich stammt der Brief aus der Zeit vor der Ladung Caecilians nach Rom, die im Spätsommer ausgesprochen wurde. 2. Der Entschluss des Kaisers, nach Afrika zu reisen, passt wesentlich besser in den Sommer 315 als später. Konstantin war auf dem Weg nach Rom und konnte erwägen, von dort in kurzer Zeit weiter nach Afrika überzusetzen. 3. Nachdem Caecilianus trotz Vorladung nicht in Rom eingetroffen war, überlegte Konstantin, „Freunde“ nach Afrika zu senden (vgl. Opt. App. VI). In die gleiche Zeit auch Überlegungen einer eigenen Reise zu stellen, ist zwar möglich, wahrscheinlicher ist es aber, dass Konstantin von diesen Vorhaben längst wieder abgekommen war. 4. Die „Fluchtversuche“ der Donatisten sind keineswegs zwingend mit jenen in ep. 43.20 beschriebenen gleichzusetzen. Vielmehr dürfte die Notiz im vorliegenden Schreiben an Celsus im Zusammenhang mit dem Vorhaben der Afrikareise des Kaisers stehen. Die Donatisten erachteten es unter den neuen Gegebenheiten einer Afrikareise Konstantins für angebracht, selbst schnellstmöglich nach Afrika zurückzukehren. 
nicht zu unterschätzen. Doch diese Reise fand nicht statt. Der Tenor des Briefes lässt indessen aufhorchen: Die bisherige Zurückhaltung gegenüber der kirchlichen Angelegenheit weicht hier dem Willen, als Herrscher für Ordnung zu sorgen, eingeschlossen klare Anweisungen zur Ausübung des christlichen Kultes. Die politische Erwägung, eine Ausweitung der Auseinandersetzung zu einem Aufruhr und damit die Gefahr von bürgerkriegsähnlichen Zuständen zu unterbinden, veranlasste den Kaiser, die causa Caeciliani durch ein eigenes Urteil zu entscheiden. ${ }^{144}$

Nachdem die Pläne der Afrikareise aus unbekannten Gründen aufgegeben worden waren, der Wille zu einem abschließenden Urteil aber nach wie vor bestand, erging wohl noch im Sommer des Jahres 315 die Aufforderung an Caecilianus und Donatus, nach Rom zu kommen. ${ }^{145}$ Während Caecilianus nach dem Konzil von Arles nach Karthago zurückgekehrt war und seitdem in Afrika weilte, ist der Aufenthaltsort des Donatus zu diesem Zeitpunkt unklar. Entweder befand er sich bereits am Hof in Italien oder er war doch zwischenzeitlich nach Afrika zurückgekehrt und wurde ebenso wie sein Kontrahent angewiesen, sich nach Rom zu begeben.

Augustinus berichtet nun, dass Caecilianus aus unbekannten Gründen nicht in Rom eintraf. Die Donatisten am Hof versuchten dies offensichtlich zu ihren Gunsten zu nutzen und forderten eine Entscheidung des Kaisers in Abwesenheit Caecilians. ${ }^{146}$ Da dies abgelehnt wurde, erbaten sie die Erlaubnis zur Rückkehr nach Afrika. Offenbar erwog man daraufhin am Hof, hochrangige Vertreter zur Untersuchung und Urteilsfindung nach Afrika zu schicken, und den anwesenden Donatisten wurde die Rückkehr gestattet. Doch schon kurze Zeit später widerrief Konstantin diese Entscheidung. Es hatte sich die Meinung durchgesetzt, dass es besser sei, nicht unmittelbar am Unruheherd in Afrika die kaiserliche Untersuchung durchzuführen, sondern die Verhandlungen doch in Europa anzusetzen. Die donatistischen Bischöfe sollten am Hof verbleiben und die Ankunft Caecilians abwarten. ${ }^{147}$

144 In dieser Hinsicht zutreffend die Beurteilung von Kraft (Entwicklung, 59, 195). Demgegenüber betont Grasmück (Coercitio, $78 \mathrm{f}$.) das Verantwortungsbewusstsein Konstantins in seiner Funktion als pontifex maximus.

145 Ep. 43.20: iussit [sc. Constantinus] enim ille, ut ei partes ad agendam causam Romam occurrerent. Vgl. Opt. App. VI. - Da sich Konstantin in den Jahren 314-316 lediglich im Sommer 315 in Rom aufhielt, ergibt sich auch die Datierung aus der Ortsangabe. Vgl. Seeck, Regesten, 162-165.

146 Ep. 43.20. Diese Interpretation der donatistischen Anliegen durch Augustinus ist durchaus plausibel.

147 Zum Vorigen vgl. Konstantins Brief an die donatistischen Bischöfe an seinem Hof (Opt. App. VI). Maier I, Nr. 25, 192 f.; von Soden, Nr. 21; vgl. Dörries, Selbstzeugnis, 33 f.; Kraft, Entwicklung, 192 f. - Zur Einordnung von App. VI in den September 315 vgl. Seeck (ZKG 30, 1909, 208 f.) und Grasmück (Coercitio, 72-74) gegen Barnes (New 
Damit enden die Informationen aus den überlieferten Konstantinbriefen. Über den vorerst letzten Akt in der causa Caeciliani, das Urteil Konstantins, bleibt als einzige Quelle Augustinus, der wiederum sich selbst nur auf ein Dokument stützt, das heute verloren ist: den Brief Konstantins an den Vikar Eumalius vom 10. November 316. ${ }^{148}$ Dieser Brief, der sich schon bald nach seinem Amtsantritt als Bischof in Augustins Händen befand, entstammte einem städtischen Archiv, wahrscheinlich dem Archiv des Vikars in Karthago. ${ }^{149}$ Bereits in seinem Gespräch in Thubursicum ließ er das Dokument vortragen, in seiner Abhandlung gegen Cresconius zitiert Augustinus aus dem Brief einige Worte des Kaisers und auf der Konferenz von 411 war es das einzige Dokument der Katholiken, das über das iudicium Constantini Auskunft geben konnte. ${ }^{150}$

Konstantin informierte in diesem Brief den Vikar über das bisherige Verfahren und die Entscheidung in der causa Caeciliani. Vermutlich war eine Anfrage des Eumalius über den Umgang mit Donatisten hinsichtlich neuerlicher Beschwerden, Streitigkeiten oder Unruhen vorausgegangen, wie sie in ähnlicher Form bereits im Jahr zuvor durch seinen Vorgänger Domitius Celsus eingebracht worden war. Entsprechend enthielt das Schreiben keine langen Ausführungen über die Verhandlungen, sondern vielmehr einen kurzen Bericht über die einzelnen Schritte, die zum endgültigen Freispruch Caecilians geführt hatten. Wahrscheinlich forderte Konstantin Eumalius abschließend auf, sich dieser Entscheidung entsprechend zu verhalten und mit allen Mitteln donatistische Umtriebe $\mathrm{zu}$ verhindern. ${ }^{151}$

Die im Brief enthaltenen Aussagen sind schnell zusammengefasst: Ende September brach Konstantin von Rom auf und begab sich nach Mailand. ${ }^{152}$ Ein Teil der anwesenden Donatisten war offensichtlich nicht gewillt, noch länger vertröstet zu werden und versuchte zu entkommen. Das Unternehmen misslang und die Donatisten wurden unter Bewachung nach Mailand gebracht. ${ }^{153} \mathrm{Nach}$

Empire, 243), der App. VI im Zusammenhang mit App. VIII betrachtet und auf den 1. Mai 315 datiert.

148 Maier I, Nr. 27, 196-198; von Soden, Nr. 25; vgl. Dörries, Selbstzeugnis, 37; Seeck, ZKG $10,1889,522 \mathrm{f}$.

149 C. Don. 20: [...] imperatoris litteras, quibus se inter partes audisse testatur, [...] prolatas de archiuo publico recitauimus.

150 Ep. 43.4, 20; Cresc. III 82; Cap. conl. Carth. III 515.

151 Über den Inhalt des Briefes an Eumalius finden sich in Augustins ep. 43 mehrere Hinweise: So enthielt das Schreiben einen Gesamtüberblick über die causa Caeciliani (ep. 43.5), dazu gehörten Informationen über das Konzil von Rom und das iudicium Miltiadis (43.14), über die Appelle nach dieser Entscheidung (43.15) sowie über das Konzil von Arles, die erneuten Klagen und schließlich über das Urteil des Kaisers (43.20).

152 Vgl. Seeck, Regesten, 164; Barnes, New Empire, 72.

153 Ep. 43.20: quo cum Caecilianus nescio qua causa non occurrisset, interpellatus ab eis praecepit, ut Mediolanium sequerentur. tunc se aliqui eorum subtrahere coeperant [...]. 
einiger Zeit traf dann Caecilianus am Hof Konstantins ein, und es kam in Mailand, wohl im Oktober oder November 315, zu der vorgesehenen Verhandlung. Nach Anhörung der beiden Parteien fällte Konstantin sein Urteil, das erwartungsgemäß die bisherigen Urteile bestätigte. An Eumalius schrieb er:

„Dabei [in der Anhörung] habe ich erkannt, dass jener Mann Caecilianus vollkommen unschuldig ist und die schuldigen Pflichten seiner Religion bewahrt und ihr dient, wie es sich gebührt. Es ist in aller Klarheit deutlich geworden, dass bei ihm keine Straftat gefunden werden konnte, wie sie ihm in seiner Abwesenheit durch die Verstellung seiner Gegner angehängt worden war.“"154

Der kurz gefasste Inhalt des Briefes an Eumalius bedingte, dass Augustinus und die Katholiken nicht mehr über das Urteil Konstantins aussagen konnten als die genannten Informationen. Von dem Verlauf der kaiserlichen Kognition, den vorgetragenen Argumenten und den Plädoyers der beiden Seiten besaßen sie keine Kenntnisse. Folglich kann auch heutzutage nur vermutet werden, welche Gründe den Ausschlag zum Urteil Konstantins gaben. Entscheidend waren wohl die eindeutigen Stellungnahmen der katholischen Bischöfe, die das donatistische Verständnis von Taufe und Weihehandlungen ablehnten. Zur Erhaltung der kirchlichen und damit staatlichen Einheit konnten keine Sonderkulte gestattet werden. Wie bereits bei den bischöflichen Urteilen bedeutete eine solche Vorentscheidung zwangsläufig das Scheitern der Argumente der Donatisten. Ihre Einsprüche gegen die bisherigen Untersuchungsmethoden wurden hinfäl-

quod ubi cognouit prouidus imperator, reliquos ab officialibus custoditos fecit Mediolanium peruenire.

154 Cresc. III 82: in quo peruidi [...] Caecilianum uirum omni innocentia praeditum ac debita religionis suae officia seruantem eique ita ut oportuit seruientem nec ullum in eo crimen repperiri potuisse euidenter apparuit, sicut absenti fuerat aduersariorum suorum simulatione compositum. - Die Datierung des iudicium Constantini auf den späten Herbst 315 ist nicht unumstritten. Terminus ante quem ist Augustins Datierung des Konstantinbriefes an Eumalius auf den 10. November 316. Aus diesem Grund nehmen Monceaux (IV 25, 196 f.) und Frend (Donatist Church, 158 f.) an, dass das Urteil erst im Laufe des Jahres 316 gefallen sei. Mit Grasmück (Coercitio, 79) sind jedoch die von Augustinus angeführten Orte, erst Rom, dann die cognitio in Mailand, als entscheidende Hinweise zu werten. Der Aufenthalt Konstantins in Mailand im Oktober 315 ist aufgrund von Frag. Vat. 273 (vgl. Seeck, Regesten, 164) recht sicher nachweisbar. Auf jeden Fall befand sich Konstantin im Januar 316 wieder in Trier (vgl. CTh I 22.1). Für das Jahr 316 ist kein Aufenthalt in Mailand bekannt. Möglich wäre eine Durchreise auf dem Weg von Arles nach Osten im August/September 316 vor der Schlacht gegen Licinius bei Cibalae. Ein erneuter Aufenthalt in Rom ist dagegen weder bezeugt noch wahrscheinlich zu machen. D. h., man müsste davon ausgehen, dass die beiden Streitparteien (zumindest aber die Donatisten) fast ein Jahr in Mailand festgehalten wurden, ehe es zur Verhandlung kam. Dies ist zwar nicht grundsätzlich auszuschließen, aber durch die gesamte Vorgeschichte im Jahre 315 mit den in Rom getroffenen Vorentscheidungen ist es wesentlich naheliegender an der Datierung des iudicium Constantini im Oktober/ November 315 festzuhalten. Zu dem Itinerarium Konstantins vgl. Barnes, New Empire, 72 f; Grünewald, Constantinus, 108-112. 
lig, da Konstantin der katholischen Dogmatik folgte. Darüber hinaus lag dem Kaiser der Freispruch des Felix von Abthugni vor. Die Anklage, Caecilianus sei von einem Traditor geweiht worden, war damit offensichtlich widerlegt. Schließlich hatte die Entwicklung der vergangenen Monate und Jahre gezeigt, welches Unruhepotenzial die Donatisten zu entwickeln in der Lage waren. Um die Stabilität und öffentliche Ruhe nicht zu gefährden, fiel Konstantins Entscheidung zu Gunsten der Katholiken.

Nach dieser Entscheidung des Kaisers scheint es bald zu Maßnahmen gegen die Donatisten in Afrika gekommen zu sein. Augustinus spricht von einem Gesetz Konstantins, in dem erstmals verfügt wurde, donatistischen Bischöfen die Kirchen zu entziehen. Außerdem wurde donatistischen Anhängern, die sich hartnäckig gegen eine Rückführung zur katholischen Kirche wehrten, die Konfiszierung ihrer Vermögen angedroht. ${ }^{155}$ Die späteren donatistischen Legenden, die von der Verfolgung unter Konstantin berichteten, zeugen ihrerseits von zum Teil gewaltsam durchgeführten Maßnahmen, die die Kircheneinheit wieder herstellen sollten. ${ }^{156}$

\subsection{Donatistische Traditionen und Deutungen}

Die donatistischen Darstellungen und Beurteilungen des iudicium Constantini weichen in einigen Bereichen vom oben dargestellten Verlauf ab. Es stellt sich die Frage, wie die Aussagen der Donatisten zustande kamen und auf welchen historischen Quellen und Überlieferungen sie basierten. Grundlagen bieten zum einen die Ausführungen der Donatisten auf der Konferenz von 411, in denen sich auch die Aussagen des Cresconius wiederfinden. Sie sollen im ersten Abschnitt analysiert werden. Zum anderen lassen sich aus Augustins Schrift gegen Parmenianus einige donatistische Überlieferungen zum Urteil Konstantins erschließen. Diese Quelle wird im zweiten Abschnitt diskutiert.

\subsubsection{Geschichtsdeutungen auf der Konferenz von Karthago}

Der Blick auf die historischen Dokumente, die während der Konferenz von den Donatisten vorgelegt wurden, zeigt sehr deutlich, dass diese Quellen erst im Nachhinein zur Untermauerung bereits bestehender Ansichten herangezogen worden sind. Die donatistischen Bischöfe verwendeten einen Textausschnitt aus Optatus, eine Supplik ihrer Vorfahren an Konstantin, das dazugehörige Reskript des Kaisers an den Vikar Verinus sowie den Brief Konstantins an den Prokonsul Probianus. Diese Auswahl lässt vermuten, dass den Donatisten außer diesen

155 Ep. 88.3; vgl. c. litt. Pet. II 205; c. ep. Parm. I 13, 18; epp. 93.14; 105.9. Vgl. o. Kap. 4.2.2. 156 Vgl. o. Kap. 6.3.1. 
Dokumenten keine anderen, zumindest keine besseren, zur Verfügung standen und sie sich zwangsläufig nicht nur zu ihrer Verteidigung gegen die Katholiken, sondern auch zu ihrer eigenen historischen Rechtfertigung und Selbstvergewisserung auf diese Dokumente stützen mussten. ${ }^{157}$ Diese vier Zeugnisse stellten die schriftlichen Beweise für drei verschiedene Traditionslinien der Donatisten dar, die erst auf der Konferenz von 411 miteinander verknüpft wurden, um dort eine stringente Argumentation vorlegen zu können.

\section{Die erste Traditionslinie: Die Verbannung Caecilians nach Brescia}

Die erste Traditionslinie ist die Idee der Verbannung Caecilians nach Brescia. Hier handelt es sich offenbar lediglich um die donatistische Lesart des Werkes von Optatus. Erwähnt wird diese Tradition auch von Cresconius, ${ }^{158}$ wodurch deutlich wird, dass sie nicht erst für die Konferenz von 411 entwickelt wurde, sondern bereits seit längerem einen Bestandteil der donatistischen Überlieferung bildete.

Die entscheidende Textstelle bei Optatus ist heute kaum leichter zu deuten als zur Zeit Augustins. Da in keiner anderen Quelle über den Brescia-Aufenthalt Caecilians berichtet wird, kann lediglich - wie bereits auf der Konferenz von Karthago - zunächst nur der Zusammenhang bei Optatus selbst näheren Aufschluss bringen: Dieser beschreibt den Verlauf der Ereignisse folgendermaßen: Nachdem er die Entscheidung des römischen Konzils mit der Sentenz des Miltiades berichtet hat (I 24), spricht Optatus von einem Appell des Donatus, woraufhin sich der Kaiser über die Kühnheit erregt habe, dass ein Bischof nach Art der Heiden appelliere (I 25). Optatus zitiert hier aus einem Brief Konstantins an katholische Bischöfe, der im Anhang seines Werkes erhalten ist und vermutlich nach dem Konzil von Arles geschrieben wurde. Da Optatus das Urteil von Arles nicht erwähnt, bleibt der genaue chronologische Zusammenhang zum nachfolgenden Bericht über Caecilians Aufenthalt in Brescia unklar. ${ }^{159}$

Donatus, so berichtet nun Optatus, habe um die Erlaubnis gebeten, nach Karthago zurückkehren zu dürfen, was ihm aber verwehrt worden sei. ${ }^{160}$ Filu-

157 Zum Verlauf der donatistischen Argumentation auf der Konferenz s. o. Kap. 5.3.2-3.

158 Cresc. III 80, 83; vgl. o. Kap. 3.4.1.

159 Opt. App. V. - Optatus zitiert bereits in I 23.1 im Zusammenhang mit den preces der Donatisten aus diesem Brief eine Antwort Konstantins. Folglich diente ihm dieser Brief als eine Fundgrube, aus der er an geeigneten Stellen den Kaiser zitieren konnte. Dabei nahm Optatus keine Rücksicht auf die chronologische Einordnung (die er vermutlich gar nicht kannte). Vgl. Girardet, Chiron 19, 1989, 189-191; Labrousse, SC 412, 63; Monceaux IV, 215.

160 Opt. I 26: Eodem tempore idem Donatus petiit ut ei reuerti licuisset * * ad Carthaginem accederet (ed. Ziwsa, Optatus, S. 28). Labrousse (SC 412, S. 226) bevorzugt die Lesart der Hs. P: [...] ut ei reuerti licuisset nec ad Carthaginem accederet. Augustinus, der die 
minus, ein Anhänger des Donatus, habe daraufhin dem Kaiser nahegelegt, dass unter diesen Umständen um des Friedens willen auch Caecilianus nicht nach Karthago zurückkehren sollte. Diesem Vorschlag sei stattgegeben worden und Caecilianus sei in Brescia zurückgehalten worden. Während der Abwesenheit beider Bischöfe sei dann eine Untersuchungskommission der Bischöfe Eunomius und Olympius nach Karthago aufgebrochen, mit dem Auftrag die Situation der Kirche zu prüfen und einen der beiden Gegner in seinem Amt zu bestätigen. Nach 40 Tagen Überprüfung hatten die Gesandten schließlich mit der pars Caeciliani kommuniziert, das Urteil von Rom bestätigt und seien anschließend heimgekehrt. Aufgeschreckt durch dieses Ergebnis sei Donatus als erster, wenig später auch Caecilianus wieder nach Karthago zurückgekehrt. ${ }^{161}$

Zum Abschluss dieser Darstellung weist Optatus darauf hin, dass er Aktenmaterial als Informationsquelle verwendet habe, das seinem Werk beigefügt und somit von jedem nachzulesen sei. Diese Akten waren jedoch schon zu Augustins Zeiten nicht mehr greifbar und sind auch heute nicht erhalten.

Textstelle selbst als unklar bezeichnet (c. Don. 54), gibt die Textstelle bei Optatus folgendermaßen wieder (breuic. III 38; vgl. Lancel. CCL 149A, 302): ,[...] ut ei reuerti licuisset et ad Carthaginem accedere. Der inhaltliche Zusammenhang bei Optatus ergibt eindeutig, dass Donatus nach seinem Gesuch an den Kaiser nicht nach Karthago zurückgekehrt war, sondern in Abwesenheit beider Bischöfe (Caecilianus und Donatus) eine Untersuchungskommission dorthin geschickt wurde und anschließend Donatus wieder in Afrika eintraf (Opt. I 26). Außerdem erschließt sich die Motivation des Donatus, auch Caecilians Rückkehr nach Karthago zu unterbinden und seine Festsetzung in Brescia zu fordern, am besten aus der Tatsache, dass ihm selbst die Rückkehr verwehrt worden war. Hinsichtlich der unsicheren Überlieferung der Optatusstelle bleiben somit zwei Möglichkeiten: Entweder die Lesart der Hs. P enthält (zumindest sinngemäß) den ursprünglichen Text, oder der ursprüngliche Text ließ offen, ob Donatus zurückkehren durfte oder nicht. Mit Labrousse (SC 412, 228 f. Anm. 1; Grasmück, Coercitio, 80) ist die erste Möglichkeit als die wahrscheinlichere anzunehmen. Vgl. auch Monceaux IV, 209; Mandouze, PAC, 298; 456, s. v. Filuminus; Lancel, SC 194, 99; Edwards, Optatus, 25 Anm. 101. Weniger wahrscheinlich erscheint mir der Vorschlag Turners (JThS 27, 1926, 292), der ausgehend von Hs. P die Lesart empfiehlt: petiit ut ei reuerti licuisset et ne C[aecilianus] ad Carthaginem accederet.

161 Opt. I 26: tunc duo episcopi ad Africam missi sunt, [...] ut remotis binis singulos ordinarent. In der Forschung wird verbreitet die Lesart der Hss. RBV bevorzugt: ut remotis binis unum ordinarent. Davon ausgehend wird postuliert, dass die Gesandten anstelle von Caecilianus und Donatus einen Dritten zum Bischof hätten erheben sollen (vgl. u.a. Frend, Donatist Church, 156; Grasmück, Coercitio, 81; Mandouze, PAC, 171; Monceaux IV, 24, 210; Monachino, AHP 2, 1964, 21 f.; Seeck, ZKG 30, 1909, 217; von Soden, Nr. 24, 36; Ziwsa, Optatus, 28). In diesem Fall stellt sich jedoch die Frage, warum kein neuer Bischof ordiniert wurde. Wenig überzeugend ist die Darstellung, dass die Unruhen der Donatisten dies verhindert hätten (so Monceaux und Grasmück). Die Entscheidung der Gesandten zu Gunsten der pars Caeciliani zeigt vielmehr, dass es von Anfang an um eine Entscheidung zwischen den zwei konkurrierenden Bischöfen gegangen war. Mit Edwards, Optatus, 26; Labrousse, SC 412, 229 Anm. 2; Turner, JThS 27 , 1926, 292. 
Dennoch ist es unangebracht, wegen der mangelnden Überprüfbarkeit Optatus' Darstellung grundsätzlich in Zweifel zu ziehen. Obwohl sich der Bericht nur schwer in den sonst bekannten Ereignisverlauf einfügen lässt und Augustinus ihn nicht für seine Argumentation benutzte, fehlen doch überzeugende Argumente, um eine Fälschung annehmen zu können. ${ }^{162}$

Wann aber wurde die Untersuchungsfahrt der Bischöfe Eunomius und Olympius durchgeführt und wann hielt sich Caecilianus in Brescia auf? In der Forschung ordnet man dieses Ereignis bisher in das Umfeld des kaiserlichen Urteils zu Gunsten Caecilians ein, also Mitte bis Ende des Jahres 315 bzw. 316. ${ }^{163}$ Aufgrund der Quellenlage ist eine gesicherte Datierung nicht

162 Seeck (ZKG 10, 1889, 562-566; 30, 1909, 216-220) hält die Akten über die bischöfliche Gesandtschaft nach Afrika für eine Fälschung und vermutet, dass Optatus selbst der Fälscher gewesen sei. In Unkenntnis des tatsächlichen Verlaufs nach dem römischen Konzil habe Optatus die kaiserliche Entsendung der Bischöfe erfunden, um ein schriftliches Zeugnis für die Bestätigung des römischen Urteils durch Konstantin und damit die Unumstößlichkeit des Freispruchs Caecilians vorlegen zu können. Folgende Indizien führt Seeck an: Die Katholiken hätten auf der Konferenz 411 auf eine Beweisführung mit Hilfe dieser Optatusstelle verzichtet, wodurch ihre Vorbehalte gegen die Darstellung des Optatus deutlich würden. Ferner hätten die Gesandten die weltweite Ausbreitung der Kirche als Kriterium zur Feststellung der Katholizität angeführt, eine Definition, die zur Zeit Konstantins noch nicht gegolten hätte. Schließlich hätte die Gesandtschaft nur vor der Durchführung der Synode von Arles stattfinden können, da sich die beiden Bischöfe ansonsten auf das Urteil dieser Synode berufen hätten und nicht auf das römische. Dies wäre aber nur sinnvoll gewesen, wenn die Gesandten in Arles ihren Bericht vorgelegt hätten. Da sie aber nicht unter den Teilnehmern aufgeführt werden, erweise sich die gesamte Episode als Schwindel. Dieses letzte Argument Seecks ist rein hypothetisch: Weder muss ein Bericht der Bischöfe in Arles vorgelegt worden sein noch lässt sich anhand des Quellenmaterials im Detail nachvollziehen, welche Informationen in Arles tatsächlich verwendet wurden. Seecks Zweifel, dass ein Hinweis auf die weltweite Verbreitung der Kirche die Katholizität bestätigen könne, sind zwar nicht ganz von der Hand zu weisen, doch greift auch Optatus in seiner $c a$ tholica-Vorstellung bereits auf ältere Traditionen zurück (vgl. Schindler, AL 1, 815 f., s. v. Catholicus, -a). Seecks Beobachtungen zu den Verhandlungen von 411 sind zwar richtig, allerdings genügen sie nicht, um die Fälschung einer Quelle zu erweisen. Nachdem er eigene Forschungen angestellt hatte, berief sich Augustinus nicht mehr auf Optatus, da er dessen Defizite erkannt hatte. Der Eumaliusbrief war nun das entscheidende Dokument für die Katholiken, so dass die bei Optatus berichtete Gesandtschaft, die sich nicht durch weitere Akten belegen ließ, als das schwächere Argument außen vor blieb. Diese Strategie zeigt sich auch auf der Konferenz von 411 (vgl. o. Kap. 5.3.2). Es darf auch nicht übersehen werden, dass die Katholiken und Augustinus die Tatsache des Brescia-Aufenthalts Caecilians niemals abstritten. Schließlich ist die von Seeck unterstellte Motivation des Optatus nicht schlüssig. Die unklaren Formulierungen zum Brescia-Aufenthalt und der wenig stringente Verlauf der Untersuchungsreise sprechen eher gegen eine gezielte Fälschung als dafür. Vgl. auch Grasmück, 82 Anm. 389.

163 Die Brescia-Episode wird entweder in das Jahr 315 vor das Urteil Konstantins (etwa Barnes, New Empire, 244; Frend, Donatist Church, 156-158; Keresztes, Constantine, 
möglich, aber entgegen bisheriger Vorschläge erscheint mir eine frühere Einordnung im historischen Zusammenhang plausibler: Es ist nahezu auszuschlieBen, dass die Inspektionsfahrt der Bischöfe nach dem iudicium Constantini im Herbst 315 stattfand. Zum einen bestätigten die Inspektoren nach Abschluss der Untersuchungen das Urteil des Miltiades. Damit bezogen sie sich auf das bisher einzige Urteil in der causa Caeciliani. Wäre bereits vom Kaiser selbst ein Urteil gesprochen worden, dürfte dieses der Bezugspunkt der Untersuchungskommission gewesen sein. Zum anderen ist es nicht einsichtig, warum Konstantin nach seinem Urteilsspruch über Caecilianus nochmals die Frage der RechtmäBigkeit von dessen Bischofsamt hätte überprüfen lassen sollen. ${ }^{164}$ Die Aufgabe von Eunomius und Olympius, lediglich die Lage der Kirchengemeinden in Karthago zu inspizieren und $\mathrm{zu}$ schlichten, deutet ganz offensichtlich auf eine frühere Phase hin, in der man am Hofe noch weitere Informationen anforderte und eine schnelle Einigung erhoffte.

Geht man nun von einer Datierung im unmittelbaren Vorfeld des kaiserlichen Urteils aus, ergibt sich ein anderes Problem: Optatus berichtet, dass nach Abschluss der Untersuchungskommission zunächst Donatus, dann auch Caecilianus sich eiligst auf den Weg nach Karthago machten, um zu ihren Gemeinden zu kommen. Folglich müsste man annehmen, dass beide Bischöfe bereits im Jahr $315 \mathrm{zu}$ Verhandlungen am Hof vorgeladen und eingetroffen waren, dann zurückkehrten und nochmals offiziell vor das kaiserliche Gericht geladen wurden. Dies ist zwar theoretisch möglich, aber in dem von Augustinus überlieferten Abriss über die Vorladung nach Rom ist davon nicht die Rede. ${ }^{165}$ Wesentlich einleuchtender ist die Annahme, dass Caecilianus und Donatus im Anschluss an das Konzil von Rom noch in Italien weilten, als die Entscheidung zur Bildung

79; Kraft, Entwicklung, 42 f.; Mandouze, PAC, 170-173; Monachino, AHP 2, 1964, 21 f.), oder sogar nach das Urteil gelegt (Duchesne, Dossier, 646; de Veer, BA 31, 822 824; Grasmück, Coercitio, 79-83; Mühlsteiger, ZRG KA 85, 1999, 45 f.). Monceaux (IV, 209 f.) datiert vor das iudicium Constantini, allerdings erst in das Jahr 316; vgl. auch Labrousse, SC 412, 64 Anm. 3; Maier I, 196 f. - Grasmück beruft sich auf die Aussagen der Donatisten und Augustins, die das „Exil“ von Brescia stets „,in direkter Beziehung zu dem Gericht und der Entscheidung des Kaisers" stellten (Coercitio, 82, Anm. 389). Doch gerade diese Beziehung ist von den Donatisten für ihre Argumentation forciert worden, so dass sie kein Argument für das tatsächliche historische Geschehen darstellt (s.o. Kap. 5.3.2). Ferner geht auch Grasmück davon aus, in Karthago hätte ein ganz neuer Bischof gewählt werden sollen und dies sei nach den bischöflichen Urteilen schwieriger zu akzeptieren gewesen als nach dem kaiserlichen Urteil. Doch gerade nach dem kaiserlichen Urteil zu Gunsten Caecilians wäre es sinnlos gewesen, die ganze Sache nochmals aufzurollen. Es ist wesentlich wahrscheinlicher, dass Konstantin nach seinem Urteil vorerst keine neuen Untersuchungen oder Entscheidungen fällte.

164 Vgl. die Argumente von Monceaux IV, $209 \mathrm{f}$.

165 Aus ep. 43.20 geht klar hervor, dass es nur eine Vorladung nach Rom gab (zur Problematik vgl. o. Kap. 4.2.1). 
der Untersuchungskommission fiel, die alsbald durchgeführt wurde. ${ }^{166}$ Insofern sind die Inspektionsreise und damit der Aufenthalt Caecilians in Brescia in das Frühjahr $314 \mathrm{zu}$ datieren. Diese Datierung wird nicht zuletzt durch Optatus bestätigt, der mit seiner Formulierung eodem tempore keinen großen Abstand zum römischen Konzil sieht. ${ }^{167}$

Die Entscheidung für die bischöfliche Untersuchungskommission in der causa Caeciliani fiel sehr wahrscheinlich am Hofe. Aus Optatus geht keineswegs hervor, dass jener Filuminus die Sache initiierte. ${ }^{168}$ Vermutlich sollten zunächst nur Donatus und seine Anhänger in Italien zurückgehalten werden, bis das weitere Verfahren geklärt war. Filuminus jedoch protestierte gegen die Ungleichbehandlung und es wurde entschieden, dass auch Caecilianus nicht nach Karthago zurückkehren durfte, sondern in Brescia die weitere Entwicklung abwarten musste. ${ }^{169}$ Die Gründe für das Einschreiten des Filuminus bleiben ungeklärt. Es ist keineswegs zwingend, die Polemik des Optatus zu übernehmen und Filuminus als Handlanger des Donatus zu titulieren. Es könnten auch andere, rechtliche oder politische Motive eine Rolle gespielt haben.

Konstantin versuchte, sich mit Hilfe der bischöflichen Gesandten einen Überblick über die verworrene Lage in Karthago zu verschaffen, die Ursachen des Streites aufzuspüren und eine Lösung anzustreben. In der Situation bot es sich an, die Gemeinden in Karthago in Abwesenheit der Kontrahenten besuchen zu lassen. Vermutlich stand die Hoffnung dahinter, Agitationen und Unruhen vorzubeugen und so leichter zu einer Schlichtung zu gelangen. Nach Abschluss der Untersuchung und der Bestätigung des römischen Urteils kehrten beide Bischöfe nacheinander zurück, ohne dass sich an der Lage etwas geändert hätte. Die weitere Entwicklung macht deutlich, dass die Donatisten ihre Position in Afrika weiter ausbauen konnten und weiterhin auf eine Entscheidung des Kaisers drängten.

Kommen wir zurück zur Argumentation der Donatisten. Optatus von Mileve besaß bei der Abfassung seines Werkes keine zusammenhängenden Informationen über das weitere kaiserliche Verfahren nach dem Urteil von Rom. Er wusste von Appellen der pars Donati beim Kaiser sowohl Caecilianus als auch Felix von Abthugni betreffend, er kannte den Prozessausgang gegen Felix und

166 So bereits Lietzmann, Geschichte III, $73 \mathrm{f}$.

167 Opt. I 26. Häufig werden die Unruhen, die während der Anwesenheit der Untersuchungskommission aufgetreten sein sollen, mit jenen Unruhen identifiziert, die Celsus im Jahre 315 an den Kaiser meldete (vgl. Opt. App. VII). Ebenso lassen sich aber die seditiosa der Donatisten (Opt. I 26) mit den Unruhen identifizieren, von denen Aelafius wohl im Frühjahr 314 aus Afrika berichtete (Opt. App. III).

168 So Frend, Donatist Church, 156; Pietri, Geschichte, 252 f.; Mühlsteiger (ZRG KA 85, 1999, 45): „Ein letzter von Donatus ausgeheckter Kompromissvorschlag“.

169 Über den Aufenthaltsort des Donatus wird nichts gesagt. Ob er ebenfalls in Brescia festgehalten wurde (so Pietri, Geschichte, $252 \mathrm{f}$.), muss offen bleiben. 
die besagten Akten über die Legation von Eunomius und Olympius. Optatus wusste, dass Caecilianus freigesprochen worden war, aber wann und unter welchen Umständen bleibt in seinem Werk offen. ${ }^{170}$

Die Donatisten nutzten nun den Mangel an chronologischer und inhaltlicher Präzision bei Optatus für ihre Zwecke aus. Für sie ging aus dessen Darstellung klar hervor, dass Caecilianus in Brescia auf kaiserliche Anweisung festgehalten worden war. Optatus, so interpretierten sie, habe in seiner Polemik eine euphemistische Formulierung gewählt, um die Wörter „Verbannung“ oder „Exil““ $\mathrm{zu}$ vermeiden. In Wahrheit habe es sich aber um ein Exil gehandelt, und dies impliziere ein kaiserliches Urteil gegen Caecilianus. Diese Auffassung vertraten Cresconius ebenso wie die donatistischen Vertreter auf der Konferenz von 411.

Die donatistische Beweisführung auf der Konferenz gibt indessen keine Auskunft über das Entstehen dieser donatistischen Tradition. In Karthago standen die Donatisten unter dem Zwang, einen Beweis ihrer Darstellung vorzulegen, und für diesen Zweck kam ihnen der Optatustext - letztlich mehr schlecht als recht - entgegen. Ohne diesen Beweiszwang genügte auch die eigene mündliche Tradition, unabhängig von Optatus, in der die Umstände von Caecilians Aufenthalt in Brescia als Erfolg ihrer Kirche beim Kaiser gedeutet wurden.

Auch wenn die Hintergründe von Caecilians Aufenthalt in Brescia sich nicht vollständig klären lassen, so wird dennoch deutlich, dass die donatistische Interpretation nicht den historischen Gegebenheiten entsprach. Selbst wenn man davon ausginge, dass Caecilianus nicht freiwillig „um des Friedens willen“ in Brescia weilte, so erlaubt der Zusammenhang mit der Untersuchung der Bischöfe Eunomius und Olympius keinesfalls den Schluss, es habe sich um ein Exil nach einem kaiserlichen Urteil gehandelt. Im weitesten Sinne könnte man Brescia vielleicht als Ort einer „Untersuchungshaft“ verstehen. Das entscheidende Dokument gegen die donatistische Auffassung bleibt jedoch heute wie im Jahre 411 der Eumaliusbrief vom November 316, in dem der Freispruch Caecilians nach der von Optatus berichteten Episode bezeugt ist.

\section{Die zweite Traditionslinie: Die Toleranz Konstantins}

Die zweite Traditionslinie, auf die sich die donatistischen Bischöfe im Jahre 411 beriefen, war die Gewährung einer religiösen Toleranz gegenüber den Donatisten, die Kaiser Konstantin im Jahre 321 erlassen hatte. ${ }^{171}$ Die beiden Dokumente, mit denen sie ihre Ansicht begründeten, sind heute nicht mehr erhalten, sondern lediglich durch Inhaltsangaben Augustins und die Informationen aus den Capitula der Konferenzakten fassbar.

170 Zur Chronologie bei Optatus vgl. Labrousse, SC 412, 68-72; Monceaux V, 276.

171 Vgl. o. Kap. 5.3.2. 
Es handelt sich hierbei um eine Bittschrift der donatistischen Partei an Kaiser Konstantin (libellus ad Constantinum) und das dazugehörige Reskript, das an den Vikar Verinus adressiert war. ${ }^{172}$ Die in Karthago vorliegenden Kopien dieser Dokumente waren nicht datiert, worauf in der Debatte allerdings kein Bezug genommen wurde. Der libellus beinhaltete Einwände und Klagen der Donatisten gegen die bisherigen Entscheidungen und Maßnahmen des Kaisers: Sie wehrten sich gegen ihre Verfolgung und betonten zugleich, dass sie trotz derartiger Repressionen Caecilianus niemals als Bischof anerkennen würden. Zudem wurde die causa Felicis thematisiert, ${ }^{173}$ vermutlich um die Anklagen gegen Caecilianus zu begründen. In seinem Reskript an den vicarius Africae äußerte sich Konstantin abfällig über die Hartnäckigkeit der Donatisten und ihre andauernden Appelle. Gleichwohl sprach er davon, dass verbannte Donatisten aus dem Exil zurückkehren und die donatistischen Gemeinden nicht weiter verfolgt werden sollten. Welche Gründe ihn dazu bewogen, ist aus den überlieferten Fragmenten nicht ersichtlich.

Nach der Konferenz ermittelte Augustinus den 5. Mai 321 als Datum des Reskriptes, als er anhand von Archivmaterial die Chronologie mehrerer Dokumente überprüfte. Diese Datierung dürfte richtig sein, da sowohl die formalen Angaben korrekt sind als auch Verinus durch andere Gesetze als Vikar vom 16. November 318 bis zum 29. August 321 nachzuweisen ist. ${ }^{174}$ Anhand dieser zeitlichen Einordnung wird deutlich, ${ }^{175}$ dass der donatistische libellus und das Reskript nicht mehr in den unmittelbaren Zusammenhang der Urteile über Caecilianus gehören, sondern in eine fortgeschrittene Phase der Auseinandersetzung. Zwangsmaßnahmen gegen die Donatisten waren bereits durchgeführt

172 Der Zusammenhang zwischen dem libellus und dem Reskript ist aus Augustins Darstellung (breuic. III 39-40; c. Don. 54; ep. 141.9) nicht zwangsläufig zu schließen, wird jedoch durch Cap. conl. Carth. III 543-548 evident. Seeck (ZKG 10, 1889, 533 f.) glaubte zunächst, es handele sich bei dem libellus um die Appellation der Donatisten gegen das Miltiadesurteil, da Konstantin offenbar erst dadurch mit der causa Felicis bekannt gemacht worden sei. Allerdings korrigierte er sich später (ZKG 30, 1909, 191; Geschichte III, 336) und stellte den libellus in den Zusammenhang mit der Toleranz von 321. Dies ist auch communis opinio in der Forschung. Vgl. zu den Dokumenten Monceaux IV 29, 198, 203, 208 f.; Pietri, Geschichte, 254 f.; Lamirande, BA 32, 734; Maier I, $239 \mathrm{f}$; mit Einschränkung allerdings von Soden, Nr. 30, $50 \mathrm{f}$.

173 Diesen wichtigen Hinweis aus Cap. conl. Carth. III 543 unterschlägt Augustinus in seinen kurzen Inhaltsangaben.

174 C. Don. 56: imperator ad Valerium [= Verinum] litteras dedit Crispo et Constantino iterum consulibus III Nonas Maias. - Zum Datum und zur Person (mit der Problematik des Namens Valerius bei Augustinus): Seeck, Regesten, 170 f.; ZKG 10. 1889. 534 f.; Barnes, New Empire, 146; PLRE I, 951 f., s. v. Verinus 2; Enßlin, RE VIII A 2, 1549 f., s. v. Verinus 3.

175 Monceaux (IV, $490 \mathrm{f}$.) datiert den libellus an Konstantin auf Anfang 321, folglich in das Frühjahr desselben Jahres das „Toleranzedikt“ gegenüber den Donatisten, von dem schließlich Verinus am 5. Mai in Kenntnis gesetzt wurde. 
worden, die unter anderem zur Verbannung einiger Bischöfe geführt hatten. ${ }^{176}$ Es ist davon auszugehen, dass Vertreter und Sympathisanten der Donatisten immer wieder versucht hatten, am Hof für ihre Sache einzutreten und gegen die Unterdrückung zu protestieren. Der 411 in Karthago vorgelegte libellus war folglich nur eine von vielen Petitionen, mit der Besonderheit, dass diese zu einem gewissen Erfolg geführt hatte. Denn es ist nicht in Abrede zu stellen, dass Verinus in dem Reskript über eine Änderung der kaiserlichen Politik gegenüber den Donatisten informiert wurde und die Anweisung erhielt, keine weiteren Maßnahmen gegen die Donatisten in seinem Verwaltungsbereich durchzuführen. Möglicherweise erhielt der amtierende Prokonsul Afrikas einen gleichlautenden Brief Konstantins.

Unter den Appendizes bei Optatus befindet sich ein Brief Konstantins an die katholischen Bischöfe und Gemeinden, der sehr wahrscheinlich in diese Zeit gehört. Der Kaiser räumt hier ein Scheitern der bisherigen Maßnahmen ein und überlässt die „Korrektur“ der „Verirrten“ nunmehr Gott selbst. Die katholischen Adressaten bittet er gleichzeitig um Toleranz und Geduld, auch gegenüber Gewalttaten der Donatisten. ${ }^{177}$

Im Hinblick auf mögliche Ursachen für die neue Politik Konstantins seit 321 wird in diesem Brief zumindest ein Grund benannt: Die bisherige Art und Weise der Bekämpfung der Donatisten hatte keinen nennenswerten Erfolg gebracht, sondern zum Teil sogar das Gegenteil hervorgerufen, weil die Verfolgten sich in ihrer Rolle als Märtyrer gefielen. Außer diesem Eingeständnis eines Misserfolgs dürften allerdings auch andere politische Erwägungen Konstantin beeinflusst haben. So war die Befriedung der Provinz Afrika sicherlich eine wichtige Voraussetzung für anstehende militärische Auseinandersetzungen sowohl im Feldzug gegen Licinius als auch hinsichtlich notwendiger Verteidigungen im Donauraum. ${ }^{178}$

$176 \mathrm{Zu}$ dieser Phase vgl. Grasmück, Coercitio, 85 ff.; Tilley, Bible, 57-69; s. o. Kap. 7.4.1.

177 Opt. App. IX. Zum Dokument: von Soden Nr. 31; vgl. Dörries, Selbstzeugnis, 38 f.; Maier I, Nr. 30, 239-242; Monceaux IV, 203; Grasmück, Coercitio, 91-93. - Seeck datiert den Brief auf das Frühjahr 316 (ZKG 30, 1909, 213). Gegen diese Datierung im direkten Zusammenhang mit dem Urteil in der causa Caeciliani spricht allerdings, dass Konstantin offensichtlich erst seine kompromisslose Haltung gegen die Donatisten aufgab, nachdem sie einige Zeit bekämpft worden waren.

178 Ein entsprechender Zusammenhang mit dem Kampf gegen Licinius deutet sich in einem Brief des Kaisers an, den er Ende des Jahres 324 an den alexandrinischen Bischof Alexander und dessen Priester Arius gesandt hatte. Konstantin schreibt dort, dass er die Lage in Afrika beruhigen wolle und nun, nach seinem Sieg über Licinius, Anstrengungen zur Wiederherstellung der Einheit treffen werde (Eus. VC II 64-68; vgl. Maier I, Nr. 31, 242-245; Monceaux IV, 203). - S. Bralewski (Est-ce que l'empereur Constantin le Grand accorda la tolérance à l'égard des donatistes?, Eos 88, 2001, 127-132) plädiert dafür, den Begriff „Toleranz“ für die Phase seit 321 nicht zu verwenden, da es sich im Gegensatz zur Toleranz gegenüber den Christen in den Jahren 311 und 313 
Die donatistischen Bischöfe im Jahre 411 beriefen sich somit hinsichtlich einer Toleranz Konstantins durchaus auf historische Tatsachen. Mit dem Reskript an Verinus konnten sie nachweisen, dass der Kaiser zu einem bestimmten Zeitpunkt den Donatismus geduldet und zuvor verbannte Bischöfe freigelassen hatte. Augustinus und die Katholiken kannten bis zu diesem Zeitpunkt weder den libellus der Donatisten noch das Reskript noch die Toleranzmaßnahmen des Kaisers an sich. Augustinus ging jedenfalls grundsätzlich von einer kontinuierlichen Gesetzgebung gegen die Donatisten aus. ${ }^{179}$ Insofern hatten die Donatisten im Jahre 411 ein Überraschungsmoment auf ihrer Seite. Allerdings verlor dieses schnell an Überzeugungskraft, da Marcellinus und die katholischen Bischöfe dem Reskript Konstantins in juristischer Hinsicht keine aktuelle Relevanz beimaßen und in historischer Hinsicht kein neues Argument zu einem Urteil gegen Caecilianus erblickten. ${ }^{180}$ Das Scheitern der donatistischen Argumentation lag insofern in diesem Fall nicht an der fehlenden Authentizität der vorgelegten Dokumente, sondern an der fälschlichen Vereinnahmung dieser Dokumente für die causa Caeciliani.

Während die donatistische Tradition einer Verbannung Caecilians nachweislich bereits vor der Konferenz von 411 existierte, lässt sich nicht eindeutig feststellen, ob Bittgesuch und kaiserliches Reskript den Donatisten schon längere Zeit als Zeugnisse ihrer Argumentation dienten. Gegen eine solche Annahme spricht, dass die Donatisten kaum mit kaiserlichen Dokumenten argumentierten und Augustinus im Gegensatz zu anderen donatistischen Zeugnissen niemals mit diesen Schreiben konfrontiert worden war. Die ältere donatistische Tradition war durch die Märtyrerakten geprägt, zu denen auch Opfer der Verfolgung unter Konstantin gehörten. ${ }^{181}$ Es ist daher sehr wahrscheinlich, dass die Zeugnisse, die Konstantin als einen Kaiser auf Seiten der Donatisten darstellen sollten, erst in der Vorbereitung zur Konferenz von 411 von den Donatisten herangezogen und ausgewertet worden sind.

\section{Die dritte Traditionslinie: Der Freispruch des Felix von Abthugni}

Die dritte Traditionslinie schließlich war die donatistische Version der causa Felicis. Felix von Abthugni galt als Urheber des Schismas und die Überzeugung von seiner Schuld gehörte zu den ältesten Überlieferungen der Donatisten. Es wurde bereits dargelegt, auf welche Weise die Donatisten auf der Konferenz von 411 versuchten, Felix von Abthugni als Traditor zu überführen und seine Re-

lediglich um eine Unterbrechung der Verfolgung, nicht aber um eine Anerkennung gehandelt habe. Zweifellos müssen die religionspolitischen Entscheidungen der Jahre 311, 313 und 321 differenziert betrachtet werden, eine Änderung der üblichen Begrifflichkeit ist jedoch in der Sache nicht weiterführend.

179 C. Don. 54.

180 Cap. conl. Carth. III 550, 552.

181 Vgl. o. Kap. 6.3.1. 
levanz für die Ordination Caecilians nachzuweisen. Der Brief des Kaisers an Probianus diente ihnen als Beweis, dass gegen Felix eine Revisionsverhandlung vor dem Kaiser mit einer Verurteilung abgeschlossen worden sei. Der Inhalt des Briefes bestätigt diese Interpretation jedoch nicht. ${ }^{182}$

Die Besonderheit der donatistischen Darstellung auf der Konferenz von 411 lag in der Zusammenführung dieser drei genannten Traditionslinien zur Präsentation eines möglichst geschlossenen Geschichtsbildes, in dem auf der einen Seite Felix von Abthugni und Caecilianus als kirchlich und weltlich verurteilte Frevler, auf der anderen Seite die Donatisten als rechtmäßige Vertreter der Kirche erscheinen sollten. In dieses vorgefasste Bild passte natürlich die Tradition einer Verbannung Caecilians nach Brescia, die Verurteilung des Felix sowie ein Dokument, das die Aufhebung von Verfolgungsmaßnahmen und eine Rückkehr von Donatisten aus dem Exil verkündete.

Während der Optatustext und der Probianusbrief tatsächlich in den Kontext der causa Caeciliani passten, versuchten die Donatisten, mit der Vorlage des Bittgesuchs ihrer Vorfahren und des Reskriptes an Verinus für sie günstige Dokumente in ihrer Argumentation einzusetzen, obwohl sie einem anderen Kontext entstammten. Die Donatisten ignorierten die tatsächliche chronologische Einordnung; möglicherweise legten sie bewusst Abschriften ohne Datierung vor, um sich in dieser Hinsicht nicht festlegen zu lassen. Auf diese Weise suggerierten die Donatisten einen direkten Zusammenhang der Petition ihrer Vorfahren und dem Reskript an Verinus mit den kaiserlichen Entscheidungen über Caecilianus und Felix von Abthugni. In der Summe sollte deutlich werden, dass der im Brief an Eumalius berichtete Inhalt, auf den sich die Katholiken stützten, nicht dem letzten Stand der Dinge entsprach. Denn, so die dreifache Begründung der Donatisten: Laut Optatus musste Caecilianus in die Verbannung, laut Brief an Probianus hatte der Kaiser auch die Schuld des Felix erkannt und dem Brief an Verinus zufolge hatte die donatistische Kirche ihre Anerkennung durch Konstantin erreicht.

Wenn nun Augustinus dieser Argumentation mit der Bemerkung entgegentrat, dass doch auch die donatistischen Zeugnisse eine Verurteilung der Donatisten belegten und keinesfalls eine Verurteilung Caecilians, ${ }^{183}$ dann verkannte oder überdeckte er absichtlich die tatsächlichen Argumentationsabsichten der Donatisten. Diese leugneten nämlich nicht ausdrücklich, dass Konstantin schon einmal ein Urteil zu Gunsten Caecilians gesprochen hatte, aber ein solches Urteil sahen sie durch ein späteres revidiert.

Die historische Argumentation der donatistischen Bischöfe auf der Konferenz von Karthago beruhte auf der Kombination von alten Traditionslinien mit

182 Vgl. o. Kap. 6.1.3.

183 Breuic. III 39; ep. 141.9; c. Don. 54. 
neu herangezogenen Dokumenten. Die Vorstellungen, dass Caecilianus und Felix vom Kaiser verurteilt worden seien, existierten bereits längere Zeit vor der Konferenz, vermutlich in unterschiedlichen Variationen. Es gab keine eigene donatistische Geschichtsschreibung, auf der die Donatisten 411 hätten aufbauen können. Erst aus der Notwendigkeit heraus entwickelten sie ein Konzept auf Grundlage der ihnen zur Verfügung stehenden schriftlichen Zeugnisse. Die zum Teil erheblichen Widersprüche dieser Quellen zu den Aussageabsichten der Donatisten zeigen jedoch, dass ihnen keine Dokumente zur Verfügung standen, die eine überzeugende historische Beweisführung ermöglichten.

Die älteren Überlieferungen der Donatisten waren nicht darauf ausgerichtet, eine kaiserliche Verurteilung Caecilians zu beweisen. Deutlich erkennt man in der Heranziehung neuer Zeugnisse, insbesondere bei der Verwendung des Reskriptes an Verinus, das Bemühen, dieses Defizit auszugleichen und sich den neuen Anforderungen zu stellen. Die älteren Überlieferungen betonten die Rolle der Donatisten als verfolgte Kirche der Märtyrer. Die Entscheidungen der Prozesse in Übersee waren für die Donatisten unerheblich, solange sie sich auf Grundlage ihres Selbstverständnisses als Kirche der Märtyrer verteidigen und behaupten konnten. Durch die Verfahrensweise der Konferenz von 411 wurden sie gezwungen juristisch und dem Kaiser loyal gegenüber zu argumentieren. Ein entsprechendes Argumentationsmodell, in dem Konstantin nicht mehr als Verfolger, sondern als anerkannter oberster Richter mit einer Entscheidung zugunsten der Donatisten auftrat, musste auf der Konferenz präsentiert werden. Die hastig vorgelegten Dokumente konnten jedoch nicht darüber hinwegtäuschen, dass die Donatisten einstmals bei Konstantin unterlegen waren.

\subsubsection{Geschichtsdeutungen bei Parmenianus}

Dass die donatistische Argumentation von 411 kein gefestigtes und vollständiges Bild donatistischer Traditionen abgibt, lässt sich durch eine von der Konferenz unabhängige Überlieferung zur causa Caeciliani bekräftigen, die in Augustins Schrift gegen Parmenianus erhalten ist. Augustinus zitiert dort Anschuldigungen Parmenians gegen den Bischof Ossius von Cordova, der zur Zeit Konstantins eine einflussreiche Persönlichkeit in der Kirchenpolitik war.

Parmenianus trat der katholischen Vorstellung entgegen, dass die Kirche über den ganzen Erdkreis verbreitet sein müsse. ${ }^{184} \mathrm{Er}$ begründete die donatistische Ablehnung der außerafrikanischen Kirchen mit dem Argument, dass diese von Sünden vergiftet worden seien, zum einen durch Verbrechen ihrer Bischöfe während der Verfolgungszeit ${ }^{185}$ zum anderen durch ihre Gemeinschaft

184 C. ep. Parm. I 1. - Augustinus analysiert und widerlegt mit den Schriften contra epistulam Parmeniani und de baptismo Parmenians Brief gegen Tyconius. Vgl. hierzu Congar, BA 28, 201-205, 718-720; Monceaux V, 231-237 und o. Kap. 2.2.2.

185 C. ep. Parm. I 4. 
mit den Traditoren Afrikas (societas criminum). ${ }^{186}$ In diesem Zusammenhang ging Parmenianus auch auf die causa Caeciliani ein und beurteilte das Prozedere der Entscheidungen aus seiner Sicht. Die vagen Formulierungen Augustins lassen jedoch nur schwer erkennen, welches Bild Parmenianus von den Ereignissen zeichnete. Offenbar berief er sich aber auf die Berichte seiner donatistischen Kollegen, die an den Verhandlungen von Rom, Arles und Mailand beteiligt waren, denn Augustinus weist mehrmals auf die mangelnde Beweiskraft solcher Aussagen hin. ${ }^{187}$ Parmenianus dagegen betonte, wie zuverlässig und wahrhaftig diese Bischöfe das Anliegen der Donatisten außerhalb Afrikas vertreten hätten.

Ohne dass die näheren Umstände erklärt werden, erwähnte Parmenianus die Gesandtschaft einiger Bischöfe in die europäischen Provinzen, die dort die Beschwerden der afrikanischen Donatisten klar und deutlich vorgebracht hätten. ${ }^{188}$ Vermutlich spielte er damit auf die Konzile von Rom und Arles an, auf denen die Anklagen gegen Caecilianus vorgetragen wurden. Dass Parmenianus die bischöflichen Urteile und die Verhandlungen vor dem Kaiser kannte und in seinem Brief erwähnte, ergibt sich aus den weiteren Ausführungen Augustins. Parmenianus sprach offensichtlich sehr positiv von einem beständigen Bemühen der donatistischen Vertreter, ihre Anliegen zu Gehör zu bringen. Letztlich ging er aber wohl von einer Niederlage und der Verurteilung der Donatisten in allen Instanzen aus, denn er versuchte nicht wie die Donatisten auf der Konferenz von 411, eine Verurteilung oder Verbannung Caecilians zu belegen. Im Gegenteil: Er versuchte die Urteile als Fehlentscheidungen darzustellen, indem er Anklagen gegen die Richter und die Prozesse erhob. Er unterstellte traditio, Korruption und einseitige Begünstigungen bei den Bischöfen und bei Konstantin, die ein gerechtes Urteil nicht zugelassen hätten. ${ }^{189}$

186 C. ep. Parm. I 2; vgl. I 6: frustra itaque dicit Parmenianus damnatos in Africa traditores in consortium sanctitatis acceptos a prouinciis transmarinis.

187 C. ep. Parm. I 2-3.

188 C. ep. Parm. I 2: dicit [Parmenianus] enim legatione functos quosdam, sicut ipse asserit, fidelissimos testes ad easdem uenisse prouincias [sc. Gallias, Hispanias, Italiam]; deinde geminato aduentu sanctissimorum, sicut ipse dicit, domini sacerdotum dilucide plenius ac uerius publicata esse quae obiciunt. - Congar (BA 28,721) verweist von dieser Stelle auf ep. 43.19 und Augustins Aussage, dass die Donatisten aus Furcht vor einer Anklage mit außerafrikanischen Kirchen in Kontakt kommen wollten. Allerdings ist dies eine Unterstellung Augustins. In der Aussage Parmenians wird deutlich, dass die Donatisten bei den europäischen Kirchen um eine Anerkennung ihres karthagischen Bischofs warben. Vgl. Monceaux IV, 21.

189 C. ep. Parm I 10-11: „Parmenianus gesteht auch ein, dass in der Stadt Arles bischöfliche Richter und die Parteien aus Afrika zusammengekommen sind, nämlich Caecilianus und die Donatisten. Er vertraute dabei vollkommen seinen Leuten, die als Besiegte nichts tun konnten, außer die Richter zu verleumden; und er leugnet auch nicht, dass sie wiederum zu Konstantin gekommen sind, und, weil sie auch dort durch ein endgültiges 
Eine gewichtige Rolle in den Prozessen gegen Caecilianus räumte Parmenianus dem Bischof Ossius von Cordova ein. ${ }^{190}$ Parmenianus erwähnte Ossius zunächst als Beispiel, um seine Anschuldigungen gegen die europäischen Kirchen zu untermauern. Er legte dar, dass Ossius von spanischen Bischöfen aufgrund irgendeines Vergehens rechtmäßig verurteilt worden, dieses Urteil jedoch später von gallischen Bischöfen aufgehoben worden sei. Ossius sei in die Kirche zurückgekehrt und die Spanier hätten sich diesem Urteil gebeugt. Sie hätten also einem falschen Urteil nachgegeben, anstatt standhaft zu bleiben. Dieses Beispiel diente Parmenianus als Parallele zum Fall Caecilianus: Anders als die spanischen Bischöfe hätten sich die Afrikaner, also die Donatisten, nicht dem Urteil gallischer Bischöfe (in Rom und Arles) untergeordnet, sondern seien im Bewusstsein der Wahrheit im Widerstand geblieben. ${ }^{191}$

Außer diesem Vergleich äußerte sich Parmenianus auch zu Tätigkeiten des Ossius von Cordova im Fall Caecilians. Dieser sei dafür verantwortlich gewesen, dass die Rückkehr wahrer Christen in die Kirchengemeinschaft Caecilians erzwungen worden sei. ${ }^{192}$ Auf den Rat des spanischen Bischofs hin, so meinte wohl Parmenianus, sei Konstantin gegen die Donatisten beeinflusst worden, was dazu geführt hätte, dass die Donatisten nach den bischöflichen Entscheidungen vom Kaiser verurteilt worden seien und Verfolgung erleiden mussten. ${ }^{193}$ Ossius war

Urteil besiegt worden sind, nun auch diesen beschuldigen, durch Gefälligkeit korrumpiert worden zu sein." (Fatetur etiam Parmenianus ad Arelatense oppidum et episcopos iudices et partes ex Africa conuenisse, Caecilianum scilicet atque Donatistas. ubi omnia suis credidit, qui nihil uicti potuerunt nisi de iudicibus conqueri, nec tamen negat rursus eos ad Constantinum uenisse et, quia ibi quoque ultimo iudicio superati sunt, etiam ipsum gratia corruptum esse criminatur). - Zu den Vorwürfen gegen die bischöflichen Richter vgl. o. Kap. 6.1.4.

190 Ossius von Cordova (ca. 256-357/58) gehörte zu den Ratgebern Konstantins, insbesondere im Arianischen Streit. Er war einer der einflussreichsten Bischöfe seiner Zeit und an den Entscheidungen der Synoden von Antiochia, Nicäa und Serdika maßgeblich beteiligt. Zur Person: V. C. de Clercq, Ossius of Cordova, A Contribution to the History of the Constantinian Period, Washington 1954; kritisch dazu: A. Lippold, Bischof Ossius von Cordova und Konstantin der Große, ZKG 92, 1981, 1-15; vgl. auch Girardet, Kaisergericht, passim; Congar, BA 28, 722 f.; Drake, Constantine and the Bishops, 217 224.

191 C. ep. Parm. I 7-8.

192 C. ep. Parm. I 10: cum enim diceret per Ossium Hispanum adiutorium praestitum Caeciliano, ut ad eorum communionem sanctorum et inlibatorum numerus cogeretur, et huic impietati fidem seruorum dei integram restitisse.

193 C. ep. Parm I 13: „Parmenianus wagt sogar sich darüber zu beklagen, dass Konstantin befohlen habe, sie [die Donatisten] auf das Schlachtfeld, das heißt einer Strafe zuzuführen. [Damit meint er] jene, die von den kirchlichen Richtern besiegt wurden, vor ihm [dem Kaiser] ihre Behauptungen nicht beweisen konnten und die durch gottlose Verblendung bis heute Spaltungen in die heilige Kirche gebracht haben. Und er beschuldigt [den Kaiser], er hätte diesen so grausamen Befehl aufgrund des Rates des Spaniers Ossius gegeben. Dies sind die üblichen Verdächtigungen, mit denen wie immer Men- 
in Parmenians Augen sowohl für die abschlägigen Urteile gegen die Donatisten als auch für die ersten Zwangsmaßnahmen zur Durchsetzung der Kircheneinheit verantwortlich. ${ }^{194}$ Parmenianus verleumdete Ossius folglich in zweifacher Weise: Er sah in ihm sowohl den von einem spanischen Konzil verurteilten, das heißt exkommunizierten Bischof, zum anderen den Kopf und die Triebfeder der antidonatistischen Politik am Kaiserhof.

Augustinus verteidigt in contra epistulam Parmeniani die Universalität der katholischen Kirche und weist die Ausführungen seines Gegners zurück. Die Vorwürfe gegen die Verfahren und die Richter in der causa Caeciliani lehnt er mit Verweis auf die vorliegenden Akten als unbegründet ab. Die katholischen Kirchen hätten sich rechtmäßigen Entscheidungen angeschlossen und könnten daher nicht pauschal abgeurteilt werden. ${ }^{195}$

Bei der Beurteilung von Ossius von Cordova hält sich Augustinus allerdings auffällig zurück. Offensichtlich wusste er nichts zu den Umständen der von Parmenianus angesprochenen Verurteilung des Ossius von spanischen Bischöfen. Er verteidigt zwar die Revisionsentscheidung der gallischen Bischöfe als Sieg der christlichen Milde gegenüber falschen Anklagen, aber dies formuliert er lediglich als Vermutung, um gleichzeitig das Sakrileg der Spaltung bei den Donatisten anzuprangern. Die Donatisten wollten nicht anerkennen, dass die europäischen Urteile im Fall Caecilianus gültig seien. Wenn Parmenianus noch lebte, folgert Augustinus, würde er ohnehin nicht mehr die spanischen Bischöfe für ihren Wankelmut verurteilen, da die Donatisten im Maximianistischen Schisma, bei Primianus wie bei Praetextatus und Felicianus, die Revisionsurteile ebenso anerkannt hätten. ${ }^{196}$ Hinsichtlich der Ratgebertätigkeit des Ossius bei Konstantin erwidert Augustinus lediglich, dass trotz eines so schweren Verbrechens, wie das der Kirchenspaltung, Ossius den Kaiser eher zu einem milderen Umgang mit den Donatisten aufgefordert hätte. Aber auch diese Aussage formuliert Augustinus als Vermutung und fügt eine scharfe Polemik gegen das

schen verurteilt werden, die nicht angehört worden sind." (Quin etiam conqueri audet Parmenianus, quod eos Constantinus ad campum id est ad supplicium duci iussit, qui uiciti aput ecclesiasticos iudices nec aput ipsum quae dicebant probare potuerunt et adhuc in sanctae ecclesiae praecisiones sacrilego furore ferebantur, et hoc eum tamquam immaniter iussisse Hispano Ossio suggerente criminatur, suspicionibus uidelicet suis, sicut semper, damnando inauditos).

194 Gegen Monceaux (V, 235 f.) sehe ich aus c. ep. Parm. I 10-11, 13 nicht, dass Ossius in der causa Felicis sowie bei den Konzilen in Rom und Arles in der causa Caeciliani direkten Einfluss genommen hätte. Die Aussagen lassen lediglich den Schluss zu, dass Ossius nach den wiederkehrenden Appellen der Donatisten dem Kaiser zu einer strengen Position geraten hatte.

195 C. ep. Parm. I 10-12. Augustinus verwendet hier die rhetorische Figur der Prosopopöie und lässt die Kirche von Philadelphia gegen die ungerechtfertigten Anklagen der Donatisten sprechen.

196 C. ep. Parm. I 8-9. 
falsche Martyriumsverständnis der Donatisten hinzu. ${ }^{197}$ Er weicht somit den direkten Anschuldigungen gegen Ossius aus und verteidigt die Maßnahmen gegen die Donatisten in allgemeiner Form.

Wann und in welcher Form Ossius von Cordova in den engeren Kreis um Konstantin gekommen war und welche Rolle er im Donatistenstreit spielte, lässt sich nicht mit Sicherheit sagen und wird in der Forschung kontrovers beurteilt. ${ }^{198}$ Fest steht lediglich, dass er wohl seit dem Jahr 324 in der Auseinandersetzung mit Anhängern des Arius im Vertrauen des Kaisers stand.

In Bezug auf den Donatismus kann außer den Aussagen Parmenians und Augustins nur eine weitere Stelle auf Ossius von Cordova bezogen werden: In einem bei Eusebius überlieferten Brief Konstantins an Bischof Caecilianus wird ein gewisser „Hosius“ (Ossius) in einer Funktion am Hofe des Kaisers erwähnt. ${ }^{199}$ Daraus geht hervor, dass dieser Hosius von Konstantin beauftragt worden sei, die Zuteilung der kaiserlichen Gelder für den Wiederaufbau der Kirchen zu verteilen und dafür eine Liste der Empfangsberechtigten angefertigt habe. Dieser Liste zufolge sollte auch Caecilianus von Karthago in Afrika Gelder empfangen und verteilen. Obwohl in der Forschung mehrheitlich angenommen wird, dass jener „Hosius“ mit Ossius von Cordova zu identifizieren ist, bleibt dies äußerst spekulativ. ${ }^{200}$ Es passt jedoch ins Bild donatistischer

197 C. ep. Parm. I 13.

198 De Clercq postuliert lediglich eine eingeschränkte Beratertätigkeit des Ossius. So sei die inkonsequente Haltung Konstantins gegenüber den Donatisten zu erklären. Weiterhin vermutet er, dass Ossius bei den europäischen Bischöfen gegen die Donatisten agitiert habe und auch der Vorschlag, Militiades als Richter zu bestimmen und das Konzil von Arles durchzuführen, auf Ossius zurückgehe. Lippold (ZKG 92, 1981, 1-15) beurteilt die Quellen zu Ossius wesentlich skeptischer und kritisiert, dass es de Clercq und anderen nur durch eine Kette an Hypothesen gelinge, etwas über Ossius' Rolle am Hof Konstantins vor dem Jahr 325 auszusagen. Die herangezogenen Zeugnisse (Eus. HE X 6.2-3, Zos. II 29.3; Eus. VC 32 sowie eine Vita Constantini aus dem 10. Jh. (Cod. Ang. gr. 22)) seien allesamt zu ungenau, um eindeutige Aussagen über Ossius zu treffen. Auf die von Parmenianus unterstellte Verurteilung in Spanien geht Lippold nur ganz am Rande ein (ebd., 8).

199 Brief Konstantins an Bischof Caecilianus bei Eus. HE X 6.2-3. - Zum Dokument: Maier I, Nr. 12, 140-142; von Soden Nr. 8; vgl. o. Kap. 7.2.

200 Vgl. die berechtigte Kritik an der communis opinio bei Lippold (ZKG 92, 1981, 5-7 und passim). Eine Identifizierung von jenem Hosius mit Ossius von Cordova liegt nahe, wenn man davon ausgeht, dass Ossius bereits zu diesem Zeitpunkt (im Jahre 312/313) am Hof Konstantins weilte und mit kirchenpolitischen Aufgaben betraut wurde, eine Hypothese, die sich, wie Lippold darlegt, kaum anhand der Quellen nachweisen lässt. Zur Interpretation von Zos. II 29.3 in Bezug auf Ossius vgl. auch Paschoud, Zosime, 57 und H.-U. Wiemer, Libanios und Zosimus über den Rombesuch Konstantins im Jahre 326, Historia 43, 1994, 469-494, hier 485 f. - Selbst unter der Annahme, es handele sich bei genanntem Hosius um Ossius von Cordova, bleiben jegliche Aussagen über die Haltung des Ossius zum Donatismus Spekulation. Es lässt sich aus den Quellen nicht 
Vorstellungen, wenn sie in Ossius einen der Hauptverantwortlichen für die Geldzuweisung an die Katholiken und an Caecilianus sahen und daran Interesse hatten, diesen Mann in Misskredit zu bringen. Denn die Donatisten klagten Caecilianus beim Kaiser an, gerade weil sie dessen Anerkennung durch den Kaiser und die europäischen Kirchen entgegentreten wollten. Die Anschuldigungen Parmenians lassen darauf schließen, dass die Rolle, die Ossius später in der Kirchenpolitik spielte, großes Misstrauen weckte. Es lag für die Donatisten nahe, dass Ossius, so wie er die Fäden im Arianischen Streit zog, auch gegen sie intrigierte. Der Brief Konstantins an Caecilianus war möglicherweise bekannt und konnte als Anlass derartiger Vermutungen herangezogen werden. Auch wenn keine weiteren Informationen oder schriftliche Zeugnisse über das Wirken des Ossius in diesen Jahren vorlagen, so genügten, wie bei den übrigen bekannten persönlichen Beschuldigungen, kleinste Hinweise und Gerüchte, um ein entsprechendes Feindbild aufzubauen.

Allerdings dürfte es falsch sein, Parmenians Darstellung als reine Erfindung zu werten. Es lässt sich aus der Erwähnung bei Augustinus durchaus schließen, dass Ossius bereits seit dem Jahr 313 bei Konstantin Einfluss besaß und die Interessen der katholischen Kirche vertrat. Mit zunehmender Schärfe des Konfliktes in Afrika drückte sich dieser Einfluss antidonatistisch aus. Möglicherweise verstand Augustinus Parmenians Anklagen in ähnlicher Weise, denn er leugnet nicht die Tätigkeit des Ossius, sondern legt sie nur zu Gunsten der katholischen Kirche aus: Ossius habe sich für die Kirche eingesetzt, indem er gegen das größere Übel, gegen das sacrilegium schismatis vorgegangen sei.

Im Gegensatz zur Darstellung der causa Caeciliani bei Cresconius und bei den donatistischen Bischöfen im Jahre 411 formulierte Parmenianus in seinem Brief eine ältere Tradition, die zweifellos den tatsächlichen Begebenheiten näher stand als die Bemühungen, Caecilians Verurteilung durch Konstantin nachzuweisen: Parmenianus ging von einem Freispruch Caecilians in Rom, Arles und im kaiserlichen Verfahren aus. Alle Entscheidungen, die kirchlichen und die kaiserlichen betrachtete er jedoch als Fehlentscheidungen, die durch Korruption und unrechtmäßiges Verfahren zustande gekommen seien. Im Falle des kaiserlichen Urteils gab er Ossius von Cordova die Schuld, den er auch für die beginnende Verfolgung der Donatisten verantwortlich machte. Parmenians Zeugnis verrät, dass Konstantin bei den Donatisten als Verfolger galt, der sich angestachelt durch falsche Ratgeber, wie etwa Ossius von Cordova, gegen die Donatisten entschieden hätte. ${ }^{201}$ Ausgehend von dieser donatistischen Überlie-

erschließen, dass Ossius eine klare antidonatistische Haltung eingenommen oder den Kaiser gegen die Donatisten beeinflusst hätte.

201 Möglicherweise griffen die donatistischen Bischöfe auf der Konferenz von Karthago auch auf die Überlieferung Parmenians und dessen Äußerungen über Ossius zurück, als sie andeuteten, dass ein „falsches Urteil“ Konstantin zu Ohren gekommen sei (Cap. Conl. Carth. III 519; vgl. breuic. III 37). 
ferung gingen Katholiken und Donatisten somit von den gleichen historischen Gegebenheiten aus. Was sie trennte, waren unterschiedliche Beurteilungen.

\subsection{Das Urteil Konstantins bei Augustinus}

Augustins Interpretation des iudicium Constantini ist bereits an verschiedenen Stellen angesprochen worden. ${ }^{202}$ Für seine Argumentation verwendete er die Informationen aus dem Brief an Eumalius. Dabei ist anzunehmen, dass er die wesentlichen Aussagen dieses Briefes weitergab. Dies bedeutet, seine Kenntnisse über den Ablauf nach dem Konzil von Arles waren wahrscheinlich geringer als unsere Kenntnisse heute, da ihm die anderen Briefe Konstantins aus diesem Zeitraum nicht bekannt waren. Diese Lücken konnten die Donatisten ausnützen und mit ihren Geschichtsinterpretationen ausfüllen, wie es unter anderem auf der Konferenz von 411 geschah. ${ }^{203}$

Bezeichnend ist die Unsicherheit Augustins hinsichtlich der Chronologie. Erst nach erneuten Recherchen nach der Konferenz von 411 stellte Augustinus fest, dass der Freispruch des Felix von Abthugni vor dem Urteil Konstantins gefällt worden war, eine für die gesamte Interpretation des Verlaufs sehr gewichtige Feststellung. ${ }^{204}$ Bei anderen Ereignissen sah sich Augustinus ebenso im Dunkeln wie die Historiker heute. So fehlten ihm bereits die Dokumente, die eine sichere Datierung des iudicium Constantini ermöglichten; wiederum erst nach der Konferenz konnte er durch die Datierung des Eumaliusbriefes eine annähernde Vorstellung der zeitlichen Abfolge gewinnen. Die bei Optatus überlieferte und von den Donatisten verwendete Brescia-Episode überforderte ebenfalls Augustins chronologische Kenntnisse. Er versuchte die Widerlegung der donatistischen Argumente, ohne eine Einordnung vornehmen zu können.

Augustins Beurteilung des iudicium Constantini orientiert sich an der Tatsache, dass Caecilianus freigesprochen wurde. Darüber hinaus betont er die Sorgfalt der kaiserlichen Untersuchung, die Umsichtigkeit des Urteils sowie die Autorität und die andauernde Gültigkeit dieser Entscheidung. Dagegen werden weder die politische Dimension des kaiserlichen Eingreifens noch die kirchenpolitischen Folgen deutlich. Gegenüber den Donatisten vermied Augustinus eine klare Stellungnahme, die über den Kontext der Ereignisse Aufschluss geben könnte. In seinen frühen Texten ist er darauf bedacht, das Urteil Konstantins im Vergleich zu den bischöflichen Urteilen abzuwerten. Die Argumentation von ep. 43 verdeutlicht diese Akzentuierung im Besonderen. ${ }^{205}$ In

202 Vgl. o. Kap. 3.4.2.2; 4.2.2; 5.3.2.

203 Vgl. o. Kap. 7.4.2.1.

204 C. Don 56; vgl. retr. II 27, 28. Zum Prozess gegen Felix von Abthugni s.o. Kap. 6.1.3.

205 Vgl. die ausführliche Analyse o. Kap. 4.2.1. 
den späteren Schriften verteidigt er zwar mit Hilfe des iudicium Constantini die Maßnahmen des Kaisers gegen die Donatisten, aber dies geschieht niemals ohne stereotype Schuldzuweisungen an sie. Auch unausgesprochen ist stets die Aussage hörbar: „Ohne eure Anklage beim Kaiser wäre es zu keinem Eingreifen Konstantins gekommen."

Wenngleich diese Aussagen aus der Argumentation erwachsen sind, so scheint Augustinus doch davon überzeugt gewesen $\mathrm{zu}$ sein, dass eine innerkirchliche Regelung des Schismas möglich gewesen wäre und so Eskalationen vermieden worden wären. Sein langes Zögern, kaiserliche Hilfe gegen die Donatisten zu erbitten, spricht für diese Einschätzung. Auf der anderen Seite konnte Augustinus ohne Schwierigkeiten das Urteil Konstantins als das eines christlichen Kaisers rechtfertigen. Hundert Jahre nach Konstantin entsprach es den Erfahrungen Augustins und seinem Bild des christlichen Römischen Reiches, dass der weltliche Herrscher auch Schützer der Kirche ist. ${ }^{206}$

206 Vgl. ciu. V 24-26; zum Konstantinbild bei Augustinus vgl. Szidat, REAug 36, 1990, 243-256. 


\section{Zusammenfassung und Schlussfolgerungen: Historische Argumente im donatistischen Streit}

Mehr als zwanzig Jahre seines Lebens befand sich Augustinus in der Auseinandersetzung mit den Donatisten. In dieser Zeit entstanden zahlreiche Abhandlungen, die heute als Quellen sowohl über die Geschichte des donatistischen Schismas als auch über den donatistischen Streit zur Zeit Augustins Auskunft geben. Eine Auswahl dieser Schriften ist unter der Fragestellung analysiert und diskutiert worden, in welchen Zusammenhängen, unter welchen Bedingungen und mit welchen Absichten die geschichtlichen Ereignisse in der Auseinandersetzung zwischen Donatisten und Katholiken zur Zeit Augustins Verwendung fanden. Die Ergebnisse der Untersuchung zeigen sehr deutlich: Ohne Augustins Streitschriften würden wesentliche Aussagen und Hintergründe fehlen, um die Entstehung und Entwicklung des Schismas nachvollziehen zu können. Allerdings verweisen diese Schriften auch darauf, auf welch tönernen Füßen manche Geschichtsrekonstruktionen bereits zur Zeit Augustins standen und bis heute stehen. Alle Darstellungen unterlagen nicht nur den jeweiligen argumentativen Prämissen und Intentionen, sondern waren auch abhängig von der Quellenlage, die schon um das Jahr 400 für viele Einzelheiten kaum ausreichend war, um sichere Aussagen über die Ereignisse treffen zu können, die knapp hundert Jahre zuvor geschehen waren.

In den vorangehenden Kapiteln sind die Zusammenhänge zwischen dem donatistischen Streit zur Zeit Augustins, der historischen Argumentation von Donatisten und Katholiken sowie dem Handeln und Wirken Augustins genau betrachtet worden. Auf diese Weise konnte gezeigt werden, auf welche Weise und auf welcher Grundlage die Donatisten einerseits und Augustinus andererseits die Geschichte des Schismas verstanden oder verstehen wollten. Überdies ist verdeutlicht worden, inwiefern die Schriften Augustins als historische Quellen eine Rekonstruktion der Ereignisse erlauben und inwieweit diese Schriften die Deutungen dieses Ausschnitts der spätantiken Geschichte beeinflussten und bis heute beeinflussen. In den folgenden Abschnitten werden die einzelnen Teilergebnisse nochmals zusammengefasst und abschließend beurteilt. 


\section{Der donatistische Streit zur Zeit Augustins}

$\mathrm{Zu}$ Beginn von Augustins Wirken als Bischof repräsentierten Donatisten und Katholiken zwei annähernd gleich weit verbreitete Konfessionen in Nordafrika. Trotz bestehender Gesetze, die eine Wiedertaufe unter Strafe stellten, besaßen die Donatisten weitgehende Freiheit, ihre Religion zu praktizieren. Das Schisma rückte lediglich dann ins Blickfeld der Öffentlichkeit, wenn sich das religiöse Bekenntnis mit besonderen Aktionen verband. Unter den Donatisten gab es gewaltbereite Gruppen, vor allem die Circumcellionen, die sich als religiöse Kämpfer verstanden und immer wieder Katholiken tyrannisierten. Außerdem kam es zu provozierenden Aktivitäten einzelner Donatisten, wie etwa die erzwungenen Wiedertaufen, die der Bischof Crispinus von Calama durchführte, oder der Widerstand des Bischofs Optatus von Thamugadi, der die Revolte des comes Africae Gildo unterstützte. Allein in diesen Fällen kamen antihäretische Gesetze zur Anwendung. Sie stellen jedoch Ausnahmen dar, auch wenn in der katholischen Darstellung die Donatisten häufig pauschal als Gewalttäter vorgestellt werden. Es ist davon auszugehen, dass die Mehrheit der Donatisten, Laien wie Kleriker, ebenso wie die Katholiken ihre jeweilige konfessionelle Zugehörigkeit aus Gewohnheit und Tradition als Teil ihres Alltagslebens verstanden, ohne dass die theologischen Differenzen eine Rolle spielten. ${ }^{1}$

Einen nachhaltigen Einschnitt in die Situation der Donatisten bewirkte erst das Unionsedikt vom 12. Februar 405. Entgegen der späteren Darstellung Augustins waren es vor allem die Bischöfe, die vom karthagischen Konzil im Juni 404 zum Kaiser gesandt worden waren, die am Hofe eine Entscheidung zu diesem Edikt erreichten, in dem die Donatisten erstmals seit langem als Häretiker bezeichnet werden. Sie sollten nun auch nach den bestehenden antihäretischen Gesetzen bestraft werden. Kaiser Honorius forderte mit diesem Gesetz, dass die Kircheneinheit in Afrika ohne Einschränkung wiederhergestellt werden müsse.

Die Donatisten beurteilten das Unionsedikt als Beginn einer neuen Verfolgungszeit. Gleichwohl scheinen die antihäretischen Gesetze nur im geringen Umfang angewandt worden zu sein. Während in den Städten donatistische Bischöfe ins Exil verbannt wurden, kam es offensichtlich vor allem in den donatistischen Hochburgen in Numidien und Mauretanien kaum zur Umsetzung einer Kircheneinheit. Dort fehlte es den zuständigen Autoritäten sowohl an Interesse als auch an Möglichkeiten, tatsächlich gegen die Donatisten vorzugehen. Obwohl es infolge des Unionsedikts auch zu Übertritten von Donatisten zur katholischen Kirche gekommen war, blieben doch in großen Teilen der Provinzen die donatistischen Gemeinden erhalten. ${ }^{2}$

1 Vgl. o. Kap. 2.1.

2 Vgl. o. Kap. 2.2.1-2. 
Nachdem auf der Konferenz von Karthago im Juni 411 erneut für die „Einheit der Kirche“ entschieden worden war, kam es nochmals zu Verschärfungen der antidonatistischen Maßnahmen. Die wenigen Quellen belegen jedoch weiterhin eine ambivalente Situation. Auf der einen Seite gab es Konversionen, auch vollständiger Gemeinden, auf der anderen Seite kam es zu ausdauerndem Widerstand gegen die Zwangseinheit und zu gewaltsamen Auseinandersetzungen. Noch Jahre nach der Konferenz existierten donatistische Gemeinden in Numidien. Die vom Kaiser und den Katholiken gewünschte Kircheneinheit kam niemals zustande. ${ }^{3}$

Augustinus ergriff gleich zu Beginn seines kirchlichen Amtes die Initiative gegen die Donatisten, nachdem in den Jahrzehnten zuvor die katholische Kirche in Afrika wenig gegen die Donatisten unternommen hatte. In seinem antidonatistischen Kampf lassen sich drei Phasen erkennen, in denen Augustinus seine Absichten und Methoden nicht grundlegend änderte, aber sehr deutlich unterschiedliche Schwerpunkte setzte:

In der ersten Phase suchte Augustinus vor allem das Gespräch mit Donatisten, unter anderem mit dem Bischof in seiner Diözese, aber auch mit interessierten Laien. Gleichzeitig begann er, Schriften von führenden Donatisten (Donatus, Parmenianus und Petilianus), die ihm nach und nach bekannt wurden, zu widerlegen. Augustinus versuchte mit diesen Abhandlungen, Predigten und Traktaten, sowohl Kleriker als auch Laien zu erreichen: Die katholischen Gläubigen wollte er aufrütteln, die donatistischen Gläubigen von ihrem „Irrtum" abbringen. Er prangerte das Sakrileg des Schismas an und forderte die Einheit der Kirche. ${ }^{4}$

In diesem Zusammenhang sind die Briefe Augustins von großer Bedeutung. ${ }^{5}$ Im Gegensatz zu den ausführlichen Abhandlungen vermittelt ein Teil der Briefe Einsicht in den direkten Dialog Augustins mit den Donatisten, ein anderer Teil weitet den Blick für seine Unterstützung der katholischen Bischofskollegen und Laien. Sowohl gegenüber den unterschiedlichen Adressatengruppen als auch hinsichtlich des Abfassungszeitraums lassen sich die Änderungen in der Argumentation Augustins gut beobachten.

In den Briefen vor 405 unterstützt Augustinus seine katholischen Adressaten in unterschiedlichen Fragen den Donatismus betreffend, in seinen Kontakten mit donatistischen Bischöfen geht es dagegen um konkrete Vorkommnisse von Wiedertaufen oder um donatistische Gewalt, gegen die er Einspruch erhebt. ${ }^{6}$ Der Plan, Religionsgespräche zwischen Donatisten und Katholiken

\footnotetext{
3 Vgl. o. Kap. 2.2.3.

4 Vgl. o. Kap. 2.2.1.

5 Vgl. o. Kap. 4.

6 Epp. 23, 33, 66.
} 
durchzuführen, findet in zahlreichen Briefen Niederschlag und demonstriert somit Augustins unablässigen Einsatz für diese Idee. Die Briefe 43 und 44 informieren ausführlich über zwei Beispiele tatsächlich abgehaltener Gespräche. Es lässt sich auf beiden Seiten ein ehrliches Bemühen um einen Dialog erkennen, gleichzeitig werden in diesen Gesprächen die kaum überbrückbaren Gegensätze katholischer und donatistischer Grundansichten zu den Fragen der Kirche und der Verfolgung sichtbar. ${ }^{7}$

In den Briefen an Laien leistet Augustinus pastorale Überzeugungsarbeit. ${ }^{8}$ In deutlicher Abgrenzung zu ihren Bischöfen leitet er die donatistischen Laien $\mathrm{zu}$ einer selbständigen Reflexion über das Schisma an und ermutigt sie zur Rückkehr in die katholische Kirche, ein Prinzip, das Augustinus ebenso in seinen Predigten oder im Psalmus contra Partem Donati verfolgte. Im Rahmen dieser Überzeugungsarbeit spielt auch die Geschichte des Schismas eine entscheidende Rolle. Die historischen Argumente dienten dazu, das Handeln der Donatisten in der Vergangenheit als unrecht und widersprüchlich darzustellen, um die donatistischen Begründungen für das Schisma infrage zu stellen.

In den Briefen an Bischöfe fehlt hingegen die historische Argumentation. Der Schwerpunkt liegt hier auf theologischen Argumenten, oftmals unter Heranziehung von Vergleichen zum Maximianistischen Schisma. ${ }^{9}$ Hier wird deutlich: Gegenüber Klerikern setzte Augustinus andere Akzente als gegenüber Laien. $^{10}$

Die zweite Phase im Wirken Augustins steht im engen Zusammenhang mit dem Unionsedikt von 405. Während sich Augustinus auf der afrikanischen Synode im Juni 404 noch gegen die Anwendung von Zwangsgewalt gegen die Donatisten ausgesprochen hatte, ließ er sich von seinen Kollegen überzeugen, dass der donatistischen Gewalt nur durch das Eingreifen der weltlichen Macht Einhalt zu gebieten sei. In der Folgezeit avancierte Augustinus zu einem überzeugten Verteidiger der antidonatistischen Gesetze, die er als notwendige Konsequenz des donatistischen Widerstands gegen die christlichen Kaiser interpretierte. Trotz der Verschärfung der Situation zwischen beiden Kirchen hielt Augustinus an seiner früheren Idee fest, ein allgemeines Religionsgespräch durchführen zu lassen. $^{11}$

Diese Entwicklung spiegelt sich in den Briefen Augustins seit dem Jahr 405 wider: Gegenüber donatistischen Adressaten steht vor allem die Rechtfertigung der coercitio im Mittelpunkt, wenngleich die theologischen Grundsatzfragen

\footnotetext{
7 Vgl. o. Kap. 4.1.1.

8 Epp. 43, 44, 52, 76.

9 Vgl. epp. 23, 44, 51, 87.

10 Vgl. o. Kap. 4.1.

11 Vgl. o. Kap. 2.2.1-2.
} 
ebenso wie der Wunsch nach Gesprächen bzw. Korrespondenzen mit donatistischen Bischöfen erhalten bleiben. Die Briefe Augustins an Beamte und Militärs sprechen eine deutliche Sprache: Augustinus versuchte Einfluss auf die staatlichen Maßnahmen zu nehmen, indem er über die Ursachen des Schismas aufklärte und die Autoritäten an ihre christliche Verantwortung erinnerte. ${ }^{12}$

Neben den Briefen ist insbesondere die Abhandlung gegen Cresconius ein wichtiges Zeugnis dieser Phase. Die Hauptthemen der Auseinandersetzung werden in dieser Schrift sehr deutlich. Der Streit zwischen Cresconius und Augustinus über die Frage, inwiefern Rhetorik und Dialektik bei der christlichen Verkündigung verwendet werden dürften, offenbart in besonderer Weise die Gegensätzlichkeit der Positionen: Beide Kontrahenten sahen sich als Vertreter der christlichen Wahrheit und unterstellten jeweils dem Gegner, die Wahrheit zu verfälschen. Diesen Ausgangspositionen entsprechend ließen die Argumente zu den theologischen und historischen Themen keinen Dialog entstehen, sondern blieben kompromisslos nebeneinander stehen. ${ }^{13}$

Da Cresconius als Laie wesentlich stärker als die donatistischen Bischöfe mit historischen und moralischen Ausführungen argumentierte und Augustinus sich in seiner Widerlegung an dieser Akzentsetzung orientierte, entstand mit contra Cresconium ein Werk, in dem historische Argumente eine zentrale Rolle spielten. Dies zeigt sich unter anderem in der Auseinandersetzung zum Thema "Verfolgung“. Aus den Erfahrungen der Geschichte und Gegenwart heraus warf Cresconius der katholischen Kirche vor, eine „Kirche der Verfolger“ zu sein. Augustinus reagiert auf diese Vorwürfe, indem er zahlreiche Beispiele donatistischer Gewalt aufzählt, um zu verdeutlichen, dass die Donatisten selbst Verfolger seien. Darüber hinaus spricht sich Augustinus für Verfolgung aus, wenn sie der Besserung der Menschen diene. So verteidigt und rechtfertigt er die Zwangsgewalt der christlichen Kaiser gegen die Donatisten. Die Diskussion um die Verfolgung veranschaulicht, wie beide Seiten in ihrer Polemik pauschal urteilten. Gerade Augustinus ignoriert die Unterschiede zwischen gewaltbereiten Donatisten und Vertretern wie Cresconius, der sich ausdrücklich von Gewalttaten distanzierte. ${ }^{14}$

Cresconius äußerte sich auch zur Entstehungsgeschichte des Schismas. Er verteidigte geschichtliche Persönlichkeiten der Donatisten, insbesondere Silvanus von Cirta, gegen die Vorwürfe der Katholiken. Dagegen bekräftigte er die traditio-Anklagen gegen die Katholiken und stellte die Verurteilung Caecilians heraus, die er mit den Akten des Konzils von Karthago begründete. Anderslautende Aussagen Augustins zur causa Caeciliani lehnte Cresconius als Fälschungen und Verleumdungen ab. Augustinus versucht dagegen in seiner Wi-

12 Epp. 89, 96, 97, 100, 112.

13 Zu den Auseinandersetzungen im Einzelnen vgl. o. Kap. 3.3.1-3.

14 Vgl. o. Kap. 3.3.4. 
derlegung, unter Heranziehung von historischen Dokumenten das Gegenteil zu beweisen, indem er donatistische Bischöfe der traditio beschuldigt und betont, dass Caecilianus freigesprochen worden sei. Er erhebt die überseeischen Bischöfe, die dieses Urteil gesprochen haben, zum Sprachrohr der Catholica, während er den Gegnern Caecilians Korruption und Falschaussagen unterstellt. Indem er darüber hinaus die Geschichte des donatistischen Schismas dem Maximianistischen Schisma gegenüberstellt, will er den Donatisten einen Spiegel vorhalten, um eine Schizophrenie in ihrem Verhalten zu enthüllen. Augustinus ist sich sicher, die wahren Beweise $\mathrm{zu}$ besitzen, stellt dies jedoch nicht als letztgültig heraus: Über allem steht für ihn die Einheit der Kirche. Da das crimen schismatis das crimen traditionis überwiege, sei es gleich, ob die Katholiken in ihrer Darstellung der Geschichte Recht hätten oder nicht. Die größere Schuld hätten ohnehin die Donatisten auf sich geladen, indem sie das Schisma vollzogen hätten.

Augustinus hatte erkannt, dass das karthagische Urteil über Caecilianus das Zentrum der donatistischen Argumentation bildete, und seine Widerlegung entsprechend eingerichtet. Seine Intention war es, die Revision dieses Urteils als richtig und gerecht darzustellen. Daraus resultiert sowohl die Anklage gegen die Kläger von Karthago als auch die Verteidigung des Urteils der europäischen Bischöfe. Der besondere Beitrag der „Bücher gegen Cresconius“ in Bezug auf die Rekonstruktion der Geschichte des Schismas liegt vor allem in der Überlieferung des Protokolls von Cirta und des Konstantinbriefes an Probianus, in dem Überblick über die Prozesse gegen Caecilianus und Felix von Abthugni sowie in den Hinweisen über die Rolle Kaiser Konstantins und seiner Entscheidungen. $^{15}$

Die dritte Phase in der Entwicklung der augustinischen Argumentation fällt schließlich in die Zeit nach der Konferenz von Karthago. In seinen Schriften und Predigten bezieht sich Augustinus von diesem Zeitpunkt an stets auf die Ergebnisse der Konferenz. Er verteidigte den Ablauf der Debatte und interpretierte die Argumente, die zu dem Urteil geführt hatten. Nach wie vor begründete Augustinus, warum es notwendig sei, die Donatisten auch mit Zwang zur Einheit zu führen. Seine Auseinandersetzungen mit den Donatisten Emeritus und Gaudentius zeugen indes von einem starken Widerstand gegen die erzwungene Einheit. Letztlich konnte sich die donatistische Kirche trotz starker Schwächung durch die staatliche Verfolgung in Nordafrika behaupten, auch über Augustins Wirken hinaus. ${ }^{16}$

15 Vgl. o. Kap. 3.4.

16 Vgl. o. Kap. 2.2.3. 


\section{Die Konferenz von Karthago}

Der Streit zwischen den beiden Kirchen fand seinen Höhepunkt in der Konferenz von Karthago im Juni des Jahres 411. Augustins Schriften aus dem Zusammenhang der Konferenz enthalten Informationen über Themen und Argumente beider Seiten und die Nachwirkungen der Ereignisse. Zusammen mit dem erhaltenen Teil der Konferenzakten bilden sie zudem eine der Hauptquellen für den gesamten Verlauf des donatistischen Schismas und damit einen zentralen Gegenstand zur Untersuchung der historischen Argumentation. Entsprechend ist auf die Betrachtung der Konferenz von 411 in der vorliegenden Studie ein besonderer Schwerpunkt gelegt worden. ${ }^{17}$ Die Quellen geben Aufschluss über den formalen Ablauf der Konferenz, die Verhandlungsstrategien sowie die Argumentation und Interpretation Augustins:

Die Konferenz von Karthago wurde auf Grundlage einer kaiserlichen Anordnung in Anlehnung an das nachklassische Zivilprozessrecht durchgeführt. Während die Katholiken den geforderten rechtlichen Bedingungen vorbehaltlos zustimmten, verfolgten die Donatisten zunächst eine Doppelstrategie: Einerseits unterwarfen sie sich den prozessrechtlichen Regeln, um durch verschiedene Einreden bestmögliche Voraussetzungen für die Verhandlung zu erstreiten, andererseits stellten sie die Prozessvoraussetzungen infrage, indem sie es ablehnten, Prozessvertreter zu benennen und diesen ein schriftliches Mandat zu erteilen. Stattdessen forderten sie die Durchführung der Konferenz nach kirchlichem Recht, d.h. als Plenarkonzil unter Beteiligung aller anwesenden Bischöfe und ohne einen weltlichen Richter. Auf diese Weise wollten die Donatisten aus ihrer (vermeintlichen) Mehrheit bei der Anzahl der Bischöfe einen Vorteil ziehen. Erst nachdem sie sich mit dieser Forderung nicht hatten durchsetzen können, folgten die Donatisten ebenfalls den gestellten Forderungen und ernannten ihre Prozessvertreter. ${ }^{18}$

Auch die weitere Verhandlungsführung der Donatisten unterlag einer wohlüberlegten Strategie. In den Vorverhandlungen wollten sie bestimmte Prozessvoraussetzungen klären lassen. Mit einer Einrede gegen die Art und Weise der Bevollmächtigung der Prozessvertreter (praescriptio de mandato) erhofften sich die Donatisten zum einen, Verfahrensfehler bei der Mandatserteilung der Katholiken zu enthüllen, zum anderen wollten sie die Zahlenverhältnisse beider Kirchen richtigstellen. Mit den Ergebnissen erwarteten sie einen strategischen Vorteil für die weiteren Verhandlungen. Zu Beginn des dritten Verhandlungstages versuchten die Donatisten mit einer Einrede über den Klägerstatus (praescriptio de persona), den weiteren Verlauf zu ihren Gunsten zu beeinflussen. Sie intendierten, entweder ein vorzeitiges Ende des

17 Vgl. o. Kap. 5.

18 Vgl. o. Kap. 5.1.2. 
Prozesses herbeizuführen, wenn nämlich die Überprüfung der Anklageschrift eine falsche Anklage beim Kaiser ergäbe. Oder aber, bei Misslingen dieses Vorhabens, sollte durch diese Einrede auf jeden Fall der Status der Donatisten als Beklagte gesichert werden, damit die Beweislast in den Hauptverhandlungen den Katholiken obliege.

Vehement und nachdrücklich forderten die Donatisten, als einzige Rechtsquelle die Heilige Schrift zuzulassen und den Katholiken den Status des Anklägers zuzuweisen. Entsprechend verfassten sie zur Vorbereitung auf die Verhandlungen eine ausschließlich theologische Verteidigungsschrift gegen die Katholiken. In den Hauptverhandlungen sollte dann mithilfe dieser Verteidigungsschrift aus der Heiligen Schrift bewiesen werden, dass allein ihre ekklesiologische Position der christlichen Wahrheit entspreche: Die traditio als Grundübel verunreinige die heilige Kirche, eine Gemeinschaft mit Traditoren sei nicht möglich. Als notwendige Schlussfolgerung daraus sollte der katholischen Kirche - als der Kirche der Traditoren - die Wahrheitsvertretung abgesprochen und die Existenzberechtigung entzogen werden. Die donatistische Kirche müsse vom Richter als einzig wahre Kirche Afrikas anerkannt werden. Um diesen letzten und entscheidenden Argumentationsschritt zu vollziehen, lag zusätzlich ein historisches Dossier bereit, mit entsprechenden traditio-Nachweisen gegen Schlüsselfiguren wie Caecilianus, Mensurius, Miltiades und Felix von Abthugni. ${ }^{19}$

Die Katholiken unter der Führung Augustins beabsichtigten zwar ebenfalls, auf Grundlage der Heiligen Schrift zu verhandeln, jedoch nur die theologischen und ekklesiologischen Fragen (causa ecclesiae). Im Gegensatz zu den Donatisten waren sie der Ansicht, dass die Frage der traditio mithilfe historischer Dokumente behandelt werden müsse. ${ }^{20}$

Die Verhandlungen des dritten Sitzungstages zeigen das Scheitern der donatistischen Strategie. Ausschlaggebend für die Niederlage der Donatisten war vor allem, dass es keine eindeutige Entscheidung über das Ende der Vorverhandlungen und den Eintritt in die Hauptverhandlungen gab. Die Forderung des Richters Marcellinus, den „ersten Ankläger“ zu bestimmen, um definieren zu können, wer während der Konferenz die Klägerrolle einzunehmen habe, führte zu einer Debatte über historische Ereignisse und Dokumente. Dadurch gerieten die Donatisten in ein Dilemma: Sie mussten sich auf die historische Argumentation einlassen, ohne dass Zwischenentscheidungen über die Heilige Schrift als einzige Rechtsnorm und über die Relevanz der traditio für die Reinheit der Kirche gefallen waren. Damit wurde ihrer Argumentation die Grundlage entzogen. Insbesondere Marcellinus' Weigerung, über das richtige Verständnis von Kirche zu urteilen, zerstörte die Argumentationskette der

19 Vgl. o. Kap. 5.2.

20 Vgl. o. Kap. 5.1.1. 
Donatisten. Denn ohne die Bestätigung ihrer Position, dass die Sünde der traditio bereits als Anklage gegen die Heiligkeit der Kirche zu gelten habe, wurden die traditio-Nachweise der Donatisten gegen Caecilianus und andere Bischöfe weder von den Katholiken noch von Marcellinus als Grund für die Kirchenspaltung akzeptiert. Folglich setzte sich der katholische Ansatz durch: Die Frage der traditio wurde allein auf Grundlage weltlicher Dokumenten debattiert, und die Katholiken überzeugten den Richter mit ihren Argumenten in der causa Caeciliani.

Obwohl weder Donatisten noch Katholiken die Diskussion über die Entstehung des Schismas in den Mittelpunkt der Debatte stellen wollten, wurde die historische Argumentation zum vieldiskutierten und entscheidenden Punkt der Konferenz. Im Verlauf der Diskussion zeigten sich vollkommen unterschiedliche Vorstellungen zu den Anfängen des Schismas: Die Katholiken verwendeten die von Augustinus bekannten Dokumente, um die Schuldlosigkeit Caecilians nachzuweisen und um darzustellen, dass es auch in den Reihen der Donatisten Traditoren gegeben habe. Die Donatisten beharrten darauf, dass Caecilianus und sein Konsekrator Felix von Abthugni als Traditoren verurteilt worden seien, und zwar nicht nur durch das Konzil von Karthago, sondern auch durch den Kaiser, nachdem dieser ein erstes Urteil revidiert habe. In dieser Form war die geschichtliche Konstruktion neu. Offensichtlich hatten die Donatisten im Vorfeld der Konferenz versucht, mithilfe der ihnen bekannten Dokumente eine stringente Abfolge der Ereignisse zu entwerfen. In der Überprüfung zeigt sich indessen, dass die Interpretationen der Donatisten, vor allem die Verurteilung Caecilians durch Konstantin, in den vorhandenen Quellen kaum eine Grundlage besitzen. ${ }^{21}$

Marcellinus fällte ein Urteil, das schon vor der Konferenz festgestanden hatte. Trotz einer formalen Objektivität in den Verhandlungen war es für Marcellinus weder möglich, eine theologisch begründete Entscheidung gegen die katholische Kirche zu treffen, noch, sich gegen den erklärten Willen des Honorius und das historisch nachgewiesene Urteil Konstantins zu stellen. Ganz im Sinne der Katholiken bestätigte Marcellinus lediglich das bereits bestehende Urteil Konstantins zu Gunsten der Katholiken. ${ }^{22}$

Augustinus verstand von Beginn an die Konferenz als ein „Zeugnis für die Wahrheit", das allen Menschen offenzulegen sei. In den Schriften nach der Konferenz verdeutlicht er die nun unwiderrufliche Entscheidung zur kirchlichen Einheit. Um möglichst viele Menschen über das Ergebnis zu unterrichten, verfasste Augustinus neben anderen Schriften selbst einen Kurzbericht über die Konferenz, in dem er die Obstruktionen und Verwirrspiele der Donatisten

21 Vgl. o. Kap. 5.3.3; u. Kap. 8.3.

22 Vgl. o. Kap. 5.1.3; 5.2. 
kritisiert und ihre vollständige Niederlage in allen behandelten Fragen aufführt. ${ }^{23}$ In seiner Argumentation griff Augustinus nun nicht mehr auf historische Dokumente zurück, sondern wählte aus den Debatten der Konferenz geeignete Teile aus, mit denen er den „Irrtum“ der Donatisten belegen konnte. Die Auseinandersetzung mit dem donatistischen Bischof Emeritus sieben Jahre nach der Konferenz verdeutlicht jedoch, dass trotz katholischer Propaganda und Zwangskonversionen eine Überwindung der Gegensätze nicht stattgefunden hatte. ${ }^{24}$

\section{Das historische Selbstverständnis der Donatisten}

Donatisten und Katholiken zur Zeit Augustins interpretierten jeweils auf Grundlage ausgewählter schriftlicher und mündlicher Traditionen die Entstehungsgeschichte des Schismas. Die historische Argumentation der Donatisten erschließt sich zum größten Teil nur indirekt durch die Schriften Augustins. Dennoch lassen sich einige Gesichtspunkte zu ihrem Umgang mit der Geschichte des Schismas erkennen: Die Donatisten zur Zeit Augustins besaßen eine reichhaltige Geschichtstradition, die sich heute nur noch in Bruchstücken erfassen lässt. Leitthema dieser Traditionen war die Rechtfertigung und Selbstvergewisserung der eigenen Identität als wahre Kirche Christi in Opposition zur Welt und der mit der Welt verbündeten Kirche der Traditoren und Persecutoren. Vieles deutet auf eine ausgeprägte Kultur mündlicher Traditionen hin, von denen nur Teile verschriftlicht worden sind. In wenigen Ausnahmefällen, wie etwa die Informationen über den interventor in Karthago, ${ }^{25}$ sind mündliche Berichte durch Zufall dokumentiert worden und damit erhalten.

Im Zentrum der donatistischen Überlieferungen steht die Anklage gegen Persecutoren und Traditoren. Im Verständnis der Donatisten sind diese beiden Kategorien synonym zu betrachten: Traditoren stellten sich auf die Seite der Verfolger und wurden damit selbst Verfolger; Verfolger waren umgekehrt Anstifter und Verbündete der Traditoren. Die Austauschbarkeit dieser Begriffe zeigt sich nicht nur in der Terminologie, sondern auch in den konkreten Anschuldigungen. So wird Caecilianus gleichzeitig als Helfershelfer der Verfolger in Karthago und des Traditors Mensurius diskreditiert. Andernorts wird die Verbindung der Traditoren mit dem Verfolger Macarius deutlich hervorgehoben. $^{26}$

Die von den Donatisten überlieferten historischen Ereignisse befassen sich zu einem großen Teil mit den Verfolgungen ihrer Kirche. Die Vergegenwärti-

23 Vgl. o. Kap. 5.4.

24 Vgl. o. Kap. 5.4.4.

25 Vgl. o. Kap. 7.1.2.

26 Vgl. o. Kap. 6.1.2; 6.3.2. 
gung ihrer Geschichte als eine Geschichte der Verfolgung war für die Donatisten ein wesentlicher Teil des Selbstverständnisses. In Fortführung der verfolgten Kirche in der heidnischen Welt sahen sich die Donatisten als verfolgte Kirche in der Welt der Traditoren und ihrer säkularen Exekutoren. Durch Gennadius wissen wir von einem donatistischen Verfasser namens Vitellius, der zur Zeit des Constans ein umfassendes Buch über die Verfolgung der Christen geschrieben hat. Dieses Werk umfasste sowohl die vorkonstantinischen Verfolgungen als auch die Verfolgung der Donatisten, ${ }^{27}$ wodurch die Kontinuität der Vorgänge unterstrichen wird.

In der Auseinandersetzung mit den Gegnern verwendeten die Donatisten ihre andauernde Verfolgung als zentrales Argument für die Rechtmäßigkeit ihrer Kirche. In ihren Augen konnte nur die verfolgte Kirche die wahre Kirche Jesu Christi sein. Als Argumentationsbasis dienten zum einen mündliche Berichte über Gewaltanwendungen gegen Donatisten, zum anderen die verbreiteten Märtyrerberichte, jene Texte, die zur Erbauung der Gläubigen die Martyrien von Glaubensgeschwistern erzählten und so die Donatisten in ihrer Rolle als Verteidiger des wahren Glaubens bestärkten. Wenig wahrscheinlich ist jedoch die Existenz einer festen Sammlung an Dokumenten, die von Donatisten bei Bedarf als schriftliche Beweismittel herangezogen wurden.

Obwohl die Donatisten die weltlichen Gewalten grundsätzlich als Verfolger beurteilten, lässt sich durchgängig eine ambivalente Haltung gegenüber den Kaisern feststellen. Sie unterließen es in ihren Darstellungen, die Kaiser ausdrücklich als Verantwortliche für ihre Verfolgung zu benennen. Eine Ausnahme war Kaiser Constans, der als Urheber der sog. macarianischen Verfolgung galt. Offenbar aus pragmatischen Überlegungen war den Donatisten daran gelegen, durch eine gewisse Loyalität gegenüber den Kaisern, die Möglichkeit aufrechtzuerhalten, durch die kaiserliche Politik unterstützt zu werden. Dass solch eine Politik zu ihren Gunsten möglich war, konnten die Donatisten in der Regierungszeit Kaiser Julians erfahren. ${ }^{28}$

Für das donatistische Geschichtsbild im Hinblick auf die Entstehung des Schismas lassen sich ebenfalls aufschlussreiche Einsichten gewinnen: Die donatistische Überlieferung, die nachweislich bereits vor Parmenianus und der Zeit Augustins existierte, konzentriert sich auf einen einzigen Beweis zur Rechtfertigung des Schismas in Karthago: den Frevel der Bischofserhebung Caecilians. In diesen Zusammenhang gehören auch die traditio-Anklagen gegen Mensurius und Felix von Abthugni sowie der Verweis auf die Entscheidung des Konzils unter Secundus. Im donatistischen Verständnis genügten diese Aussagen, um Caecilianus und allen seinen Nachfolgern die Bischofswürde abzu-

27 Gennadius, de vir. ill. 4; vgl. Maier II, Nr. 120, 303-305.

28 Vgl. o. Kap. 6.3.3. 
sprechen; explizite Beweise waren dabei nicht vonnöten. Es ist unwahrscheinlich, dass die später verwendeten schriftlichen Dokumente über Caecilianus und Felix in donatistischen Kreisen als Beweismittel kursierten. Vielmehr dürften die entscheidenden Aussagen mündlich und durch Gemeindebriefe oder Traktate verbreitet worden sein. Die nicht erhaltenen Briefe und Predigten des Donatus von Karthago waren mit Sicherheit auch hinsichtlich der geschichtlichen Ereignisse Multiplikatoren der donatistischen Auffassung in dieser Zeit. ${ }^{29}$

Durch diese Überlieferungen verfestigten sich im Laufe der Zeit die Überzeugungen über Traditoren und Verfolger in der Anfangsphase des Schismas. Sie trugen dazu bei, dass die Donatisten selbstsicher und überzeugt ihre historischen Positionen vertraten. Von diesen älteren Überlieferungen müssen die späteren, apologetischen Aussagen, die in direkter Auseinandersetzung mit den Gegnern entstanden sind, deutlich abgegrenzt werden. Erst die Herausforderung durch die Gegenpartei nötigte die Donatisten, in Bezug auf die causa Caeciliani ihre Argumentation auszuweiten und historische Zeugnisse als Beweismittel heranzuziehen. Zu diesen gehören insbesondere die zu der Zeit Augustins offenbar recht weitverbreiteten Akten des Konzils von Karthago mit den Verdammungssentenzen über Caecilianus. Hinzu kommen die Angriffe auf den Prozess gegen Felix von Abthugni mit den Bestechungs- und Korruptionsvorwürfen sowie der Verteidigung des Ingentius, der das belastende Material gegen Felix in Umlauf gebracht hatte. ${ }^{30}$ Bei Cresconius findet sich zudem die Verteidigung des Silvanus von Cirta gegen die traditio-Vorwürfe Augustins. ${ }^{31}$

Der Blick der Donatisten richtete sich auch auf die Prozesse in Europa, die Entscheidungen der Bischöfe in Rom und Arles sowie das Urteil Konstantins. Der Freispruch Caecilians durch Miltiades wurde als rechtswidrig angesehen, der durch Missgunst und Korruption zustande gekommen sei, Aussagen, die sich vor allem in den Schriften der donatistischen Bischöfe Parmenianus und Petilianus zeigen. Mit der Verleumdung des Miltiades als Traditor und den Unterstellungen von Bestechungen der Richter sollten die von den Katholiken als entscheidend dargestellten Urteile infrage gestellt werden. Bei Parmenianus ist zudem das Bemühen erkennbar, das Urteil des Kaisers als Fehlurteil darzustellen und mit den Angriffen auf Ossius von Cordova die kaiserliche Politik abzulehnen. Hinter allen diesen Argumenten steht die Absicht der Donatisten, das Konzilsurteil von Karthago gegen Caecilianus als das allein gültige zu verteidigen. $^{32}$

Dieselbe Zielsetzung verfolgte auch Cresconius, allerdings mit anderen Argumenten. Augustins Darstellungen zur causa Caeciliani lehnte Cresconius

29 Vgl. o. Kap. 6.1; 7.1.

30 Vgl. o. Kap. 6.1.3.

31 Vgl. o. Kap. 3.4.1.

32 Vgl. o. Kap. 7.3-4. 
als Fälschungen und Verleumdungen ab und postulierte dagegen, dass Caecilianus durch den Kaiser verurteilt worden sei. Damit wollte er zwar auch die Sentenz des Konzils von Karthago bestärken, jedoch nicht mehr gegen das Urteil Konstantin, sondern nunmehr auf der Grundlage einer kaiserlichen Entscheidung und ihrer allseits anerkannten Autorität. Diese Tradition ist mit Sicherheit wesentlich jünger als jene, die Parmenianus noch vertreten hatte. $\mathrm{Ob}$ sie erst zur Zeit Augustins (von Petilianus?) entworfen wurde oder bereits länger in donatistischen Kreisen kursierte, lässt sich den Quellen nicht entnehmen. Die erste Möglichkeit erscheint allerdings plausibler, da vieles darauf hindeutet, dass zuvor Parmenians Einfluss die donatistische Meinung entscheidend geprägt hatte und somit erst nach seinem Tod eine veränderte Position bezogen wurde. ${ }^{33}$

Die veränderte Auffassung zur causa Caeciliani, die bei Cresconius erstmals auftaucht, wird auch auf der Konferenz von 411 deutlich. Die donatistischen Vertreter behaupteten auch hier, dass Caecilianus durch Kaiser Konstantin verurteilt und den Donatisten Freiheit gewährt worden sei. Während Cresconius diese Ansicht lediglich vortrug, versuchten die Vertreter auf der Konferenz, sie mit einer Sammlung historischer Dokumente zu beweisen. Dieses neue Konzept der historischen Beweisführung spielt für das Geschichtsbild der Donatisten eine Sonderrolle. Die donatistischen Bischöfe mussten sich während der Konferenz auf die vorgegebenen, juristischen Argumentationsstrukturen einlassen. Sie taten es, indem sie in den Archiven nach weiteren geeigneten Zeugnissen suchten, mit denen ihre Anklage gegen Caecilianus bewiesen werden konnte. $\mathrm{Zu}$ diesen erstmals herangezogenen Dokumenten gehörten die Akten aus Rom, das kaiserliche Reskript an Verinus mit der dazugehörigen Petition, der Brief Konstantins an Probianus und wahrscheinlich der Briefwechsel zwischen Mensurius und Secundus sowie die Schriften des Optatus von Mileve. Aus den nunmehr zur Verfügung stehenden Überlieferungen und Dokumenten erarbeiteten die Donatisten einen strukturierten Ablauf der causa Caeciliani, der darauf ausgerichtet war, durch einen Schuldnachweis gegen Caecilianus den Kommunionsentzug der Väter mit der pars Caeciliani glaubhaft zu begründen, sei es durch den Nachweis der traditio Caecilians, sei es der Nachweis der Schuld seiner Ordinatoren. Die Rechtsauffassung der Gegner sollte so widerlegt werden. Diese Präsentation der donatistischen Vertreter zeugt von einer guten Vorbereitung auf die Diskussion über die Entstehung des Schismas auf der Konferenz von Karthago. ${ }^{34}$

Die historischen Rekonstruktionen der Donatisten verdeutlichen ebenso wie ihre Traditionen zur traditio und persecutio, dass die Deutungen der Rechtfer-

33 Vgl. o. Kap. 3.4.1.

34 Vgl. o. Kap. 7.4.2.1; 8.2. 
tigung ihrer eigenen theologischen und ekklesiologischen Dogmen untergeordnet waren. Vor den offensichtlichen Ungereimtheiten in Bezug auf die traditio zur Zeit der Verfolgung und der Abläufe in der causa Caeciliani verschlossen die Donatisten die Augen. Sie ignorierten oder leugneten die Widersprüche, vielleicht auch in der Vorahnung, dass die Offenlegung der Vergangenheit die eigenen Glaubensüberzeugungen infrage stellen könnte.

\section{Augustins historische Quellen und ihre Interpretation}

Augustinus verfolgte in der historischen Argumentation trotz unterschiedlicher Akzentsetzungen gegenüber seinen Gesprächspartnern und Lesern ein gleichbleibendes Argumentationsmodell. Stets ging es um die Verteidigung des Bischofs Caecilianus und um den Nachweis, dass es keinen Grund zur Kirchenspaltung gegeben habe. Im Einzelnen lassen sich innerhalb dieses Modells folgende Ansätze erkennen:

Um auf das Hauptargument der Donatisten, die Verurteilung Caecilians durch das Konzil von Karthago, zu entgegnen, setzte Augustinus alles daran, dieses Urteil als unrechtmäßig darzustellen. In seinen Schriften vor dem Jahr 405 stand der Vorsitzende dieses Konzils, Secundus von Tigisi, im Zentrum der Argumentation Augustins. Auf Grundlage des Protokolls der Synode von Cirta (um 305/6) warf Augustinus Secundus vor, die traditio mit unterschiedlichen Maßstäben beurteilt zu haben: Auf der Synode von Cirta habe er geständige Traditoren dem Urteil Gottes überlassen, in Karthago habe er Caecilianus verurteilt und dadurch die Spaltung heraufbeschworen. Secundus habe aus Selbstsucht, Hochmut und Habgier gehandelt und ein Schisma in Kauf genommen. Außer diesen Anschuldigungen kritisierte Augustinus Verfahrensfehler: Caecilianus sei während der Verhandlungen abwesend gewesen und die numidischen Bischöfe hätten gar kein Recht gehabt, einen neuen karthagischen Bischof zu weihen. Beide Argumente verfehlen jedoch die rechtliche Situation zu Beginn des 4. Jahrhunderts, da es offenbar in dieser Hinsicht noch keine eindeutigen Regelungen gab.

Schließlich griff Augustinus das Fundament donatistischer Ekklesiologie an, indem er behauptete, dass sich unter den Anklägern Caecilians Traditoren befunden hätten. Die donatistische Begründung der Spaltung, es müsse eine Trennung von der „Kirche der Traditoren“ vollzogen werden, sollte dadurch hinfällig werden. Neben den übrigen Bischöfen, die im Protokoll der Synode von Cirta genannt werden, bezog sich Augustinus vor dem Jahr 405 vor allem auf Silvanus von Cirta, dessen traditio er durch jene Akten nachweisen konnte, die aus dem Prozess gegen Silvanus vor dem Konsular Zenophilus stammten. Allerdings kam er lediglich in der Kontroverse mit Petilianus von Cirta und Cresconius auf diesen Fall zu sprechen; gegenüber Generosus, einem Bewohner 
Cirtas (ep. 53), verwies er auf die vorhandenen Dokumente. Offensichtlich spielte bei der Heranziehung des Falles Silvanus der regionale Bezug eine Rolle. Den Donatisten Cirtas sollte vor Augen gestellt werden, dass gerade in ihrer Stadt die stets behauptete Reinheit der bischöflichen Sukzession nicht gewahrt worden sei. ${ }^{35}$

Außer der Diskussion um das Konzil von Karthago war Augustins zweites zentrales Argument, dass Caecilianus in drei Instanzen von allen Anschuldigungen freigesprochen worden sei. Hier zeigt sich Augustins katholisches Verständnis gegen einen afrikanischen Separatismus: Die Bischöfe der weltweiten Kirche und die christlichen Kaiser hätten sich alle für Caecilianus ausgesprochen. Ergänzend führte Augustinus an, dass auch Felix von Abthugni von allen traditio-Vorwürfen freigesprochen worden sei. Dadurch sollte auch der Vorwurf entkräftet werden, dass Caecilianus durch einen Traditor geweiht worden sei. ${ }^{36}$

Augustinus kam es stets darauf an, seine Leser auf die Tatsache dieser Freisprüche hinzuweisen. Deshalb vereinfachte und schematisierte er die historische Darstellung und verzichtete zumeist auf Ausführungen zu den Verhandlungen. So zitierte er niemals wörtlich aus den Akten der römischen Synode von 313 unter Miltiades, obwohl er sie kannte. Allerdings fehlten aber auch aussagekräftige Quellen, insbesondere in Bezug auf das Konzil von Arles und das Urteil Konstantins, so dass ihm eine ausführlichere Darlegung der Ereignisse gar nicht möglich war. ${ }^{37}$

Um das Jahr 405 entdeckte Augustinus im prokonsularischen Archiv Karthagos die relatio Anullini von 313. Auf Grundlage dieses Dokuments änderte er seine Argumentation. Anstatt die Darstellung des Optatus von Mileve zu übernehmen, in der von der donatistischen Bitte, ein Bischofsgericht einzusetzen, die Rede ist, rückte nun eine genaue Beschreibung des gerichtlichen Instanzenweges bis zum Urteil Konstantins in den Vordergrund. Augustinus stellte für seine Argumentation zwei Aspekte heraus: Zum einen wollte er nachweisen, dass die erste Anklage beim Kaiser und damit die Anrufung der weltlichen Gewalt von den Donatisten ausgegangen sei, zum anderen, dass die Donatisten mit dieser Anklage ein Urteil erbeten hätten, das sie später nicht akzeptieren wollten. Zwar verschwieg Augustinus den geschichtlichen Hintergrund dieser Anklage, doch wies er zu Recht auf die widersprüchliche Haltung der Donatisten bezüglich der römischen Kaiser und säkularen Obrigkeiten hin. Überdies zog Augustinus nach dem Unionsedikt von 405 einen geschichtlichen Bogen, indem er ausgehend vom Urteil Konstantins in der causa Caeciliani eine kontinuierliche antidonatistische Gesetzgebung bis in seine Zeit postulierte. So

35 Vgl. o. Kap. 3.4.2.1; 4.2.1; 6.2.

36 Vgl. o. Kap. 3.4.2.2; 4.2.1.

37 Vgl. o. Kap. 7.3; 7.4.3. 
wollte er die gegenwärtigen Gesetze der coercitio verteidigen und als notwendige Folge des schon von Konstantin gefällten Urteils legitimieren. Die gegenwärtigen Kaiser vollzögen lediglich das Urteil, das die Donatisten selbst gefordert hätten. Das Urteil Konstantins wurde dadurch zu Augustins Ausgangspunkt für eine Verbindung von Vergangenheit und Gegenwart. Die Kontinuität in der Gesetzgebung der christlichen Kaiser begründete für ihn das geltende Recht, auch für die Religionspolitik seiner Zeit. ${ }^{38}$

Allerdings stellt Augustinus die historische Argumentation stets in einen theologischen Zusammenhang. Er verknüpft sie mit der zentralen Aussage: Es sei unerheblich, ob die Katholiken in ihrer Darstellung der Geschichte Recht hätten oder nicht, da zum einen die traditio-Schuld Einzelner keine Auswirkung auf die gesamte Kirche habe, zum anderen die Kirchenspaltung immer das größere Verbrechen darstelle. So relativierte Augustinus selbst die historischen Argumente und den Streit über die traditio, indem er sie dem Anliegen der Kircheneinheit unterordnete. Aus seiner Sicht müssten die Donatisten um des Friedens und der Einheit willen die Spaltung beenden, auch bei erwiesener traditio in der katholischen Kirche. ${ }^{39}$

Im Rahmen der historischen Argumentation Augustins ist es eine wesentliche Frage, auf welcher Grundlage seine Geschichtsdarstellungen beruhen. Es erscheint notwendig zu überprüfen, welche Quellen Augustinus tatsächlich verwendete und wie er sie interpretierte. Die folgende Zusammenstellung soll diesen Überblick geben.

Bereits in den ersten Jahren seiner Tätigkeit als Bischof nutzte Augustinus eine Anzahl historischer Dokumente zum Donatismus. Es ist anzunehmen, dass er diese Zeugnisse nach den ersten Konfrontationen mit Donatisten in Hippo von Mitarbeitern zusammentragen ließ, um für die Auseinandersetzung mit den Gegnern gerüstet zu sein. ${ }^{40}$ Diese Quellensammlung ist indessen sehr überschaubar. Sie bestand soweit ersichtlich lediglich aus sieben Schriften oder Dokumenten unterschiedlichen Charakters:

1. Das Werk des Optatus von Mileve. Optatus vermittelte Augustinus die grundlegenden Kenntnisse und Zusammenhänge zur Entstehungsgeschichte des Schismas. Diesem Werk konnte er einige Informationen entnehmen, die anderweitig nicht bezeugt waren. Hierzu zählen vor allem der Bericht über die Intrigen in der karthagischen Gemeinde zur Zeit der Wahl Caecilians (Opt. I 16-20), der vermeintliche Text des donatistischen Bittgesuchs an Konstantin (I 22), der Hinweis über den Aufenthalt Caecilians in Brescia und die Untersu-

38 Vgl. o. Kap. 4.2.2; 5.3.2; 7.4.3.

39 Vgl. o. Kap. 3.4.2.2; 5.4.

40 Einblick in die Sammlung gewähren die epp. 43, 53 und 76. Vgl. o. Kap. 4.2. 
chungskommission in Afrika (I 26) sowie Hintergründe der Verfolgungen unter Macarius (III 3-6).

2. Das Protokoll des Konzils von Cirta. Augustinus nutzte ein Exemplar des Protokolls von Cirta, das vermutlich aus einem kirchlichen Archiv in Cirta stammte. Dieses Manuskript war ausführlicher als die von Augustinus in Cresc. III 30 zitierten Textausschnitte. Die Überlieferung Augustins war unabhängig von der Dokumentensammlung des Optatus von Mileve, die dieser unter der Bezeichnung scripta Nundinarii zusammengestellt hatte und auch das Protokoll beinhaltete. Zur Zeit Augustins befand sich das Protokoll nicht mehr im Anhang des Optatus (App. I), ebenso wenig wie heute. ${ }^{41}$

3. Die Protokolle des Konzils von Rom des Jahres 313. Augustinus war im Besitz der Akten jener von Konstantin angeordneten Zusammenkunft in Rom, bei der Caecilianus freigesprochen wurde. Er wertete den Inhalt für seine historische Argumentation aus (ep. 43.14-16; breuic. III 24), allerdings zitiert er niemals wörtlich aus den Dokumenten. ${ }^{42}$ Über die Herkunft gibt Augustinus keinen Hinweis. Möglicherweise sind bereits kurz nach der Synode Abschriften angefertigt und nach Afrika gebracht worden, um ausführlich über das Ergebnis zu informieren. Vermutlich waren daher Abschriften der Protokolle in kirchlichen Archiven zugänglich.

4. Der Brief Konstantins an Miltiades mit dem Auftrag, in der causa Caeciliani zu entscheiden. Augustinus erwähnt diesen Brief in ep. 53.5 und in s. Denis 19.8. ${ }^{43}$ Er wurde zudem auf der Konferenz von 411 vorgelegt (breuic. III 24). Während Augustinus im Zusammenhang mit den Protokollen des römischen Konzils in den Besitz des Dokumentes gekommen sein dürfte, ist der Wortlaut heute durch die Kirchengeschichte des Eusebius (HE X 5.18-20) überliefert. ${ }^{44}$

5. Die Akten des Prozesses gegen Felix von Abthugni (acta purgationis Felicis). Diese Akten konnte Augustinus möglicherweise dem Anhang des Optatus entnehmen (heute fragmentarisch App. II). Ebenso waren sie aber im Archiv des Prokonsuls in Karthago zugänglich. Der in den Akten belegte Freispruch des Felix von Abthugni lieferte Augustinus eine Ergänzung zum Nachweis der Unschuld Caecilians. Die Donatisten indessen sahen auf Grundlage der Prozessakten die Schuld des Felix für erwiesen an. ${ }^{45}$

41 Vgl. o. Kap. 6.2.1.

42 Zur möglichen Begründung vgl. o. Kap. 7.3.

43 Vgl. o. Kap. 4 Anm. 72.

44 Vgl. o. Kap. 7 Anm. 82.

45 Vgl. o. Kap. 6.1.3. 
6. Die Akten des Prozesses gegen Silvanus von Cirta (gesta apud Zenophilum). Diese Akten befanden sich laut ep. 53.5 im Archiv des numidischen Konsulars in Cirta. Augustinus kannte wahrscheinlich dieses Exemplar. Möglicherweise waren sie ihm auch durch den Anhang bei Optatus bekannt (heute fragmentarisch App. I). Mithilfe dieses Dokuments führte Augustinus gegenüber Petilianus und Cresconius den Nachweis, dass sich auch unter den donatistischen Bischöfen Traditoren befanden. ${ }^{46}$

7. Der Brief Konstantins an den Vikar Eumalius. Heute bis auf ein Fragment bei Augustinus nicht erhalten, war dieser Brief ebenfalls in einem karthagischen Archiv aufzufinden. Da es der einzige Brief Konstantins ist, den Augustinus schon früh in Händen hielt, ist es denkbar, dass sich in Hippo Regius bereits eine Abschrift des Dokuments befand, bevor Augustinus die Auseinandersetzung mit den Donatisten begann. Der Brief an Eumalius war das einzige Dokument, aus dem Augustinus Informationen über die Abfolge der Prozesse gegen Caecilianus und den Freispruch Caecilians durch Konstantin gewinnen konnte. Er enthielt wahrscheinlich einen zusammenfassenden Bericht über die kaiserlichen Maßnahmen. ${ }^{47}$ Obwohl das Datum des Briefes erhalten ist (10. November 316), ${ }^{48}$ lässt sich daraus kein präzises Datum über das Ende des Verfahrens gegen Caecilianus ableiten. Mit Sicherheit ist der Bericht erst einige Zeit später abgefasst worden, wie viel später kann jedoch aus den Brieffragmenten selbst nicht beantwortet werden. Es kann aber als sicher gelten, dass bereits zur Zeit Augustins die genauen Daten fehlten. Aufgrund der Einzigkeit dieser Quelle ist es erstaunlich, dass Augustinus nirgends den gesamten Wortlaut des Briefes zitiert. Andererseits passt dies in Augustins Argumentationsinteresse, nicht die genauen Abläufe, sondern Entscheidungen in den Vordergrund zu stellen.

Augustinus unterteilte die Aktenzeugnisse nach ihrer Herkunft in kirchliche und weltliche Dokumente, wobei er keine Abstufung der Glaubwürdigkeit bezweckte, sondern umgekehrt eine beiderseitige Bekräftigung der Argumente. Kirchliche und weltliche Dokumente bezeugten gleichermaßen die Schuld der Donatisten.

Augustins Quellengrundlage erweiterte sich um das Jahr 405. Vermutlich veranlassten die vorangegangen Diskussionen mit Donatisten, sehr wahr-

46 Vgl. o. Kap. 6.2.2.

47 Augustinus referiert in ep. 43.20 aus dem Eumaliusbrief. Die Verwendung des Dokuments 411 bezeugen Cap. conl. Carth. III 516, 521-535. Einige weitere Inhaltshinweise in Aug. breuic. III 37. Augustinus bezieht sich häufig auf die Aussage über die Entscheidung im Fall Caecilianus: ep. 53.5; 76.2; 88.3; 89.3; 105.8; Cresc. III 61, 67; IV 9; c. Don. 19, 54; cath. fr. 46.

48 C. Don. 20. 
scheinlich auch die Verschärfung der Gesetzgebung durch das Unionsgesetz des Jahres 405 Augustinus, nach weiteren historischen Dokumenten zu recherchieren. Seine Suche im prokonsularischen Archiv Karthagos (breuic. III 8) brachte zwei, vielleicht auch drei Dokumente zum Vorschein, die Augustins Kenntnisse über die Anklage der Donatisten vor dem Kaiser sowie zum Prozessverlauf der causa Caeciliani erweiterten und die er entsprechend für seine Argumentation heranzog:

1. Der erste Bericht des Anullinus an Konstantin vom 15. April 313 über die Anklage Caecilians durch die Donatisten (relatio Anullini). Augustinus verwendete dieses Dokument, um zu beweisen, dass sich die Donatisten in dem Streit als erste und freiwillig an den Kaiser gewandt hätten. ${ }^{49}$

2. Der Brief Konstantins an den Prokonsul Probianus über die Vorladung des Ingentius nach Abschluss des Falles Felix von Abthugni. Augustinus zitiert aus diesem Brief in ep. 88.4 und Cresc. III 81, um mithilfe der causa Felicis die Unschuld Caecilians zu beweisen. ${ }^{50}$ An anderen Stellen verweist er nicht mehr auf diese Quelle. Auf der Konferenz von Karthago gehörte das Schreiben jedoch zu den Dokumenten der Donatisten, die mit dem Inhalt beweisen wollten, dass Felix in einem weiteren Verfahren verurteilt worden sei. ${ }^{51}$ Aufschlussreich ist der Brief vor allem bezüglich der Verbindung der causa Felicis mit der causa Caeciliani: Da Konstantin darauf hoffte, mithilfe von Ingentius die Ankläger Caecilians zum Verstummen zu bringen, lässt sich schließen, dass ein Teil der donatistischen Anschuldigungen eindeutig gegen die ungültige Weihe Caecilians gerichtet waren.

3. Der zweite Bericht des Anullinus an Konstantin über die Entsendung der Streitparteien zum Konzil nach Rom. Der Inhalt dieser relatio scheint für Augustins Argumentation unwichtig gewesen zu sein, denn er verwendete sie nicht für seine Schriften. Der Bericht wurde lediglich auf der Konferenz von 411 herangezogen, aber auch dort nicht weiter diskutiert (vgl. breuic. III 24). Es ist also durchaus möglich, dass dieses Dokument erst zur Vorbereitung der Konferenz aus dem Archiv herbeigebracht worden war.

Insgesamt verwendet Augustinus also lediglich zehn Quellen zur Ausgestaltung seiner historischen Argumentation. Sicherlich kannte Augustinus darüber hinaus weitere Berichte, die sein Bild an der einen oder anderen Stelle ergänzten. Bei der Suche nach Dokumenten dürfte er auch auf weitere Schriftstücke ge-

49 Vgl. o. Kap. 7.2.

50 Vgl. o. Kap. 3.4.2.2; 4.2.2.

51 Cap. conl. Carth. III 554-558; breuic. III 41-42; c. Don 19, 55; vgl. o. Kap. 6.1.3. 
stoßen sein, die ihm jedoch für seine Argumentation nicht relevant erschienen. Nicht zuletzt kannte er zu großen Teilen die Überlieferungen und Zeugnisse, die von den Donatisten vorgelegt wurden. Dennoch hat die Analyse von Augustins Argumentation und die Rekonstruktion aus den Quellen deutlich gezeigt, dass es nicht mehr als diese zehn Dokumente waren, aus denen Augustinus geschichtliche Kenntnisse schöpfen konnte. Alle anderen verfügbaren Zeugnisse gaben ihm keine weitere Auskunft über die Menschen und die Ereignisse aus der Anfangszeit des Schismas.

Es fällt auf, dass Augustinus bis auf eine Ausnahme weder die bei Eusebius überlieferten Briefe Konstantins kannte noch die Briefe, die heute im Anhang des Optatus von Mileve erhalten sind. Die beiden Protokolle aus den Prozessen gegen Felix und Silvanus müssen ebenfalls nicht zwangsläufig aus dem Dokumentenanhang des Optatus entnommen worden sein, sie könnten ebenso aus den städtischen Archiven stammen. Es ist daher durchaus möglich, dass Augustinus das Werk des Optatus ohne den vom Verfasser zusammengestellten Anhang kannte. ${ }^{52}$ Abgesehen von den donatistischen Akten des Konzils von Karthago gab es nur vier Quellen, die Augustinus und Optatus gleichermaßen in Anspruch nahmen: Das Protokoll von Cirta, die gesta apud Zenophilum, die acta purgationis Felicis und die Akten des Konzils von Rom. Von keinem dieser Zeugnisse kann jedoch die Abhängigkeit Augustins von den Quellen des Optatus bewiesen werden. Im Falle des Protokolls von Cirta und der gesta apud Zenophilum ist sogar eine Verwendung unterschiedlicher Kopien als sicher anzunehmen. Augustinus verließ sich auf jene Dokumente, die seine Mitstreiter und er selbst in den Archiven fanden. Bereits existierende Quellensammlungen zum Donatismus standen ihm nicht zur Verfügung. ${ }^{53}$ Die Entstehungsgeschichte des Donatismus konstruierte Augustinus nach seinem Vermögen und unter der Zielsetzung, Donatisten zur Rückkehr zu bewegen und Katholiken in ihrem Glauben zu stärken. Er nutzte Optatus von Mileve vor allem zu Beginn seiner Arbeit, um die Zusammenhänge kennenzulernen. Er las jedoch auch die Werke der Gegner: Donatus, Tyconius und Parmenianus, später Petilianus und Cresconius sowie andere Donatisten, die mit ihren Traktaten an der Auseinandersetzung beteiligt waren. Sie führten Augustinus zu der Frage der traditio und

52 Auch die Akten der Untersuchungsfahrt von Eunomius und Olympius kannte Augustinus nicht, die Optatus nach eigener Auskunft angefügt hatte (Opt. I 26). Dies weist ebenfalls auf das Fehlen dieses Anhangs zur Zeit Augustins.

53 Der Blick auf Augustins Quellen zeigt erneut, dass die Annahme Duchesnes (Dossier, $589 \mathrm{ff}$., vor allem $649 \mathrm{f}$.), es habe ein um 340 entstandenes und noch 411 verwendetes katholisches „Dossier des Donatismus“ gegeben, unhaltbar ist. Duchesne unterscheidet weder die donatistischen von den katholischen Zeugnissen, noch berücksichtigt er die Quellenangaben Augustins, noch findet er eine befriedigende Erklärung, warum einige Akten des postulierten Dossiers niemals von Augustinus zitiert werden. Vgl. hierzu bereits die Kritik bei Seeck, ZKG 30, 1909, 192-198) und Roethe (Synode, 118-123). 
damit zum Ursprung des Schismas. Sie forderten ihn heraus, die Geschichte für die Argumentation heranzuziehen und das donatistische Verständnis von Kirche mit historischen Argumenten zu widerlegen.

\section{Die Entstehungsgeschichte des donatistischen Schismas}

Die Untersuchungen der donatistischen und katholischen Interpretationen zur Entstehungsgeschichte des donatistischen Schismas führen abschließend zur Rekonstruktion der Vergangenheit selbst. In den zahlreichen Darstellungen zum donatistischen Schisma ist der Blick auf den Entstehungskontext der Quellen oftmals zu kurz gekommen. Dies führte zu Verallgemeinerungen oder auch zu problematischen Verengungen der Interpretationen, wie es sich vor allem in den sozialgeschichtlichen Ansätzen zeigte. Die Untersuchungen der neueren Forschung verdeutlichen dagegen auf unterschiedliche Weise, welche Möglichkeiten Detailanalysen von Quellen bieten, um neues Licht auf Einzelheiten der Geschichte des Donatismus zu werfen.$^{54}$ Hier schließen sich die Ergebnisse der vorangegangenen Kapitel an: Die Schriften Augustins sind zweifellos wertvolle Quellen, die bei zahlreichen Fragen zur Geschichte des Schismas verlässliche Antworten bereithalten. Die systematische Verwendung geschichtlicher Argumente in einer zum Teil sehr heftig geführten Kontroverse verlangt jedoch, die Einzelheiten kritisch zu hinterfragen und entsprechend vorsichtig zu urteilen. Bei der Darstellung der historischen Zusammenhänge müssen die Ansatzpunkte der historischen Argumentation beider Seiten mitbedacht werden. Bei Augustinus sind die polemischen Vereinfachungen, die gezielten Verkürzungen und Zuspitzungen sowie - nach der Konferenz von 411 - die Siegerperspektive zu berücksichtigen, bei den Donatisten die ekklesiologisch begründeten Traditionen und die juristisch und apologetisch motivierten Konstruktionen. Die Ergebnisse, die unter diesen Voraussetzungen erarbeitet wurden, seien abschließend zusammengefasst:

Der überlieferte Teil der Konzilsprotokolle von Cirta bestätigt zweifellos, dass sich auf diesem Konzil numidische Bischöfe zur traditio bekannten und dennoch in ihrem Amt verbleiben durften. Dem Vorsitzenden des Konzils, Secundus von Cirta, ging es zu diesen Zeitpunkt lediglich darum, die Voraussetzungen für eine rechtmäßige Weihe des neuen Bischofs von Cirta zu schaffen; der grundsätzliche Umgang mit Traditoren stand hier noch nicht zur Debatte. Erst im späteren Verständnis der Donatisten wurde das Protokoll von Cirta zu einem Rechtfertigungsproblem, da aus ihrer Sicht niemals überführte Traditoren in ihrer Kirche verblieben sein konnten. Sowohl Augustinus, der lediglich einen Beweis für

54 Vgl. o. Kap. 1.2. 
donatistische Traditoren suchte, als auch seine donatistischen Gegner, die das Protokoll als Fälschung betrachteten, waren jedoch nicht mehr in der Lage, Secundus' Entscheidung im geschichtlichen Kontext zu deuten. ${ }^{55}$

Der Prozess des Silvanus von Cirta vor dem Konsular Zenophilus im Jahre 320 zeigt, dass Silvanus nach rigoristischem Verständnis ein Traditor war, da er Gegenstände aus der Basilika in Cirta herausgegeben hatte. Andere Anschuldigungen, die vor Gericht gegen ihn erhoben wurden, wie Diebstahl und Korruption, scheinen dagegen ohne nachweisbare Grundlage erfunden worden zu sein. Bei der Wahl des Silvanus zum Bischof von Cirta wurde ihm seine traditio nicht angelastet. Dadurch lässt sich an diesem Fall ebenfalls erkennen, dass das Vergehen der traditio auch bei Bischöfen der späteren donatistischen Partei ursprünglich differenzierter beurteilt wurde als später, nachdem sich ein rigoristisches Verständnis verfestigt hatte. ${ }^{56}$

Die Informationen über einen interventor, der nach der Weihe Caecilians zwischen den Anhängern und Gegnern Caecilians in Karthago vermittelt haben soll, zeigen, dass in der Anfangsphase des Schismas sehr unterschiedliche Ansichten und Handlungsmotive die Situation bestimmten. Sowohl Kompromissversuche als auch persönliche Machtkämpfe und Bestechung spielten eine Rolle. In den späteren Darstellungen von Katholiken und Donatisten jedoch fehlen zumeist diese Hintergründe und werden zu Gunsten einer Fokussierung auf die Frage der traditio ausgeklammert. ${ }^{57}$

Die traditio-Anschuldigungen der Donatisten gegen afrikanische und römische Bischöfe lassen sich heute kaum verifizieren. Bei Caecilianus und Mensurius von Karthago existieren lediglich Berichte über Verhaltensweisen während der diokletianischen Verfolgung, die aus rigoristischer Sicht nicht hinnehmbar waren, wie Mensurius' Kritik an der Martyriumsbereitschaft von Konfessoren oder die freiwillige Auslieferung häretischer Schriften. Spätere Quellen, in denen die beiden Bischöfe als gewalttätige Märtyrergegner dargestellt werden oder die von Weihrauch- und Evangelienverbrennung sprechen, sind zweifellos Erfindungen. Caecilianus galt jedoch vor allem als Traditor, weil er seine Weihe durch den vermeintlichen Traditor Felix von Abthugni empfangen hatte. Die Anschuldigungen gegen Felix von Abthugni selbst gingen im Wesentlichen auf die offensichtlich falschen Aussagen seines Gegners Ingentius zurück. Höchstwahrscheinlich hatte sich Felix am dies traditionis ähnlich verhalten wie viele andere Bischöfe. Er hinterließ unwichtigere Schriften in der Basilika und verließ selbst die Stadt, um einer möglichen Verhaftung zu entgehen. $^{58}$

55 Vgl. o. Kap. 6.2.1.

56 Vgl. o. Kap. 6.2.2.

57 Vgl. o. Kap. 7.1.2.

58 Vgl. o. Kap. 6.1.1-3. 
Die Anschuldigungen gegen die römischen Bischöfe haben kaum einen historischen Hintergrund, soweit die spärlichen Quellen überhaupt Auskunft geben. Die Anklage gegen Miltiades von Rom war ganz offensichtlich konstruiert, um etwas gegen den Vorsitzenden des Konzils von Rom 313 vorbringen zu können. Die übrigen Vorwürfe gegen die Bischöfe Marcellinus, Marcellus und Silvester sind mit hoher Wahrscheinlichkeit spätere Legenden.

Der von den Donatisten verwendete Begriff „Traditor“ bezog sich folglich nicht notwendigerweise auf eine Bücherauslieferung, sondern wurde vorwiegend als Topos benutzt. Es genügte der kleinste Anhaltspunkt eines Fehlverhaltens bei einem Bischof oder die Verbindung zu einem anderen Traditor, um als solcher gebrandmarkt zu werden. ${ }^{59}$

Die im Frühjahr 313 von den Donatisten durch den Prokonsul Anullinus eingereichte Petition an den Kaiser führte zu einer Ausweitung des Streites über Afrika hinaus. Auch wenn Augustinus in seinen Schriften von einer „Anklage“ gegen Caecilianus spricht, handelte es sich im Kern um eine Beschwerde gegen die kaiserlichen Zuwendungen und Begünstigungen an die pars Caeciliani in Karthago. Die Donatisten forderten die Anerkennung ihrer Gemeinde als rechtmäßige Vertreter der katholischen Kirche ${ }^{60}$ Erst im weiteren Verlauf der Auseinandersetzung wurden die Donatisten in eine Anklägerrolle gegen Caecilianus gedrängt. Das Verhalten des Donatus während der Anhörung vor der Synode in Rom belegt, dass für die Donatisten die Verurteilung Caecilians in Karthago bereits den Fall entschieden hatte. Die römische Synode als „Appellationsinstanz" für Caecilianus lehnten die Donatisten ab und beharrten auf einer Entscheidung des Kaisers. ${ }^{61}$

Bei dem von Optatus von Mileve (I 22) überlieferten Text einer Petition der pars Donati an Konstantin handelt es sich nicht um den Wortlaut der genannten Bittschrift. Allerdings ist dieses Zitat auch nicht als Fälschung zu betrachten; vermutlich gehört es in einen anderen Kontext und wurde von Optatus in den falschen Zusammenhang gebracht. Es ist möglich, dass das Zitat einer Petition entstammt, die unmittelbar vor Beginn der Synode in Rom an den Kaiser gerichtet wurde. $^{62}$

Der Verlauf des donatistischen Streits zwischen dem Konzil von Rom (Herbst 313) und dem Urteil Konstantins (Ende 315) ist aufgrund der Quellenlage mit großen Unsicherheiten behaftet. Dennoch erscheint mir für einen stringenten Ablauf der Ereignisse folgende chronologische Einordnungen sinnvoll zu sein:

59 Vgl. o. Kap. 6.1.4.

60 Vgl. o. Kap. 7.2.

61 Vgl. o. Kap. 7.3.

62 Vgl. o. Kap. 7.2. 
Die von Optatus (I 26) berichtete Untersuchungskommission der Bischöfe Eunomius und Olympius, die sich in Karthago ein Bild von der Auseinandersetzung machen sollten, fand wahrscheinlich im Frühjahr 314 statt. Konstantin hatte zuvor Caecilianus und Donatus die Rückkehr nach Afrika untersagt und in Brescia festhalten lassen, nachdem die Donatisten gegen das Urteil des Miltiades Beschwerde eingelegt hatten (Opt. App. III). Erst nachdem dieser Versuch gescheitert war, eine Lösung für den Streit zu erreichen, entschied Konstantin, erneut Bischöfe über den Fall entscheiden zu lassen, und rief zum August 314 das Konzil von Arles zusammen. ${ }^{63}$

Die Appelle der Donatisten an Konstantin nach dem Urteil des Miltiades führten unter anderem zur Anklageerhebung gegen Felix von Abthugni. Der Prozess vor dem Vikar in Karthago sollte eine Klärung der donatistischen Vorwürfe herbeiführen. Das Urteil zu Gunsten des Felix wurde am 15. Februar 315 gesprochen, die zentralen Anklagepunkte des Ingentius als Fälschung entlarvt (Opt. App. II). ${ }^{64}$

Nach den Appellen der Donatisten an den Kaiser gegen die Entscheidung der Synode von Arles (August 314) unternahm Konstantin verschiedene Versuche, die Donatisten zum Einlenken zu bewegen: Die donatistischen Vertreter von Arles beorderte er an seinen Hof, ebenso sollten aufrührerische Bischöfe aus Afrika zu ihm geschickt werden (Opt. App. V). Im Frühjahr oder Sommer 315 wurde der Prokonsul Probianus aufgefordert, den schuldig gesprochenen Ankläger des Felix von Abthugni, Ingentius, an den Hof zu überstellen, damit dieser die „widerspenstigen“ Donatisten von der Sinnlosigkeit ihres Handelns überzeugen könne (Aug. ep. 88.4). Es ist nicht bekannt, ob dieses Vorhaben durchgeführt wurde.

Nachdem Konstantin über Unruhen in Afrika informiert worden war, kam es ebenfalls im Sommer 315 zu ersten Überlegungen, den Fall selbst anzuhören und zu entscheiden. Offenbar wurde sogar eine Reise Konstantins nach Afrika erwogen, um vor Ort die Sache zu klären. ${ }^{65}$

Aus unbekannten Gründen wurden zwar die Pläne der Afrikareise Konstantins aufgegeben, die Anhörung der causa Caeciliani sollte jedoch durchgeführt werden. Die beiden Streitparteien wurden wohl noch im Sommer 315 nach Rom geladen. Während Donatus zum vorgegebenen Zeitpunkt in Rom erschien, traf Caecilianus nicht ein (Aug. ep. 43.20). Die Donatisten erbaten eine Entscheidung zu ihren Gunsten. Als dies abgelehnt wurde, stellten sie den Antrag, zurückkehren zu dürfen (Opt. App. VI). Am Hof wurde die Möglichkeit erwogen und verworfen, eine Verhandlung in Afrika durch hochrangige

63 Vgl. o. Kap. 7.3.

64 Vgl. o. Kap. 6.1.3.

65 Voraussetzung dieser Chronologie ist die Datierung des Reskripts an Celsus (Opt. App. VII) auf den Juli 315. Vgl. o. Kap. 7.4.1 mit Anm. 143. 
Vertreter durchzuführen. Die am Hof anwesenden Donatisten wurden gezwungen, zusammen mit dem Kaiser im Herbst 315 nach Mailand zu ziehen. Dort traf nun auch Caecilianus ein. Wahrscheinlich im Oktober/November 315 wurde in Mailand die Verhandlung durchgeführt. Konstantin entschied zu Gunsten Caecilians ${ }^{66}$ Dieses Urteil bedeutete mehr als nur eine Entscheidung für die pars Caeciliani in Afrika. Es stellte zugleich einen eindeutigen Ausweis der neuen Phase im Verhältnis der christlichen Kirche zum römischen Staat dar, in der Konstantin das Christentum zum privilegierten Kult emporhob und gleichzeitig nach seinen Vorstellungen beeinflusste und formte.

66 Ep. 43.20; Cresc. III 82; Vgl. o. Kap. 7.4.1. 


\section{Exkurs: Zur Datierung des Konzils von Cirta}

Die Datierung des Protokolls bzw. der Synode von Cirta ist aufgrund der Quellenlage sehr schwierig und nach wie vor umstritten. In den Quellen sind folgende Datierungshinweise enthalten:

1. Optatus überliefert keine Jahresangabe, benennt aber den 13. Mai als Termin und sagt, dass die Verfolgung bereits geendet habe (Opt. I 14).

2. Augustinus zitiert in Cresc. III 30 das Dokument mit der Datierung: Diocletiano VIII et Maximiano VII CSS IIII Non Mart (= 4. März 303). Er gibt ebenfalls an, dass das Konzil post persecutionem abgehalten worden sei (Cresc. III 29).

3. Das von den Katholiken auf der Konferenz in Karthago 411 vorgelegte Dokument war datiert, allerdings findet sich das genaue Datum weder in den Capitula noch bei Augustinus.

4. Der Streit über das Protokoll auf der Konferenz lässt einige Rückschlüsse zu: Die Donatisten forderten den Vergleich der Datierungen ihrer Märtyrerakten ${ }^{1}$ mit dem Protokoll von Cirta, um zu zeigen, dass das Datum der Synode noch in die Verfolgungszeit falle. Augustins Breviculus zufolge gingen die Katholiken zunächst davon aus, dass die Differenz zwischen der Darstellung der Verfolgung in den Märtyrerakten (Februar 304) und der Synode von Cirta ein knappes Jahr (propre annum) bzw. elf Monate betragen habe. Die Überprüfung durch die Sekretäre des Marcellinus habe jedoch ergeben, dass lediglich ein Monat Differenz zwischen den beiden Dokumenten bestand. Entsprechend müssten die beiden Datierungen, die in Karthago gehandelt wurden, wie folgt festgesetzt werden:

a) Katholische Angabe: Januar 305 (nämlich Februar 304 zuzüglich elf Monate),

b) Auskunft des Büros: März 304 (nämlich Februar 304 zuzüglich eines Monats).

5. Augustinus versuchte nach der Konferenz diese Angaben zu erklären (breuic. III 32): gesta martyrum [...] consulibus facta sunt Diocletiano nouies et Maximiano octies pridie Idus Februarias, gesta autem episcopalia decreti Cirtensis post eorundem consulatum tertio Nonas Martias [...]. Während also die Märtyrerakten auf den 14. Februar 304 datieren, sei das richtige Datum für die Synode von Cirta nunmehr der 5. März 305. Dies seien 13 Monate Differenz. Der Zeitraum von einem Monat sei durch den Fehler des Büros entstanden; der Schreiber habe das Wort post überlesen.

6. In den gesta apud Zenophilum (Opt. App. 1) ist die Rede davon, dass Silvanus post pacem zum Bischof ernannt worden sei. Da Silvanus auf der Synode von Cirta gewählt wurde, ist dieser Hinweis zu berücksichtigen.

1 Es handelt sich dabei wahrscheinlich um eine frühere Fassung der „Akten der abitinischen Märtyrer“, die nach der Konferenz in der passio s. Dativi bearbeitet wurden; vgl. o. Kap. 6 Anm. 19. In einigen Handschriften wird die passio auf den 12. Februar 304 datiert. Das ist dasselbe Datum, das Augustinus für die zitierten Märtyrerakten angibt. Vgl. Lancel, REAug 25, 1979, 220. 
Es ergeben sich somit zwei unabhängige Aussagen über den Zeitpunkt des Konzils: Zum einen die von Augustinus überlieferten Datierungen nach Konsul und Tag, zum anderen die Anspielungen bei Optatus und in den gesta apud Zenophilum, denen zufolge die Synode von Cirta in die Zeit nach Beendigung der Verfolgungen gelegt werden muss.

Ein Teil der Forschung akzeptiert Augustins Korrektur aus breuic. III 32 und datiert die Synode auf den 5. März 305. Zwar entstehen daraus die Schwierigkeiten, das genannte Datum mit der Aussage post persecutionem in Einklang zu bringen sowie eine Erklärung für die Datierung nach einem Postkonsulat zu finden, doch scheinen die Einwände nicht so schwerwiegend, als dass sie nicht zurückgewiesen werden konnten. ${ }^{2}$ Serge Lancel hat jedoch überzeugend dargelegt, dass die Angabe aus breuic. III 32 nichts anderes als eine Erfindung Augustins ist. ${ }^{3}$ Folgende Argumente führt er an: Das von den Katholiken in Karthago 411 vorgelegte Dokument habe dasselbe Datum getragen wie Augustins Vorlage bei der Abfassung von Cresc., nämlich den 4. März 303 (Diocletiano VIII et Maximiano VII CSS IIII Non Mart). Wenn Augustinus berichtet, die Katholiken hätten zunächst zwischen den donatistischen Märtyrerakten und dem Konzil von Cirta einen Abstand von elf Monaten festgestellt, dann passe dies vorzüglich zusammen, denn vom März 303 bis zum Februar 304 sind es exakt elf Monate, allerdings hätte das Konzil demnach elf Monate $\mathrm{v}$ o $\mathrm{r}$ und nicht nach den Verfolgungsberichten stattgefunden. Der Schreiber in Karthago habe nun beim Vergleich der beiden Dokumente beim Protokoll von Cirta aus Versehen anstelle des achten Konsulats Diokletians, das neunte gelesen und entsprechend den Zeitabstand zu den Märtyrerakten auf einen Monat festgelegt. Augustinus habe diesen Fehler erkannt und versucht, im Breviculus sowohl eine Erklärung für die Ungereimtheiten zu finden als auch den Lesern ein überzeugendes Datum zu präsentieren. Dazu habe er das Konsulatsjahr in ein Postkonsulat verändert und so einen Abstand von 13 Monaten erzielt und das Konzil auf den 5. März 305 datiert.

Dieser Darstellung Lancels ist zuzustimmen; seine Rekonstruktion erklärt die Abläufe in Karthago 411 bestmöglich. Alle anderen Rechnungen mit den elf Monaten Differenz führen zu Daten, die weder mit Augustins späterem Korrekturversuch noch mit der in Cresc. überlieferten Datierung in Übereinstimmung zu bringen wären. An dem Datum der Märtyrerakten ist nicht zu rütteln, da Augustinus es selbst benennt und jeder Leser seine Angabe leicht hätte

2 Die Argumente sollen hier nicht referiert werden. Vgl. vor allem die Ausführungen von Seeck (ZKG 10, 1889, 526 f.). Vgl. Monceaux IV, 487; Frend, Donatist Church, 12; Lamirande, BA 32, 729; de Veer, BA 31, 797; Grasmück, Coercitio, 17 f.; Schindler, TRE 1, 1977, 653; Fischer, AHC 18, 1986, 285; Y. Duval, Antiquité tardive 3, 1995, 55 63.

3 S. Lancel, Le débuts du Donatisme: la date du „Protocole de Cirta“ et de l'élection épiscopale de Silvanus, REAug 25, 1979, 217-229. 
überprüfen können. ${ }^{4}$ Somit ist eindeutig, dass beide Dokumente nach den Konsulaten Diokletians und Maximians datiert waren. In Karthago wurde letztendlich mit einem Monat Differenz gerechnet, d.h. man ging von der Datierung 5. März 304 für das Protokoll aus. Bei der Kontrolle des Datums muss auf die eine oder andere Weise ein Fehler vorgekommen sein; wahrscheinlicher als das Überlesen des Wortes post ist eine falsch gelesene Haste in der vorliegenden Kopie. Diese These LANCELs lässt sich noch um ein Argument erweitern: Die Katholiken zeigten während der Konferenz eine erstaunliche Eile und Beflissenheit, die abweichende Auskunft des Büros zu akzeptieren und ihre frühere Angabe zu streichen. Eher hätte man doch einen Einspruch erwartet, wenn sich die Katholiken ihrer Sache sicher gewesen wären. Bedenkenswert ist zudem, dass Augustinus in den ebenfalls nach der Konferenz abgefassten Werken c. Don. und c. Gaud. kein Wort über die umstrittene Datierung verliert, obwohl er das Dokument inhaltlich auswertet. ${ }^{5}$ Auch in den Retraktationen verzichtet Augustinus auf eine Korrektur der falschen Datierung in Cresc., ${ }^{6}$ während er einen anderen chronologischen Irrtum hinsichtlich der Reihenfolge der Prozesse gegen Caecilianus und Felix von Abthugni zweimal verbessert. Dies alles deutet darauf hin, dass Augustinus einer Vertiefung der Datierungsfrage aus dem Weg gehen wollte.

Die Datierung des Konzils von Cirta auf den 4. oder 5. März 305 ist somit eine Schöpfung Augustins zur Erklärung der Widersprüche auf der Konferenz von 411. ${ }^{7}$ Es bleibt jedoch die Datierung auf den 4. März 303, die das Dokument getragen hatte. Dass dieses Datum nicht richtig sein kann, ist implizit schon von Donatisten und Katholiken in Karthago festgestellt worden. Die Erlasse Kaiser Diokletians zur Verfolgung der Christen hatten zu diesem Zeitpunkt Afrika noch nicht erreicht; und der dies traditionis in Cirta fand nachweislich erst im Mai 303 statt. Aller Wahrscheinlichkeit nach wurde also das Datum mit Konsulat und Tag nachträglich hinzugefügt, um die Glaubwürdigkeit des Dokumentes zu erhöhen. Da bei Optatus die Jahresangabe fehlt, ist anzunehmen, dass seine Vorlage noch kein entsprechendes Datum enthielt. Augustinus war folglich der erste, der das Protokoll von Cirta mit einer Datierung an die Öffentlichkeit brachte. Auch wenn sich die Donatisten irrten, als sie die Echtheit des Dokumentes bestritten, ihre Kritik an der konsularischen Datierung war

4 An der Richtigkeit dieses Datums für die Vorlage von 411 ändert sich auch dann nichts, wenn man in der heute bekannten Fassung der passio s. Datiui der ebenfalls bezeugten Lesart $X V \mathrm{kl}$. Februarii folgt. In Karthago 411 wurde eindeutig der 12. Februar 304 genannt.

5 C. Don. $18-19$; c. Gaud. I 47.

6 Retr. II 26.

7 So auch Kriegbaum, Kirche der Traditoren, 132; Maier I, 114. Dagegen bleibt Mandouze (PAC, 1078 mit Anm. 8) bei der Datierung auf den 5. März 305, da er Augustins korrigierte Angabe in breuic. III 32 als Ergebnis einer erneuten Recherche betrachtet. 
richtig: Das Protokoll von Cirta besaß ursprünglich wohl keine derartige Angabe. $^{8}$

Ist es dennoch möglich, das Konzil von Cirta zu datieren? Ohne Augustins Datierungen bleiben allein die vagen Angaben, die das Datum mit der Verfolgung in Zusammenhang bringen. S. Lancel und vor allem B. Kriegbaum versuchten eine Neubestimmung des Termins. Entscheidend ist bei jeder Argumentation, welcher Quellenwert den Aussagen post persecutionem bzw. post pacem zugebilligt werden darf bzw. auf welchen historischen Kontext diese Aussagen bezogen werden können. LANCEL geht von der Aussage über die Bischofsweihe des Silvanus biduo post pacem aus und setzt eine Maßnahme voraus, die zur Beendigung der Christenverfolgung geführt hat. ${ }^{9}$ Als Terminus post quem für diesen Frieden benennt Lancel die Abdankung der Kaiser Diokletian und Maximian am 1. Mai 305. Unter Heranziehung der Darstellung von Opt. I 17-18 glaubt er aber, dass sich die pax bei Optatus auf die Toleranz unter Maxentius beziehen müsse, die er zwischen den Oktober 306 und Früjahr 307 datiert. ${ }^{10}$ Insofern könne mit post pacem das Frühjahr 307 gemeint sein, und zu diesem Zeitpunkt habe die Synode von Cirta stattgefunden.

Kriegbaum folgt Lancel in der Interpretation des biduo post pacem; er betont darüber hinaus Optatus' Aussage, dass die Versammlung des Konzils in einem Privathaus stattgefunden habe, da die Basiliken noch nicht wieder zurückgegeben worden seien (Opt. I 14). Allerdings kommt Kriegbaum zu dem Ergebnis, dass Maxentius erst im Frühjahr 308 die vollständige Herrschaft über Afrika besessen und erst nach dem Bruch mit seinem Vater einen Toleranzerlass für die Christen etabliert habe. Ferner sei der Überlieferung des Optatus durchaus zu vertrauen, die den 13. Mai als Datum nennt. Insofern sei das Konzil von Cirta auf den 13. Mai des Jahres 308 zu legen. ${ }^{11}$

Sowohl Lancel als auch Kriegbaum stützen ihre Chronologie auf die von Optatus berichteten Ereigniszusammenhänge. Insbesondere die Datierung der sog. „Affäre Felix“ soll einen begründeten Anhaltspunkt für das Konzil von Cirta sowie die gesamte Chronologie der Anfänge des donatistischen Schismas

8 Vgl. Kriegbaum, Kirche der Traditoren, 133 f. - Kriegbaum, der von der Abhaltung des Konzils unter Maxentius ausgeht, hält auch eine Tilgung der ursprünglichen Datierung aufgrund der damnatio memoriae des Maxentius für möglich.

9 Gesta apud Zenophilum (Opt. App. I 16): biduo post pare. Die Lesart biduo post pacem ist Konjektur von M. Deutsch, der Lancel (REAug 25, 1979; 225 Anm. 37) folgt im Sinne von ,zwei Tage nach dem Ende der Verfolgung“.

10 Lancel, REAug, 25, 1979, 225 f. Möglich sei auch, so Lancel, dass Afrika, nach dem 1. Mai 305 unter der Verwaltung des Constantius den Frieden erhielt, doch lasse sich dies nicht in den Quellen erhärten (226 Anm. 40).

11 Kriegbaum, Kirche der Traditoren, 131-149. 
liefern. ${ }^{12}$ Ohne die Diskussion im Einzelnen darzustellen sind hinsichtlich der Datierungsversuche einige Bemerkungen angebracht:

Die Heranziehung von Opt. App. I 16 zur Datierung der Synode von Cirta halte ich für untauglich. Der Ausschnitt aus den Prozessakten lautet wörtlich:

„Nundinarius sagte: Jedenfalls soll er [ein gewisser Donatus als Zeuge] kommen, von dem das Kirchenvolk zwei Tage nach dem Frieden rief: Erhöre uns Gott! Wir wollen einen Bürger von uns!“13

Der Diakon Nundinarius berichtet hier vor dem Gericht des Zenophilus die Umstände der Bischofswahl in Cirta. Demnach hatte Silvanus mit unlauteren Mitteln seinen Gegner Donatus ausgeschaltet, bevor es zu seiner Weihe und Wahl kam. Ungeachtet dieser Faktoren ${ }^{14}$ ist hier nur von Belang, was die Angabe biduo post pacem tatsächlich aussagt.

Zunächst ist festzuhalten, dass es sich beim Wort pacem um eine Konjektur handelt. Trotz allgemeiner Akzeptanz dieser Konjektur ${ }^{15}$ scheint mir diese Textgrundlage kein guter Ausgangspunkt für weitergehende Datierungsfragen zu sein. Die Aussagekraft bleibt sehr gering, ${ }^{16}$ denn es ist mit großer Unsicherheit behaftet, ob die Aussage ,nach dem Frieden“ mit „nach der Verfolgung" gleichzusetzen ist, und selbst wenn man dies so interpretiert, bleibt fraglich, wann ein solcher Friede in Cirta wirksam geworden ist. Von einer „präzisen Angabe“, aus der Kriegbaum weitere Schlüsse zieht, kann also nicht die Rede sein. ${ }^{17}$

Ebenso problematisch sind die Versuche, Optatus' Aussagen post persecutionem und quia basilicae necdum fuerant restitutae, in domum Urbani Carisi

12 Die „Affäre Felix“ berichtet Optatus (I 17): Ein karthagischer Diakon namens Felix soll ein Pamphlet gegen einen tyrannus imperator verfasst haben. Bischof Mensurius schützte Felix und musste sich deshalb am Hofe verantworten. Von seiner Reise nach Italien kehrte Mensurius nicht mehr zurück. Kriegbaums Versuch, diese Vorgänge genauer zu datieren (Kirche der Traditoren, 135-143), um weitere Rückschlüsse auf die Datierungsfragen zu Beginn des Schismas ziehen zu können, sind letztlich nicht überzeugend.

13 Opt. App. I 16 (ed. Ziwsa, S. 194): utique uenit, de quo clamauit populus biduo post pacem [Hs.: pare]: 'Exaudi, deus; ciuem nostrum uolumus.'

14 Vgl. dazu Kriegbaum, Kirche der Traditoren, 86 f.; Mandouze, PAC, 291, s. v. Donatus 4. - Monceaux (IV 232, 236) identifizierte jenen Donatus von Cirta mit dem vorher erwähnten Dontius. Dafür gibt es jedoch keinen Anhaltspunkt.

15 Die Konjektur wurde von Seeck (ZKG 10, 1889, 527 Anm. 2) verworfen; von Soden (S. 47) führt auch die Lesart post pascha auf.

16 Vgl. Edwards, Optatus, 165 Anm. 86 und Fischer, AHC 18, 1986, 285.

17 Kriegbaum (Kirche der Traditoren, 132): „Eine so präzise Angabe [sc. ,zwei Tage nach dem Frieden'] ist nur dann verständlich, wenn die Verfolgung durch einen formellen Rechtsakt der Reichsregierung eingestellt wurde." Vgl. auch die Kritik Y. Duvals, Fautil voir dans les Gesta apud Zenophilum une mention de la paix de Maxence?, BCTH n. s. $24,1993-95,242-246$. 
consederunt die III. Iduum Maiarum (Opt. I 14) zeitlich präziser zu fassen. Die Angaben deuten zwar in der Tat auf eine allgemeine und nicht allein auf Cirta bezogene Einschätzung der Lage durch Optatus, doch heißt dies nicht, dass damit die in Opt. I 18 angesprochene christianis libertas unter Maxentius gemeint ist, wie etwa Kriegbaum vertritt. ${ }^{18}$ Es bleibt zu fragen, ob nicht doch entweder ein de facto-Friede ausreichte um von post persecutionem zu sprechen, oder ob ein späterer Zeitpunkt, etwa nach dem Ende der Herrschaft des Domitius Alexander, ebenso gut möglich sein kann.

Historisch richtig dürfte die Aussage in Opt. I 14 sein, dass die noch nicht vollzogene Rückgabe der Basiliken der Grund für die Abhaltung der Synode in einem Privathaus gewesen sei. Dennoch hilft dies in der Datierungsfrage nicht weiter, da auch für den Zeitpunkt der Rückgabe von Kirchengütern wenig sichere Informationen existieren. Der Terminus ante quem der Rückgabe der Basiliken in Karthago ist die Wahl und Weihe Caecilians bzw. das Konzil von Karthago, und damit Ereignisse, die sich ebenfalls nicht eindeutig datieren lassen. ${ }^{19}$ Einen weiteren Anhaltspunkt gibt der Brief Konstantins an den Prokonsul Anullinus, in dem die Rückgabe von Kircheneigentum angeordnet wird. ${ }^{20}$ Dieses Schreiben lässt sich nur ungefähr in den Winter 312/13 datieren. Da außerdem Eusebius mitteilt, dass bereits durch Maxentius eine Rückgabe erfolgte, ${ }^{21}$ wird deutlich, dass Erlass und Ausführung zu unterschiedlichen Zeiten erfolgt sein können. Ferner ist zu berücksichtigen, dass es zu regionalen Unterschieden gekommen sein kann. Selbst wenn man für Karthago eine Datierung erhält, so ist die Lage in Cirta noch nicht geklärt. ${ }^{22}$

So achtbar das Bemühen ist, Licht in das Dunkel der Chronologie zu bringen, für die Datierung des Konzils von Cirta helfen die bisherigen Versuche wenig. Wie schon Monceaux erkannte und FISCHER nachdrücklich formulierte, ist es alles andere als sicher, welcher Frieden gemeint war und ob man die Angaben überhaupt mit einem der offiziellen Aufhebungserlasse in Verbindung bringen darf. Der faktische Friede in der Stadt Cirta genügte, um eine Versammlung stattfinden zu lassen. Nicht zuletzt die Katholiken selbst legten in Karthago 411 ausführlich dar, dass sich theoretisch auch während der Verfolgung zwölf Bischöfe in einem Privathaus treffen konnten. Dennoch ist wohl aufgrund der Einführung durch Optatus (I 14) tatsächlich von dem Ende der Verfolgung in Afrika auszugehen. Nicht verlässlich ist dagegen die Stelle in den gesta ad Ze-

18 Kriegbaum, Kirche der Traditoren, $145 \mathrm{f}$.

19 Vgl. o. Kap. 7.1.1.

20 Eus. HE X 5.15-17; Maier I, Nr. 11, 138 f.; von Soden, Nr. 7; vgl. Dörries, Selbstzeugnis, 16; Corcoran, Empire, 153.

21 Eus. HE VIII 14.

22 Für Cirta vgl. Lepelley, Cités II, 384-389. 
nophilum. Die allgemein akzeptierte Konjektur ist sehr problematisch und selbst bei Annahme ohne große Aussagekraft.

Es lässt sich schließlich nur vermuten, dass das Konzil von Cirta in relativer Nähe zu den Verfolgungsereignissen in Numidien stand, da das Verhalten der Konzilsteilnehmer während der Verfolgung zuvor noch nicht diskutiert worden war. Dies bedeutet, eine Datierung 305/6 ist wahrscheinlich, wenngleich nicht zu belegen. 


\section{Abkürzungen}

Monographien werden mit Autor und Kurztitel zitiert, Zeitschriftenaufsätze mit Autor, Zeitschrift, Jahrgang (Ausnahmen unter 2.). Die vollständigen Titel finden sich im Quellen- und Literaturverzeichnis.

Zeitschriften werden in der Regel abgekürzt zitiert nach J. S. Wellington, Dictionary of Bibliographic Abbreviations Found in the Scholarship of Classical Studies and Related Disciplins. Revised and Expanded Edition, Westport/Conn. 2003.

Die Abkürzungen für die Schriften Augustins folgen dem Werkverzeichnis im Augustinus Lexikon [AL], Bd. 1, Würzburg 1994, XXVI-XLI. Sonstige Abkürzungen antiker Autoren und Schriften werden zitiert nach: Der neue Pauly, Enzyklopädie der Antike, hg.v. H. Cancik/H. Schneider, Bd. 1, Stuttgart/Weimar 1996, XXXIX-XLVII.

1. Schriften Augustins

bapt. De baptismo

breuic. Breuiculus conlationis cum Donatistis

cath. fr. Epistula ad catholicos de secta Donatistarum

c. Don. Contra Donatistas liber unus

c. ep. Parm. Contra epistulam Parmeniani

c. Fel. Contra Felicem Manicheum

c. Gaud. Contra Gaudentium Donatistarum episcopum

c. litt. Pet. Contra litteras Petiliani

conf. Confessiones

correct. De correctione Donatistarum liber unus [= ep. 185]

Cresc. Contra Cresconium grammaticum et donatistam

doctr. Chr. De doctrina christiana

Emer. Gesta cum Emerito Donatistarum episcopo

en. Ps. Enarrationes in Psalmos

ep. Epistula

f. et symb. De fide et symbolo

haer. De haeresibus

Io. eu. tr. In Iohannis euangelium tractatus

ps. c. Don. Psalmus contra Partem Donati

retr. Retractationes

s. Sermo

s. Caes. eccl. Sermo ad Caesariensis ecclesiae plebem

trin. De trinitate libri quindecim

uera rel. De uera religione

un. bapt. De unico baptismo 
2. Häufig verwendete Abkürzungen
AL
Augustinus Lexikon, Würzburg
BA
Bibliothèque Augustinienne, Paris
CCL
Corpus Christianorum Latinorum, Turnhout
Conc. Afr.
Conciliae Africae
CSEL
Corpus scriptorum ecclesiasticorum latinorum, Wien
CTh
Codex Theodosianus
Gesta conl. Carth. Gesta conlationis Carthaginiensis anno 411
LACL
Lexikon der antiken christlichen Literatur, Freiburg
Maier
Jean-Louis Maier, Le dossier du Donatisme
Mandouze, PAC
André Mandouze, Prosopographie de l'Afrique chrétienne
Monceaux
Paul Monceaux, Histoire littéraire de l'Afrique chrétienne
Opt.
Perler/Maier Optatus von Mileve
Pietri, PIC
PL
Othmar Perler/J.-L. Maier, Les voyages de saint Augustin
PLRE
Charles u. Luce Pietri, Prosopographie de l'Italie chrétienne J.-P. Migne, Patrologia Latina
Poss.
J. R. Martindale u.a., The Prosopography of the Later Roman Empire
Reg. Carth.
Possidius von Calama
$\mathrm{SC}$
Registri ecclesiae Carthaginiensis excerpta
Sources Chrétiennes, Paris 


\section{Zeittafel}

\begin{tabular}{|c|c|}
\hline Jahr & Ereignis \\
\hline $303-305$ & Christenverfolgungen in den afrikanischen Provinzen \\
\hline Nach 303 & $\begin{array}{l}\text { Briefwechsel zwischen Mensurius von Karthago und Secundus } \\
\text { von Tigisi über die traditio }\end{array}$ \\
\hline $305 / 6(?)$ & Konzil von Cirta: Wahl des Silvanus zum Bischof \\
\hline $309 / 10$ & $\begin{array}{l}\text { Konzil des Secundus in Karthago: Absetzung des Bischofs } \\
\text { Caecilianus und Wahl des Maiorinus zum Bischof von Kar- } \\
\text { thago: Beginn des donatistischen Schismas }\end{array}$ \\
\hline 15. April 313 & $\begin{array}{l}\text { Petition der Donatisten beim Prokonsul Anullinus gegen } \\
\text { Caecilianus (relatio Anullini) }\end{array}$ \\
\hline September/ & Konzil von Rom: Verurteilung des Donatus (iudicium \\
\hline Oktober 313 & Miltiadis) \\
\hline Frühjahr 314 & Untersuchungskommission der Bischöfe Eunomius und \\
\hline$(?)$ & $\begin{array}{l}\text { Olympius in Karthago - Caecilianus und Donatus werden in } \\
\text { Brescia festgehalten }\end{array}$ \\
\hline August 314 & Konzil von Arles: Bestätigung des Urteils von Rom \\
\hline $314 / 15$ & $\begin{array}{l}\text { Prozess gegen Felix von Abthugni vor dem Prokonsul } \\
\text { Aelianus }\end{array}$ \\
\hline Oktober/ & Freispruch Caecilians durch Konstantin in Mailand (iudicium \\
\hline November 315 & Constantini) \\
\hline Um 320 & $\begin{array}{l}\text { Verfolgungen von Donatisten durch die Militärs Ursacius und } \\
\text { Leontius }\end{array}$ \\
\hline $\begin{array}{l}\text { 13. Dezember } \\
320\end{array}$ & $\begin{array}{l}\text { Prozess gegen Bischof Silvanus von Cirta vor dem numidi- } \\
\text { schen Konsular Zenophilus in Cirta }\end{array}$ \\
\hline 321 & $\begin{array}{l}\text { Einstellung der Verfolgung von Donatisten (Reskript Kon- } \\
\text { stantins an Verinus) }\end{array}$ \\
\hline 347 & Verfolgungen von Donatisten unter Macarius \\
\hline $361-363$ & $\begin{array}{l}\text { Kaiser Julian: Toleranz gegenüber allen Religionsgemein- } \\
\text { schaften }\end{array}$ \\
\hline $366 / 7$ & Optatus von Mileve schreibt sein Werk gegen die Donatisten \\
\hline $372-375$ & Herrschaft des Firmus in Nordafrika \\
\hline 391 & Augustinus wird Priester in Hippo Regius \\
\hline 392 & $\begin{array}{l}\text { Tod des donatistischen Bischofs Parmenianus von Karthago - } \\
\text { Nachfolger wird Primianus }\end{array}$ \\
\hline
\end{tabular}


Jahr Ereignis

$392 / 3$

24. Juni 393

8. Oktober 393

393

24. April 394

17. Januar 395

395

395-398

397

Juni und August

397

400/1

404

25. August 403

16. Juni 404

404/5 (?)

12. Februar 405 405/6

23. August 405

30. Januar 406

13. Juni 407

August 408

13. Oktober 408

Herbst 408

409

Frühjahr 410

14. Juni 410

25. August 410

410/11
Aurelius wird katholischer Bischof von Karthago

Konzil von Cabarsussa (Beginn des Maximianistischen Schismas)

Kath. Konzil von Hippo Regius

Psalmus contra Partem Donati

Konzil von Bagaï (Maximianistisches Schisma)

Tod des Kaisers Theodosius: Honorius wird Kaiser im Westen des Reiches

Augustinus wird Bischof von Hippo Regius

Revolte und Herrschaft Gildos in Afrika

epistulae $43 / 44$

Kath. Konzile in Karthago

Contra litteras Petiliani I-II

Ad catholicos fratres

Contra litteras Petiliani III

Kath. Konzil von Karthago

Kath. Konzil von Karthago (Gesandtschaft der Bischöfe Theasius und Evodius zum Kaiser)

Contra epistulam Parmeniani

De baptismo

Unionsedikt des Kaisers Honorius gegen die Donatisten Ad Cresconium grammaticum partis Donati

Konzil von Karthago

Gesandtschaft donatistischer Bischöfe am Hof in Ravenna

Konzil von Karthago (Entscheidung über die Aufnahme konvertierter donatistischer Bischöfe)

Sturz und Tod des Heermeisters Stilicho

Konzil von Karthago (Gesandtschaft der Bischöfe Restitutus und Florentius zum Kaiser)

Brief Augustins an den magister officiorum Olympius (ep. 97) Brief Augustins an den Prokonsul Donatus (ep. 100)

„Toleranzerlass“ gegenüber den Donatisten

Konzil von Karthago (Auseinandersetzung mit der Toleranz für die Donatisten)

Aufhebung des Erlasses zur religiösen Toleranz (CTh XVI 5.51)

De unico baptismo 


\begin{tabular}{ll}
\hline Jahr & Ereignis \\
\hline 1.-8. Juni 411 & Konferenz von Karthago \\
411 & $\begin{array}{l}\text { Breuiculus conlationis cum Donatistis } \\
\text { Post conlationem contra Donatistas }\end{array}$ \\
30. Januar 412 & Unionsedikt des Kaisers Honorius (CTh XVI 5.52) \\
413 & Revolte des comes Heraclianus \\
417 & de correctione Donatistarum (ep. 185) \\
20. September & Treffen Augustins mit Emeritus in Caesarea (Gesta cum \\
418 & Emerito Donatistarum episcopo) \\
Herbst 419 & $\begin{array}{l}\text { Aufstand des donatistischen Bischofs Gaudentius in Thamu- } \\
\text { gadi }\end{array}$ \\
$419 / 20$ & Contra Gaudentium Donatistarum episcopum \\
430 & Tod Augustins \\
\hline
\end{tabular}

Kursiv gesetzt sind die antidonatistischen Schriften Augustins. 


\title{
Quellen- und Literaturverzeichnis
}

\section{Verwendete Quellenausgaben}

\author{
1.1 Augustinus
}

\section{Antidonatistische Schriften}

Sancti Aureli Augustini scripta contra donatistas, ed. Michael Petschenig, 3 Bde.:

- Bd. 1: Psalmus contra Partem Donati, contra epistulam Parmeniani libri tres, de baptismo libri septem, Wien/Leipzig 1908 (CSEL 51),

- Bd. 2: Contra litteras Petiliani libri tres, epistula ad catholicos de secta Donatistarum, contra Cresconium grammaticum libri quattuor, Wien/Leipzig 1909 (CSEL 52),

- Bd. 3: Liber de unico baptismo, breviculus collationis cum Donatistis, contra Partem Donati post gesta, sermo ad Caesariensis ecclesiae plebem, gesta cum Emerito Donatistarum episcopo, contra Gaudentium Donatistarum episcopum libri II, Wien/Leipzig 1910 (CSEL 53).

De baptismo - Über die Taufe, eingel., komm. und hg.v. Hermann-Josef Sieben, Paderborn 2006 (Augustinus Opera - Werke Bd. 28).

Traités anti-donatistes, Vol. I - V, Bibliothèque Augustinienne [BA], Euvres de saint Augustin, Vol. 28-32, quatrième série:

- Vol. I [BA 28]: Psalmus contra partem Donati - Contra epistulam Parmeniani libri tres - Epistula ad catholicos de secta donatistarum, traduction de G. Finaert, introduction et notes par Yves M.-J. Congar, Brügge 1963,

- Vol. II [BA 29]: De baptismo libri VII, traduction de G. Finaert, introduction et notes par G. Bavaud, Brügge 1964,

- Vol. III [BA 30]: Contra litteras Petiliani libri tres, traduction de G. Finaert, introduction et notes par B. Quinot, Brügge 1967,

- Vol. IV [BA 31]: Contra Cresconium libri IV - De unico baptismo, traduction G. Finaert, introductions et notes par A.C. de Veer, Brügge 1968,

- Vol. V [BA 32]: Breuiculus collationis cum Donatistis - Ad Donatistas post collationem - Sermo ad Caesariensis ecclesiae plebem - Gesta cum Emerito Donatistarum episcopo - Contra Gaudentium Donatistarum episcopo libri duo, traduction de G. Finaert, introduction et notes par E. Lamirande, Brügge 1965.

Opere di Sant'Agostino, Nuova Biblioteca Agostiniana XV, Polemica con i Donatista:

- XV/1: Salmo abecedario, contro la lettera di Parmeniano, sul battesimo, introduzione generale di Robert A. Markus, introduzione particolari, traduzione e note di Antonio Lombardi, Rom 1998,

- XV/2: Contro le lettere di Petiliano, lettera ai cattolici sulla setta die Donatisti, introduzione particolari, traduzione e note di Antonio Lombardi, Rom 1999,

- XVI/1: Contro Crescono Grammatica donatista, unicità battesimo contro Petiliano, introduzione particolari, traduzione e note di Eugenio Cavallari, Rom 2002,

- XVI/2: interventi alla conferenza di Cartagine, Sommario della conferenza con i Donatista, Ai Donatisti dopo la conferenza, Discorso ai fedeli della chiesa di 
Cesarea, Atti del confronto con Emerito, contro Gaudenzio, introduzione particolari, traduzione e note di Eugenio Cavallari, Rom 2000.

Anastasi, R., Psalmus contra Partem Donati. Introduzione, Testo critico, Traduzione e Note, Padova 1957.

Lambot, D. C., Texte complété et amendé du „psalmus contra partem Donati“ de saint Augustin, RevBen 47, 1935, 318-328.

\section{Weitere Schriften}

Confessiones [conf.]

- Confessionum libri tredecim, ed. L. Verheijen, Turnhout 1981 (CCL 27).

- Bekenntnise, übers. v. C. J. Perl, Paderborn ${ }^{4} 1955$.

De dialectica [dial.]

- Augustine, de dialectica, ed. B. Darrell/J. Pinborg, Dordrecht/Boston Mass. 1975.

De doctrina christiana [doctr. chr.]

- De doctrina christiana libri quattuor, ed. Joseph Martin, Tournhout 1962 (CCL 32).

- Le magistère chretienne: de catechizandis rudibus, de doctrina christiana, ed./übers. v. G. Combrès /J. Farges, Brügge 1949 (BA 11).

Ennarationes in Psalmos [en. Ps.]

- Ennarationes in Psalmos, ed. E. Dekkers/J. Fraipont, 3 Bde., Turnhout 1955/1956 (CCL 38-40).

- Ennarationes in Psalmos 1-32, ed. C. Weidmann, Wien 2003 (CSEL 93, 1A).

- Über die Psalmen, übers. v. H. U. von Balthasar, Einsiedeln ${ }^{2} 1983$ (Christliche Meister 20).

- Die Auslegung der Psalmen. Christus und sein mystischer Leib, übers. v. H. Weser, Paderborn 1955.

Epistulae [ep.]

- Epistulae, ed. A. Goldbacher, 4 Bde., Wien 1895-1923 (CSEL 34, 44, 57, 58).

- Epistulae ex duobus condicibus nuper in lucem prolatae, ed. J. Divjak, Wien 1981 (CSEL 88).

- Des heiligen Kirchenvaters Aurelius Augustinus ausgewählte Briefe, übers. v. A. Hoffmann, 2 Bde., Kempten/München 1917 (BKV 29/30).

— Augustine, Letters 1* - 29*, übers. v. R. Eno, Washington 1987 (FCh).

— Lettres 1* - 29*, ed. J. Divjak, Paris 1987 (BA 46B).

De fide et symbolo [f. et symb.]

- De fide et symbolo, ed. J. Zycha, Wien 1900 (CSEL 41).

- De fide et symbolo, ed./übers. v. E.P. Meijering, Amsterdam 1987.

In Iohannis evangelium tractatus CXXIV [Io. eu. tr.]

- In Iohannis evangelium tractatus CXXIV, ed. D.R. Willems, Turnhout 1954 (CCL 36).

Contra Iulianum

- Contra Iulianum libri VI [c. Iul.], ed. J.P. Migne, Paris 1865 (PL 44).

- Contra Iulianum opus imperfectum [c. Iul. imp.], ed. M. Zelzer, 2 Bde., Wien 1974/ 2004 (CSEL 85).

Retractationes [retr.]

- Rectractationum libri duo, ed. A. Mutzenbecher, Turnhout 1984 (CCL 57).

- Die Retractationen in zwei Büchern - Retractationum libri duo, übers. v. C. J. Perl, Paderborn 1976 (A. Augustinus' Werke in deutscher Sprache).

Sermones [s.]

— Sermones ad populum, ed. J.P. Migne, Paris 1841/1865 (PL 38/39). 
- Sermones, ed. A. Hamman, Paris 1960 (PLS 2).

- Sermones de Vetere Testamento, ed. C. Lambot, Turnhout 1961 (CCL 41).

- Sermones post Maurinos reperti, ed. G. Morin, Rom 1930 (Miscellanea Agostiniana 1).

- Vingt-six sermons au peuple d'Afrique. Retrouvés à Mayence et commentés par François Dolbeau, Paris 1996 (Collection des Études Augustiennes, Série Antiquité 147).

\subsection{Quellensammlungen}

Corpus Augustinianum Gissense [CAG], ed. C. Mayer, Basel 1996 [überarb. Ausgabe 2005].

Donatist Martyr Stories, The Church in Conflict in Roman North Africa, translated with notes and introduction by Maureen A. Tilley, Liverpool 1996 (Translated Texts For Historians 24).

Duchesne, Luc, Le Dossier du Donatisme, in: Mélanges d'Archéologie et d'Histoire de l'École française de Rome 10, 1890, 589-650.

Maier, Jean-Louis, Le Dossier du Donatisme, 2 Bde., Berlin 1987/1989 (TU 134/135).

Soden, Hans von, Urkunden zur Entstehungsgeschichte des Donatismus, 2. Aufl. hg.v. Hans von Campenhausen, Berlin 1950.

\subsection{Sonstige Quellen}

Ammianus Marcellinus [Amm.]

- Römische Geschichte, ed./übers. v. W. Seyfarth, 4 Bde., Berlin 1968-1971 (Schriften und Quellen der Alten Welt 21).

Athanasius, Apologia secunda [Athan. apol. sec.]

- Athanasius Werke II 1: Die Apologien, ed. H.-G. Opitz, Berlin/Leipzig 1935, 87168.

Aurelius Victor [Aur. Vict.]

- Liber de Caesaribus, Epitome de Caesaribus, ed. F. Pichlmayr, Leipzig 1970.

- Die römischen Kaiser - Liber de Caesaribus, ed./übers. v. K. Groß-Albenhausen/M. Fuhrmann, Zürich 1997.

Claudian [Claud. carm.]

- Carmina, ed. Julius Koch, Leipzig 1893.

- Poèmes politiques (395-398), ed./übers. v. J.-L. Charlet, Paris 2000 (Claudian (Euvres 2).

Codex Theodosianus [CTh]

- Theodosiani libri XVI cum Constitutionibus Sirmondianis, ed. Th. Mommsen/P. Krüger, Berlin ${ }^{2} 1954$.

Concilia Africae

- Concilia Africae A. 345-A. 525, ed. Ch. Munier, Turnhout 1974 (CCL 149).

Concilia Gallia

- Concilia Gallia A. 314-A. 506, ed. Ch. Munier, Turnhout 1963 (CCL 148).

- Conciles gaules du IV ${ }^{\mathrm{e}}$ siècle, ed./übers. v. J. Gaudemet, Paris 1977 (SC 241).

Cyprian von Karthago [Cypr.]

- Epistulae [ep.] 
- Sancti Cypriani Episcopi Epistularum, 2 Bde., ed. G. F. Diercks, Turnhout 1994/1996 (CCL 3B-3C).

- The Letters of St. Cyprian of Carthage, 4 Bde., ed./übers. v. G. W. Clarke, New York 1984-1989 (ACW 43/44/46/47).

- De ecclesiae catholicae unitate [de un. eccl.]

- De ecclesiae catholicae unitate, ed. M. Bévenot/R. Weber, Turnhout 1972 (CCL 3).

Damasus, Epigrammata [Dam. epigr.]

- Damasi Epigrammata, ed. M. Ihm, Leipzig 1895 (Anthologia Latinae supplementa 1).

Eusebius von Caesarea [Eus.]

- Historia Ecclesiastica [HE]

- Kirchengeschichte, ed. E. Schwartz, Leipzig ${ }^{5} 1955$ [= $\left.{ }^{2} 1914\right]$.

- Kirchengeschichte, übers. v. Ph. Haeuser, ed. H. Kraft, Darmstadt 1967.

- Vita Constantini [VC]

- Über das Leben des Kaisers Konstantin, ed. F. Winkelmann, Berlin 1975.

Gesta conlationis Carthaginiensis [gesta conl. Carth.]

- Gesta conlationis Carthaginiensis anno 411, ed. S. Lancel, Turnhout 1974 (CCL 149 A).

- Actes de la conférence de Carthage en 411, ed. Serge Lancel, 3 Bde., Paris:

- Bd 1: Introduction générale, 1972 (SC 194),

- Bd. 2: Texte et traduction de la capitulation générale et des actes de la première séance, 1972 (SC 195),

- Bd. 3: Texte et traduction des actes de la deuxième et de la troisième séance, 1975 (SC 224),

- Bd. 4: Additamentum criticum, notices sur les sièges et les toponymes, notes complémentaires et index, 1991 (SC 373).

Gennadius, de viris inlustribus [Gen. de vir. inl.]

— Liber de viris inlustribus, ed. E.C. Richardson, Leipzig 1896 (TU 14,1).

Hilarius von Poitiers [Hil.]

- S. Hilarius episcopus Pictaviensis opera pars quarta, ed. A. Feder, Wien/Leipzig 1916 (CSEL 65).

Libellus adversus Fulgentium Donatistam [c. Fulg.]

- Libellus adversus Fulgentium Donatistam, ed. M. Petschenig, Wien 1910 (CSEL 53).

- Cyrille Lambot, L'écrit attribué à saint Augustin Adversus Fulgentium donatistam, RevBen 58, 1948, 177-222.

Liber Genealogus [Lib. Gen.]

- Liber genealogus, Chronica minora Bd.1, ed. Th. Mommsen, Berlin 1892 (MGH AA Bd. 9).

Liber Pontificalis [Lib. Pontif.]

- Libri Pontificalis, ed. Th. Mommsen, Berlin 1898 (MGH Gestorum Pontificum Romanorum 1) [ND München 1982].

- Liber Pontificalis, ed. L. Duchesne, Paris 1955.

Notitia Dignitatum [Not. dign.]

- Notitia Dignitatum. Accedunt Notitia Urbis Constantinopolitanae et Laterculi Provinciarum, ed. Otto Seeck, Berlin 1876.

Optatus von Mileve [Opt.]

— S. Optati Milevitani libri VII, ed. C. Ziwsa, Leipzig 1893 (CSEL 26). 
- Optat de Milève, Traité contre les Donatistes, 2 Bde., ed. M. Labrousse, Paris 1995/ 1996 (SC 412/413).

- Against the Donatists, übers. v. M. Edwards, Liverpool 1997 (Translated Texts for Historiens 27).

Origenes, Contra Celsum [Orig. c. Cel.]

- Contre Celse, ed./übers. v. M. Borret, 5 Bde., Paris 1967-1976 (SC 132/136/147/150/ 227).

Orosius, Historiae adversum Paganos [Oros.]

- Historiae adversum Paganos, ed. C. Zangemeister, Wien 1882 (CSEL 5).

- Histoires contre les Païens, ed./übers. v. M.-P. Arnaud-Lindet, 3 Bde., Paris 1990/ 1991.

Passio benedicti martyris Marculi [passio Marculi], ed. J.P. Migne, Paris 1855 (PL 8), $760-766$.

Passio Ss. martyrum Maximiani et Isaac [passio Max et Isaac], ed. J.P. Migne, Paris 1855 (PL 8), 767-774.

Passio sancti Felicis episcopi, ed. H. Delehaye, AnBoll 39, 1921, 268-270.

Passio sanctorum Dativi, Saturnii presbyteri et aliorum [passio Dat.], ed. Fr. de Cavalieri, Studi et testi 65, Rom 1935, 49-71.

Possidius von Calama [Poss.]

- Vita Augustini [vita]

- Vita di S. Agostino, ed. M. Pellegrino, Alba 1955.

- Possidius: Augustins Leben, übers. v. A. v. Harnack, Berlin 1931.

- Possidius, Vita Augustini, ed./übers. v. Wilhelm Geerlings, Paderborn 2005.

- Indiculus [indic.]

- Andrea Wilmart, Operum S. Augustini elenchus a Possidio eiusdem discipulo Calamensi episcopo digestus, in: Studi Agostiniani, ed. Antonio Casamassa, Rom 1931, S. 149-233 (Miscellanea Agostiniana 2).

- Indiculus librorum, tractatum et epistularum sancti Augustini, ed. J.P. Migne, Paris 1865 (PL 46).

Quintilian [Quint.]

- Marcus Fabius Quintilianus, Institutionis oratoriae libri XII - Ausbildung des Redners, ed./übers. v. H. Rahn, 2 Bde., Darmstadt 1972/1975.

Sanctuarium seu vitae sanctorum, ed. B. Mombritius, Bd. 2, Paris 1910.

Sermo de passione sancti Donati episcopi Abiocalensis, ed. J.P. Migne, Paris 1855 (PL 8), $752-758$.

Symmachus, orationes [Sym. or.]

- Quintus Aurelius Symmachus, Reden, ed./übers. v. A. Pabst, Darmstadt 1989 (Texte zur Forschung 53).

Tertullian, Apologeticum [Tert. apol.]

- Tertulliani opera 1, Opera catholica, adversus Marcionem, Turnhout 1954 (CCL 1).

Zosimus [Zos.]

- Historia Nova, ed. L. Mendelssohn, Leipzig 1887.

- Historia Nova, ed./übers. v. F. Paschoud, 3 Bde., Paris 1971-1989.

- Neue Geschichte, übers. v. O. Veh, erläutert v. S. Rebenich, Stuttgart 1990 (Bibliothek der griechischen Literatur 31). 


\section{Verzeichnis der verwendeten Literatur}

Alexander, James S., A Note on the Interpretation of the Parable of the Treshing Floor at the Conference of Carthage of A.D. 411, JThS 24, 1973, 512-519.

- The Motive for a Distinction between Donatus of Carthage and Donatus of Casae Nigrae, JThS 31, 1980, 540-547.

- Aspects of Donatist Scriptural Interpretation at the Conference of Carthage, Studia Patristica 15, 1984 (TU 128), 125-130.

- A Quotation from Terence in the De correctione Donatistarum of St. Augustine, in: Studia Patristica 27 (Papers Presented on the Eleventh International Conference of Patristic Studies in Oxford 1991, hg.v. Elizabeth A. Livingstone) Leuven 1993, 221-224.

- The Goths in St. Augustine's De correctione Donatistarum (= Ep. 185), in: Studia Patristica 33 (Papers Presented at the Twelfth International Conference on Patristic Studies in Oxford 1995, hg. v. Elizabeth A. Livingstone) Leuven 1997, 11-15.

- Count Taurinus and the Persecutors of Donatism, ZAC 2, 1998, 247-267.

- Criteria for Discerning Donatist Sermons, in: Studia Patristica 38, 2001, 3-7.

Alexanderson, Bengt, Adnotationes criticae et interpretationes in libros aliquot Augustini contra Donatistas, ElectronAnt 5 (3), 1999/2000, o. S.

- Collatio Carthaginiensis: konferensen i Karthago år 411, Kyrkohistorisk årsskrift 2002, 9-20.

Alfonsi, Luigi, Unità cattolica e romana nel ,Psalmus contra Partem Donati' di S. A., Studi Romani (Rom) 6, 1958, 407-412.

Altendorf, Erich, Einheit und Heiligkeit der Kirche. Untersuchungen zur Entwicklung des altkirchlichen Kirchenbegriffs von Tertullian bis zu den antidonatistischen Schriften Augustins, Berlin/Leipzig 1932 (Arbeiten zur Kirchengeschichte 20).

Amore, Agostino, Il preteso „Lapsus“ di Papa Marcellino, Antonianum 32, 1957, 411426.

— È esistito Papa Marcello?, Antonianum 33, 1958, 57-75.

Atkinson, J. E. Out of Order: The Circumcellions and Codex Theodosianus 16, 5, 52, Historia 41, 1992, 488-499.

Augustinus-Lexikon [AL], hg.v. Cornelius Mayer, Würzburg 1986 ff.

Augustine through the Ages, an Encyclopedia, hg.v. Allan D. Fitzgerald, Cambridge/ Michigan 1999.

Baker-Brian, Nic, Modern Augustinian Biographies: Revisions and Counter-Memories, ZAC 11, 2007, 151-167.

Bardenhewer, Otto, Geschichte der altchristlichen Literatur, 5 Bde., Freiburg im Breisgau 1913-1932 (ND Darmstadt 1962).

Barnard, Leslie W., The Council of Serdica: some Problems re-assessed, AHC 12, 1980, $1-25$.

- The council of Serdica 343 A.D., Sofia 1983.

Barnes, Timothy D., The Beginnings of Donatism, JThS 26, 1975, 13-22.

- Constantine and Eusebius, Cambridge/London 1981.

- The New Empire of Diocletian and Constantine, Cambridge/London 1982.

- Hilarius on his Exile, VChr 46, 1992, 129-140.

- The Constantinian Settlement, in: Eusebius, Christianity and Judaism, hg.v. W. H. Attridge/G. Hata, Leiden/New York/Köln 1992, 635-657.

- Athanasius and Constantius: Theology and Politics in the Constantinian Empire, London 1993. 
Barnwell, P. S., Emperor, Prefects \& Kings: The Roman West, 395-565, London 1992.

Bartolome-Gil, Juan Carlos, La cuestión donatista en las Enarraciones de los Salmos, Cor Unum 48, 1993, 163-175.

Baus, Karl, Von der Urgemeinde zur frühchristlichen Großkirche, Freiburg/Basel/Wien ${ }^{3} 1965$ (HKG 1).

Baxter, James H., On St. Augustines Psalmus contra Partem Donati, Sacris Erudiri 4, $1952,18-26$.

Beaver, R. P., The Donatist Circumcellions, ChHist 4, 1935, 123-133.

Beddoe, Paul V., Contagio in the Donatists and St. Augustine, in: Studia Patristica 27 (Papers Presented on the Eleventh International Conference of Patristic Studies in Oxford 1991, hg.v. Elizabeth A. Livingstone) Leuven 1993, 231-236.

Beltram Torreira, F.M., Historia y profecia en el Donatismo tardio el liber genealogus, Antigüedad y christianismo 7, 1990, 343-351.

Birley, A. R., Some Notes on the Donatist Schism, Libyan Studies 18, 1987, 29-41.

Bleicken, Jochen, Constantin der Große und die Christen. Überlegungen zur konstantinischen Wende, München 1992 (HZ Beih. N.F. 15).

Blockley, R. C., The dynasty of Theodosius, in: The Late Empire, A.D. 337-425, hg.v. A. Cameron/P. Garnsey, Cambridge 1998 (CAH XIII), 111-137.

Bonner, Gerald, Augustine of Hippo: Life and Controversies, Norwich ${ }^{2} 1986$.

- „Christus sacerdos“: The Roots of Augustine's Anti-Donatist Polemic, in: Signum Pietas, FS Cornelius Mayer OSA, hg.v. Adolar Zumkeller, Würzburg 1989 (Cassiciacum 40), 325-339.

Boojamra, John L., Constantine and the Council of Arles, The Greek orthodox-theological Review 43, 1998, 129-141.

Bralewski, Slawomir, Est-ce que l'empereur Constantin le Grand accorda la tolérance à l'égard des donatistes?, Eos 88, 2001, 127-132.

Brandt, Hartwin, Konstantin der Große. Der erste christliche Kaiser, München 2006.

Brisson, Jean-Paul, Autonomisme et christianisme dans l'Afrique romaine de Septime Sévère à l'invasion vandale, Paris 1958.

Brown, Peter, Augustine of Hippo, London 1967.

- Religion and Society in the Age of St. Augustine, London 1972.

- Christianization and religious conflict, CAH XIII, Cambridge 1998, 632-664.

- Augustine of Hippo (a New Edition with an Epilogue), Berkeley/Los Angeles 2000.

Bruckmayr, A., Studie zu St. Augustins Traktat Contra Cresconium, in: ProfessorenFestschrift zum 400 jährigen Bestande des öffentlichen Obergymnasiums der Benediktiner zu Kremsmünster, Wels 1949, 201-219.

Bruyne, D. de, Les anciennes collections et la chronologie des lettres de saint Augustin, RevBen 43, 1931, 284-295.

Carotenuto, Erica, Six Constantinian Documents (Eus. H. E.10, 5-7), VChr 56, 2002, $56-74$.

Caspar, Erich, Geschichte des Papsttums von den Anfängen bis zur Höhe der Weltherrschaft, Bd. 1: Römische Kirche und Imperium Romanum, Tübingen 1930.

Cavalieri, Pio Franchi de, La „passio“ dei martiri Abitinensi, Studi et testi 65, Rom 1935, 3-71.

Cavallari, Eugenio, Due documenti antidonatisti, Presenza agostiniana 30, 2003, 14-25.

Cecconi, Giovanni A., Elemosina e propaganda. Un'analisi della 'Macariana persecutio' nel III libro di Ottato di Milevi, RÉAug 36, 1990, 42-66.

Chadwick, Henry, Donatism and the Confessions of Augustine, in: Philatropia kai Eusebeia, FS A. Dihle, hg.v. G. W. Most, Göttingen 1993, 23-35.

- New Semons of S. Augustin, JThS 47, 1996, 69-91. 
- Orthodoxy and heresy from the death of Constantine to the eve of the first council of Ephesus, in: The Late Empire, A.D. 337-425, hg.v. A. Cameron/P. Garnsey, Cambridge 1998 (CAH XIII), 561-600.

Clauss, Manfred, Der magister officiorum in der Spätantike (4.-6. Jahrhundert). Das Amt und sein Einfluß auf die kaiserliche Politik, München 1980.

Clercq, Victor Charles de, Ossius of Cordova: A Contribution to the History of the Constantinian Period, Washington 1954.

Corcoran, Gervase, St. Augustine on Slavery, Rom 1985 (Studia euphemeridis Augustinianum 22).

Corcoran, Simon, The Empire of the Tetrarchs: Imperial Pronouncements and Government AD 284-324, Oxford 1996.

Crespin, Rémi, Ministère et sainteté. Pastorale du Clergé et solution de la crise donatiste dans la vie et la doctrine de St. Augustine, Paris 1965 (Études Augustinienne 22) [= Diss. Lyon 1961].

Cross, F.L., History and Fiction in the African Canons, JThS 12, 1961, 227-247.

Curran, John, From Jovian to Theodosius, in: The Late Empire, A.D. 337-425, hg.v. A. Cameron/P. Garnsey, Cambridge 1998 (CAH XIII), 78-110.

Davis, Raymond, Pre-Constantinian Chronology: the Roman Bishopric from AD 258 to 314 , JThS 48, 1997, 439-470.

Dearn, Alan, The Passio S. Typasii Veterani as a Catholic Construction of the Past, VChr 40, 2001, 87-98.

- The Abitinian Martyrs and the Outbreak of the Donatist Schism, JEH 55, 2004, 1 18.

Decker, D. de, La politique religieuse de Maxence, Byzantion 38, 1968, 472-562.

Decret, François, Augustin et l'esclavage, Dialogues d'histoire ancienne 11, 1985, 675685.

Demandt, Alexander, Die Spätantike. Römische Geschichte von Diocletian bis Justinian 284-565 n. Chr., München 1989 (HAW III 6).

De Veer, Albert C., Le date du „De unico baptismo“ de saint Augustin, RÉAug 10, 1964, 35-38.

- L'exploitation du schisme maximianiste par S. Augustine dans sa lutte contre le Donatisme, RechAug 13, 1965, 219-237.

- Une mesure de tolérance de l'empereur Honorius, REByz 24, 1966, 189-195.

Diesner, Hans-Joachim, Die Circumcellionen von Hippo Regius, ThLZ 85, 1960, 497 508 [= Kirche und Staat im spätrömischen Reich, 78-90].

- Die Laufbahn des comes Africae Bonifatius und seine Beziehungen zu Augustin, in: Kirche und Staat im spätrömischen Reich, Berlin 1963, 100-126.

- Kirche und Staat im spätrömischen Reich. Aufsätze zur Spätantike und zur Geschichte der Alten Kirche, Berlin 1963 [2. Aufl. 1964].

- Gildos Herrschaft und die Niederlage bei Theueste (Tebessa), Klio 40, 1962, 178 186.

Digeser, E. D., Lactantius and Constantine's Letter to Arles: Dating the Divine Institutes, JECS 2, 1994, 33-52.

Dihle, Albrecht, Die griechische und lateinische Literatur der Kaiserzeit von Augustus bis Justinian, München 1989.

Dillistone, Frederick W., The Antidonatist Writings, in: A Companion to the study of St. Augustin, hg.v. Roy W. Battenhouse, New York/Oxford 1955, 175-202.

Di Maio, M., The Emperor Julian's Edicts of Religious Toleration, The Ancient World 20, 1989, 99-109. 
Dolbeau, Francois, La ,passion' des martyrs d'Abitnia: remarques sur l'etablissement du texte, Analecta Bollandiana 121, 2003, 273-296.

Dörries, Hermann, Das Selbstzeugnis Kaiser Konstantins, Göttingen 1954 (Abhandlungen der Akademie der Wissenschaften in Göttingen, Phil.-hist. Klasse, dritte Folge Nr. 34).

Doyle, Daniel Edward, Spread throughout the world: hints on Augustine's understanding of Petrine ministry, JECS 13, 2005, 233-246.

Drake, H. A., Constantine and the Bishops: the Politics of Intolerance, Baltimore 2000.

Duchesne, Luc, Le dossier du donatisme, in: Mélanges d'Archéologie et d'Histoire de l'École française de Rome 10, 1890, 589-650.

- Histoire ancienne de l'église, 4 Bde., Paris 1906-1925.

Duval, Yvette, Loca sanctorum Africae. Le culte des martyrs en Afrique du IV ${ }^{\mathrm{e}}$ au VII ${ }^{\mathrm{e}}$ siècle, 2 Bde., Rom 1982 (Collection de l'école française de Rom 58).

- Faut-il voir dans les Gesta apud Zenophilum une mention de la paix de Maxence?, BCTH n.s. 24, 1993-95, 242-246.

- La gesta apud Zenophilum et la „paix de Maxence“, Antiquité tardive 3, 1995, 55 63.

- La gouverneur de Numidie en sa capitale. Le lieu et les acteurs du procès de l'évêque de Cirta en 320, Antiquitè tardive 6, 1998, 193-207.

- Chrétiens d'Afrique à l'aube de la paix constantinienne. Les premiers échos de la grande persécution, Paris 2000 (Collection des Études Augustiniennes, Série Antiquité 164).

Eck, Werner, Der Episkopat im spätantiken Africa. Organisatorische Entwicklung, Herkunft und öffentliche Funktion, HZ 236, 1983, 265-295.

Eno, Robert B., The Work of St. Optatus as a Turning Point in the African Ecclesiology, The Thomist 37, [Washington] 1973, 668-685.

- Doctrinal Authority in Saint Augustine, AugSt 12, 1981, 133-172.

- The Significance of the List of Roman Bishops in the Anti-Donatist Polemic, VChr 47, 1993, 158-169.

- Radix catholica, RÉAug 43, 1997, 3-13.

Errington, R. Malcolm, The Pretorian Prefectures of Virius Nicomachus Flavianus, Historia 41, 1992, 439-461.

- Church and State in the First Years of Theodosius I, Chiron 27, 1997, 21-72.

Evans, Robert Franklin, One and Holy, The Church in Latin Patristic Thought, London 1972.

Feder, Alfred, Studien zu Hilarius von Poitiers, 3 Bde., Wien 1910-1912 (SB der kaiserl. Akademie der Wissenschaften, Phil-hist. Klasse 162/166/169).

Fellermayr, Josef, Tradition und Sukzession im Lichte des römisch-antiken Erbdenkens, Untersuchungen zu den lateinischen Vätern bis zu Leo dem Großen, München 1979 [Diss. München 1979].

Fischer, Joseph A., Die ersten Konzilien im römischen Nordafrika, in: Pietas, FS B. Kötting, hg.v. E. Dassmann, Münster 1980 (JbAC Erg. Bd. 8), 217-227.

- Das kleine Konzil zu Cirta im Jahr 305(?), AHC 18, 1986, 281-292.

Flores Colín, Miguel Santiago, El sermón Dolbeau 26: teología y pastoral en la predicación de San Agustín, Augustinus 51, 2006, 255-272.

Fontaine, Jaques, RAC Suppl. 1/2, 1985, 134-137, 152-177, s. v. Africa II (literaturgeschichtlich).

Frakes, Robert M., Contra Potentium Iniurias, The Defensor Civitatis and Late Roman Justice, München 2001 (Münchener Beiträge zur Papyrusforschung und antiken Rechtsgeschichte 90). 
Frend, W. H. C., The Donatist Church, A Movement of Protest in Roman North Africa, Oxford ${ }^{3} 1983$ [= 11952].

- The Cellae of the African Circumcellions, JThS 3, 1952, 87-89.

- Martyrdom and Persecution in the Early Church: A Study of a Conflict from the Maccabees to Donatus, Oxford 1965.

- Circumcellions and the Monks, JThS 20, 1969, 542-549.

- When did the Donatist Schism Begin?, JThS 28, 1977, 104-109.

- Donatus ,paene totam Africam decepit“ How?, JEH 48, 1997, 611-629.

Gaddis, Michael, There Is no Crime for Those who Have Christ: Religious Violence in the Christian Roman Empire, Berkeley/Los Angeles/London 2005.

Gamber, Klaus, Ordo Missae Africanae - Der nordafrikanische Meßritus zur Zeit des hl. Augustinus, RQA 64, 1969, 139-153.

García Mac Gaw, Carlos, Le problème du baptême dans le schisme donatiste, Paris 2008 (Scripta antiqua 21).

Gaudemet, Jean, L'Église dans l'Empire romaine (IV ${ }^{\mathrm{e}}-\mathrm{V}^{\mathrm{e}}$ siècles), Paris 1958 (Histoire du Droit et des Institutions de l'Eglise en Occident 3).

- La formation du droit séculier et du droit de l'église aux $\mathrm{IV}^{\mathrm{e}}$ et $\mathrm{V}^{\mathrm{e}}$ siècles, Paris ${ }^{2} 1979$.

- Les sources du droit de l'église en occident du $\mathrm{II}^{\mathrm{e}}$ au VII ${ }^{\mathrm{e}}$ siècle, Paris 1985.

Gebbia, Clara, Ancora sulle 'rivolte' di Firmo e Gildone, in: L'Africa romana, Atti del V convegno di studio Sassari, 11-13 dicembre 1987, hg.v. Attilo Mastino, Sassari 1988, 117-129.

Geerlings, Wilhelm, Haeresis und Schisma in den Canones der nordafrikanischen Konzilien von 345-525, in: Ministerium iustitiae, FS H. Heinemann, hg.v. A. Gabriels und H. J. F. Reinhardt, Essen 1985, 161-167.

- Foris inveniatur necessitas nascitur intus voluntas, Augustins Rechtfertigung des Zwangs, in: Universalität und Toleranz, Der Anspruch des christlichen Glaubens, FS Georg Bernhard Langemeyer, hg.v. N. Klimek, Essen 1989, 41-47.

- Augustini Psalmus contra partem Donati. Ein Versuch zur Überwindung der Kirchenspaltung, in: Kirche sein: nachkonziliare Theologie im Dienst der Kirchenreform, FS Hermann Josef Pottmeyer, hg.v. W. Geerlings und Max Seckler, Freiburg/Basel/Wien 1994, 39-65.

- Augustinus - Leben und Werk. Eine bibliographische Einführung, Paderborn u.a. 2002.

Gessel, Wilhelm, Der nordafrikanische Donatismus, Antike Welt 11, 1980, 3-16.

- Die Stadt des Aurelius Augustinus, Augustiniana 40, 1990, 73-85.

Gherro, Sandro, Stato e Chiesa di fronte alla controversia donatista nei primi anni dell'età constantiniana, SDHI 36, 1970, 359-409.

Girardet, Klaus Martin, Appellatio, Historia 23, 1974, 98-127.

- Kaisergericht und Bischofsgericht, Studien zu den Anfängen des Donatistenstreits (313-315) und zum Prozeß des Athanasius von Alexandrien (328-346), Bonn 1975 (Antiquitas 21).

- Konstantin d. Gr. und das Reichsgericht von Arles, in: Oecumenica et Patristica, FS Wilhelm Schneemelcher, hg.v. W. A. Bienert/D. Papandreou/K. Schäferdick, Stuttgart/Berlin/Köln 1989, 151-174.

- Die Petition der Donatisten an Kaiser Konstantin (Frühjahr 313), Historische Voraussetzungen und Folgen, Chiron 19, 1989, 185-206.

- Das Reichskonzil von Rom (313) - Urteil, Einspruch, Folgen, Historia 41, 1992, 104-116.

- Gericht über den Bischof von Rom, HZ 259, 1994, 1-38. 
- Die Konstantinische Wende und ihre Bedeutung für das Reich, Althistorische Überlegungen $\mathrm{zu}$ den geistigen Grundlagen der Religionspolitik Konstantins d. Gr., in: Die Konstantinische Wende, hg.v. E. Mühlenberg, Gütersloh 1998, 9-122.

Gottlieb, Gunther, Die Circumcellionen, Bemerkungen zum donatistischen Streit, AHC 10, 1978, 1-15.

Grasmück, Ernst Ludwig, Coercitio, Staat und Kirche im Donatistenstreit, Bonn 1964 (Bonner historische Forschungen 22) [= Diss. Bonn 1959].

Grünewald, Thomas, Constantinus Maximus Augustus, Herrschaftspropaganda in der zeitgenössischen Überlieferung, Suttgart 1990 (Historia Einzelschriften 64).

Habicht, Christian, Zur Geschichte des Kaisers Konstantin, Hermes 86, 1958, 360-378.

Hahn, Traugott, Tyconius-Studien, ein Beitrag zur Kirchen- und Dogmengeschichte des vierten Jahrhunderts, Leipzig 1900 (Studien zur Geschichte der Theologie und der Kirche 6.2).

Hakizimana, Innocent, Recherches augustiniennes des dernières 35 années sur la controverse antidonatiste: synthèse critique, Teresianum 57, 2006, 335-389.

Hamilton, Louis I., Possidius' Augustine and Post-Augustinian Africa, JECS 12, 2004, $85-105$.

Härtle, Gottfried, Bemerkungen zur Religionspolitik Konstantins I., Klio 71, 1989, 374-382.

Henry, Nathalie, The City and the Thorns: Augustines Refutation of the Donatist Exegesis of the Song of Songs, RÉAug 42, 1996, 255-266.

Hermanowicz, Erika T., Catholic Bishops and Appeals to the Imperial Court, A Legal Study of the Calama Riots in 408, JECS 12, 2004, 481-521.

Herzog, Ernst, Ein Schreiben Augustins über kirchenpolitischen Zwang (Ep. 93), Internationale kirchliche Zeitschrift 6, 1916, 1-26.

Hess, Hamilton, The Early Development of Canon Law and the Council of Serdica, Oxford 2002 (Oxford Early Christian Studies).

Hettinger, Anette, Katholiken und Donatisten, Die afrikanische Kirche im Spiegel der Briefe Gregors des Großen, AHC 24, 1992, 35-77.

Honoré, Tony, The Making of the Theodosian Code, ZRG Rom. Abt. 103, 1986, $133-$ 222.

- Virius Nicomachus Flavianus, Konstanz 1989.

Houlou, R., Le droit pénal chez saint Augustin, Revue historique de droit français et étranger 52, 1974, 5-29.

Instinsky, Hans Ulrich, Bischofsstuhl und Kaiserthron, München 1955.

Joly, Robert, Augustin et la intolérance, Revue Belge de Philologie et d'Histoire 33, $1955,263-294$.

Jones, A. H. M., The Later Roman Empire 284-602: A Social, Economic and Administrative Survey, 3 Bde., Oxford 1964.

- Were Ancient Heresies National or Social Movements in disguise?, JThS 10, 1959, 280-298.

Kaser, Max, Das römische Zivilprozessrecht, München 1966 (HdAW X 3.4).

Kaser, Max u. Karl Hackl [Kaser/Hackl], Das römische Zivilprozessrecht, München 1996 (HdAW X 3.4, 2. Aufl.).

Kaster, Robert A., Guardians of Language: The Grammarian and Society in Late Antiquity, Berkeley/Los Angeles/London 1988.

Kaufmann, Peter Iver, Augustine, Evil, and Donatism: Sin and Sanctity Before the Pelagian Controversy, ThS 51, 1990, 115-126.

Keresztes, Paul, Constantine - A great Christian Monarch and Apostle, Amsterdam 1981. 
Kirchner, Hubert, Der Ketzertaufstreit zwischen Karthago und Rom und seine Konsequenzen für die Frage nach den Grenzen der Kirche, ZKG 18, 1970, 290-307.

Klein, Richard, Die neuen Augustinus-Predigten, Gymnasium 100, 1993, 370-384.

- Die neu gefundenen Augustinus-Predigten aus der Mainzer Stadtbibliothek (Fortsetzung), Gymnasium 102, 1995, 242-262.

- Die neuentdeckten Mainzer Augustinus-Predigten, Gymnasium 103, 1996, 25-31.

- Geschichte und Alltag: $\mathrm{Zu}$ einigen Themen der neugefundenen Predigten aus der Mainzer Stadtbibliothek, in: Studia Patristica 33 (Papers Presented at the Twelfth International Conference on Patristic Studies in Oxford 1995, hg.v. Elizabeth A. Livingstone) Leuven 1997, 140-151.

Kraft, Heinrich, Kaiser Konstantins religiöse Entwicklung, Tübingen 1955.

Kriegbaum, Bernhard, Kirche der Traditoren oder Kirche der Märtyrer? Die Vorgeschichte des Donatismus, Innsbruck 1986 [= Diss. München 1984].

- Ein neuer Lösungsvorschlag für ein altes Problem: die sogenannten preces der Donatisten (Optatus I. 22), Studia Patristica 22, 1989, 277-282.

- Zwischen den Synoden von Rom und Arles, Die donatistische Supplik bei Optatus, AHP 28, 1990, 23-61.

- Die Religionspolitik des Kaisers Maxentius, AHP 30, 1992, 7-54.

- Die donatistischen Konzilien von Cebarsussa (393) und Bagaï (394), ZKTh 124, 2002, 267-277.

Kunzelmann, A., Die Chronologie der Sermones des hl. Augustinus, Miscellanea Agostiniana 2, Rom 1931, 417-520.

La Bonnardière, Anne-Marie, Recherches de Chronologie Augustinienne, Paris 1965 (Collections des Études Augustiniennes, Série Antiquité 23).

Labrousse, Mireille, Le baptême des hérétiques d'apres Cyprien, Optat et Augustin: influences et divergences, RÉAug 42, 1996, 223-242.

- Le Constantin d'Optat de Milève: l'empereur serviteur de Dieu (IV ${ }^{\mathrm{e}}$ siècle), in: Antiquité tardive et humanisme: de Tertullien à Beatus Rhenanus, Mélanges offerts à François Heim à l'occasion de son $70^{\mathrm{e}}$ anniversaire, hg. v. Yves Lehmann/ Gérard Freyburger /James S. Hirstein, Turnhout 2005 (Studia humanitatis Rhenana 2), 237-256.

Lamirande, Émilien, La situation ecclésiologique des donatistes d'apres saint Augustin, Ottawa 1972.

- L'offre conciliatrice des catholiques aux donatistes relativement à l'episcopat (Gesta collationis Carthaginiensis I 16), Église et théologie 2, 1971, 285-308.

- Church, State and Toleration: An Intriguing Change of Mind in Augustine, Villanova 1975 (The Saint Augustine Lecture, 1974).

- Aux origines du dialogue interconfessionnel: saint Augustin et les donatistes: vingt ans de tentatives infructueuses (393-411), Studia canonica 32, 1998, 203-228.

- La Conférence de Carthage (411) et les réactions de saint Augustin: un procès singulier, fatal aux donatistes, Studia canonica 32, 1998, 415-440.

Lancel, Serge, Les débutes du Donatisme, la date du Protocole de Cirta et l'élection épiscopale de Silvanus, RÉAug 25, 1979, 217-229.

- Le sort des évêques et de communentés donatistes après la Conférence de Carthage en 411, in: Internationales Symposion über den Stand der Augustinus-Forschung 1987, hg.v. Cornelius Mayer u. Karl Heinz Chelius, Würzburg 1989 (Cassiciacum 39/Res et Signa 1), 149-167.

- Saint Augustin, Paris 1999.

Langa Aguilar, Pedro, La Autoridad de la Sagrada Escritura en Contra Cresconium, Augustiniana 41, 1991, 691-721. 
- Tolerancia e intolerancia en los escritos antidonatistas de Agustín, Augustinus 51, 2006, 293-321.

Lepelley, Claude, Les cités de l'Afrique romaine au Bas-Empire, 2 Bde., Paris 1979/80 (Collections des Études augustiniennes, Série Antiquité 80/81).

- Augustin dans l'Afrique romaine de son temps: Les continuités avec la cité classique, in: Internationales Symposion über den Stand der Augustinus-Forschung 1987, hg. v. Cornelius Mayer u. Karl Heinz Chelius, Würzburg 1989 (Cassiciacum 39 / Res et Signa 1), 169-188.

Leschi, L., Le dernier proconsul païen de la province d'Afrique (410 apr. J.-C.), in: IIe Congrès national des Sciences historiques, Algier 1930, 253-260.

Liebs, Detlef, Römische Jurisprudenz in Africa, Berlin 1993.

Lietzmann, Hans, Geschichte der Alten Kirche Bde. 3-4, Berlin ${ }^{3} 1961$.

Lippold, Adolf, Bischof Ossius von Cordova und Konstantin der Große, ZKG 92, 1981, $1-15$.

Lohse, B., Augustins Wandlung in seiner Beurteilung des Staates, Studia Patristica VI 6, Berlin 1962 (TU 81).

Lorenz, Rudolf, Circumcelliones - cotopitae - cutzupitani, ZKG 82, 1971, 54-59.

Ludwig, Dagmar Luise, Der sogenannte Indiculus des Possidius. Studien zur Entstehungs- und Wirkungsgeschichte einer spätantiken Augustin-Bibliographie, Diss. Göttingen 1984.

MacMullen, Ramsay, Corruption and the Decline of Rome, New Haven u.a. 1988.

- Changes in the Roman Empire, Princton/New Jersey 1990.

- The Preacher's Audience (AD 350-400), JThS 40, 1989, 503-511.

Madec, Goulven, Introduction aux Revisions et à la lecture de saint Augustin, Paris 1996 (Collection des Études Augustiniennes, Série Antiquité 150).

- Augustin évêque (pour un renouvellement de la problématique doctrinale), in: Augustin prédicateur (395-411), Actes du Colloque International de Chantilliy (5-7 septembre 1996), hg.v. G. Madec, Paris 1998 (Collection des Études Augustiniennes, Série Antiquité 159), 11-32.

Maier, Jean-Louis, Le Dossier du Donatisme, 2 Bde., Berlin 1987/1989 (TU 134/135).

Mandouze, André, L'Afrique chretiénne, Le donatisme et S. Augustine, in: Découverte de Ecuménisme, Paris 1961, 279-297.

- Prosopographie de l'Afrique chrétienne (303-533) [PAC], Paris 1982 (Prosopographie chrétienne du Bas-Empire 1).

- Le mystère Donat, in: Bulletin de la Société Nationale des Antiquaires de France [BSAF], Paris 1982, 98-104.

- Les Donatistes entre ville et campagne, in: Histoire et archéologie de l'Afrique du Nord, Actes du III ${ }^{\mathrm{e}}$ Colloque de Montpellier (avril 1985), Paris 1986, 193-216.

- Augustin et Donat, in: Augustinus Afer: Saint Augustin: africanité et universalité: actes du colloque international, Alger-Annaba, $1-7$ avril 2001, Bd. 1, hg.v. PierreYves Fux / Jean-Michel Roessli / Otto Wermelinger, Fribourg 2003, 125-130.

Markus, Robert A., Saeculum, History and Society in the Theology of St. Augustine, Cambridge ${ }^{2} 1988$.

- From Augustine to Gregory the Great. History and Christianity in Late Antiquity, London 1983.

Marone, Paola, L'esegesi biblica di Ottato di Milevi come veicolo della trasformazione della teologia africana, AnnSE 23, 2006, 217-224.

Marrou, Henri-Irénée, Saint Augustin et la fin de la culture antique, Paris ${ }^{4} 1958$ [ $\left.{ }^{1} 1938\right]$. [dt.: Augustinus und das Ende der antiken Bildung, Paderborn u.a. 1982, übers. v. Lore Wirth-Poelchau]. 
- Histoire de l'éducation dans l'antiquité, Paris ${ }^{2} 1965$.

Martin, Thomas F., „Paulus autem apostolus dicit“ (Cresc. 2.21.26): Augustine's Pauline polemic against the Donatists, Augustiniana, 56, 2006, 235-259.

Martroye, F., La répression du donatisme et la politique religieuse de Constantin et ses successeurs en Afrique, MSNAF 3,1913, 23-140.

- Une tentative de révolution sociale en Afrique: Donatistes et Circumcellions, Revue des questions historiques 32, 1904, 353-416; 33, 1905, 5-53. [RQH]

Matthews, John, The Making of the Text, in: The Theodosian Code: Studies in the Imperial Law of Late Antiquity, hg.v. Jill Harris/Ian Wood, London 1993, 19-44.

Mayer, Cornelius P., Taufe und Erwählung, Zur Dialektik des sacramentum-Begriffes in der antidonatistischen Schrift Augustins: De baptismo, in: Scientia Augustiniana, FS A. Zumkeller, Würzburg 1975, 22-42.

- Legitimation des Rechts bei Augustinus, in: Geschichtliche Rechtswissenschaft, FS Alfred Söllner, hg.v. G. Köblen, M. Heinze, J. Schapp, Gießen 1990 (Gießener Rechtswissenschaftliche Abhandlungen 6), 383-401.

Mazzucco, Clementina, Ottato di Milevi in un seculo di studi, problemi e prospettive, Bologna 1993 (Università degli Studi di Torino, Pubblicazioni del Dipartimento di Filologia Linguistica e Tradizione Classica 3).

McLynn, Neil, Augustine's Roman Empire, AugStud 30, 1999, 29-44.

Meeres, John Reginald, The History of the Donatist Schism, Leeds 1950.

Merdinger, Jane, Augustine and Church Authority: The Developing Role of the Provincial Primate, in: Studia Patristica 33 (Papers Presented at the Twelfth International Conference on Patristic Studies in Oxford 1995, hg.v. Elizabeth A. Livingstone) Leuven 1997, 183-189.

- Rome and the African Church in the Time of Augustine, New Heaven/London 1997.

Migl, Joachim, Die Ordnung der Ämter, Prätorianerpräfektur und Vikariat in der Regionalverwaltung des Römischen Reiches von Konstantin bis zur Valentinianischen Dynastie, Frankfurt 1994 [= Diss. Freiburg 1993].

Millar, Fergus, The Emperor in the Roman World 31BC - AD 337, London ${ }^{3} 2001$.

Mombritius, Boninus, Sanctuarium seu vitae sanctorum, 2 Bde., Paris 1910.

Monachino, Vincenzo, Le origini del donatismo, RSFil 4, 1950/1, 90-118.

- Il primato nello schisma donatista, AHP 2, 1964, 7-44.

Monceaux, Paul, Histoire littéraire de l'Afrique chrétienne, 7 Bde., Paris 1912-1923.

Moreau, Madeleine, Le dossier Marcellinus dans la correspondance de saint Augustinus, RechAug 9, 1973, 3-181 (Collection des Études Augustinienne, Série Antiquité 57).

Morgenstern, Frank, Die Briefpartner des Augustinus von Hippo, Prosopographische, sozial- und ideologiegeschichtliche Untersuchungen, Bochum 1993 [= Diss. Leipzig 1991].

- Die Kaisergesetze gegen die Donatisten in Nordafrika (Mitte 4. Jh. bis 429), ZRG RA 110, 1993, 103-123.

Mühlenberg, Ekkehard, Augustins Predigten, in: Predigt in der Alten Kirche, Kampen 1994, 9-24.

Mühlsteiger, Johannes, Donatismus und die verfassungsrechtlichen Wirkungen einer Kirchenspaltung, ZRG 116, Kan. Abt. 85, 1999, 1-59.

Munier, Charles, L'influence de saint Augustin sur la législation ecclésiastique de son temps, in: Augustinus Afer: Saint Augustin: africanité et universalité: actes du colloque international, Alger-Annaba, 1-7 avril 2001, Bd. 1, hg.v. Pierre-Yves Fux / Jean-Michel Roessli / Otto Wermelinger, Fribourg 2003, 109-123. 
Nash, Ernest, Convenerant in domum Faustae in Laterano. S. Optati Milevitani I, 23, RQA 71, 1976, 1-21.

Noethlichs, Karl Leo, Beamtentum und Dienstvergehen, Zur Staatsverwaltung in der Spätantike, Wiesbaden 1981.

- Die gesetzgeberischen Maßnahmen der christlichen Kaiser des vierten Jahrhunderts gegen Häretiker, Heiden, Juden, Diss. Köln 1971.

Odahl, Charles Matson, Constantine's Epistle to the Bishops of the Council of Arles, JRH 17, 1993, 274-289.

O’Donnell, James J., Augustine: An New Biography, New York 2005.

Opelt, Ilona, Die Polemik in der christlichen lateinischen Literatur von Tertullian bis Augustin, Heidelberg 1980 (Bibliothek der klassischen Altertumswissenschaften N.F. R.2, Bd. 63).

Overbeck, Mechthild, Augustin und die Circumcellionen seiner Zeit, Chiron 3, 1973, 457-463.

Pallu de Lessert, A. Clement, Fastes des provinces africaines, Bd. 2: Bas-Empire, Paris 1901.

Pépin, Jean, Saint Augustin et la dialectique, Paris 1976.

Perler, Othmar u. Jean-Louis Maier, Les voyages de saint Augustin, Paris 1969 (Collections des Études Augustiniennes, Série Antiquité 36).

Picard, Gilbert Charles, La Civilisation de l'Afrique romaine, Paris ${ }^{2} 1990\left[={ }^{1} 1959\right]$.

Piétri, Charles, Das Entstehen der einen Christenheit (250-430), Die Geschichte des Christentums Bd. 2, Freiburg/Basel/Wien 1996 [deutsche Bearbeitung der Histoire du christianisme, t. II: Naissance d'une chrétienté, Paris 1995].

- Luce Piètri, Prosopographie de l'Italie chrétienne (313-604) [PIC], 2 Bde., Paris 1999/2000 (Prosopographie chrétienne du Bas-Empire 2).

Pincherle, Alberto, Il Donatismo, Rom 1960.

Pollmann, Karla, Doctrina christiana. Untersuchungen zu den Anfängen der christlichen Hermeneutik unter besonderer Berücksichtigung von Augustinus, De doctrina christiana, Freiburg/Schweiz 1996 (Paradosis 41).

The Prosopography of the Later Roman Empire [PLRE], 2 Bde., hg.v. A. H. M. Jones/ J. R. Martingale/R. Morris., Bd. 1: A. D. 260-395, Cambridge 1972, Bd. 2: A. D. 395-527, Cambridge 1980.

Quasten, Johannes, Musik und Gesang in den Kulten der heidnischen Antike und der christlichen Frühzeit, Münster 1930 (Liturgiegeschichtliche Quellen und Forschungen 25).

Ratzinger, Josef, Volk und Haus Gottes in Augustins Lehre von der Kirche, München 1954 (Münchener theologische Studien II. Abt. Bd. 7).

Restauration und Erneuerung. Die lateinische Literatur von 284 bis 374 n. Chr., hg.v. Reinhart Herzog, München 1989 (HAW Neubearbeitung 8,5).

Rist, John M., Augustine. Ancient thought baptized, Cambridge 1994.

Rives, J. B., Religion and Authority in Roman Carthage, Oxford 1995.

Roethe, Gerwin, Zur Geschichte der römischen Synoden im 3. und 4. Jahrhundert, Suttgart 1937 [= Diss. Berlin 1936] (Forschungen zur Kirchen- und Geistesgeschichte 11).

Roldanus, Johannes, The church in the age of Constantine: the theological challenges, London 2006.

Röttges, E. H., Marcellinus - Marcellus, Zur Papstgeschichte der diokletianischen Verfolgungszeit, ZKTh 78, 1956, 385-420.

Russel, Frederick H., Persuading the Donatists: Augustine's Coercion by Words, in: The Limits of Ancient Christianity. Essays on Late Antique Thought and Culture 
in Honor of R. A. Markus, hg.v. William E. Klingshirn/Mark Vessey, University of Michigan 1999, 115-130.

Saumagne, Charles, Ouvriers agricoles ou rôdeurs de celliers? Les circoncellions d'Afrique, Annales d'histoire économique et sociale 6 (28), 1934, 351-364.

Saxer, Victor, Morts, martyrs, reliques en Afrique chrétienne aux premiers siècles, Témoignages de Tertullien, Cyprien et Augustin à la lumière de l'archéologie africaine, Paris 1980 (Théologie historique 55).

Scalise, Charles J., Exegetical Warrants for Religious Persecution: Augustine versus the Donatist, Review and Expositor 93, 1996, 497-506.

Schäferdiek, Knut, Der Sermo de passione sanctorum Donati et Aduocati als donatistisches Selbstzeugnis, in: Oecumenica et Patristica, FS Wilhelm Schneemelcher, hg.v. D. Papandreou/W. Bienert/K. Schäferdiek, Stuttgart u. a. 1989, 175-198.

Schindler, Alfred, Die Unterscheidung von Schisma und Häresie in Gesetzgebung und Polemik gegen die Donatisten (mit einer Bemerkung zu Augustins Schrift: Contra epistulam Parmeniani), in Pietas, FS B. Kötting, Münster 1980 (JbAC Erg.-Bd. 8), $228-236$.

- Kritische Bemerkungen zur Quellenbewertung in der Circumcellionenforschung, Studia Patristica 15, 1980, 238-241.

- Vermitteln die neuentdeckten Augustin-Briefe auch neue Erkenntnisse über die Donatisten?, in: Les Lettres de saint Augustin découvertes par Johannes Divjak. Communications presentées au colloque des 20 et 21 Septembre 1982, Paris 1983, 117-121.

- Die Theologie der Donatisten und Augustins Reaktion, in: Internationales Symposion über den Stand der Augustinus-Forschung 1987, hg.v. Cornelius Mayer u. Karl Heinz Chelius, Würzburg 1989 (Cassiciacum 39/Res et Signa 1), 131-147.

- L'Histoire de Donatisme considérée du point de vue de sa propre théologie, Studia Patristica 17, Oxford u.a. 1982, 1306-1315.

- Katholizität bei Augustinus und seinem Umkreis, in: Philanthropia kai Eusebia, FS Albrecht Dihle, hg.v. G. W. Most, Göttingen 1993, 438-453.

Schönebeck, Hans von, Beiträge zur Religionspolitik des Maxentius und Constantin, 1939 (Klio Beih. 43) [ND Aaalen 1962].

Seeck, Otto, Geschichte des Untergangs der antiken Welt, 6 Bde., Berlin/Stuttgart 1895-1913.

- Quellen und Urkunden über die Anfänge des Donatismus, ZKG 10, 1889, 505-568.

- Urkundenfälschungen des 4. Jahrhunderts, ZKG 30, 1909, 181-227.

- Regesten der Kaiser und Päpste für die Jahre 311 bis 476 n. Chr., Stuttgart 1919.

Sève, R., Le loi civile dans la pensée de saint Augustin, Cahiers de philosophie politique et juridique 12, 1987, 31-42.

Simonis, Walter, Ecclesia visibilis et invisibilis, Untersuchungen zur Ekklesiologie und zur Sakramentenlehre in der afrikanischen Tradition von Cyprian bis Augustinus, Frankfurt 1970 [= Diss. Würzburg 1970].

Sirks, Boudewijn, The Sources of the Code, in: The Theodosian Code: Studies in the Imperial Law of Late Antiquity, hg.v. Jill Harris/Ian Wood, London 1993, 45-67.

Soden, Hans von, Urkunden zur Entstehungsgeschichte des Donatismus, 2. Aufl. hg.v. Hans von Campenhausen, Berlin 1950.

Speyer, Wolfgang, Der bisher älteste lateinische Psalmus Abecedarius - Zur Editio Princeps von R. Roca-Puig, JbAC 10, 1967, 211-216.

Springer, Carl P. E., The Artistry of Augustine's Psalmus contra Partem Donati, AugStud 16, 1985, 65-75. 
- The Prosopopeia of Church as Mother in Augustine's Psalmus contra Partem Donati, AugStud 18, 1987, 52-65.

Stein, Ernst, Geschichte des spätrömischen Reiches, Bd. 1: Vom römischen zum byzantinischen Staate (284-476 n. Chr.), Wien 1928.

Steinhauser, Kenneth B., Augustines Reading of the Passio Sanctorum Perpetuae et Felicitatis, in: Studia Patristica 33 (Papers Presented at the Twelfth International Conference on Patristic Studies in Oxford 1995, hg.v. Elizabeth A. Livingstone) Leuven 1997, 244-249.

Steinwenter, Artur, Beiträge zum öffentlichen Urkundenwesen der Römer, Graz 1915.

- Der antike kirchliche Rechtsgang und seine Quellen, ZRG KA 23, 1934, 1-116.

- Eine kirchliche Quelle des nachklassischen Zivilprozesses, in: Acta Congressus Iuridici Internationalis, Bd. II, Rom 1935, 125-144.

- Studien zum römischen Versäumnisverfahren, München 1914.

Stelzenberger, Johannes, Conscientia bei Augustinus. Studie zur Geschichte der Moraltheologie, Paderborn 1959.

Szidat, Joachim, Constantin bei Augustin, RÉAug 36, 1990, 243-256.

Teitler, Hans Carel, Notarii et exceptores, an inquiry into role and significance of shorthand writers in the imperial and ecclesiastical bureaucracy of the Roman Empire, Amsterdam 1985.

Tengström, Emin, Die Protokollierung der Collatio Carthaginensis, Beiträge zur Kenntnis der römischen Kurzschrift nebst einem Exkurs über das Wort scheda (schedula), Göteborg 1962 (Studia Graeca et Latina Gothoburgensia 14).

- Donatisten und Katholiken: Soziale, wirtschaftliche und politische Aspekte einer nordafrikanischen Kirchenspaltung, Göteborg 1964 (Studia Graeca et Latina Gothoburgensia 18).

Tetz, Martin, Ante omnia de sancata fide et de integritate veritatis, Glaubensfragen auf der Synode von Serdica (342), ZNW 76, 1985, 243-269.

The Theodosian Code. Studies in the Imperial Law of Late Antiquity, hg. v. J. Harrie/I. Wood, London 1993.

Tilley, Maureen A., Dilatory Donatist or Procrastinating Catholics: the Trial at the Conference of Carthage, ChHist 60, 1991, 7-19.

- The Bible in Christian North Africa: the Donatist World, Minneapolis 1997.

- From Seperatist Sect to Majority Church: the Ecclesiologies of Parmenian and Tyconius, in: Studia Patristica 33 (Papers Presented at the Twelfth International Conference on Patristic Studies in Oxford 1995, hg.v. Elizabeth A. Livingstone), Leuven 1997, 260-265.

- Sustaining Donatist Self Identity from the Church of the Martyrs to the collecta of the Desert, JECS 5, 1997, 21-35.

- Augustine's unacknowledged debt to the Donatists, in: Augustinus Afer: Saint Augustin: africanité et universalité: actes du colloque international, Alger-Annaba, 1-7 avril 2001, Bd. 1, hg.v. Pierre-Yves Fux / Jean-Michel Roessli / Otto Wermelinger, Fribourg 2003, 141-148.

Thümmel, Wilhelm, Zur Beurtheilung des Donatismus, eine kirchengeschichtliche Untersuchung, Halle 1893.

Thraede, Klaus, Abecedarius, JbAC 3, 1960, 159.

Turner, C. H., Adversaria Critica: Notes on the Anti-Donatist Dossier and on Optatus Books I, II, JThS 27, 1926, 283-296.

Van der Lof, L. F., Warum wurde Tyconius nicht katholisch?, ZNW 57, 1966, 260-283.

- Augustin a-t-il changé d'intention pendant la composition des Retractationes?, Augustiniana 16, 1966, 5-10. 
- Gaudentius de Thamugadi, Augustiniana 17, 1967, 5-13.

- Richtete sich das Gesetz vom 31. Januar 412 gegen die Donatisten?, RÉAug 15, 1969, 163-166.

Van der Meer, F., Augustinus der Seelsorger, Leben und Wirken eines Kirchenvaters, Köln 1951.

Voelter, Daniel, Der Ursprung des Donatismus nach den Quellen untersucht und dargestellt. Freiburg/Tübingen 1883.

Vössing, Karl, Schule und Bildung im römischen Nordafrika, Stuttgart 1996.

Walchs, Christian Wilhelm Franz, Entwurf einer vollständigen Historie der Ketzereien, Spaltungen und Religionsstreitigkeiten, bis auf die Zeiten der Reformation, Vierter Theil, Leipzig 1768.

Warmington, B. H., The North African Provinces from Diocletian to the Vandal Conquest, Cambridge 1954.

- The Sources of Some Constantinian Documents in Eusebius' Ecclesiastical History and Life of Constantine, Studia Patristica 18, 1985, 93-98.

Weidmann, Clemens, Augustinus und das Maximianistenkonzil von Cabarsussi. Zur historischen und textgeschichtlichen Bedeutung von Ennaratio in Psalmum 36,2,18-23, Wien 1998 (SB Öster. Ak. d. Wiss. Phil.-hist. Kl. Bd. 655).

- Pax Christi und Pax Donati. Zu einem Wortspiel bei Augustinus, Wiener Studien 112, 1999, 129-141.

Weissengruber, Franz, Augustins Wertung von Grammatik und Rhetorik im Traktat contra Cresconium, Hermes 105, 1977, 101-124.

Whittaker, Charles R., Land and Labour in North Africa, Klio 60, 1978, 331-362.

Wiemer, Hans-Ulrich, Libanios und Zosimus über den Rombesuch Konstantins im Jahre 326, Historia 43, 1994, 469-494.

Willis, Geoffrey Grimshaw, St. Augustin and the Donatist Controversy, London 1950 [ND 2005].

Winkelmann, Friedhelm, Konstantins Religionspolitik und ihre Motive im Urteil der literarischen Quellen des 4. und 5. Jahrhunderts, Acta antiqua 9, 1961, 239-256.

Wischmeyer, Wolfgang, Die Bedeutung des Sukzessionsgedankens für eine theologische Interpretation des donatistischen Streites, ZNW 70, 1979, 68-85.

Wundt, Max, Zur Chronologie augustinischer Schriften, ZNW 21, 1922, 128-135.

Zarb, S., Chronologia operum Sancti Augustini secundum ordinem Retractationem digesta, Rom 1934.

Zepf, M., Zur Chronologie der antidonatistischen Schriften Augustins, ZNW 28, 1929, $46-61$.

Zwinggi, Anton, Chronologie der Predigten des hl. Augustinus, Augustiniana 20, 1970, $5-34$. 


\section{Personenregister}

Adeodatus, don. Bischof von Mileve 157, 186, 191

Aelafius, vicarius Africae 286, 292, 298-300, 304, 316

Aelianus, proconsul Africae 89, 99, 138, 151, 237-240, 306, 364

Aelius Paulinus, vicarius Africae 237, 305

Alarich, Gotenkönig 51

Alypius, kath. Bischof von Thagaste 44, 108, 110, 114, 129, 158, 165, 222, $224 \mathrm{f}$.

Ambrosius, kath. Bischof von Mailand 26

Anastasius, röm. Bischof 129

Anullinus, proconsul Africae 146, 152, 200, 231-233, 279-281, 284-286, 288, 290, 348, 352, 360, 364

Apringius, proconsul Africae 56, 109

Arbogast, magister militum 17

Arcadius, Kaiser 17, 19, 149

Attalus, Kaiser 51

Augentius, duumvir in Abthugni 238

Aurelius, kath. Bischof von Karthago 21, 28, 30f., 108, 128, 158, 163, 365

Aurelius, kath. Bischof von Macomades 215

Benenatus, kath. Bischof von Simitthus 50,154

Bonifatius, comes Africae 19, 33, 35, 57f., 109

Botrus, Kleriker in Karthago 273

Caecilianus, praefectus praetorio 49, 57, 109, 131

Caelestius, röm. Bischof 108

Candidus, Bischof von Villa Regia 69

Cassianus, röm. Diakon 202, 229, 244

Castorius, kath. Laie aus Bagaï 108

Castus, Diakon in Cirta 254

Celer, kath. Laie 108, 129

Celestius, Kleriker in Karthago 273
Celsus, vicarius Africae 304-307, 309, 316, 353

Centurius, don. Laie 32

Chrestus, kath. Bischof von Syrakus 299f.

Consentius, kath. Laie 108

Constans, Kaiser 19, 37f., 77, 257, 262-264, 266, 269, 340

Crescentianus, Subdiakon in Cirta 254

Cresconius, Grammatiklehrer, Donatist $35,38,46,61-80,82-102,104$, 113-115, 132, 136, 146, 173, 234, 239, 246-248, 251, 253f., 257, 260, 262, 270, 275, 298, 303, 309, 311f., 317, 327, 334f., 341-343, 347, 349

Cresconius, don. Schreiber 158

Crispinus, kath. Bischof von Calama 27, 31, 33, 107f., 116, 132, 261, 331

Cyprian, kath. Bischof von Karthago 11, 31, 59, 64f., 67, 69, 71, 75f., 78f., $87,125,128,160,177 \mathrm{f} ., 212,217$, 232, 297

Deuterius, kath. Bischof von Caesarea 224

Didymus Speretius, duumvir in Karthago 236,238

Diokletian, Kaiser $\quad 1,17,230,233,241$, 356-358

Diotimus, proconsul Africae 37, 41

Dominator, vicarius Africae 26

Domitius Alexander, Usurpator 272, 360

Donatus, Bischof von Bagaï 262-264, $266 \mathrm{f}$

Donatus, Bischof von Calama 93, 213

Donatus, Bischof von Macomades 69

Donatus, Bischof von Mascula 93, 213

Donatus, don. Bischof von Casae Nigrae 293f., 292

Donatus, don. Priester von Mutugenna 56

Donatus, Kleriker in Cirta 254, 259 
Donatus, Namensgeber der Donatisten $1,29,65,76-78,104,114,139$, 148, 204, 208, 219, 258f., 263f., 272, 282, 284, 286, 292-296, 302f., 305, 308, 312f., 315f., 332, 341, 349, $352 \mathrm{f}$, , 359, 346

Donatus, proconsul Africae 42-44, 48, 109,365

Dulcitius, Tribun und Notar, kaiserlicher Sonderbeauftragter 57f., 109

Emeritus, don. Bischof von Caesarea 21, 46, 55f., 107, 115-119, 132, 157, 162f., 166, 168f., 171f., 175, 177, 179, 184-187, 191, 222-227, 335, 339, 366

Eugenius, Flavius, Kaiser 17

Eumalius, vicarius Africae 100f., 134, 143, 174, 202f., 206f., 298, 300, 309f., 321, 328, 347

Eunomius, kath. Bischof 45, 236, 313-315, 317, 349, 353, 364

Eusebius, röm. Beamter in Hippo 109, 112

Eusebius, von Caesarea 134, 284, 291, 301, 326, 346, 349, 360

Eusebius, röm. Bischof 242

Evodius, kath. Bischof von Uzalis 32, $36,44,365$

Faustinus, kath. Bischof von Thuburbo 236, 273

Felicia, kath. Laie 108

Felicianus, don. Bischof von Musti 73, 130, 211, 217, 325

Felix, Diakon in Karthago 272

Festus, röm. Beamter in Africa 109, 129f., 145, $150 \mathrm{f}$.

Filuminus, Donatist 313, 316

Firmus, maurischer Fürst, Usurpator 18, 21f., 26, 28, 125, 364

Flavianus, Virius Nicomachus, vicarius Africae, praefectus praetorio 21, 26, 116

Florentius, kath. Bischof 44, 50, 365

Fortunatianus, kath. Bischof von Sicca 158, 170, $181 \mathrm{f}$.

Fortunatus, kath. Bischof von Cirta $129,158,245$
Fortunius, don. Bischof von Thubursicum 29, 76f., 109f., 112 115, 119, $132,262,276 \mathrm{f}$.

Fulgentius, don. Autor 59, 234

Galatius, Christ aus Abthugni 237, 239

Gaudentius, don. Bischof von Thamugadi $57-59,157,335,366$

Geiserich, König der Vandalen 19

Generidus, magister militum 52

Genethlius, kath. Bischof von Karthago 21

Gennadius 340

Georgius, proconsul Africae 59

Gildo, comes Africae 18f., 21-23, 26-28, 43, 331, 365

Gratian, Kaiser 17, 25f., 28, 148

Gratus, kath. Bischof von Karthago 28, 77, 263

Gregor I., Papst 60

Hadrianus, praefectus praetorio $37-40$

Heraclianus, comes Africae 19, 50f., 57,366

Herotes, don. Laie 108

Hesperius, proconsul Africae 26

Hilarius, kath. Bischof von Poitiers und Autor 77, 125

Honoratus, don. Bischof in Numidien 107, 116, 132

Honorius, Kaiser 17, 19, 26, 36f., 40-43, 48, 50-52, 54, 57, 145, 149, 154f., 175, 331, 338, $365 \mathrm{f}$.

Ianuarianus, don. Bischof von Casae Nigrae 35f., 107f., 118f., 145-147, $151 \mathrm{f}$.

Ianuarius, don. Schreiber von Sifitis 158

Ianuarius, Subdiakon in Cirta 154

Ingentius, Schreiber in Abthugni 88f., 91, 99-101, 138, 203, 205f., 237-240, 306, 341, 348, 351, 353

Iovius, praefectus praetorio $\quad 43,51$

Isaac, don. Laie und Märtyrer 38, 262-265

Iulianus, proconsul Africae 25, 54, 57

Jovian, Kaiser 148 
Julian, Kaiser $\quad 20,25,28,40,125,127$, 148f., 266, 269, 340, 364

Julian von Eclanum 59

Konstantin, Kaiser $1,8,13,37,88,91$, 97, 99-103, 105, 132, 134f., 141-152, 170, 174f., 193f., 200, 202-208, 221, 235-237, 257f., 261, 269f., 278f., 281-287, 289-292, 296-312, 314-329, 335, 338, 341f., 344-349, $352-354,360,364$

Leontius, comes $\quad 257-261,266,364$

Licinius, Kaiser 310, 319

Lucilla, Laie in Karthago 94f., 140, 255, 273f., 276

Macarius, kaiserlicher Sonderbeauftragter Seiten s.u.

Macarius, Opfer der Donatisten 44

Macarius, kaiserlicher Sonderbeauftragter 20, 23, 28, 81f., 113f., 257f., 262-267, 272, 339, 346, 364

Macedonius, vicarius Africae 57, 109

Macrobius, don. Bischof von Hippo Regius 50, 107f., 264

Macrobius, proconsul Africae 51

Magnus Maximus, Usurpator 17

Maiorinus, don. Bischof von Karthago 1, 29, 84, 91, 95, 139f., 146, 198, 208, 254, 270, 272f., 276, 281, 284f., 364

Marcellinus, kaiserlicher Tribun und Notar 44, 46, 51, 54, 56f., 109, 154-159, 161-167, 169-183, 185-190, 192-198, 200-210, 214-216, 218f., 225, 288, 320, 337f., 355

Marcellinus, röm. Bischof 229, 240-242, 244f., 352

Marcellinus, Tribun 259f.

Marcellus, röm. Bischof 55, 173, 211

Marcellus, röm. Bischof 229, 240-242, 352

Marcianus 49, 271, 274

Marculus, don. Bischof und Märtyrer $80,82,262,265 \mathrm{f}$.

Marcus 49, 134, $291 \mathrm{f}$.

Marinus, Bischof von Aquae Tibilitanae 93
Marinus, Bischof von Arles 134, 291, 301

Marinus, comes 57

Maternus, Bischof von Köln 134, 291

Maurus, Bischof von Utica 238

Maxentius, Kaiser 201, 242, 272, 358, 360

Maximian, Kaiser 20, 242, 272, 357f.

Maximianus, Bischof, Gründer der Maximianisten $25,80,102-106,213$, 217,225

Maximianus, don. Laie und Märtyrer 262, $264 \mathrm{f}$.

Maximianus, kath. Bischof von Bagaï 34-37

Maximinus, don. Bischof später kath. Priester von Siniti 46, 49f., 107

Maximinus, don. Bischof von Hippo Regius 26

Mazciel, maurischer Fürst 19

Menalius, don. Bischof 247, 306

Mensurius, kath. Bischof von Karthago 173, 187, 196f., 229-236, 238, 240, 244, 250, 272, 280, 337, 339f., $342,351,359,364$

Miltiades, röm. Bischof 134, 138f., 147, 174, 187, 200-202, 207f., 216, 218, 229, 240-245, 280, 283, 286, 290-293, 295-298, 300-302, 312, 315, 318, 337, 341, 344, 346, 352f.

Montanus, don. Bischof von Zama 157, 184

Munatius Felix, curator civitatis in Cirta 255

Naucellio, don. Laie aus Thabraca 108

Novatus, kath. Bischof von Sitifis 108

Novellus, kath. Bischof von Thizica 236, 273

Nubel, maurischer Fürst 18

Nundinarius, Diakon in Cirta 95, 247-250, 253-256, 359

Olympius, kath. Bischof 236, 313-315, 317, 349, 353, 364

Olympius, magister officiorum $42 \mathrm{f}$, 47-49, 51f., 109, 131

Optatus, don. Bischof von Thamugadi $27,33,58,66,72-74,80-82,96,112$, 116f., 120, 124, 331 
Optatus, kath. Bischof von Mileve 6,9, $13,15,20,23,88,99,101,104,151$, 173f., 199, 204, 209, 213, 221, 230, $237,242,247-250,253,257 \mathrm{f}$., 260-264, 266-268, 271-279, 281-284, 291f., 295, 298-300, 304, 311-317, 319, 321, 328, 342, 344-347, 349, 352f., 355-361, 363f.

Ossius, Bischof von Cordova, Berater Konstantins 257, 292, 322, 324-327, 341

Pammachius, Senator 108

Parmenianus, don. Bischof von Karthago $10,20,24,31,61,230,243,257$, 280, 298, 303, 311, 322-327, 332, 340-342, 349, 364

Paulus, Bischof von Cirta 95, 231, 255

Paulus, kaiserlicher Sonderbeauftragter 263-267

Paulus, kath. Bischof von Cataqua 108

Petilianus, don. Bischof von Cirta 7, 10, 30, 32, 44, 46f., 61f., 64, 67, 69, 71-74, 80, 82, 84-87, 89-92, 115, 117, 130, 132f., 146, 157, 163f., 166, 168, 170-173, 175, 178f., 181f., 185-187, 191, 214, 229f., 234, 242, 244f., 252, 257, 262, 267f., 332, 341-343, 347, 349

Pontius, don. Bischof 148f.

Porphyrius, proconsul Africae 41

Possidius, kath. Bischof von Calama 5, 20, 23, 31, 49f., 58, 61, 108, 116, 126, $154,158,215,222,224,226,363$

Praesidius, kath. Bischof in Numidien 50,154

Praetextatus, don. Bischof von Assuras $73,129 \mathrm{f} ., 325$

Primianus, don. Bischof von Karthago 20, 24f., 31, 46, 102-104, 157, 165, 179, 187, 199, 213, 287, 325, 364

Probianus, proconsul Africae 99-101, 151f., 175, 205-207, 209, 236, 240, 304, 306, 311, 321, 335, 342, 348, 353

Proculeianus, don. Bischof von Hippo Regius 29, 31, 107, 112

Profuturus, kath. Bischof von Cirta 245

Protasius, don. Bischof von Tubunae 157
Purpurius, Bischof von Liniata $93 \mathrm{f}$. 136, 197, 247, 249f., 255

Quodvultdeus, don. Bischof von Cissi 211

Restitutus, kath. Bischof 44, 49, 365

Restitutus, kath. Diakon 128

Reticius, Bischof von Autun 134, 291

Rogatianus, don. Bischof 148f.

Rogatus, Bischof von Cartenna 125, 127

Romanus, comes Africae 18, 266

Rufinianus, Schreiber 165

Rufinus, praefectus praetorio $\quad 26,38$

Saturninus, Friedhofsgräber in Cirta 254

Secundus, Bischof, Neffe des Secundus von Tigisi 93f., 247

Secundus, Bischof von Tigisi, Primas Numidiens 1, 84, 92-94, 96f., 111, 133-137, 140, 196-198, 200, 208, 213, 228, 230-232, 235f., 246f., 249-252, 271f., 275-277, 293f., 340, 342f., 350f., 364

Seleucus, praefectus praetorio 54

Septiminus, proconsul Africae 30, $171 \mathrm{f}$.

Servus, kath. Bischof von ThubursicumBure $35 \mathrm{f}$.

Severinus, don. Laie 116, 132

Severus, Opfer der Donatisten 44

Silvanus, don. Bischof von Cirta 13, 84-87, 90-97, 133, 145, 215, 247-250, 252-257, 270, 306, 334, 341, 343f., 347, 349, 351, 356, 358f., 364

Silvanus, kath. Bischof von Summa, Primas Numidiens 158

Silvester, comes 264

Silvester, röm. Bischof 229, 240, 242f., 245, 299, 301, 352

Siricius, römischer Bischof 29

Stilicho, magister militum 17, 19, 41, 43, 47f., 51, 365

Straton, röm. Diakon 201f., 229, 244

Tatianus, praefectus praetorio 33 
Taurinus, comes Africae 14, 18, 266-268

Theasius, kath. Bischof von Memblone $32,36,44,365$

Theodorus, kath. Laie 108

Theodorus, praefectus praetorio $41 \mathrm{f}$.

Theodosius, Flavius 18

Theodosius I., Kaiser 17f., 26, 32, 148f., 365

Theodosius II., Kaiser 41

Tyconius, don. Schriftsteller 20, 31, $128,272,322,349$

Ursacius, dux 85f., 257-261, 266, 364

Ursus, röm. Beamter 161

Valens, comes domesticorum 52

Valentinian I., Kaiser 25, 28, 148

Valentinian II., Kaiser 17, 26

Valentinian III., Kaiser 59
Valentinus, kath. Bischof 45

Verinus, vicarius Africae 148, 175, 204, 221, 258, 311, 318-322, 342, 364

Victor, Bischof von Russicade $93 \mathrm{f}$.

Victor, don. Schreiber 158

Victor, Grammatiklehrer und Lektor in Cirta 254

Victor, Handwerker in Cirta 254

Victor, kath. Bischof 44

Victorianus, kath. Priester 108

Vincentius, Bischof der Rogatisten von Cartenna 47, 107f., 125-128, 145, 147, 149, 151

Vincentius, kath. Bischof von Culusi 158

Vitellius, don. Schriftsteller 340

Zenophilus, Konsular Numidiens 85-87, 95f., 247f., 253f., 256f., 343, $351,359,364$ 



\section{Sach- und Ortsregister}

acta 87, 90, 95, 99, 133, 135, 138, 155, $181,205,231,237-239,242,248$, 254f., 346, 349

Archiv 31, 33, 46f., 97, 99, 201, 220, 248, 279f., 309, 318, 342, 344, 346-349

Arles/Konzil von Arles 1, 13, 88f., 101, 105f., 132, 134-136, 143-145, 147, 202, 208, 235, 242-244, 270, 283, 290f., 298-305, 308-310, 312, 314, 323-328, 341, 344, 353

Brescia 88, 99-101, 203-205, 300, 304, $312-317,321,328,345,353$

Byzacena 17f., 25, 157

causa Caeciliani 7, 84, 91f., 97, 99f., 102-104, 111, 132, 134, 136, 141, 143-146, 159-161, 168, 185, 191, 193, 195, 200, 203-205, 207, 214, 217 , 220f., 228, 258, 270, 278f., 281, 287, 290f., 295, 300, 302, 304, 307-309, 315f., 319-323, 325, 327, 334, 338, 341-344, 346, 348, 353

causa ecclesiae 159, 160, 172, 178, 185, 188-193, 207f., 212, 214, 216f., 337

causa Felicis 84, 138, 151, 205f., 220f., 238f., 318, 320, 325, 348

causa Silvani $84-86,92,96,101,130$, 145, 248f., 260

Christus 70-72, 120, 122f., 216, 226

Circumcellionen 23f., 28, 32, 34, 50, 56, 80f., 108, 112, 118, 123, 124f., 219, 263, 266-268, 278, 331

Cirta 7, 17, 30, 47, 55f., 62, 84f., 87, 91, 108, 110, 129f., 133, 145, 157f., 173, 231, 252-257, 334, 341, 343f., 346f., $350 \mathrm{f}$.

- Konzil von Cirta 92-97, 111, 133, 135-138, 145, 173f., 195-198, 213, 215, 230, 245-252, 256, 343, 346, 355-361

- Protokoll von Cirta 13, 93-95, 133, 135f., 173f., 195f., 198, 200f., 207f.,
$213,215,218,245-252,256,335,346$, 349f., 355-358

Codex Theodosianus 6, 24-26, 37, 50f.

coercitio (Zwangsgewalt) 11, 13, 29, 35f., 57f., 80, 119, 123-131, 148, 210, $224,261,265,307,318,325,332-334$, 339,345

Constantina s. Cirta

Einrede 162-164, 168, 176, 179-186, 188-190, 212, 218, 220-222, 296, 336f.

Ekklesiologie 2, 11, 31, 65, 71, 115, $178,183,186,188,193,202,209,252$, 290, 297, 301

- donatistische Ekklesiologie 73, 86, 178, 212, 290, 337, 343, 350

- katholische Ekklesiologie 128, 160, 194, 217

Eunomianer 32

Exil 19, 39f., 44, 50, 54, 85f., 88, 96, 99-101, 205, 242, 256-258, 315, 317f., 321, 331

Gesetz 6, 25-28, 32-55, 58f., 63, 79-81, 109, 116, 118f., 121-127, 130f., 145-151, 154, 163, 178, 185, 191, 258, 261, 263f., 269, 311, 318, 331, 333, 345

gesta apud Zenophilum 87, 94f., 133, 136, 140, 247-249, 253, 255, 347, 349, $355 \mathrm{f}$, , 358f.

Goten 19, 51, 57

Häresie/Häretiker 25-28, 32-36, 38-44, 47, 49f., 54, 59, 64, 69-71, 75-77, 79, 81, 96f., 127f., 148, 154, 159, 212, 231f., 294, 301, 331, 351

Heilige Schrift 1, 3, 65, 68, 78, 94, 99, 108, 116, 122-125, 128, 130, 159f., 163f., 169, 171f., 177f., 181, 185-187, 189-191, 217, 219, 221f., $229,231,235,238,255,301,337$ 
Hippo Regius 2, 28-30, 49, 50, 55, 56, 107-109, 112f., 118, 121, 125, 130, $345,347,364 \mathrm{f}$.

iudicium Constantini 88, 91, 101, 103 , 105f., 141-150, 174f., 193f., 202-204, 206f., 258, 270, 303-311, 314f., 321f., 327-329, 354

iudicium Miltiadis 139, 174, 200f., 207, 243-245, 292, 295-298, 302f., 309, $312,315,318,341,353$

Konferenz von Karthago 6f., 15, 21, 54, 108f., 118, 153ff., 239f., 247, 269 , 277, 311f., 321, 327, 332, 335-339, 342,348

Konfiskation 19f., 26, 38, 40, 52, 147, $264,284,311$

Konzil

- Konzil von Arles s. Arles

- Konzil von Cirta s. Cirta

- Konzil (des Secundus) von Karthago 86f., 89, 93f., 97, 101, 105, 132-145, 173, 195f., 209, 213, 228, 235f., 238, 246, 251f., 263, 270-275, 285f., 293f., 296, 334, 338, 340-344, 349,360

- Konzil von Rom 1, 88f., 101, 104-106, 134-147, 150, 195, 200f., 207, 278, 283, 290-299, 304, 309, 315, $323,325,346,348 f$. , 352

Litisdenuntiationsprozess 180f., 184, 190, 285

Mailand 17, 33, 142-144, 203, 291, 304, 309f., 323, 354

Mandat 155-159, 162-166, 168f., 172, 176-191, 193, 195, 199, 207, 211f., 217, 219f., 222, 258, 336

Manichäer 26, 37f., 40, 245

Märtyrer 4, 7, 14, 22f., 31, 58f., 80, 82, 86, 122f., 150, 197, 219, 223, 231-235, 259-262, 264-269, 306, $319,322,351$

Märtyrerberichte 14f., 20, 36, 197f., 232-235, 241, 244, 263-266, 269, $320,340,355 \mathrm{f}$.

Mauretanien 18, 20, 45, 115, 125, 222, 237,331
Maximianisten 22, 25, 27, 56, 62f., 65, 72-74, 80, 82f., 97, 102f., 106, 114, 116f., 120, 124, 127, 130, 149, 156, 160, 187, 214, 218f., 225, 287

Numidien 1, 17f., 20, 23, 35, 44f., 53, 56, 60, 109, 118, 157f., 215, 231, 237, 248, 265, 331f., 361

praefectus praetorio $26,33,38,40-43$, 45, 54, 57

proconsul Africae 18, 25-27, 30f., 35, 37, 42-44, 48, 51, 54, 56f., 59, 88f., 99, 109, 138, 146, 151, 171f., 175, 200, 205-207, 231, 233, 236-240, 265, 279-281, 284f., 288, 304, 306, 311, 319, 346, 348, 352f., 360

Protokoll von Cirta s. Cirta

Ravenna 32, 34, 37, 41, 44-46, 49, 52, $118,170,288$

relatio Anullini 146, $151 \mathrm{f} ., 170,172$, $185,191,193,200,207,221,279-282$, 285-291, 344, 348, 352

Rogatisten 21, 107, 125-129, 145

Rom 1, 13f., 19, 32-37, 40, 51f., 77, 88f., 95, 101, 104-106, 132, 133-136, 138f., 141-147, 150, 155, 193, 199-201, 204, 207, 229, 235f., 241-245, 264, 270, 273, 283f., 287f., 290-294, 296-300, 302, 306-310, 313, 315f., 323-327, 327, 341f., 346, $348,352 \mathrm{f}$.

Sakrament $70-73,117,123,125,223$, $234,250,275$

Serdica $76-78,105,114,263$

Taufe 3, 25-28, 31f., 38-40, 45, 47, 64-66, 69-76, 79, 84, 108, 111, 115, 117, 120, 123, 160, 212, 223f., 226, 229f., 293, 296, 301, 310, 331f.

Thamugadi 21, 23f., 27, 33, 56, 58, 66, $72,74,80-82,96,112,117,120,157$, 261, 331

Thubursicum 29, 35, 77, 109f., 112f., $132,134,136,138,239,248,271,276$, 278, 290, 309

Toleranzedikt von $410 \quad 50-53,365$

Trier 291, 299, 305f., 310 
Unionsedikt von 405 25, 27f., 37, 40f., vicarius Africae 18, 21f., 26, 30f., 38, 43, 46f., 49, 53, 63, 80, 116, 118f., 121, 130f., 145, 153, 261, 331, 333, $344,348,365$ $57,109,116,143,148,151,174 \mathrm{f}$. 202, 204, 237, 292, 298, 304-307, 309, $311,318,347,353$

Vandalen 19, 59f.

Zivilprozessrecht 105, 155f., 179f., 190, 285f., 336 
